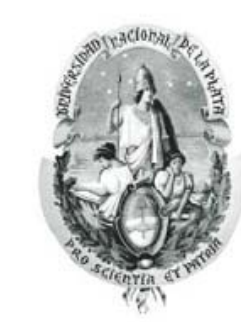

Facultad de Ciencias Naturales y Museo

Universidad Nacional La Plata

\title{
ESTRATEGIAS DE TRANSMISIÓN DE DIGENEOS PARÁSITOS QUE UTILIZAN GASTERÓPODOS COMO HOSPEDADORES INTERMEDIARIOS EN LA COSTA PATAGÓNICA
}

\author{
Trabajo de Tesis para optar por el título de \\ Doctor en Ciencias Naturales
}

Lic. Carmen Gilardoni

Directora: Dra. Florencia Cremonte

Co-directora: Dra. Julia I. Diaz

2013 


\section{AGRADECIMIENTOS}

Todas las etapas de la vida tienen un final. Y los finales felices se alcanzan con voluntad, esfuerzo, constancia, motivación y con ayuda de muchas personas que te acompañan en el camino. Por eso quiero agradecer....

A mi directora Florencia Cremonte, por su apoyo incondicional, por la motivación, por darme alas para crecer en la investigación, por su amistad.

A mi codirectora Julia Diaz, por su predisposición y entusiasmo, por estar presente siempre que la necesité.

Al Dr. Cristián Ituarte, por su objetividad y ejemplo, por ayudarme en numerosas instancias, en las colectas y en los trabajos de laboratorio, por enseñarme a realizar cortes histológicos y por enriquecer con sus conocimientos este trabajo. Los cortes histológicos se realizaron en la División Zoológica de Invertebrados, Museo Argentino de Ciencias Naturales, en el marco de una pasantía dirigida por el Dr. Ituarte.

A mis compañeras de trabajo, Gise, Emi, Nuri y Estefa, por colaborar conmigo en diferentes etapas de este trabajo (colectas, búsqueda de bibliografía, trabajos de laboratorio), darme ánimo y por mantener siempre el espíritu de equipo.

Al Centro Nacional Patagónico (CENPAT-CONICET) y especialmente al Laboratorio de Parasitología, por permitirme desarrollar todas mis actividades de doctorado y brindarme los espacios y herramientas para el desarrollo de esta tesis.

A ALUAR S.A. por brindarnos el servicio de Microscopía Electrónica de Barrido y especialmente a Jaime Groizard que siempre nos recibe con mucho entusiasmo y se esfuerza para que las fotografías queden perfectas.

A los Dres. Pedro Rodrigues y Susana Pina por enseñarme sobre técnicas moleculares y por brindarme su amistad. Los estudios moleculares se realizaron en el Laboratorio de Sanidad e Inmunología del Instituto de Ciencias Biomédicas Abel Salazar (ICBAS), Universidad de Porto, Portugal, en colaboración con el Dr. Rodrigues y la Dra. Pina, en el marco de una beca Eurotango otorgada por la Fundación Erasmus Mundus.

Al Dr. Vasyl Tkach por realizar los estudios moleculares de una especie descripta en este estudio. Las larvas y adultos de Parorchis sp., fueron secuenciadas por el Dr. Tkach, Universidad de Dakota del Norte, Estados Unidos, en colaboración con el grupo de trabajo.

Al Dr. Andrés Averbuj por el material provisto para los estudios moleculares.

A los Dres. Atila Goztonyi y David Galván por brindarme información sobre los peces de arrecife.

A los Dres. Luis Bala, Ana Millones y a la Mg. Annick Morgenthaler por brindarme información sobre aves marinas.

A los Dres. Diego Zelayas, Gregorio Bigatti, Federico Márquez y Fabrizio Scarabino por brindarme información sobre los moluscos.

Al. Dr. Hermes Mianzán por la información provista sobre ctenóforos.

A todos aquellos que me acompañaron y ayudaron en los muestreos, Mica, Joaco, Ema, Estefa, Gise y Cristián.

A los jurados de esta tesis, Dra. Verónica Flores, Dres. Sergio Martorelli y Néstor Ciocco por sus sugerencias que contribuyeron a mejorar el manuscrito. 
A mi familia, padres, hermanos, tíos, sobrinos, primos y amigos de la vida, que fueron mi principal motivación y mi fuerza para siempre seguir adelante.

A mi papá Carlos, por su confianza, sus consejos, su protección, por todo lo que me enseñó y me acompaño durante toda mi vida.

A mi mamá Rosita, por su paciencia, su entendimiento, su amor de madre, por estar siempre presente en mi vida.

A mi hermana Luján, por su alegría y entusiasmo, por ser mi amiga y darme el regalo más lindo del mundo, mi sobrino ahijado Lucca.

A mi hermano Marcelo, por su fortaleza, sus charlas y su sinceridad.

A mis hermanas de la vida, Gise, Cintia, Lucía, Lau y Flor por estar en las buenas y en las malas.

A mis suegros Elba y Miguel, por cuidarme y quererme como una hija propia

A Mica, Mauricio y Vicente, por llenar mi vida de alegría y amor estos últimos años. 
INDICE

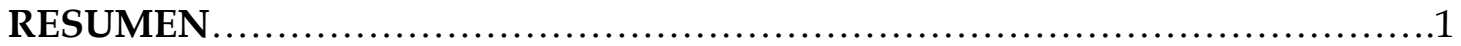

ABSTRACT ................................................................ 5

INTRODUCCIÓN GENERAL Y OBJETIVOS................................

MATERIALES Y MÉTODOS GENERALES ...................................13

Sitios de estudio...........................................................

Hospedadores...................................................................

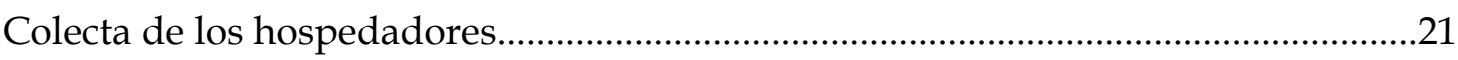

CAPÍTULO 1: DESCRIPCIÓN DE LOS DIGENEOS LARVALES.................22

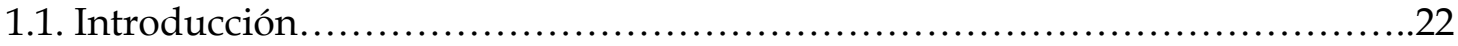

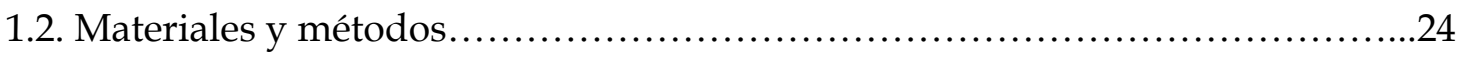

1.2.1. Procesamiento y estudio morfológico de los estadios larvales.................24

1.2.2. Estudios moleculares....................................................26

1.3. Resultados............................................................. 32

Hemiuroidea.....................................................................

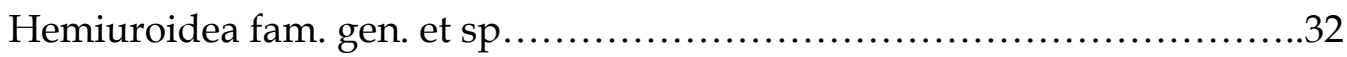

Lepocreadiidae............................................................

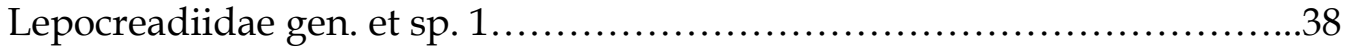

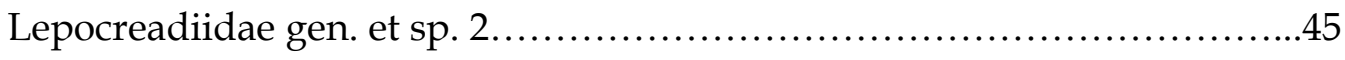

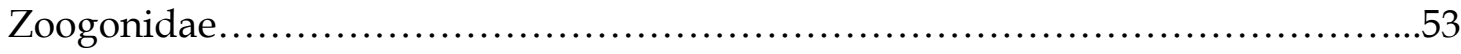

Diphterostomum sp.....................................................53

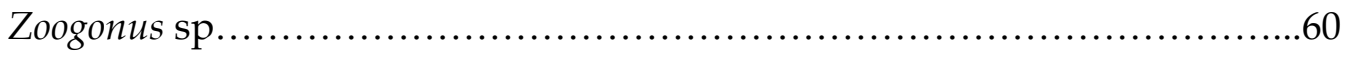

Gymnophallidae.........................................................63

Gymnophalloides nacellae............................................63

Microphallidae.........................................................68

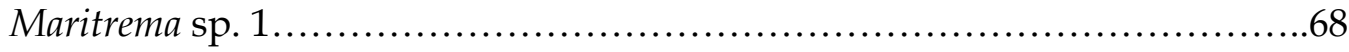

Maritrema madrynense..............................................75

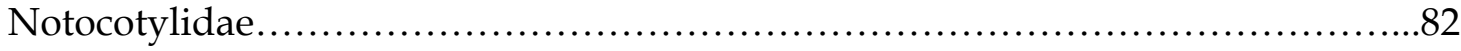

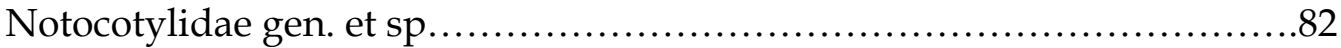

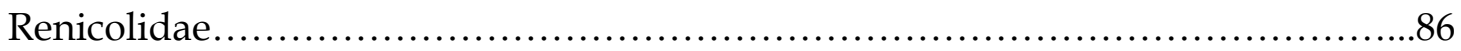




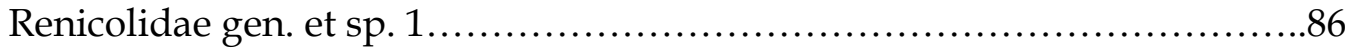

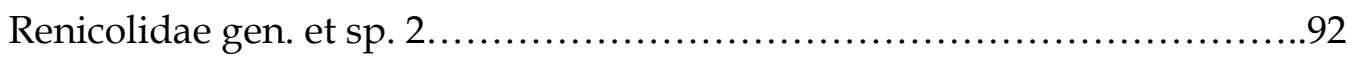

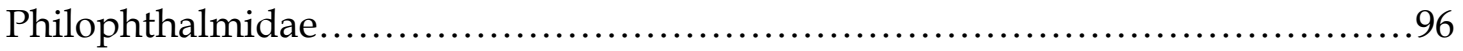

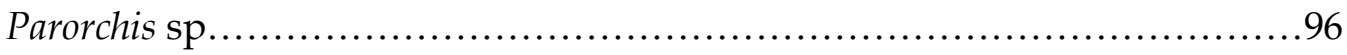

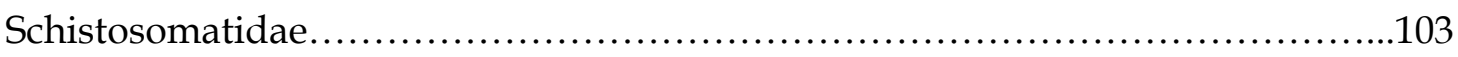

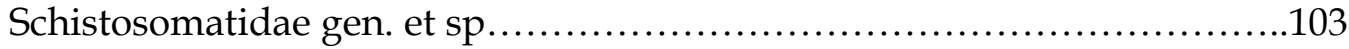

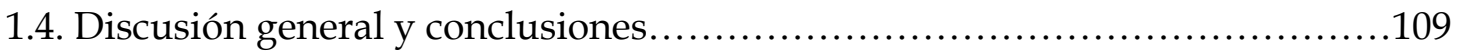

CAPÍTULO 2: CICLOS DE VIDA DE LOS DIGENEOS..........................113

2.1. Introducción.....................................................................113

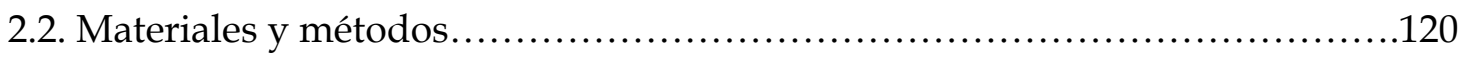

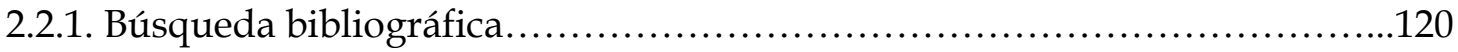

2.2.2. Estudio de potenciales segundos hospedadores intermediarios...............120

2.2.3. Infecciones experimentales.................................................121

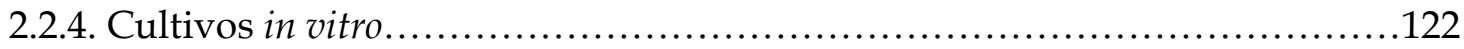

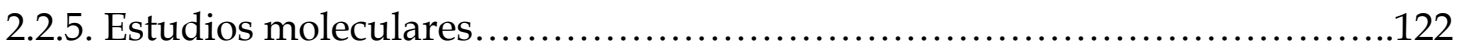

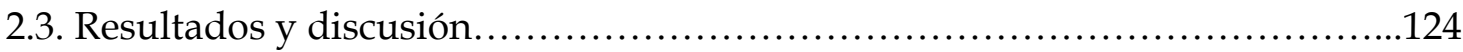

2.3.1. Digeneos que finalizan su ciclo de vida en peces...............................124

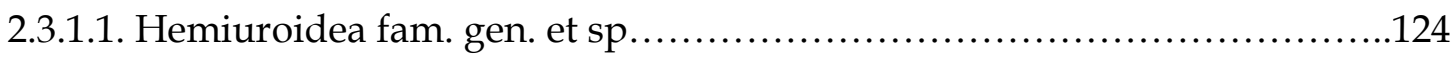

2.3.1.2. Lepocreadiidae gen. et sp. 1 y Lepocreadiidae gen. et sp. 2.................130

2.3.1.3. Diphterostomum sp. y Zoogonus sp. (Zoogonidae).............................135

2.3.2. Digeneos que finalizan su ciclo de vida en aves.................................140

2.3.2.1. Gymnophalloides nacellae (Gymnophallidae)...................................140

2.3.2.2. Maritrema sp. 1 y Maritrema madrynense (Microphallidae).....................143

2.3.2.3. Notocotylidae gen. et sp..................................................153

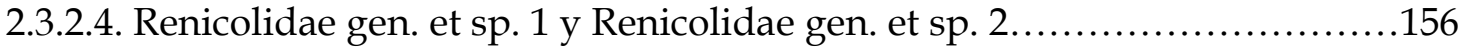

2.3.2.5. Parorchis sp. (Philophthalmidae)............................................163

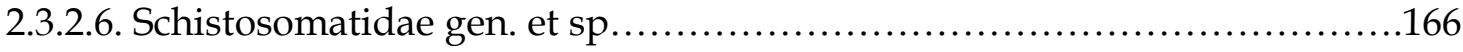

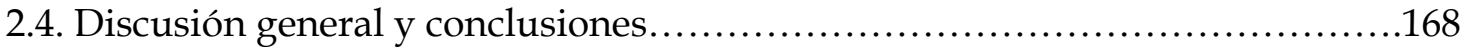

CAPÍTULO 3: DINAMICA ESPACIAL Y ESTACIONAL DE LAS

POBLACIONES Y COMUNIDADES DE LOS DIGENEOS ESTUDIADOS......180

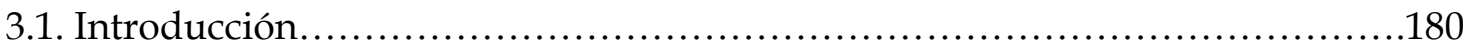

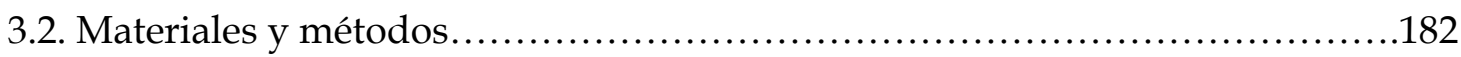


3.2.1. Estudios descriptivos y análisis estadísticos de la prevalencia en función de la talla y el sexo del hospedador, la estación del año y el sitio de estudio..............182

3.2.2. Análisis de las comunidades de digeneos en los dos sitios de estudio.........183

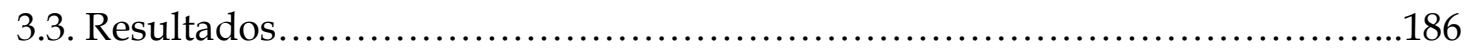

3.3.1. Digeneos larvales del intermareal de Puerto Madryn...........................186

3.3.2. Digeneos larvales del intermareal de Puerto Deseado..........................191

3.3.3. Comparación de la prevalencia y diversidad de las comunidades de digeneos en los intermareales de Puerto Madryn y Puerto Deseado............................201

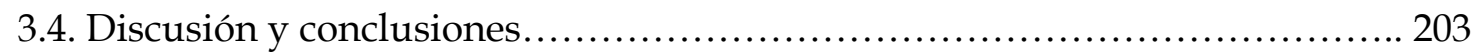

DISCUSIÓN Y CONCLUSIONES GENERALES................................211

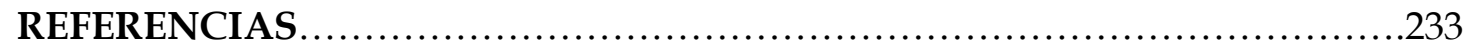

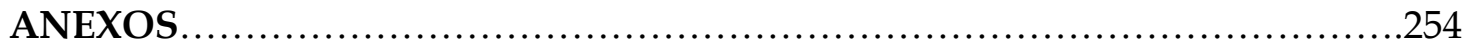




\section{RESUMEN}

En el siguiente trabajo se describieron los estadios larvales de los digeneos parásitos presentes en los gasterópodos más abundantes de los intermareales de Puerto Madryn, Chubut (4246'47"S, 6500'06"O) y Puerto Deseado, Santa Cruz (47²5'15"S, 6552'53"O): Buccinanops globulosus, Crepipatella dilatata, Fissurella radiosa, Kerguelenella lateralis, Nacella (Patinigera) magellanica, Pareuthria plumbea, Siphonaria lessonii, Tegula patagonica y Trophon geversianus.

Siete de las nueve especies de gasterópodos estudiadas estuvieron infectados por al menos una de las 13 especies de digeneos halladas. Sólo los gasterópodos $T$. patagonica de Puerto Madryn y F. radiosa de Puerto Deseado no presentaron trematodes digeneos. Buccinanops globulosus de Puerto Madryn estuvo parasitado por Diphterostomum sp. (Zoogonidae) (esporocistos con cercarias y/o metacercarias). Crepipatella dilatata estuvo parasitado por dos especies, Maritrema sp. 1 (Microphallidae) (esporocistos con cercarias) en ambos sitios de estudio y Lepocreadiidae gen. et sp. 1 (redias con cercarias) sólo en Puerto Deseado. Kerguelenella lateralis de Puerto Deseado estuvo parasitado por Maritrema madrynense (Microphallidae) (esporocistos con cercarias). Nacella (Patinigera) magellanica de Puerto Deseado estuvo parasitado por tres especies, Gymnophalloides nacellae (Gymnophallidae) (metacercarias), Notocotylidae gen. et sp. (redias con cercarias y metacercarias) y Renicolidae gen. et sp. 2 (esporocistos con cercarias). Pareuthria plumbea de Puerto Deseado estuvo parasitado por dos especies, Lepocreadiidae gen. et sp. 2 (redias con cercarias) y Zoogonus sp. (Zoogonidae) (esporocistos con cercarias). Siphonaria lessonii estuvo parasitado por tres especies, Hemiuroidea fam. gen. et sp. (esporocistos con cercarias) y M. madrynense (esporocistos con cercarias y/o metacercarias) en ambos sitios de estudio y Schistosomatidae gen. et sp. (esporocistos con cercarias) sólo en Puerto Deseado. Trophon geversianus estuvo parasitado por dos especies en ambos sitios de estudio, Parorchis sp. (Philophthalmidae) (redias con cercarias) y Renicolidae gen. et sp. 1 (esporocistos con cercarias). 
Seis especies de digeneos fueron registradas por primera vez en gasterópodos, dos de las cuales (Parorchis sp. y Zoogonus sp.) constituyen los primeros registros de la familia en Sudamérica y cuatro (Lepocreadiidae gen. et sp. 1, Lepocreadiidae gen. et sp. 2, Maritrema sp. 1 y Renicolidae gen. et sp. 1) son primeros registros de la familia en gasterópodos del Mar Argentino. Se completaron las descripciones y se ampliaron las distribuciones geográficas de las seis especies restantes (Hemiuroidea fam. gen. et sp., Diphterostomum sp., G. nacellae, M. madrynense, Notocotylidae gen. et sp., Renicolidae gen. et sp. 2 y Schistosomatidae gen. et sp.), se describieron hasta nivel de especie los digeneos G. nacellae y $M$. madrynense, se reubicó en otro género al digeneo G. nacellae (antes Lacunovermis sp.) y se reubicó en otra familia al digeneo Notocotylidae gen. et sp. (antes Pronocephalidae gen. et sp.).

Se lograron dilucidar en forma completa dos ciclos de vida (Maritrema madrynense y Parorchis sp.), que ocurren en ambos sitios de estudio y, en forma parcial, los ciclos de vida de Diphterostomum sp. y Renicolidae gen. et sp. 1 en Puerto Madryn y de Gymnophalloides nacellae en Puerto Deseado. El resto de los ciclos de vida fueron inferidos o propuestos mediante hipotesis a partir del análisis bibliográfico, el conocimiento de la disponibilidad de hospedadores en el área y de las características morfológicas y comportamentales de las cercarias.

Se observó una mayor proporción de ciclos de vida que utilizan aves como hospedadores definitivos (62\%); sin embargo, la proporción de ciclos que finalizan en peces $(38 \%)$ es alta comparada con otros registros de digeneos larvales en intermareales marinos. Los sitios de estudio son áreas con un bajo hidrodinamismo (aguas calmas), poca pendiente y con gran amplitud de marea. Estas condiciones favorecen que una gran variedad de peces se acerquen a alimentarse durante la pleamar y que una gran diversidad de aves se alimente más tiempo durante la bajamar. Teniendo en cuenta que la gaviota cocinera, Larus dominicanus es el ave con mayor abundancia y distribución geográfica y que posee una dieta oportunista y generalista, era esperable que cumpliera un rol predominante en los ciclos de vida, aún desconocidos. En este trabajo se ha establecido con certeza que dos especies de digeneos utilizan como hospedador definitivo a esta ave (M. madrynense y Parorchis 
sp.) y se sospecha que otras cinco también lo hacen (G. nacellae, Notocotylidae gen. et sp., Renicolidae gen. et sp. 1, Renicolidae gen. et sp. 2 y Schistosomatidae gen. et sp.).

El $62 \%$ de los digeneos hallados en el presente estudio presentan ciclos de vida triexenos, el 23\% presentan ciclos de vida diexeneos y el 15\% presentan ambas estrategias de transmisión (ciclos diexenos y/o triexenos). La gran diversidad de invertebrados, peces y aves en los intermareales aquí estudiados favorecen la predominancia de ciclos de vida triexenos; sin embargo, la proporción de ciclos diexenos y abreviados es elevada, ya que algunos factores ambientales (desecación, variación de temperatura, viento) y la disponibilidad de algunos hospedadores podría estar determinando un sistema mixto en el cual se utilizan ambas estrategias de transmisión.

La mayoría de las especies de digeneos halladas presentaron bajas prevalencias (entre 0,16 y 4,84\%). Sólo los Microphallidae presentaron prevalencias altas (entre 8,95 y 33,45\%) en ambos sitios de estudio y G. nacellae, que se halló sólo en estadio metacercaria $(92,47 \%)$. Las altas prevalencias de los microfálidos en los moluscos está determinada por la gran abundancia de hospedadores definitivos (la gaviota cocinera), por poseer estrategias de transmisión alternativas (ciclo diexeno y triexeno) y por presentar un amplio espectro de crustáceos como segundos hospedadores intermediarios.

A nivel poblacional, las prevalencias estuvieron correlacionadas con la talla del hospedador en la mayoría de los casos, hallándose las mayores prevalencias en las tallas mayores e intermedias. En Maritrema sp. 1, M. madrynense y Parorchis sp. en Puerto Madryn y Lepocreadiidae gen. et sp. 2, Maritrema sp. 1 y Renicolidae gen. et sp. 1 en Puerto Deseado, la prevalencia fue mayor en las tallas mayores y en Hemiuroidea fam. gen. et sp., Diphterostomum sp. y Renicolidae gen. et sp. 1 en Puerto Madryn y en M. madrynense, Notocotylidae gen. et sp. y Parorchis sp. en Puerto Deseado, la prevalencia fue mayor en las tallas intermedias. En general, la prevalencia de parásitos no estuvo afectada por el sexo del hospedador y no presentó un patrón estacional; sin embargo, en ambos sitios de estudio se hallaron algunas especies en las estaciones frías del año que no se hallaron en las estaciones 
cálidas (Hemiuroidea fam. gen. et sp. y Renicolidae gen. et sp. 1 en Puerto Madryn y Lepocreadiidae gen. et sp. 1, Notocotylidae gen. et sp., Parorchis sp., Schistosomatidae gen. et sp y Zoogonus sp. en Puerto Deseado). En estos casos, la presencia de los digeneos en los moluscos podría verse afectada por la variación estacional que presentan algunas especies de aves y peces que actuarían como hospedadores definitivos.

La diversidad de parásitos estuvo mayormente explicada por la riqueza de especies y fue más alta en Puerto Deseado, lo cual estaría directamente relacionado con la mayor diversidad de moluscos en el área. La gran diversidad de moluscos atrae peces y aves marinas, permitiendo que los intermareales sean áreas activas de alimentación para estos vertebrados que mantienen los complejos ciclos de vida de los digeneos. Adicionalmente, una mayor oferta de primeros hospedadores intermediarios permite una mayor especificidad de los digeneos, de manera que en ambientes intermareales marinos, el número de especies por gasterópodos es de una a tres. Aunque la diversidad de digeneos fue mayor en Puerto Deseado, las prevalencias más altas se observaron en Puerto Madryn, en las dos especies de digeneos Microphallidae. Esto sería debido a un incremento en la abundancia de gaviotas por la intensa actividad pesquera y basureros a cielo abierto que constituyen una fuente adicional de alimento para estas aves.

Este estudio constituye una contribución a la biodiversidad, al incrementar el número de especies conocidas en los ecosistemas marinos de Argentina. Se describieron siete nuevas especies de digeneos en la costa patagónica, se registraron y completaron las descripciones de otras seis especies conocidas, se lograron dilucidar dos ciclos de vida en forma completa y tres ciclos de vida en forma parcial, se determinaron diferentes estrategias de transmisión y se dieron a conocer algunos de los factores que afectan las poblaciones y comunidades de digeneos larvales en gasterópodos. A partir del conocimiento generado y futuros estudios, los digeneos podrían utilizarse como bioindicadores de algunos aspectos de las comunidades, tales como impacto antrópico, redes tróficas, biogeografía, entre otros. 


\section{ABSTRACT}

In the present study, the digenean larval stages parasitizing the most abundant intertidal gastropods from Puerto Madryn, Chubut province (4246'47"S, $\left.65^{\circ} 00^{\prime} 06^{\prime \prime} \mathrm{W}\right)$ and Puerto Deseado, Santa Cruz province $\left(47^{\circ} 45^{\prime} 15^{\prime \prime} \mathrm{S}, 65^{\circ} 52^{\prime} 53^{\prime \prime} \mathrm{W}\right)$ were described: Buccinanops globulosus, Crepipatella dilatata, Fissurella radiosa, Kerguenerella lateralis, Nacella (Patinigera) magellanica, Pareuthria plumbea, Siphonaria lessonii, Tegula patagonica and Trophon geversianus.

Seven of nine gastropod species were infected for at least one of 13 digenean species found. Only the gastropods T. patagonica from Puerto Madryn and F. radiosa from Puerto Deseado did not were parasitized by trematode digeneans. Buccinanops globulosus from Puerto Madryn was parasitized by Diphterostomum sp. (Zoogonidae) (sporocysts with cercariae and/or metacercariae). Crepipatella dilatata was parasitized by two species, Maritrema sp. 1 (Microphallidae) (sporocysts with cercariae) in both study sites and Lepocreadiidae gen. et sp. 1 (rediae with cercariae) only in Puerto Deseado. Kerguelenella lateralis from Puerto Deseado was parasitized by Maritrema madrynense (Microphallidae) (sporocysts with cercariae and/or metacercariae). Nacella (Patinigera) magellanica from Puerto Deseado was parasitized by three species, Gymnophalloides nacellae (Gymnophallidae) (metacercariae), Notocotylidae gen. et sp. (rediae with cercariae and metacercariae) and Renicolidae gen. et sp. 2 (sporocysts with cercariae). Pareuthria plumbea from Puerto Deseado was parasitized by two species, Lepocreadiidae gen. et sp. 2 (rediae with cercariae) and Zoogonus sp. (Zoogonidae) (sporocysts with cercariae). Siphonaria lessonii was parasitized by three species, Hemiuroidea fam. gen. et sp. (sporocysts with cercariae) and M. madrynense (sporocysts with cercariae and/or metacercariae) in both study sites and Schistosomatidae gen. et sp. (sporocysts with cercariae) only on Puerto Deseado. Trophon geversianus was parasitized by two species in both study sites, Parorchis sp. (Philophthalmidae) (rediae with cercariae) and Renicolidae gen. et sp. 1 (sporocysts with cercariae).

Six digenean species were registered for first time in gastropods, three of them (Parorchis sp. and Zoogonus sp.) are the first records of the family on South 
America and four of them (Lepocreadiidae gen. et sp. 1, Lepocreadiidae gen. et sp. 2, Maritrema sp. 1 and Renicolidae gen. et sp. 1) are the first record of the family in Argentina. Furthermore, in this study, descriptions were completed and geographic distribution was extended for other six species (Hemiuroidea fam. gen. et sp., Diphterostomum sp., G. nacellae, M. madrynense, Notocotylidae gen. et sp., Renicolidae gen. et sp. 2 and Schistosomatidae gen. et sp.). The digeneans G. nacellae and M. madrynense were described at species level, G. nacellae (before Lacunovermis sp.) were located in other genus, and Notocotylidae gen. et sp. (before Pronocephalidae gen. et sp.) were located in other family.

Two life cycles were completely elucidated (Maritrema madrynense and Parorchis sp.), both occur in two study sites, and three life cycles were partially elucidated (Diphterostomum sp. and Renicolidae gen. et sp. 1 from Puerto Madryn and G. nacellae from Puerto Deseado). The others life cycles were inferred or hypothesized based on bibliographic information, known hosts in the study areas and morphological and behavioral characteristics of cercariae.

A higher proportion of life cycles finish in sea birds (62\%); but the proportion of life cycle finishing in fish $(38 \%)$ is high compared with other records of larval digeneans in marine intertidal zones. Study sites are areas with low hidrodynamism (quiet waters), low slope and a great tidal range; these conditions would present a useful habitat for fish feeding during high tide and for bird feeding during low tide. The Kelp gull, Larus dominicanus presents a great abundance, a wide geographic distribution and a generalist and opportunist diet; for these conditions, these birds would have a predominant role in the life cycles of described digeneans. In this work, two digenean species use the Kelp gull as definitive host (M. madrynense and Parorchis sp.) and other five species would finish in this bird species (G. nacellae, Notocotylidae gen. et sp., Renicolidae gen. et sp. 1, Renicolidae gen. et sp. 2 and Schistosomatidae gen. et sp.).

The $62 \%$ of digeneans found in this study present trixenous life cycles, the $23 \%$ presents dixenous life cycles, and the $15 \%$ present both transmission strategies (dixenous and/or trixenous). A great diversity of invertebrates, fish and seabirds in intertidal zones studied promote the predominance of trixenous life cycles; 
however, the proportion of dixenous and abbreviated life cycles is high, due to some environmental factors (desiccation, temperature variation, wind) and availability of some hosts would be create a mixed system where parasite use both transmission strategies.

Most digenean species presented low prevalences (0.16 - 4.84\%). Only microphallid digeneans presented high prevalences $(8.95-33.45 \%)$ and G. nacellae, unique species found only in metacercariae stage $(92.47 \%)$. High prevalences of microphallids in mollusks were determined for a great abundance of definitive hosts (Kelp gull), for present alternative transmission strategies (dixenous and trixenous cycles), and for present a wide spectrum of crustaceans as second intermediate hosts.

At population level, prevalences were correlated with size of gastropod hosts. In Maritrema sp. 1, M. madrynense and Parorchis sp. from Puerto Madryn and Lepocreadiidae gen. et sp. 2, Maritrema sp. 1 and Renicolidae gen. et sp. 1 from Puerto Deseado, the prevalence was higher in higher sizes. In Hemiuroidea fam. gen. et sp., Diphterostomum sp. and Renicolidae gen. et sp. 1 from Puerto Madryn and in M. madrynense, Notocotylidae gen. et sp. and Parorchis sp. from Puerto Deseado, the prevalence was higher in intermediate sizes. Prevalence was not affected by sex of host and did not presented seasonal patterns; however, in both study sites, some species were presented in cold seasons and were absent in hot seasons. In these cases, the presence of digeneans in mollusks would be affected by seasonal variation of fish and seabirds (definitive hosts).

Parasite diversity was mainly explained by species richness and was higher on Puerto Deseado. This result would be directly related with the higher mollusk diversity on the area. Great mollusk diversity attracts fish and seabirds and improves intertidal areas to act as feeding zones for these vertebrates promoting the digenean life cycles. Additionally, a higher offer of first intermediate hosts allows a higher specificity for digeneans, and consequently, each gastropod species is parasitized by few digenean species (one to three). Despite digenean diversity was higher on Puerto Deseado, the higher prevalences were observed on Puerto Madryn in two microphallid species. This result would be explained by an increment in the 
abundance of Kelp gulls due to intense fishery and open garbage man that constitute an additional food source by these birds.

This study contributes to the knowledge of biodiversity increasing the species number known in the marine ecosystem from Argentina. Seven new digenean species on Patagonian coast were described, descriptions to other six species were completed, two life cycles were completely elucidated and other three were partially elucidated, different transmission strategies were determined and some factors affecting the populations and communities were known. Based on new knowledge and future studies, digeneans could be used as bioindicators of some aspects of communities, like human impact, food webs, biogeography and others. 


\section{INTRODUCCIÓN GENERAL Y OBJETIVOS}

El parasitismo es una asociación ecológica entre dos organismos (parásito y hospedador) en la cual existe dependencia metabólica o fisiológica (Fried \& Graczyk, 1997). Es una forma de vida muy exitosa, se calcula que el 50\% de todas las especies animales albergan algún estadio de vida parásito (Bush et al., 2001). Los parásitos tienen un impacto significativo en los ecosistemas marinos, ya que pueden afectar directamente a sus hospedadores (disminuyendo la fecundidad, alterando el crecimiento, la tasa de mortalidad y el comportamiento) y modificar su desempeño en las cadenas tróficas (aumentando la posibilidad de depredación sobre los organismos parasitados, ejerciendo un control top-down, desde los niveles superiores de las redes tróficas hacia los inferiores y manteniendo la diversidad de los niveles tróficos más bajos) (e.g., Curtis, 1990; Poulin \& Morand, 2004; Hudson, 2005; Lafferty et al., 2006a, c; Bartoli \& Boudouresque, 2007; Dunne et al., 2013).

Los parásitos de los moluscos gasterópodos y bivalvos marinos que son más abundantes y que ejercen una mayor influencia sobre sus hospedadores son los estadios larvales de los trematodes digeneos, cuyos adultos parasitan a peces y a aves (Lauckner, 1980; Lauckner, 1983; Bartoli, 1984; Cremonte, 2011). Los ciclos de vida más frecuentes de digeneos incluyen dos hospedadores intermediarios (HI); el primero es siempre un molusco gasterópodo o bivalvo y alberga esporocistos y/o redias que originan cercarias, las cuales son emitidas al medio e ingresan a un $2^{\circ}$ $\mathrm{HI}$, invertebrado o vertebrado. El $2^{\circ} \mathrm{HI}$ puede ser omitido, al enquistar la cercaria en el ambiente o al ingresar directamente en el vertebrado hospedador definitivo. En algunos casos, la cercaria se enquista dentro de los esporocistos o de las redias y entonces el molusco actúa como $1^{\circ}$ y $2^{\circ} \mathrm{HI}$. Cuando una metacercaria es ingerida por un vertebrado, completa su desarrollo alcanzando la madurez sexual (adulto). El adulto produce huevos que son liberados al medio, generalmente con las heces del hospedador definitivo, del cual emerge el miracidio (forma infectante) que ingresa en el $1^{\circ} \mathrm{HI}$ o bien el huevo es ingerido por el molusco y eclosiona en su interior (Galaktionov, 1996; Bush et al., 2001). 
Las zonas intermareales marinas y los niveles superiores de las zonas submareales albergan una abundante fauna de invertebrados y de peces y aves que se alimentan de ellos, promoviendo los complejos ciclos de vida de los trematodes (Mouritsen \& Poulin, 2002). La estructura de las comunidades de trematodes en los moluscos depende de varios factores, como el tipo de ciclo de vida, el número de hospedadores involucrados, los patrones de distribución espacial de los primeros hospedadores intermediarios, las características biológicas de los hospedadores definitivos y diversos factores ambientales (e.g. Kuris, 1990; Sousa, 1990; Curtis, 1996; Huspeni et al., 2005; Galaktionov et al., 2006; Studer \& Poulin, 2012). En sistemas acuáticos, numerosos estudios han utilizado efectivamente a los parásitos como indicadores de algunos aspectos biológicos del hospedador (determinación de stocks, dieta, migraciones, biogeografía y filogenia) (e.g. Marcogliese \& Cone, 1997; Marcogliese, 2004). Por otra parte, los parásitos pueden ser utilizados como indicadores de estrés ambiental, estructura de redes tróficas y biodiversidad. Por ejemplo, los digeneos que necesitan de las redes tróficas para transmitirse son buenos indicadores de estas relaciones (Lafferty, 1997; Marcogliese \& Cone, 1997; Lafferty et al., 2006a; Hechinger et al., 2011; Dunne et al., 2013). Para poder utilizar a los parásitos como indicadores de aspectos biológicos de poblaciones y comunidades hospedadoras, deben conocerse su identidad, sus ciclos de vida, sus estrategias de transmisión y los factores que condicionan estos procesos. La necesidad de este tipo de estudios es particularmente importante en regiones donde la cantidad de moluscos intermareales infectados con larvas de digeneos se está incrementando. Este fenómeno es el resultado de un incremento en la abundancia de aves costeras de dieta generalista (principalmente gaviotas) en áreas con gran actividad antrópica como los puertos pesqueros (Bustnes \& Galaktionov, 1999; Bustnes, 2000; Galaktionov \& Skimisson, 2000).

En los últimos años, la aplicación de herramientas moleculares ha permitido resolver en forma más rápida y sencilla los ciclos de vida de los digeneos (e.g. Jousson \& Bartoli, 2000; Pina et al., 2009; Al-Kandari et al., 2011; Born-Torrijos et al., 2012). Fracciones específicas de algunos genes ribosomales y mitocondriales han sido ampliamente utilizados en la sistemática de trematodes digeneos (Nolan \& 
Cribb, 2005). El ADN ribosomal es particularmente útil debido a que su secuencia es altamente repetitiva y contiene regiones variables alternadas con regiones conservadas (Adlard et al., 1993). Las regiones $18 \mathrm{~S}$ y $28 \mathrm{~S}$ del ADN ribosomal son poco variables, presentan una baja tasa evolutiva y se aplican en el estudio de interrelaciones dentro y entre familias de platelmintos. En cambio, las regiones ITS1 e ITS2 (internal transcribed spacer) del ADN ribosomal presentan secuencias más variables y una alta tasa evolutiva, por lo que se utilizan para el reconocimiento de especies y para indicar la correspondencia de distintos estadios de desarrollo a la misma especie.

Los estudios sobre larvas de digeneos que afectan a gasterópodos y a bivalvos del litoral patagónico se han incrementado en los últimos años y están referidos principalmente a aspectos taxonómicos (Martorelli, 1991; Martorelli \& Morriconi, 1998; Cremonte, 2001; Martorelli et al., 2005; Cremonte et al., 2008; Alda \& Martorelli, 2009; Averbuj \& Cremonte, 2010; Vázquez et al., 2013) y patológicos (Ituarte et al., 2001; Cremonte \& Ituarte, 2003; Cremonte \& Figueras, 2004; Cremonte et al., 2005; Ituarte et al., 2005; Vázquez et al., 2006). Si bien en los últimos años se logró un avance considerable en la dilucidación de algunas de las etapas de los complejos ciclos de vida de los digeneos, sólo dos de ellos se conocen de forma completa en la región, el ciclo de vida del gymnofálido Bartolius pierrei Cremonte, 2004 y el ciclo de vida del monórquido Proctorema bartolii Gilardoni, Carballo \& Cremonte, 2013. Con respecto a los digeneos adultos, se cuenta con numerosos estudios realizados en peces, principalmente de importancia comercial (e.g. Szidat, 1950; Suriano \& Sutton, 1980; Timi 2003; Timi et al., 2008; Carballo et al., 2011) y registros en algunas aves como la gaviota cocinera, Larus dominicanus Lichtenstein (Laridae), el playero rojizo Calidris canutus rufa (Wilson) (Scolopacidae) y el pingüino de Magallanes Spheniscus magellanicus Forster (Spheniscidae) (Cremonte, 2001; Diaz \& Cremonte 2004, 2010; Diaz et al., 2010; 2011).

El objetivo general de este estudio es conocer los patrones de transmisión de los digeneos que utilizan a gasterópodos como hospedadores intermediarios en diferentes latitudes de la costa patagónica y evaluar las principales condiciones bióticas y/o abióticas que los determinan. 
Introducción general y objetivos

\section{Los objetivos particulares son:}

1) Hallar y describir a los estadios larvales de digeneos parásitos en los gasterópodos más abundantes que habitan los intermareales de Puerto Madryn y Puerto Deseado (Buccinanops globulosus, Crepipatella dilatata, Fissurella radiosa, Kerguelenella lateralis, Nacella (Patinigera) magellanica, Pareuthria plumbea, Siphonaria lessonii, Tegula patagonica y Trophon geversianus).

2) Determinar qué órganos de los hospedadores gasterópodos están afectados por los parásitos digeneos.

3) Dilucidar los ciclos de vida de los digeneos hallados mediante la aplicación de diferentes herramientas como cultivos in vitro, infecciones experimentales $\mathrm{y}$ estudios moleculares.

4) Reconocer los patrones de transmisión (ciclos con uno o dos hospedadores intermediarios) y examinar si alguno predomina sobre el otro en los dos sitios de estudio.

5) Describir la dinámica poblacional espacial (en las diferentes tallas y sexos de cada población de molusco) y temporal (en las diferentes estaciones del año) de las especies de digeneos halladas.

6) Comparar la comunidad de estadios larvales de digeneos en gasterópodos en dos sitios de estudio a diferentes latitudes (Puerto Madryn, provincia de Chubut y Puerto Deseado, provincia de Santa Cruz). 


\section{MATERIALES Y MÉTODOS GENERALES}

\section{Sitios de estudio}

Los sitios de estudio comprendieron los niveles intermareales de las localidades de Puerto Madryn (ecotono entre las provincias biogeográficas Argentina y Magallánica) y Puerto Deseado (provincia biogeográfica Magallánica) (Fig. 1). El sitio de colecta en la localidad de Puerto Madryn es Punta Cuevas (4246'47"S, $\left.65^{\circ} 00^{\prime} 06^{\prime \prime} \mathrm{O}\right)$ que se encuentra en el extremo sur de la ciudad, sobre el Golfo Nuevo, provincia del Chubut (Fig. 2). El sitio de muestreo en la localidad de Puerto

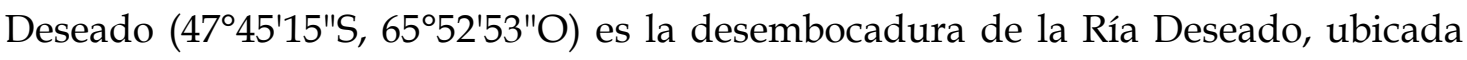
en el sector noreste de la provincia de Santa Cruz (Fig. 3). Ambos intermareales están ubicados en áreas de aguas calmas, presentan poca pendiente y una amplitud de marea de aproximadamente 6 m como máximo (Servicio de Hidrografía Naval). El intermareal de Punta Cuevas esta formado por sustrato consolidado en el área rocosa y una extensa playa de arena (Torres \& Caille, 2009). El intermareal de Puerto Deseado se extiende sobre un afloramiento de pórfido cuarcífero alternado con sustratos limosos (Ringuelet et al., 1962).

El Golfo Nuevo, con una extensión de $2.200 \mathrm{~km}^{2}$, presenta una boca de entrada que supera apenas los $15 \mathrm{~km}$. Las márgenes del golfo exponen tramos de acantilados y tramos de playa con suave pendiente hacia el interior que alcanzan en general los $10 \mathrm{~m}$ de profundidad a una distancia de $1.000 \mathrm{~m}$ desde la línea de costa. El fondo es arenoso-rocoso, con restingas de sedimento consolidado que comienzan a unos $300 \mathrm{~m}$ de la orilla. Estas zonas intermareales albergan distintas especies de poríferos, cnidarios, nemertinos, moluscos, anélidos, crustáceos y equinodermos, constituyendo un área altamente diversa (Plan de Manejo, 2001). La salinidad varía entre 33,7 y 34,15 ups. Presenta una precipitación media anual de $230 \mathrm{~mm}$ y una temperatura media anual de $13,4^{\circ} \mathrm{C}$ (Videla et al., 2008). Puerto Madryn es una ciudad turística, principalmente en verano. A su vez, es el segundo puerto nacional por volumen de descarga, por lo que sus aguas presentan actividad pesquera intensa; operan buques de altura convencional, congeladores y factorías (Armada Argentina, 2007). 
El Golfo Nuevo se encuentra ubicado en una región de clima templado $\left(\sim 42^{\circ}\right.$ y $43^{\circ} \mathrm{S}$ ), en una transición entre dos provincias biogeográficas, la Argentina y la Magallánica. La provincia Argentina se desarrolla sobre la plataforma submarina, con un límite norte fluctuante, entre $\operatorname{los} 30^{\circ}$ y $32^{\circ} \mathrm{S}$ frente al estado de Río Grande do Sul, el cual presenta un conjunto biológico fuertemente termófilo, y un límite sur que se ubica en el norte de la Patagonia, entre los $41^{\circ}$ y $44^{\circ} \mathrm{S}$. Esta provincia presenta fondos móviles y arenosos que más al sur son reemplazados por los de plataformas de abrasión de ola que permiten el arraigamiento de las grandes algas. Desde el punto de vista biológico, ésta provincia se caracteriza por su acentuada heterogeneidad, producto de la mezcla de elementos subtropicales y subantárticos, lo cual determina también un bajo endemismo. Las dos terceras partes de la provincia tienen un predominio de fauna de aguas cálidas (Balech \& Ehrlich, 2008).

El intermareal de la Ría de Puerto Deseado se encuentra localizado en la costa norte de la provincia de Santa Cruz (Patagonia austral), dicha Ría penetra 40 $\mathrm{km}$ tierra adentro. La profundidad máxima es de $30 \mathrm{~m}$ y la transparencia de las aguas es por lo general muy reducida, debido a la gran carga de sedimentos que las aguas arrastran desde la naciente de la ría (Martin \& Bastida, 2008). La salinidad varía entre 33,6 y 34,1 ups y es mayor a fines del verano (marzo) (Isla et al., 2004). La precipitación media anual es de $254 \mathrm{~mm}$ (Isla et al., 2004) y la temperatura media anual es de $9,8^{\circ} \mathrm{C}$. Puerto Deseado es un puerto pesquero, en donde operan buques pesqueros factorías, congeladores, poteros y fresqueros (Armada Argentina, 2007).

La provincia Magallánica, desde Península Valdés hasta el extremo sur del país, es algo más extensa que la provincia Argentina y tiene una plataforma submarina mucho más ancha. Esta provincia se caracteriza por ser más homogénea debido a la dominancia de aguas frías subantárticas, por eso son muchos los taxa que le son propios, pero no exclusivos. Posee plataformas de abrasión de ola en la zona costera y eulitoral, con playas de arena y cascajo, y presenta mareas muy amplias que generan corrientes muy fuertes (Balech \& Ehrlich, 2008). 

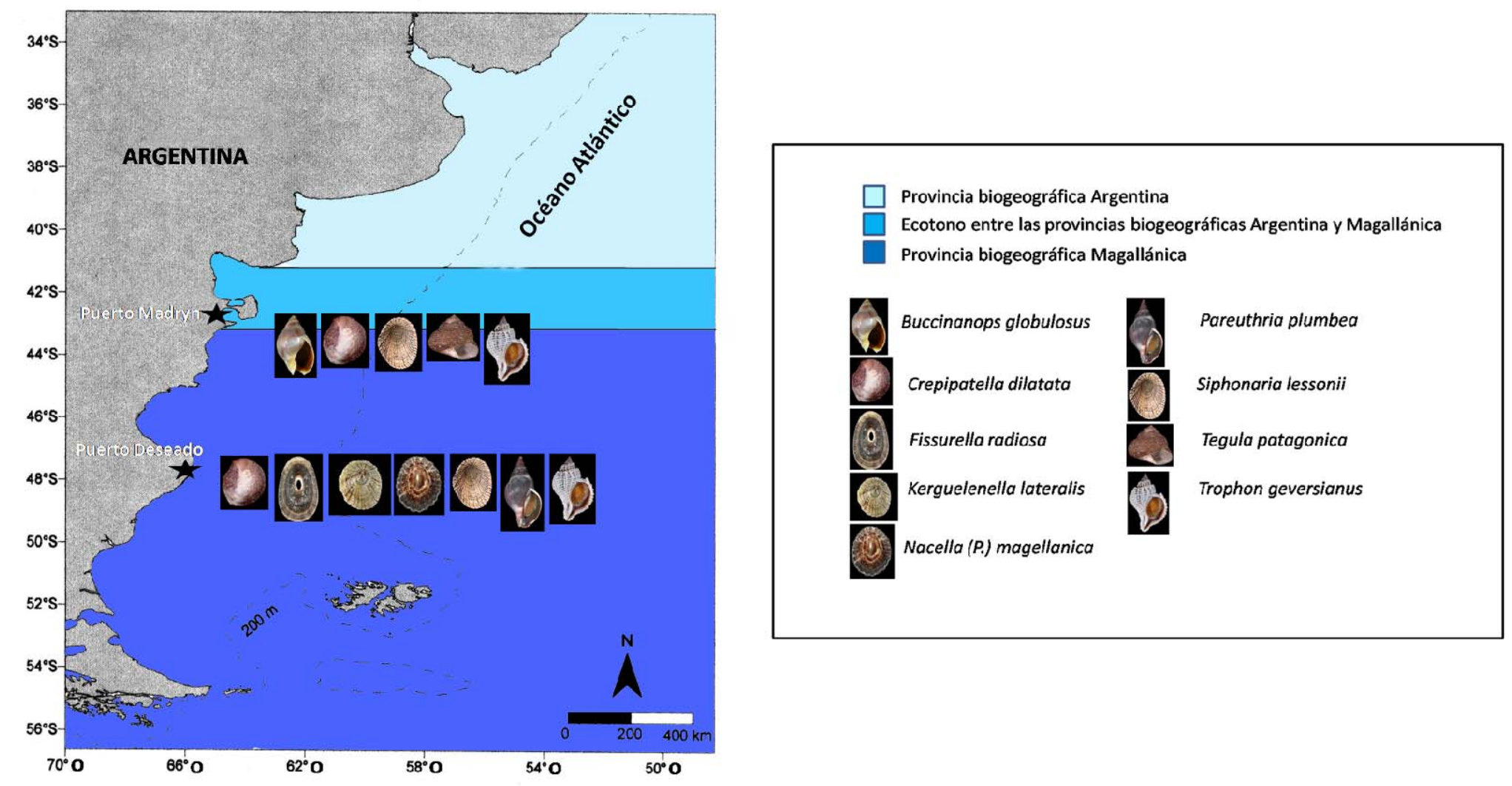

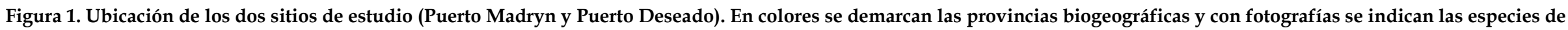
gasterópodos colectadas en cada zona. 


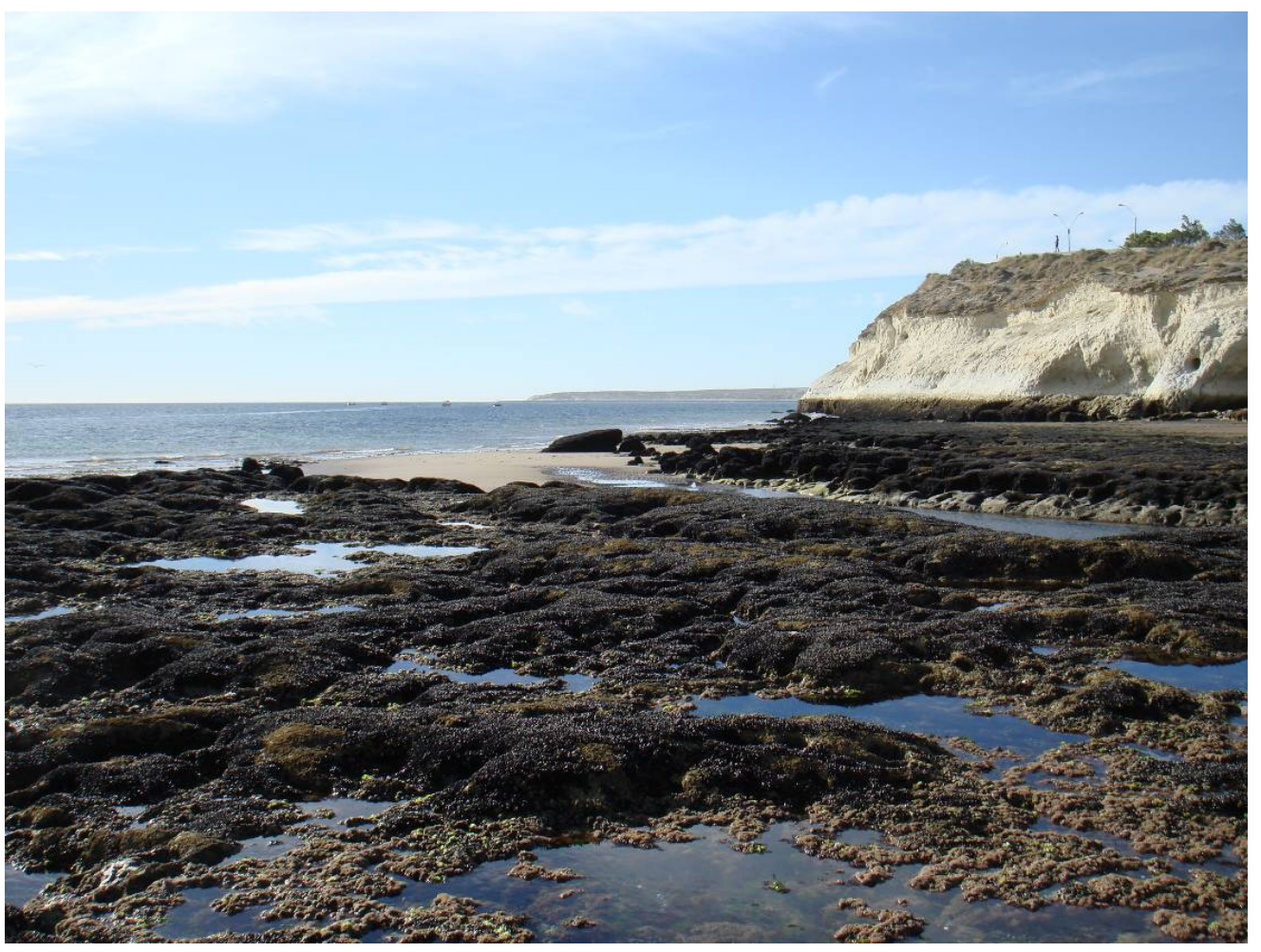

Figura 2. Intermareal de Punta Cuevas, Puerto Madryn, Chubut.

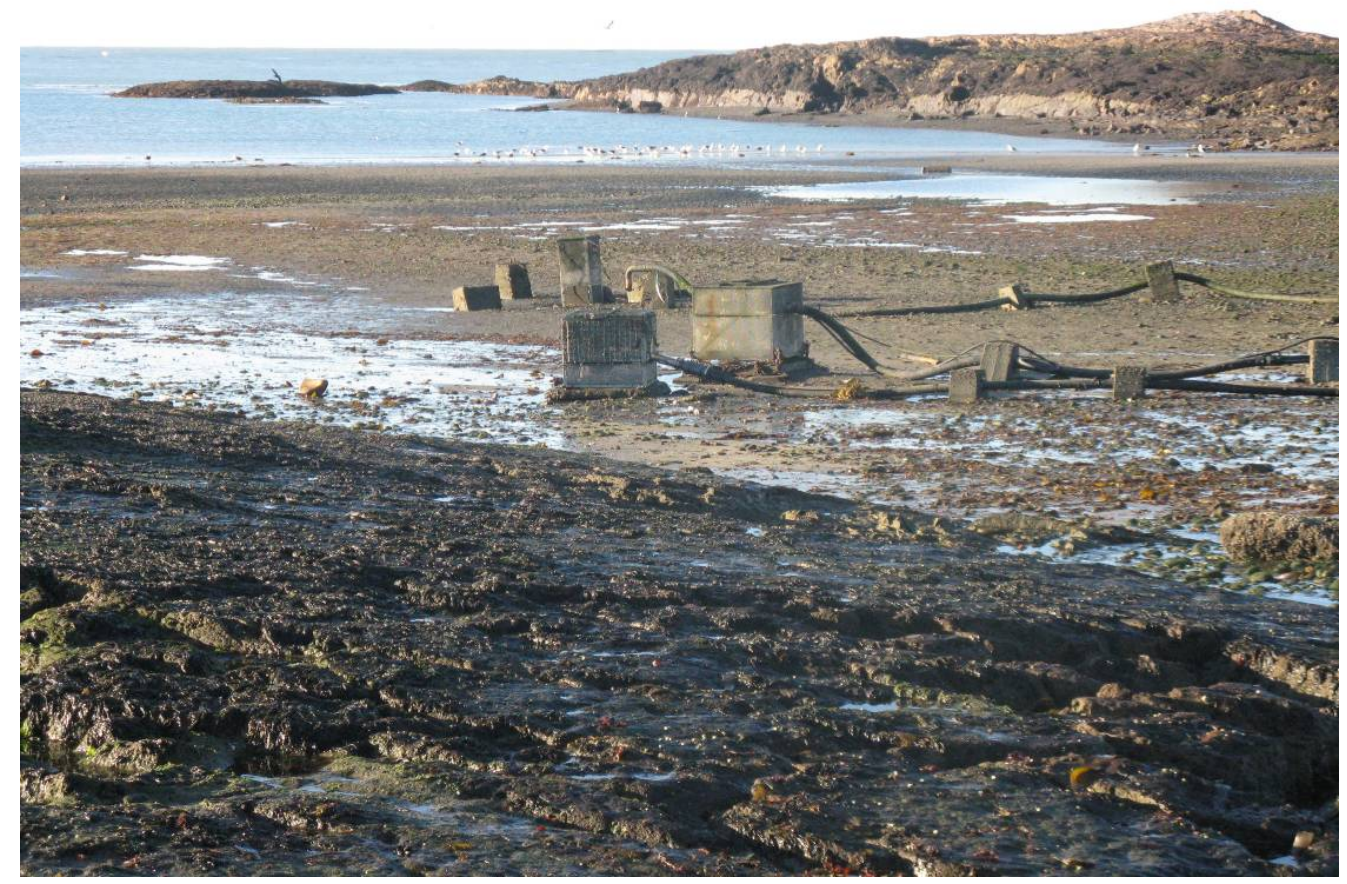

Figura 3. Intermareal de Puerto Deseado, Santa Cruz. 


\section{Hospedadores}

Para el estudio de los digenos larvales que afectan a gasterópodos, se seleccionaron las especies más abundantes que habitan los intermareales de Puerto Madryn y Puerto Deseado (Buccinanops globulosus, Crepipatella dilatata, Fissurella radiosa, Kerguelenella lateralis, Nacella (Patinigera) magellanica, Pareuthria plumbea, Siphonaria lessonii, Tegula patagonica y Trophon geversianus).

Buccinanops globulosus (Kiener) (Nassariidae) (Fig. 4A) es un componente común de la macrofauna bentónica del Atlántico Sudoccidental. Habita sustratos arenosos o fangosos de la costa hasta los $10 \mathrm{~m}$ de profundidad, pasa la mayor parte del tiempo enterrado y formando agregaciones densas (Scarabino, 1977). Es una especie necrófaga; se alimenta principalmente de moluscos y cangrejos muertos,

siendo Cyrtograpsus angulatus Danna (Varunidae) la especie de cangrejo más consumida (Narvarte, 2006). Es una especie dioica, presenta desarrollo directo, las hembras retienen sus ovicápsulas en la zona del callo de la valva (Penchaszadeh, 1971; Averbuj et al., 2010). Los juveniles emergen y viven dentro del mismo área que los adultos, por lo que poseen poca capacidad de dispersión (Penchaszadeh, 1971). Algunas poblaciones han comenzado a ser explotadas económicamente por turistas y para consumo familiar (Narvarte, 2006; Avaca et al., 2013).

Crepipatella dilatata (Lamarck) (Calyptraeidae) (Fig. 4B) se distribuye por la costa Pacífica desde los $21^{\circ} \mathrm{S}$ hasta el Estrecho de Magallanes, y desde allí por el Atlántico hasta el Golfo Nuevo, Chubut (Penchaszadeh et al., 2001). Este molusco habita en sustratos consolidados o rocosos intermareales y submareales hasta aproximadamente los $20 \mathrm{~m}$ de profundidad; viven adheridos sin desplazarse, en ocasiones asociados a valvas de mitílidos. Los individuos adultos son filtradores y en cuanto a su sexualidad, son hermafroditas consecutivos protándricos. La presencia de ovicápsulas en el proceso reproductivo, sumado al cuidado parental, confiere ventajas en el desarrollo de los embriones hasta alcanzar la eclosión (e.g. provisión de huevos nutricios, protección, etc.) (Penchaszadeh et al., 2001).

Fissurella radiosa Lesson (Fissurellidae) (Fig. 4C) presenta dos subespecies, Fissurella radiosa radiosa que se distribuye en la región magallánica de Argentina y Chile y Fissurella radiosa tixierae que se distribuye en el Golfo San Matías y la 
Península Valdés. Es una especie dioica y habita en zonas intermareales inferiores hasta los $20 \mathrm{~m}$ de profundidad. Se alimenta de esponjas, algas o detritos (McLean, 1984).

Kerguelenella lateralis (Gould) (Siphonariidae) (Fig. 4G) es endémica del Estrecho de Magallanes, la costa de la Patagonia, las Islas Malvinas, Georgias del Sur, Kerguelen y Macquerie (Carcelles \& Williamson, 1951). Habita en zonas intermareales sobre sustratos duros, donde generalmente se agrupa en grietas (McClintock \& Lawrence, 1986). Es un herbívoro ramoneador sobre algas incrustantes. Es una especie hermafrodita, la reproducción ocurre con la deposición de masas ovígeras sobre el sustrato y el desarrollo de los juveniles dentro de las mismas (Simpson \& Harrington, 1985).

Nacella (Patinigera) magellanica (Gmelin) (Nacellidae) (Fig. 4E) se distribuye en la provincia biogeográfica Magallánica de Argentina y Chile, así como en las Islas Malvinas. Es la lapa más abundante en el sector argentino de la provincia biogeográfica y presenta una alta variabilidad de caracteres morfológicos y patrones de coloración (Aranzamendi et al., 2011). Vive sobre sustratos rocosos, entre o debajo de las rocas o en grietas, en el intermareal y hasta los $5 \mathrm{~m}$ de profundidad. Es una especie hervíbora, se alimenta de micro y macroalgas. Es una especie dioica, la fecundación es externa y el desarrollo es indirecto a través de una larva planctónica. Se utiliza como un recurso alimenticio en Chile y en menor medida en Patagonia Argentina (Cortés \& Narosky, 1997).

Pareuthria plumbea (Philippi) (Buccinidae) (Fig. 4F) se distribuye en el Atlántico Sudoccidental desde el sur de la provincia de Chubut $\left(\sim 45^{\circ} \mathrm{S}\right)$ hasta los $49^{\circ} \mathrm{S}$ en Chile (Dell, 1971). Habita sustratos rocosos hasta los $80 \mathrm{~m}$ de profundidad, debajo de las rocas, en grietas, paredes rocosas y pozas de marea; también sobre algas pardas. Es una especie dioica y presenta desarrollo directo, las puestas se componen de cuatro a 19 ovicápsulas, que son fijadas al sustrato por una membrana; en su interior se desarrollan un a cinco embriones que eclosionan como juveniles (Pastorino \& Penchaszadeh, 2002).

Siphonaria lessonii Blainville (Siphonariidae) (Fig. 4D) se distribuye desde Santa Catarina, Brasil, hacia el sur, islas del Atlántico Sur y Malvinas y por el 
Pacífico hasta Paita, Perú. Es muy abundante en el supralitoral y mediolitoral rocoso, mostrando un fenómeno de migración con la edad, desde el mediolitoral hacia el supralitoral. En su hábitat en el supralitoral, los individuos se agrupan en las grietas de las rocas. Es un herbívoro ramoneador sobre algas incrustantes y recientemente asentadas; posee un rol preponderante en el proceso de recolonización de costas rocosas, se alimenta del film de algas y bacterias en los primeros estadios de la sucesión. Es una especie hermafrodita y se reproduce durante casi todo el año, excepto de junio a julio. Depositan los huevos en masas ovígeras gelatinosas que contienen cerca de 80.000 huevos que se desarrollan hasta formar una larva velíger que pasa a formar parte del plancton (Olivier \& Penchaszadeh, 1968; Penchaszadeh et al., 2003).

Tegula patagonica (d'Orbigny, 1835) (Trochidae) (Fig. 4H) se distribuye desde Rio de Janeiro, Brasil, hasta Tierra del Fuego (Penchaszadeh, 2004). Vive en fondos pedregosos o agregaciones calcáreas del litoral a una profundidad entre los 10 y 55 $\mathrm{m}$, donde se alimenta de algas, diatomeas o sustancias vegetales en descomposición. Es muy abundante en el Golfo Nuevo, donde se la encuentra recubierta por el alga incrustante Litothamnium y constituye una presa importante de la estrella de mar Cosmasterias lurida (Philippi) (Stichasteridae). Es una especie dioica, presenta fecundación externa y desarrollo indirecto (Cortés \& Narosky, 1997).

Trophon geversianus (Pallas) (Muricidae) (Fig. 4I) presenta una distribución bioceánica que abarca la costa del Atlántico Sudoccidental desde los $36^{\circ} \mathrm{S}$ hasta los $56^{\circ} \mathrm{S}$ de latitud, entre las localidades de Buenos Aires y Tierra del Fuego, incluyendo a las Islas Malvinas y el archipiélago de Isla de los Estados. Mientras que en la costa Pacífica suroriental se encuentra desde los $42^{\circ} \mathrm{S}$ hasta la $56^{\circ} \mathrm{S}$ de latitud, entre la Isla Grande de Chiloé y el archipiélago del cabo de Hornos (Castellanos \& Landoni, 1993; Griffin \& Pastorino, 2005). La distribución batimétrica de esta especie se extiende desde el intermareal hasta los $100 \mathrm{~m}$ de profundidad (Linse, 1999). Es uno de los carnívoros característicos de las comunidades intermareales y submareales, siempre asociados a bancos de mejillones o mejillines, de los que se alimentan (Andrade \& Ríos, 2007). Es un gasterópodo dioico y 
gonocórico con fertilización interna y desarrollo directo; deposita varias ovicápsulas que contienen embriones y huevos nutricios como suplemento alimenticio (Penchaszadeh, 1976; Cumplido et al., 2010). Esta especie tiene un potencial reproductivo bajo, con crecimiento lento. Es una de las especies bentónicas explotadas comercialmente en la región de Magallanes (Andrade et al., 2009).

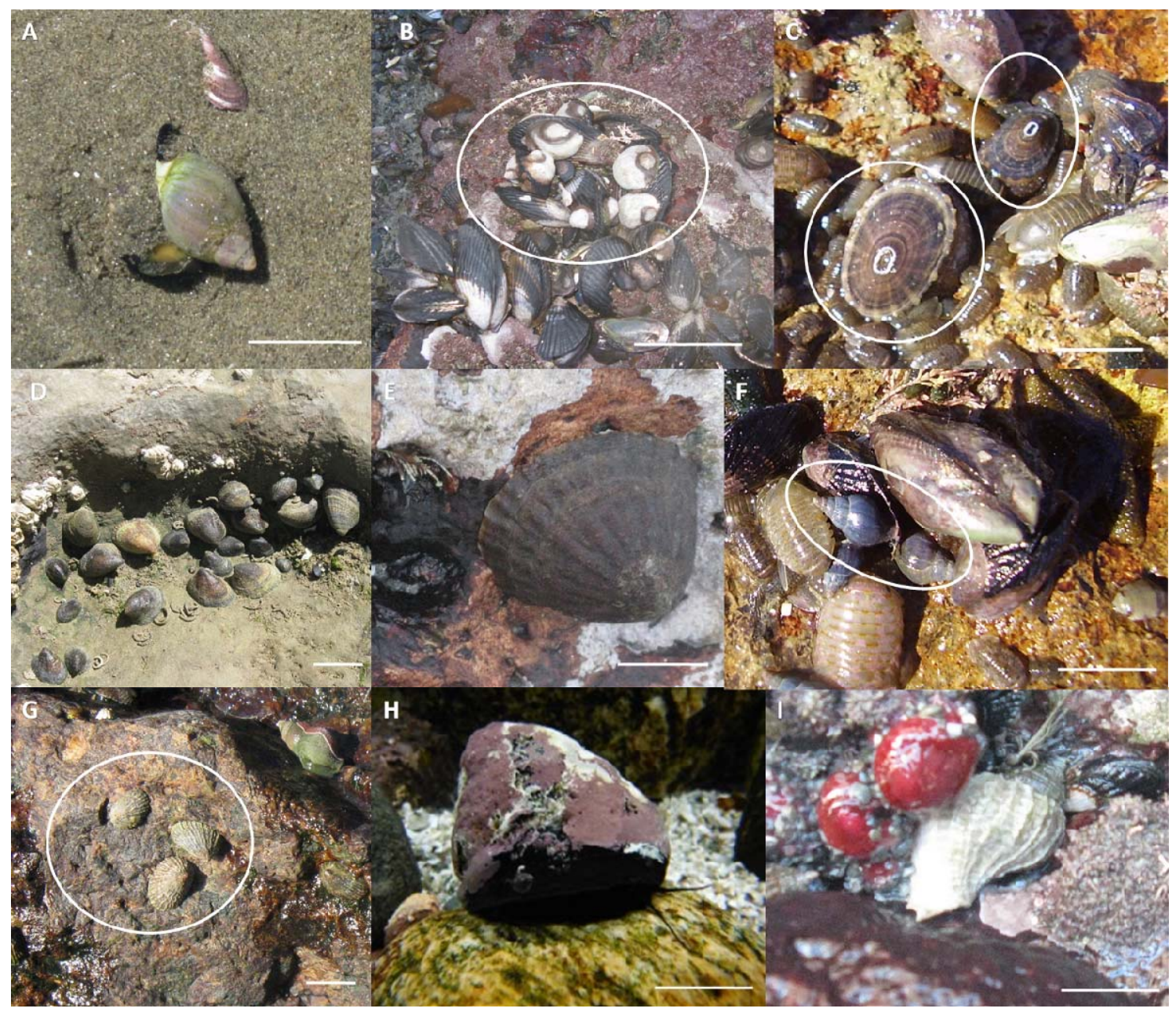

Figura 4. Especies de gasterópodos estudiadas. A- Buccinanops globulosus en el intermareal arenoso (Punta Cuevas); B- Ejemplares de Crepipatella dilatata sobre cholgas (Puerto Deseado); C- Ejemplares de Fissurella radiosa debajo de las rocas (Puerto Deseado); D- Ejemplares de Siphonaria lessonii agrupados en una grieta en el intermareal (Punta Cuevas); E- Nacella (P.) magellanica en las paredes verticales de las rocas (Puerto Deseado); F- Ejemplares de Pareuthria plumbea debajo de las rocas (Puerto Deseado); G- Ejemplares de Kerguelenella lateralis en las paredes verticales de las rocas (Puerto Deseado); H- Tegula patagonica en el intermareal rocoso (Punta Cuevas); I- Trophon geversianus en el intermareal rocoso (Puerto Deseado). Escalas: $25 \mathrm{~mm}$ (A); $30 \mathrm{~mm}$ (B, D, G); $10 \mathrm{~mm}$ (C, I); $20 \mathrm{~mm}$ (E, F); $5 \mathrm{~mm} \mathrm{(H).}$ 


\section{Colecta de los hospedadores}

En Punta Cuevas se realizaron colectas mensuales de los gasterópodos desde septiembre de 2008 hasta julio de 2010. Se colectaron 30 ejemplares por mes de las especies Buccinanops globulosus, Tegula patagonica y Trophon geversianus. En los casos de Crepipatella dilatata y Siphonaria lessonii, se colectaron 100 especímenes por mes, ya que los ejemplares fueron también destinados a cumplir otros objetivos. Adicionalmente, en enero de 2010, se colectaron 59 ejemplares de la especie $B$. globulosus en fondo arenoso a $3 \mathrm{~m}$ de profundidad, mediante buceo autónomo en Bahía Nueva, Puerto Madryn.

En Puerto Deseado se colectaron durante bajamares máximas en dos estaciones del año (invierno en julio de 2009 y verano en febrero de 2010), aproximadamente 100 ejemplares de cada especie de los gasterópodos: Crepipatella dilatata, Fissurella radiosa, Kerguelenella lateralis, Nacella (Patinigera) magellanica, Pareuthria plumbea, Siphonaria lessonii y Trophon geversianus. El número de individuos colectados fue menor en las especies que presentan baja abundancia en la zona.

Las colectas se realizaron aleatoriamente sobre transectas perpendiculares a la costa, respetando la estructura de tallas observadas. Los gasterópodos fueron colectados en forma manual, se colocaron en recipientes acondicionados con algas humedecidas en agua de mar y geles refrigerantes y fueron transportados vivos hasta el laboratorio. En el laboratorio, los gasterópodos fueron separados por especie y se mantuvieron en acuarios acondicionados con aireador y filtros de agua en una cámara de temperatura controlada $\left(12{ }^{\circ} \mathrm{C}\right)$ hasta el momento de su procesamiento. 


\section{CAPÍTULO 1: DESCRIPCIÓN DE LOS DIGENEOS LARVALES}

\subsection{Introducción}

A pesar de la importancia de los digeneos en las áreas marinas costeras, sólo ocho especies han sido registradas infectando gasterópodos en la costa Atlántica Sudoccidental. Una cercaria Notocotilidae en Laevilitorina caliginosa (Gould) (Littorinidae) (Graefe, 1968), una cercaria Lepocreadiidae en Buccinanops monilifer (Kiener) y Buccinanops cochlidium (Dillwyn) (Nassariidae) (Martorelli, 1991; Averbuj \& Cremonte, 2010), una metacercaria Gymnophallidae en Nacella (Patinigera) magellanica y en Nacella (Patinigera) daeurata (Gmelin) (Nacellidae) (Martorelli \& Morriconi, 1998), una cercaria Renicolidae en N. (P.) magellanica y una cercaria Pronocephalidae en N. (P.) deaurata (Martorelli et al., 2005), una cercaria y una metacercaria Microphallidae en Siphonaria lessonii y Kerguelenella lateralis y una cercaria Hemiuroidea y otra Schistosomatidae en S. lessonii (Alda \& Martorelli, 2009).

Los ciclos de vida más frecuentes de los digeneos incluyen dos hospedadores intermediarios (HI), de los cuales el primero es siempre un molusco gasterópodo o bivalvo que alberga esporocistos y/o redias que originan cercarias. Los digeneos larvales han sido utilizados en los últimos años en estudios ecológicos de las comunidades a mayor escala (e.g. Lafferty, 1997; Huspeni et al., 2005; Poulin \& Mouristen, 2006; Hechinger et al., 2011). La identificación taxonómica de nuevos digeneos larvales constituye el primer paso para la dilucidación de sus ciclos de vida y el uso de los mismos como herramienta ecológica y predictiva en otro tipo de estudios.

Históricamente, la identificación de digeneos larvales se ha realizado en función a un conjunto de caracteres morfológicos, teniendo en cuenta también el hospedador y su distribución geográfica (Nolan \& Cribb, 2005). Sin embargo, tanto la identificación, como la inferencia sobre los ciclos de vida utilizando sólo caracteres morfológicos, puede ser difícil de llevar a cabo y dar lugar a errores (Jousson et al., 1999). Algunas de estas dificultades son la escasez de caracteres

taxonómicos y la dudosa validez de alguno de ellos (Schulenburg et al., 1999; 
Maldonado et al., 2001), la gran similitud morfológica entre especies muy cercanas (Tkach et al., 2000) y la plasticidad fenotípica, como la variación producida por la edad y el hospedador utilizado (Galazzo et al., 2002).

Recientemente surgieron los estudios moleculares como una herramienta poderosa para la identificación de especies y para resolver los ciclos de vida, ya que permiten establecer, a partir de la comparación de la información molecular, la correspondencia entre larvas y adultos (e.g., Jousson et al., 1999; Bartoli et al., 2000; Jousson \& Bartoli, 2000; Nolan \& Cribb, 2005; Pina et al., 2009). El ADN ribosomal y los genes mitocondriales suelen ser las opciones más difundidas para el estudio taxonómico de los trematodes (Nolan \& Cribb, 2005). El ADN ribosomal, que codifica el ARN estructural de los ribosomas, suele ocurrir en organismos eucariotas como una serie de unidades repetidas en tándem; cada una de ellas contiene tres regiones codificantes (18S, $2000 \mathrm{pb} ; 5.8 \mathrm{~S}, \sim 150 \mathrm{pb} ; 28 \mathrm{~S}, \sim 4500 \mathrm{pb})$ separadas por dos regiones no codificantes "internal transcribed spacers" (ITS1 e ITS2) (Blair et al., 1996). La tasa evolutiva difiere entre y dentro de estas regiones, proporcionando información útil para resolver problemas a distintos niveles taxonómicos (Blair et al., 1996; Nolan \& Cribb, 2005). Las regiones que codifican para funciones particulares, acumulan pocas mutaciones, ya que la preservación de las funciones es vital para la superviviencia de los organismos. La regiones que no están restringidas a codificar para funciones particulares, como los intrones y regiones no codificantes, evolucionan más rápidamente que las regiones codificantes (Nolan \& Cribb, 2005). Por lo tanto, las regiones 18S, 5.8S y $28 \mathrm{~S}$ del ADN ribosomal, que presentan secuencias más conservadas, se aplican en el estudio de interrelaciones dentro y entre familias de platelmintos. En cambio, las regiones ITS1 e ITS2 del ADN ribosomal, que presentan secuencias más variables, se utilizan para el reconocimiento de especies y para indicar la correspondencia de distintos estadios de desarrollo a la misma especie.

Con el fin de ampliar el conocimiento de la fauna parasitaria en la costa patagónica, el objetivo de este capítulo es describir los estadios larvales de los digeneos parásitos hallados en los gasterópodos más abundantes que habitan los intermareales de Puerto Madryn y Puerto Deseado (Buccinanops globulosus, 
Capítulo 1. Digeneos hallados

Crepipatella dilatata, Fissurella radiosa, Kerguelenella lateralis, Nacella (Patinigera) magellanica, Pareuthria plumbea, Siphonaria lessonii, Tegula patagonica y Trophon geversianus).

\subsection{Materiales y métodos}

\subsubsection{Procesamiento y estudio morfológico de los estadios larvales}

Los gasterópodos colectados fueron colocados en frascos individuales con agua de mar durante 48 hs y expuestos a diferentes factores de estrés (lámpara de luz y calor, período de 3 a 4 hs de desecación) para facilitar la emisión de las cercarias. Cada frasco fue examinado dos veces por día. En el caso de observarse emisión de cercarias, los gasterópodos infectados fueron separados en acuarios para el estudio de las cercarias emitidas y posteriores experimentos de infección en potenciales segundos hospedadores intermediarios. El comportamiento de las cercarias emitidas fue estudiado bajo lupa, observándose el tipo de movimiento y el tiempo de vida a temperatura ambiente $\left(20-22^{\circ}\right.$ C) y en una cámara de temperatura controlada $\left(12^{\circ} \mathrm{C}\right)$.

Los gasterópodos que no emitieron cercarias fueron medidos, sexados y disecados en busca de infecciones prepatentes. Las medidas fueron tomadas sobre la valva con un calibre $(0,1 \mathrm{~mm}$ de precisión). Se utilizó como medida principal la longitud desde el ápex hasta el extremo opuesto de la valva (según el eje de la cochilla). El sexo fue determinado bajo lupa, observando estructuras reproductivas (pene, ovario, glándulas anexas según la especie en estudio). La disección, destinada a la búsqueda de infecciones prepatentes, también se realizó bajo lupa, separando la masa visceral de la valva con pinzas o bisturí. Los estadios larvales (esporocistos o redias con cercarias y/o metacercarias) fueron estudiados en vivo utilizando un Microscopio Óptico (MO) Leica DM 2500. Las larvas fueron montadas transitoriamente entre porta y cubreobjeto con agua de mar, teñidas con colorantes vitales como rojo neutro y azul de Nilo, dibujadas con una cámara clara y fotografiadas con una cámara digital Leica DFC 280. 
Entre 15 y 20 estadios larvales de cada especie fueron colocados en agua de mar caliente y fijados en una solución de formol 10\% en agua de mar (Cribb \& Bray, 2010). Las larvas fueron teñidas con Carmín acético, deshidratadas en una serie progresiva de etanoles $(70 \%, 80 \%, 90 \%, 96 \%, 100 \%)$, aclaradas con metilsalicilato y montadas en forma permanente en bálsamo de Canadá para su estudio al MO. Sobre estos preparados definitivos se midieron las estructuras utilizando un ocular micrométrico. Las medidas se presentan en micrómetros, con la media seguida del rango entre paréntesis. Las medidas de ciertas estructuras difíciles de observar, se basan en un número más acotado de especímenes; en estos casos, el número de mediciones se indica entre paréntesis.

Aproximadamente 30 larvas de cada especie destinadas a su estudio al Microscopio Electrónico de Barrido (MEB) fueron fijadas en una solución de glutaraldehído 2,5\% en buffer de cacodilato de sodio 0,1M, pH 7,4. Luego de la fijación, las larvas fueron deshidratadas en una serie progresiva de etanoles (30\%, $40 \%, 50 \%, 60 \%, 70 \%, 80 \%, 90 \%, 96 \%, 100 \%)$ y sumergidas durante 5 minutos en hexamethyldisilazano (reemplazando el punto crítico). Las larvas fueron secadas al aire bajo campana y montadas en un portaobjeto con cinta bifaz, metalizadas, y fotografiadas utilizando un Microscopio Jeol JSM-6460LV operando a $15 \mathrm{KV}$.

Uno o dos ejemplares de cada especie de gasterópodo parasitado se fijaron en una solución Bouin por 12 horas, luego se lavaron en agua corriente por 24 horas y se conservaron en etanol 70\%. La masa visceral fue deshidratada e infiltrada en resina Historesin Leica ${ }^{\circledR}$; se realizaron cortes histológicos de 3-4 $\mu \mathrm{m}$ y se colorearon con hematoxilina de Guill y eosina con el fin de establecer la localización de cada parásito, determinando órganos y tejidos afectados.

Se registró la prevalencia de cada especie parásita (expresada como \%) como el número de hospedadores parasitados dividido por el número de hospedadores totales examinados. En el caso de Gymnophalloides nacellae, se contabilizó el número de metacercarias por hospedador parasitado y se calculó la intensidad media como el número total de metacercarias dividido el número de hospedadores parasitados. La intensidad de infección se presenta con la media seguida del rango entre paréntesis. 
Algunos especímenes de cada especie, fijados, teñidos y montados fueron depositados en la Colección Helmintológica del Museo de La Plata (MLP), La Plata y en la Colección Parasitológica del Centro Nacional Patagónico (CNP-Par), Puerto Madryn, Argentina. En el caso particular de G. nacellae, los especímenes fueron depositados en el Museo Argentino de Ciencias Naturales (MACN) y en la Colección Parasitologica Nacional, Belstville, Maryland, Estados Unidos (USNPC).

\subsubsection{Estudios moleculares}

Entre dos y 30 larvas de cada especie en estudio (Tabla 1) fueron fijados en etanol 96\% y luego lavados durante 24 hs en una solución buffer de TRIS (10 mM)-EDTA (1 mM). Previamente a la fijación, las larvas fueron adecuadamente identificadas al MO. El ADN de las especies que se detallan en la Tabla 1 se extrajo utilizando el kit Sigma (St. Louis, Missouri, USA, GenEluteTM mammalian genomic DNA kit) siguiendo el protocolo del fabricante. Se trabajó con regiones de ADN ribosomal; entre ellas, regiones codificantes como 18S o "small subunit rDNA gene" (SSU), 5.8S y $28 \mathrm{~S}$ o "large subunit rDNA gene" (LSU). También se secuenciaron las "internal transcribed spacer" (ITS1 e ITS2) localizadas entre las regiones 18S y 28S y separadas en el medio por la región 5.8S (Fig. 5). Estas regiones son menos conservadas y proveen mayor información a nivel de género y especie (Blair et al., 1996). Para todas las especies estudiadas se secuenciaron las regiones ITS1 y/o ITS2 y, en algunos casos particulares, se secuenciaron regiones codificantes (18S y/o 28S). 


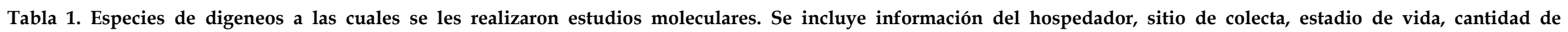

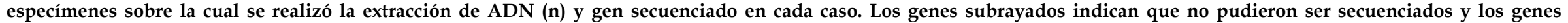
marcados con un asterisco $(*)$ indican que la secuencia se obtuvo en forma parcial.

\begin{tabular}{|c|c|c|c|c|c|c|c|}
\hline Especie & $\begin{array}{l}\text { No Gen }^{\circ} \text { Bank } \\
\text { Bank }\end{array}$ & $\begin{array}{c}\text { Estadio } \\
\text { larval }\end{array}$ & Hospedador & Sitio de infección & Sitio de colecta & $\mathbf{N}$ & Gen \\
\hline Hemiuroidea fam. gen. et sp. & KF451931 & esporocisto & Siphonaria lessonii & $\begin{array}{c}\text { gónada, glándula } \\
\text { digestiva }\end{array}$ & Puerto Madryn & 16 & ITS1 \\
\hline Lepocreadiidae gen. et sp. 1 & $\begin{array}{l}\text { KF451932, } \\
\text { KF451933 }\end{array}$ & redia & $\begin{array}{l}\text { Crepipatella } \\
\text { dilatata }\end{array}$ & $\begin{array}{c}\text { gónada, glándula } \\
\text { digestiva }\end{array}$ & Puerto Deseado & 26 & $\begin{array}{c}\text { 18S, ITS1*, ITS2, } \\
28 \mathrm{~S}\end{array}$ \\
\hline Lepocreadiidae gen. et sp. 2 & $\begin{array}{l}\text { KF451934, } \\
\text { KF451935 }\end{array}$ & redia & Pareuthria plumbea & $\begin{array}{c}\text { gónada, glándula } \\
\text { digestiva }\end{array}$ & Puerto Deseado & 51 & $\begin{array}{c}\text { 18S, ITS1*, ITS2, } \\
28 \mathrm{~S}\end{array}$ \\
\hline Lepocreadium album & $\begin{array}{l}\text { KF656703, } \\
\text { KF656704 }\end{array}$ & cercarias & $\begin{array}{l}\text { Nassarius } \\
\text { reticulatus }\end{array}$ & gónada & Aveiro, Portugal & 50 & 18S, ITS2, $28 S$ \\
\hline Opechona sp. & $\begin{array}{l}\text { KF451938, } \\
\text { KF451939 }\end{array}$ & redia & $\begin{array}{l}\text { Buccinanops } \\
\text { cochlidium }\end{array}$ & $\begin{array}{c}\text { gónada, glándula } \\
\text { digestiva }\end{array}$ & Playa Fracasso & 28 & $\begin{array}{c}\text { 18S, ITS1 * ITS2, } \\
28 S\end{array}$ \\
\hline Opechona sp. & $\begin{array}{l}\text { KF451936, } \\
\text { KF451937 }\end{array}$ & adulto & Scomber japonicus & ciegos intestinales & Playa Fracasso & 7 & $\begin{array}{c}\text { 18S, ITS1* ITS2, } \\
28 \mathrm{~S}\end{array}$ \\
\hline Diphterostomum sp. & KF358772 & esporocisto & $\begin{array}{l}\text { Buccinanops } \\
\text { globulosus }\end{array}$ & $\begin{array}{c}\text { gónada, glándula } \\
\text { digestiva }\end{array}$ & Puerto Madryn & 27 & $\underline{\text { ITS1, 5.8S, ITS2 }}$ \\
\hline Diphterostomum sp. & KF483875 & adulto & $\begin{array}{l}\text { Pinguipes } \\
\text { brasilianus }\end{array}$ & ciegos intestinales & Puerto Madryn & 19 & ITS1, 5.8S, ITS2 \\
\hline Zoogonus sp. & KF358773 & esporocisto & Pareuthria plumbea & $\begin{array}{c}\text { gónada, glándula } \\
\text { digestiva }\end{array}$ & Puerto Deseado & 16 & ITS1, 5.8S, ITS2 \\
\hline Gymnophalloides nacellae & JN381025 & metacercaria & $\begin{array}{l}\text { Nacella }(P .) \\
\text { magellanica }\end{array}$ & $\begin{array}{c}\text { entre manto y } \\
\text { valva }\end{array}$ & Puerto Deseado & 50 & $\begin{array}{c}\text { 18S, ITS1, 5.8S, } \\
\text { ITS2, 28S }\end{array}$ \\
\hline Gymnophalloides nacellae & KF575168 & esporocisto & $\begin{array}{l}\text { Gaimardia } \\
\text { trapesina }\end{array}$ & $\begin{array}{c}\text { gónada, glándula } \\
\text { digestiva }\end{array}$ & Puerto Deseado & 21 & ITS1 \\
\hline
\end{tabular}


Tabla 1. Especies de digeneos a las cuales se les realizaron estudios moleculares. Se incluye información del hospedador, sitio de colecta, estadio de vida, cantidad de especímenes sobre la cual se realizó la extracción de ADN (n) y gen secuenciado en cada caso. Los genes subrayados indican que no pudieron ser secuenciados y los genes marcados con un asterisco $(*)$ indican que la secuencia se obtuvo en forma parcial.

\begin{tabular}{|c|c|c|c|c|c|c|c|}
\hline Especie & $\begin{array}{c}\text { No Gen }^{\circ} \\
\text { Bank }\end{array}$ & $\begin{array}{c}\text { Estadio } \\
\text { larval }\end{array}$ & Hospedador & $\begin{array}{l}\text { Sitio de } \\
\text { infección }\end{array}$ & Sitio de colecta & $\mathbf{N}$ & Gen \\
\hline Maritrema sp. 1 & KC012521 & esporocisto & $\begin{array}{l}\text { Crepipatella } \\
\text { dilatata }\end{array}$ & $\begin{array}{c}\text { gónada, glándula } \\
\text { digestiva, pie, } \\
\text { manto }\end{array}$ & Puerto Madryn & 47 & ITS1, 5.8S, ITS2 \\
\hline Maritrema madrynense & KC222022 & metacercaria & Siphonaria lessonii & $\begin{array}{c}\text { gónada, glándula } \\
\text { digestiva }\end{array}$ & Puerto Madryn & 120 & ITS1, 5.8S, ITS2 \\
\hline Maritrema madrynense & KC222023 & metacercaria & $\begin{array}{c}\text { Cyrtograpsus } \\
\text { altimanus }\end{array}$ & $\begin{array}{l}\text { branquias, } \\
\text { hemocele }\end{array}$ & Puerto Madryn & 13 & ITS1, 5.8S, ITS2 \\
\hline Maritrema madrynense & KC222024 & metacercaria & Idotea baltica & hemocele & Puerto Madryn & 15 & ITS1, 5.8S, ITS2 \\
\hline Maritrema madrynense & KF575167 & adultos & Larus dominicanus & intestino & Puerto Madryn & 70 & ITS1 \\
\hline Notocotylidae gen. et sp. & KF656705 & metacercaria & $\begin{array}{l}\text { Nacella }(P .) \\
\text { magellanica }\end{array}$ & $\begin{array}{c}\text { gónada, glándula } \\
\text { digestiva }\end{array}$ & Puerto Deseado & 60 & ITS1 \\
\hline Parorchis sp. & KF451927 & esporocisto & $\begin{array}{c}\text { Trophon } \\
\text { geversianus }\end{array}$ & $\begin{array}{c}\text { gónada, glándula } \\
\text { digestiva }\end{array}$ & Puerto Madryn & & $\begin{array}{c}\text { ITS1-5.8S-ITS2- } \\
28 S\end{array}$ \\
\hline Parorchis sp. & $\begin{array}{l}\text { KF451928, } \\
\text { KF451929 }\end{array}$ & adulto & Larus dominicanus & cloaca & Puerto Deseado & 1 & $\begin{array}{l}\text { ITS1-5.8S- } \\
\text { ITS2*-28S }\end{array}$ \\
\hline Parorchis sp. & KF451930 & adulto & Calidris fuscicollis & cloaca & Bahía Lomas & 1 & $\begin{array}{c}\text { ITS1-5.8S-ITS2- } \\
28 S\end{array}$ \\
\hline Renicolidae gen. et sp. 1 & KF358774 & esporocisto & $\begin{array}{c}\text { Trophon } \\
\text { geversianus }\end{array}$ & $\begin{array}{c}\text { gónada, glándula } \\
\text { digestiva }\end{array}$ & Puerto Madryn & 14 & ITS1 \\
\hline Renicolidae gen. et sp. 2 & KF358775 & esporocisto & $\begin{array}{l}\text { Nacella (P.) } \\
\text { magellanica }\end{array}$ & $\begin{array}{c}\text { gónada, glándula } \\
\text { digestiva }\end{array}$ & Puerto Deseado & 20 & ITS1 \\
\hline Renicolidae gen. et sp. 1 & KF425522 & metacercaria & Mytilus edulis & $\begin{array}{l}\text { glándula } \\
\text { digestiva }\end{array}$ & $\begin{array}{l}\text { Comodoro } \\
\text { Rivadavia }\end{array}$ & 32 & ITS1 \\
\hline Schistosomatidae gen. et sp. & - & esporocisto & Siphonaria lessonii & $\begin{array}{c}\text { gónada, glándula } \\
\text { digestiva }\end{array}$ & Puerto Deseado & 20 & $\underline{\text { ITS1 }}$ \\
\hline
\end{tabular}




\section{5-185For}

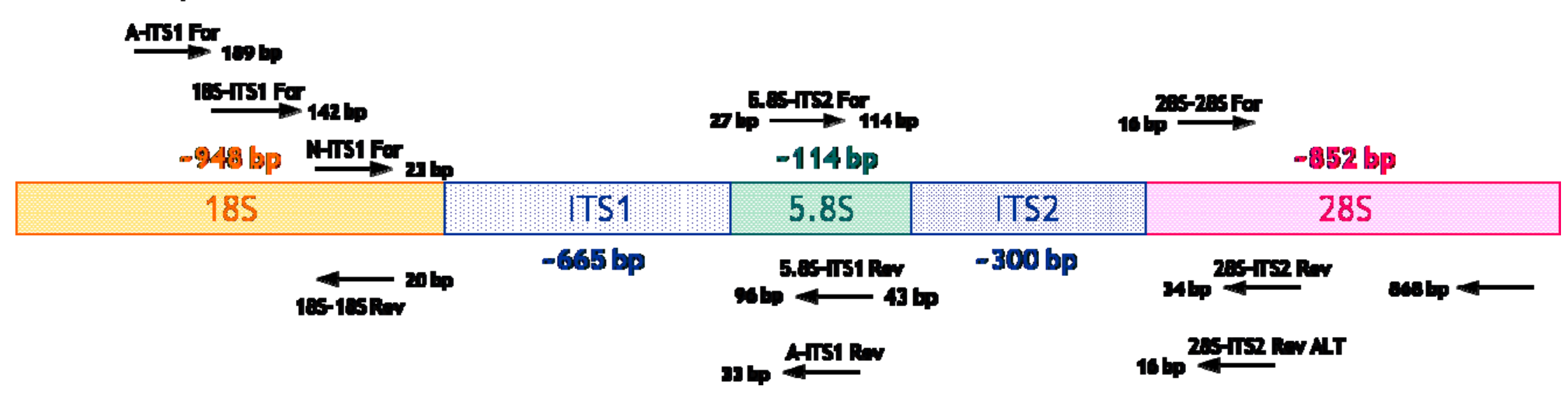

Figura 5. Diagrama de la organización nuclear del ADN ribosomal de un eucariota tipo y su ARN primario transcripto. Las regiones 18S, $5.8 \mathrm{~S}$ y $28 \mathrm{~S}$ son regiones codificantes y las regiones ITS1 e ITS2 son espaciadores transcriptos internos. En color y sobre o debajo de la barra se encuentra el tamaño (medido como pares de bases) de cada región. Las flechas indican en qué lugar de la secuencia comienza a amplificar cada primer. 
Se realizaron amplificaciones de ADN mediante Reacción en Cadena de la Polimerasa (PCR) utilizando un volumen total de $50 \mu 1$ por muestra ( $38,3 \mu 1$ de agua destilada, $5 \mu \mathrm{l}$ de Taq buffer, $1 \mu \mathrm{l}$ de dNTPs, $1,5 \mu \mathrm{l}$ de $\mathrm{MgCl}_{2}, 0,5 \mu 1$ de cada primer, 0,2 $\mu \mathrm{l}$ de Taq polimerasa platinum y $2 \mu \mathrm{l}$ de ADN molde). Los programas de termociclados para cada región fueron:

- $\quad 18 \mathrm{~S}$ y 28S: 5 min de desnaturalización a $94{ }^{\circ} \mathrm{C} ; 40$ ciclos durante 30 seg a $94{ }^{\circ} \mathrm{C}, 30$ seg a $52^{\circ} \mathrm{C}, 2 \mathrm{~min}$ a $72^{\circ} \mathrm{C}$; y una extensión final por $10 \mathrm{~min}$ a $72^{\circ} \mathrm{C}$.

- ITS1: 5 min de desnaturalización a $94{ }^{\circ} \mathrm{C} ; 40$ ciclos durante 30 seg a $94{ }^{\circ} \mathrm{C}, 30$ seg a $54{ }^{\circ} \mathrm{C}, 2 \mathrm{~min}$ a $72{ }^{\circ} \mathrm{C}$; y una extensión final por $10 \mathrm{~min}$ a $72{ }^{\circ} \mathrm{C}$.

- ITS2: 5 min de desnaturalización a $94{ }^{\circ} \mathrm{C} ; 40$ ciclos durante $30 \mathrm{seg}$ a $94{ }^{\circ} \mathrm{C}, 30 \mathrm{seg}$ a $56^{\circ} \mathrm{C}, 2 \mathrm{~min}$ a $72^{\circ} \mathrm{C}$; y una extensión final por $10 \mathrm{~min}$ a $72^{\circ} \mathrm{C}$.

Los primers utilizados para amplificar las diferentes regiones fueron provistos por los Dres. Rodrigues y Pina del ICBAS (Universidad de Porto) y se detallan en la Tabla 2.

Los productos de la PCR fueron corridos en un gel de agarosa $1 \%$ mediante electroforesis $(120$ V) y el ADN se purificó utilizando un Kit de Extracción Qiagen Qiaquick® (Valencia, California, USA). El ADN purificado fue enviado a secuenciar a Stabvida, Oeiras, Portugal y las secuencias fueron analizadas y comparadas utilizando el software Multalin (http://bioinfo.genotoul.fr/multalin/multalin.html) $\quad$ y $\quad$ BLAST (http://blast.ncbi.nlm.nih.gov/). Las secuencias de las especies estudiadas fueron depositadas en Gen Bank bajo los números de acceso que se detallan en la Tabla 1. En la Tabla 1 también se incluyen secuencias de otros digeneos (larvas y adultos) que se obtuvieron con el fin de completar los ciclos de vida de algunas de las especies estudiadas. En el capítulo 2 se detallará la obtención de dichas muestras. 
Tabla 2. Secuencias de los primers utilizados para la secuenciación de las regiones del ADN ribosomal de los digeneos estudiados.

\begin{tabular}{|c|c|c|c|}
\hline $\begin{array}{l}\text { Región del ADN } \\
\text { ribosomal }\end{array}$ & Primers & Secuencia & $\begin{array}{c}\text { Temperatura de } \\
\text { unión }\left({ }^{\circ} \mathrm{C}\right)\end{array}$ \\
\hline \multirow{2}{*}{$18 \mathrm{~S}$} & 18S-18S Fw & $5^{\prime}$ - ATCCGAAGTAATGGTTAAGAGGG -3' & 53 \\
\hline & 18S-18S Rev & 5'- ACCTACGGAAACCTTGTTACG -3' & 50 \\
\hline \multirow{6}{*}{ ITS1 } & A-ITS1 Fw & $5^{\prime}$ - GGTAAGTGCAAGTCATAAGC - $3^{\prime}$ & 58 \\
\hline & A-ITS1 Rev & 5'- GCTGCGCTCTTCATCGACA -3' & 60 \\
\hline & N-ITS1 Fw & 5' - CGTAACAAGGTTTCCGTAG -3' & 56 \\
\hline & N-ITS1 Rev & $5^{\prime}$ - TGTTGAGGCAATGGAACA - ${ }^{\prime}$ & 52 \\
\hline & 18S-ITS1 Fw & 5' - CCGTCGCTACTACCGATTGAA -3' & 54 \\
\hline & 5.8S-ITS1 Rev & 5' - CGCAATGTGCGTTCAAGATGTC -3' & 58 \\
\hline \multirow{2}{*}{ ITS2 } & 5.8S-ITS2 Fw & $5^{\prime}$ - GCTCGTGTGTCGATGAAGAG -3' & 50 \\
\hline & 28S-ITS2 Rev & 5'- AGGCTTCGGTGCTGGGCT -3' & 57 \\
\hline \multirow{2}{*}{$28 S$} & 28S-28S Fw & $5^{\prime}$ - GTGAATACCCGCTGAACTTAAGC -3' & 54 \\
\hline & 28S-28S Rev & 5' - TCTCCTTGGTCCGTGTTTCAA -3' & 54 \\
\hline
\end{tabular}




\subsection{Resultados}

Hemiuroidea Looss, 1899

Hemiuroidea fam. gen. et sp. (Figuras 6-9) ${ }^{1}$

\section{Descripción de las larvas}

Esporocisto: muy grande, largo y delgado, de forma irregular, con un extremo anterior estrecho y un extremo posterior levemente expandido. Mide 4.461 (2.7007.410) de longitud por 269 (180-310) de ancho máximo. El poro de puesta es largo y delgado y se localiza en el extremo anterior (Fig. 7A). El número de cercarias por esporocisto es de 250 (130-400).

Cercaria: tipo cistófora, cuerpo elongado. Mide 138 (117-162) de longitud por 27 (2230) de ancho y se desarrolla dentro de un quiste caudal esférico que mide 105 (92128) de diámetro (Figs., 7B, 8A). La distancia desde el extremo anterior del cuerpo hasta el margen anterior de la ventosa ventral es de 45 (32-58). El tubo eyector está adherido al extremo posterior de la cavidad del quiste y es ligeramente aplanado (Fig. 8C) y mide 329 (267-369) de longitud $(n=3)$. Posee un surco longitudinal medio y una aleta apical. La vesícula excretora es epiteliocistida y mide 43 (32-50) de longitud por 21 (14-26) de ancho. La ventosa oral tiene un diámetro de 20 (15-25) y la ventosa ventral tiene un diámetro de 16 (14-20). La relación entre ventosa oralventral es 1:0,8 (0,7-0,93). No se observa faringe, esófago ni ciegos intestinales. Presenta dos filamentos caudales delgados a ambos lados del quiste, uno más largo que el otro. El filamento más largo mide 416 (320-490) de longitud y el más corto mide 226 (196-290) de longitud.

Comportamiento de la cercaria y tiempo de vida: debido a que no se obtuvieron emisiones, las cercarias fueron extraídas de los esporocistos para su estudio. En dichas condiciones, las cercarias se mueven lentamente en el fondo del recipiente durante unos pocos minutos.

\footnotetext{
${ }^{1}$ La descripción de los estadios larvales de esta especie fue publicada en Gilardoni et al. (2011)
} 


\section{Secuencias moleculares}

Se secuenció la región ITS1 del ADN ribosomal de esporocistos. Se obtuvieron en forma parcial las regiones $18 \mathrm{~S}$ y $5.8 \mathrm{~S}$ y en forma completa la región ITS1. Las secuencias parciales de las regiones $18 \mathrm{~S}$ y $5.8 \mathrm{~S}$ tienen 86 y 117 pares de bases $(\mathrm{pb})$ respectivamente; la secuencia completa de la región ITS1 tiene 690 pb. La secuencia no presentó similitud con ninguna disponible en la base de datos de Gen Bank. Las secuencias disponibles de la superfamilia Hemiuroidea pertenecen a regiones $18 \mathrm{~S}$, ITS2, 28S, microsatélites y genes mitocondriales. Las futuras secuenciaciones de la especie en cuestión sobre estas regiones y genes disponibles contribuirán a resolver su identificación taxonómica.

\section{Resumen taxonómico}

Hospedador: Siphonaria lessonii Blainville (Pulmonata, Basommatophora, Siphonariidae).

Localidades: Puerto Madryn y Puerto Deseado.

Prevalencia total: 0,48\% ( $n=1.050)$ en Puerto Madryn y 4,84\% ( $n=186)$ en Puerto Deseado.

Sitio de infección: los esporocistos invaden principalmente la gónada, el complejo glandular paleal asociado y la glándula digestiva. En infecciones altas pueden afectar otros órganos, invadiendo tejido conectivo del manto y branquia secundaria (Fig. 9).

Especímenes depositados: MLP 6283, CNP-Par 26.

\section{Comentarios taxonómicos}

La cercaria descripta pertenece a la superfamilia Hemiuroidea debido a que su morfología es compatible con la diagnosis de la familia: la cercaria desarrolla dentro de un quiste caudal que puede presentar apéndices y posee una estructura delgada denominada tubo eyector (Cable, 1956). En Argentina se han registrado tres cercarias de esta superfamilia, Genarchella genarchella Travassos, 1928 en Heleobia parchappii d'Orbigny (Cochliopidae), una cercaria cistófora en Potamolithus agapetus Pilsbry (Hydrobiidae) en lagunas de la provincia de Buenos Aires (Martorelli, 
1989a, 1994) y otra cercaria cistófora en Siphonaria lessonii de Comodoro Rivadavia, Chubut (Alda \& Martorelli, 2009). La larva aquí descripta es similar a la registrada en Comodoro Rivadavia y es probable que pertenezca a la misma especie; sin embargo, se observaron dos filamentos caudales en el quiste en lugar de uno.

A

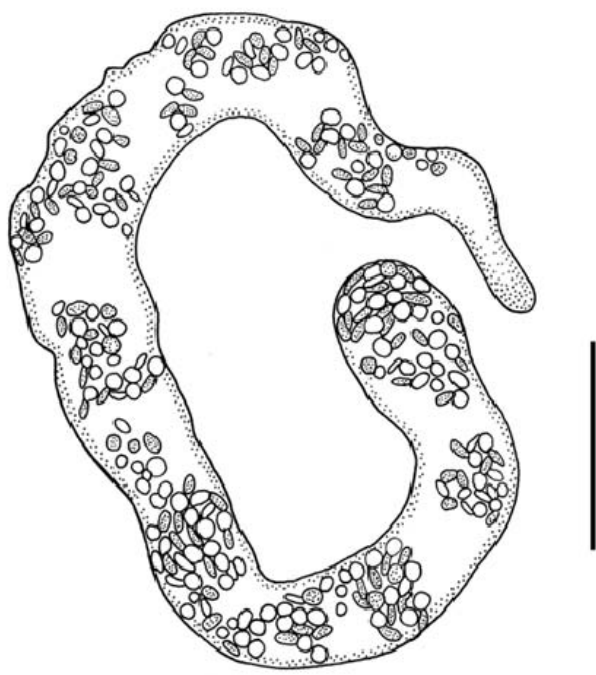

B

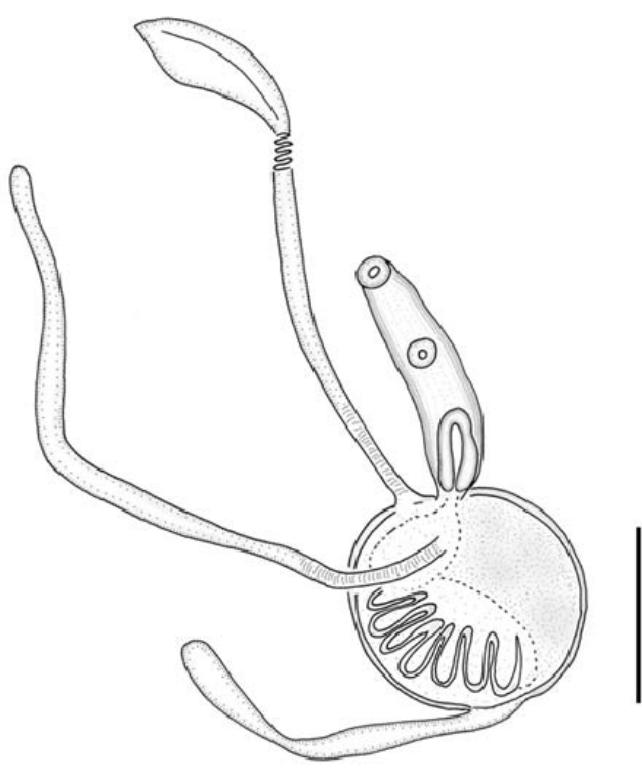

Figura 6. Estadios larvales de Hemiuroidea fam. gen. et sp. A- Esporocisto; B- Cercaria. Escalas: $500 \mu \mathrm{m}$ (A); $100 \mu \mathrm{m}(\mathrm{B})$. 


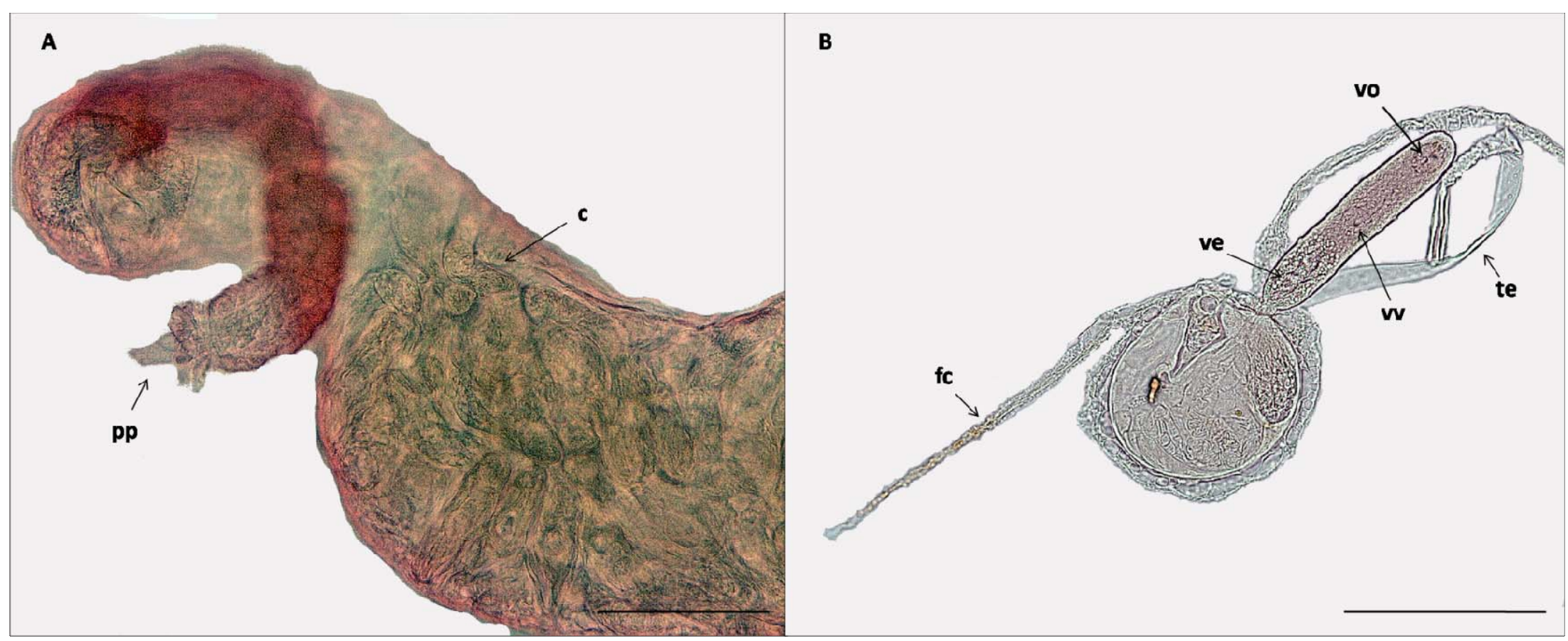

Figura 7. Estadios larvales de Hemiuroidea fam. gen. et sp. (fotografías al MO). A- Extremo anterior del esporocisto repleto de cercarias; B- Cercaria. Escalas: 100 $\mu \mathrm{m}(\mathrm{A}, \mathrm{B})$. Abreviaturas: c- cercaria; fc- filamento caudal; pp- poro de puesta; te- tubo eyector; ve- vesícula excretora; vo- ventosa oral; vv- ventosa ventral. 


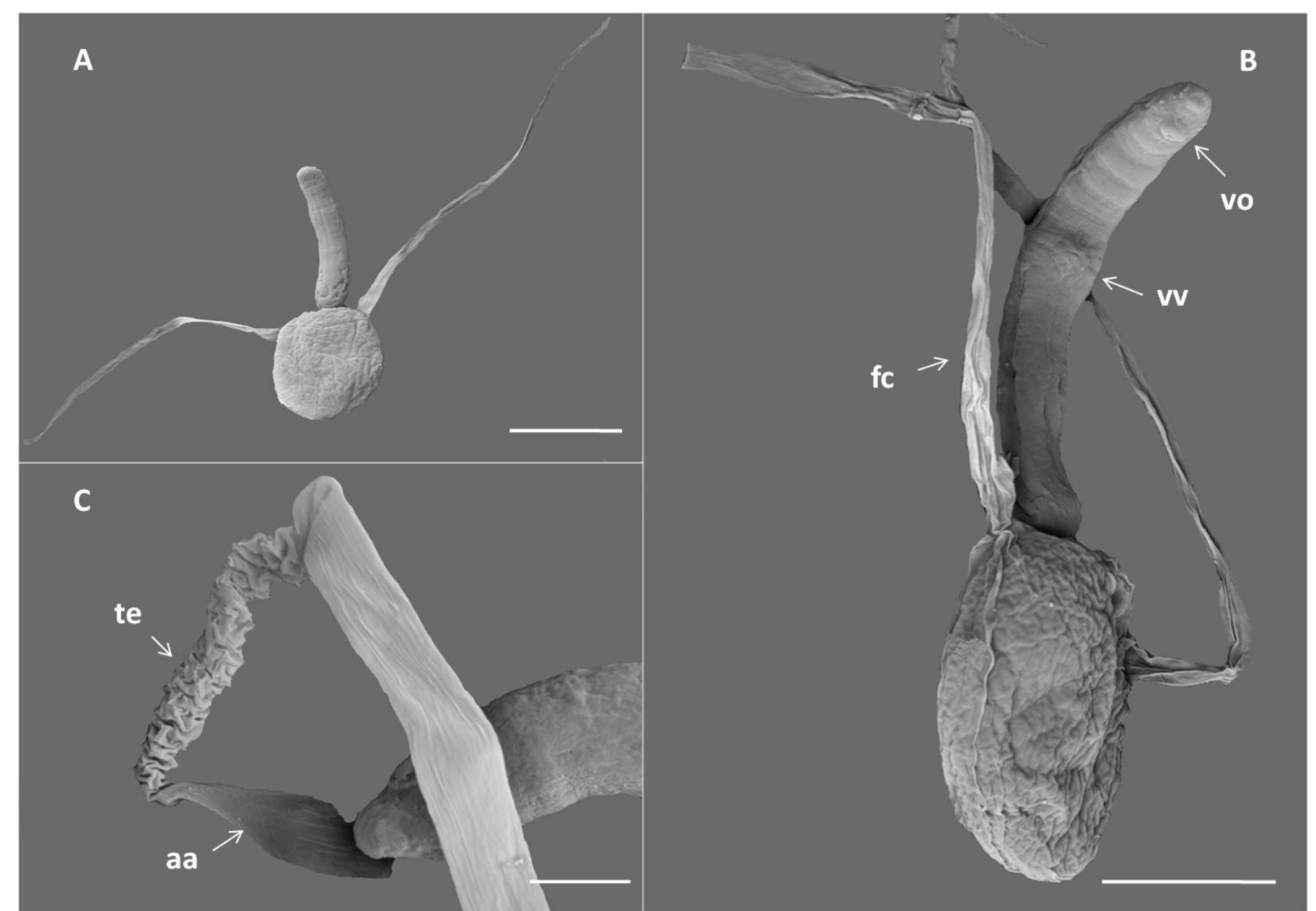

Figura 8. Estadios larvales de Hemiuroidea fam. gen. et sp. (fotografías al MEB). A- Cercaria, vista del quiste, cuerpo y filamentos caudales; B- Detalle de las ventosas oral y ventral y de los filamentos caudales; C- Detalle del tubo eyector. Escalas: $100 \mu \mathrm{m}$ (A, B); 25 $\mu \mathrm{m}(\mathrm{C})$. Abreviaturas: aa- aleta apical; fc-filamento caudal; te- tubo eyector; vo- ventosa oral; vv- ventosa ventral. 


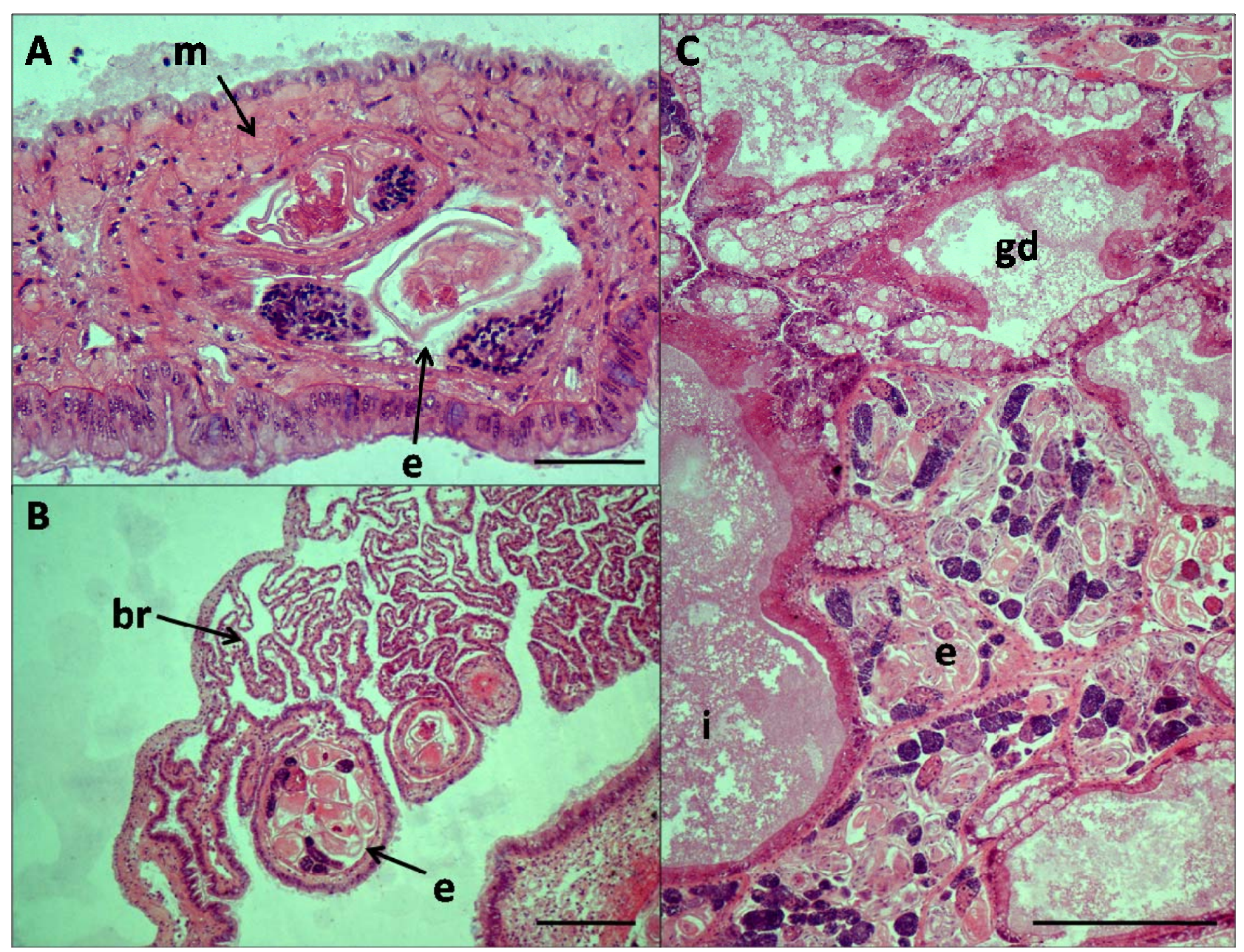

Figura 9. Cortes histológicos de Siphonaria lessonii parasitada por esporocistos de Hemiuroidea fam. gen. et sp. A- Esporocistos en el manto; B- Esporocistos encapsulados en branquia; C- Esporocistos entre los acinos de la glándula digestiva. Escalas: 500 rm (A, B, C). Abreviaturas: br- branquia; e- esporocisto; gd- glándula digestiva; i- intestino; m- manto. 
Capítulo 1. Digeneos hallados

Lepocreadiidae Odhner, 1905

Lepocreadiidae gen. et sp. 1 (Figuras 10-13)

\section{Descripción de las larvas}

Redia: elongada, con el extremo anterior aguzado, mide 669 (491-829) de longitud por 130 (105-154) de ancho máximo. La pared presenta un espesor de 5 (3-7) y posee un poro de puesta lateral en el extremo anterior (Fig. 11C). La faringe es grande y muscular, mide 70 (50-82) de longitud por 50 (43-64) de ancho. El intestino sólo pudo ser observado en las redias recién desarrolladas (Fig. 11A); en las redias con cercarias no se observó el intestino debido a que se hallaba enmascarado por las cercarias. El número de larvas por redia es de 15 (5-29), de las cuales 12 (5-29) son cercarias y 3 (2-6) son esferas germinales. Las esferas germinales se localizan en el extremo posterior de la redia; las cercarias están poco desarrolladas dentro de las redias; cuando emergen de las redias, aumentan considerablemente de tamaño y completan su desarrollo.

Cercaria: tipo oftalmotricocerca (con manchas oculares y cola con setas). El cuerpo es espinoso y mide 226 (145-286) de longitud por 98 (84-125) de ancho máximo. La distancia desde el extremo anterior del cuerpo hasta el margen anterior de la ventosa ventral es de 106 (78-109). Presenta dos manchas oculares ovaladas (Figs. $11 \mathrm{D}, \mathrm{E})$ localizadas posteriormente a la ventosa oral, a una distancia de 70 (40-99) del extremo anterior del cuerpo; miden 24 (17-31) de longitud por 17 (14-20) de ancho y están separadas entre sí por una distancia de 21 (13-30). La ventosa oral mide 53 (38-72) de longitud por 46 (34-54) de ancho. La boca es subterminal y está rodeada por un círculo exterior de por lo menos ocho papilas y un círculo interior de por lo menos cuatro papilas grandes en la mitad posterior y por lo menos doce papilas en la parte anterior (observado al MEB, Fig. 12D). Desde el extremo posterior de la ventosa oral hasta la parte posterior de la ventosa ventral, se extienden dos hileras de ocho papilas a cada lado del cuerpo (observado al MEB, Fig. 12D). La prefaringe es larga y mide 20 (14-31) de longitud; la faringe mide 21 (15-24) de longitud por 18 (13-25) de ancho; el esófago es corto, mide 16 (11-21) de longitud y se bifurca inmediatamente anterior a la ventosa ventral. Los ciegos 
intestinales son estrechos, miden 153 (93-174) de longitud y se extienden hasta el extremo posterior del cuerpo. La ventosa ventral se localiza a nivel medio del cuerpo, mide 39 (29-48) de longitud por 45 (41-49) de ancho y presenta seis papilas internas en la mitad anterior y nueve papilas externas formando un anillo concéntrico (observado al MEB, Fig. 12D). La relación entre ventosa oral-ventral es 1:0,98 $(0,91-1,2)$. Presenta cuatro pares de glándulas de penetración que se abren dorsalmente en el extremo anterior del cuerpo; los citones se localizan detrás de las manchas oculares a nivel del esófago; ninguna de estas glándulas se tiñe con rojo neutro (Fig. 11E). Posteriormente a la ventosa ventral se observa el ovario pretesticular que mide 11 (8-15) de longitud por 16 (10-21) de ancho y dos testículos en tándem; el testículo anterior mide 12 (8-17) de longitud por 22 (15-27) de ancho y el testículo posterior mide 14 (9-19) de longitud por 23 (19-29) de ancho. El metratermo y el saco del cirro desembocan en un atrio genital submediano localizado a la izquierda de la ventosa ventral (Fig. 10D). La vesícula excretora es alargada y delgada, mide 145 (103-180) de longitud por 14 (5-31) de ancho (el ancho es muy variable dependiendo del grado de repleción); se extiende hacia el extremo anterior y se curva rodeando la ventosa ventral; contiene gránulos de excreción grandes y refringentes (Fig. 11D). Los ductos colectores principales se originan en la vesícula y se ramifican al nivel de los citones de las glándulas de penetración. En el extremo posterior de la vesícula excretora se observa un esfínter muscular. Se observaron algunas células flamígeras aunque la fórmula excretora no pudo ser determinada. La cola supera el doble del largo del cuerpo y mide 566 (435-692) de longitud por 35 (28-39) de ancho en la base; presenta 25 pares de grupos de setas que miden 107 (97-120) de longitud; cada grupo posee seis o siete setas y hay un par de setas en la punta de la cola $(n=5)$.

Comportamiento de la cercaria y tiempo de vida: las cercarias emitidas nadan por la columna de agua alternando movimientos lentos del cuerpo y movimientos rápidos de la cola girando sobre sí mismas. Tanto a temperatura ambiente como a $12{ }^{\circ} \mathrm{C}$ viven aproximadamente $48 \mathrm{hs}$. 


\section{Secuencias moleculares}

Se secuenciaron las regiones 18S, ITS1, ITS2 y 285 del ADN ribosomal de redias. Se obtuvieron en forma parcial las regiones 18S, ITS1, 5.8S y 285 y en forma completa la región ITS2. Las secuencias parciales de las regiones 18S, ITS1, 5.8S y 28S tienen 946, 484, 93 y 936 pares de bases (pb) respectivamente; la secuencia completa de la región ITS2 tiene $330 \mathrm{pb}$. Las secuencias presentaron similitudes con otras disponibles en la base de datos de Gen Bank pertenecientes a especies de la familia

Lepocreadiidae (ver Anexo I). Aquellas con mayor porcentaje de similitud fueron las correspondientes a Opechona sp. (99,79\% de similitud en la región 28S), Opechona baciliaris $(87,4 \%$ de similitud en la región ITS1), Lepocreadium album (94,64\% de similitud en la región ITS2 y 98,25\% de similitud en la región 28S), Opechona kahawai (98,48\% de similitud en la región 285$)$ y Prodistomum keyam (98,5\% de similitud en la región 28S).

\section{Resumen taxonómico}

Hospedador: Crepipatella dilatata Lamarck (Caenograstropoda, Calyptraeidae).

Localidad: Puerto Deseado.

Prevalencia total: $3,76 \%(\mathrm{n}=266)$.

Sitio de infección: las redias invaden la gónada y en intensidades altas también la glándula digestiva (Fig. 13).

Especimenes depositados: CNP-Par 52.

\section{Comentarios taxonómicos}

La cercaria descripta pertenece a la familia Lepocreadiidae debido a que su morfología es compatible con la diagnosis de la familia: cercaria distoma, ocelada y tricocerca, se desarrolla dentro de una redia, posee cuerpo espinoso, papilas sensoriales y cola variablemente ornamentada, con pares de setas laterales individuales o en grupos que no están unidas por una membrana formando aletas. Los ciegos intestinales se extienden hasta el extremo posterior del cuerpo. El sistema excretor es variable y la vesícula suele presentar forma de saco y extenderse hasta la ventosa ventral (Cable, 1963). 
Hasta el momento se han descripto 23 especies de cercarias de la familia Lepocreadiidae; seis de ellas fueron halladas en el hemisferio sur y sólo una ha sido registrada en el Mar Argentino (ver Tabla 7 en el capítulo 2). La cercaria aquí descripta es una nueva especie, morfológicamente similar a las cercarias pertenecientes al género Lepocreadium Stossich, 1904. Presenta cuatro pares de glándulas de penetración, al igual que Lepocreadium areolatum (Linton, 1900) y por la presencia de manchas oculares, la forma de la vesícula excretora y el número de pares de setas en la cola (aproximadamente 25) se asemeja a Lepocreadium pegorchis (Stossich, 1900) (Bartoli, 1967; Stunkard, 1980a). Sin embargo, los resultados moleculares mostraron una mayor similitud de las secuencias con especies del género Opechona y con Lepocreadium album (Stossich, 1890) (la única especie de este género cuyas secuencias se hallan disponibles) (Palombi, 1937; Russell-Pinto et al., 2006). A nivel morfológico, las cercaria aquí descripta se asemeja a L. album en el tamaño del cuerpo, el tamaño de las ventosas y la localización y forma de las manchas oculares; sin embargo, difieren en el número de glándulas de penetración (4 vs. 3), número de pares de setas en la cola (27 vs. 25) y en la forma y extensión de los ciegos digestivos (delgados, se extienden hasta el extemos posterior de cuerpo vs. gruesos, se extienden hasta al nivel del extremo anterior del esfínter). 


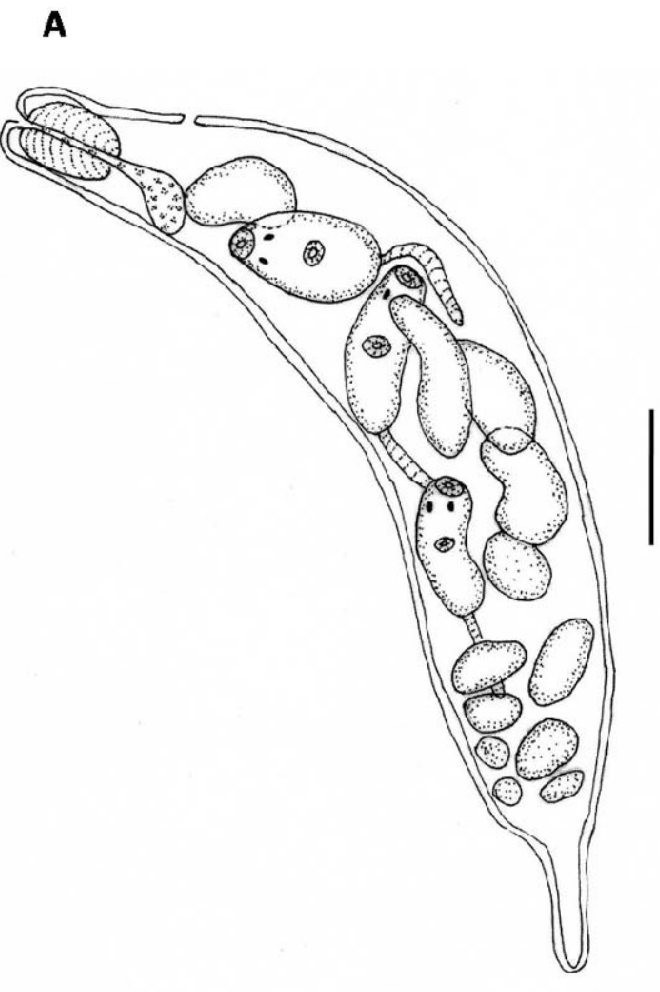

B

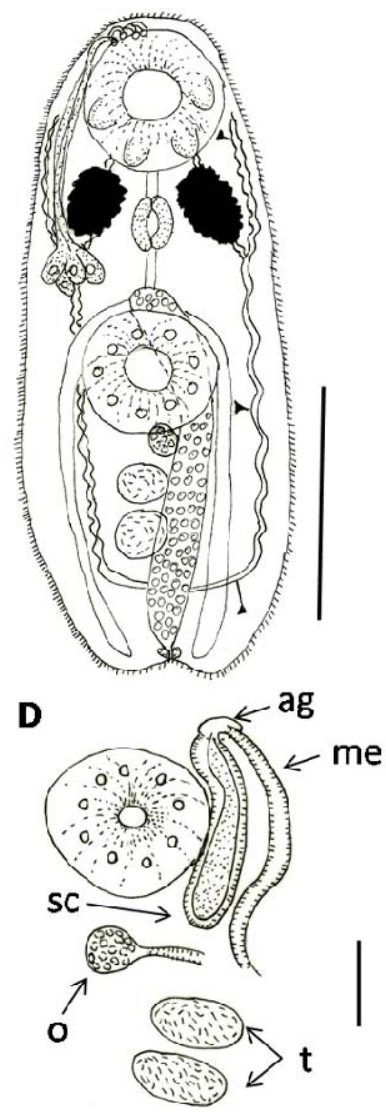

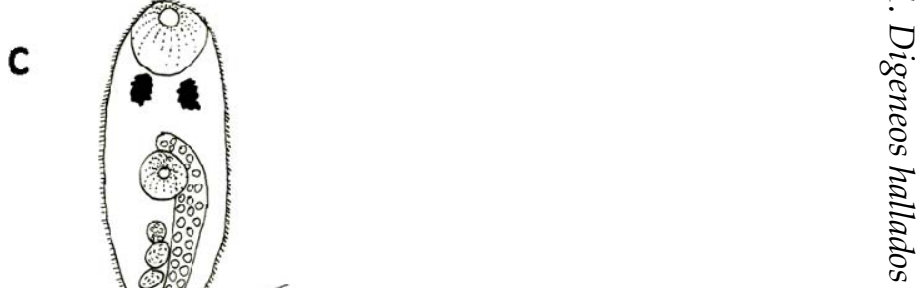

Figura 10. Estadios larvales de Lepocreadiidae gen. et sp. 1. A-Redia; B- Cuerpo de la cercaria, vista ventral, se omitieron las glándulas de penetración del lado izquierdo y las células flamígeras del lado derecho; C- Cercaria, vista ventral; D- Detalle del aparato genital. Escalas: $100 \mu \mathrm{m}(\mathrm{A}, \mathrm{B}, \mathrm{C}) ; 20 \mu \mathrm{m}$ (D). Abreviaturas: ag- atrio genital; memetratermo; o- ovario; sc- saco del cirro; t- testículo. 


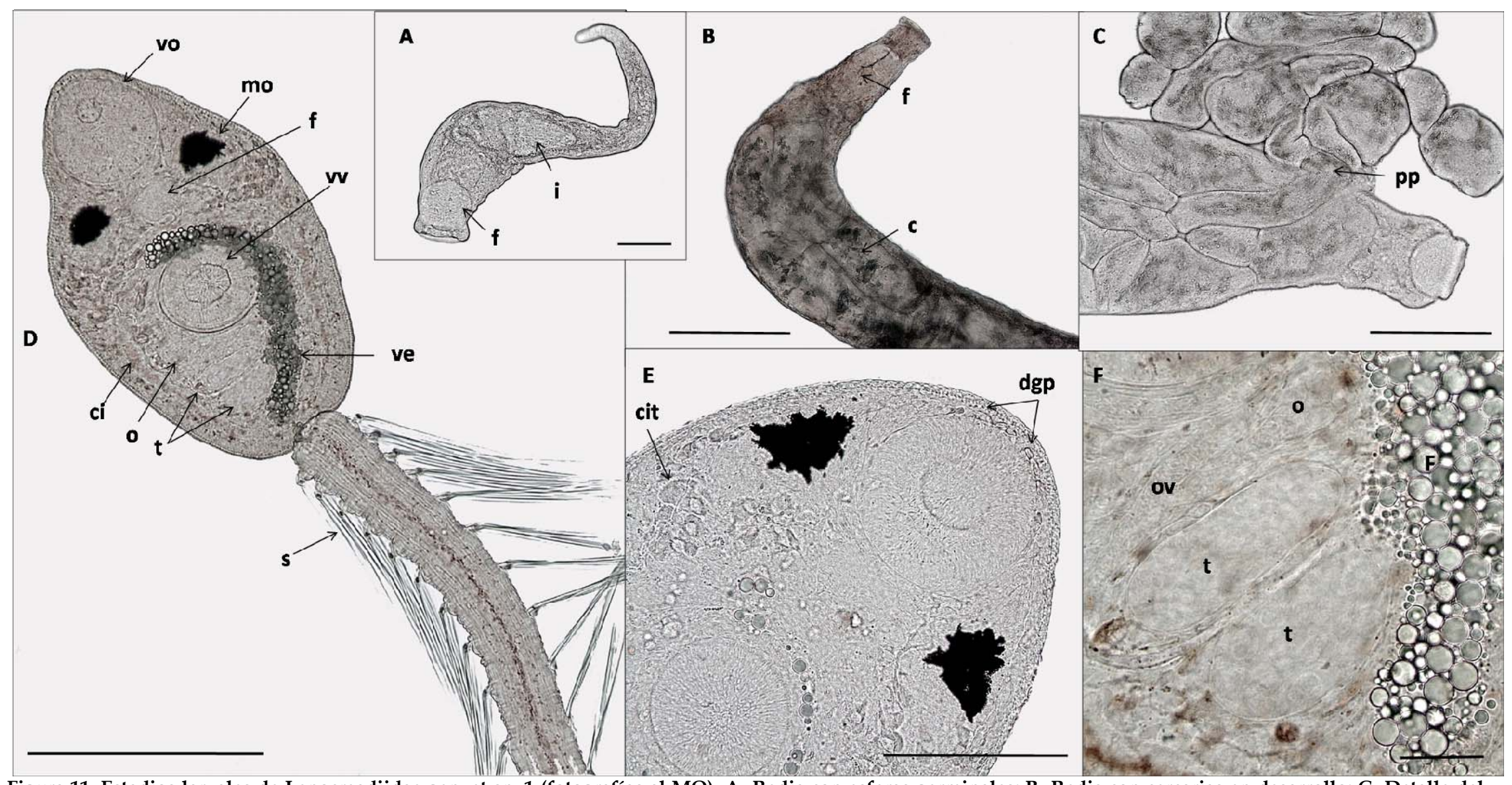

Figura 11. Estadios larvales de Lepocreadiidae gen. et sp. 1 (fotografías al MO). A- Redia con esferas germinales; B- Redia con cercarias en desarrollo; C- Detalle del extremo anterior de la redia con cercarias saliendo por el poro de puesta; D- Cercaria, vista ventral; E- Cercaria, parte anterior del cuerpo, detalle de los citones y desembodadura de las glándulas de penetración en el extremo anterior; F- Detalle de parte del aparato genital. Escalas: $50 \mu \mathrm{m}(\mathrm{A}, \mathrm{E}) ; 100 \mu \mathrm{m}(\mathrm{B}, \mathrm{C}, \mathrm{D})$; $10 \mu \mathrm{m}$ (F). Abreviaturas: c- cercaria; ci-ciego; cit-citones; dgp- desembocadura de las glándulas de penetración; f- faringe; i- intestino; mo- mancha ocular; pp- poro de puesta; ssetas; t- testículo; o- ovario; ov- oviducto; ve- vesícula excretora; vo- ventosa oral; vv- ventosa ventral. 


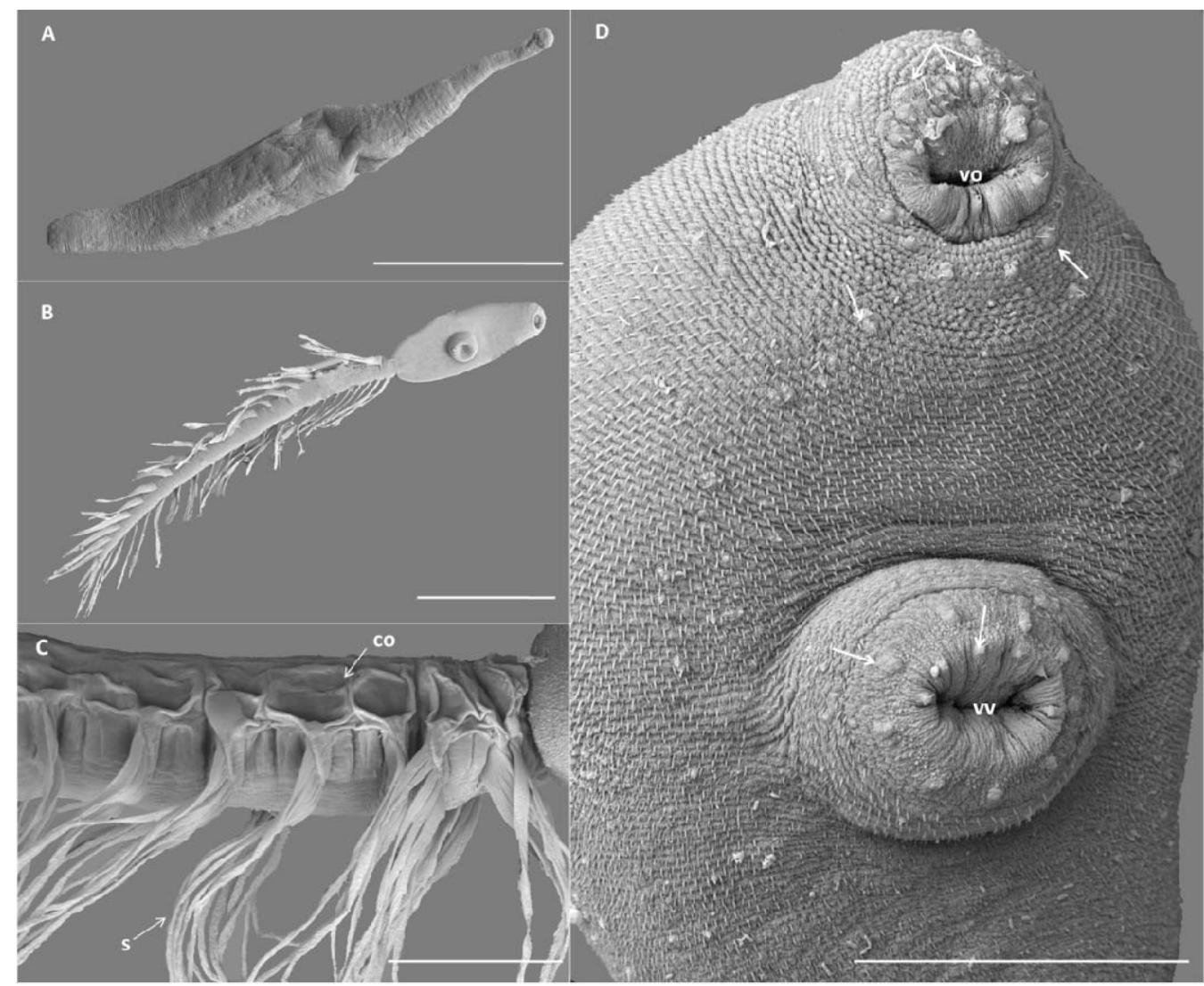

Figura 12. Estadios larvales de Lepocreadiidae gen. et sp. 1 (fotografías al MEB). A- Redia; BCercaria, vista ventral; C- Detalle de la inserción de las setas en la cola; D- Detalle de la parte anterior del cuerpo, vista ventral, papilas en el cuerpo y en las ventosas oral y ventral (algunas de ellas están indicadas con flechas blancas). Escalas: $200 \mu \mathrm{m}$ (A, B); $50 \mu \mathrm{m}$ (C, D). Abreviaturas: cocola; s- setas; vo- ventosa oral; vv- ventosa ventral.

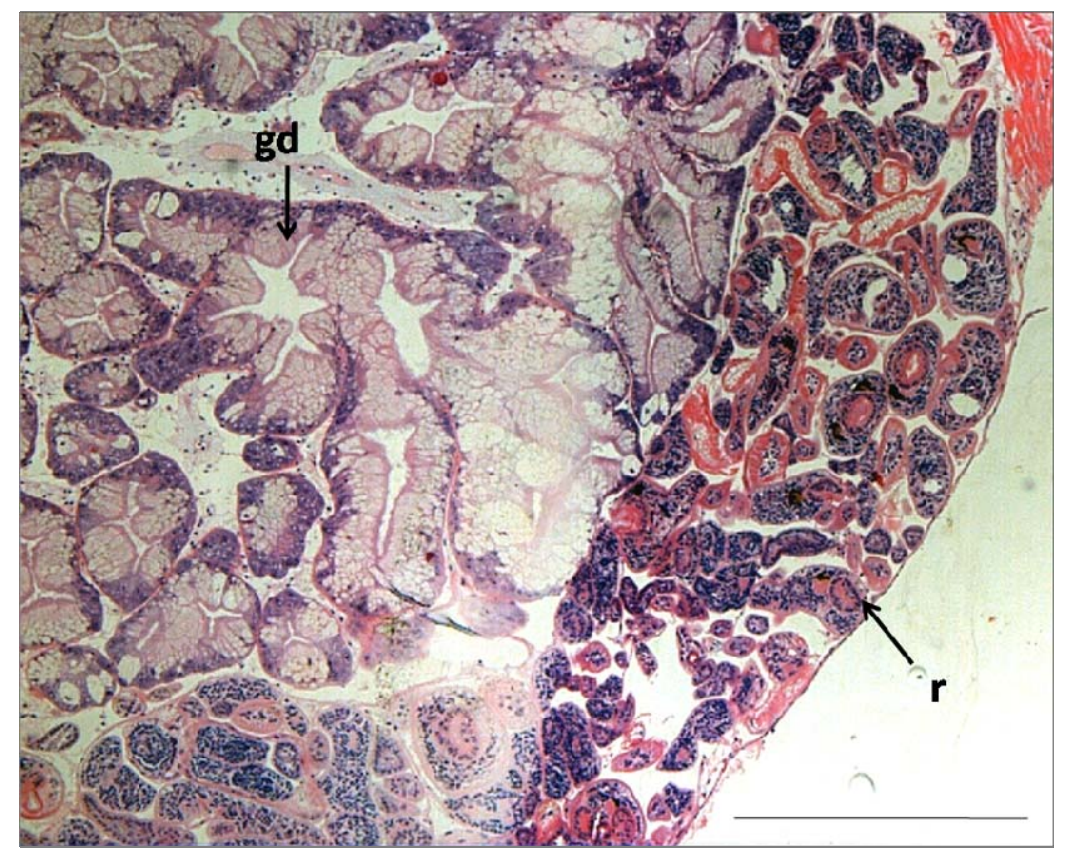

Figura 13. Corte histológico de Crepipatella dilatata parasitado por redias de Lepocreadiidae gen. et sp. 1. El espacio de la gónada está ocupado por las redias y la glándula digestiva no se encuentra afectada. Escala: $500 \mu \mathrm{m}$. Abreviaturas: gdglándula digestiva; r- redia. 
Capítulo 1. Digeneos hallados

Lepocreadiidae gen. et sp. 2 (Figuras 14-17)

\section{Descripción de las larvas}

Redia: elongada, con el extremo anterior aguzado, mide 978 (846-1153) de longitud por 172 (143-212) de ancho máximo. La pared presenta un espesor de 7 (5-8) y posee un poro de puesta cerca del extremo anterior. La faringe es grande y mide 48 (40-59) de diámetro. El intestino es corto (Fig. 15A). El número de larvas por redia es de 25 (11-34), de las cuales 16 (9-23) son cercarias y 9 (3-15) esferas germinales. Las esferas germinales se localizan en el extremo posterior de la redia; las cercarias están poco desarrolladas dentro de las redias; cuando emergen de las redias aumentan considerablemente de tamaño y completan su desarrollo.

Cercaria: tipo oftalmotricocerca (con manchas oculares y cola con setas). El cuerpo es espinoso y mide 308 (219-389) de longitud por 94 (76-132) de ancho máximo. La distancia desde el extremo anterior del cuerpo hasta el margen anterior de la ventosa ventral es 154 (126-185). Presenta dos manchas oculares de forma variable (generalmente en media luna) (Fig. 15C) localizadas posteriormente a la ventosa oral, a un distancia de 74 (50-91) del extremo anterior del cuerpo; miden 22 (16-32) de longitud por 14 (8-24) de ancho y están separadas entre sí por una distancia de 12 (8-14). La ventosa oral mide 58 (51-63) de longitud por 56 (45-68) de ancho. La boca es subterminal y está rodeada por un círculo de por lo menos cuatro papilas grandes en la mitad posterior y por lo menos 12 papilas en la parte anterior (observado al MEB, Fig. 16C). Desde el extremo posterior de la ventosa oral hasta el extremo posterior de la ventosa ventral se extienden dos hileras de ocho papilas a cada lado del cuerpo (observado al MEB, Fig. 16D). La prefaringe es larga y mide 27 (17-44) de longitud. La faringe es muscular y mide 27 (16-35) de longitud por 18 (1521) de ancho. El esófago es corto, mide 13 (9-19) de longitud y se bifurca anteriormente a la ventosa ventral. Los ciegos intestinales miden 177 (139-219) de longitud y se extienden hasta el extremo posterior del cuerpo. La ventosa ventral se localiza a nivel medio del cuerpo, mide 46 (38-58) de longitud por 48 (39-54) de ancho y presenta seis papilas internas en la mitad anterior y nueve papilas externas formando un anillo concéntrico (observado al MEB, Fig. 16D). La relación entre 
ventosa oral-ventral es 1:0,86 (0,8-0,87). Presenta seis pares de glándulas de penetración que se abren dorsalmente en el extremo anterior del cuerpo; los citones se localizan posteriormente a las manchas oculares, a nivel del esófago; ninguna de estas glándulas se tiñe con rojo neutro (Fig. 15C). Posteriormente a la ventosa ventral se observa el ovario pretesticular que mide $15(9-25)$ de diámetro $(n=7)$ y dos testículos en tándem; el testículo anterior mide 17 (11-22) de longitud por 21 (14-28) de ancho y el testículo posterior mide 18 (14-23) de longitud por 22 (15-29) de ancho (Fig. 15B). Se observa el metratermo y el saco del cirro desembocando en un atrio genital submediano a la izquierda de la ventosa ventral (Fig. 14D). La vesícula excretora es alargada y delgada, mide 183 (123-252) de longitud por 34 (1446) de ancho (el ancho es muy variable dependiendo del grado de repleción); se extiende hacia el extremo anterior y se curva en el extremo rodeando la ventosa ventral. La vesícula contiene gránulos de excreción grandes y refringentes (Fig. 15B). Los ductos colectores principales se originan en la vesícula y se ramifican al nivel de los citones de las glándulas de penetración. En el extremo posterior de la vesícula excretora se visualiza un esfínter muscular. Se observaron algunas células flamígeras aunque la fórmula excretora no pudo ser determinada. La cola es aproximadamente el doble del largo del cuerpo, mide 662 (424-951) de longitud por 34 (30-42) de ancho en la base; presenta 23 pares de grupos de setas que miden 102 (81-123) de longitud; cada grupo posee cinco ó seis setas y un par de setas en el extremo de la cola (Fig. 16B).

Comportamiento de la cercaria y tiempo de vida: similar a Lepocreadiidae gen. et sp. 1

\section{Secuencias moleculares}

Se secuenciaron las regiones 18S, ITS1, ITS2 y 28S del ADN ribosomal de redias. Se obtuvieron de forma parcial las regiones 18S, ITS1, 5.8S y 28S y en forma completa la región ITS2. Las secuencias parciales de las regiones 18S, ITS1, 5.8S y 28S tienen 949, 480, 94 y 905 pares de bases (pb) respectivamente; la secuencia completa de la región ITS2 tiene $329 \mathrm{pb}$. Las secuencias presentaron similitudes con otras disponibles en la base de datos de Gen Bank pertenecientes a especies de la familia Lepocreadiidae (ver Anexo I). Las secuencias de todas las regiones presentaron 
mayor similitud con las secuencias de Lepocreadiidae gen. et sp. 1 que con otras secuencias disponibles en la base de datos $(99,26 \%$ de similitud en la región 18S, 98,34\% de similitud en la región ITS1, 99,7\% de similitud en la región ITS2 y 99,45\% en la región 28S). El porcentaje de similitud entre las secuencias de digeneos pertenecientes a esta familia es alto, principalmente en las regiones $18 \mathrm{~S}$ y $28 \mathrm{~S}$ más

conservadas; asimismo las secuencias de las regiones ITS1 e ITS2 disponibles en Gen Bank son pocas (3 especies con ITS1 y 5 especies con ITS2).

\section{Resumen taxonómico}

Hospedador: Pareuthria plumbea Philippi (Neograstropoda, Buccinidae).

Localidad: Puerto Deseado.

Prevalencia total: $3,49 \%(\mathrm{n}=458)$.

Sitio de infección: las redias invaden la gónada y en intensidades altas también la glándula digestiva (Fig. 17).

Especimenes depositados: CNP-Par 53.

\section{Comentarios taxonómicos}

La cercaria aquí descripta pertenece a la familia Lepocreadiidae y es morfológicamente compatible a la diagnosis del género Opechona Looss, 1907. Las manchas oculares (en forma de media luna) y el número de pares de grupos de setas en la cola (23) la asemejan a Opechona pyriforme (Linton, 1900) (antes Neopechona pyriforme) y Opechona cablei (Stunkard, 1980) (antes Neopechona cablei) (Stunkard, 1969, 1980b, 1983). La cercaria Lepocreadiidae gen. et sp. 1 (en C. dilatata) difiere de la cercaria Lepocreadiidae gen. et sp. 2 (en P. plumbea) en el número de glándulas de penetración (cuatro vs. seis) y en la forma de las manchas oculares (ovalada vs. media luna). Al igual que Lepocreadiidae gen. et sp. 1, esta cercaria sería una nueva especie. Debido a la gran similitud en las secuencias moleculares, es probable que esta especie pertenezca al mismo género que Lepocreadiidae gen. et sp. 1, aunque a diferentes especies. Los géneros Lepocreadium y Opechona comparten varios caracteres morfológicos (Stunkard, 1969). Para la identificación de estas larvas a nivel de género y especie es preciso hallar a los adultos en peces del área de 
estudio y completar su ciclo de vida. A pesar del alto porcentaje de similitud entre las secuencias de las dos especies Lepocreadiidae registradas en este estudio, se puede concluir que pertenecerían a especies diferentes, debido a que existieron algunas diferencias en todas las regiones analizadas. Además, otras especies de la familia también presentan un alto porcentaje de similitud. Por otro lado, ambas especies poseen algunas diferencias morfológicas y parasitan gasterópodos diferentes. 


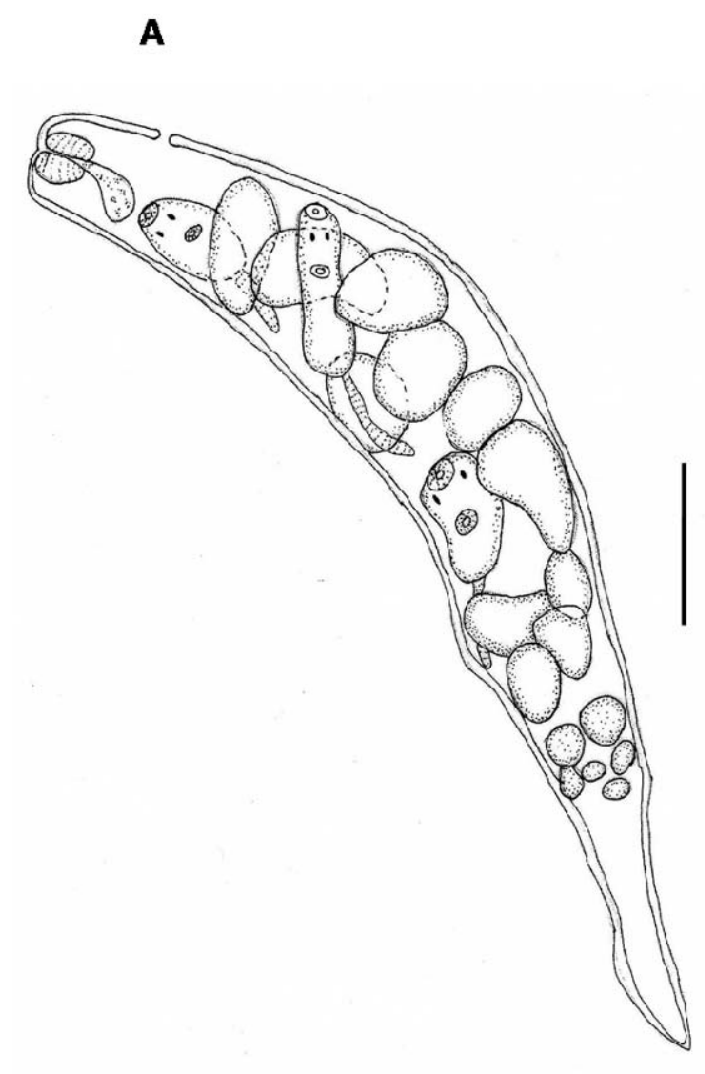

B

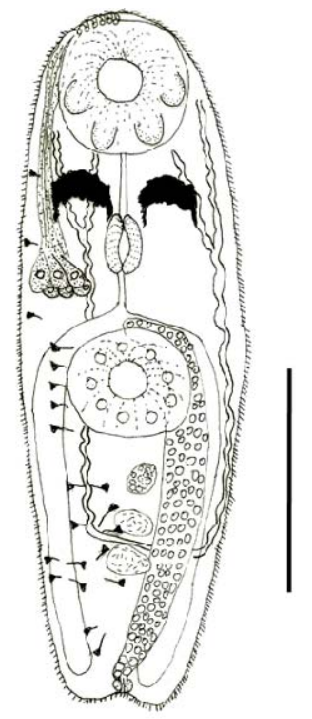

D

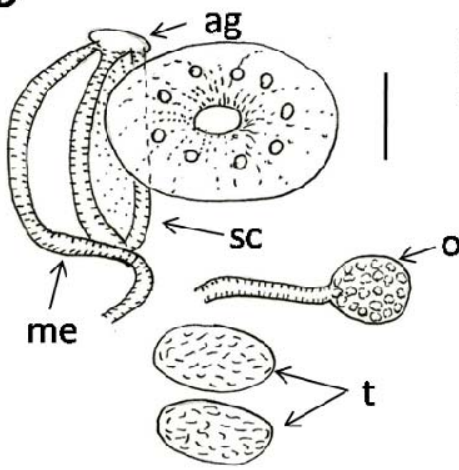

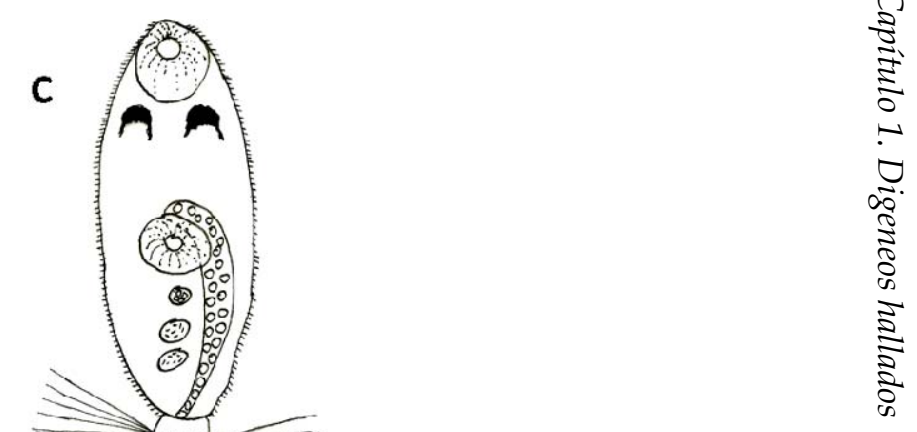

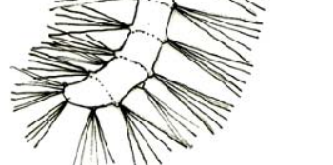

Figura 14. Estadios larvales de Lepocreadiidae gen. et sp. 2. A-Redia; B- Cuerpo de la cercaria, vista ventral; las glándulas de penetración y las células flamígeras del lado izquierdo fueron omitidas; C- Cercaria, vista ventral; D- Detalle del aparato genital. Escalas: $100 \mu \mathrm{m}$ (A, B, C); $20 \mu \mathrm{m}$ (D). Abreviaturas: ag- atrio genital; me- metratermo; o- ovario; sc- saco del cirro; ttestículo. 


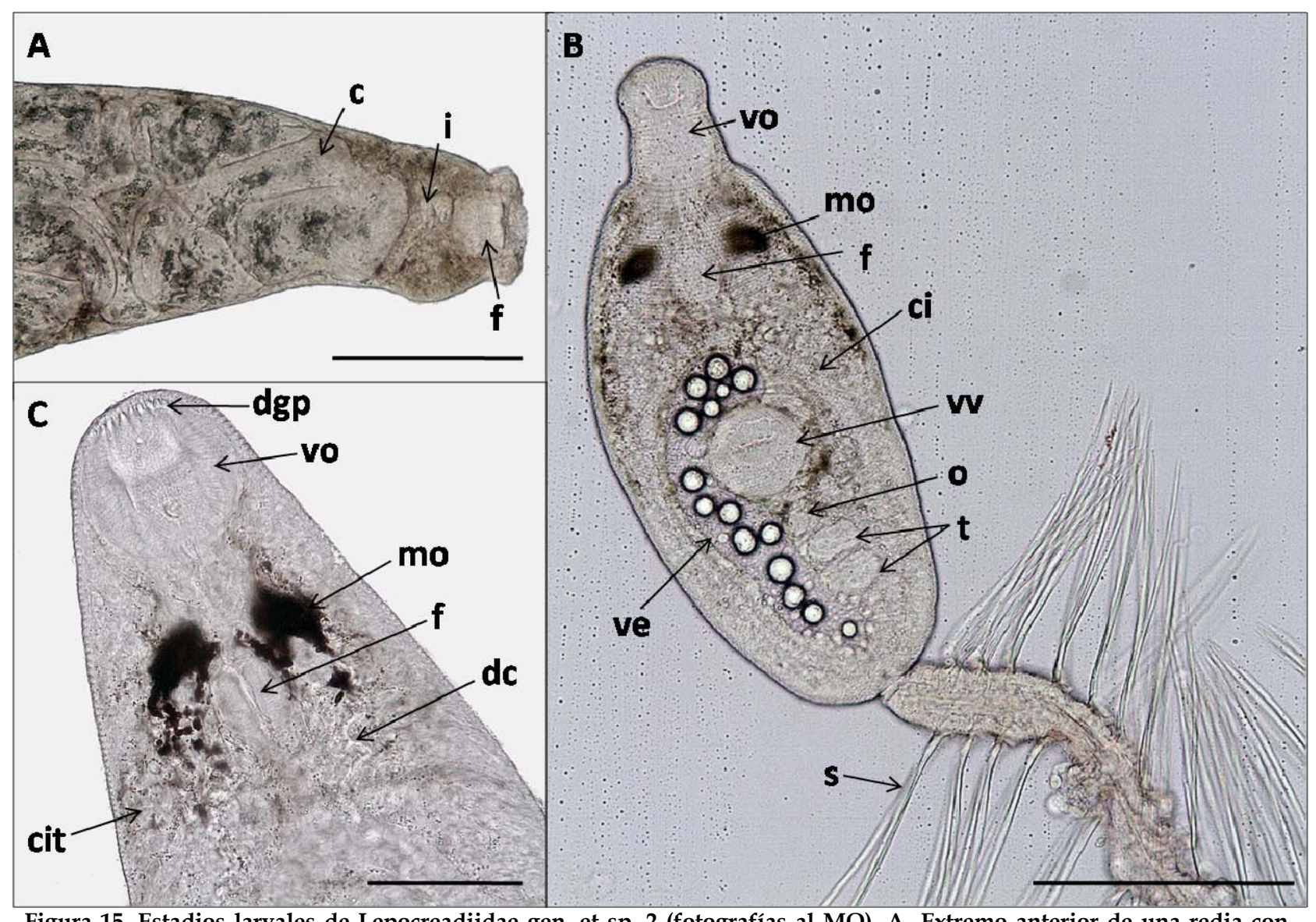

Figura 15. Estadios larvales de Lepocreadiidae gen. et sp. 2 (fotografías al MO). A- Extremo anterior de una redia con cercarias; B- Cercaria, vista ventral; C- Cercaria, parte anterior del cuerpo, detalle de los citones (sin teñir) y desembocadura de las glándulas de penetración en el extremo anterior; detalle de los ductos colectores de la vesícula excretora. Escalas: $100 \mu \mathrm{m}(\mathrm{A}, \mathrm{B}) ; 50 \mu \mathrm{m}$ (C). Abreviaturas: c- cercaria; ci- ciego; cit- citones; dgp- desembocadura de las glándulas de penetración; dc- ductos colectores; f- faringe; i- intestino; mo- mancha ocular; o- ovario; s- seta; t- testículo; ve- vesícula excretora; vo- ventosa oral; vv- ventosa ventral. 


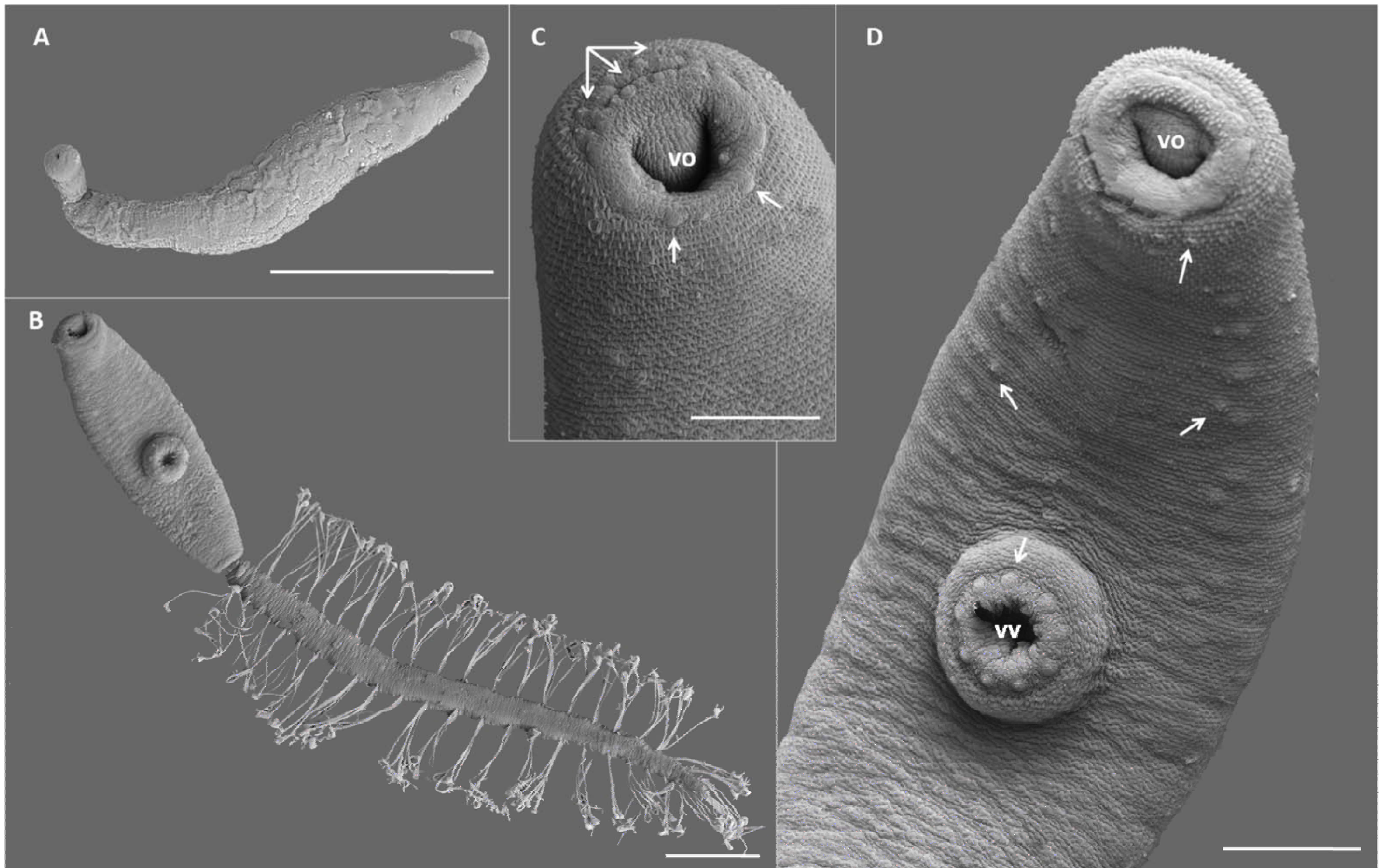

Figura 16. Estadios larvales de Lepocreadiidae gen. et sp. 2 (fotografías al MEB). A- Redia, B- Cercaria, vista ventral; C- Extremo anterior del cuerpo, detalle de las papilas en la ventosa oral; D- Detalle de las papilas en el cuerpo y en la ventosa ventral (algunas de ellas están indicadas con flechas blancas). Escalas: $500 \mu \mathrm{m}$ (A); $100 \mu \mathrm{m}$ (B); $50 \mu \mathrm{m}$ (C, D). Abreviaturas: vo- ventosa oral; vv- ventosa ventral. 


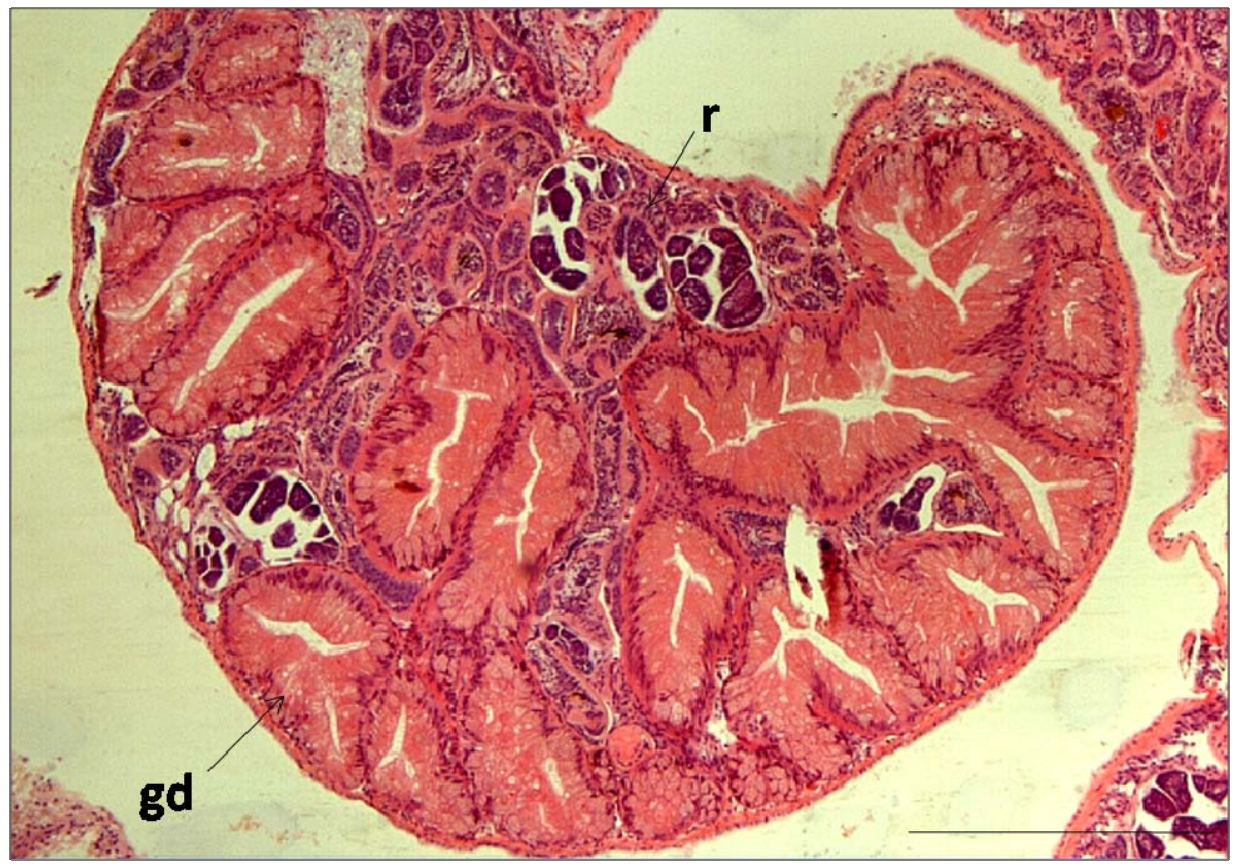

Figura 17. Corte histológico de Pareuthria plumbea parasitada por redias de Lepocreadiidae gen. et sp. 2. El espacio de la gónada está ocupado por las redias que también se localizan entre los acinos de la glándula digestiva. Escala: $500 \mu \mathrm{m}$. Abreviaturas: gd- glándula digestiva; r- redias. 
Capítulo 1. Digeneos hallados

Zoogonidae Odhner, 1902

Diphterostomum sp. (Figuras 18-21)²

\section{Descripción de las larvas}

Esporocisto: de color amarillento y generalmente elongado (el movimiento de las cercarias en su interior puede distorsionar la forma); mide 962 (530-1420) de longitud por 222 (170-260) de ancho. La pared tiene un espesor de 6 (2-14). Se observaron esporocistos en tres estados de desarrollo: 1) repleto de esferas germinales y cercarias en desarrollo, 2) repleto de metacercarias y 3) repleto de ambos estadios larvales (Fig. 19B). El número total de larvas por esporocisto (cercarias y/o metacercarias) es de 7 (6-11).

Cercaria: tipo xifidocercaria (con estilete), sin cola, posee un cuerpo pequeño y elongado que mide 323 (263-392) de longitud por 120 (90-160) de ancho y está cubierto por pequeñas espinas desde el nivel de la ventosa oral hasta el extremo posterior del cuerpo. Posee células cistógenas dispersas en el parénquima. La distancia desde el extremo anterior del cuerpo hasta el margen anterior de la ventosa ventral es de 134 (110-154). La ventosa oral es subterminal y mide 63 (50-76) de longitud por 50 (36-69) de ancho. El estilete es pequeño, lanceolado y mide 14 (12-20) de longitud por 4 (3-6) de ancho en la base (Fig. 19C). No presenta prefaringe; la faringe es globosa y mide 26 (22-30) de longitud por 21 (20-23) de ancho; el esófago es corto y se bifurca en dos ciegos intestinales en forma de saco, que miden 55 (46-66) de longitud y finalizan en el margen anterior de la ventosa ventral $(n=5)$. La ventosa ventral es grande y muscular y mide 96 (54-143) de longitud por 106 (69-126) $\mu \mathrm{m}$ de ancho. Presenta cuatro labios musculares, dos anteriores y dos posteriores, que pueden estar invaginados (Figs. 19D, 20B). La relación entre ventosa oral-ventral es 1:1,92 (1,83-2,12). Se observan tres pares de glándulas de penetración que abren ventralmente en la base del estilete (Fig. 19C). En el lado derecho del cuerpo, entre la ventosa ventral y la vesícula excretora, se observa un primordio de ovario, que mide 23 (18-30) de longitud por 24 (20-30) de ancho $(n=5)$. Al mismo nivel, a cada lado del cuerpo, se observan dos testículos; el

\footnotetext{
${ }^{2}$ La descripción de los estadios larvales de esta especie fue publicada en Gilardoni et al. (2011)
} 
testículo izquierdo mide 27 (23-32) de longitud por 21 (17-24) de ancho y el testículo derecho mide 29 (25-31) de longitud por 19 (17-22) de ancho (n= 3) (Fig. 19E). El saco del cirro está localizado entre los ciegos intestinales y el poro genital abre a la izquierda del cuerpo cerca de la faringe. La vesícula excretora es ovalada, mide 70 (46-86) de longitud por 59 (44-80) de ancho y está repleta de gránulos de excreción refringentes (Figs. 19A, E). La fórmula excretora es $2[(2+2+2)]=12$.

Comportamiento de la cercaria y tiempo de vida: la cercaria se mueve activamente dentro del esporocisto y emerge mediante la ruptura de la pared del mismo. En condiciones de laboratorio, algunas cercarias enquistan dentro de los esporocistos. Las cercarias emitidas caen al fondo del recipiente y se mueven rápidamente mediante contracciones y estiramientos del cuerpo. El tiempo de vida es menor a 24 hs a temperatura ambiente y hasta 96 hs a $12{ }^{\circ} \mathrm{C}$.

Metacercaria: se observaron enquistadas dentro de los esporocistos (Fig. 19B); los quistes son esféricos y miden 269 (245-285) de diámetro. La pared del quiste posee un espesor de 9 (6-13).

\section{Secuencias moleculares}

Se intentaron secuenciar las regiones ITS1, 5.8S e ITS2 del ADN ribosomal de esporocistos. De las secuencias mencionadas se obtuvieron en forma parcial las regiones $5.8 \mathrm{~S}$ y $28 \mathrm{~S}$ y en forma completa la región ITS2. La región ITS1 no pudo ser reamplificada. Las secuencias parciales de las regiones 5.8S y $28 \mathrm{~S}$ tienen 123 y 121 pares de bases $(\mathrm{pb})$ respectivamente; la secuencia completa de la región ITS2 tiene $230 \mathrm{pb}$. La secuencia presentó similitud con otra disponible en la base de datos de Gen Bank perteneciente a la especie Diphterostomum brusinae (ver Anexo II). El porcentaje de similitud entre las secuencias de la región ITS2 de ambas especies fue de $86,96 \%$. 


\section{Resumen taxonómico}

Hospedador: Buccinanops globulosus Kiener (Caenogastropoda, Nassariidae).

Localidad: Puerto Madryn.

Prevalencia total: $0,16 \% \quad(\mathrm{n}=632$, especimenes intermareales $)$ y 5,1\% $(\mathrm{n}=59$, especimenes submareales).

Sitio de infección: los esporocistos invaden la gónada y en infecciones altas también la glándula digestiva (Fig. 21).

Especímenes depositados: MLP 6280,6281; CNP-Par 21, 22, 23.

\section{Comentarios taxonómicos}

La cercaria descripta pertenece a la familia Zoogonidae debido a que es una xifidocercaria sin cola, que posee una ventosa ventral grande y muscular localizada en la mitad posterior del cuerpo. Posee glándulas cistógenas dispersas en el parénquima, vesícula excretora en forma de saco repleta de gránulos de excreción; dos testículos opuestos, un ovario mediano y saco del cirro con poro genital lateral (Stunkard, 1983). La cercaria pertenece al género Diphterostomum Stossich, 1903 debido a la presencia de dos ciegos intestinales cortos y divergentes (Bray, 2008). La especie aquí descripta es similar a Diphterostomum brusinae (Stossich, 1889) registrada por Pina et al. (2009) en el norte de Portugal, debido a las medidas y la

presencia de cuatro labios en la ventosa ventral. Sin embargo, debido a las diferencias en las secuencias moleculares, la especie aquí descripta pertenecería a una especie nueva. 
A

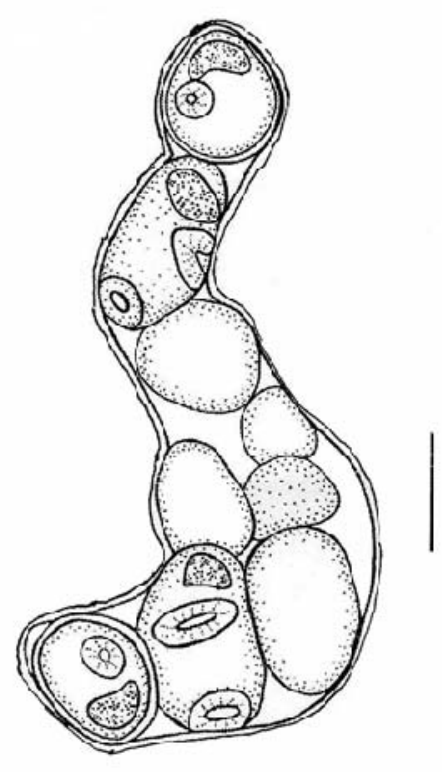

B

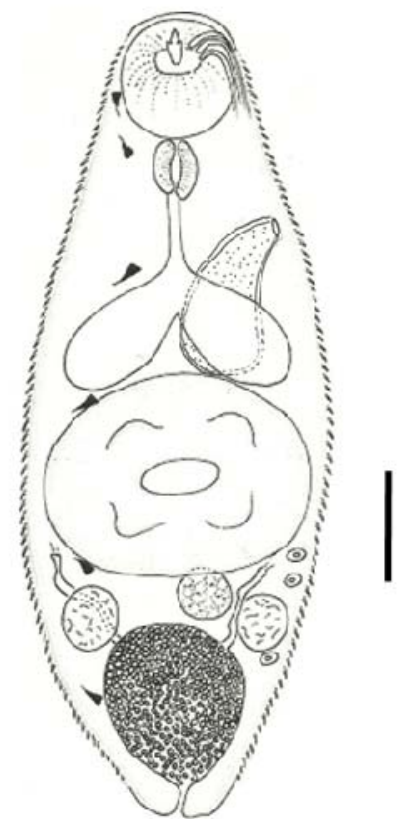

Figura 18. Estadios larvales de Diphterostomum sp. A-Esporocisto, B-Cercaria, vista ventral; las células flamígeras del lado izquierdo fueron omitidas, se dibujaron algunas células cistógenas. Escalas: $100 \mu \mathrm{m}$ (A); $50 \mu \mathrm{m}$ (B). 


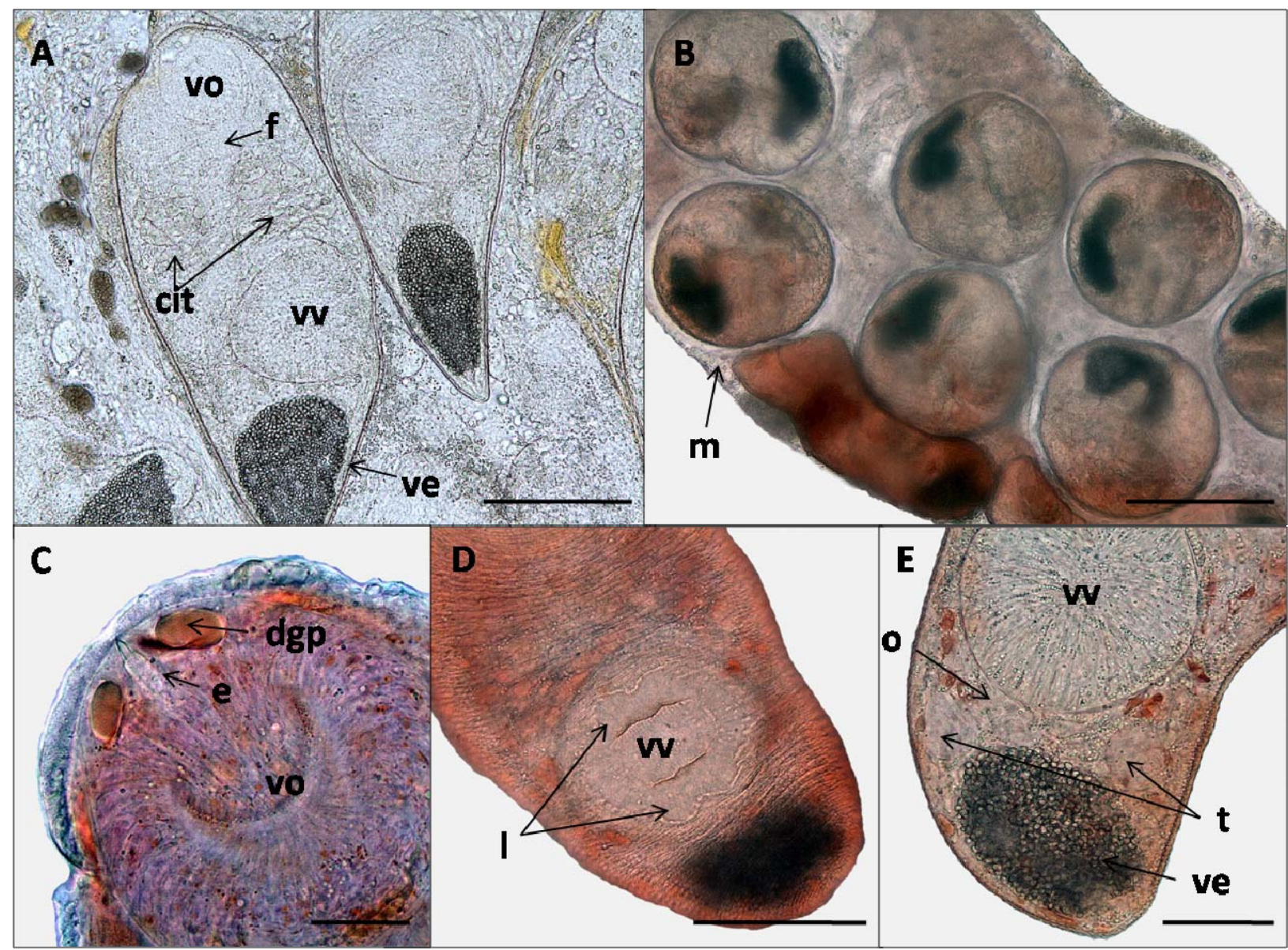

Figura 19. Estadios larvales de Diphterostomum sp. (fotografías al MO). A- Cercarias dentro de los esporocistos; BEsporocisto con metacercarias; C- Ventosa oral, detalle del estilete y desembocadura de las glándulas de penetración D- Detalle de los cuatro labios en la ventosa ventral de la cercaria; E- Extremo posterior, detalle del aparato genital. Escalas: $100 \mu \mathrm{m}(\mathrm{A}, \mathrm{D}, \mathrm{E}) ; 200 \mu \mathrm{m}$ (B); $20 \mu \mathrm{m}$ (C). Abreviaturas: cit- citones; e- estilete; f- faringe; dgp- desembocadura de las glándulas de penetración; l- labios; $\mathrm{m}$ - metacercaria; o- ovario; $\mathrm{t}$ - testículo; ve- vesícula excretora; vo- ventosa oral; vv- ventosa ventral. 


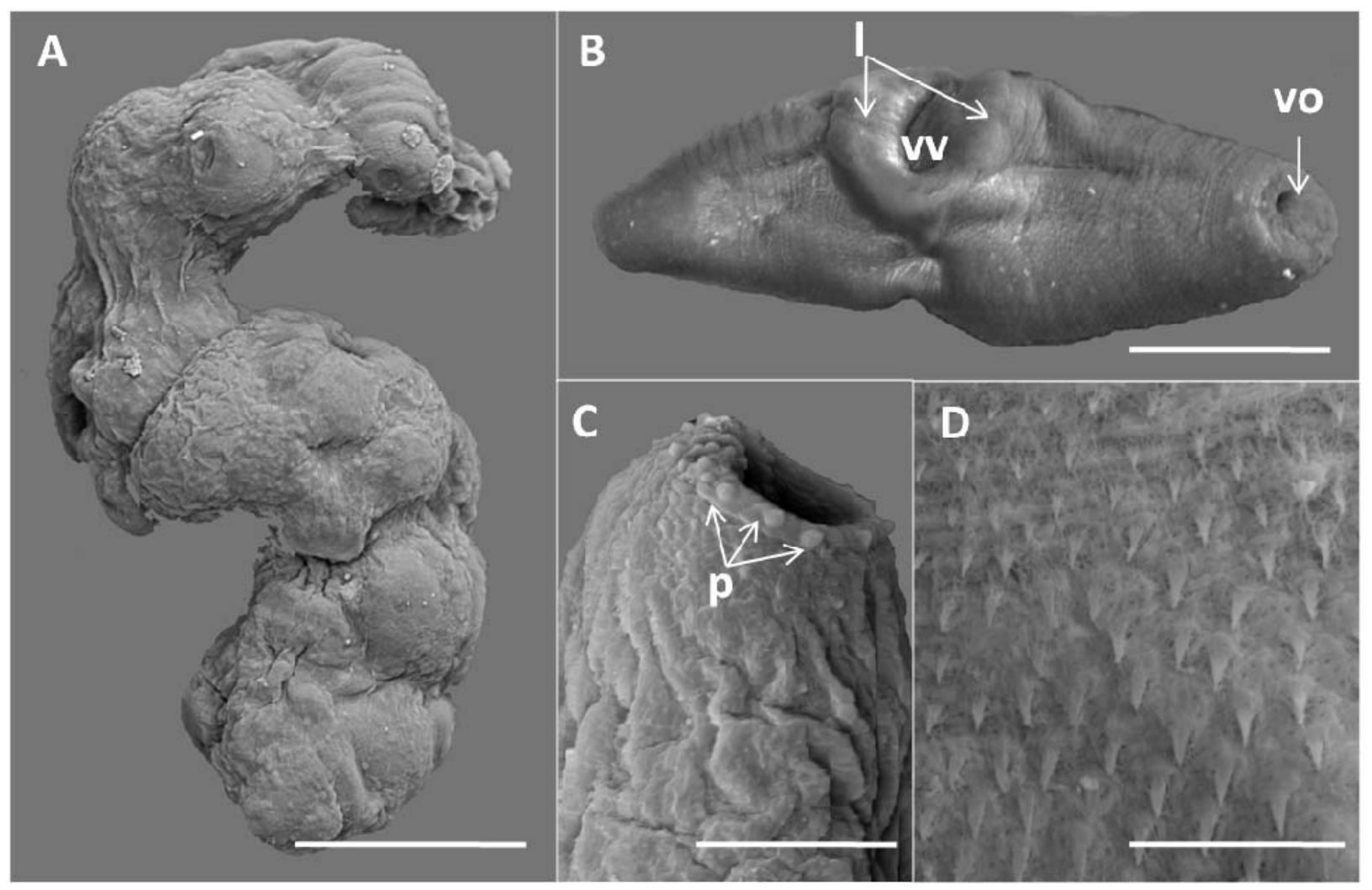

Figura 20. Estadios larvales de Diphterostomum sp. (fotografías al MEB). A- Esporocistos, B- Cercaria, vista ventral; CExtremo anterior de la cercaria, vista lateral, detalle de las papilas de la ventosa oral; D- Detalle de las espinas del cuerpo. Escalas: $200 \mu \mathrm{m}$ (A); $100 \mu \mathrm{m}$ (B); $50 \mu \mathrm{m}$ (C); $2 \mu \mathrm{m}$ (D). Abreviaturas: 1- labios; p- papilas; vo- ventosa oral; vvventosa ventral. 


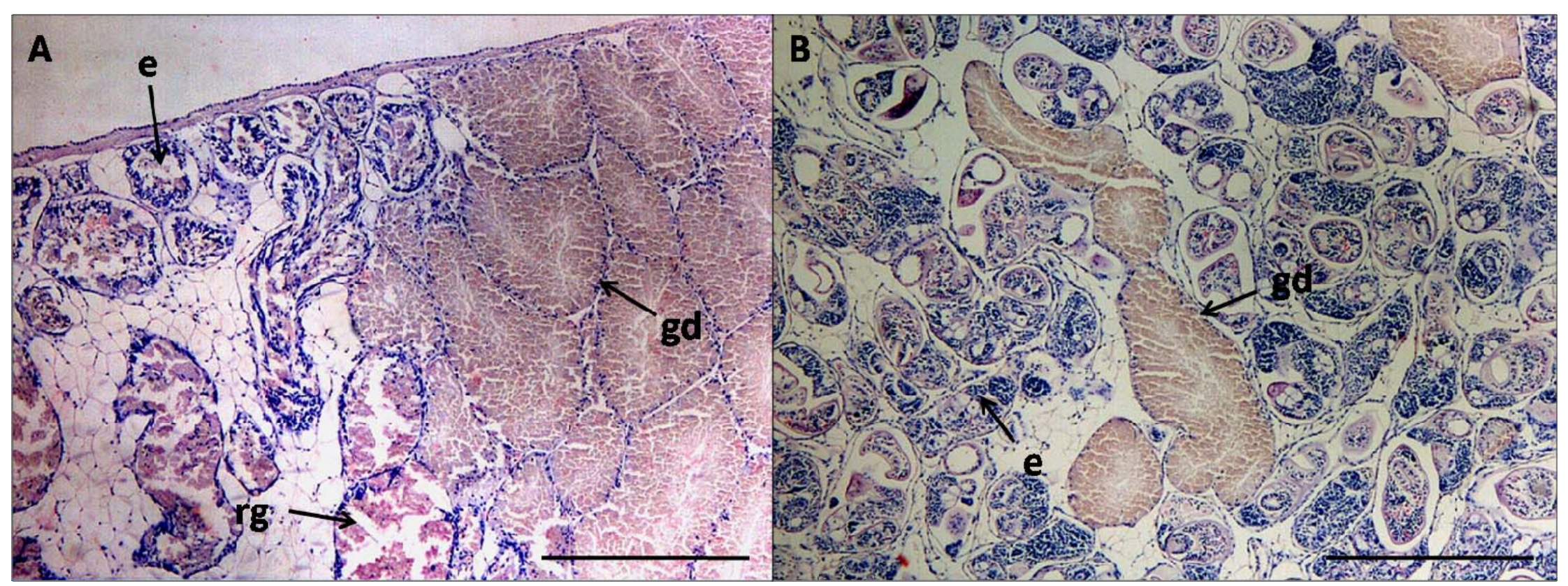

Figura 21. Cortes histológicos de Buccinanops globulosus parasitado por esporocistos de Diphterostomum sp. A- Esporocistos ocupando el espacio de la gónada femenina, se observan restos gonadales; B- Esporocistos ocupando el espacio de la glándula digestiva, se observan algunos acinos con morfología atípica. Escalas: $500 \mu \mathrm{m}$. Abreviaturas: e- esporocisto; gd- glándula digestiva; rg- restos de acinos gonadales. 
Capítulo 1. Digeneos hallados

Zoogonus sp. (Figura 22)

\section{Descripción de las larvas}

Esporocisto: de color blanquecino, de forma variable, ovalada, arriñonada o en forma de S; mide 1.000 (721-1.255) de longitud por 212 (177-244) de ancho; la pared tiene un espesor de 5 (4-8). El número de cercarias por esporocisto es de 42 (28-61). Sólo se halló un ejemplar de gasterópodo parasitado por esta especie, en el cual las cercarias estaban poco desarrolladas.

Cercaria (descripción basada en diez cercarias poco desarrolladas, dentro del esporocisto): tipo xifidocercaria (con estilete), sin cola. Cuerpo pequeño y elongado que mide 124 (106-167) de longitud por 59 (55-66) de ancho; está cubierto por pequeñas espinas desde el nivel de la ventosa oral hasta el extremo posterior del cuerpo. Presenta células cistógenas distribuidas en el parénquima. La distancia desde el extremo anterior del cuerpo hasta el margen anterior de la ventosa ventral es de 62 (44-87). La ventosa oral es subterminal y mide 30 (24-35) de longitud por 28 (24-33) de ancho. El estilete es pequeño. La prefaringe es larga y mide 18 (15-25) de longitud $(n=3)$; la faringe es globosa y mide 11 (10-14) de longitud por 12 (10-14) de ancho $(n=4)$; el esófago es corto, mide 12 (8-15) de longitud y se bifurca en dos ciegos intestinales en forma de saco, que miden 16 (12-19) de longitud y finalizan en el margen anterior de la ventosa ventral $(n=3)$. La ventosa ventral mide $24(22-27)$ de longitud por 25 (21-30) de ancho. La relación entre ventosa oral-ventral es 1:0,89 $(0,87-0,91)$. Se observan cuatro pares de glándulas de penetración que abren ventralmente en la base del estilete, se tiñen con rojo neutro y sus citones se localizan al nivel de la ventosa ventral. La vesícula excretora es pequeña y ovalada, mide 30 (21-35) de longitud por 24 (15-34) de ancho $(n=6)$. Anteriormente a la vesícula excretora se observa un primordio genital que mide 16 (12-19) de longitud por $15(10-21)$ de ancho $(n=3)$. El cuerpo presenta una pequeña extensión en el extremo posterior con espinas. El poro excretor se localiza en el extremo distal de esta extensión.

Comportamiento de la cercaria y tiempo de vida: el comportamiento de la cercaria no pudo ser observado de manera natural, ya que no se obtuvieron emisiones. En 
condiciones de laboratorio, las cercarias extraídas de los esporocistos se mueven lentamente en el fondo del recipiente plegando el cuerpo en forma alternada.

\section{Secuencias moleculares}

Se secuenciaron las regiones ITS1, 5.8S e ITS2 del ADN ribosomal de esporocistos. Se obtuvieron en forma parcial las regiones ITS1 y 28S y en forma completa las regiones 5.8S e ITS2. Las secuencias parciales de las regiones ITS1 y 28S, tienen 509 y 120 pares de bases $(\mathrm{pb})$ respectivamente; las secuencias completas de las regiones $5.8 \mathrm{~S}$ y ITS2 tienen 160 y 249 pb respectivamente. Las secuencias presentaron similitudes con otras disponibles pertenecientes a especies de la familia Zoogonidae en la base de datos de Gen Bank (ver Anexo II). Las secuencias de todas las regiones presentaron mayor similitud con las secuencias de Zoogonus rubelus (98,34\% de similitud en la región ITS1 y 99,7\% de similitud en la región ITS2).

\section{Resumen taxonómico}

Hospedador: Pareuthria plumbea Philippi (Neograstropoda, Buccinidae).

Localidad: Puerto Deseado.

Prevalencia total: $0,22 \%(n=458)$.

Sitio de infección: los esporocistos invaden la gónada y la glándula digestiva. Especimenes depositados: CNP-Par54.

\section{Comentarios taxonómicos}

Los géneros Zoogonus Loos, 1901 y Zoogonoides Odhner, 1902 están estrechamente relacionados y ambos están representados por pocas especies (Bray, 2008). Hasta el momento se conocen sólo tres cercarias pertenecientes a estos géneros, Zoogonus rubelus (Olson, 1869), Zoogonoides laevis Linton, 1940 y Zoogonoides viviparus (Olsson, 1868) (Stunkard, 1938, 1940; Køie, 1976). La cercaria aquí descripta es una nueva especie y fue asignada provisoriamente al género Zoogonus, ya que comparte características con Z. rubelus, tales como una prefaringe larga, ciegos cortos y una ventosa ventral pequeña en comparación con la de las especies pertenecientes al género Zoogonoides. Estos resultados quedan pendientes a ser corroborados cuando 
se hallen y estudien cercarias desarrolladas y emitidas. Por otra parte, es preciso secuenciar otras regiones, como 185 y 28S, ya que existen secuencias disponibles de otras especies en Gen Bank, como Z. viviparus, Deretrema nahaense Yamaguti, 1942 y Lepidophyllum steenstrupi Odhner, 1902.

A

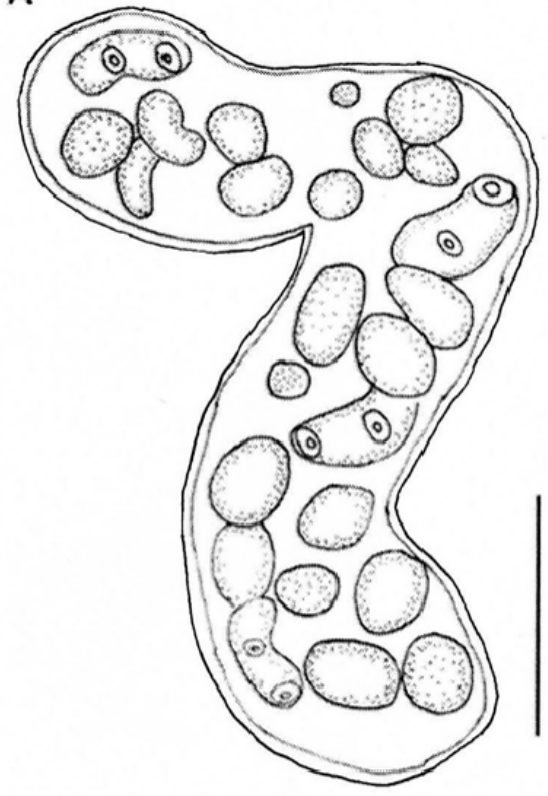

B

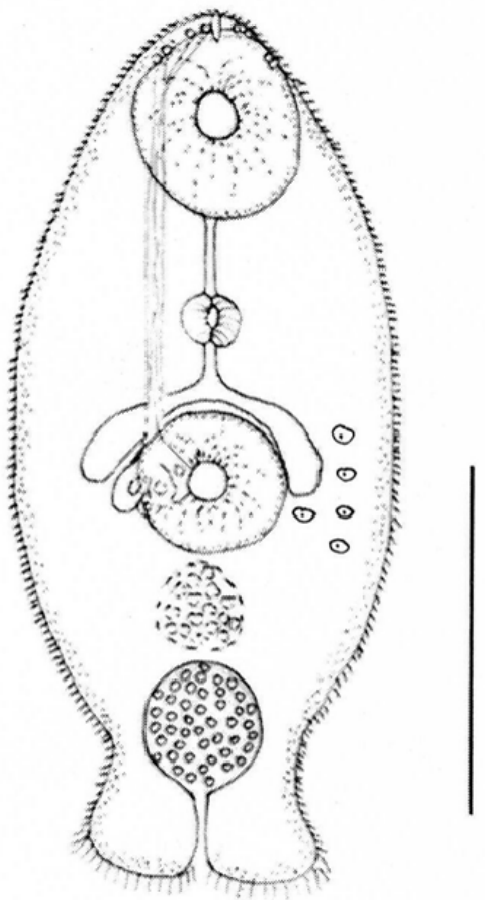

Figura 22. Estadios larvales de Zoogonus sp. A- Esporocisto, B- Cercaria, vista ventral; las glándulas de penetración del lado izquierdo se han omitido, se dibujaron algunas células flamígeras. Escalas: $200 \mu \mathrm{m}$ (A); $50 \mu \mathrm{m}(\mathrm{B})$. 
Capítulo 1. Digeneos hallados

\section{Gymnophallidae Odhner, 1905}

Gymnophalloides nacellae Cremonte, Gilardoni, Pina, Rodrigues, Chai \& Ituarte, 2011 (Figuras 23-25) ${ }^{3}$

\section{Descripción de las larvas}

Metacercaria: cuerpo oval, extremo anterior redondeado y extremo posterior levemente aguzado; mide 338 (301-380) de longitud por 183 (142-215) de ancho máximo. Las espinas están dispuestas transversalmente cubriendo la totalidad de la superficie del cuerpo, excepto en la región comprendida entre la faringe y la ventosa ventral. La distancia desde el extremo anterior del cuerpo hasta el margen anterior de la ventosa ventral es de 202 (165-255). La ventosa oral es retráctil y mide 96 (85-102) de longitud por 102 (91-112) de ancho; presenta un círculo de 16 papilas rodeando la boca, 18 papilas esparcidas alrededor de la boca y dos labios laterales eversibles (Figs. 24B, 25B). Presenta 22 glándulas cefálicas y un ventosa adicional (ventral pit) localizada anteriormente a la ventosa ventral, que mide 41 (30-50) de longitud por 52 (30-66) de ancho (Figs. 24A, 25A). Presenta aproximadamente 30 papilas entre la ventosa oral y el ventral pit (Figs. 24B, C). La ventosa ventral mide 38 (30-46) de longitud por 47 (42-52) de ancho y presenta un círculo externo de 6 papilas (Fig. 25C). La relación entre ventosa oral-ventral es 1:0,46 (0,41-0,53). La faringe es ovalada y mide 31 (27-38) de longitud por 29 (26-30) de ancho. Los ciegos tienen forma de saco; están repletos de material granular, miden 53 (36-73) de longitud por 31 (23-47) de ancho máximo y alcanzan la región del ventral pit. Los testículos son ovalados y se localizan a los lados de la ventosa ventral (Fig. 23); el testículo derecho es posterior al ovario y en ocasiones se ubica en diagonal al testículo izquierdo. El testículo izquierdo mide 46 (30-60) de longitud por 31 (23-47) de ancho y el testículo derecho mide 43 (28-53) de longitud por 30 (24-42) de ancho. La vesícula seminal es unipartita; no presenta pars prostática por lo que las células prostáticas desembocan en el atrio genital. El poro genital es pequeño e inconspicuo y está localizado en el margen anterior de la ventosa ventral. El ovario es más o menos redondeado, mide 29 (23-36) de longitud por 21 (16-28) de ancho. El

\footnotetext{
${ }^{3}$ La descripción de esta especie fue publicada en Cremonte et al. (2013)
} 
oviducto es corto y se origina dorsalmente al ovario. La cámara de fertilización es ciliada. El útero asciende hacia el atrio genital formando una larga vuelta anterior al ventral pit. Presenta un par de glándulas de vitelo ovaladas, localizadas a ambos lados de la ventosa ventral, formadas por ocho folículos cada una. La vesícula excretora presenta forma de $\mathrm{Y}$, con un tronco corto y dos brazos largos que se extienden y se bifurcan al nivel de la ventosa oral, ramificándose dorsalmente. La vesícula excretora se halla repleta de gránulos de excreción esféricos (Fig. 24B). La fórmula excretora es $2[(2+2)+(2+2)]=16$.

\section{Secuencias moleculares}

Se secuenciaron las regiones 18S, ITS1, 5.8S, ITS2 y 285 del ADN ribosomal de metacercarias. Se obtuvieron en forma parcial las regiones $18 \mathrm{~S}$ y $28 \mathrm{~S}$ y en forma completa las regiones ITS1, 5.8S y 28S. Las secuencias parciales de las regiones $18 \mathrm{~S}$ y 285 tiene 1015 y 967 pb pares de bases (pb) respectivamente; las secuencias completas de las regiones ITS1, 5.8S e ITS2 tiene 694, 145 y 311 pb respectivamente. Las secuencias presentaron similitudes con otras disponibles en la base de datos de Gen Bank pertenecientes a la familia Gymnophallidae (ver Anexo III). Las secuencias de todas las regiones presentaron mayor similitud con las secuencias de metacercarias de Gymnophalloides seoi de Korea (90,48\% de similitud en las regiones 18S, ITS1, 5.8S, ITS2 y 28S).

\section{Resumen taxonómico}

Hospedador: Nacella (P.) magellanica (Gmelin) (Patellogastropoda, Nacellidae).

Localidad: Puerto Deseado.

Prevalencia total: $92,47 \%(\mathrm{n}=306)$.

Intensidad de infección: $33(1-171)(\mathrm{n}=306)$.

Sitio de infección: las metacercarias se hallan en forma agrupada en el espacio extrapaleal (entre el manto y la valva), principalmente en el área de inserción de la musculatura del manto en la valva.

Especímenes depositados: MACN-Pa 532/1, 532/2; CNP-Par 50; USNPC 105642. 


\section{Comentarios taxonómicos}

La metacercaria descripta pertenece a la familia Gymnophallidae debido a que su morfología es compatible con la diagnosis de la familia: posee un cuerpo pequeño y oval; la ventosa oral es subterminal de mayor tamaño que la ventosa ventral y está situada entre el tercio anterior y el tercio posterior del cuerpo. No posee prefaringe, el esófago es corto y los ciegos no alcanzan la mitad del cuerpo. Los testículos se ubican ligeramente diagonales, localizados a nivel de la ventosa ventral. Las glándulas vitelinas son foliculares y se disponen de a pares a los lados de la ventosa ventral. La vesícula excretora en forma de $\mathrm{Y}$ se extiende hasta el nivel de la ventosa oral presentando divertículos (James, 1964). La metacercaria pertenece al género Gymnophalloides Fujita in Dollfus, 1925 debido a la presencia de una ventosa accesoria denominada ventral pit y a la ausencia de pars prostática (Cremonte et al., 2013). Gymnophalloides nacellae fue originalmente descripta por Martorelli \& Morriconi (1998) como Lacunovermis sp. Debido a la evidencia molecular y a estudios morfológicos adicionales sobre material vivo, esta especie fue reubicada en el género Gymnophalloides (Cremonte et al., 2013). Gymnophalloides nacellae difiere de las otras especies del género, como Gymnophalloides tokiensis Fujita, 1925, Gymnophalloides seoi Lee, Chai \& Hong, 1993 y Gymnophalloides heardi Ching, 1995 debido a la presencia de un grupo de papilas localizadas entre el ventral pit y la ventosa ventral. Además, esta especie difiere de G. heardi en la forma del vitelario (pares de folículos vs. un solo lóbulo) (Ching, 1995). Por último, G. tokiensis y G. seoi poseen una vesícula seminal bipartita (Ching, 1972; Lee et al., 1993), mientras que G. nacellae posee una vesícula seminal unipartita. 
Capítulo 1. Digeneos hallados

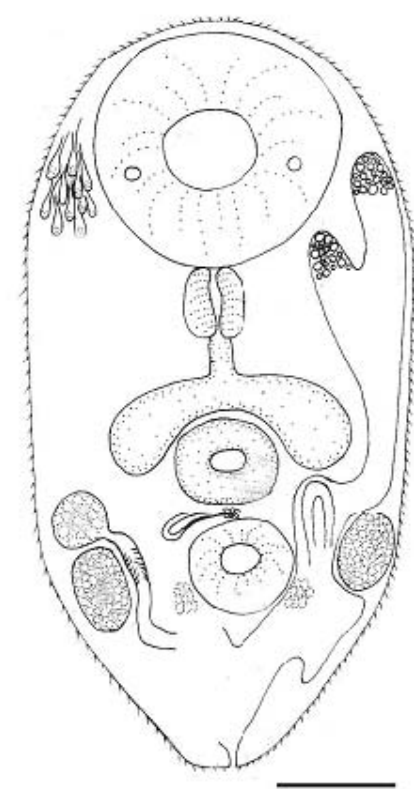

Figura 23. Metacercaria de Gymnophalloides nacellae, vista ventral. La vesícula excretora del lado derecho fue omitida, así como solo se han dibujado unos pocos gránulos de excreción. Las glándulas cefálicas del lado izquierdo fueron omitidas. Escala: $50 \mu \mathrm{m}$.

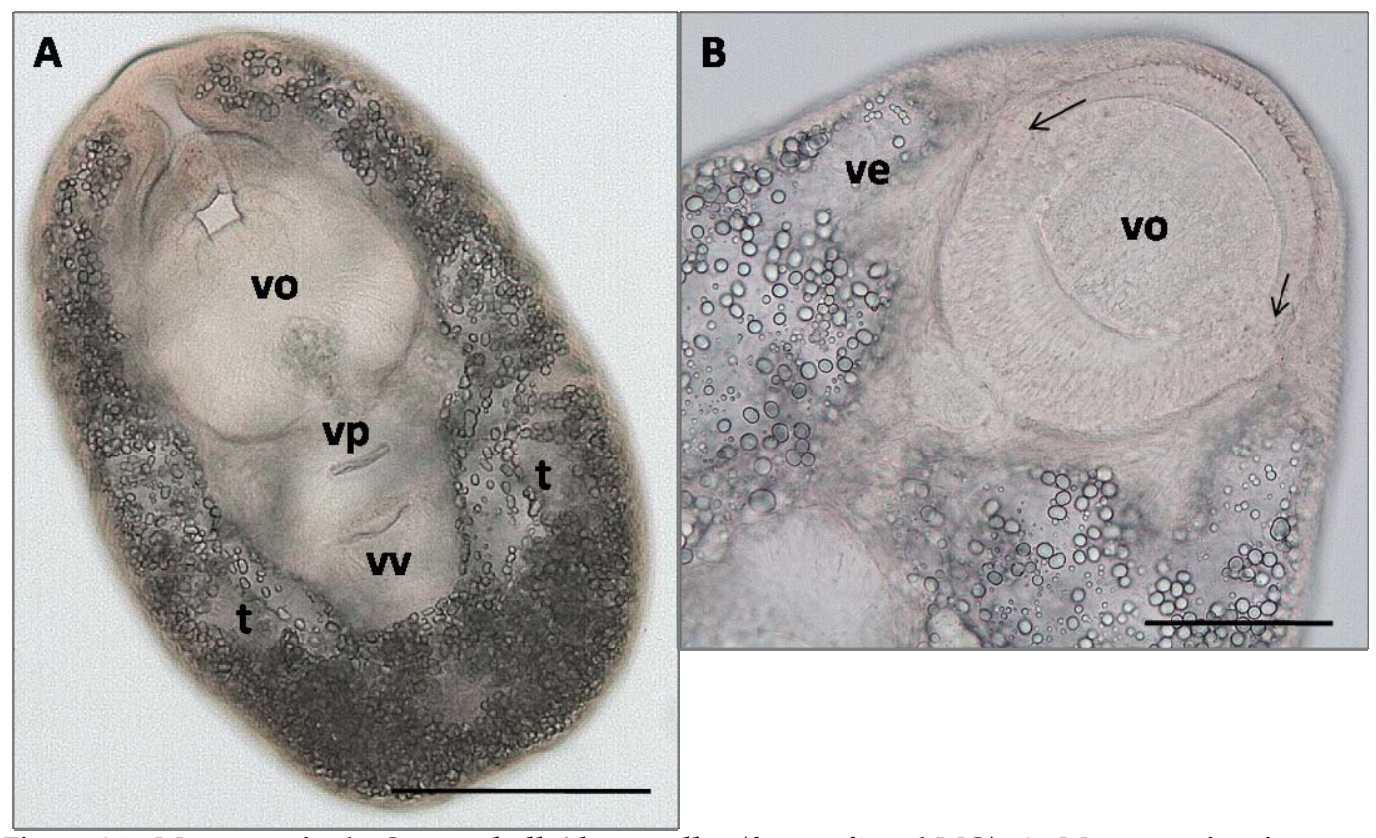

Figura 24. Metacercaria de Gymnophalloides nacellae (fotografías al MO). A- Metacercaria, vista ventral; BExtremo anterior, detalle de los labios de la ventosa oral (flechas). Escalas: $100 \mu \mathrm{m}$ (A); $50 \mu \mathrm{m}$ (B). Abreviaturas: $t$ - testículo; ve- vesícula excretora; vo- ventosa oral; vp- ventral pit; vv- ventosa ventral. 


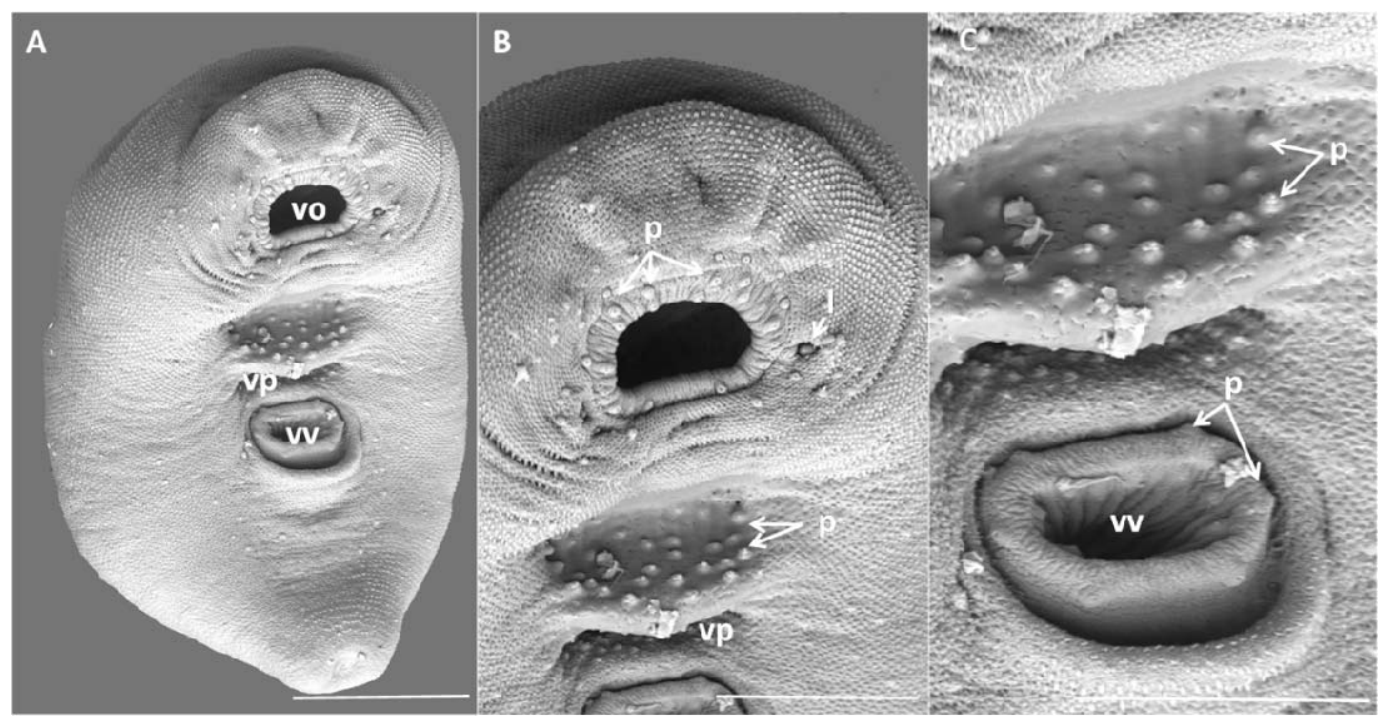

Figura 25. Metacercaria de Gymnophalloides nacellae (fotografías al MEB). A- Vista ventral; BExtremo anterior, detalle de los labios y las papilas de la ventosa oral y detalle de las papilas entre la ventosa oral y el ventral pit; C- Detalle de las papilas de la ventosa ventral. Escalas: $100 \mu \mathrm{m}(\mathrm{A}, \mathrm{B}) ; 50$ $\mu \mathrm{m}(\mathrm{C})$. Abreviaturas: 1- labio invaginado; p- papilas; vo- ventosa oral; vp- ventral pit; vv- ventosa ventral. 
Microphallidae Travassos, 1920

Maritrema sp. 1 (Figuras 26-29) ${ }^{4}$

\section{Descripción de las larvas}

Esporocisto: incoloro, de forma oval con la extremidad anterior ligeramente aguzada; mide 279 (160-379) de longitud por 198 (130-279) de ancho máximo. La pared del cuerpo mide 7 (5-10) de espesor. El movimiento de las cercarias dentro del esporocisto puede distorsionar su forma; las cercarias desarrolladas emergen del esporocisto por un poro de puesta terminal (Fig. 28A). Se observan esporocistos en dos estados de desarrollo: 1) esporocistos sólo con esferas germinales, 2) esporocistos con esferas germinales 6 (3-9), cercarias 9 (4-22) y/o metacercarias 7 (311) (Fig. 27A). Los esporocistos que contienen muchas esferas germinales presentan pocas cercarias y viceversa. El número total de estadios larvales (esferas germinales, cercarias y metacercarias) por esporocisto es de 16 (6-31).

Cercaria: xiphidocercaria monostoma (con estilete, sin ventosa ventral). Presenta un cuerpo pequeño y elongado que mide 116 (93-143) de longitud por 36 (26-49) de ancho máximo, está cubierto uniformemente por espinas diminutas desde el nivel de la ventosa oral hasta el extremo posterior. La ventosa oral es subterminal y mide 22 (17-28) de diámetro. Presenta un estilete conspicuo, lanceolado y cubierto por una pared gruesa refractiva en la mitad superior, que mide 18 (15-21) de longitud por $6(5-8)$ de ancho en la base (Fig. 27D). No presenta ventosa ventral. Posee cuatro pares de glándulas de penetración con citones de forma irregular ubicados en la mitad del cuerpo; dos pares anteriores cuyos ductos se extienden dorsalmente desembocando a ambos lados en el extremo anterior de la ventosa oral y dos pares posteriores que se extienden ventralmente y quedan enmascarados por los ductos dorsales; estos últimos abren a ambos lados del estilete. El material de secreción en los ductos anteriores presenta gránulos gruesos y se tiñe fuertemente con colorantes vitales; en cambio, el material de secreción en los ductos posteriores presenta gránulos finos y no se tiñe con colorantes vitales (Figs. 27B, D). La distancia desde el extremo anterior del cuerpo al extremo posterior de las glándulas de penetración es

\footnotetext{
${ }^{4}$ La descripción de esta especie fue publicada en Gilardoni et al. (2011)
} 
de 70 (66-77). La boca y otras partes del sistema digestivo no están desarrolladas. La vesícula excretora presenta una pared delgada y forma de V (Fig. 27C). El poro excretor se localiza en el extremo distal de la cola. La cola es cilíndrica y contráctil, mide 87 (70-100) de longitud por 11 (9-15) de ancho en la base, su diámetro disminuye hacia el extremo posterior. Presenta un tegumento con numerosas membranas musculares en forma de anillo.

Comportamiento de la cercaria y tiempo de vida: bajo condiciones de laboratorio, las cercarias desarrolladas emergen naturalmente, nadan en forma activa durante unos minutos y caen al fondo del recipiente. Cuando nadan, la extremidad posterior del cuerpo se pliega ventralmente y la cola permanece paralela a la superficie ventral del cuerpo. La cercaria se mueve alternando contracciones del cuerpo con vigorosos movimientos de la cola a modo de látigo. El tiempo de vida de las cercarias es menor a 24 hs a temperatura ambiente y 48 hs a $12^{\circ} \mathrm{C}$.

Metacercaria: presenta un quiste esférico y mide 74 (67-80) de diámetro. La pared del quiste mide 5 (3-6) de espesor. Las cercarias bajo condiciones de laboratorio enquistan dentro de los esporocistos (Fig. 27A), cesando gradualmente su movimiento, comenzando a girar sobre sí mismas y secretando una pared delgada.

\section{Secuencias moleculares}

Se secuenciaron las regiones ITS1, 5.8S e ITS2 del ADN ribosomal de esporocistos. Se obtuvieron en forma parcial las regiones 185 y $28 \mathrm{~S}$ y en forma completa las regiones ITS1, 5.8S e ITS2. Las secuencias parciales de las regiones $18 \mathrm{~S}$ y $28 \mathrm{~S}$ tienen 167 y 100 pares de bases (pb) respectivamente; las secuencias completas de las regiones ITS1, 5.8S e ITS2 tienen 677, 110 y 374 pb respectivamente. Las secuencias presentaron similitudes con otras disponibles en la base de datos de Gen Bank pertenecientes a especies del género Maritrema Nicoll, 1907 (ver Anexo IV). Las secuencia de la región ITS1 de Maritrema sp. 1 presentó mayor similitud con la secuencia de Maritrema portucalensis Pina, Russell-Pinto \& Rodrigues, 2011 (80,5\%). El resto de las secuencias, tanto ITS1 como ITS2, presentaron menos de un $75 \%$ de similitud. 


\section{Resumen taxonómico}

Hospedador: Crepipatella dilatata Lamarck (Caenograstropoda, Calyptraeidae).

Localidades: Puerto Madryn y Puerto Deseado.

Prevalencia total: 33,45\% ( $=1.665)$ en Puerto Madryn y 16,5\% ( $=266)$ en Puerto Deseado.

Sitio de infección: los esporocistos invaden principalmente la gónada y la glándula digestiva. En intensidades altas, el pie y el manto también se ven afectados (Fig. 29). Especimenes depositados: MLP 6285; CNP-Par 28.

\section{Comentarios taxonómicos}

La cercaria descripta pertenece a la familia Microphallidae debido a que su morfología es compatible con la diagnosis de la familia: presenta una ventosa oral con musculatura pobremente definida y un estilete prominente (xiphidocercaria), no presenta ventosa ventral (cercaria monostoma), el tegumento es espinoso, el sistema digestivo no está desarrollado (cercaria anentérica), la vesícula excretora tiene forma de V y la cola es pequeña y simple (cercaria leptocerca) (Schell, 1970). La cercaria sería una nueva especie y pertenece al género Maritrema debido a la forma y localización de las glándulas de penetración (Bridgman, 1971). Este registro constituye el cuarto reporte de una cercaria Maritrema en gasterópodos de Argentina. Previamente, Etchegoin \& Martorelli (1997) describieron a Maritrema bonaerensis Etchegoin y Martorelli, 1997 en Heleobia australis d'Orbigny (Cochliopidae) de la Laguna de Mar Chiquita $\left(37^{\circ} 46^{\prime} \mathrm{S}, 5^{\circ} 27^{\prime} \mathrm{O}\right)$, provincia de Buenos Aires; Alda \& Martorelli (2009) describieron una especie de Maritrema parasitando a Siphonaria lessonii y Kerguelenella lateralis en el intermareal rocoso de

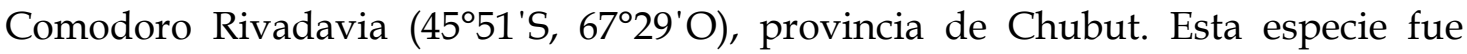
hallada también en Playa Fracasso, Golfo San José, Chubut (Bagnato, 2012) y en el presente estudio. Recientemente, se describió la cercaria de Maritrema orensense Cremonte \& Martorelli, 2008 en H. australis en el estuario de Bahía Blanca, provincia de Buenos Aires ( $\left.38^{\circ} 44^{\prime} \mathrm{S}, 62^{\circ} 22^{\prime} \mathrm{O}\right)$ (Alda et al., 2013). Los caracteres diferenciales de la especie aquí descripta con Maritrema madrynense hallada en S. lessonii y K. lateralis se presenta en los comentarios taxonómicos de Maritrema madrynese. 
A

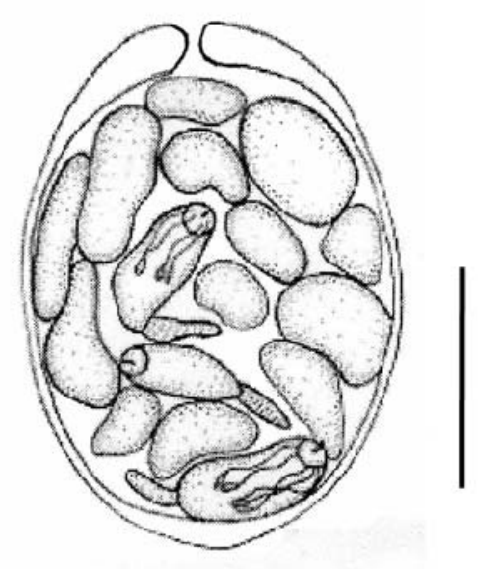

B

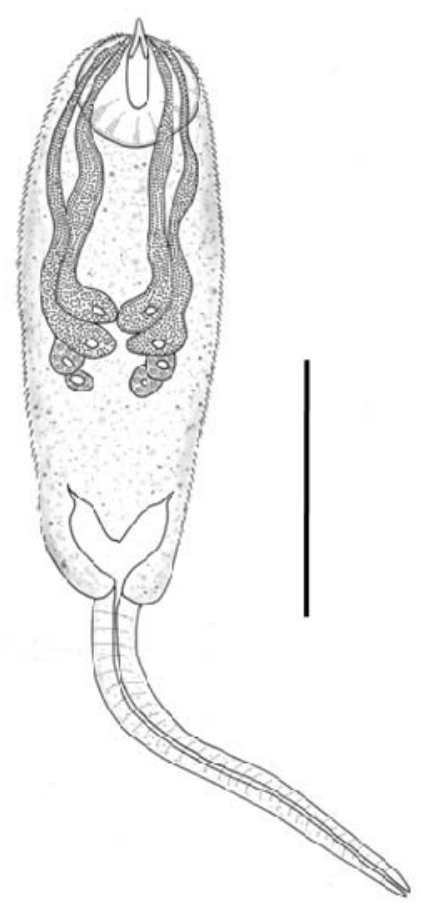

Figura 26. Estadios larvales de Maritrema sp. 1. A- Esporocisto; B- Cercaria, vista ventral. Escalas: 100 $\mu \mathrm{m}(\mathrm{A}) ; 50 \mu \mathrm{m}$ (B). 


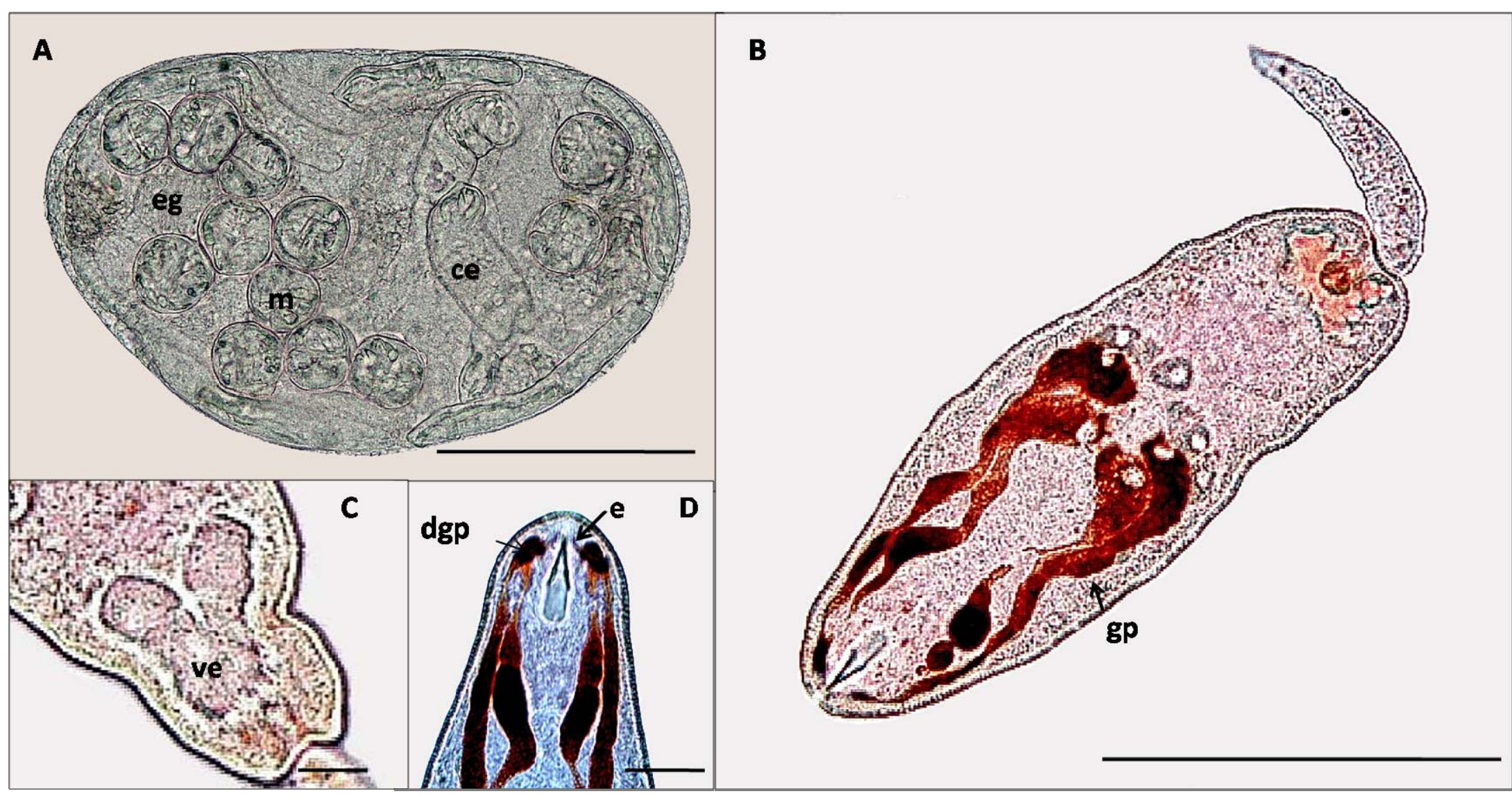

Figura 27. Estadios larvales de Maritrema sp. 1 (fotografías al MO). A- Esporocisto con cercarias y metacercarias; B- Cercaria, vista dorsal; C- Extremo posterior de la cercaria, detalle de la vesícula excretora; D- Extremo anterior de la cercaria, detalle del estilete y desembocaduras de las glándulas de penetración. Escalas: 100 $\mu \mathrm{m}$ (A); $50 \mu \mathrm{m}$ (B); $10 \mu \mathrm{m}$ (C); $20 \mu \mathrm{m}$ (D). Abreviaturas: ce- cercaria; dgp- desembocadura de las glándulas de penetración; e- estilete; eg- esferas germinales; gpglándulas de penetración; $\mathrm{m}$ - metacercaria; ve- vesícula excretora. 


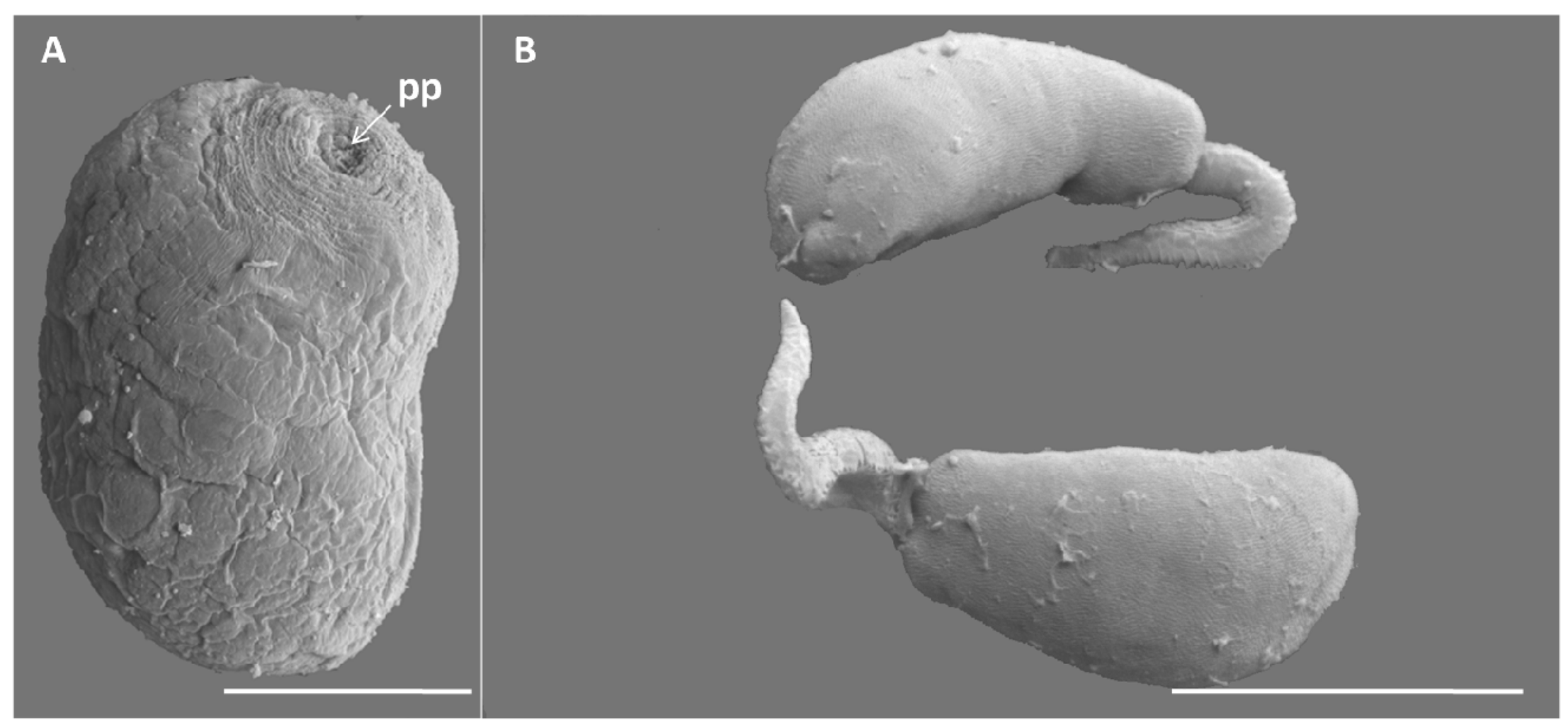

Figura 28. Estadios larvales de Maritrema sp. 1 (fotografías al MEB). A- Esporocisto; B- Cercarias, vistas dorsales. Escala: $100 \mu \mathrm{m}$ (A, B). Abreviaturas: pp- poro de puesta. 


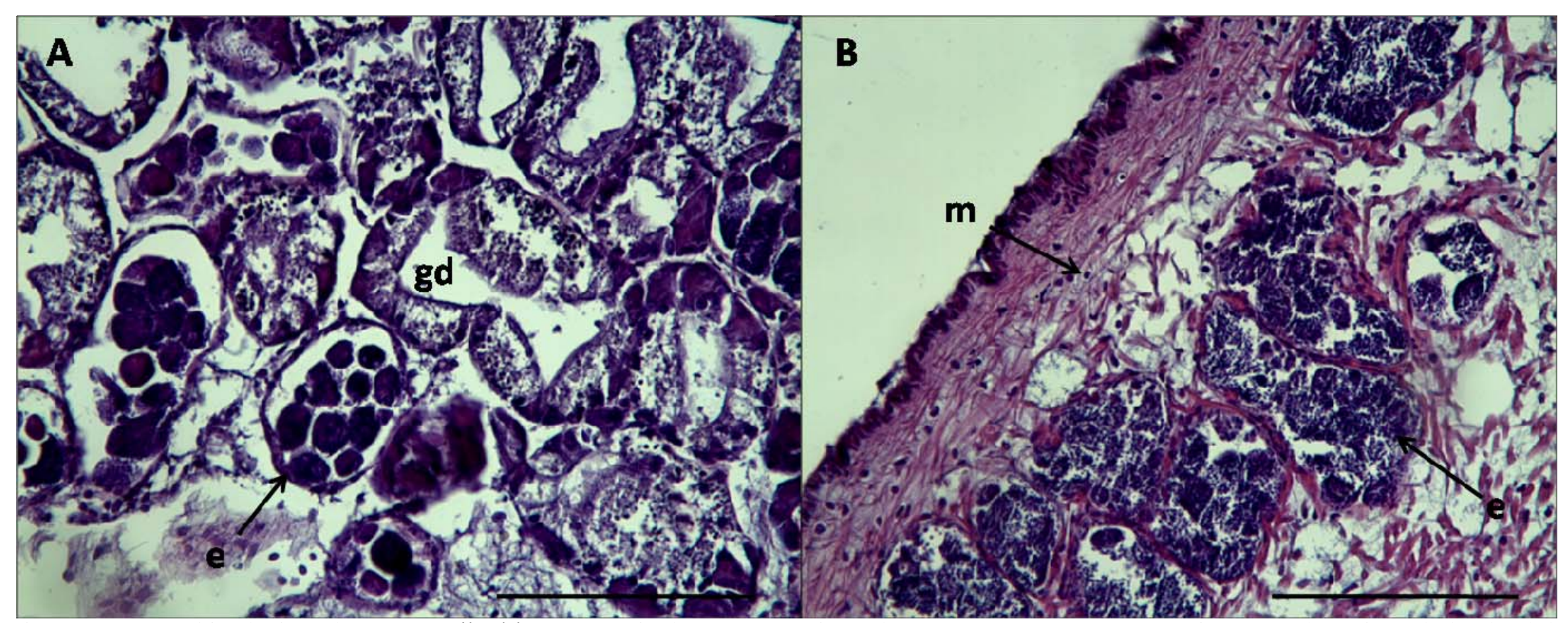

Figura 29. Cortes histológicos de Crepipatella dilatata parasitada por esporocistos de Maritrema sp. 1. A- Esporocistos ente los acinos de la glándula digestiva; B- Esporocistos en el manto. Escalas: $500 \mu \mathrm{m}$ (A, B). Abreviaturas: e- esporocisto; gd- glándula digestiva; m- manto. 
Maritrema madrynense Diaz \& Cremonte, 2010 (Figuras 30-33) ${ }^{5}$

\section{Descripción de las larvas}

Esporocisto: color amarillento, de forma alargada, mide 709 (520-1.000) de longitud por 245 (170-290) de ancho. El movimiento de las cercarias distorsiona la forma del esporocisto. El poro de puesta es terminal. Se observan esporocistos en tres estados de desarrollo: 1) esporocistos con esferas germinales y cercarias poco desarrolladas, 2) esporocistos con cercarias desarrolladas (Fig. 31A), y 3) esporocistos repletos de metacercarias (Fig. 31D). El número total de larvas (esferas germinales, cercarias y/o metacercarias) por esporocisto es de 37 (15-50).

Cercaria: tipo xiphidocercaria (con estilete) y monostoma (sin ventosa ventral). Presenta un cuerpo pequeño y elongado que mide 132 (105-200) de longitud por 52 (48-70) de ancho máximo. El cuerpo está cubierto por diminutas espinas, desde el extremo anterior hasta el extremo posterior del cuerpo y presenta tres pares de papilas entre la ventosa oral y el tercio medio del cuerpo (observado al MEB, Fig. 32A). La ventosa oral es subterminal y mide 34 (29-38) de diámetro. Presenta un anillo de por lo menos diez papilas (observado al MEB, Fig. 32A) y un estilete bien desarrollado con forma de punta de flecha que mide 18 (14-22) de longitud por 4 $(2,5-4,5)$ de ancho en la base; cubierto por una capa refractiva (Fig. 31C). No presenta ventosa ventral. Posee cuatro pares de glándulas de penetración de forma irregular cuyos citones se localizan en la mitad posterior del cuerpo. Los dos pares anteriores son conspicuos y se extienden dorsalmente dando tres vueltas y abriendo uno a cada lado del extremo posterior de la ventosa oral. Los dos pares anteriores son delgados y se extienden ventralmente enmascarados por los ductos dorsales; éstos abren en el extremo anterior, uno a cada lado del estilete (Figs. 31B, C). El material de secreción en los ductos anteriores presenta gránulos gruesos y se tiñe fuertemente con colorantes vitales, en cambio el material de secreción en los ductos posteriores presenta gránulos finos y no se tiñe con colorantes vitales. La distancia desde el extremo anterior del cuerpo al extremo posterior de las glándulas de penetración es de 93 (82-109). La boca y otras partes del sistema digestivo no están

\footnotetext{
${ }^{5}$ La descripción de los estadios larvales de esta especie fueron publicados en Gilardoni et al. (2011)
} 
desarrolladas. La vesícula excretora presenta una pared delgada y forma de V (Fig. 31B). La fórmula excretora es $2[(2+2)+(2+2)]=16$. El poro excretor se localiza en el extremo distal de la cola. La cola es cilíndrica y contráctil, mide 103 (95-125) de longitud por 10 (8-11) de ancho en la base, su diámetro disminuye hacia el extremo posterior. Presenta un tegumento con numerosas membranas musculares en forma de anillo (Fig. 32B).

Comportamiento de la cercaria y tiempo de vida: similar a Maritrema sp. 1.

Metacercaria: quiste oval, mide 74 (65-85) de longitud por 125 (110-135) de ancho. Presenta una capa hialina gruesa de 10 (7-13) de espesor (Figs. 31E, 32C). Dentro del quiste se observan faringe, ciegos y cirro espinoso.

\section{Secuencias moleculares}

Se secuenciaron las regiones ITS1, 5.8S e ITS2 del ADN ribosomal de esporocistos. Se obtuvieron en forma parcial las regiones 185 y 285 y en forma completa las regiones ITS1, 5.8S e ITS2. Las secuencias parciales de las regiones 18S y 28S tienen 2 y 100 pares de bases $(\mathrm{pb})$ respectivamente; las secuencias completas de las regiones ITS1, 5.8S e ITS2 tienen 670, 109 y 378 pb respectivamente. Las secuencias presentaron similitudes con otras disponibles en la base de datos de Gen Bank pertenecientes a especies del género Maritrema (ver Anexo IV). La secuencias moleculares de Maritrema madrynense presentaron mayor similitud con Maritrema eroliae Yamaguti, 1939 (92,39\% de similitud en la región ITS1) y con Maritrema oocysta Lebour, 1907 (85,61\% de similitud en la región ITS1 y 87,3\% de similitud en la región ITS2).

\section{Resumen taxonómico}

Hospedador: Siphonaria lessonii Blainville (Pulmonata, Bassommatophora, Siphonariidae) y Kerguelenella lateralis Gould (Pulmonata, Bassommatophora, Siphonariidae).

Localidades: Puerto Madryn y Puerto Deseado.

Prevalencia total: 8,95\% ( $n=1.050)$ en Puerto Madryn y 4,02\% ( $n=423)$ en Puerto Deseado. 
Sitio de infección: los esporocistos invaden principalmente la gónada y la glándula digestiva. En intensidades altas también invaden las branquias y el complejo glandular paleal (Fig. 33).

Especimenes depositados: MLP 6284; CNP-Par 27.

\section{Comentarios taxonómicos}

Maritrema madrynense es muy similar a la descripta por Alda \& Martorelli (2009) en los mismos hospedadores (Siphonaria lessonii y Kerguelenella lateralis) de Comodoro Rivadavia, localidad intermedia entre Puerto Madryn y Puerto Deseado, por lo que podría tratarse de la misma especie. Los especímenes aquí descriptos difieren de Maritrema sp. 1 presente en C. dilatata en el tamaño del cuerpo, la forma del estilete y la localización de las glándulas de penetración y sus ductos. Los esporocistos de M. madrynense son de mayor tamaño que los esporocistos de Maritrema sp. 1 y contienen una mayor cantidad de cercarias (37 vs. 16). El estilete presenta un tamaño similar $(18 \mu \mathrm{m})$ en ambas especies, pero en Maritrema sp. 1 es lanceolado y está cubierto con una capa refractiva en el extremo anterior; en cambio en $M$. madrynense presenta forma de flecha y está cubierto con una capa refractiva en su totalidad. Los citones de las glándulas de penetración están situados en la mitad del cuerpo en Maritrema sp. 1 y en la parte posterior del cuerpo en M. madrynense. La metacercaria de Maritrema sp. 1 sólo se halló recién enquistada (conservando las estructuras de la cercaria) dentro de los esporocistos, ocasionalmente; en cambio, los esporocistos de M. madrynense se hallaron frecuentemente repletos de metacercarias. Maritrema bonaerensis es similar a M. madrynense en el tamaño de los estadios larvales y en la forma del estilete. Sin embargo, las especies difieren en la posición de los citones de las glándulas de penetración y en el recorrido de los ductos (Etchegoin \& Martorelli, 1997). Las secuencias de Maritrema sp. 1 y M. madrynense presentan un porcentaje de similitud bajo (62\% de similitud en la región ITS1 y 69,79\% de similitud en la región ITS2), por lo que pertenecerían a especies diferentes. 
A

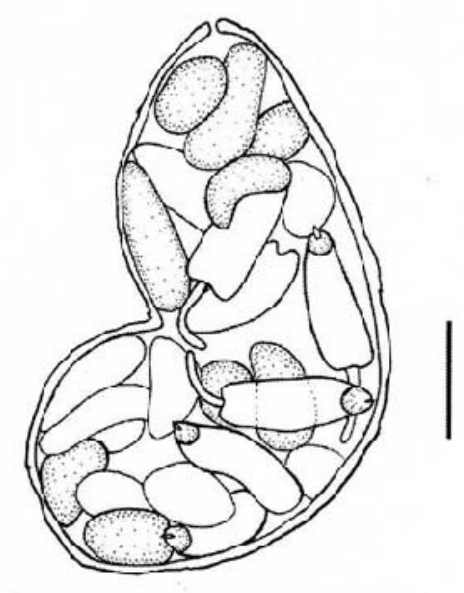

B

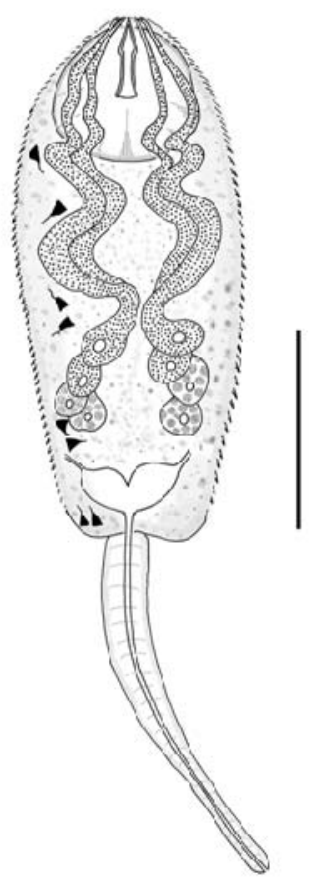

Figura 30. Estadios larvales de Maritrema madrynense. A- Esporocisto; B- Cercaria, vista dorsal, las células flamígeras del lado derecho fueron omitidas. Escalas: $100 \mu \mathrm{m}$ (A); $50 \mu \mathrm{m}$ (B). 


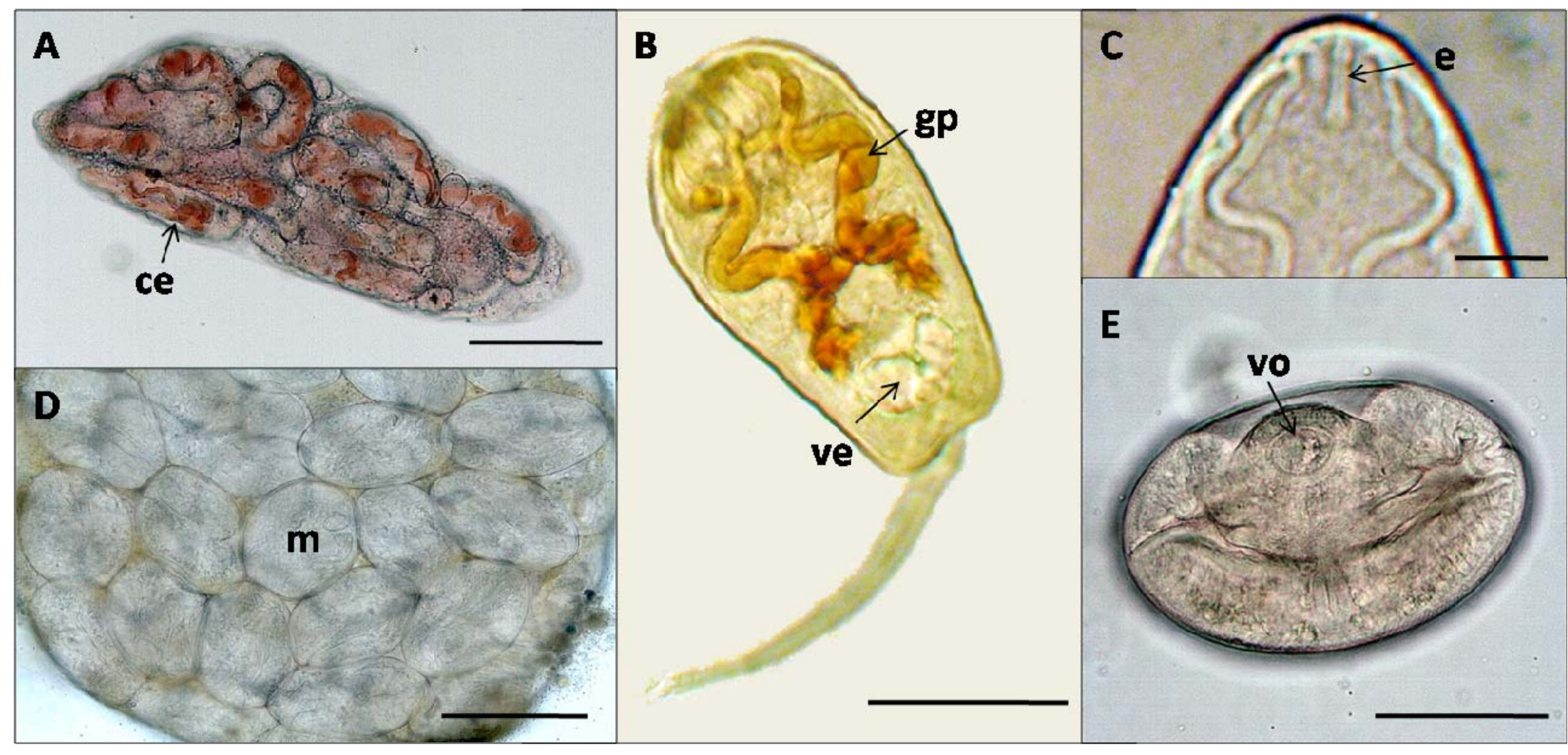

Figura 31. Estadios larvales de Maritrema madrynense (fotografías al MO). A- Esporocisto con cercarias desarrolladas; B- Cercaria, vista dorsal, detalle de las glándulas de penetración y la vesícula excretora; C- Extremo anterior de la cercaria, detalle del estilete; D- Esporocisto con metacercarias; E- Metacercaria. Escalas: $200 \mu \mathrm{m}$ (A); $50 \mu \mathrm{m}$ (B, E); $20 \mu \mathrm{m}$ (C); $100 \mu \mathrm{m}$ (D). Abreviaturas: ce- cercaria; e- estilete; gp- glándulas de penetración; m- metacercaria; ve- vesícula excretora; voventosa oral. 


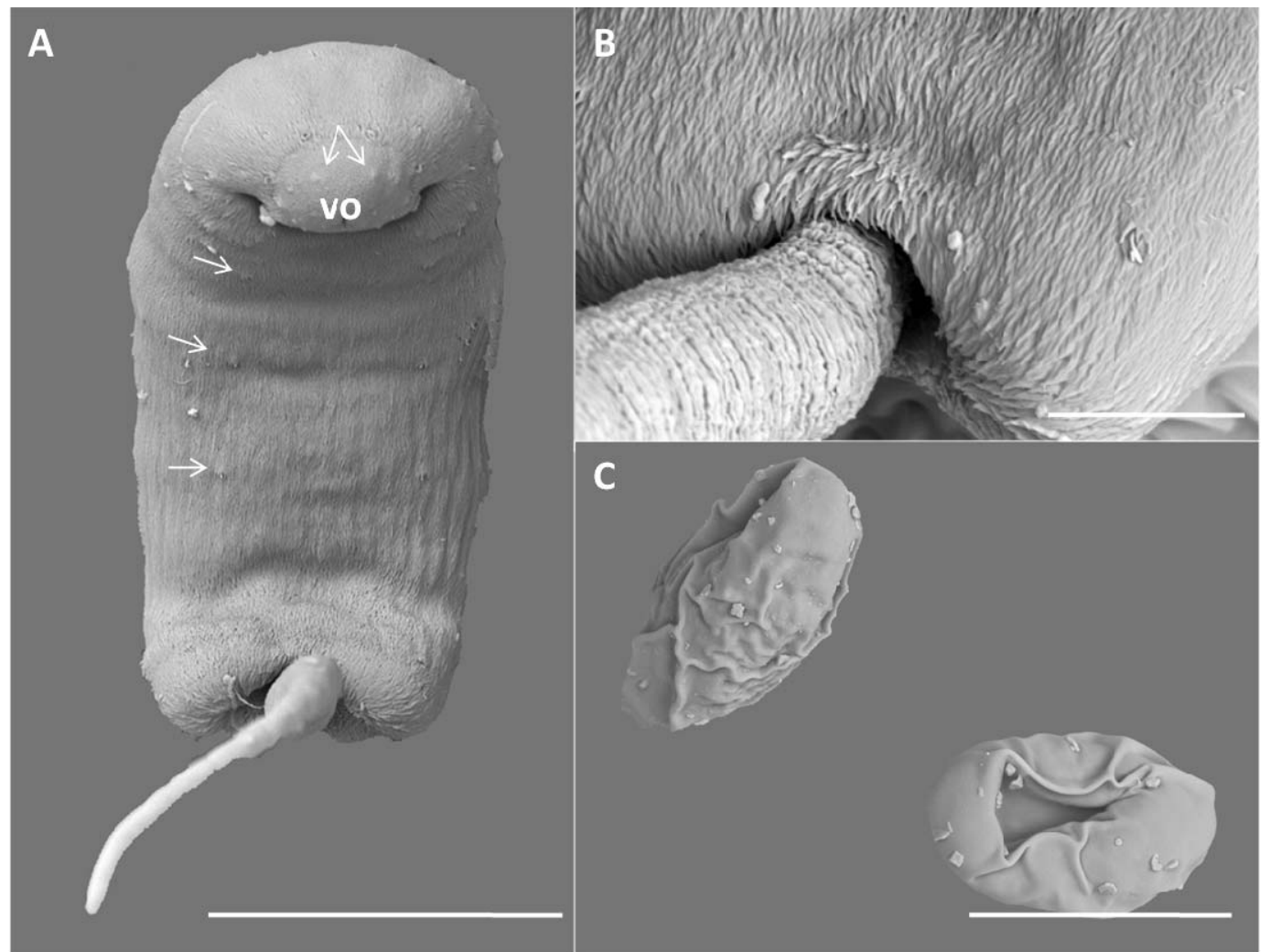

Figura 32. Estadios larvales de Maritrema madrynense (fotografías al MEB). A- Cercaria, vista ventral, las flechas señalan las papilas presentes en la ventosa oral y en el cuerpo; B- Extremo posterior de la cercaria, detalle de la inserción de la cola; C- Metacercarias. Escalas: $50 \mu \mathrm{m}$ (A); $10 \mu \mathrm{m}$ (B); $100 \mu \mathrm{m}(\mathrm{C})$. Abreviaturas: vo- ventosa oral. 


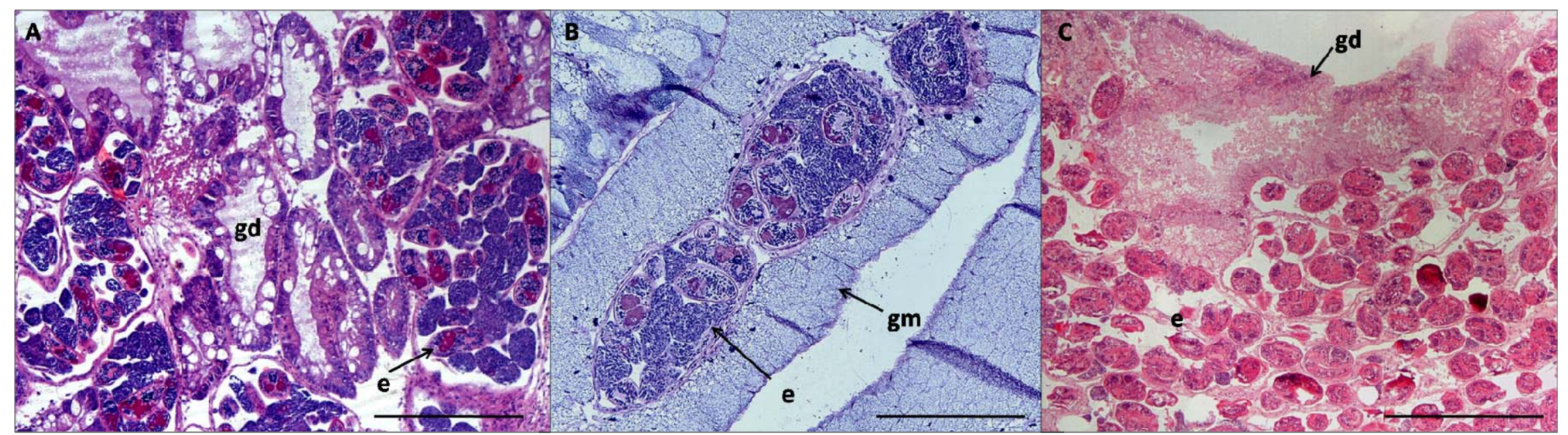

Figura 33. Cortes histológicos de Siphonaria lessonii parasitada por esporocistos de Maritrema madrynense. A- Esporocistos entre los acinos de la glándula digestiva; BEsporocistos entre la glándula mucosa y el complejo glandular paleal; C- Esporocistos repletos de metacercarias ocupando el espacio de la gónada y la glándula digestiva. Escalas: $500 \mu \mathrm{m}(\mathrm{A}, \mathrm{B}, \mathrm{C})$. Abreviaturas: e- esporocisto; gd- glándula digestiva; gm- glándula de la mucosa. 
Capítulo 1. Digeneos hallados

\section{Notocotylidae Lühe, 1909}

Notocotylidae gen. et sp. (Figuras 34, 35)

\section{Descripción de las larvas}

Redia: sólo se halló un ejemplar de gasterópodo parasitado por esta especie, en el cual la mayoría de las redias estaban repletas de metacercarias. Estas redias no pudieron ser medidas debido a que se rompen fácilmente por la gran cantidad de metacercarias que contienen. Las medidas que se presentan son de redias con cercarias. La redia es grande y elongada, mide 950 (700-1.171) de longitud por 212 (166-276) de ancho máximo. La pared presenta un espesor de 10 (6-13). No se observó el poro de puesta. La faringe es pequeña, mide 60 (38-74) de longitud por 54 (44-63) de ancho. El intestino presenta forma de saco y mide 224 (172-274) de longitud por 53 (36-82) de ancho. El número de larvas por redia es de 16 (8-22); de las cuales 6 (3-9) son esferas germinales y 11 (4-17) son cercarias.

Cercaria: monostoma (no posee ventosa ventral) presenta un cuerpo pequeño y ovalado que mide 299 (229-494) de longitud por 97 (69-161) de ancho. La ventosa oral mide 45 (34-66) de longitud por 47 (37-75) de ancho. La boca es terminal. No presenta prefaringe ni faringe. El esófago es corto, mide 34 (27-47) de longitud; los ciegos son largos, miden 184 (165-217) de longitud y se extienden hasta el extremo posterior del cuerpo (Fig. 35E). La vesícula excretora es pequeña y ovalada y mide 41 (21-65) de longitud por 36 (15-50) de ancho. Los ductos colectores de la vesícula excretora son largos, corren paralelos a los ciegos y alcanzan el nivel del esófago, donde se vuelven a unir (Fig. 35E). Presenta una cola pequeña y redondeada que mide 34 (25-43) de longitud por 29 (25-33) de ancho (Fig. 35F).

Metacercaria: presenta un quiste esférico que mide 168 (128-190) de diámetro y la pared tiene un espesor de 5 (4-8). La ventosa oral mide 31 (28-33) de longitud por 43 (35-51) de ancho. La metacercaria presenta una vesícula excretora bien desarrollada con gránulos de excreción grandes, conspicuos y refringentes (Fig. 35C).

Comportamiento de la cercaria y tiempo de vida: el comportamiento de la cercaria y el tiempo de vida no pudo ser observado ya que no se obtuvieron emisiones. 


\section{Secuencias moleculares}

Se secuenció la región ITS1 del ADN ribosomal de metacercarias. Se obtuvieron en forma parcial las regiones $18 \mathrm{~S}$ y $5.8 \mathrm{~S}$ y en forma completa la región ITS1. Las secuencias parciales de las regiones $18 \mathrm{~S}$ y $5.8 \mathrm{~S}$ tienen 3 y 10 pares de bases $(\mathrm{pb})$ respectivamente; la secuencia completa de la región ITS1 tiene 832 pb. La secuencia presentó similitud con otra disponible en la base de datos de Gen Bank perteneciente al género Notocotylus (ver Anexo V). El porcentaje de similitud de las secuencias de las regiones ITS1 fue de 89,78\%. Otras secuencias publicadas de la familia Notocotylidae pertenecen a regiones 18S, ITS2, $28 \mathrm{~S}$ y genes mitocondriales. Futuras secuenciaciones de la especie en cuestión sobre estas regiones y genes publicados contribuirán a conocer su identidad taxonómica.

\section{Resumen taxonómico}

Hospedador: Nacella (P.) magellanica (Gmelin) (Patellogastropoda, Nacellidae).

Localidad: Puerto Deseado.

Prevalencia total: $0,33 \%(\mathrm{n}=306)$.

Sitio de infección: los esporocistos invaden la gónada y la glándula digestiva. Especímenes depositados: CNP-Par 57.

\section{Comentarios taxonómicos}

La cercaria descripta pertenece a la familia Notocotylidae debido a que su morfología es compatible con la diagnosis de la familia: cercaria monostoma, no presenta faringe, la vesícula excretora es pequeña y ovalada y presenta dos tubos colectores que se extienden hasta el nivel del esófago y que se unen formando un circuito tubular. No posee glándulas de penetración y enquista en el $1^{\circ}$ hospedador intermediario (Rothschild, 1938; Yamaguti, 1975). Estadios larvales de similares características fueron hallados en Nacella $(P$.) deaurata e identificados como pertenecientes a la familia Pronocephalidae (Martorelli et al., 2005). Los adultos de la familia Pronocephalidae finalizan su ciclo de vida principalmente en el intestino de reptiles acuáticos, como tortugas y unas pocas especies en peces (Barton \& Blair, 2005). Es más probable que la especie registrada pertenezca a la familia 
Notocotylidae, que finalizan su ciclo de vida en el tracto digestivo (principalmente ciegos) de aves y mamíferos (Barton \& Blair, 2005). Las cercarias Notocotylidae pueden dividirse en dos grupos morfológicos: 1) cercarias con ocelos y cola larga y 2) cercarias sin ocelos y cola corta o sin cola. Existen al menos 25 especies de cercarias pertenecientes al grupo 1 (e.g. Yamaguti, 1975; Alda, 2011; Hechinger, 2012). La cercaria aquí descripta pertenece al grupo 2. Otras cercarias pertenecientes al grupo 2 son Parapronocephalum symmetricum Belopol'skaia, 1952, Notocotyloides petasatus (Deslongchamps, 1824), Catatropis verrucosa (Froelich, 1789) Odhner, 1905 y pronocephaloid sp. I (Yamaguti, 1975; Hechinger, 2012). Las cercarias P. symmetricum y N. petasatus fueron incluidas dentro de la familia Pronocephalidae y luego reubicadas en la familia Notocotylidae (Barton \& Blair, 2005). Todas estas cercarias, incluyendo la aquí descripta, presentan similitudes en la longitud de los ciegos y la forma de la vesícula excretora. La cercaria aquí descripta es similar a $C$. verrucosa en las medidas del cuerpo de la cercaria (aprox. $300 \mu \mathrm{m}$ ) y en la forma de la metacercaria.

A

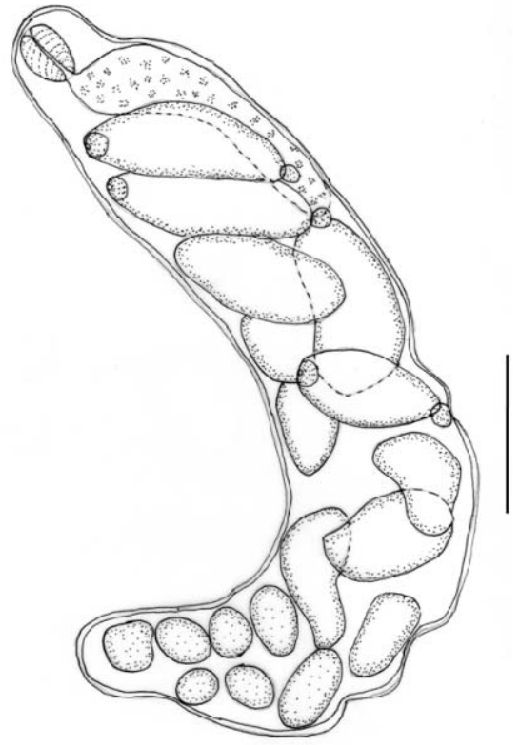

B

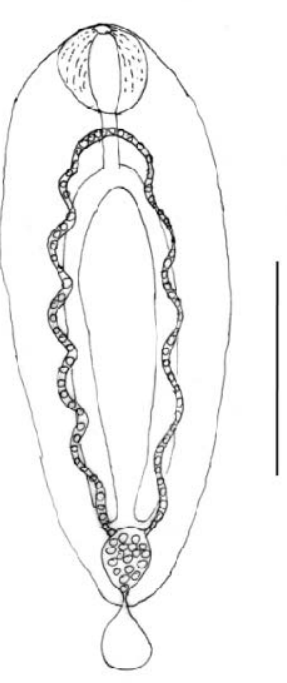

Figura 34. Estadios larvales de Notocotylidae gen. et sp. A- Redia; B- Cercaria, vista dorsal. Escalas: $200 \mu \mathrm{m}$ (A); $100 \mu \mathrm{m}$ (B). 

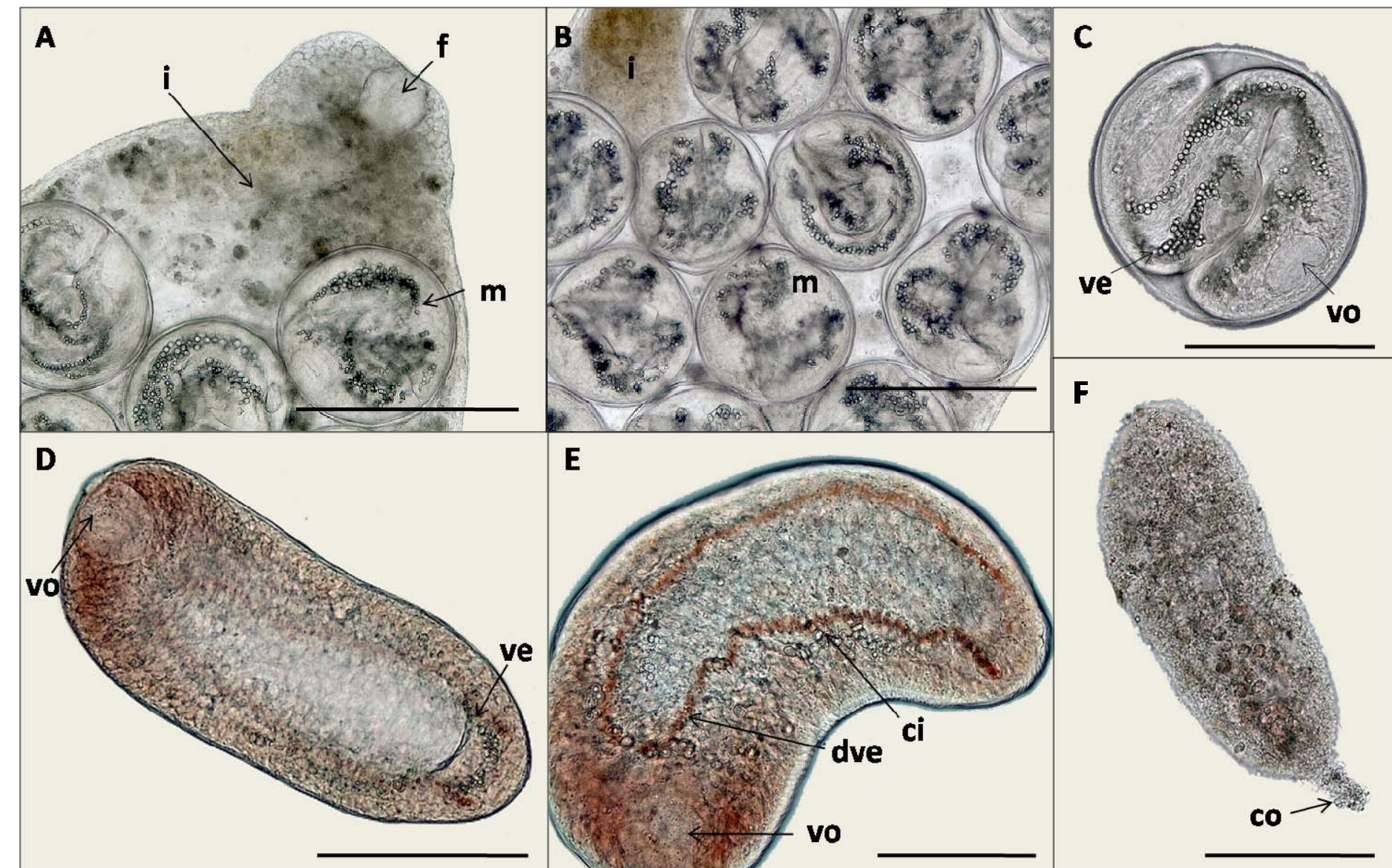

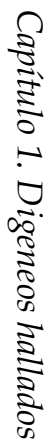

Figura 35. Estadios larvales de Notocotylidae gen. et sp. (fotografías al MO). A- Redia con metacercarias, extremo anterior; BMetacercarias dentro de la redia; C- Metacercaria enquistada; D. Cercaria, vista ventral; E- Cercaria, detalle de los ciegos digestivos teñidos con rojo neutro y la unión de los conductos de la vesícula excretora a nivel del esófago; F- Cercaria poco desarrollada, detalle de la cola pequeña- Escalas: $200 \mu \mathrm{m}(\mathrm{A}, \mathrm{B}) ; 100 \mu \mathrm{m}(\mathrm{C}, \mathrm{D}, \mathrm{F}) ; 50 \mu \mathrm{m}$ (E). Abreviaturas: ci- ciego; co- cola; dve- ductos de la vesícula excretora; f- faringe; i- intestino; m- metacercaria; ve- vesícula excretora; vo- ventosa oral. 
Capítulo 1. Digeneos hallados

\section{Renicolidae Dollfus, 1939}

Renicolidae gen. et sp. 1 (Figuras 36-39)6

\section{Descripción de las larvas}

Esporocisto: forma ovalada con el extremo anterior aguzado; mide 381 (227-502) de longitud por 207 (132-330) de ancho máximo. La pared tiene un espesor de 10 (6-15) y el poro de puesta es terminal. El número total de larvas por esporocisto es de 13 (3-27), pudiendo albergar 10 (2-24) esferas germinales y 5 (1-8) cercarias.

Cercaria: xiphidocercaria (con estilete) y distoma (dos ventosas). El cuerpo es elongado y mide 258 (197-286) de longitud por 58 (46-77) de ancho. La superficie del cuerpo está cubierta por espinas pequeñas que se extienden desde la ventosa oral hacia el extremo posterior y se distribuyen de manera más espaciada en la mitad posterior del cuerpo (Fig. 38A). En la superficie ventral se observan cuatro filas de papilas que se distribuyen longitudinalmente desde la ventosa oral hasta la ventosa ventral (observadas al MEB, Fig. 38A). Presenta una gran cantidad de glándulas cistógenas, desde el nivel de la faringe hasta el extremo posterior del cuerpo, distribuyéndose de manera más densa en los laterales del cuerpo (Fig. 37D). La distancia desde el extremo anterior del cuerpo hasta el margen anterior de la ventosa ventral es de 111 (104-125). La ventosa oral es subterminal, mide 37 (22-44) de longitud por 25 (18-42) de ancho y presenta cuatro grupos de tres papilas cada uno (observado al MEB, Fig. 38E). El estilete es pequeño, con forma de gota, y mide 7 (6-8) de longitud por 2 (1-3) de ancho en la base (Fig. 37B). La ventosa ventral mide 27 (20-32) de longitud por 21 (13-30) de ancho y presenta dos filas concéntricas de espinas (observado al MEB, Fig. 38C). La relación entre ventosa oral-ventral es 1:1,08 (0,76-1,11). Se observan cinco pares de glándulas de penetración; tres pares abren dorsalmente cerca del estilete y los otros dos pares abren en la ventosa oral. Los citones no fueron observados ya que se encuentran enmascarados por las glándulas cistógenas. No presenta prefaringe; la faringe mide 11 (9-13) de longitud por 9 (7-12) de ancho; el esófago es largo y mide 50 (35-55); los ciegos son cortos y miden 45 (35-52) de longitud, extendiéndose hasta la mitad de la ventosa ventral. La

\footnotetext{
${ }^{6}$ La descripción de los estadios larvales de esta especie fueron publicados en Gilardoni et al. (2011)
} 
vesícula excretora tiene forma de $\mathrm{Y}$, con una rama principal corta y dos ramas secundarias que alcanzan la ventosa ventral. El poro excretor abre en el extremo distal de la cola. Las células flamígeras no pudieron ser observadas, ya que se encuentran enmascaradas por las glándulas cistógenas. La cola es simple y mide 135 (104-164) de longitud por 19 (16-24) de ancho en la base.

Comportamiento de la cercaria y tiempo de vida: bajo condiciones de laboratorio las cercarias naturalmente emitidas nadan varias horas con vigorosos movimientos del cuerpo, doblando el extremo posterior hacia abajo y con vibraciones de la cola. Cuando caen al fondo del recipiente, se apoyan sobre la parte dorsal del cuerpo y repliegan la cola sobre la superficie ventral. El tiempo de vida es de 48 hs a temperatura ambiente.

\section{Secuencias moleculares}

Se secuenció la región ITS1 del ADN ribosomal de esporocistos. Se obtuvieron en forma parcial las regiones $18 \mathrm{~S}$ y $5.8 \mathrm{~S}$ y en forma completa la región ITS1. Las secuencias parciales de las regiones 18S y 5.8S tienen 166 y 103 pares de bases (pb) respectivamente; la secuencia completa de la región ITS1 tiene 493 pb. La secuencia no presentó similitud con ninguna otra disponible en la base de datos de Gen Bank. Las secuencias publicadas de la familia Renicolidae pertenecen a las regiones 18S, 285 y genes mitocondriales. Las futuras secuenciaciones de la especie en cuestión sobre estas regiones y genes disponibles contribuirán a resolver su identificación taxonómica.

\section{Resumen taxonómico}

Hospedador: Trophon geversianus Pallas (Caenogastropoda, Muricidae).

Localidades: Puerto Madryn y Puerto Deseado.

Prevalencia total: 0,29\% ( $n=689)$ en Puerto Madryn y 4,64\% ( $n=151)$ en Puerto Deseado.

Sitio de infección: los esporocistos invaden la gónada y la glándula digestiva (Fig. 39). Especimenes depositados: MLP 6278-6279; CNP-Par 20. 


\section{Comentarios taxonómicos}

La cercaria descripta pertenece a la familia Renicolidae debido a que su morfología es compatible con la diagnosis de la familia: xifidocercaria (con estilete), con vesícula excretora en forma de $\mathrm{Y}$, prefaringe ausente y numerosas glándulas cistógenas. Por lo menos 31 especies de la familia Renicolidae han sido descriptas en el mundo (e.g., Cable, 1956; Sannia \& James, 1977; Galaktionov \& Skimisson, 2000; Martorelli et al., 2008). Sin embargo, este es el segundo registro de una cercaria de esta familia en Sudamérica (Pinto \& Melo, 2012). Es probable que la cercaria descripta pertenezca al género Renicola Cohn, 1904, ya que presenta similitudes con otras cercarias del mismo género. Actualmente, solo hay dos géneros válidos dentro de la familia, Renicola y Nephromonorcha Leonov, 1958 (Gibson, 2008).

A

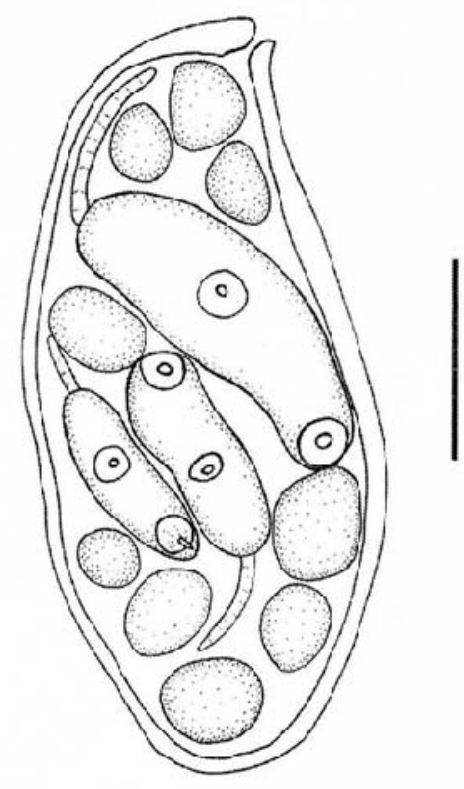

B

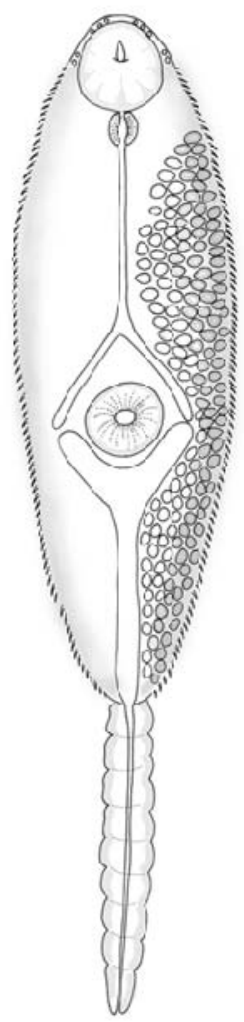

Figura 36. Estadios larvales de Renicolidae gen. et sp. 1. A- Esporocisto; B- Cercaria, vista ventral, sólo han sido dibujadas las glándulas cistógenas en la mitad izquierda del cuerpo. Escalas: $100 \mu \mathrm{m}(\mathrm{A}) ; 50 \mu \mathrm{m}$ (B). 


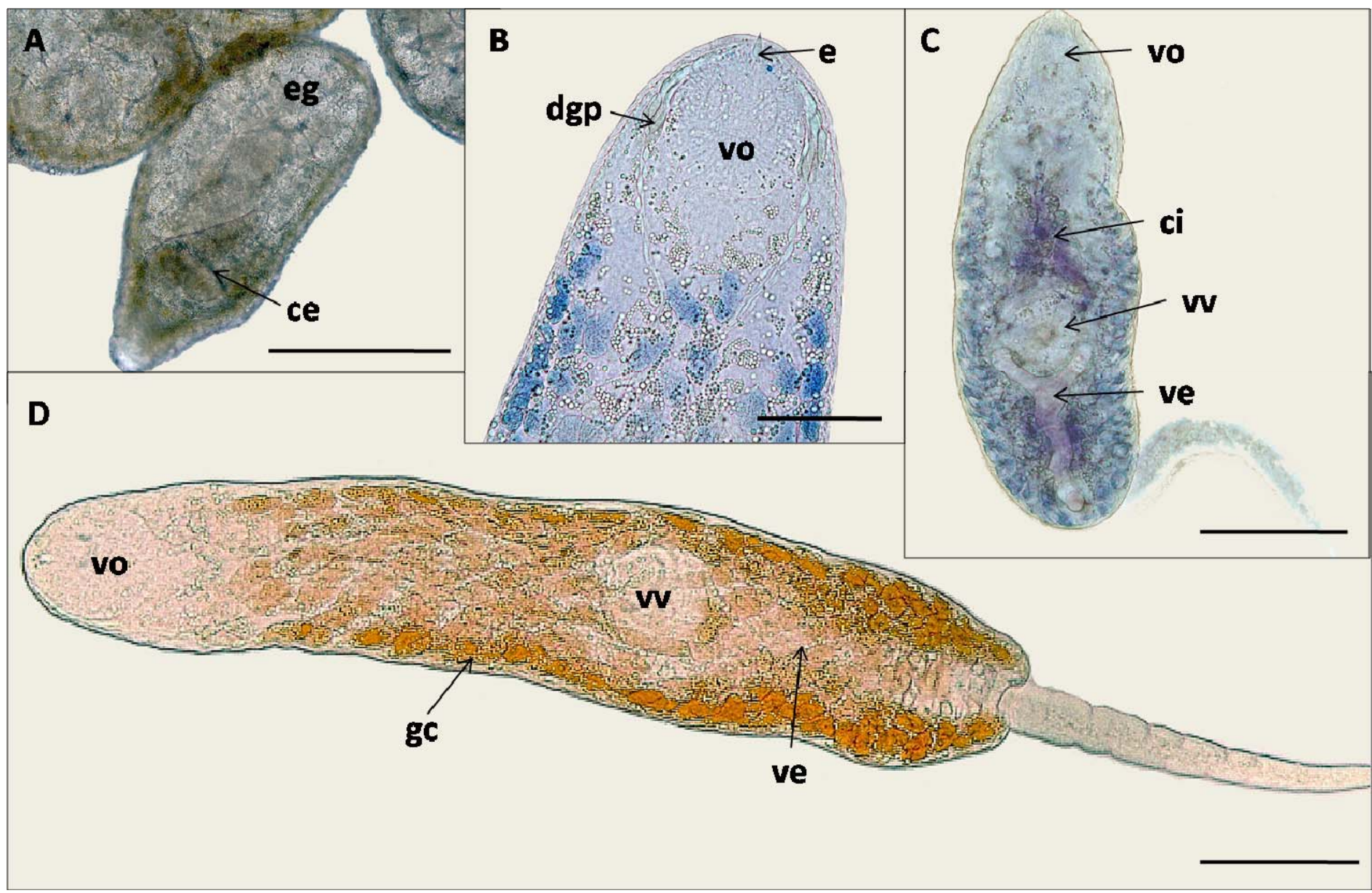

Figura 37. Estadios larvales de Renicolidae gen. et sp. 1 (fotografías al MO). A- Esporocisto; B- Extremo anterior de la cercaria, detalle del estilete; C- Cercaria, vista dorsal, detalle de los ciegos digestivos y de la vesícula excretora; D- Cercaria, vista ventral. Escalas: 200 $\mu \mathrm{m}(\mathrm{A}) ; 20 \mu \mathrm{m}(\mathrm{B}) ; 50 \mu \mathrm{m}$ (C, D). Abreviaturas: ce- cercaria; ci- ciego digestivo; dgp- ductos de las glándulas de penetración; e- estilete; eg- esferas germinales; gc- glándulas cistógenas; ve- vesícula excretora; vo- ventosa oral; vv- ventosa ventral. 


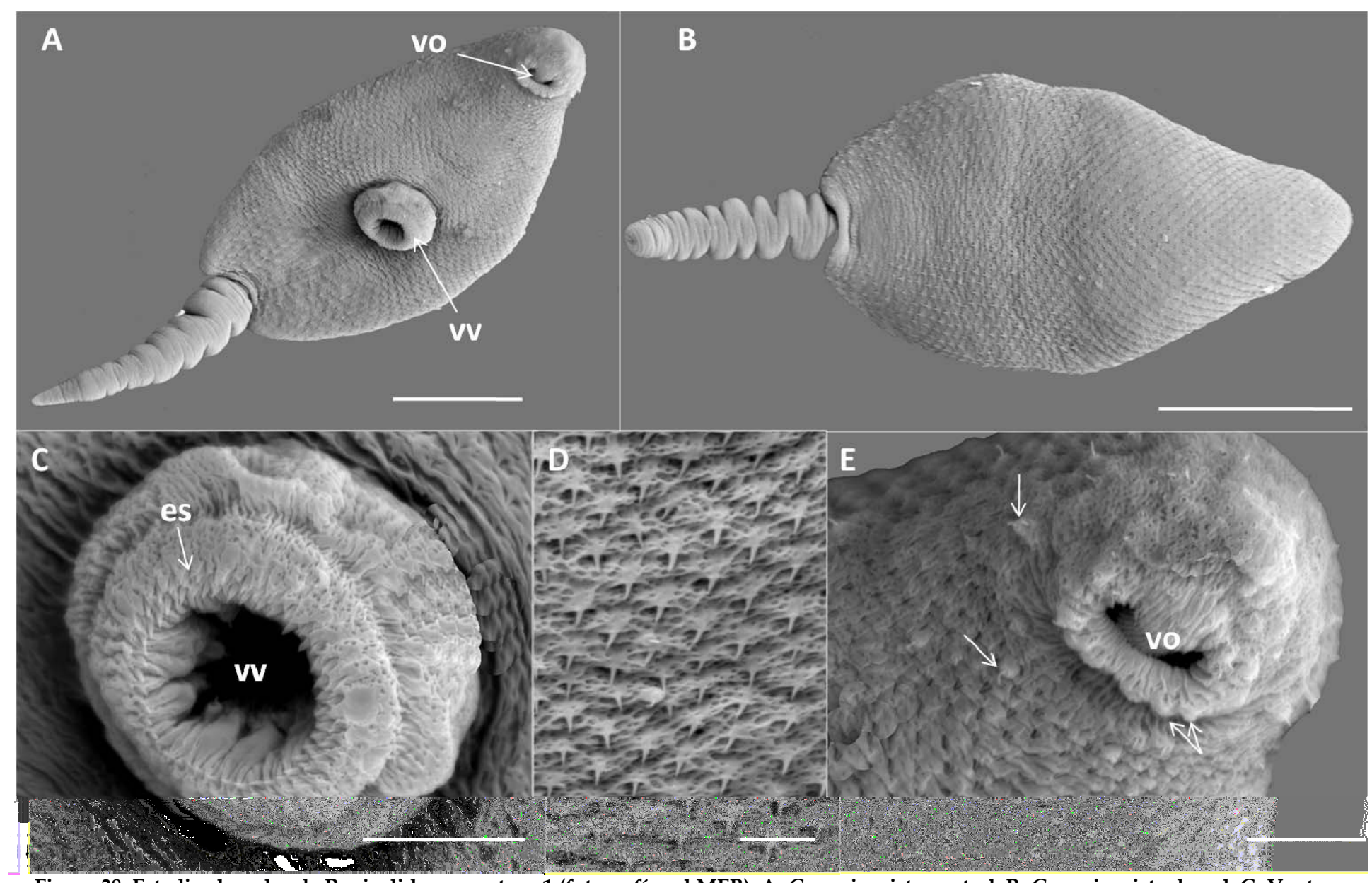

Figura 38. Estadios larvales de Renicolidae gen. et sp. 1 (fotografías al MEB). A- Cercaria, vista ventral; B- Cercaria, vista dorsal; C- Ventosa ventral; D- Detalle de las espinas del cuerpo; E- Extremo anterior de la cercaria, detalle de las papilas en la ventosa oral y en la parte anterior del cuerpo (señaladas con flechas blancas). Escalas: $50 \mu \mathrm{m}$ (A, B); $10 \mu \mathrm{m}$ (C, D); $5 \mu \mathrm{m}$ (E). Abreviaturas: es- espinas, vo- ventosa oral, vv- ventosa ventral. 


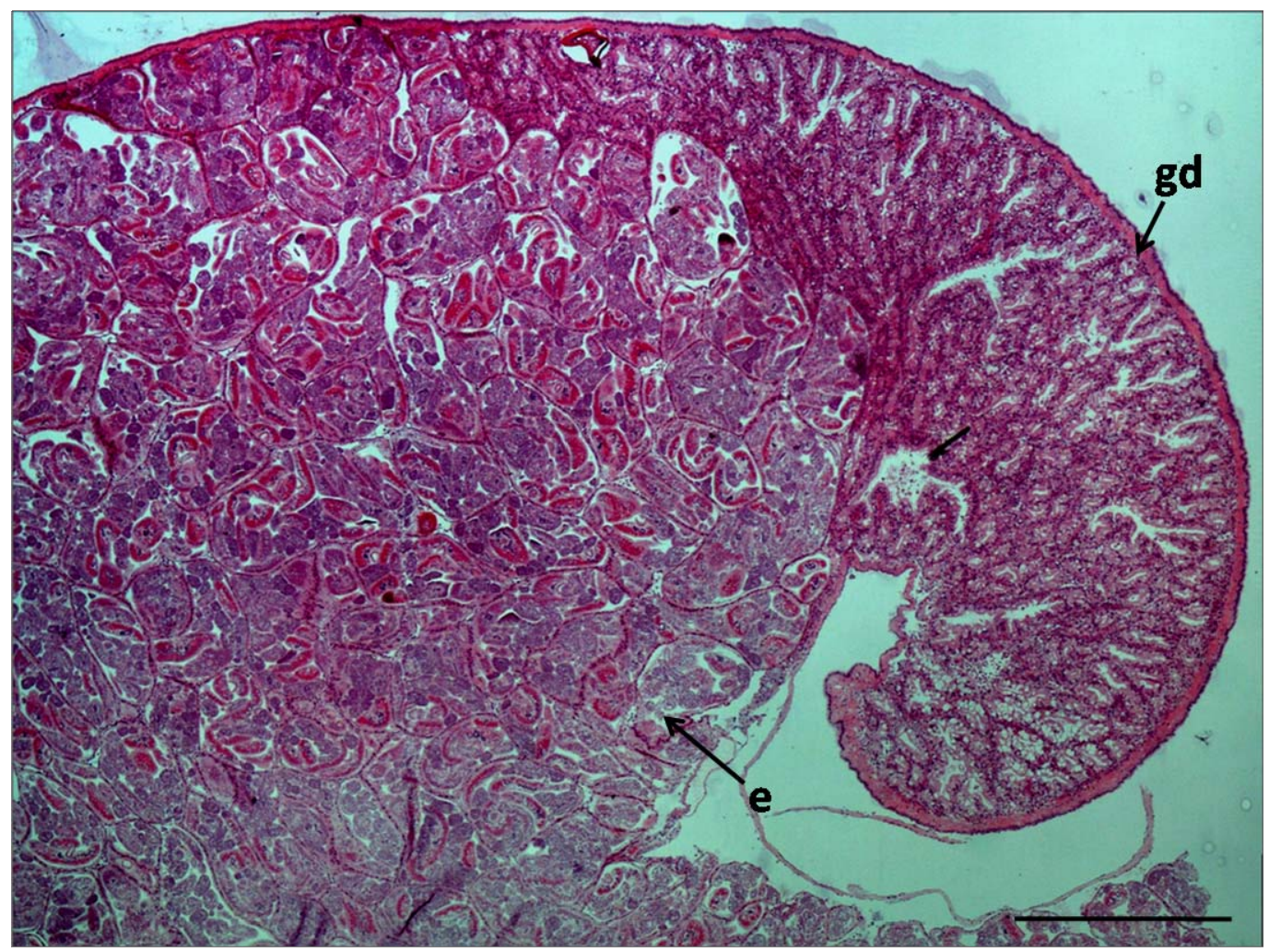

Figura 39. Corte histológico de Trophon geversianus parasitado por esporocistos de Renicolidae gen. et sp. 1. Los esporocistos ocupan el espacio de la gónada y parte de la glándula digestiva. Escala: $500 \mu \mathrm{m}$. Abreviaturas: e- esporocistos; gd- glándula digestiva. 
Capítulo 1. Digeneos hallados

Renicolidae gen. et sp. 2 (Figuras 40-42)

\section{Descripción de las larvas}

Esporocisto: forma ovalada con el extremo anterior aguzado. Mide 294 (156-488) de longitud por 171 (109-269) de ancho máximo; la pared es gruesa, tiene un espesor de 11 (8-17) y el poro de puesta es terminal (Fig. 41A). El número total de larvas por esporocisto es de 35 (22-47), pudiendo albergar 30 (16-37) esferas germinales y 8 (322) cercarias.

Cercaria: (la descripción de las cercarias está basada en diez ejemplares poco desarrollados que se obtuvieron del interior de los esporocistos, ya que en las tres ocasiones donde se hallaron gasterópodos parasitados por esta especie no se lograron emisiones y los esporocistos estaban repletos de esferas germinales y/o cercarias poco desarrolladas). Xiphidocercaria (con estilete) y distoma (dos ventosas). El cuerpo es elongado y mide 154 (120-202) de longitud por 67 (58-72) de ancho. Presenta una gran cantidad de glándulas cistógenas que se distribuyen desde la faringe hasta el extremo posterior del cuerpo. La distancia desde el extremo anterior del cuerpo hasta el margen anterior de la ventosa ventral es de 65 (53-84). La ventosa oral es subterminal, mide 34 (28-42) de longitud por 37 (35-40) de ancho. El estilete es pequeño y presenta forma lanceolada. La ventosa ventral mide 31 (28-33) de longitud por 30 (24-39) de ancho. La relación entre ventosa oralventral es 1:0,81 (0,68-0,97). No se observaron glándulas de penetración. No presenta prefaringe; la faringe mide 11 (10-12) de longitud por 10 (9-11) de ancho $(n=3)$; el esófago y los ciegos digestivos no pudieron observarse. La vesícula excretora tiene forma de $\mathrm{Y}$, con una rama principal larga y dos ramas secundarias que alcanzan la ventosa ventral (Fig. 41B). El poro excretor abre en el extremo distal de la cola. Las células flamígeras no pudieron ser observadas, ya que las cercarias estaban poco desarrolladas. La cola es simple y mide 128 (117-138) de longitud por 18 (16-23) de ancho en la base.

Comportamiento de la cercaria y tiempo de vida: el comportamiento de la cercaria así como el tiempo de vida no pudieron ser determinados debido a que las cercarias halladas estaban poco desarrolladas. 


\section{Secuencias moleculares}

Se secuenció la región ITS1 del ADN ribosomal de esporocistos. Se obtuvieron en forma parcial las regiones $18 \mathrm{~S}$ y $5.8 \mathrm{~S}$ y en forma completa la región ITS1. Las secuencias parciales de las regiones 18S y 5.8S tienen 166 y 102 pb respectivamente; la secuencia completa de la región ITS1 tiene 567 pb. La secuencia no presentó similitud con ninguna otra disponible en la base de datos de Gen Bank. Las secuencias publicadas de la familia Renicolidae pertenecen a regiones 18S, $28 \mathrm{~S}$ y genes mitocondriales. Las futuras secuenciaciones de la especie en cuestión sobre estas regiones y genes publicados contribuirán a resolver su identificación taxonómica. La secuencia de Renicolidae gen. et sp. 1 presentó un bajo porcentaje de similitud con la secuencia de Renicolidae gen. et sp. 2 (66,49\%) (Ver Anexo VI).

\section{Resumen taxonómico}

Hospedador: Nacella (P.) magellanica (Gmelin) (Patellogastropoda, Nacellidae).

Localidad: Puerto Deseado.

Prevalencia total: $0,98 \%(\mathrm{n}=306)$.

Sitio de infección: los esporocistos invaden la glándula digestiva; la gónada no se observó afectada (Fig. 42). Sin embargo, Martorelli et al. (2005) hallaron digeneos de esta especie en gónada. Es probable, que en este caso la gónada no haya sido afectada ya que la infección era incipiente.

Especimenes depositados: CNP-Par 55.

\section{Comentarios taxonómicos}

La cercaria aquí descripta es morfológicamente similar a Renicolidae gen. et sp. 1 (en T. geversianus) en la forma de la vesícula excretora y las medidas del cuerpo, la cola y las ventosas. Sin embargo, el porcentaje de similitud de las secuencias moleculares de la región ITS1 es bajo, $(66,49 \%)$ indicando que se trataría de especies diferentes. Martorelli et al. (2005) registraron por primera vez una cercaria Renicolidae en N. (P.) magellanica. Posteriores estudios de cercarias emitidas permitirán completar su descripción. 
A

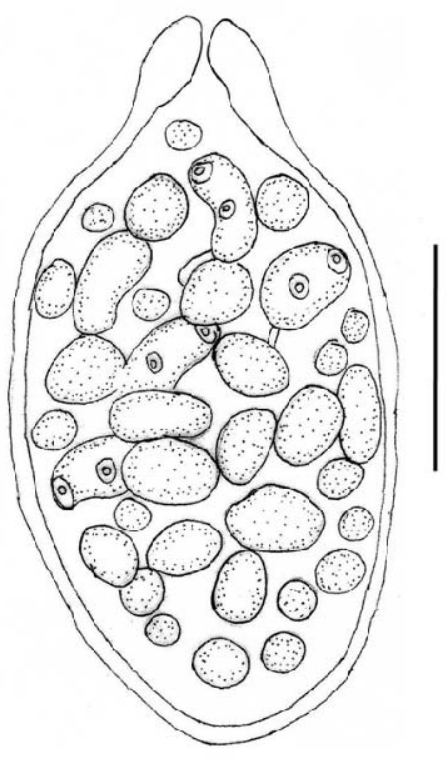

B

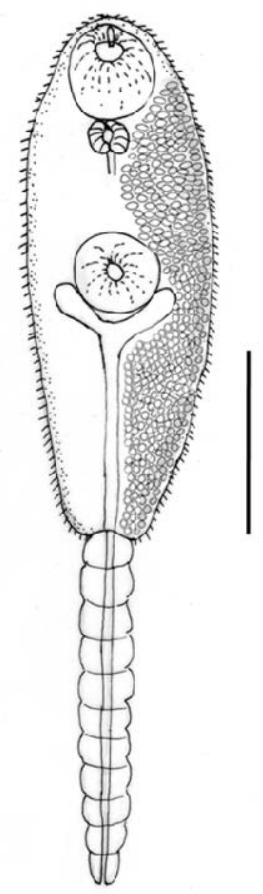

Figura 40. Estadios larvales de Renicolidae gen. et sp. 2. A- Esporocisto; BCercaria, vista ventral. Sólo han sido dibujadas las glándulas cistógenas en la mitad izquierda del cuerpo. Escalas: $100 \mu \mathrm{m}$ (A. B).

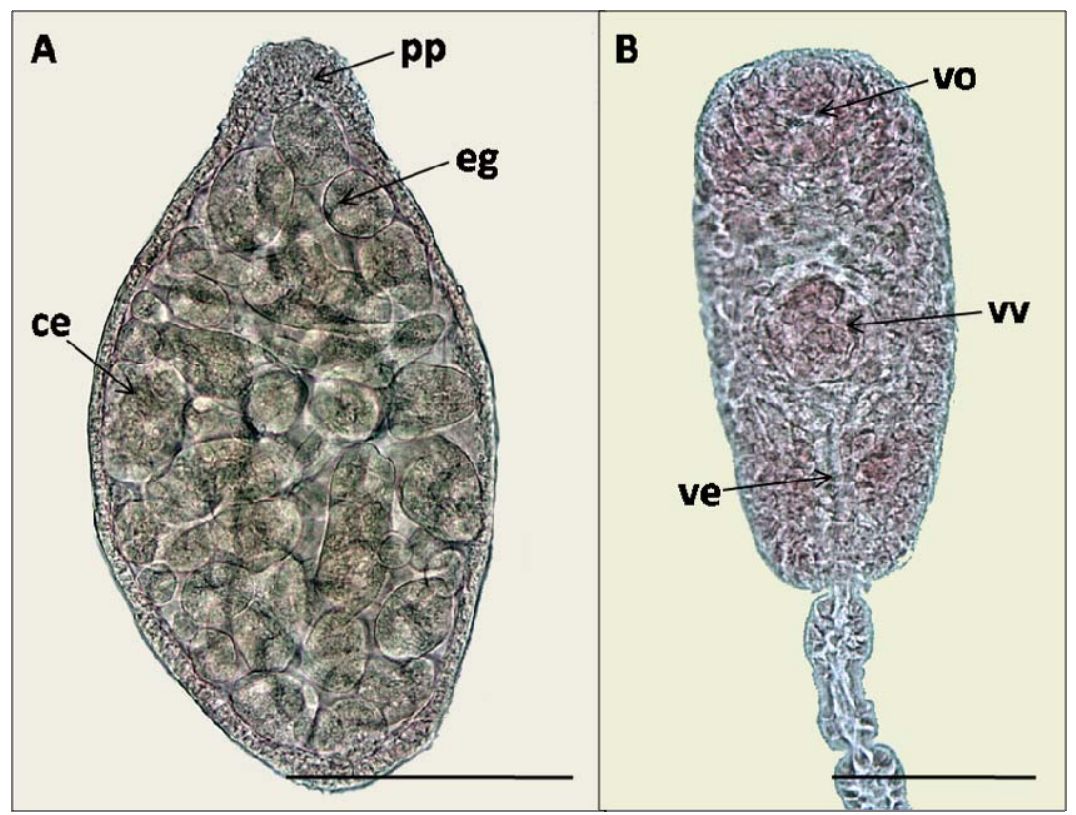

Figura 41. Estadios larvales de Renicolidae gen. et sp. 2 (fotografías al MO). AEsporocisto; B- Cercaria, vista ventral. Escalas: $100 \mu \mathrm{m}$ (A); $50 \mu \mathrm{m}$ (B). Abreviaturas: ce- cercaria; eg- esfera germinal; pp- poro de puesta; ve- vesícula excretora; vo- ventosa oral; vv- ventosa ventral. 


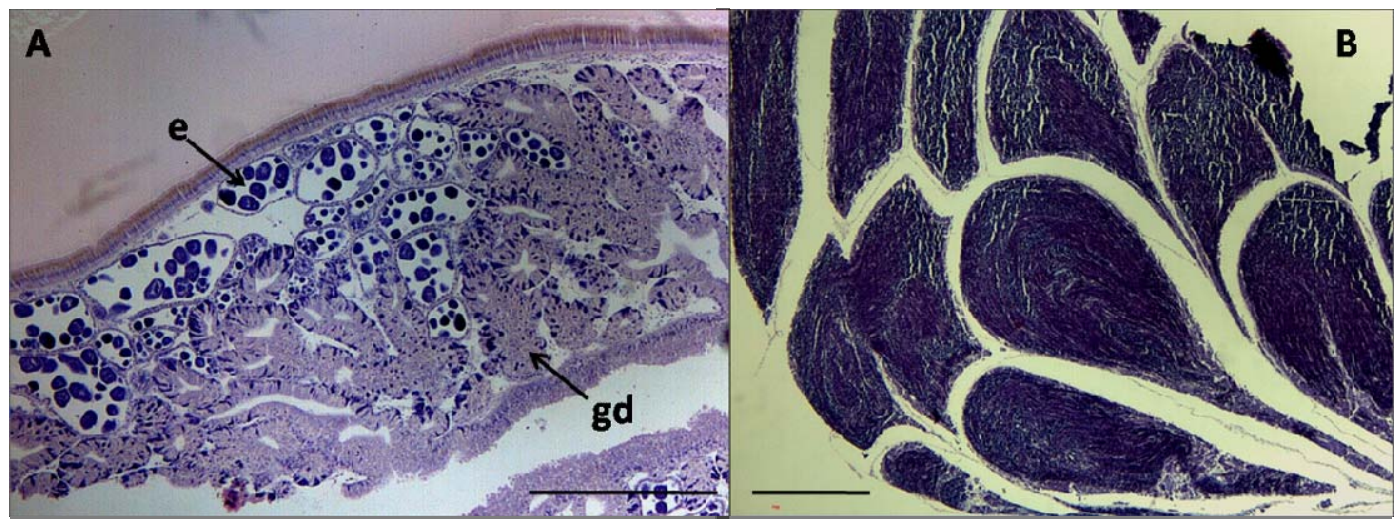

Figura 42. Cortes histológicos de Nacella (Patinigera) magellanica parasitada por Renicolidae gen. et sp. 2. A- Esporocistos entre los acinos de la glándula digestiva; B- Gónada masculina no invadida por esporocistos en un espécimen parasitado. Abreviaturas: e- esporocisto; gd- glándula digestiva. Escalas: $500 \mu \mathrm{m}(\mathrm{A}, \mathrm{B})$. 
Capítulo 1. Digeneos hallados

\section{Philophthalmidae Travassos, 1918}

Parorchis sp. (Figuras 43-46) 7

\section{Descripción de las larvas}

Redia: grande y elongada, mide 1.128 (620-1.350) de longitud por 271 (140-380) de ancho máximo. La pared presenta un espesor de 9 (6-16) y posee un poro de puesta lateral en el extremo anterior. La faringe es pequeña, mide 83 (38-135) de longitud por 68 (32-110) de ancho. El intestino tiene forma de saco, es de color anaranjado y mide 273 (180-340) de longitud por 43 (35-60) de ancho (n=5) (Fig. 44A). El número de larvas por redia es de 10 (8-14), de las cuales 5 (4-9) son cercarias y 4 (2-8) son esferas germinales.

Cercaria: tipo echinostoma (posee un collar de espinas en el extremo anterior). El cuerpo es espinoso y mide 328 (260-408) de longitud por 172 (130-230) de ancho al nivel de la ventosa ventral. Presenta numerosas glándulas cistógenas en el cuerpo, desde el nivel de la faringe al extremo posterior, que se tiñen con rojo neutro y están repletas de inclusiones granulares (Fig. 44E). La distancia desde el extremo anterior del cuerpo hasta el margen anterior de la ventosa ventral es de 104 (98-114). La ventosa oral mide 49 (36-60) de longitud por 58 (50-70) de ancho. La boca es subterminal y está rodeada por un círculo exterior de doce papilas y un círculo interior de ocho papilas (observado al MEB, Fig. 45E). Presenta un collar con aproximadamente 77 espinas en una fila que se interrumpe ventralmente (Fig. 45D). La prefaringe es corta, la faringe es muscular y mide 52 (28-80) de longitud por 39 (24-55) de ancho, el esófago es largo y se bifurca aproximadamente a $3 / 4$ de distancia entre la faringe y la ventosa ventral. Los ciegos intestinales son estrechos, miden 119 (62-156) de longitud y se extienden hasta el nivel de la vesícula excretora $(n=3)$. La ventosa ventral se localiza a nivel medio del cuerpo, mide 73 (46-93) de longitud por 78 (60-105) de ancho y presenta un círculo interno de ocho papilas (observado al MEB, Fig. 45E). El cuerpo está cubierto por espinas, excepto alrededor de la ventosa ventral. Dos filas de papilas se extienden dorsal y ventralmente desde el extremo anterior hasta el nivel de la ventosa ventral y otras papilas están dispersas desde el

\footnotetext{
${ }^{7}$ Las descripciones de los digeneos larvales de esta especie fueron publicados en Gilardoni et al. (2011)
} 
collar de espinas hasta el extremo anterior (observado al MEB, Fig. 45C). Presenta seis pares de glándulas de penetración que abren dorsalmente en el extremo anterior del cuerpo; ninguna de estas glándulas se tiñen con rojo neutro y tanto los citones como los ductos se encuentran enmascarados por las glándulas cistógenas. La vesícula excretora es pequeña y esférica; las ramas se extienden en forma recta hasta la ventosa ventral y luego los túbulos ascienden en forma sinuosa por los márgenes posterolaterales hasta la ventosa oral (Figs. 44C, E). Las ramas presentan concreciones esféricas diminutas desde la ventosa ventral hasta la faringe. La fórmula excretora es $2[(3+3+3)]=18$. La cola mide $303(200-455)$ de longitud por 52 (40-60) de ancho en la base, presenta parénquima vacuolar y finaliza con una punta glandular que suele estar invaginada (Fig. 44D).

Comportamiento de la cercaria y tiempo de vida: bajo condiciones de laboratorio la cercaria emitida nada durante unos pocos minutos ondulando su cuerpo, alternando rápidas contracciones y estiramientos. Luego cae al fondo del recipiente y se desliza por unos minutos, con ayuda de la ventosa ventral. Por último, el movimiento de la cercaria cesa y las secreciones de las glándulas citógenas forman el quiste, que permanece adherido al fondo. El tiempo de vida de la cercaria es de 24 hs a temperatura ambiente y de 72 hs a $12{ }^{\circ} \mathrm{C}$.

Metacercaria: se encuentra enquistada en el sustrato adherida fuertemente mediante una sustancia pegajosa. El quiste es ligeramente oval y aplanado en la base que se adhiere al sustrato (Fig. 45F); mide 234 (212-260) de longitud por 204 (198-213) de ancho y presenta doble pared. La pared externa tiene un espesor de 9 (8-10) y la pared interna tiene un espesor de 13 (8-19).

\section{Secuencias moleculares}

Se secuenciaron las regiones ITS1, ITS2 y 28S del ADN ribosomal de redias pertenecientes a Parorchis sp. Se obtuvieron en forma parcial la región 285 y en forma completa las regiones ITS1, 5.8S e ITS2. La secuencia parcial de la región 28S tienen $1.299 \mathrm{pb}$; las secuencias completas de las regiones ITS1, 5.8S e ITS2 tienen 448, 157 y 743 pb respectivamente. Las secuencias presentaron similitudes con otras disponibles pertenecientes a especies de la familia Philophthalmidae en la base de 
datos de Gen Bank (ver Anexo VII). Las secuencias ITS1 e ITS2 presentan aproximadamente $88 \%$ de similitud con otras de especies del género Philophthalmus Looss, 1899 y la secuencia 285 presenta aproximadamente un 95\% con otras de especies pertenecientes a los géneros Philophthamus y Cloacitrema Yamaguti, 1935. Hasta el presente trabajo, no existen registros disponibles de secuencias del género Parorchis Nicoll, 1907.

\section{Resumen taxonómico}

Hospedador: Trophon geversianus Pallas (Caenogastropoda, Muricidae).

Localidades: Puerto Madryn y Puerto Deseado.

Prevalencia total: 0,87\% $(n=689)$ en Puerto Madryn y 0,66\% $(n=151)$ en Puerto Deseado.

Sitio de infección: las redias invaden la gónada y la glándula digestiva (Fig. 46). Especimenes depositados: MLP 6282; CNP-Par 24-25.

\section{Comentarios taxonómicos}

La cercaria descripta pertenece a la familia Philophthalmidae y al género Parorchis debido a que es una cercaria tipo echinostoma, con collar de espinas y cola con extremo glandular invaginado. La metacercaria posee quiste oval y el enquistamiento ocurre sobre el sustrato. Existen al menos siete cercarias descriptas pertenecientes al género Parorchis, todas en el Hemisferio Norte (Nicoll, 1907; Cable, 1963; Lauckner, 1980). Este es el primer registro de una larva de la familia Philophthalmidae en Sudamérica. Las descripciones taxonómicas de los estadios larvales de Parorchis spp. fueron extensamente discutidas debido a que las diferencias morfológicas que existen entre las cercarias descriptas son insuficientes para diferenciar especies (e.g., Stunkard \& Cable, 1932; Holliman, 1961). 
A

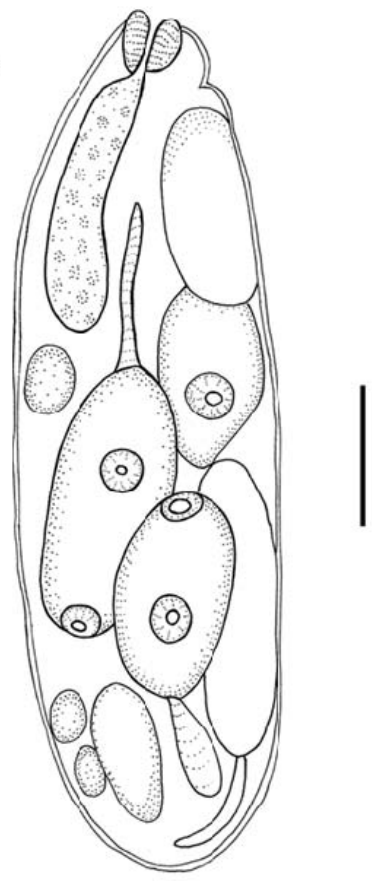

B

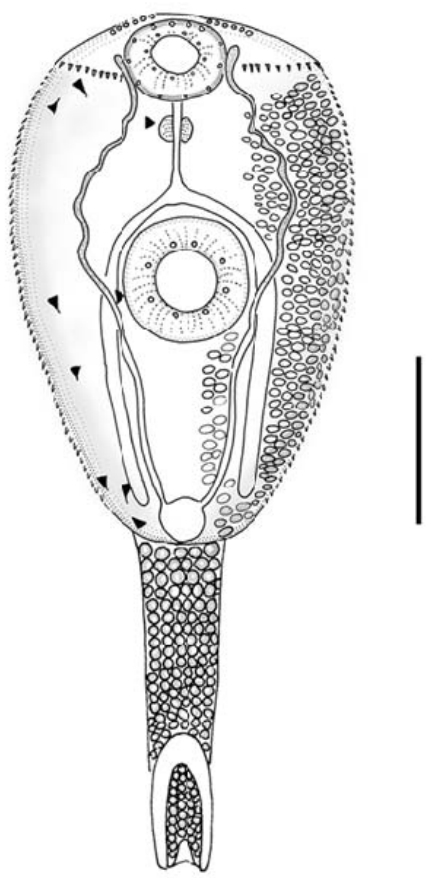

Figura 43. Estadios larvales de Parorchis sp. A- Redia con cercarias; B- Cercaria, vista ventral, las células flamígeras del lado izquierdo y las glándulas cistógenas del lado derecho han sido omitidas. Escalas: $200 \mu \mathrm{m}$ (A); $100 \mu \mathrm{m}$ (B). 


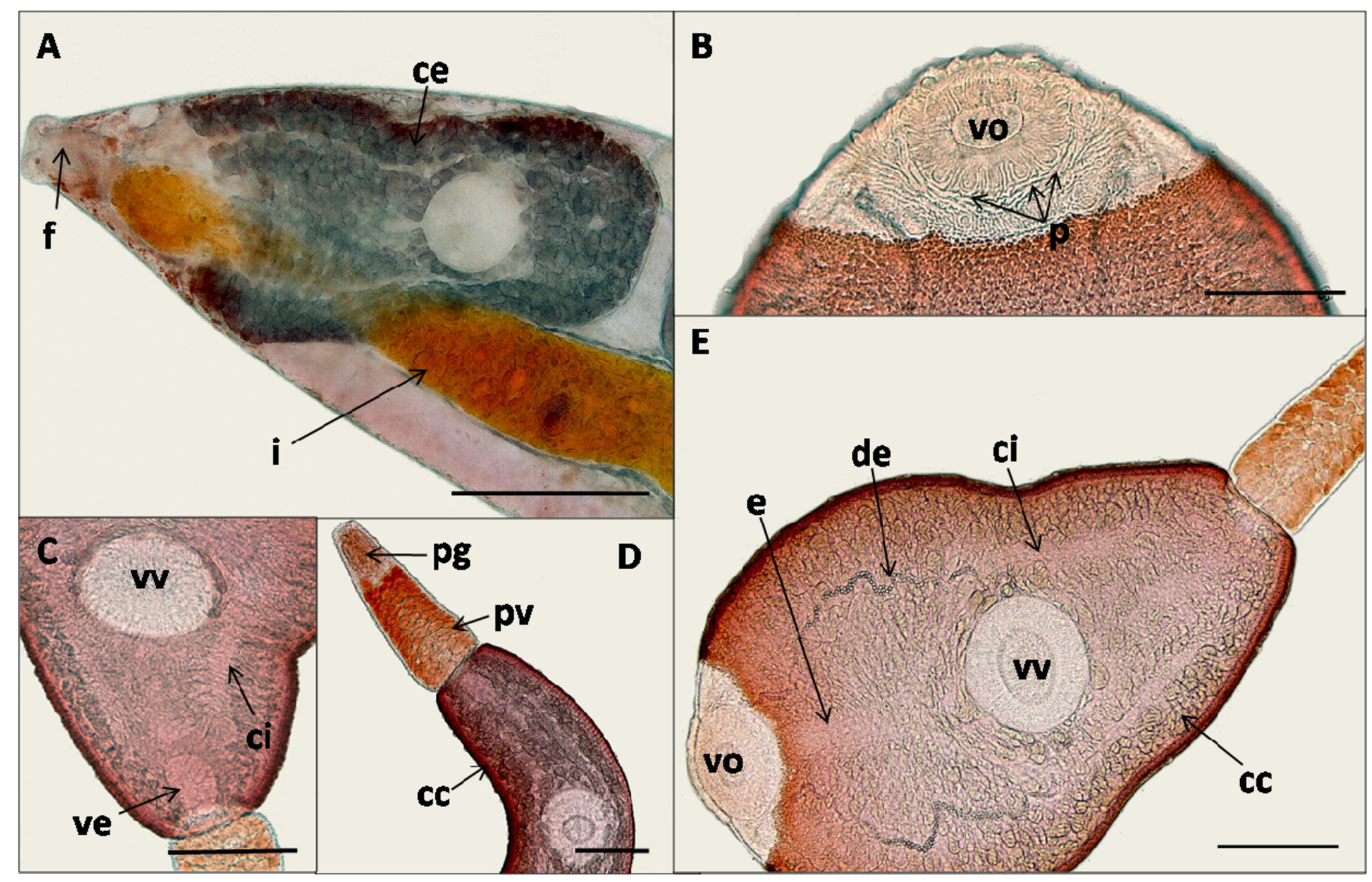

Figura 44. Estadios larvales de Parorchis sp. (fotografías al MO). A- Redia, extremo anterior; B- Cercaria, extremo anterior del cuerpo, detalle de las papilas en la ventosa oral; C- Cercaria, extremo posterior del cuerpo, detalle de la vesícula excretora; D- Cercaria, cola invaginada; E- Cercaria, vista ventral. Escalas: $100 \mu \mathrm{m}(\mathrm{A})$; $50 \mu \mathrm{m}$ (B, C, D, E). Abreviaturas: ce- cercaria; ci- ciego digestivo; ccglándulas cistógenas; de- ductos excretores; e- esófago; f- faringe; i- intestino; p- papilas; pg- extremo glandular; pv- parénquima vacuolar; ve- vesícula excretora; vo- ventosa oral; vv- ventosa ventral. 


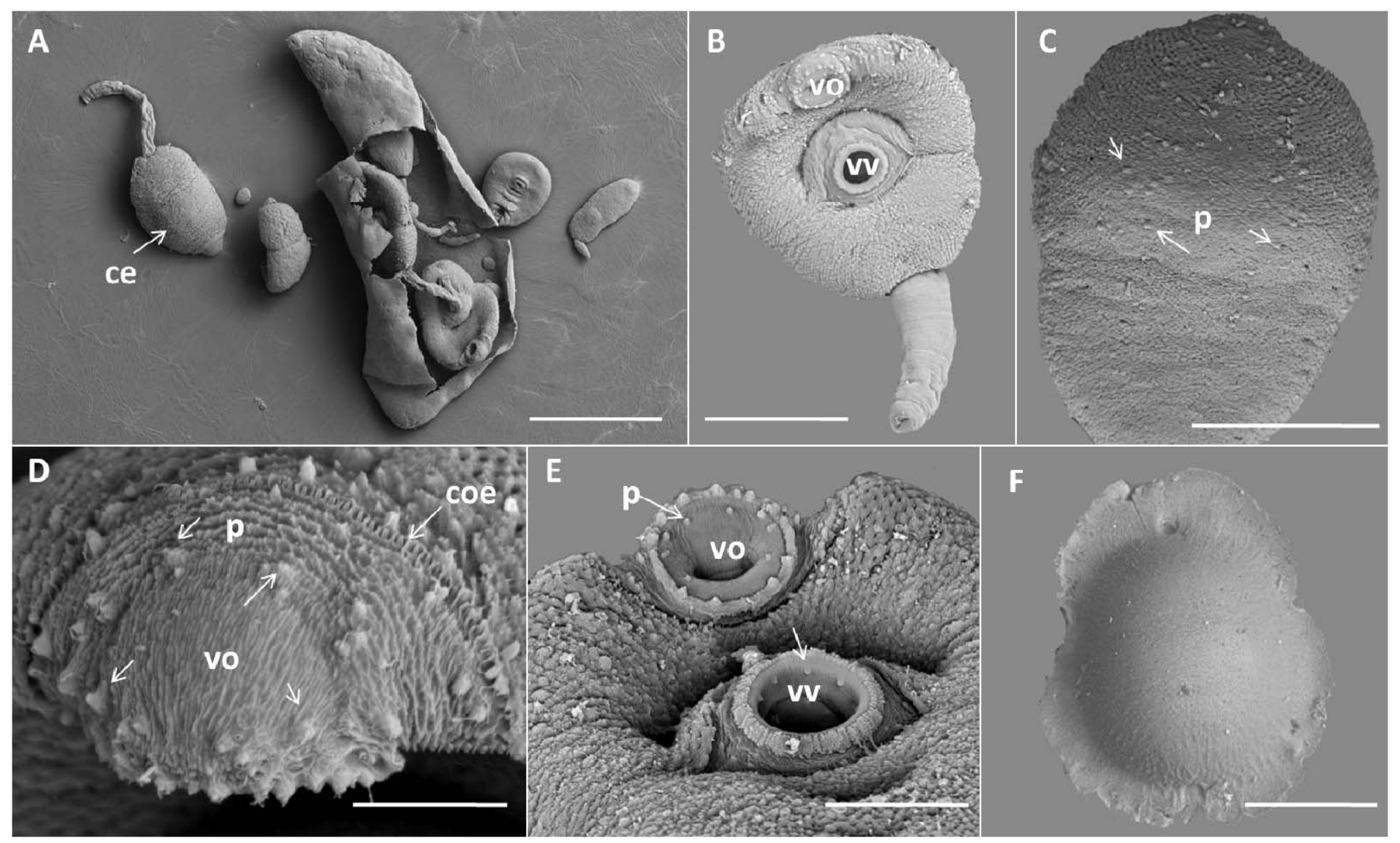

Figura 45. Estadios larvales de Parorchis sp. (fotografías al MEB). A- Redia rota con cercarias en diferentes estadios de desarrollo; B- Cercaria, vista ventral; C- Cuerpo de la cercaria, , vista dorsal; D- Extremo anterior de la cercaria, detalle de la corona de espinas y papilas en la ventosa oral; EDetalle de las papilas internas en las ventosas oral y ventral; F- Metacercaria enquistada. Escalas: $200 \mu \mathrm{m}$ (A); $100 \mu \mathrm{m}$ (B, C, F); $20 \mu \mathrm{m}$ (D); $50 \mu \mathrm{m}$ (E). Abreviaturas: ce- cercaria; coe- collar de espinas; p- papilas; vo- ventosa oral; vv- ventosa ventral. Algunas papilas están señaladas con flechas blancas en las figuras $C$, $D$ y $E$. 


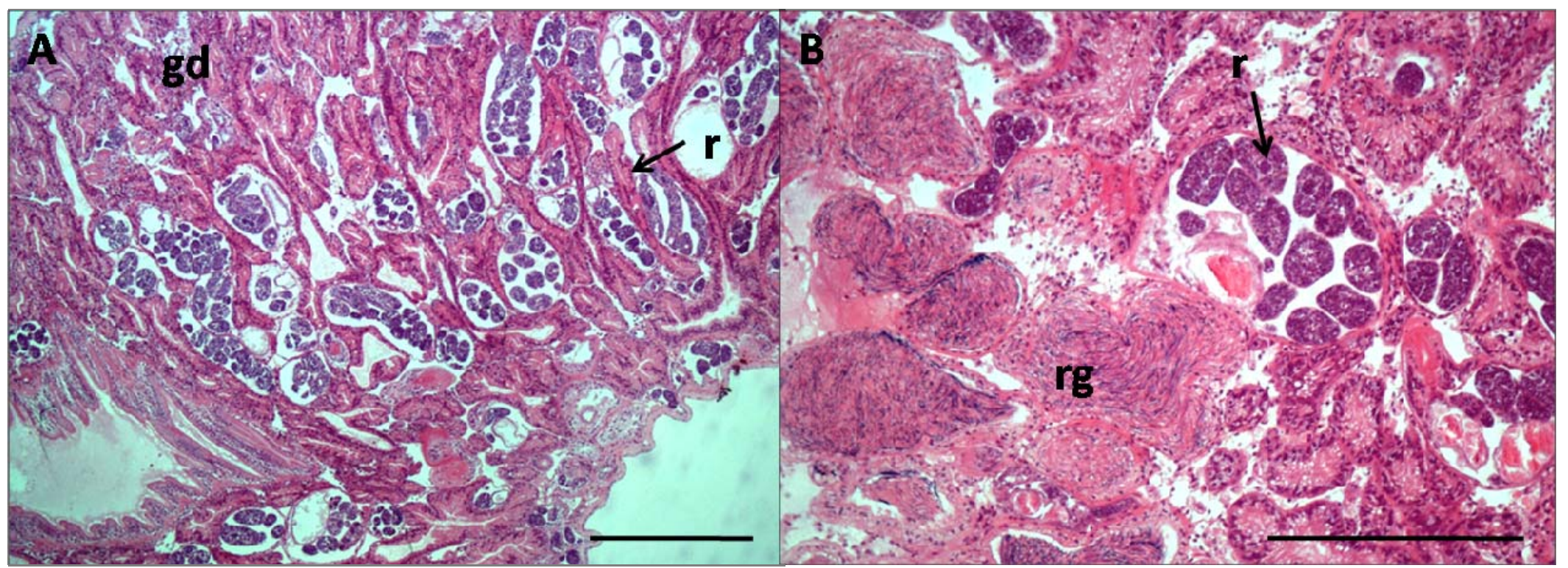

Figura 46. Cortes histológicos de Trophon geversianus parasitado por redias de Parorchis sp. A- Redias entre los acinos de la glándula digestiva; B- Redias ocupando el espacio de la gónada masculina; se observan restos de tejidos gonadales. Escalas $500 \mu \mathrm{m}$ (A, B). Abreviaturas: gd- glándula digestiva; r- redia; rgrestos de acinos gonadales. 
Capítulo 1. Digeneos hallados

\section{Schistosomatidae Stiles \& Hassall, 1898}

Schistosomatidae gen. et sp. (Figuras 47-50)

\section{Descripción de las larvas}

Esporocisto: de forma elongada, con extremos redondeados o truncados y un poro de puesta terminal; mide 2.073 (605-4.550) de longitud por 418 (160-850) de ancho máximo, la pared tiene un espesor de 21 (10-30). Se observan esporocistos en dos estados de desarrollo: 1) esporocistos con esferas germinales y 2) esporocistos con cercarias en diferentes estadios de desarrollo. El número de cercarias por esporocisto es de 20 (4-50) (este resultado estaría subestimado debido a la dificultad de extraer enteros los esporocistos).

Cercaria: tipo furcocercaria (cola con un tronco largo y dos furcas). El cuerpo y la cola son espinosos (Fig. 49B, E). El cuerpo mide 180 (125 -220) de longitud por 62 (45-80) de ancho máximo. La cola presenta un tronco hasta la base de las furcas, que mide 168 (110-230) de longitud por 26 (19-40) de ancho máximo; las furcas miden 93 (32-150) de longitud por 12 (8-19) de ancho y están rodeadas de aletas festoneadas (Figs. 48C, 49B). El órgano de penetración es piriforme, más angosto posteriormente y mide 64 (45-85) de longitud por 36 (28-45) de ancho (Figs. 48B, 49B, C). La boca es subterminal; no presenta faringe y posee un ciego con extremo en forma de corazón. Presenta un par de manchas oculares pigmentadas dorsales de 7 (4-9) de diámetro, localizadas a una distancia de 85 (55-115) desde el extremo anterior y de 20 (15-28) entre cada mancha ocular (Fig. 48B). La ventosa ventral muscular situada en la parte media-posterior del cuerpo, está localizada posteriormente a las manchas oculares y posee un diámetro de 26 (20-35), con una abertura plegada en forma de herradura. Presenta cinco pares de glándulas de penetración (Fig. 48B), ocupando la mayor parte del espacio entre los extremos anterior y el posterior del cuerpo; los dos pares anteriores no se tiñen con colorantes vitales y los tres posteriores sí; son glándulas granulares largas; sus ductos miden 164 (120-210) de longitud, se disponen en un ramillete simple a cada lado del cuerpo y se extienden desde el órgano de penetración, pasando entre las manchas oculares, hasta el extremo posterior del cuerpo. También existen numerosas 
glándulas pobremente definidas, en posición lateral, con ductos poco conspicuos extendiéndose antero-lateralmente a las manchas oculares. Algunos de estos ductos se abren en la superficie dorsal. La vesícula excretora en la base de la cola presenta ramas muy cortas. Posee un canal excretor que desemboca en el extremo distal de las furcas, a través de dos poros excretores. La fórmula excretora es $2[3+3+(1)]=14$, con seis pares de células flamígeras en el cuerpo y un par en la cola.

Comportamiento de la cercaria y tiempo de vida: las cercarias viven poco tiempo y poseen un comportamiento característico con respecto a la forma de natación y posición de descanso. Realizan movimientos rápidos alternados con breves pausas y mueven la cola acompañando el cuerpo con vibraciones. El tiempo de vida, tanto a temperatura ambiente como a $12{ }^{\circ} \mathrm{C}$, es menor a $24 \mathrm{hs}$.

\section{Secuencias moleculares}

No se logró obtener la secuencia molecular (región ITS1) para esta especie, ya que no funcionó la reamplificación del ADN con los primers disponibles.

\section{Resumen taxonómico}

Hospedador: Siphonaria lessonii Blainville (Pulmonata, Basommatophora, Siphonariidae).

Localidad: Puerto Deseado.

Prevalencia total: $0,54 \%(\mathrm{n}=186)$.

Sitio de infección: los esporocistos invaden la gónada y la glándula digestiva. Se observaron esporocistos en la glándula de la mucosa y en la proximidad de la vesícula seminal (Fig. 50).

Especimenes depositados: CNP-Par 56.

\section{Comentarios taxonómicos}

La cercaria descripta pertenece a la familia Schistosomatidae debido a que su morfología es compatible con la diagnosis de la familia: cuerpo sin aleta dorsomedia, ocelos, dos tipos de glándulas de penetración, ventosa ventral bien desarrollada y cola furcada. En Argentina se han registrado digeneos de esta familia 
en agua dulce (Martorelli, 1989b; Ostrowski et al., 1990; Ostrowski, 1992; Flores \& Semenas, 2008) y una cercaria en S. lessonii en Comodoro Rivadavia (Alda \& Martorelli, 2009). La cercaria aquí descripta sería la misma especie que la registrada en Comodoro Rivadavia por Alda \& Martorelli (2009). En la actualidad existen tres géneros de la familia registrados en ambientes marinos, Gigantobilharzia Odhner, 1910, Ornithobilharzia Odhner, 1912 y Trichobilharzia Skrjabin \& Zakharow, 1920 (Huffman \& Fried, 2008). La cercaria descripta pertenecería al género Gigantobilharzia debido a la presencia de ocelos, cola furcada con aletas y por utilizar un gasterópodo marino pulmonado como primer hospedador intermediario (Huffman \& Fried, 2008; Alda \& Martorelli, 2009).
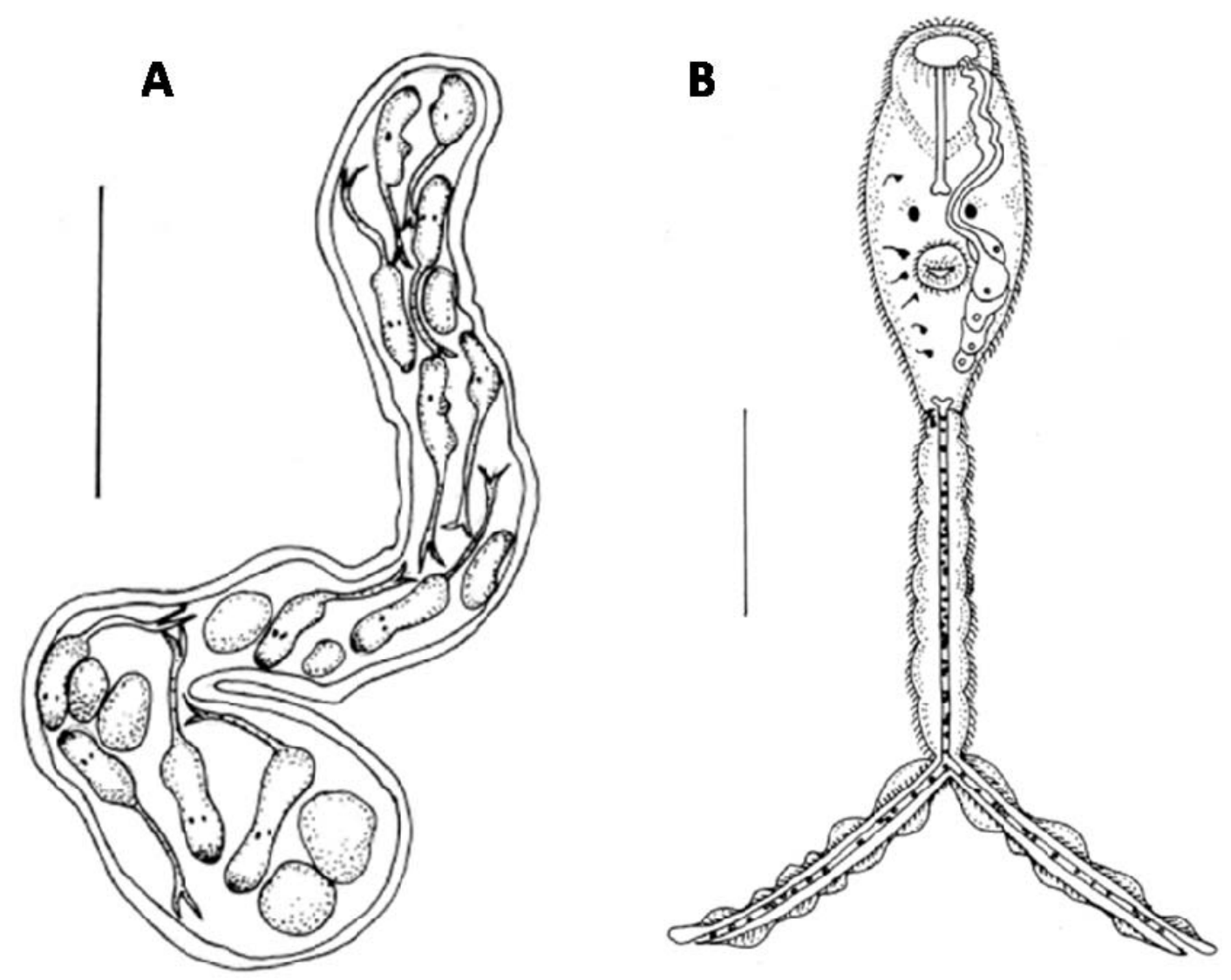

Figura 47. Estadios larvales de Schistosomatidae gen. et sp. A- Esporocisto; B- Cercaria, vista dorsal, las células flamígeras del lado derecho y las glándulas de penetración del lado izquierdo han sido omitidas. Escalas: $500 \mu \mathrm{m}$ (A); $100 \mu \mathrm{m}$ (B). 


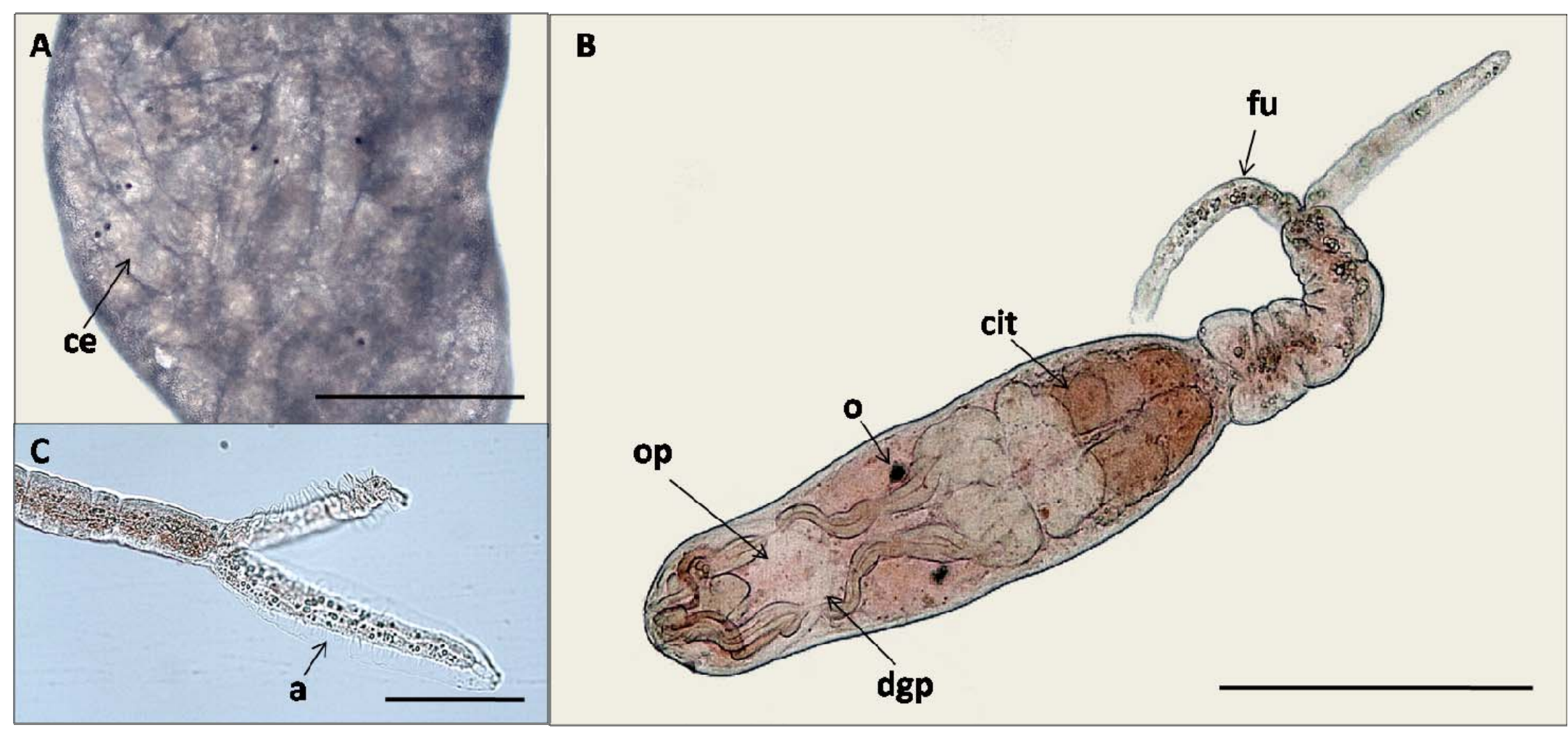

Figura 48. Estadios larvales de Schistosomatidae gen. et sp. (fotografías al MO). A- Esporocisto con cercarias; B- Cercaria, vista dorsal; C- Cola de la cercaria detalle de las aletas festoneadas en las furcas. Escalas: $200 \mu \mathrm{m}(\mathrm{A}), 100 \mu \mathrm{m}, 50 \mu \mathrm{m}$ (C). Abreviaturas: a- aleta; ce- cercaria; cit- citones; dgp- ductos de las glándulas de penetración; fu-furca; o- ocelo; op- órgano de penetración. 


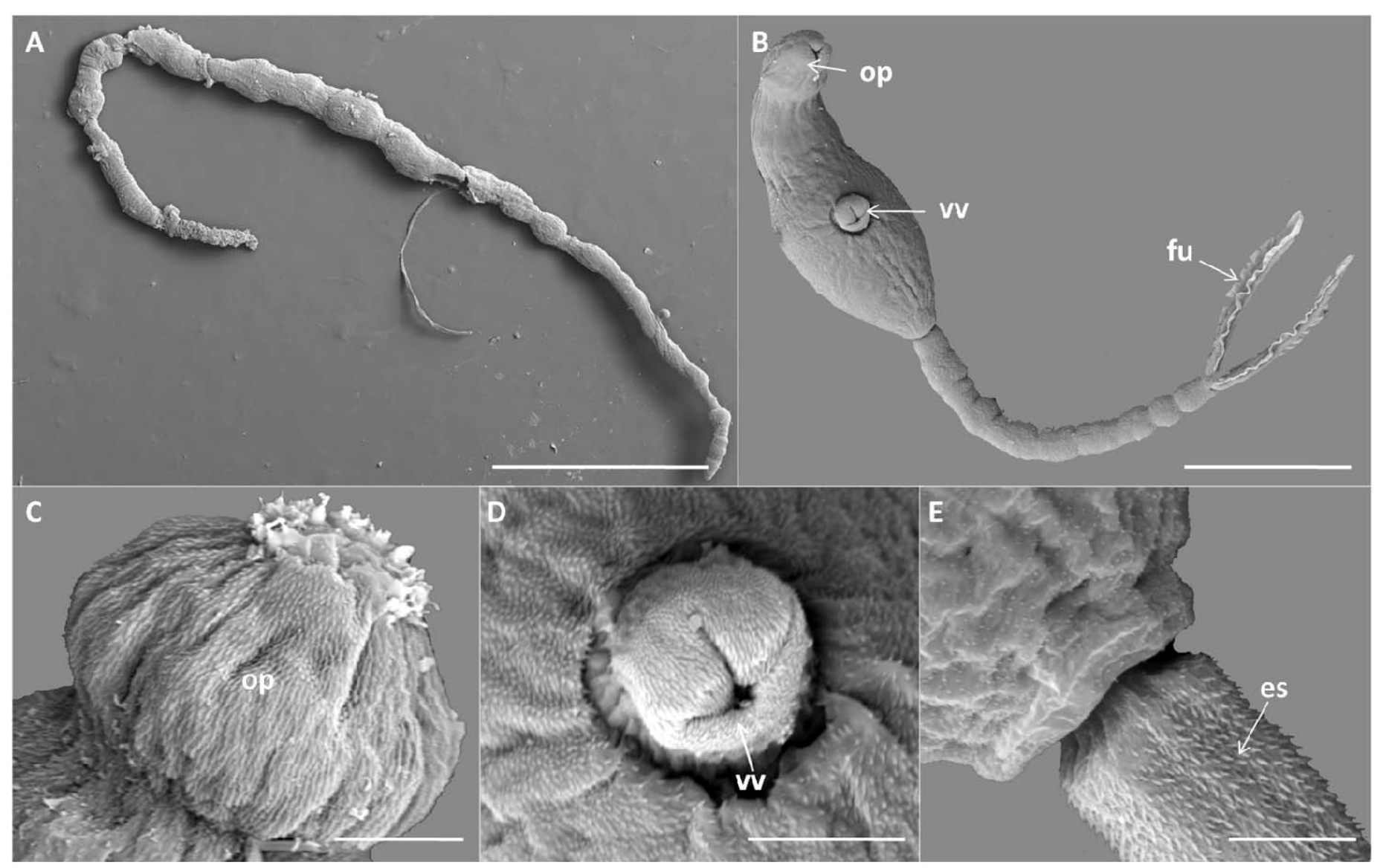

Figura 49. Estadios larvales de Schistosomatidae gen. et sp. (fotografías al MEB). A- Esporocisto; B- Cercaria, vista ventral; C- Extremo anterior de la cercaria; D- Ventosa ventral de la cercaria; E- Inserción de la cola en el cuerpo y detalle de las espinas en la cola. Escalas: $500 \mu \mathrm{m}$ (A); $100 \mu \mathrm{m}$ (B); $20 \mu \mathrm{m}$ (C, D, E). Abreviaturas: es- espinas; fu- furca; op- órgano de penetración; vv- ventosa ventral. 


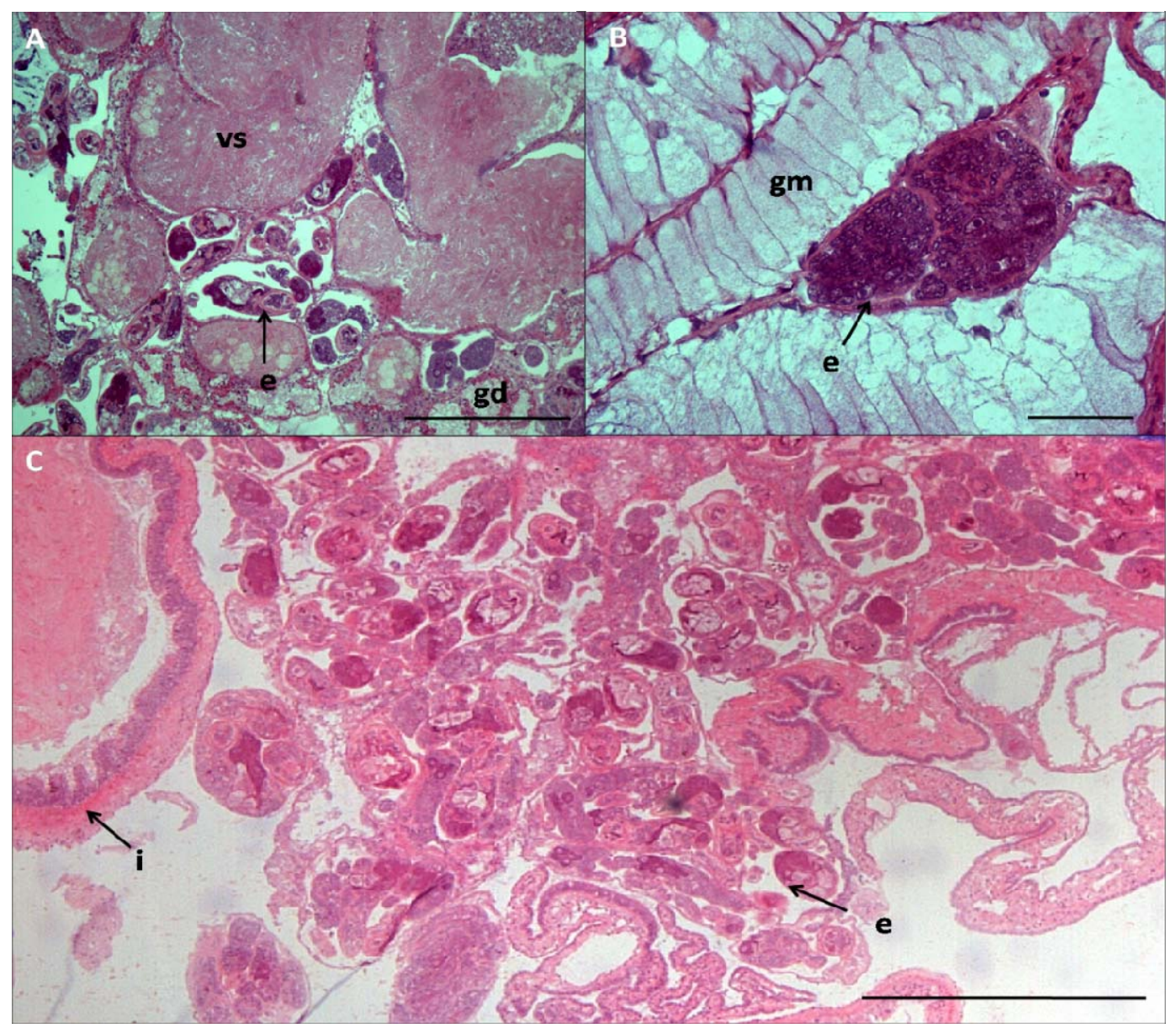

Figura 50. Cortes histológicos de Siphonaria lessonii parasitado por esporocistos de Schistosomatidae gen. et sp. A- Esporocistos entre los acinos de la glándula digestiva y la vesícula seminal. B- Esporocisto entre la glándula mucosa del complejo glandular paleal; C- Esporocistos ocupando el espacio de la glándula digestiva. Escalas: $500 \mu \mathrm{m}$ (A, B, C). Abreviaturas: e- esporocisto; gd- glándula digestiva; gmglándula mucosa; i- intestino; vs- vesícula seminal. 


\subsection{Discusión general y conclusiones}

En el presente capítulo se describieron 13 especies de digeneos larvales de los cuales dos fueron determinados hasta nivel de especie (Gymnophalloides nacellae Cremonte, Pina, Gilardoni, Rodrigues, Chai \& Ituarte, 2013 y Maritrema madrynense Diaz \& Cremonte, 2010), cuatro fueron determinados a nivel de género (Diphterostomum sp., Maritrema sp. 1, Parorchis sp. y Zoogonus sp.), seis fueron determinados a nivel de familia (Lepocreadiidae gen. et sp. 1, Lepocreadiidae gen. et sp. 2, Notocotylidae gen. et sp., Renicolidae gen. et sp. 1, Renicolidae gen. et sp. 2 y Schistosomatidae gen. et sp.) y uno fue determinado a nivel de superfamilia (Hemiuroidea fam. gen. et sp.).

Seis de los 13 estadios larvales descriptos constituyen nuevos registro en la costa de Argentina. Previamente al presente trabajo, se registraron estadios larvales de Hemiuroidea, Maritrema y Schistosomatidae parasitando a Siphonaria lessonii y estadios larvales de Maritrema parasitando a Kerguelenella lateralis en Comodoro Rivadavia, Chubut (Alda \& Martorelli, 2009). Dichas larvas fueron registradas en el presente estudio y se determinaron a nivel de especie los estadios larvales de $M$. madrynense hallados en K. lateralis y S. lessonii. Los estadios larvales de Hemiuroidea fam. gen. et sp. y M. madrynense se registraron tanto en Puerto Madryn como en Puerto Deseado y los estadios larvales de Schistosomatidae gen. et sp. sólo se registraron en Puerto Deseado. Por otro lado, Martorelli \& Morriconi (1998) describieron una metacercaria Gymnophallidae en Nacella (Patinigera) magellanica y Nacella (Patinigera) deaurata, adjudicándola al género Lacunovermis Ching, 1965. A través de estudios morfológicos y moleculares se determinó que esta especie pertenece al género Gymnophalloides y fue nombrada G. nacellae (Cremonte et al., 2013). Además, Martorelli et al. (2005) registraron estadios larvales de las familias Renicolidae y Pronocephalidae parasitando a N. (P.) magellanica y N. (P.) deaurata respectivamente en Ushuaia, Tierra del Fuego. Estos estadios larvales corresponderían a los mismos registrados en el presente estudio; sin embargo, los digeneos de la familia Pronocephalidae fueron reubicados en la familia Notocotylidae en el presente estudio (Barton \& Blair, 2005). Por último, una cercaria Zoogonidae fue registrada en Buccinanops globulosus en Bahía Samborombon, 
provincia de Buenos Aires (Martorelli et al., 2006); esta cercaria correspondería a Diphterostomum sp. hallada en el presente estudio.

Previamente a este trabajo, en Argentina, se registraron dos cercarias Hemiuroidea (Martorelli, 1989a, 1994), una cercaria Microphallidae (Etchegoin \& Martorelli, 1997) y varias cercarias Schistosomatidae en gasterópodos de agua dulce (Martorelli, 1989b; Ostrowski et al., 1990; Ostrowski, 1992; Flores \& Semenas, 2008). Además, dos cercarias Lepocreadiidae y una cercaria Notocotylidae se han registrado en la costa del Océano Atlántico Sudoccidental (Graefe, 1968; Martorelli, 1991; Averbuj \& Cremonte, 2010). Las cercarias de Parorchis sp. (Philophthalmidae), Renicolidae gen. et sp. 1, Renicolidae gen. et sp. 2 y Zoogonus sp. (Zoogonidae), constituyen los primeros registros de estas familias en Argentina, y en los casos particulares de Parorchis sp. y Zoogonus sp., los primeros registros en Sudamérica.

Los estudios moleculares contribuyeron favorablemente en la determinación de algunas especies descriptas. Mediante la comparación de secuencias con otras disponibles en Gen Bank fue posible corroborar la determinación realizada por morfológia de Diphterostomum sp., G. nacellae, Lepocreadiidae gen. et sp. 1, Lepocreadiidae gen. et sp. 2, Maritrema sp., M. madrynense, Notocotylidae gen. et sp., Parorchis sp. y Zoogonus sp. A su vez, se logró diferenciar dos especies morfológicamente idénticas, Diphterostomum sp. y Diphterostomum brusinae, las dos especies de la familia Lepocreadiidae y las dos especies de la familia Microphallidae. En estos dos últimos casos las diferencias morfológicas eran pocas, por lo cual las diferencias en las secuencias moleculares y la utilización de diferentes gasterópodos como primeros hospedadores intermediarios soportan la diferenciación de especies. El ADN ribosomal, y particularmente las regiones ITS1 e ITS2 han sido ampliamente utilizadas en estudios taxonómicos de digeneos debido a su alta tasa evolutiva (Adlard et al., 1993). Sin embargo, el ADN mitocondrial presenta una mayor tasa evolutiva que las regiones ITS y además, presenta un tamaño poblacional efectivo menor, por lo que se perfilan como secuencias mas adecuadas para el reconocimiento de especies crípticas (Vilas et al., 2005). En este trabajo, no se pudo determinar la variación intra-específica, ya que se realizaron las extracciones de ADN tomando un pool de especímenes. Futuros estudios 
moleculares utilizando regiones ITS del ADN ribosomal y regiones cytocromo c oxidasa I del ADN mitocondrial (con réplicas), contribuirán a ampliar los determinación y diferenciación de las especies descriptas.

Cinco especies de digeneos larvales fueron registradas en ambos sitios de estudio (Puerto Madryn y Puerto Deseado), Hemiuroidea fam. gen. et sp., Maritrema sp. 1, M. madrynense, Parorchis sp. y Renicolidae gen. et sp. 1. Crepipatella dilatata estuvo parasitada por Lepocreadiidae gen. et sp. 1 y Maritrema sp. 1. A pesar del gran número de gasterópodos examinados en Puerto Madryn, Lepocreadiidae gen. et sp. 1 sólo se registró en Puerto Deseado, indicando una distribución más restringida de la especie, probablemente debido a la distribución de su hospedador definitivo (algún pez costero). En el caso de Schistosomatidae gen. et sp., que sólo se registró en S. lessonii de Puerto Deseado, la situación podría ser diferente. Los hospedadores definitivos son aves, que, en general, presentan una mayor amplitud de desplazamiento. Además, Bagnato (2012) registró la misma especie en S. lessonii de Playa Fracasso (Golfo San José), un sitio localizado 100 km al norte de Puerto Madryn. Por lo tanto, la ausencia de esta especie en Puerto Madryn podría deberse a la baja prevalencia que presenta y no a la distribución del hospedador definitivo. Las especies Diphterostomun sp., G. nacellae, Lepocreadiidae gen. et sp. 1, Lepocreadiidae gen. et sp. 2, Notocotylidae gen. et sp., Renicolidae gen. et sp. 2 y Zoogonus sp., sólo fueron registradas en un sitio de estudio (Puerto Madryn en el primer caso y Puerto Deseado en el resto). En estos casos, a excepción de Lepocreadiidae gen. et sp. 1, la distribución de las larvas dependería estrictamente de la distribución de los gasterópodos que actúan como primeros hospedadores intermediarios, debido a la alta especificidad de los digeneos en estos estadios de vida (Lauckner, 1980; Ginetsinkaya, 1988; Galaktionov \& Dobrovolskij, 2003). Crepipatella dilatata, presente en ambos sitios de estudio, actúa como hospedador de Lepocreadiidae gen. et sp. 1 sólo en Puerto Deseado. En este caso, la distribución de las larvas depende de la distribución del pez que actúa como hospedador definitivo de esta especie. Buccinanops globulosus, hospedador de Diphterostomun sp., si bien alcanza los $48^{\circ}$ de latitud, no se halló en Puerto Deseado, ya que habita fondos arenosos y el sitio en el cual se colectaron los gasterópodos en Puerto Deseado no 
presentó este tipo de fondo. Por otro lado, los gasterópodos $N(P$.) magellanica (hospedador de Renicolidae gen. et sp. 2, Notocotylidae gen. et sp. y G. nacellae) y Pareuthria plumbea (hospedador de Lepocreadiidae gen. et sp. 2 y Zoogonus sp.) sólo se registraron en Puerto Deseado, ya que estas especies presentan una mayor abundancia en la provincia biogeográfica Magallánica (Dell, 1971; Aranzamendi et al., 2011).

Los sitios de estudio en este trabajo fueron zonas intermareales marinas resguardadas, con poco oleaje y mareas de gran amplitud. Seis de las nueve familias halladas fueron registradas también en gasterópodos de ambientes similares en otras partes del mundo. Por ejemplo, en el gasterópodo Ilyanassa obsoleta (Say) (Nassariidae) en Bahía Rehoboth, Estados Unidos, se registraron digeneos larvales de las familias Lepocreadiidae y Zoogonidae (Curtis, 2007); en Zeacumantus subcarinatus (Sowerby) (Batillariidae) en Bahía Lower Portobello, Nueva Zelanda se registraron digeneos larvales de las familias Renicolidae, Microphallidae y Phillophthalmidae (Martorelli et al., 2008); en Peringia ulvae (Pennant) (Hydrobiidae) y Littorina littorea (Linnaeus) (Littorinidae) que habitan pozas de marea en el Mar de Frisia, Europa, se registraron digeneos larvales de las familias Microphallidae, Notocotylidae y Renicolidae (Thieltges et al., 2006). Otras familias registradas comúnmente en zonas intermareales marinas, pero que no fueron halladas en este estudio son Echinostomatidae, Heterophydae, Opecoelidae y Strigeidae (Sannia \& James, 1977; Galaktionov \& Skirnisson, 2000; Thieltges et al., 2006; Curtis, 2007; Martorelli et al., 2008). Sin embargo, se han reportado adultos de algunas de estas familias en la costa patagónica; Himasthla escamosa Diaz \& Cremonte, 2004, Stephanoprora podicipei Etchegoin \& Martorelli, 1997 (Echinostomatidae) y Cardiocephaloides physalis (Lutz, 1927) (Strigeidae) en la gaviota cocinera Larus dominicanus (Diaz \& Cremonte, 2004; Diaz et al., 2011) y Neolebouria georgenascimentoi Bray, 2002 (Opecoelidae) en el turco Pinguipes brasilianus Cuvier (Pinguipedidae) (Timi et al., 2008). Futuros estudios de los estadios larvales de digeneos en gasterópodos que habitan sólo el submareal somero o presentan un menor abundancia en el intermareal, tales como Epitonium fabrizioi Pastorino \& Penchaszadeh (Epitoniidae) y Olivella plata (Ihering) (Olivellidae) (Pastorino \& 
Penchaszadeh, 1998, Pastorino, 2009), permitirán incrementar el conocimiento de este grupo de parásitos.

Las familias Microphallidae, Notocotylidae y Schistosomatidae registradas en ambientes marinos, son también ampliamente halladas en ambientes de agua dulce y estuariales, como son los digeneos larvales de esta familia registrados en Biomphalaria peregrina (Orbigny) (Planorbidae), Chilina dombeyana (Bruguiere), Chilina fluminea (Maton) (Chilinidae), Heleobia conexa (Gaillard) (Cochliopidae), entre otros (Ostrowski, 1992; Flores \& Semenas, 2008; Merlo \& Etchegoin, 2010). Estas familias utilizan principalmente aves como hospedadores definitivos y también mamíferos. Algunas aves que frecuentan las costas patagónicas presentan comportamiento migratorio (Coconier, 2006; Hernández et al., 2008) y de esa manera pueden diversificar los ambientes en los cuales transcurren los ciclos de vida de estos digeneos. 


\section{CAPÍTULO 2: CICLOS DE VIDA DE LOS DIGENEOS}

\subsection{Introducción}

La diversidad de trematodes larvales en los moluscos bivalvos y gasterópodos es relativamente fácil de relevar, una vez que se conocen los parásitos presentes en el área. A través de sus complejos ciclos de vida, estos parásitos están funcionalmente acoplados a la diversidad de organismos de vida libre, vertebrados e invertebrados que los rodean (Etchegoin, 1997; Hechinger \& Lafferty, 2005; Fredensborg et al., 2006; Hechinger et al., 2007). Sin embargo, para utilizar a los parásitos como una herramienta confiable en estudios a una mayor escala, es necesario conocer primero su identidad taxonómica y sus ciclos de vida, incluyendo el espectro de posibles hospedadores.

Debido a que en los digeneos los caracteres morfológicos que permiten su identificación a nivel de especie se presentan sólo en los adultos, existen dos maneras para establecer la correspondencia específica entre estadios larvales y adultos. Una de ellas es la experimentación, mediante infestaciones, para lo cual se deben obtener organismos parasitados con estadios infectivos y mantenerlos en acuarios para infectar organismos que no lo estén (e.g. Fredensborg \& Poulin, 2005; Galaktionov, 2007; Gilardoni et al., 2013). Sin embargo, en ocasiones se hace imposible obtener organismos para experimentación que no estén parasitados y, además, muchos de los organismos marinos presentan serias dificultades para sobrevivir en los acuarios. Por esto, una herramienta muy útil para dilucidar ciclos de vida, es la secuenciación de ADN correspondiente a fracciones específicas de genes (e.g., Al-Kandari et al., 2009; Born-Torrijos et al., 2012). El ADN ribosomal es particularmente útil debido a que su secuencia es altamente repetitiva y contiene regiones variables alternadas con regiones conservadas (Adlard et al., 1993). Particularmente, las regiones ITS1 e ITS2 (internal transcribed spacer) del ADN ribosomal presentan secuencias más variables y una alta tasa evolutiva, por lo que se utilizan para indicar la correspondencia de distintos estadios de desarrollo a la misma especie.

Los ambientes intermareales de la costa patagónica son altamente diversos y soportan una rica fauna de invertebrados y aves (Balech \& Ehrlich, 2008), lo cual 
promueve los complejos ciclos de vida de los digeneos. Si bien en los últimos años se logró un avance considerable en la dilucidación de algunas de las etapas de los complejos ciclos de vida de estos parásitos, sólo dos de ellos se conocen de forma completa en la región, el ciclo de vida del gymnofálido Bartolius pierrei Cremonte, 2001 (Cremonte, 2004) y el ciclo de vida del monórquido Proctotrema bartolii Carballo, Laurenti \& Cremonte, 2011 (Gilardoni et al., 2013).

Con respecto a los digeneos adultos presentes en el área de estudio, se cuenta principalmente con la información de aquellos que parasitan a la gaviota cocinera, Larus dominicanus, al pingüino de Magallanes, Spheniscus magellanicus y un registro en Calidris canutus rufa (ref. en Tabla 3). En lo que respecta a peces de la costa patagónica, se tiene información sobre los digeneos de Pinguipes brasilianus Cuvier, Pseudopercis semifasciata Cuvier (Pinguipedidae), Odontesthes smitti Lahille, O. nigricans Richardson (Atherinopsidae), Eleginops maclovinus Cuvier (Eleginopidae), Engraulis anchoita Hubbs \& Marini (Engraulidae), Genypterus blacodes Schneider (Ophidiidae), Merluccius hubbsi Marini (Merlucciidae) y Percophis brasiliensis Quoy et Gaimard (Percophidae) (ref. en Tabla 4).

El objetivo de este capítulo es conocer los ciclos de vida de los digeneos hallados mediante la aplicación de diferentes herramientas, cultivos in vitro, infecciones experimentales y estudios moleculares; en aquellos casos en que no se haya hallado alguno de los hospedadores que intervienen, se propone una hipótesis basada en la bibliografía. Asimismo, se pretende reconocer los diferentes patrones de transmisión (ciclos con uno o dos hospedadores intermediarios) y analizar cuál de ellos presenta predominio sobre los otros. 
Tabla 3. Estudios realizados previamente a esta tesis en las costas patagónicas sobre digeneos parásitos de aves, sus localidades y hospedadores intermediarios conocidos (c), hipotetizados (h) o inferidos mediante referencias bibliográficas (b). Referencias: HI= hospedador intermediario, GN = Golfo Nuevo, GSJ= Golfo San José, CP= costa patagónica, $\mathrm{CR}=$ Comodoro Rivadavia, $\mathrm{PD}=$ Puerto Deseado, U= Ushuaia. Referencias bibliográficas: (1) (Yamaguti, 1975) (2) (Gilardoni et al., 2011) (3) (Diaz \& Cremonte, 2010) (4) (Stunkard, 1979a) (5) (Cremonte, 2004) (6) (Cremonte et al., 2008) (7) Cremonte (com. pers.) (8) (La Sala et al., 2009) (9) (Timi et al., 1999).

\begin{tabular}{|c|c|c|c|c|c|c|}
\hline Ave hospedador & Digeneo hallado & Referencia & Localidad & $1^{\circ} \mathrm{HI}$ & $2^{\circ} \mathrm{HI}$ & $\begin{array}{c}\text { Referencias } \\
\text { del ciclo de } \\
\text { vida }\end{array}$ \\
\hline \multirow{8}{*}{$\begin{array}{l}\text { Larus dominicanus } \\
\text { Lichtenstein (Laridae) }\end{array}$} & Parorchis sp. (Philophtalmidae) & Diaz et al. (2011) & GN, GSJ & gasterópodos Muricidae (b) & $\begin{array}{c}\text { metacercaria enquista en el } \\
\text { ambiente (b) }\end{array}$ & (1) \\
\hline & Maritrema formicae (Microphallidae) & Diaz et al. (2012) & GN, GSJ & Crepipatella dilatata (Gastropoda) (h) & $\begin{array}{c}\text { Crepipatella dilatata y crustáceos } \\
(\mathrm{h})\end{array}$ & (2) \\
\hline & Maritrema madrynense (Microphallidae) & $\begin{array}{l}\text { Diaz \& Cremonte (2010); } \\
\text { Diaz et al. (2011) }\end{array}$ & GN, GSJ & Siphonaria lessonii (Gastropoda) (h) & $\begin{array}{c}\text { Siphonaria lessonii y } \\
\text { Cyrtograpsus altimanus } \\
\text { (Crustacea) (h) }\end{array}$ & $(2,3)$ \\
\hline & Odhneria odhneri (Microphallidae) & $\begin{array}{l}\text { Cremonte \& Etchegoin } \\
\text { (2002) ; Diaz et al. (2011) }\end{array}$ & GSJ & gasterópodos Littorinidae (b) & crustáceos (b) & (4) \\
\hline & Bartolius pierrei (Gymnophallidae) & $\begin{array}{c}\text { Cremonte (2001); Diaz et } \\
\text { al. (2011) }\end{array}$ & $\mathrm{CP}$ & Darina solenoides (Bivalvia) (c) & Darina solenoides (c) & (5) \\
\hline & $\begin{array}{l}\text { Gymnophallus australis } \\
\text { (Gymnophallidae) }\end{array}$ & $\begin{array}{l}\text { Cremonte et al. (2008); } \\
\text { Diaz et al. (2011) }\end{array}$ & $\begin{array}{l}\text { CR, PD, } \\
\text { U }\end{array}$ & Lasaea adansoni (Bivalvia) (h) & mitílidos (c) y otros bivalvos (h) & $(6,7)$ \\
\hline & Himasthla escamosa (Echinostomatidae) & Diaz \& Cremonte (2004) & GN & $\begin{array}{l}\text { Nassariidae, Hydrobiidae, } \\
\text { Littorinidae, Eatoniellidae y } \\
\text { Potamididae (b) }\end{array}$ & $\begin{array}{l}\text { bivalvos, gasterópodos y } \\
\text { poliquetos }(\mathrm{b})\end{array}$ & $(1,8)$ \\
\hline & $\begin{array}{l}\text { Stephanoprora podicipei } \\
\text { (Echinostomatidae) }\end{array}$ & Diaz et al. (2011) & GN & $\begin{array}{l}\text { Hydrobiidae y otros gasterópodos } \\
\text { (b) }\end{array}$ & peces teleósteos (b) & (1) \\
\hline $\begin{array}{c}\text { Calidris canutus rufa } \\
\text { Linnaeus } \\
\text { (Scolopacidae) }\end{array}$ & Bartolius pierrei (Gymnophallidae) & Cremonte (2001) & $\mathrm{CP}$ & Darina solenoides (c) & Darina solenoides (c) & (5) \\
\hline $\begin{array}{l}\text { Spheniscus magellanicus } \\
\text { (Forster) } \\
\text { (Spheniscidae) }\end{array}$ & Cardiocephaloides physalis (Strigeidae) & Diaz et al. (2010) & GN, GSJ & gasterópodos Nassariidae (b) & Engraulis anchoita $(\mathrm{h})$ & $(1,9)$ \\
\hline
\end{tabular}

\section{节}


Tabla 4. Estudios realizados previamente a esta tesis en las costas patagónicas sobre digeneos parásitos de peces, sus localidades y hospedadores intermediarios conocidos (c), hipotetizados (h) o inferidos mediante referencias bibliográficas (b). Referencias: * indica que el estadio hallado es el de metacercaria, ** Cremonte \& Etchegoin (com. pers.), $\mathrm{HI}=$ hospedador intermediario, $\mathrm{HD}=$ hospedador definitivo, GN = Golfo Nuevo, IM= Islas Malvinas, PV= Península Valdés, GSJ= Golfo San José, TF= Tierra del Fuego, $\mathrm{PD}=$ Puerto Deseado, PN= Patagonia Norte, $\mathrm{CP}=$ Plataforma patagónica, IE= Isla Escondida y GSJO= Golfo San Jorge y GSM = Golfo San Matías. Referencias bibliográficas: (1) (Rocka, 2006) (2) (Pina et al., 2009) (3) (Gibson \& Bray, 1986) (4) (Køie, 1979) (5) (Køie, 1990c) (6) (Køie, 1991) (7) (Yamaguti,1975) (8) (Williams \& Williams, 1996) (9) (Køie, 1989) (10) (Gilardoni et al., 2013) (11) (Szidat, 1961) (12) (Szidat, 1963) (13) (Szidat, 1965) (14) (Suriano \& Martorelli, 1983) (15) (Tanzola \& Guagliardo, 2000) (16) (Etchegoin et al., 2005) (17) (Cremonte et al., 1999) (18) Cremonte (com. pers) (19) (Daponte et al., 2006) (20) (Timi et al., 1999) (21) (Cremonte \& Sardella, 1997) (22) (Cribb et al., 2011).

\begin{tabular}{|c|c|c|c|c|c|c|}
\hline Pez hospedador & Digeneos hallados & Localidad & Referencias & $1^{\circ} \mathrm{HI}$ & $2^{\circ} \mathrm{HI}$ & $\begin{array}{l}\text { Referencias del } \\
\text { ciclo de vida }\end{array}$ \\
\hline \multirow{2}{*}{$\begin{array}{l}\text { Pinguipes brasilianus } \\
\text { Cuvier (Pinguipedidae) }\end{array}$} & $\begin{array}{c}\text { Neolebouria georgenascimentoi } \\
\text { (Opecoelidae) }\end{array}$ & \multirow[b]{2}{*}{ GSM, GN } & \multirow[b]{2}{*}{ Timi et al. (2008); ** } & gasterópodos (b) & crustáceos (b) & $(1)$ \\
\hline & $\begin{array}{l}\text { Diphterostomum sp. } \\
\text { (Zoogonidae) }\end{array}$ & & & $\begin{array}{l}\text { gasterópodos } \\
\text { Nassariidae (b) }\end{array}$ & $\begin{array}{l}\text { mismo gasterópodo } 1^{\circ} \mathrm{HI}(\mathrm{b}) \\
\text { bivalvos }(\mathrm{b}), \text { crinoideos }(\mathrm{b})\end{array}$ & (2) \\
\hline \multirow{4}{*}{$\begin{array}{c}\text { Pseudopercis semifasciata } \\
\text { (Cuvier) } \\
\text { (Pinguipedidae) }\end{array}$} & $\begin{array}{l}\text { Elytrophalloides oatesi } \\
\text { (Hemiuridae) }\end{array}$ & \multirow{4}{*}{ PV } & \multirow{4}{*}{ Timi \& Lanfranchi (2009) } & gasterópodos (b) & copépodos o quetognatos (b) & (3) \\
\hline & $\begin{array}{l}\text { Derogenes varicus } \\
\text { (Derogenidae) }\end{array}$ & & & $\begin{array}{l}\text { gasterópodos Naticidae } \\
\text { (b) }\end{array}$ & copépodos o quetognatos (b) & (4) \\
\hline & $\begin{array}{l}\text { Lecithochirium microstomum } \\
\text { (Hemiuridae) }\end{array}$ & & & $\begin{array}{l}\text { gasterópodos Trochidae } \\
\text { (b) }\end{array}$ & $\begin{array}{l}\text { teleósteos góbidos, lábridos y } \\
\text { bénidos }(\mathrm{b})\end{array}$ & (5) \\
\hline & $\begin{array}{l}\text { Lecithocladium cristatum } \\
\text { (Hemuiridae) }\end{array}$ & & & $\begin{array}{l}\text { gasterópodos Philinidae } \\
\text { (b) }\end{array}$ & $\begin{array}{l}\text { copépodos, ctenóforos y poliquetos } \\
\text { (b) }\end{array}$ & (6) \\
\hline \multirow{5}{*}{$\begin{array}{c}\text { Odontesthes smitti } \\
\text { (Lahille) y O. nigricans } \\
\text { (Richardson) } \\
\text { (Atherinopsidae) }\end{array}$} & $\begin{array}{c}\text { Diphterostomum sp. } \\
\text { (Zoogonidae) }\end{array}$ & GN, GSJ & \multirow{5}{*}{$\begin{array}{c}\text { Carballo (2006); Carballo et al. } \\
\text { (2011) }\end{array}$} & $\begin{array}{c}\text { gasterópodo } \\
\text { Nassariidae (b) }\end{array}$ & $\begin{array}{l}\text { mismo gasterópodo } 1^{\circ} \mathrm{HI}(\mathrm{b}) \\
\text { bivalvos }(\mathrm{b}) \text {, crinoideos }(\mathrm{b})\end{array}$ & (2) \\
\hline & $\begin{array}{l}\text { Aponurus laguncula } \\
\text { (Lecithasteridae) }\end{array}$ & GSJ & & gasterópodos (b) & copépodos (h) & (7) \\
\hline & Lecithaster sp. (Lecithasteridae) & GN, GSJ & & $\begin{array}{c}\text { gasterópodos } \\
\text { Pyramidellidae (b) }\end{array}$ & $\begin{array}{l}\text { Acartia sp. (Copepoda), otros } \\
\text { copépodos (b) }\end{array}$ & $(8,9)$ \\
\hline & $\begin{array}{l}\text { Proctotrema bartolii } \\
\text { (Monorchiidae) }\end{array}$ & GN, GSJ & & $\begin{array}{l}\text { Darina solenoides } \\
\text { (Bivalvia) (c) }\end{array}$ & Darina solenoides (c) & (10) \\
\hline & $\begin{array}{l}\text { Prosorhynchoides sp. } \\
\text { (Bucephalidae)* }\end{array}$ & GN, GSJ & & bivalvos mitílidos (h) & peces (HD) (b) & $\begin{array}{c}(7,11,12,13,14,15,1 \\
6,17)\end{array}$ \\
\hline
\end{tabular}


Tabla 4 (continuación I). Estudios realizados previamente a esta tesis en las costas patagónicas sobre digeneos parásitos de peces, sus localidades y hospedadores intermediarios conocidos (c), hipotetizados (h) o inferidos mediante referencias bibliográficas (b). Referencias: * indica que el estadio hallado es el de metacercaria, ** Cremonte \& Etchegoin (com. pers.), HI= hospedador intermediario, HD= hospedador definitivo, GN = Golfo Nuevo, IM= Islas Malvinas, PV= Península Valdés, GSJ= Golfo San José, TF= Tierra del Fuego, PD= Puerto Deseado, PN= Patagonia Norte, CP= Plataforma patagónica, IE= Isla Escondida y GSJO= Golfo San Jorge y GSM = Golfo San Matías. Referencias bibliográficas: (1) (Rocka, 2006) (2) (Pina et al., 2009) (3) (Gibson \& Bray, 1986) (4) (Køie, 1979) (5) (Køie, 1990c) (6) (Køie, 1991) (7) (Yamaguti,1975) (8) (Williams \& Williams, 1996) (9) (Køie, 1989) (10) (Gilardoni et al., 2013) (11) (Szidat, 1961) (12) (Szidat, 1963) (13) (Szidat, 1965) (14) (Suriano \& Martorelli, 1983) (15) (Tanzola \& Guagliardo, 2000) (16) (Etchegoin et al., 2005) (17) (Cremonte et al., 1999) (18) Cremonte (com. pers) (19) (Daponte et al., 2006) (20) (Timi et al., 1999) (21) (Cremonte \& Sardella, 1997) (22) (Cribb et al., 2011).

\begin{tabular}{|c|c|c|c|c|c|c|}
\hline Pez hospedador & Digeneos hallados & Localidad & Referencias & $1^{\circ} \mathrm{HI}$ & $2^{\circ} \mathrm{HI}$ & $\begin{array}{c}\text { Referencias } \\
\text { del ciclo de } \\
\text { vida }\end{array}$ \\
\hline \multirow{10}{*}{$\begin{array}{c}\text { Eleginops maclovinus } \\
\text { (Cuvier) } \\
\text { (Eleginopsidae) }\end{array}$} & Derogenes varicus (Derogenidae) & $\mathrm{TF}, \mathrm{IM}$ & \multirow{10}{*}{$\begin{array}{c}\text { Szidat (1950); Gosztonyi (1979); } \\
\text { Mackenzie (2003); Carballo et al. } \\
\text { (2011) }\end{array}$} & $\begin{array}{l}\text { gasterópodos Naticidae } \\
\text { (b) }\end{array}$ & copépodos o quetognatos (b) & (4) \\
\hline & Derogenes parvus (Derogenidae) & $\mathrm{TF}$ & & $\begin{array}{l}\text { gasterópodos Naticidae } \\
\text { (b) }\end{array}$ & copépodos o quetognatos (b) & (4) \\
\hline & $\begin{array}{l}\text { Elytrophalloides merluccii } \\
\text { (Hemiuridae) }\end{array}$ & $\mathrm{TF}$ & & gasterópodos (b) & copépodos o quetognatos (b) & (3) \\
\hline & Elytrophalloides oatesi (Hemiuridae) & IM & & gasterópodos (b) & copépodos o quetognatos (b) & (3) \\
\hline & Aponurus sp. (Lecithasteridae) & $\mathrm{TF}$ & & gasterópodos (b) & copépodos (b) & (7) \\
\hline & Lepocreadium sp. (Lepocreadiidae) & $\mathrm{PD}, \mathrm{TF}$ & & $\begin{array}{l}\text { gasterópodos } \\
\text { Nassariidae (b) }\end{array}$ & bivalvos (b) & (7) \\
\hline & $\begin{array}{l}\text { Monorcheides popovicii } \\
\text { (Monorchiidae) }\end{array}$ & $\mathrm{PD}, \mathrm{TF}$ & & $\begin{array}{l}\text { Lasaea adansoni (Bivalvia) } \\
\text { (h) }\end{array}$ & $\begin{array}{c}\text { Lasaea adansoni (h), bivalvos u otros } \\
\text { invertebrados (b) }\end{array}$ & $(7,18)$ \\
\hline & $\begin{array}{l}\text { Postmonorcheides maclovini } \\
\text { (Monorchiidae) }\end{array}$ & $\mathrm{PD}, \mathrm{TF}, \mathrm{IM}$ & & Lasaea adansoni $(\mathrm{h})$ & $\begin{array}{l}\text { Lasaea adansoni (h), bivalvos u otros } \\
\text { invertebrados (b) }\end{array}$ & $(7,18)$ \\
\hline & Neolepidapedon sp. (Lepocreadiidae) & IM & & $\begin{array}{l}\text { gasterópodos } \\
\text { Nassariidae (b) }\end{array}$ & bivalvos u otros invertebrados (b) & (7) \\
\hline & Proctotrema bartolii (Monorchiidae) & GSJ, GN & & Darina solenoides (c) & Darina solenoides (c) & $(10)$ \\
\hline $\begin{array}{l}\text { Genypterus blacodes } \\
\text { (Forster) (Ophidiidae) }\end{array}$ & $\begin{array}{l}\text { Lecithochirium genypteri } \\
\text { (Hemiuridae) }\end{array}$ & GSJO, IE & $\begin{array}{l}\text { Suriano \& Sutton (1980); } \\
\text { Sardella et al. (1998) }\end{array}$ & $\begin{array}{c}\text { gasterópodos Trochidae } \\
\text { (b) }\end{array}$ & teleósteos góbidos, lábridos y bénidos (b) & (5) \\
\hline
\end{tabular}


Tabla 4 (continuación II). Estudios realizados previamente a esta tesis en las costas patagónicas sobre digeneos parásitos de peces, sus localidades y hospedadores intermediarios conocidos (c), hipotetizados (h) o inferidos mediante referencias bibliográficas (b). Referencias: * indica que el estadio hallado es el de metacercaria, ** Cremonte \& Etchegoin (com. pers.), HI= hospedador intermediario, HD= hospedador definitivo, GN = Golfo Nuevo, IM= Islas Malvinas, PV= Península Valdés, GSJ= Golfo San José, TF= Tierra del Fuego, PD= Puerto Deseado, PN= Patagonia Norte, CP= Plataforma patagónica, IE= Isla Escondida y GSJO= Golfo San Jorge y GSM = Golfo San Matías. Referencias bibliográficas: (1) (Rocka, 2006) (2) (Pina et al., 2009) (3) (Gibson \& Bray, 1986) (4) (Køie, 1979) (5) (Køie, 1990c) (6) (Køie, 1991) (7) (Yamaguti,1975) (8) (Williams \& Williams, 1996) (9) (Køie, 1989) (10) (Gilardoni et al., 2013) (11) (Szidat, 1961) (12) (Szidat, 1963) (13) (Szidat, 1965) (14) (Suriano \& Martorelli, 1983) (15) (Tanzola \& Guagliardo, 2000) (16) (Etchegoin et al., 2005) (17) (Cremonte et al., 1999) (18) Cremonte (com. pers) (19) (Daponte et al., 2006) (20) (Timi et al., 1999) (21) (Cremonte \& Sardella, 1997) (22) (Cribb et al., 2011).

\begin{tabular}{|c|c|c|c|c|c|c|}
\hline Pez hospedador & Digeneos hallados & Localidad & Referencias & $1^{\circ} \mathrm{HI}$ & $2^{\circ} \mathrm{HI}$ & $\begin{array}{c}\text { Referencias } \\
\text { del ciclo de } \\
\text { vida }\end{array}$ \\
\hline \multirow{4}{*}{$\begin{array}{c}\text { Engraulis anchoita } \\
\text { Hubbs \& Marini } \\
\text { (Engraulidae) }\end{array}$} & $\begin{array}{c}\text { Parahemiurus merus } \\
\text { (Hemiuridae) }\end{array}$ & \multirow{4}{*}{$\mathrm{CP}$} & \multirow{4}{*}{$\begin{array}{l}\text { Timi et al. (1999); Timi } \\
\text { (2003) }\end{array}$} & gasterópodos (b) & Sagitta friderici (Chaetognata) (c) & (19) \\
\hline & $\begin{array}{c}\text { Lecithochirium microstomum } \\
\text { (Hemiuridae) }\end{array}$ & & & $\begin{array}{l}\text { gasterópodos } \\
\text { Trochidae (b) }\end{array}$ & $\begin{array}{c}\text { teleósteos góbidos, lábridos y } \\
\text { bénidos }(\mathrm{b})\end{array}$ & (5) \\
\hline & $\begin{array}{c}\text { Cardiocephaloides sp. } \\
{\text { (Strigeidae) })^{*}}^{\text {(Stid }}\end{array}$ & & & $\begin{array}{l}\text { gasterópodos } \\
\text { Nassariidae (b) }\end{array}$ & $\begin{array}{c}\text { Spheniscus magellanicus } \\
\text { (Aves)(también actúa como HD) (c) }\end{array}$ & $(20)$ \\
\hline & $\begin{array}{l}\text { Rhipidocotyle sp. } \\
\text { (Bucephalidae)* }\end{array}$ & & & bivalvos (b) & Scomber japonicus (h) & $(21)$ \\
\hline \multirow{5}{*}{$\begin{array}{c}\text { Merluccius hubbsi } \\
\text { Marini } \\
\text { (Merlucciidae) }\end{array}$} & $\begin{array}{l}\text { Aporocotyle argentinensis } \\
\text { (Aporocotylidae) }\end{array}$ & $\begin{array}{l}\text { GSM, } \\
\text { GSJ, PP }\end{array}$ & \multirow{5}{*}{$\begin{array}{l}\text { Suriano \& Sutton (1980); } \\
\text { Sardella \& Timi (2004) }\end{array}$} & bivalvos (b) & cercaria ingresa en HD & $(7)$ \\
\hline & $\begin{array}{l}\text { Derogenes varicus } \\
\text { (Derogenidae) }\end{array}$ & $\begin{array}{l}\text { GSM, } \\
\text { GSJ, PP }\end{array}$ & & $\begin{array}{l}\text { gasterópodos } \\
\text { Naticidae (b) }\end{array}$ & copépodos o quetognatos (b) & $(4)$ \\
\hline & $\begin{array}{l}\text { Elytrophalloides oatesi } \\
\text { (Hemuiridae) }\end{array}$ & $\begin{array}{l}\text { GSM, } \\
\text { GSJ, CP }\end{array}$ & & gasterópodos (b) & copépodos o quetognatos (b) & (3) \\
\hline & $\begin{array}{l}\text { Elytrophallus merlucci } \\
\text { (Hemiuridae) }\end{array}$ & $\mathrm{PN}$ & & gasterópodos (b) & copépodos o quetognatos (b) & (3) \\
\hline & Hemiuridae gen. et sp. & GSJ, CP & & gasterópodos (b) & copépodos o quetognatos (b) & $(7)$ \\
\hline
\end{tabular}


Tabla 4 (continuación III). Estudios realizados previamente a esta tesis en las costas patagónicas sobre digeneos parásitos de peces, sus localidades y hospedadores intermediarios conocidos (c), hipotetizados (h) o inferidos mediante referencias bibliográficas (b). Referencias: * indica que el estadio hallado es el de metacercaria, ** Cremonte \& Etchegoin (com. pers.), HI= hospedador intermediario, HD= hospedador definitivo, GN = Golfo Nuevo, IM= Islas Malvinas, PV= Península Valdés, GSJ= Golfo San José, TF= Tierra del Fuego, PD= Puerto Deseado, PN= Patagonia Norte, CP= Plataforma patagónica, IE= Isla Escondida y GSJO= Golfo San Jorge y GSM = Golfo San Matías. Referencias bibliográficas: (1) (Rocka, 2006) (2) (Pina et al., 2009) (3) (Gibson \& Bray, 1986) (4) (Køie, 1979) (5) (Køie, 1990c) (6) (Køie, 1991) (7) (Yamaguti,1975) (8) (Williams \& Williams, 1996) (9) (Køie, 1989) (10) (Gilardoni et al., 2013) (11) (Szidat, 1961) (12) (Szidat, 1963) (13) (Szidat, 1965) (14) (Suriano \& Martorelli, 1983) (15) (Tanzola \& Guagliardo, 2000) (16) (Etchegoin et al., 2005) (17) (Cremonte et al., 1999) (18) Cremonte (com. pers) (19) (Daponte et al., 2006) (20) (Timi et al., 1999) (21) (Cremonte \& Sardella, 1997) (22) (Cribb et al., 2011).

\begin{tabular}{|c|c|c|c|c|c|c|}
\hline Pez hospedador & Digeneos hallados & Localidad & Referencias & $1^{\circ} \mathrm{HI}$ & $2^{\circ} \mathrm{HI}$ & $\begin{array}{l}\text { Referencias del } \\
\text { ciclo de vida }\end{array}$ \\
\hline \multirow{10}{*}{$\begin{array}{l}\text { Percophis brasiliensis } \\
\text { Quoy \& Gaimard } \\
\text { (Percophidae) }\end{array}$} & $\begin{array}{l}\text { Elytrophalloides oatesi } \\
\text { (Hemiuridae) }\end{array}$ & \multirow{10}{*}{ GSM } & \multirow{10}{*}{$\begin{array}{l}\text { Braicovich \& Timi (2008); } \\
\text { Braicovich et al. (2009) }\end{array}$} & gasterópodos (b) & copépodos y quetognatos (b) & (3) \\
\hline & $\begin{array}{l}\text { Parahemiurus merus } \\
\text { (Hemiuridae) }\end{array}$ & & & gasterópodos (b) & Sagitta friderici (c) & (19) \\
\hline & $\begin{array}{l}\text { Aponurus laguncula } \\
\text { (Lecithasteridae) }\end{array}$ & & & gasterópodos (b) & copépodos (b) & (7) \\
\hline & $\begin{array}{l}\text { Ectenurus virgulus } \\
\text { (Hemiuridae) }\end{array}$ & & & gasterópodos (b) & $\begin{array}{l}\text { copépodos, quetognatos, } \\
\text { ctenóforos, poliquetos, peces (b) }\end{array}$ & $(3,5,6)$ \\
\hline & $\begin{array}{l}\text { Lecithocladium cristatum } \\
\text { (Hemiuridae) }\end{array}$ & & & $\begin{array}{l}\text { gasterópodos Philinidae } \\
\text { (b) }\end{array}$ & $\begin{array}{l}\text { copépodos, ctenóforos y poliquetos } \\
\text { (b) }\end{array}$ & (6) \\
\hline & $\begin{array}{l}\text { Lecithochirium microstomum } \\
\text { (Hemiuridae) }\end{array}$ & & & $\begin{array}{l}\text { gasterópodos Trochidae } \\
\text { (b) }\end{array}$ & $\begin{array}{c}\text { teleósteos góbidos, lábridos y } \\
\text { bénidos }(\mathrm{b})\end{array}$ & (5) \\
\hline & $\begin{array}{l}\text { Prosoryhnchus sp. } \\
\text { (Bucephalidae) }^{*}\end{array}$ & & & bivalvos mitílidos (h) & peces (también actúa como HD) (b) & $(7,11,12,13,14,15,16,17)$ \\
\hline & $\begin{array}{l}\text { Cardicola ambrosioi } \\
\text { (Aporocotylidae) }\end{array}$ & & & $\begin{array}{l}\text { bivalvos, poliquetos, } \\
\text { gasterópodos }(\mathrm{b})\end{array}$ & cercaria ingresa en $\mathrm{HD}$ & $(7,22)$ \\
\hline & $\begin{array}{l}\text { Derogenes varicus } \\
\text { (Derogenidae) }\end{array}$ & & & $\begin{array}{l}\text { gasterópodos Naticidae } \\
\text { (b) }\end{array}$ & copépodos y quetognatos (b) & (4) \\
\hline & Hemiuridae gen. et sp. & & & gasterópodos (b) & $\begin{array}{l}\text { copépodos, quetognatos, } \\
\text { ctenóforos, poliquetos, peces (b) }\end{array}$ & $(3,5,6)$ \\
\hline
\end{tabular}




\subsection{Materiales y métodos}

\subsubsection{Búsqueda bibliográfica}

Para el estudio de los ciclos de vida se realizó una búsqueda bibliográfica de los antecedentes de los géneros o familias a las que pertenecen los digeneos hallados en este trabajo. Los datos obtenidos por especie fueron, primer y/o segundo hospedador intermediario $\left(1^{\circ} \mathrm{y} / \mathrm{o} 2^{\circ} \mathrm{HI}\right)$, hospedador definitivo, localidad y referencias. En las tablas sólo se incluyen las especies de cada familia, género o grupo morfológico, según corresponda, cuyos estadios larvales en el primer hospedador intermediario son conocidos.

\subsubsection{Estudio de potenciales segundos hospedadores intermediarios}

En algunos muestreos se colectaron en forma adicional invertebrados que pudieran actuar como $2^{\circ} \mathrm{HI}$ de los digeneos hallados en este estudio (Tabla 5). La selección de estos invertebrados se basó en la abundancia observada en el intermareal y en los grupos taxonómicos registrados en la bibliografía. Los especímenes fueron disecados en el laboratorio y examinados en busca de metacercarias de digeneos, en el caso de hallarse fueron estudiadas en vivo e identificadas morfológicamente hasta el nivel taxonómico más preciso posible. Unas 30 metacercarias de cada especie fueron fijadas en etanol 96\% para realizar estudios moleculares. 
Tabla 5. Especies de invertebrados examinados con el fin de hallar segundos hospedadores intermediarios de digeneos en Puerto Madryn y Puerto Deseado.

\begin{tabular}{|c|c|c|}
\hline Potencial hospedador & Localidad & $\begin{array}{l}\mathrm{N}^{\circ} \text { individuos } \\
\text { examinados }\end{array}$ \\
\hline $\begin{array}{l}\text { Cyrtograpsus altimanus Rathbun } \\
\text { (Crustacea, Varunidae) }\end{array}$ & Punta Cuevas (Puerto Madryn) & 10 \\
\hline $\begin{array}{l}\text { Leucippa pentagona Milne Edwards } \\
\text { (Crustacea, Epialtidae) }\end{array}$ & Cerro Avanzado (Puerto Madryn) & 3 \\
\hline $\begin{array}{l}\text { Idotea baltica (Pallas) } \\
\text { (Crustacea, Idoteidae) }\end{array}$ & Cerro Avanzado (Puerto Madryn) & 11 \\
\hline $\begin{array}{l}\text { Exosphaeroma sp. } \\
\text { (Crustacea, Sphaeromatidae) }\end{array}$ & Punta Cuevas (Puerto Madryn), Puerto Deseado & 152 \\
\hline $\begin{array}{l}\text { Balanus glandula Darwin } \\
\text { (Crustacea, Ballaneidae) }\end{array}$ & Punta Cuevas (Puerto Madryn) & 50 \\
\hline $\begin{array}{l}\text { Mytilus edulis Linnaeus } \\
\text { (Mollusca, Mytilidae) }\end{array}$ & Puerto Deseado & 10 \\
\hline $\begin{array}{l}\text { Perumytilus purpuratus (Lamarck) } \\
\text { (Mollusca, Mytilidae) }\end{array}$ & Puerto Deseado & 11 \\
\hline $\begin{array}{l}\text { Lasaea adansoni (Gmelin) } \\
\text { (Mollusca, Lasaeidae) }\end{array}$ & Puerto Deseado & 517 \\
\hline $\begin{array}{l}\text { Neolepton cobbi (Cooper \& Preston) } \\
\text { (Mollusca, Neoleptonidae) }\end{array}$ & Puerto Deseado & 146 \\
\hline $\begin{array}{l}\text { Gaimardia trapesina (Lamarck) } \\
\text { (Mollusca, Gaimardiidae) }\end{array}$ & Puerto Deseado & 50 \\
\hline $\begin{array}{l}\text { Eulalia sp. } \\
\text { (Annelida, Phyllodocidae) }\end{array}$ & Punta Cuevas (Puerto Madryn) & 6 \\
\hline $\begin{array}{l}\text { Antholoba achates (Drayton \& Dana) } \\
\text { (Cnidaria, Actinostolidae) }\end{array}$ & Punta Cuevas (Puerto Madryn) & 10 \\
\hline $\begin{array}{l}\text { Mnemiopsis leydi Agassiz } \\
\text { (Ctenophora, Bolinopsidae) }\end{array}$ & Punta Cuevas (Puerto Madryn) & 50 \\
\hline $\begin{array}{l}\text { Plaxiphora aurata (Spalowsky) } \\
\text { (Mollusca, Mopaliidae) }\end{array}$ & Cerro Avanzado (Puerto Madryn) & 11 \\
\hline
\end{tabular}

\subsubsection{Infecciones experimentales}

Para dilucidar el ciclo de vida de las dos especies de Maritrema que utilizan crustáceos como $2^{\circ} \mathrm{HI}$ (Yamaguti, 1975), se colectaron 13 cangrejos Cyrtograpsus altimanus Rathbun (Varunidae) y 10 isópodos Exosphaeroma sp. Estudios previos registraron metacercarias de Maritrema en C. altimanus (Diaz \& Cremonte, 2010) y las tallas pequeñas presentaron menor intensidad de infección (J. Diaz, com. pers.), por lo que se utilizaron cangrejos pequeños para realizar las infecciones experimentales. Para dilucidar el ciclo de vida de una especie de Renicolidae que utiliza bivalvos como $2^{\circ} \mathrm{HI}$, se colectaron cinco mejillones Mytilus edulis Linnaeus (Mytilidae) del intermareal de Puerto Madryn. Previamente, se observaron metacercarias de la familia Renicolidae en mejillones procedentes de Comodoro Rivadavia (Cremonte, 1999); sin embargo los mejillones de Puerto Madryn no se hallaron parasitados (F. Cremonte, com. pers). 
Los invertebrados (cangrejos, isópodos y mitílidos) fueron colocados en recipientes individuales con agua de mar. Las cercarias de Maritrema sp. emitidas por los gasterópodos Crepipatella dilatata y Siphonaria lessonii fueron succionadas con una pipeta Pasteur y colocadas en los recipientes que contenían cangrejos e isópodos. De la misma forma se colectaron cercarias Renicolidae emitidas del gasterópodo Trophon geversianus y se colocaron en los recipientes con mitílidos. Los crustáceos y los mitílidos fueron mantenidos en acuarios a temperatura controlada $\left(12^{\circ} \mathrm{C}\right)$. Al cabo de 5, 15, 30, 45 y 60 días se disecaron 1 ó 2 invertebrados de cada especie y se buscaron metacercarias. En el caso de hallarse, fueron estudiadas en vivo utilizando un microscopio óptico y se compararon con las metacercarias halladas naturalmente.

\subsubsection{Cultivos in vitro}

Las metacercarias halladas naturalmente en los cangrejos C. altimanus e Idotea baltica (Pallas) (Idoteidae), así como aquellas que se obtuvieron de la infección experimental de los cangrejos, se colocaron en un recipiente con solución fisiológica en una estufa a $39-40^{\circ} \mathrm{C}$. Las metacercarias fueron inspeccionadas bajo microscopio óptico al cabo de 6, 12, 18, 24, 36 y 48 horas, observándose el desarrollo de las estructuras reproductoras y la producción de huevos.

\subsubsection{Estudios moleculares}

Las secuencias moleculares fueron obtenidas como se especifica en la sección 3.2.4. del capítulo 1. En algunos casos, como en el de los digeneos de la familia Lepocreadiidae, los del género Maritrema, los de la familia Renicolidae, Diphterostomum sp., Gymnophalloides nacellae y Parorchis sp., se obtuvieron las secuencias moleculares de distintos estadios del ciclo de vida (esporocistos, metacercarias y adultos) hallados en otros hospedadores examinados o descriptos previamente (gasterópodos, bivalvos, crustáceos, peces y aves) (Tabla 1, cap. 1). Se secuenciaron cercarias Lepocreadiidae provenientes del gasterópodo Buccinanops cochlidium y adultos de esta familia provenientes de la caballa Scomber japonicus (F. Cremonte, datos no publicados). Este material fue provisto por A. Averbuj y F. 
Cremonte, colectado en el Golfo San José. También se secuenciaron esporocistos Gymnophallidae del bivalvo Gaimardia trapesina (Lamarck) (Gaimardiidae), colectados en Puerto Deseado en diciembre de 2011 y metacercarias Renicolidae del bivalvo Mytilus edulis Linnaeus (Mytilidae). Estas metacercarias fueron provistas por F. Cremonte, colectadas en Comodoro Rivadavia. Adicionalmente, se secuenciaron metacercarias de Maritrema sp. halladas en los crustáceos Cyrtograpsus altimanus e Idotea baltica y adultos de Diphterostomum sp. hallados en el turco Pinguipes brasilianus colectados en Bahía Nueva, Puerto Madryn mediante buceo autónomo y caza submarina. Por último, se secuenciaron adultos de Maritrema madrynense y Maritrema formicae hallados en la gaviota cocinera Larus dominicanus, colectadas en Península Valdés en septiembre de 2012 por M. Bertellotti. Tanto los adultos de Parorchis sp. hallados en la gaviota cocinera L. dominicanus y en el playero de rabadilla blanca Calidris fuscicollis (Vieillot) (Scolopacidae) fueron provistos por J. Diaz y secuenciados por V. Tkach (Universidad de Dakota del Norte).

Las secuencias obtenidas fueron comparadas utilizando el software Multalin (http://bioinfo.genotoul.fr/multalin/multalin.html) para analizar la correspondencia entre los estadios larvales y/o adultos. 


\subsection{Resultados y Discusión}

\subsubsection{Digeneos que finalizan su ciclo de vida en peces}

\subsubsection{Hemiuroidea fam. gen. et $\mathrm{sp}$.}

La superfamilia Hemiuroidea Loos, 1899 está comprendida por siete familias y numerosas especies que finalizan su ciclo de vida principalmente en peces teleósteos marinos (Gibson, 2002). Tanto adultos como estadios larvales fueron reportados en distintas partes del mundo (e.g. Tabla 6, Gibson, 2002; Klimpel et al., 2003; Kohn et al., 2007; Gómez del Prado-Rosas et al., 2007; Almeida et al., 2009).

Los ciclos de vida de las especies de la superfamilia Hemiuroidea involucran casi siempre gasterópodos como $1^{\circ} \mathrm{HI}$ (Tabla 6). Sólo en tres casos se registraron un bivalvo y un escafópodo como $1^{\circ} \mathrm{HI}$ (Wardle, 1975; Køie et al., 2002). Copépodos y ostrácodos son los invertebrados mayormente conocidos como $2^{\circ} \mathrm{HI}$ (Cable, 1963; Yamaguti, 1975; Køie, 1990a, 1992, 1995; Køie \& Gibson, 1991); no obstante, también se han registrado como $2^{\circ} \mathrm{HI}$ poliquetos, quetognatos, anfípodos y ctenóforos (Cable, 1963; Køie, 1991, 1995). Diferentes especies de peces teleósteos y una especie de quetognato del género Sagitta fueron registradas como hospedadores definitivos de larvas Hemiuroidea (Yamaguti, 1975, Køie, 1990a, 1990b, 1991, 1992, 1995). Algunas especies presentan ciclos monoxenos, es decir, que todos los estadios del ciclo de vida ocurren en el gasterópodo. Las cercarias cistóforas sufren metamorfosis dentro del esporocisto $y$ se transforman en metacercarias progenéticas que luego continúan su desarrollo hasta convertirse en adultos (Jamieson, 1966; Martorelli, 1989a).

En la costa patagónica se registraron 26 especies de digeneos de la superfamilia Hemiuroidea pertenecientes a las familias Hemiuridae, Derogenidae y Lecithasteridae, parasitando ocho especies de peces (Tabla 4). La cercaria Hemiuroidea en $S$. lessonii es la primera larva marina registrada en gasterópodos de Argentina y se halló en Playa Fracasso (Golfo San José), Puerto Madryn (Golfo Nuevo), Comodoro Rivadavia y Puerto Deseado (Alda \& Martorelli, 2009; Gilardoni et al., 2011; Bagnato, 2012). Hasta el momento, sólo se han registrado cuatro metacercarias de la superfamilia Hemiuroidea en el área de estudio. Las 
metacercarias de las especies Ectenurus sp. y Derogenes sp. se hallaron parasitando al quetognato Parasagitta friderici (Ritter-Záhony) (Sagittidae) (Daponte et al., 2006), una metacercaria Hemiuridae se registró parasitando a dos especies de meduzas y una especie de ctenóforo en el Océano Atlántico Sudoccidental (Martorelli 2001) y otra metacercaria de dicha familia se registró en tres especies de medusas en la costa de Argentina, Uruguay y sur de Brasil (Diaz Briz et al., 2012). Adicionalmente, en este trabajo, se observaron metacercarias Hemiuridae en el ctenóforo Mnemiopsis leydi (Fig. 51). Futuros estudios morfológicos y moleculares contribuirán a resolver si ésta metacercaria corresponde a la misma especie que la cercaria hallada en $S$. lessonii. Posteriores disecciones de peces costeros e invertebrados contribuirán a dilucidar el ciclo de vida de esta especie de digeneo (Fig. 52).

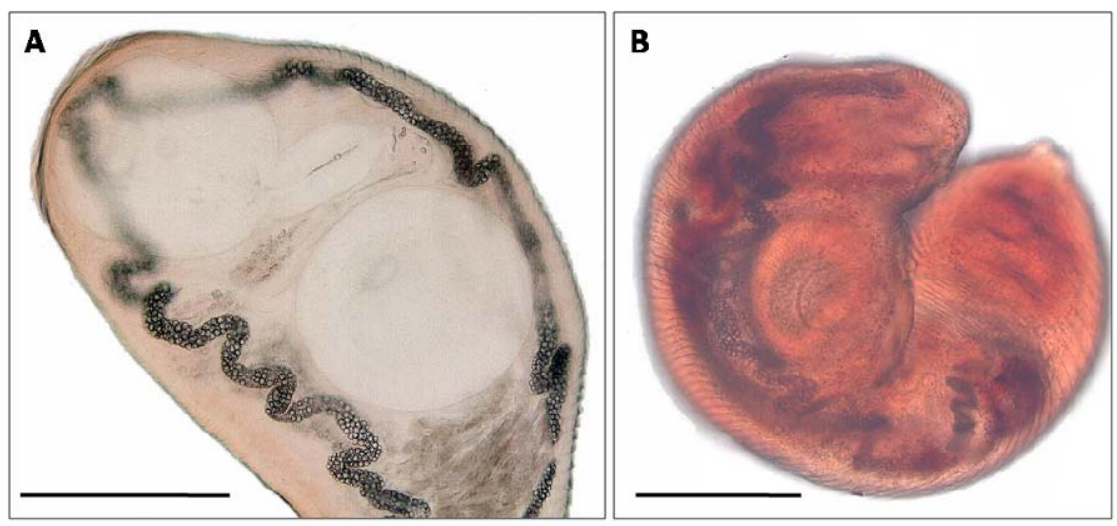

Figura 51. Metacercaria Hemiuridae hallada en el ctenóforo Mnemiopsis leydi en Punta Cuevas, Puerto Madryn. Escalas: $50 \mu \mathrm{m}$ (A, B). 


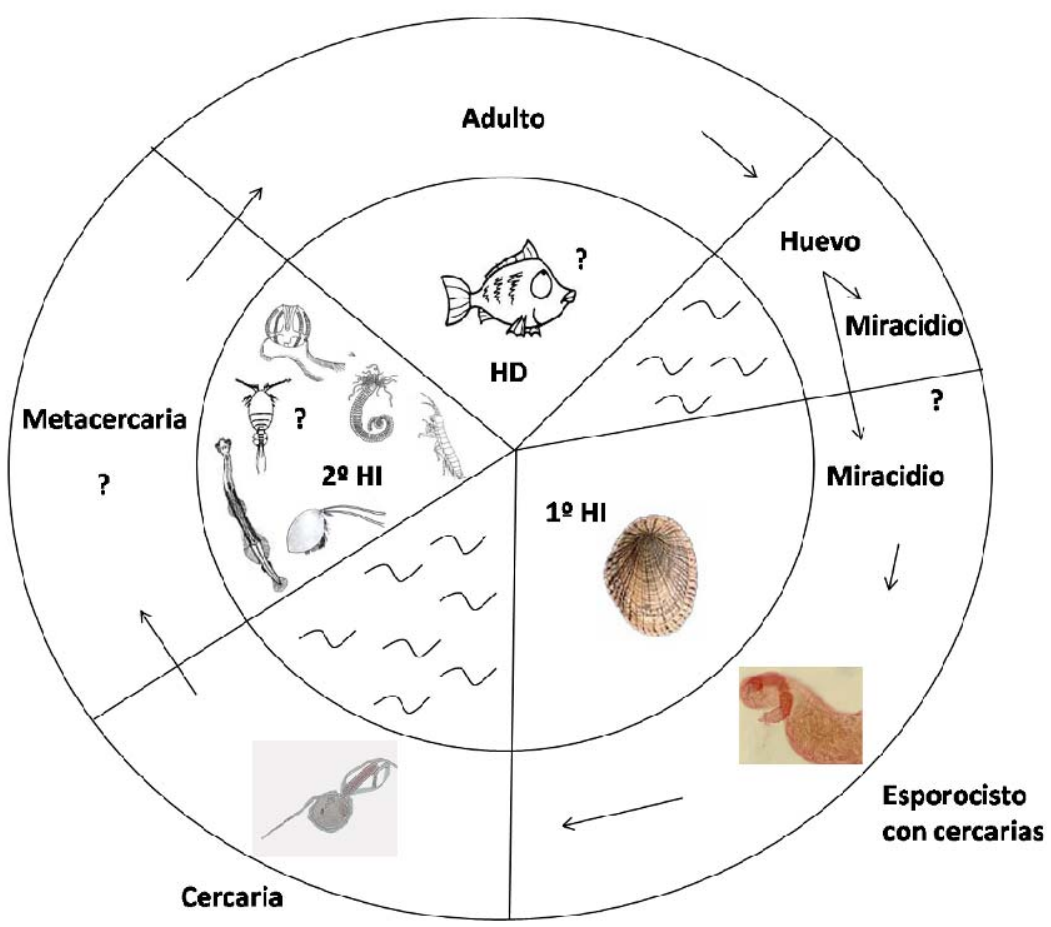

Figura 52. Ciclo de vida de Hemiuroidea fam. gen. et sp. Los dibujos de hospedadores y los estadios larvales indicados con signo de interrogación no se conocen. Abreviaturas: HIhospedador intermediario; HD- hospedador definitivo. 
Tabla 6. Estadios larvales (en los $1^{\circ}$ hospedadores intermediarios) de la superfamilia Hemiuroidea registrados en el mundo. Se incluye información de los ciclos de vida conocidos $\left(2^{\circ}\right.$ hospedador intermediario y hospedador definitivo), la localidad y las referencias. Los hospedadores indicados entre corchetes fueron determinados a partir de infecciones experimentales.

\begin{tabular}{|c|c|c|c|c|c|}
\hline Especie & $1^{\circ}$ Hosp. Intermediario & $2^{\circ}$ Hosp. Intermediario & Hosp. Definitivo & Localidad & Referencias \\
\hline $\begin{array}{l}\text { Bunocotyle meridionalis } \\
\text { Odhner, } 1928 \\
\text { (Chabaud \& Büttner, } \\
\text { 1959) }\end{array}$ & $\begin{array}{l}\text { Heleobia stagnorum (Gmelin) } \\
\text { (Cochliopidae) }\end{array}$ & $\begin{array}{l}\text { Popella guerni (Maxillopoda) } \\
\text { Heleobia stagnorum }\end{array}$ & $\begin{array}{l}\text { Heleobia stagnorum } \\
\text { (progénesis) }\end{array}$ & Mar Báltico & $\begin{array}{l}\text { Jamieson } \\
(1966) \\
\text { Yamaguti } \\
(1975)\end{array}$ \\
\hline $\begin{array}{l}\text { Bunocotyle progenetica } \\
\text { (Markowski, 1936) }\end{array}$ & $\begin{array}{l}\text { Heleobia stagnorum (Gmelin) } \\
\text { (Cochliopidae) }\end{array}$ & Heleobia stagnorum & $\begin{array}{l}\text { Heleobia stagnorum } \\
\text { (progénesis) }\end{array}$ & Mar Báltico & $\begin{array}{l}\text { Jamieson } \\
(1966)\end{array}$ \\
\hline $\begin{array}{l}\text { Parahemiurus bennetae } \\
\text { Jamieson, } 1966\end{array}$ & $\begin{array}{l}\text { Salinator fragilis (Lamarck) } \\
\text { (Amphibolidae) }\end{array}$ & Salinator fragilis & $\begin{array}{l}\text { Salinator } \\
\text { fragilis (progénesis) }\end{array}$ & $\begin{array}{l}\text { Río Cook, New South } \\
\text { Wales, Estados Unidos }\end{array}$ & $\begin{array}{l}\text { Jamieson, } \\
(1966)\end{array}$ \\
\hline $\begin{array}{l}\text { Genarchella genarchella } \\
\text { Travassos, } 1928\end{array}$ & $\begin{array}{l}\text { Heleobia parchappii } \\
\text { (d'Orbigny) (Cochliopidae) }\end{array}$ & Littoridina parchappii & $\begin{array}{l}\text { Heleobia parchappii } \\
\text { (progénesis) }\end{array}$ & $\begin{array}{l}\text { Laguna de } \\
\text { Chascomús, Buenos } \\
\text { Aires, Argentina }\end{array}$ & $\begin{array}{l}\text { Martorelli } \\
\text { (1989a) }\end{array}$ \\
\hline $\begin{array}{l}\text { Cercaria cistofora } \\
\text { Martorelli, } 1994\end{array}$ & $\begin{array}{l}\text { Potamolithus agapetus Pilsbry } \\
\text { (Hydrobiidae) }\end{array}$ & desconocido & desconocido & $\begin{array}{l}\text { Río de La Plata, } \\
\text { Buenos Aires, } \\
\text { Argentina }\end{array}$ & $\begin{array}{l}\text { Martorelli } \\
(1994)\end{array}$ \\
\hline $\begin{array}{l}\text { Lecithaster confusus } \\
\text { Odhner, } 1905\end{array}$ & $\begin{array}{l}\text { Boonea bisuturalis (Say) } \\
\text { (Pyramidellidae) }\end{array}$ & Acartia tonsa (Maxillopoda) & $\begin{array}{l}\text { [Fundulus spp., Apeles } \\
\text { quadracus] y otros peces }\end{array}$ & $\begin{array}{l}\text { Woods Hole, } \\
\text { Massachusetts, } \\
\text { Estados Unidos }\end{array}$ & $\begin{array}{l}\text { Stunkard } \\
(1970) \\
\text { Yamaguti } \\
(1975)\end{array}$ \\
\hline $\begin{array}{l}\text { Cercaria anadarae } \\
\text { Wardle, } 1975\end{array}$ & $\begin{array}{l}\text { Anadara brasiliana (Lamarck) } \\
\text { (Arcidae) }\end{array}$ & desconocido & desconocido & $\begin{array}{l}\text { Golfo Noroeste, } \\
\text { México }\end{array}$ & $\begin{array}{l}\text { Wardle } \\
\text { (1975) }\end{array}$ \\
\hline $\begin{array}{l}\text { Cercaria chilkaensis } N^{\circ} . \\
1 \text { Rhao \& Madhavi, } 1990\end{array}$ & $\begin{array}{l}\text { Stenothyra blanfordiana (Nevill) } \\
\text { (Stenothyridae) }\end{array}$ & desconocido & desconocido & Lago Chilka, India & $\begin{array}{l}\text { Shameem et } \\
\text { al. (1990) }\end{array}$ \\
\hline $\begin{array}{l}\text { Cercaria B } \\
\text { Miller, } 1925\end{array}$ & Nucella lamellosa (Gmelin) (Muricidae) & desconocido & desconocido & $\begin{array}{l}\text { costa de Friday } \\
\text { Harbor, Washinton, } \\
\text { Estados Unidos } \\
\end{array}$ & Ching (1991) \\
\hline $\begin{array}{l}\text { Cercaria C } \\
\text { Ching, } 1960\end{array}$ & $\begin{array}{l}\text { Dentalium dalli (Pilsbry \& Sharp) } \\
\text { (Dentallidae) }\end{array}$ & desconocido & desconocido & $\begin{array}{l}\text { costa de Friday } \\
\text { Harbor, Washinton, } \\
\text { Estados Unidos } \\
\end{array}$ & Ching (1991) \\
\hline
\end{tabular}


Tabla 6 (continuación). Estadios larvales (en los $1^{\circ}$ hospedadores intermediarios) de la superfamilia Hemiuroidea registrados en el mundo. Se incluye información de los ciclos de vida conocidos $\left(2^{\circ}\right.$ hospedador intermediario y hospedador definitivo), la localidad y las referencias. Los hospedadores indicados entre corchetes fueron determinados a partir de infecciones experimentales.

\begin{tabular}{|c|c|c|c|c|c|}
\hline Especie & $1^{\circ}$ Hosp. Intermediario & $2^{\circ}$ Hosp. Intermediario & Hosp. Definitivo & Localidad & Referencias \\
\hline $\begin{array}{l}\text { Cercaria hemiuridae } \\
\text { mihi I }\end{array}$ & $\begin{array}{l}\text { Alvania compacta (Carpenter) } \\
\text { (Rissoidae) }\end{array}$ & desconocido & desconocido & $\begin{array}{l}\text { costa de Vancouver, } \\
\text { British Columbia, } \\
\text { Canadá }\end{array}$ & Ching (1991) \\
\hline $\begin{array}{l}\text { Lecithaster salmonis } \\
\text { Yamaguti, } 1934\end{array}$ & $\begin{array}{l}\text { Nucella canaliculata (Duclos) } \\
\text { (Muricidae) }\end{array}$ & desconocido & desconocido & $\begin{array}{l}\text { costas de Friday } \\
\text { Harbor, Washinton, } \\
\text { Estados Unidos y } \\
\text { Vancouver, British } \\
\text { Columbia, Canadá }\end{array}$ & Ching (1991) \\
\hline $\begin{array}{l}\text { Dichadena acuta } \\
\text { Cable \& Nahhas, } 1963\end{array}$ & $\begin{array}{l}\text { Zebina browniana (d’Orbigny) } \\
\text { (Rissoinidae) }\end{array}$ & desconocido & Acanthurus hepatus & $\begin{array}{l}\text { costa de Curaçao, } \\
\text { Países Bajos }\end{array}$ & $\begin{array}{l}\text { Yamaguti } \\
(1975)\end{array}$ \\
\hline $\begin{array}{l}\text { Cercaria caribbea } \\
\text { LXXIV } \\
\text { Cable, } 1963 \\
\end{array}$ & $\begin{array}{l}\text { Diodora cayenensis (Lamarck) } \\
\text { (Fissurellidae) }\end{array}$ & $\begin{array}{l}\text { [copépodos y anfípodos no } \\
\text { identificado] }\end{array}$ & desconocido & costa de Jamaica & Cable (1963) \\
\hline $\begin{array}{l}\text { Cercaria caribbea } \\
\text { XXXIV } \\
\text { Cable, } 1956\end{array}$ & $\begin{array}{l}\text { Pyrene mercatoria (Linné) } \\
\text { (Columbellidae) }\end{array}$ & desconocido & desconocido & $\begin{array}{l}\text { costa de Punta Arena, } \\
\text { Joyuda, Puerto Rico }\end{array}$ & Cable (1956) \\
\hline $\begin{array}{l}\text { Tangiopsis chinensis } \\
\text { (Tang, 1951) Skrj. \& } \\
\text { Gusch., 1955 }\end{array}$ & $\begin{array}{l}\text { Paludomus tangi (Cheng) } \\
\text { (Pachychiilidae) y Melania joretiana } \\
\text { (Heude) (Thiaridae) }\end{array}$ & $\begin{array}{l}\text { Cypretta sp., Heterocypris } \\
\text { sp. y Dolerocypris sinensis } \\
\text { (Ostracoda) }\end{array}$ & [Rhinogobius giurinus] & costa de China & $\begin{array}{l}\text { Yamaguti } \\
(1975) \\
\text { Wang (1995) }\end{array}$ \\
\hline $\begin{array}{l}\text { Derogenes varicus } \\
\text { (Müller, 1784) Looss, } \\
1901\end{array}$ & Natica spp. (Naticidae) & $\begin{array}{l}\text { Calanus finmarchicus } \\
\text { (Maxillopoda) }\end{array}$ & [peces gobios] & $\begin{array}{l}\text { costas de Dinamarca y } \\
\text { Goenlandia }\end{array}$ & Køie (1979) \\
\hline $\begin{array}{l}\text { Lecithaster gibbosus } \\
\text { (Rudolphi, 1802) Lühe, } \\
1901\end{array}$ & $\begin{array}{l}\text { Odostomia eulimoides Hanley } \\
\text { (Pyramidellidae) }\end{array}$ & $\begin{array}{l}\text { copépodos Calanoidea, } \\
\text { [Acartia sp.] }\end{array}$ & [Gasterosteus aculeatus] & $\begin{array}{l}\text { Océano Atlántico } \\
\text { Norte }\end{array}$ & Køie (1989) \\
\hline $\begin{array}{l}\text { Lecithochirium } \\
\text { rufoviride (Rudolphi, } \\
\text { 1819) Lühe, } 1901\end{array}$ & $\begin{array}{l}\text { Gibbula cineraria (Linnaeus) } \\
\text { (Trochidae) }\end{array}$ & desconocido & $\begin{array}{l}\text { Anguilla anguilla, Conger } \\
\text { coger }\end{array}$ & $\begin{array}{l}\text { costa de Kattegat, } \\
\text { Dinamarca }\end{array}$ & Køie, (1990c) \\
\hline $\begin{array}{l}\text { Hemiurus luehei } \\
\text { Odhner, } 1905\end{array}$ & $\begin{array}{l}\text { Philine denticulata (Adams) } \\
\text { (Philinidae) }\end{array}$ & $\begin{array}{l}\text { copépodos calanoides, [Temora } \\
\text { longicornis, Acartia } \\
\text { tonsa](Maxillopoda) }\end{array}$ & Sagitta sp. & $\begin{array}{l}\text { costa Atlántica de } \\
\text { Europa, Mar } \\
\text { Mediterráneo y Mar } \\
\text { Báltico } \\
\end{array}$ & Køie (1990b) \\
\hline $\begin{array}{l}\text { Cercaria cystophora } \\
\text { Køie, } 1990\end{array}$ & $\begin{array}{l}\text { Lunatia pallida (Broderip \& } \\
\text { Sowerby) (Naticidae) }\end{array}$ & desconocido & desconocido & $\begin{array}{l}\text { costa de Oresund, } \\
\text { Dinamarca }\end{array}$ & Køie (1990a) \\
\hline
\end{tabular}


Tabla 6 (continuación I). Estadios larvales (en los $1^{\circ}$ hospedadores intermediarios) de la superfamilia Hemiuroidea registrados en el mundo. Se incluye información de los ciclos de vida conocidos $\left(2^{\circ}\right.$ hospedador intermediario y hospedador definitivo), la localidad y las referencias. Los hospedadores indicados entre corchetes fueron determinados a partir de infecciones experimentales.

\begin{tabular}{|c|c|c|c|c|c|}
\hline Especie & $1^{\circ}$ Hosp. Intermediario & $2^{\circ}$ Hosp. Intermediario & Hosp. Definitivo & Localidad & Referencias \\
\hline $\begin{array}{l}\text { Lecithocladium excisum } \\
\text { (Rudolphi, 1819) }\end{array}$ & Philine aperta (Linnaeus) (Philinidae) & $\begin{array}{l}\text { [Acartia tonsa] (Maxillopoda), } \\
\text { Pleurobrachia pileus } \\
\text { (Tentaculata) y Tomopteris } \\
\text { helgolandica (Polychaeta) }\end{array}$ & Scomber spp. & $\begin{array}{l}\text { costa de Oresund, } \\
\text { Dinamarca }\end{array}$ & Køie (1991) \\
\hline $\begin{array}{l}\text { Magnibursatus } \\
\text { caudofilamentosa } \\
\text { (Reimer, 1971) }\end{array}$ & $\begin{array}{l}\text { Rissoa membranácea (Adams) } \\
\text { (Rissoidae) }\end{array}$ & copépodos Harpacticoida & Gasterosteus aculeatus & $\begin{array}{l}\text { costa de Isefjord, } \\
\text { Dinamarca }\end{array}$ & $\begin{array}{l}\text { Køie \& } \\
\text { Gibson (1991) }\end{array}$ \\
\hline $\begin{array}{l}\text { Brachyphallus crenatus } \\
\text { (Rudolphi, 1802) } \\
\text { Odhner, } 1905\end{array}$ & Retusa obtusa (Montagu) (Retusidae) & [Acartia tonsa] (Maxillopoda) & Gasterosteus aculeatus & $\begin{array}{l}\text { costas de Oresund e } \\
\text { Isefjord, Dinamarca }\end{array}$ & Køie (1992) \\
\hline $\begin{array}{l}\text { Hemiurus communis } \\
\text { Odhner, } 1905\end{array}$ & $\begin{array}{l}\text { Retusa truncatula (Bruguiére) } \\
\text { (Retusidae) }\end{array}$ & $\begin{array}{l}\text { [Acartia tonsa] (Maxillopoda) } \\
\text { Pleurobrachia pileus } \\
\text { (Tentaculata) y Sagitta sp. } \\
\text { (Sagittoidea) }\end{array}$ & Gasterosteus aculeatus & $\begin{array}{l}\text { costas de Oresund e } \\
\text { Isefjord, Dinamarca }\end{array}$ & Køie (1995) \\
\hline $\begin{array}{l}\text { Cercaria calliostomae } \\
\text { Dollfus, } 1923\end{array}$ & $\begin{array}{l}\text { Calliostoma zizyphinum } \\
\text { (Linnaeus)(Calliostomatidae) }\end{array}$ & desconocido & desconocido & costa de Gran Bretaña & $\begin{array}{l}\text { Matthews } \\
(1982)\end{array}$ \\
\hline $\begin{array}{l}\text { Lecithophyllum } \\
\text { botryophorum (Olsson, } \\
\text { 1868) Odhner, } 1905\end{array}$ & Antalis entalis (Linnaeus) (Dentaliidae) & [Antalis entalis] (Schaphopoda) & Argentina silus & costa de Noruega & $\begin{array}{l}\text { Køie et al. } \\
(2002)\end{array}$ \\
\hline $\begin{array}{l}\text { Cercaria prenanti } \\
\text { Arvy, } 1949\end{array}$ & Antalis entalis (Linnaeus) (Dentaliidae) & desconocido & desconocido & costa de Francia & $\begin{array}{l}\text { Køie et al. } \\
(2002)\end{array}$ \\
\hline $\begin{array}{l}\text { Hemiuroidea fam. gen. } \\
\text { et sp. }\end{array}$ & $\begin{array}{l}\text { Siphonaria lessonii (Blainville) } \\
\text { (Siphonariidae) }\end{array}$ & desconocido & desconocido & $\begin{array}{l}\text { Playa Fracasso (Golfo } \\
\text { San José), Puerto } \\
\text { Madryn, Comodoro } \\
\text { Rivadavia y Puerto } \\
\text { Deseado, Argentina }\end{array}$ & $\begin{array}{l}\text { Alda \& } \\
\text { Martorelli, } \\
\text { (2009) } \\
\text { Gilardoni et } \\
\text { al. }(2011) \\
\text { Bagnato } \\
\text { (2012) }\end{array}$ \\
\hline
\end{tabular}




\subsubsection{Lepocreadiidae gen. et sp. 1 y Lepocreadiidae gen. et sp. 2}

Los miembros de la familia Lepocreadiidae Odhner, 1905 son parásitos intestinales de peces teleósteos marinos con una distribución geográfica cosmopolita (Bray \& Justine, 2012). Hasta el momento han sido reportadas 27 especies de cercarias y se conocen doce ciclos de vida (Tabla 7).

En general, el ciclo de vida de los digeneos Lepocreadiidae presenta $2 \mathrm{HI}$. El $1^{\circ} \mathrm{HI}$ es generalmente un gasterópodo en el cual se desarrollan redias. Sólo existen dos registros de cercarias Lepocreadiidae en la gónada de bivalvos de la familia Ostreidae (Aguirre-Macedo \& Kennedy, 1999; Hassanine, 2006). Si bien los gasterópodos que actúan como $1^{\circ} \mathrm{HI}$ pueden pertenecer a diferentes familias, existe una predominancia de gasterópodos de la familia Nassariidae (e.g. Villot, 1875; Stunkard, 1970, 1980a, 1983; Køie, 1975; Bray \& Gibson, 1990). Las cercarias emergen de las redias y completan su desarrollo en el medio; luego penetran en el $2^{\circ} \mathrm{HI}$ donde se desarrolla la metacercaria. Una amplia variedad de invertebrados han sido registrados como $2^{\circ} \mathrm{HI}$ de Lepocreadiidae, como ctenóforos, medusas, quetognatos, gasterópodos, bivalvos, anélidos, peces, y anfibios (renacuajos) (e.g. Bartoli, 1966, 1967, 1983; Stunkard, 1970, 1983; Køie, 1975; Watson, 1984; Bray \& Gibson, 1990; Martorelli, 1996; Morandini et al., 2005). Sólo en un ciclo descripto, en el cual un bivalvo actúa como $1^{\circ} \mathrm{HI}$, las metacercarias se desarrollan enquistando en la vegetación aledaña (Hassanine, 2006).

En este trabajo se reportaron dos larvas de la familia Lepocreadiidae, una en Crepipatella dilatata y otra en Pareuthria plumbea de Puerto Deseado, con características morfológicas similares y secuencias moleculares (18S, ITS1 parcial, ITS2, 28S) con pocos pares de bases diferentes. Ambas pertenecerían al mismo género y a especies diferentes. En la costa patagónica existen dos registros de adultos de la familia Lepocreadiidae; Lepocreadium sp. y Neolepidapedon sp., ambos en el róbalo Eleginops maclovinus (Tabla 3; Gosztonyi, 1979; MacKenzie, 2003). También se hallaron adultos de esta familia en la caballa Scomber japonicus Houttuyn (Scombridae) en el Golfo San José (F. Cremonte, com. pers) que anteriormente se habían registrado en las costas de la provincia de Buenos Aires (Cremonte \& Sardella, 1997). La secuencia molecular de esta última especie (18S, 
ITS1 parcial, ITS2, 28S) no presentó correspondencia con ninguna de las dos larvas halladas. Por otro lado, se registraron metacercarias Lepocreadiidae en el bivalvo Gaimardia trapesina (Lamarck) (Gaimardiidae) en el Atlántico Sudoccidental y en el Estrecho de Magallanes (Ituarte et al., 2001, 2005), metacercarias de Opechona sp. en varias especies de medusas y en una especie de ctenóforo en las costas del sur de Brasil, Uruguay y Argentina (Martorelli, 1991; Martorelli, 2001: Diaz-Briz et al., 2012), metacercarias Lepocreadiidae en el quetognato Parasagitta friderici (Daponte et al., 2006). Futuros estudios morfológicos y moleculares permitirán establecer la correspondencia entre las larvas descriptas en este estudio, la metacercaria hallada en G. trapesina y N. cobbi y adultos en peces. Posteriores disecciones de peces e invertebrados en Puerto Deseado contribuirán a dilucidar el ciclo de vida de estas especies (Fig. 53).

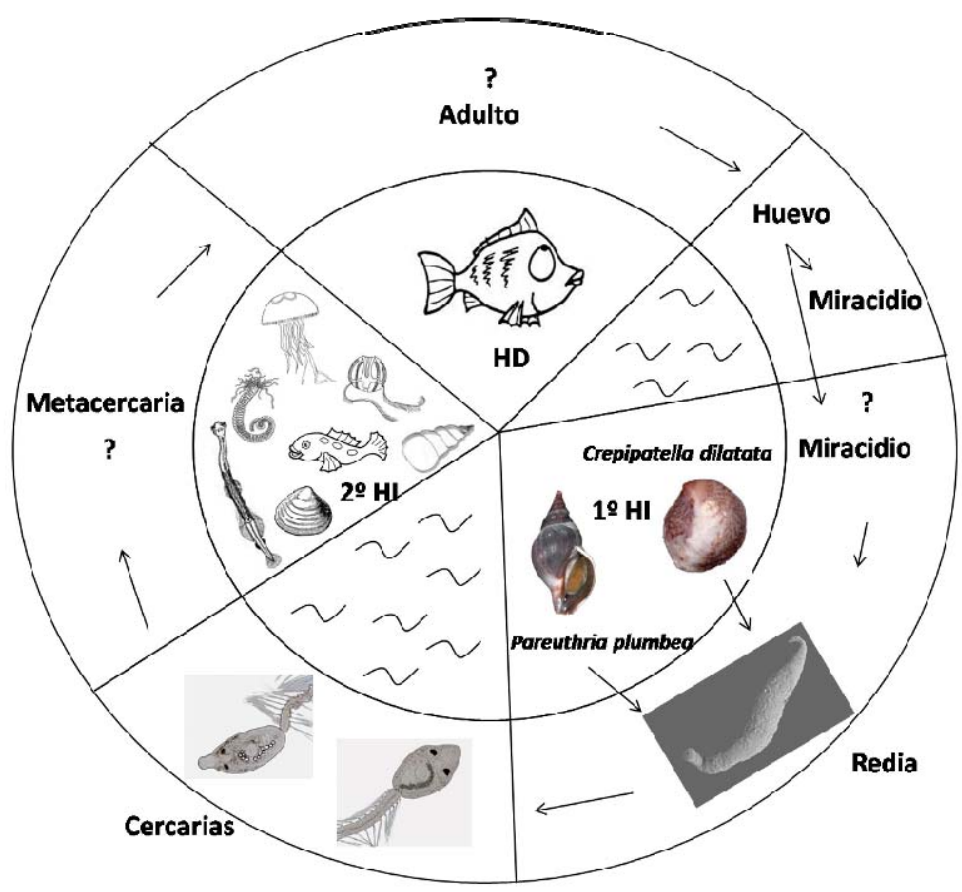

Figura 53. Ciclo de vida de Lepocreadiidae gen. et sp. 1 y Lepocreadiidae gen. et sp. 2. Los dibujos de hospedadores y los estadios larvales indicados con signo de interrogación no se conocen. Abreviaturas: HI- hospedador intermediario; HD- hospedador definitivo. 
Tabla 7. Estadios larvales (en los $1^{\circ}$ hospedadores intermediarios) de la familia Lepocreadiidae reportados en el mundo. Se incluye información de los ciclos de vida conocidos $\left(2^{\circ}\right.$ hospedador intermediario y hospedador definitivo), la localidad y las referencias. Los hospedadores indicados entre corchetes fueron determinados a partir de infecciones experimentales.

\begin{tabular}{|c|c|c|c|c|c|}
\hline Especie & $1^{\circ}$ Hosp. Intermediario & $2^{\circ}$ Hosp. Intermediario & Hosp. Definitivo & Localidad & Referencias \\
\hline $\begin{array}{l}\text { Opechona baciliaris } \\
\text { (Molin, 1859) }\end{array}$ & $\begin{array}{l}\text { Nassarius pygmaeus } \\
\text { (Lamarck) } \\
\text { (Nassariidae) }\end{array}$ & $\begin{array}{l}\text { ctenóforos, quetognatos, } \\
\text { pequeñas medusas y anélidos }\end{array}$ & peces Scombridae & $\begin{array}{l}\text { aguas cálidas y frías en ambos } \\
\text { hemisferios }\end{array}$ & $\begin{array}{l}\text { Køie (1975) } \\
\text { Bray \& Gibson } \\
(1990)\end{array}$ \\
\hline $\begin{array}{l}\text { Cercaria } \\
\text { fascicularis Villot, } \\
1875\end{array}$ & $\begin{array}{l}\text { Nassarius reticulatus } \\
\text { (Linnaeus) } \\
\text { (Nassariidae) }\end{array}$ & desconocido & desconocido & $\begin{array}{l}\text { costa Atlántica Noreste de } \\
\text { Gran Bretaña y Francia }\end{array}$ & Villot (1875) \\
\hline $\begin{array}{l}\text { Lepocreadium album } \\
\text { (Stossich, 1890) }\end{array}$ & $\begin{array}{l}\text { Nassarius mutabilis, } N . \\
\text { reticulatus (Linnaeus), N. } \\
\text { corniculum (Olivi) } \\
\text { (Nassariidae) y Conus } \\
\text { ventricosus (Gmelin) } \\
\text { (Conidae) }\end{array}$ & $\begin{array}{l}\text { Aplysia punctata (Gastropoda), } \\
\text { Ruditapes decussatus y R. aureus } \\
\text { (Bivalvia) }\end{array}$ & [Blennius gattorugine] & $\begin{array}{l}\text { Mar Tirreno, Golfo de } \\
\text { Nápoles, Italia }\end{array}$ & $\begin{array}{l}\text { Palombi (1934, } \\
\text { 1937) } \\
\text { Russell-Pinto } \\
\text { et al. (2006) }\end{array}$ \\
\hline $\begin{array}{l}\text { Lepocreadium } \\
\text { pegorchis (Stossich, } \\
1900 \text { ) }\end{array}$ & $\begin{array}{l}\text { Nassarius mutabilis } \\
\text { (Linnaeus) y N. corniculum } \\
\text { (Olivi) (Nassariidae) }\end{array}$ & $\begin{array}{l}\text { Donax semistristus, Venus gallina, } \\
\text { Spisula substruncata, Mactra } \\
\text { corallina, Acanthocardia } \\
\text { tuberculata (Bivalvia) y [otros } \\
\text { bivalvos y un gasterópodo] }\end{array}$ & $\begin{array}{l}\text { Gobiups microps, Maena } \\
\text { smaris, Sparus auratus, } \\
\text { Pagellus erythrinus y } \\
\text { P.mormyrus }\end{array}$ & costa mediterránea de Francia & $\begin{array}{l}\text { Bartoli (1966, } \\
\text { 1967, 1983) }\end{array}$ \\
\hline $\begin{array}{l}\text { Halorchis } \\
\text { pycnoporus } \\
\text { Stossich, } 1901\end{array}$ & $\begin{array}{l}\text { Barleeia rubra (Adams) } \\
\text { (Barleeidae) }\end{array}$ & $\begin{array}{l}\text { Barleeia rubra (Gastropoda) y } \\
\text { [Parvicardium papillosum] } \\
\text { (Bivalvia) }\end{array}$ & $\begin{array}{l}\text { Diplodus vulgaris, Pagellus } \\
\text { erythrinus, [Diplodus sargus y } \\
\text { D. anularis] }\end{array}$ & costa mediterránea de Francia & $\begin{array}{l}\text { Bartoli \& } \\
\text { Prévot (1978) }\end{array}$ \\
\hline $\begin{array}{l}\text { Opechona pyriforme } \\
\text { (Linton, 1900) }\end{array}$ & $\begin{array}{l}\text { Costoanarchis avara (Say) } \\
\text { (Columbellidae) }\end{array}$ & $\begin{array}{l}\text { Mnemiopsis leidyi (Ctenophora) y } \\
\text { medusas }\end{array}$ & [Stenotomus chrysops] & $\begin{array}{l}\text { Océano Atlántico } \\
\text { Noroeste,Woods Hole, } \\
\text { Massachusetts, Estados } \\
\text { Unidos }\end{array}$ & $\begin{array}{l}\text { Stunkard } \\
(1969)\end{array}$ \\
\hline $\begin{array}{l}\text { Cercaria isoninae } \\
\text { Ito \& Shimura, } \\
1980\end{array}$ & $\begin{array}{l}\text { Japeuthria ferrea (Reeve) } \\
\text { (Buccinidae) }\end{array}$ & desconocido & desconocido & costa de Japón & $\begin{array}{l}\text { Ito \& Shimura } \\
\text { (1980) }\end{array}$ \\
\hline $\begin{array}{l}\text { Lepocreadium } \\
\text { areolatum } \\
\text { (Linton, 1900) }\end{array}$ & $\begin{array}{l}\text { Ilyanassa triviatta (Say) } \\
\text { (Nassariidae) }\end{array}$ & ctenóforos y medusas & $\begin{array}{l}\text { Morone americana, } \\
\text { Tautoglabrus adspesus y } \\
\text { Menticirrhus saxatilis }\end{array}$ & $\begin{array}{l}\text { Océano Atlántico Noroeste, } \\
\text { Woods Hole, Massachusetts, } \\
\text { Estados Unidos }\end{array}$ & $\begin{array}{l}\text { Stunkard } \\
(1980 a, 1983)\end{array}$ \\
\hline
\end{tabular}


Tabla 7 (continuación I). Estadios larvales (en los $1^{\circ}$ hospedadores intermediarios) de la familia Lepocreadiidae reportados en el mundo. Se incluye información de los ciclos de vida conocidos $\left(2^{\circ}\right.$ hospedador intermediario y hospedador definitivo), la localidad y las referencias. Los hospedadores indicados entre corchetes fueron determinados a partir de infecciones experimentales.

\begin{tabular}{|c|c|c|c|c|c|}
\hline Especie & $1^{\circ}$ Hosp. Intermediario & $2^{\circ}$ Hosp. Intermediario & Hosp. Definitivo & Localidad & Referencias \\
\hline $\begin{array}{l}\text { Lepocreadium } \\
\text { setiferoides } \\
\text { (Miller \& } \\
\text { Northup,1926) }\end{array}$ & $\begin{array}{l}\text { Ilyanassa obsoleta (Say) } \\
\text { (Nassariidae) }\end{array}$ & $\begin{array}{l}\text { turbelarios triclados y poliquetos } \\
\text { espiónidos }\end{array}$ & lenguados & $\begin{array}{l}\text { Océano Atlántico Noroeste, Woods } \\
\text { Hole, Massachusetts, USA) }\end{array}$ & $\begin{array}{l}\text { Miller \& Northup } \\
(1926) \\
\text { Martin (1938) } \\
\text { Stunkard (1970, } \\
\text { 1983) }\end{array}$ \\
\hline $\begin{array}{l}\text { Cercaria caribbea } \\
\text { LXV } \\
\text { Cable, } 1963\end{array}$ & $\begin{array}{l}\text { Parvanachis obesa (Adams) } \\
\text { (Columbellidae) }\end{array}$ & desconocido & desconocido & Mar Caribe & Cable (1963) \\
\hline $\begin{array}{l}\text { Cercaria caribbea } \\
\text { LXVI } \\
\text { Cable, } 1963\end{array}$ & $\begin{array}{l}\text { Nassarius vibex (Say) } \\
\text { (Nassariidae) }\end{array}$ & desconocido & desconocido & Mar Caribe & Cable (1963) \\
\hline $\begin{array}{l}\text { Cercaria caribbea } \\
\text { LXVII } \\
\text { Cable, } 1963\end{array}$ & $\begin{array}{l}\text { Caecum cornucopiae } \\
\text { (Carpenter) (Caecidae) }\end{array}$ & desconocido & desconocido & Mar Caribe & Cable (1963) \\
\hline $\begin{array}{l}\text { Cercaria } \\
\text { sebastopoli } \\
\text { Dolgikh,1965 }\end{array}$ & $\begin{array}{l}\text { Nassarius reticulatus } \\
\text { (Linnaeus) (Nassariidae) }\end{array}$ & desconocido & desconocido & Mar Negro & Køie (1975) \\
\hline $\begin{array}{l}\text { Cercaria levantina } \\
\text { Lengy \& Shchory, } \\
1970\end{array}$ & $\begin{array}{l}\text { Nassarius circumcintus } \\
\text { (Adams) (Nassariidae) }\end{array}$ & desconocido & desconocido & costa mediterránea de Israel & Køie (1975) \\
\hline $\begin{array}{l}\text { Cercaria cythari } \\
\text { Dolgikh, } 1970\end{array}$ & $\begin{array}{l}\text { Cytharella rugulosa } \\
\text { (Philippi) (Turridae) }\end{array}$ & desconocido & desconocido & Mar Negro & Køie (1975) \\
\hline $\begin{array}{l}\text { Tetracerasta blepta } \\
\text { Watson, } 1984\end{array}$ & $\begin{array}{l}\text { Posticobia brazieri (Smith) } \\
\text { (Hydrobiidae) }\end{array}$ & $\begin{array}{l}\text { Gobiomorphus y Hypseleotris spp. } \\
\text { (Actinopterygii) y renacuajos de } \\
\text { rana de árbol }\end{array}$ & $\begin{array}{l}\text { Anguilla } \\
\text { reinhardtii }\end{array}$ & Ríos Brisbane y Richmond, Australia & Watson (1984) \\
\hline $\begin{array}{l}\text { Stegodexamene } \\
\text { callista } \\
\text { Watson, } 1984\end{array}$ & $\begin{array}{l}\text { Posticobia brazieri (Smith) } \\
\text { (Hydrobiidae) }\end{array}$ & $\begin{array}{l}\text { Retropinna, Craterocephalus, } \\
\text { Pseudomugiland Ambasszs }\end{array}$ & $\begin{array}{l}\text { Anguilla } \\
\text { reinhardtii }\end{array}$ & Ríos Brisbane y Richmond, Australia & Watson (1984) \\
\hline $\begin{array}{l}\text { Lepidapedon } \\
\text { elongatum } \\
\text { (Lebour, 1908) }\end{array}$ & $\begin{array}{l}\text { Onoba aculeus (Gould) } \\
\text { (Rissoidae) }\end{array}$ & $\begin{array}{l}\text { poliquetos, moluscos y [Ophiura } \\
\text { albida] (Ophiuroidea) }\end{array}$ & $\begin{array}{l}\text { Gadus morbua y } \\
\text { G. ogac }\end{array}$ & costa de Orensud, & Køie (1985) \\
\hline $\begin{array}{l}\text { Cercaria mihi } 11 \\
\text { Ching, } 1991\end{array}$ & $\begin{array}{l}\text { Astyris carinata (Hinds) } \\
\text { (Columbellidae) }\end{array}$ & desconocido & desconocido & Océano Pacífico Noreste & Ching (1991) \\
\hline
\end{tabular}

\section{$\underset{+}{\breve{\omega}}$}


Tabla 7 (continuación II). Estadios larvales (en los $1^{\circ}$ hospedadores intermediarios) de la familia Lepocreadiidae reportados en el mundo. Se incluye información de los ciclos de vida conocidos $\left(2^{\circ}\right.$ hospedador intermediario y hospedador definitivo), la localidad y las referencias. Los hospedadores indicados entre corchetes fueron determinados a partir de infecciones experimentales.

\begin{tabular}{|c|c|c|c|c|c|}
\hline Especie & $1^{\circ}$ Hosp. Intermediario & $2^{\circ}$ Hosp. Intermediario & Hosp. Definitivo & Localidad & Referencias \\
\hline $\begin{array}{l}\text { Opechona cablei } \\
\text { (Stunkard, 1980) }\end{array}$ & $\begin{array}{l}\text { Astyris lunata (Say) } \\
\text { (Columbellidae) }\end{array}$ & ctenóforos y medusas & $\begin{array}{l}\text { [Stenotomus } \\
\text { chrysops] }\end{array}$ & $\begin{array}{l}\text { Océano Atlántico Noroeste, } \\
\text { Woods Hole, Massachusetts, } \\
\text { Estados Unidos }\end{array}$ & $\begin{array}{l}\text { Stunkard (1980b, } \\
1983)\end{array}$ \\
\hline $\begin{array}{l}\text { Lepocreadiidae gen. } \\
\text { et sp. }\end{array}$ & $\begin{array}{l}\text { Crassostrea gigas } \\
\text { (Thunberg) (Ostreidae) }\end{array}$ & desconocido & desconocido & Estuario Exe, Inglaterra & $\begin{array}{l}\text { Aguirre-Macedo \& } \\
\text { Kennedy (1999) }\end{array}$ \\
\hline $\begin{array}{l}\text { Diploproctodaeum } \\
\text { arothroni } \\
\text { Bray \& Nahhas, } \\
1998\end{array}$ & $\begin{array}{l}\text { Crassostrea cuccullata } \\
\text { (Born) (Ostreidae) }\end{array}$ & enquista en la vegetación & Arothron hispidus & Golfo de Aqaba, costa de Egipto & Hassanine (2006) \\
\hline $\begin{array}{l}\text { Opechona sp. } \\
\text { Averbuj \& } \\
\text { Cremonte, } 2010 \\
\end{array}$ & $\begin{array}{l}\text { Buccinanops monilifer } \\
\text { (Kiener) y B. cochlidium } \\
\text { (Dilwyn) (Nassariidae) } \\
\end{array}$ & ctenóforos y medusas & desconocido & Golfo San José, Argentina & $\begin{array}{l}\text { Martorelli (1991) } \\
\text { Averbuj \& } \\
\text { Cremonte (2010) }\end{array}$ \\
\hline $\begin{array}{l}\text { Stegodexamene } \\
\text { anguillae }\end{array}$ & $\begin{array}{l}\text { Potamopyrous antipodarum } \\
\text { (Gray) (Tateidae) }\end{array}$ & $\begin{array}{l}\text { Gobiomorphus y Galaxias spp. } \\
\text { (Actinopterygii) }\end{array}$ & $\begin{array}{l}\text { Anguilla } \\
\text { dieffenbachii y A. } \\
\text { australis }\end{array}$ & Isla del Sur, Nueva Zelanda & MacFarlane (1951) \\
\hline $\begin{array}{l}\text { Lepocreadiidae gen. } \\
\text { et sp. } 1\end{array}$ & $\begin{array}{l}\text { Crepipatella dilatata } \\
\text { (Lamarck) (Calyptraeidae) }\end{array}$ & desconocido & desconocido & $\begin{array}{l}\text { costa de Puerto Deseado, } \\
\text { Argentina }\end{array}$ & presente estudio \\
\hline $\begin{array}{l}\text { Lepocreadiidae gen. } \\
\text { et sp. } 2\end{array}$ & $\begin{array}{l}\text { Pareuthria plumbea } \\
\text { (Phillipi) (Buccinidae) }\end{array}$ & desconocido & desconocido & $\begin{array}{l}\text { costa de Puerto Deseado, } \\
\text { Argentina }\end{array}$ & presente estudio \\
\hline
\end{tabular}




\subsubsection{Diphterostomum sp. y Zoogonus sp. (Zoogonidae)}

Los digeneos de la familia Zoogonidae Odhner, 1902 son parásitos intestinales de peces teleósteos marinos y están representados por una gran cantidad de especies (Bray, 2008). Hasta el momento han sido descriptos seis cercarias y sólo cuatro ciclos de vida (Tabla 8).

Diversas familias de gasterópodos (i.e. Nassariidae, Buccinidae, Columbellidae y Cardiidae) actúan como $1^{\circ} \mathrm{HI}$ de digeneos de esta familia. Zoogonus rubelus, Zoogonoides laevis y Zoogonoides viviparus pueden utilizar poliquetos, gasterópodos o equinodermos como $2^{\circ} \mathrm{HI}$ (Stunkard, 1938, 1940; Køie, 1976; Curtis 2007). Diphterostomum brusinae utiliza una especie de crinoideo y dos especies de bivalvos como $2^{\circ} \mathrm{HI}$ y puede enquistar en la vegetación o enquistar dentro de los esporocistos en el gasterópodo que actúa como $1^{\circ} \mathrm{HI}$ (Palombi, 1930; Prévot, 1966; Pina et al., 2009).

En la costa patagónica se han registrado dos adultos del género Diphterostomum, uno en el turco Pinguipes brasilianus (Timi et al., 2008) que fue erróneamente identificado como Opecoelidae gen. et sp. y luego fue redescripto como D. brusinae por Gilardoni et al. (2011) y otro en los pejerreyes Odontesthes smitti y Odontesthes nigricans descriptos por Carballo (2006). Los estadios larvales de Diphterostomum sp. hallados en Buccinanops globulosus presentaron secuencias moleculares idénticas (región ITS2) a los adultos en P. brasilianus. Dichos adultos son morfológicamente similares a D. brusinae, sin embargo, una comparación de las secuencias moleculares (ITS2) de D. brusinae y el adulto del turco revelaron que esta última sería una nueva especie.

Los turcos son peces depredadores que se alimentan de una amplia variedad de presas en zonas de arrecife. En su dieta predominan organismos herbívoros (erizos y gasterópodos) y moluscos filtradores, principalmente el bivalvo mitílido Aulacomya atra (Molina) (Galván et al., 2009). Los gasterópodos B. globulosus habitan fondos arenosos a poca profundidad en las costas de Puerto Madryn, en cuyas cercanías existen varios arrecifes que albergan turcos (Irigoyen \& Galván, 2009). Estos gasterópodos actuarían como $1^{\circ}$ y $2^{\circ} \mathrm{HI}$ de Diphterostomum sp., ya que se hallaron metacercarias dentro de los esporocistos. Sin embargo, es posible que 
exista otra especie de invertebrado que actúe como $2^{\circ} \mathrm{HI}$, teniendo en cuenta que se obtuvieron emisiones de cercarias en el laboratorio y la cercaria presenta estilete (Fig. 54). Es probable que el invertebrado que cumpla este rol se localice cerca de los gasterópodos, puesto que la cercaria no posee cola, por lo que su desplazamiento es limitado. El bivalvo más abundante de la zona es Tellina petitiana d'Orbigny (Tellinidae) (Hernández et al., 2008). Futuras disecciones de estos bivalvos y otros invertebrados de la zona (poliquetos, erizos) contribuirán a dilucidar este ciclo de vida.

Zoogonus sp. se registró sólo en una ocasión en el gasterópodo Pareuthria plumbea en Puerto Deseado. Es probable que su prevalencia sea mayor en gasterópodos submareales. Futuras disecciones de invertebrados (poliquetos, bivalvos, equinodermos) y peces de la zona contribuirán a dilucidar su ciclo de vida (Fig. 55).

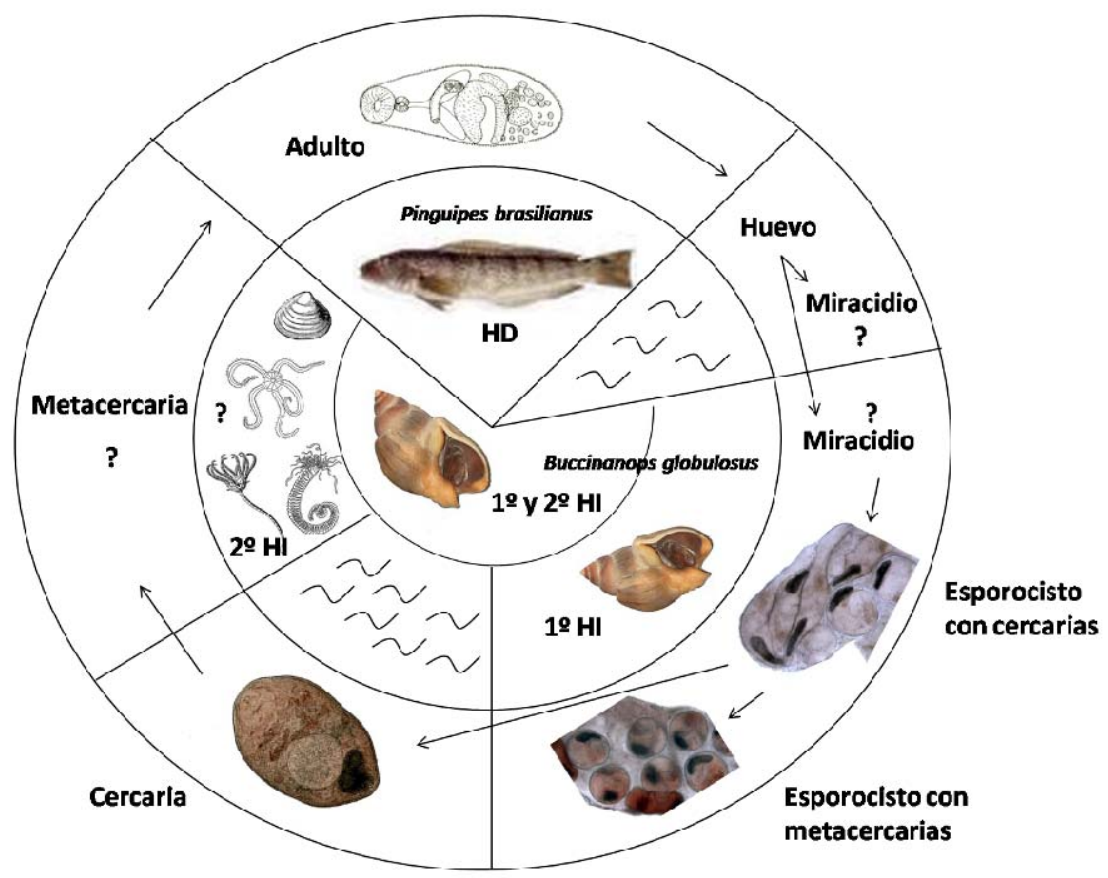

Figura 54. Ciclo de vida de Diphterostomum sp. (Zoogonidae). Los dibujos de hospedadores y los estadios larvales indicados con signo de interrogación no se conocen. Abreviaturas: HI- hospedador intermediario; HD- hospedador definitivo. 


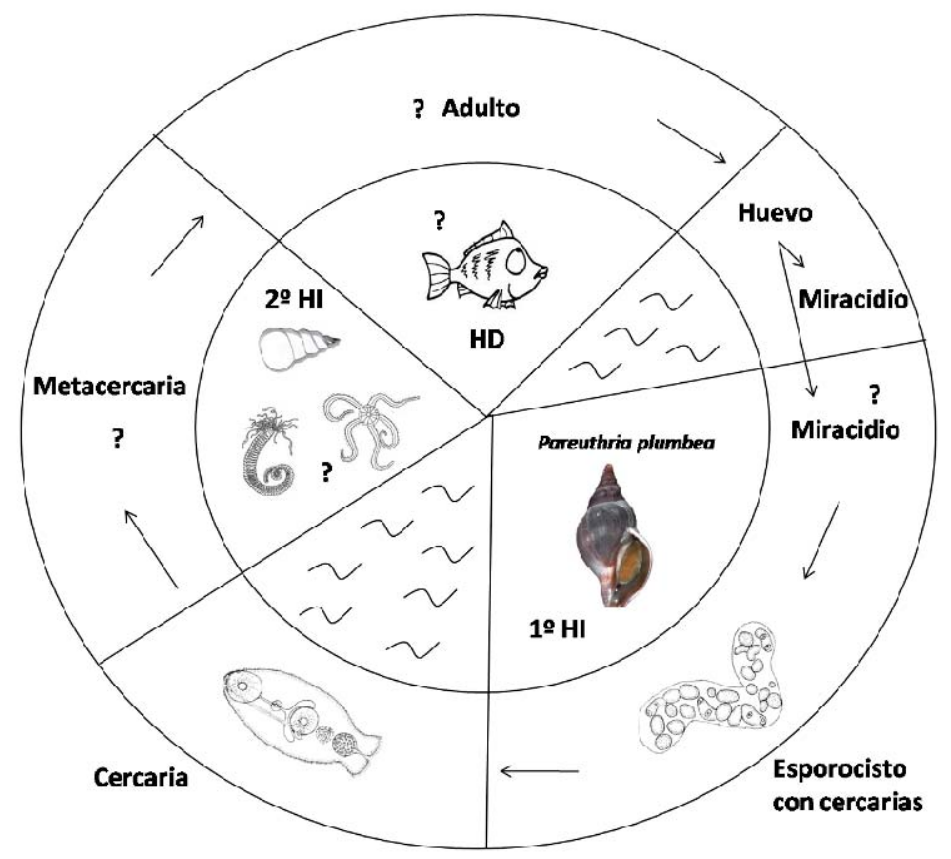

Figura 55. Ciclo de vida de Zoogonus sp. (Zoogonidae). Los dibujos de hospedadores y los estadios larvales indicados con signo de interrogación no se conocen. Abreviaturas: HI- hospedador intermediario; HD- hospedador definitivo. 
Tabla 8. Estadios larvales (en los $1^{\circ}$ hospedadores intermediarios) de la familia Zoogonidae reportados en el mundo. Se incluye información de los ciclos de vida conocidos $\left(2^{\circ}\right.$ hospedador intermediario y hospedador definitivo), la localidad y las referencias. Los hospedadores indicados entre corchetes fueron determinados a partir de infecciones experimentales.

\begin{tabular}{|c|c|c|c|c|c|}
\hline Especie & $1^{\circ}$ Hosp. Intermediario & $2^{\circ}$ Hosp. Intermediario & Hosp. Definitivo & Localidad & Referencias \\
\hline $\begin{array}{l}\text { Zoogonus rubellus } \\
\text { (Olson, 1868) }\end{array}$ & $\begin{array}{l}\text { Ilyanassa obsoleta } \\
\text { (Say) (Nassariidae) }\end{array}$ & $\begin{array}{l}\text { Nereis virens (Polychaeta) } \\
\text { [Notoacmea intestinalis] } \\
\text { (Gastropoda) }\end{array}$ & $\begin{array}{l}\text { Anguilla rostrata, Opsanus } \\
\text { tau y otros peces. } \\
\text { [Tautoga onitis] }\end{array}$ & $\begin{array}{l}\text { Océano Atlántico } \\
\text { Noroeste,Woods Hole, } \\
\text { Massachusetts, Estados Unidos } \\
\text { costa de Roscoff, Francia }\end{array}$ & $\begin{array}{l}\text { Stunkard (1938) } \\
\text { Curtis (2007) }\end{array}$ \\
\hline $\begin{array}{l}\text { Zoogonoides laevis } \\
\text { Linton, } 1940\end{array}$ & $\begin{array}{l}\text { Astyris lunata } \\
\text { (Say) } \\
\text { (Columbellidae) }\end{array}$ & Nereis virens (Polychaeta) & Tautoga onitis & $\begin{array}{l}\text { Océano Atlántico Noroeste, } \\
\text { Woods Hole, Massachusetts, } \\
\text { Estados Unidos }\end{array}$ & Stunkard (1940) \\
\hline $\begin{array}{l}\text { Zoogonoides viviparous } \\
\text { (Olsson, 1868) } \\
\text { Odhner, } 1902\end{array}$ & $\begin{array}{l}\text { Buccinum undatum } \\
\text { (Linnaeus) (Buccinidae) }\end{array}$ & $\begin{array}{l}\text { Trochochaeta multisetosa } \\
\text { (Polychaeta) } \\
\text { Ophiura albida } \\
\text { (Ophiuroidea); otros } \\
\text { poliquetos y ophiuridos }\end{array}$ & $\begin{array}{l}\text { leguados y otros peces } \\
\text { planos }\end{array}$ & Océano Atlántico Norte & Køie (1976) \\
\hline $\begin{array}{l}\text { Cercaria crispata } \\
\text { Pelseneer, } 1906\end{array}$ & $\begin{array}{l}\text { Euspira nitida (Donovan) } \\
\text { (Naticidae) }\end{array}$ & desconocido & desconocido & costa de Bolougne, Francia & $\begin{array}{l}\text { Madhavi \& } \\
\text { Shameem (1991) }\end{array}$ \\
\hline $\begin{array}{l}\text { Cercaria brachycaeca } \\
\text { Shimura \& Ito, } 1980\end{array}$ & $\begin{array}{l}\text { Turbo (Batillus) cornutus } \\
\text { Lightfoot (Turbinidae) }\end{array}$ & desconocido & desconocido & costa de Japón & $\begin{array}{l}\text { Shimura \& Ito } \\
(1980)\end{array}$ \\
\hline Cercaria chilkaensis II & $\begin{array}{l}\text { Nassarius orissaensis (Preston) } \\
\text { (Nassariidae) }\end{array}$ & desconocido & desconocido & costa de Orissa, India & $\begin{array}{l}\text { Madhavi \& } \\
\text { Shameem (1991) }\end{array}$ \\
\hline Zoogonus sp. & $\begin{array}{l}\text { Pareuthria plumbea (Philippi) } \\
\text { (Buccinidae) }\end{array}$ & desconocido & desconocido & $\begin{array}{l}\text { costa de Puerto Deseado, } \\
\text { Argentina }\end{array}$ & presente estudio \\
\hline
\end{tabular}


Tabla 8 (continuación). Estadios larvales (en los $1^{\circ}$ hospedadores intermediarios) de la familia Zoogonidae reportados en el mundo. Se incluye información de los ciclos de vida conocidos $\left(2^{\circ}\right.$ hospedador intermediario y hospedador definitivo), la localidad y las referencias. Los hospedadores indicados entre corchetes fueron determinados a partir de infecciones experimentales.

\begin{tabular}{|c|c|c|c|c|c|}
\hline Especie & $1^{\circ}$ Hosp. Intermediario & $2^{\circ}$ Hosp. Intermediario & Hosp. Definitivo & Localidad & Referencias \\
\hline $\begin{array}{l}\text { Diphterostomum } \\
\text { brusinae } \\
\text { (Stossich, 1904) }\end{array}$ & $\begin{array}{l}\text { Nassarius sufflatus (Gould), } \\
\text { Nassarius reticulatus } \\
\text { (Linnaeus), Cyclope pellucida } \\
\text { (Risso) (Nassariidae), Euspira } \\
\text { nitida (Donovan) (Naticidae), } \\
\text { Cerastoderma edule (Linnaeus) } \\
\text { (Cardiidae), }\end{array}$ & $\begin{array}{l}\text { ciclo abreviado (enquista } \\
\text { en el } 1^{\circ} \mathrm{HI} \text { ) } \\
\text { Antedon mediterránea } \\
\text { (Crinoidea) } \\
\text { Chamelea gallina, Spisula } \\
\text { subtruncata (Bivalvia) } \\
\text { Enquista en la vegetación }\end{array}$ & $\begin{array}{l}\text { peces Sparidae, Gobiidae, } \\
\text { Labridae, Bleniidae }\end{array}$ & $\begin{array}{l}\text { Mar Mediterráneo, Mar Negro, } \\
\text { costa de Portugal }\end{array}$ & $\begin{array}{l}\text { Palombi (1930) } \\
\text { Prévot (1966) } \\
\text { Pina et al. (2009) }\end{array}$ \\
\hline Diphterostomum sp. & $\begin{array}{l}\text { Buccinanops globulosus (Kiener) } \\
\text { (Nassariidae) }\end{array}$ & desconocido & desconocido & Península Valdés, Argentina & $\begin{array}{l}\text { Gilardoni et al. } \\
\text { (2011) } \\
\text { Bagnato (2012) }\end{array}$ \\
\hline
\end{tabular}




\subsubsection{Digeneos larvales que finalizan su ciclo de vida en aves}

\subsubsection{Gymnophalloides nacellae (Gymnophallidae)}

Los digeneos de la familia Gymnophallidae Odhner, 1905 constituyen un grupo pequeño y homogéneo de digeneos marinos que finalizan su ciclo de vida principalmente en aves Charadriiformes y Anseriifornes (Bartoli, 1974; Scholz, 2002). Moluscos bivalvos son los principales $1^{\circ} \mathrm{HI}$; la metacercaria nunca enquista y utiliza, en la mayoría de los casos, la misma u otra especie de bivalvo como $2^{\circ} \mathrm{HI}$. En algunos casos las metacercarias pueden desarrollarse en gasterópodos, braquiópodos o poliquetos (Bartoli, 1974; Ching, 1995).

Hasta el momento se conocen tres metacercarias del género Gymnophalloides y en ningún caso se dilucidó el ciclo de vida completo (Tabla 9). Gymnophalloides tokiensis sería sinónimo de G. seoi (Lee \& Chai, 2001). No se conoce su $1^{\circ} \mathrm{HI}$ y sólo se registró una especie de gasterópodo como $2^{\circ} \mathrm{HI}$ (Ching, 1995). Gymnophalloides seoi es parásito del ostrero Haematopus ostralegus Linnaeus (Haematopodidae), aunque también se conoce un caso de pancreatitis producido por este digeneo en una mujer en Korea, y G. heardi se reportó en la rata Oryzomys palustris (Harlan) (Lee et al., 1993; Ryang et al., 2000; Lee \& Chai, 2001).

En Argentina se reportaron varias especies de la familia Gymnophallidae, de las cuales se conoce en forma completa un único ciclo de vida (Cremonte, 2004). Bartolius pierrei utiliza al bivalvo Darina solenoides como $1^{\circ}$ y $2^{\circ} \mathrm{HI}$. Gymnophallus australis Szidat, 1962 utiliza a los bivalvos mitílidos Mytilus edulis, Perumytilus purpuratus (Lamarck) y Aulacomya atra como $2^{\circ} \mathrm{HI}$ y se desconoce el $1^{\circ} \mathrm{HI}$. Ambas especies utilizan como hospedador definitivo a la gaviota cocinera L. dominicanus (Cremonte, 2001; 2004, Cremonte et al., 2008; Diaz et al., 2011). Por otra parte, varios estadios larvales han sido registrados en la costa patagónica; esporocistos y cercarias de tres especies de Gymnophallidae en Lasaea adansoni (Gmelin) (Lasaeidae), Gaimardia trapesina (Lamarck) (Gaimardiidae) y Neolepton cobbi (Cooper \& Preston) (Neoleptoneidae) y metacercarias de seis especies en L. adansoni (1), G. trapesina (2), N. cobbi (2) y Brachidontes rodriguezi (1) (d'Orbigny) (Mytilidae) (Cremonte, 1999; Ituarte et al., 2001, 2005; Presta et al., 2013; datos no publicados). 
Los esporocistos y cercarias de G. nacellae fueron recientemente hallados en el bivalvo G. trapesina (datos no publicados). Se secuenciaron los esporocistos y dichas secuencias (ITS1) resultaron ser idénticas a las de G. nacellae halladas en Nacella (P.) magellanica. Este bivalvo, que actúa como $1^{\circ} \mathrm{HI}$, habita próximo a la costa, sobre las frondas del alga Macrocystis pyrifera (Linnaeus) Agardh (Laminariaceae), teniendo una mayor cercanía con las lapas $N$. $(P)$ magellanica que se encuentran en el intermareal inferior y que actúan como únicos $2^{\circ} \mathrm{HI}$. Es probable que la gaviota cocinera, L. dominicanus, o el ostrero negro Haematopus ater Vieillot \& Oudart (Charadriidae) actúen como hospedadores definitivos de esta especie, ya que se conoce que se alimentan de lapas (Yorio \& Bertellotti, 2002; Sapoznikow et al., 2008). Nacella $(P$.$) magellanica \left(2^{\circ} \mathrm{HI}\right)$ es una lapa de gran tamaño que se adhiere fuertemente al sustrato, por lo que es inaccesible para otras aves como patos o playeros que presentan picos de menor potencia u otro régimen alimenticio (Fig. 56). Posteriores disecciones de aves en Puerto Deseado contribuirán a dilucidar el ciclo de vida de este digeneo.

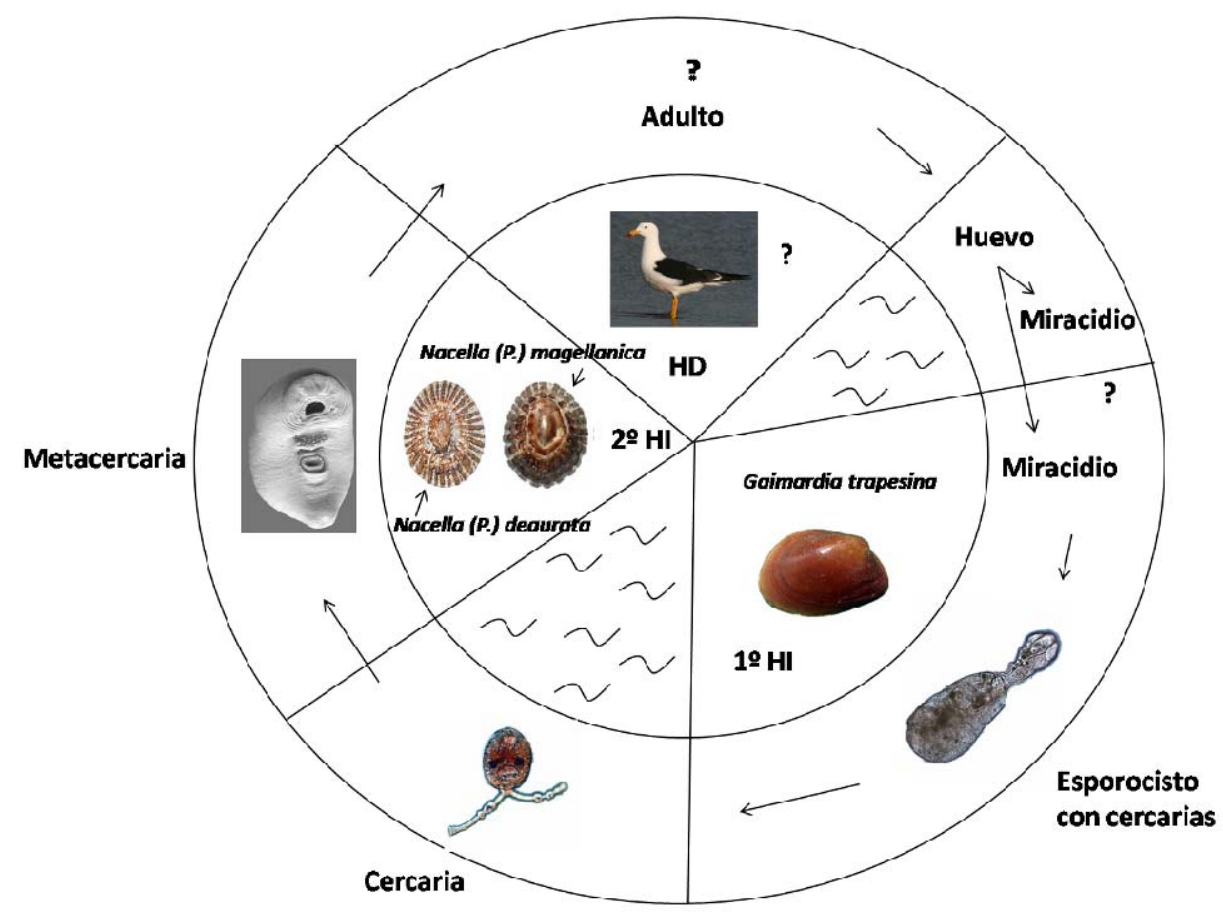

Figura 56. Ciclo de vida de Gymnophalloides nacellae (Gymnophallidae). Los dibujos de hospedadores y los estadios larvales indicados con signo de interrogación no se conocen. Abreviaturas: HI- hospedador intermediario; HD- hospedador definitivo. 
Tabla 9. Estadios larvales (metacercarias en el $2^{\circ}$ hospedador intermediarios) del género Gymnophalloides (Gymnophallidae) reportados en el mundo. Se incluye información de los ciclos de vida conocidos $\left(1^{\circ}\right.$ hospedador intermediario y hospedador definitivo), la localidad y las referencias. Los hospedadores indicados entre corchetes fueron determinados a partir de infecciones experimentales.

\begin{tabular}{|c|c|c|c|c|c|}
\hline Especie & $\begin{array}{l}1^{\circ} \text { Hosp. } \\
\text { Intermediario }\end{array}$ & $\begin{array}{l}2^{\circ} \text { Hosp. } \\
\text { Intermediario }\end{array}$ & Hosp. Definitivo & Localidad & Referencias \\
\hline $\begin{array}{l}\text { Gymnophalloides } \\
\text { tokiensis } \\
\text { Fujita, } 1925\end{array}$ & desconocido & $\begin{array}{l}\text { Crassostrea gigas } \\
\text { (Bivalvia) }\end{array}$ & desconocido & $\begin{array}{l}\text { Bahía Tokio, } \\
\text { Japón }\end{array}$ & Fujita (1925) \\
\hline $\begin{array}{l}\text { Gymnophalloides } \\
\text { seoi } \\
\text { Lee, Chai \& Hong, } \\
1993\end{array}$ & desconocido & $\begin{array}{l}\text { Crassostrea gigas } \\
\text { (Bivalvia) }\end{array}$ & $\begin{array}{l}\text { Homo sapiens, } \\
\text { Haematopus } \\
\text { ostralegus, } \\
\text { [Charadrius } \\
\text { alexandrines, } \\
\text { hámster, gatos, } \\
\text { ratones y } \\
\text { lauchas] }\end{array}$ & $\begin{array}{l}\text { costa de } \\
\text { Korea }\end{array}$ & $\begin{array}{l}\text { Lee } \text { et al. } \\
(1993) \\
\text { Lee \& Chai } \\
(2001)\end{array}$ \\
\hline $\begin{array}{l}\text { Gymnophalloides } \\
\text { heardi } \\
\text { Ching, } 1995\end{array}$ & desconocido & $\begin{array}{l}\text { Melampus } \\
\text { bidentatus } \\
\text { (Gastropoda) }\end{array}$ & $\begin{array}{l}\text { Oryzomys } \\
\text { palustris }\end{array}$ & $\begin{array}{l}\text { costa de } \\
\text { Florida, USA }\end{array}$ & Ching (1995) \\
\hline $\begin{array}{l}\text { Gymnophalloides } \\
\text { nacellae } \\
\text { Cremonte, Pina, } \\
\text { Gilardoni, } \\
\text { Rodrigues, Chai \& } \\
\text { Ituarte, } 2013\end{array}$ & $\begin{array}{l}\text { Gaimardia } \\
\text { trapesina } \\
\text { (Lamarck) } \\
\text { (Gaimardiidae) }\end{array}$ & $\begin{array}{l}\text { Nacella }(P .) \\
\text { magellanica y } N . \\
(P .) \text { deaurata } \\
\text { (Gastropoda) }\end{array}$ & desconocido & $\begin{array}{l}\text { costas de } \\
\text { Puerto } \\
\text { Deseado y } \\
\text { Usuahia, } \\
\text { Argentina }\end{array}$ & $\begin{array}{l}\text { Martorelli \& } \\
\text { Morriconi } \\
\text { (1998) } \\
\text { Cremonte et } \\
\text { al. (2013) }\end{array}$ \\
\hline
\end{tabular}




\subsubsection{Maritrema sp. 1 y Maritrema madrynense (Microphallidae)}

Las especies del género Maritrema Nicoll, 1907 son parásitos cuyos hospedadores definitivos son aves marinas, aunque pueden hallarse también en mamíferos; utilizan gasterópodos como $1^{\circ} \mathrm{HI}$ y principalmente crustáceos como $2^{\circ} \mathrm{HI}$ (Deblock, 1971; Yamaguti, 1971, 1975).

Hasta el momento se han registrado doce larvas de este género en sus $1^{\circ}$ hospedadores intermediarios (Tabla 10) de los cuales tres son registros realizados en Argentina. Maritrema orensense Cremonte \& Martorelli, 1998 y Maritrema bonaerense Etchegoin \& Martorelli, 1997 utilizan al gasterópodo Heleobia australis como $1^{\circ} \mathrm{HI}$, a los cangrejos Neohelice granulata (Dana) y Cyrtograpsus angulatus Dana (Varunidae) como $2^{\circ} \mathrm{HI}$ y a las gaviotas Larus atlanticus Olrog y Larus dominicanus (Laridae) como hospedador definitivo en lagunas y estuarios de la provincia de Buenos Aires (Cremonte \& Martorelli, 1998; Etchegoin \& Martorelli, 1997; Alda et al., 2013). Una cercaria marina de esta especie se registró por primera vez en Argentina en Siphonaria lessonii y Kerguelenella lateralis en Comodoro Rivadavia (Alda \& Martorelli, 2009), posteriormente en Playa Fracasso, Golfo San José (Bagnato, 2012), en Puerto Madryn (Gilardoni et al., 2011) y en Puerto Deseado (presente trabajo). Adicionalmente, se registró una metacercaria del género Maritrema en el isópodo Exosphaeroma sp. en Comodoro Rivadavia (Alda \& Martorelli, 2009) y se conocen dos adultos de Maritrema en el área de estudio, Maritrema madrynense Diaz \& Cremonte, 2010 y Maritrema formicae Diaz, Gilardoni \& Cremonte, 2012 parasitando a la gaviota cocinera L. dominicanus (Diaz \& Cremonte, 2010; Diaz et al., 2012). 
Tabla 10. Estadios larvales (en el $1^{\circ}$ hospedador intermediario) del género Maritrema (Microphallidae) reportados en el mundo. Se incluye información de los ciclos de vida conocidos $\left(2^{\circ}\right.$ hospedador intermediario y hospedador definitivo), la localidad y las referencias. Los hospedadores indicados entre corchetes fueron determinados a partir de infecciones experimentales.

\begin{tabular}{|c|c|c|c|c|c|}
\hline Especie & $1^{\circ}$ Hosp. Intermediario & $2^{\circ}$ Hosp. Intermediario & Hosp. Definitivo & Localidad & Referencias \\
\hline $\begin{array}{l}\text { Maritrema } \\
\text { rhodanicum } \\
\text { Carrére, } 1936\end{array}$ & $\begin{array}{l}\text { Paludestrina acuta Drap, } \\
\text { Pseudamnicola similis } \\
\text { (Draparnaud) } \\
\text { (Hydrobiidae) }\end{array}$ & Gammarus pulex (Malacostraca) & $\begin{array}{l}\text { Larus argentatus var. } \\
\text { michahellesii y anátidos }\end{array}$ & costa de Francia & $\begin{array}{l}\text { Yamaguti } \\
(1975)\end{array}$ \\
\hline $\begin{array}{l}\text { Maritrema arenaria } \\
\text { Hadley \& Castle, } \\
1940\end{array}$ & $\begin{array}{l}\text { Littorina saxatilis (Olivi) } \\
\text { (Littorinidae) }\end{array}$ & Balanus balanides (Maxillopoda) & [Larus argenteus] & costa de Gran Bretaña & $\begin{array}{l}\text { Yamaguti } \\
(1975) \\
\text { Popiel (1976) }\end{array}$ \\
\hline $\begin{array}{l}\text { Maritrema eroliae } \\
\text { Yamaguti, } 1939\end{array}$ & Clypeomorus bifasciata & $\begin{array}{l}\text { Scopimera globosa, S. pusilla y Xantho } \\
\text { exaratus (Malacostraca) }\end{array}$ & [ratones] & $\begin{array}{l}\text { costa de Urayasu, Chiba } \\
\text { Prefecture, Japón }\end{array}$ & $\begin{array}{l}\text { Yamaguti } \\
\text { (1975) } \\
\text { Al Kandari et } \\
\text { al. (2011) }\end{array}$ \\
\hline $\begin{array}{l}\text { Maritrema } \\
\text { subdolum } \\
\text { Jägerskiöld, } 1908\end{array}$ & $\begin{array}{l}\text { Paludestrina stagnalis } \\
\text { (Baster), } \\
\text { Ventriosa ventrosa } \\
\text { (Montagu), H. acuta } \\
\text { (Draparnaud) y Hydrobia } \\
\text { ulvae (Hydrobiidae) }\end{array}$ & $\begin{array}{l}\text { Gammarus locusta, Sphaeroma hoockeri, S. } \\
\text { serratus, Orchestia gamarella, Carcinus moena, } \\
\text { Corophium arenarium (Malacostraca) y } \\
\text { ocasionalmente Paludestrina stagnalis (ciclo } \\
\text { abreviado) }\end{array}$ & $\begin{array}{l}\text { [ratones, pollitos, Larus } \\
\text { argentatus var. michaellis] } \\
\text { varias especies de aves } \\
\text { Charadriiformes }\end{array}$ & $\begin{array}{l}\text { Península Melabakkar, } \\
\text { oeste de Islandia }\end{array}$ & $\begin{array}{l}\text { Deblock et al. } \\
(1961) \\
\text { Rebecq (1960) } \\
\text { Yamaguti } \\
(1975) \\
\text { Skirnisson et } \\
\text { al. (2004) }\end{array}$ \\
\hline $\begin{array}{l}\text { Maritrema laricola } \\
\text { Ching, } 1963\end{array}$ & $\begin{array}{l}\text { Littorina sitkana Philippi y } \\
\text { L. scutulata Gould } \\
\text { (Littorinidae) }\end{array}$ & $\begin{array}{l}\text { Hemigrapsus oregonensis y H. nudus } \\
\text { (Malacostraca) }\end{array}$ & $\begin{array}{l}\text { [gaviotas], cultivo in vitro, } \\
\text { Larus glaucescens }\end{array}$ & $\begin{array}{l}\text { costa de Vancouver, } \\
\text { British Columbia y } \\
\text { Bahía Bodega, } \\
\text { California, Estados } \\
\text { Unidos }\end{array}$ & $\begin{array}{l}\text { Ching (1963, } \\
\text { 1991) } \\
\text { Yamaguti } \\
(1975)\end{array}$ \\
\hline $\begin{array}{l}\text { Maritrema } \\
\text { syntomocyclus } \\
\text { Deblock \& Ky, } \\
1966\end{array}$ & $\begin{array}{l}\text { Hydrobia acuta } \\
\text { (Draparnaud) } \\
\text { (Hydrobiidae) }\end{array}$ & Hydrobia acuta (ciclo abreviado) & desconocido & costa de Europa & $\begin{array}{l}\text { Deblock \& } \\
\text { Tran Van Ky } \\
(1966) \\
\text { Yamaguti } \\
(1975)\end{array}$ \\
\hline $\begin{array}{l}\text { Maritrema } \\
\text { setoenense } \\
\text { Bridgman, } 1971\end{array}$ & $\begin{array}{l}\text { Littorina brevicula } \\
\text { (Philippi) (Littorinidae) }\end{array}$ & $\begin{array}{l}\text { Hemigrapsus sanguineus, H. penicillatus y } \\
\text { Macrophtalmus dilatatus (Malacostraca) }\end{array}$ & $\begin{array}{l}\text { [Numenius } \\
\text { madagascariensis, Mus } \\
\text { musculus albinus y Rattus } \\
\text { norvegicus albinus] }\end{array}$ & $\begin{array}{l}\text { costa de Iwashima, } \\
\text { Kagawa Prefecture, } \\
\text { Japón }\end{array}$ & $\begin{array}{l}\text { Bridgman } \\
(1971) \\
\text { Yamaguti } \\
(1975)\end{array}$ \\
\hline
\end{tabular}


Tabla 10 (continuación). Estadios larvales (en el $1^{\circ}$ hospedador intermediario) del género Maritrema (Microphallidae) reportados en el mundo. Se incluye información de los ciclos de vida conocidos $\left(2^{\circ}\right.$ hospedador intermediario y hospedador definitivo), la localidad y las referencias. Los hospedadores indicados entre corchetes fueron determinados a partir de infecciones experimentales.

\begin{tabular}{|c|c|c|c|c|c|}
\hline Especie & $1^{\circ}$ Hosp. Intermediario & $2^{\circ}$ Hosp. Intermediario & Hosp. Definitivo & Localidad & Referencias \\
\hline $\begin{array}{l}\text { Maritrema misenensis } \\
\text { (Palombi, 1940) }\end{array}$ & $\begin{array}{l}\text { Cerithium mediterraneum } \\
\text { y C. vulgatum Bruguière } \\
\text { (Cerithiidae) }\end{array}$ & $\begin{array}{l}\text { Orchestia mediterranea y } O . \\
\text { montagui (Malacostraca) }\end{array}$ & $\begin{array}{l}\text { Charadrius alexandrinus } \\
\text { y [Larus cachinnans } \\
\text { michaelis] }\end{array}$ & $\begin{array}{l}\text { Laguna de Brusc, Marsella, } \\
\text { Francia }\end{array}$ & $\begin{array}{l}\text { Prévot et al., } \\
(1976) \\
\text { Bartoli (1986) } \\
\end{array}$ \\
\hline $\begin{array}{l}\text { Maritrema } \\
\text { novaezealandensis } \\
\text { Martorelli, } \\
\text { Fredensborg, } \\
\text { Mouristen \& Poulin, } \\
2004\end{array}$ & $\begin{array}{l}\text { Zeacumantus subcarinatus } \\
\text { (Sowerby) (Batillaridae) }\end{array}$ & $\begin{array}{l}\text { Hemigrapsus crenulatus, } \\
\text { Macrophtalmus hirtipes, } \\
\text { Halicarcinus whitei y varias } \\
\text { especies de anfípodos }\end{array}$ & $\begin{array}{l}\text { Larus novaehollandiaes } \\
\text { copulinus }\end{array}$ & $\begin{array}{l}\text { costa de Otago Harbor, South } \\
\text { Island, Nueva Zelanda }\end{array}$ & $\begin{array}{l}\text { Martorelli et al. } \\
\text { (2004) }\end{array}$ \\
\hline $\begin{array}{l}\text { Maritrema orensense } \\
\text { Cremonte \& Martorelli, } \\
1998\end{array}$ & $\begin{array}{l}\text { Heleobia australis } \\
\text { (d’Orbingy) } \\
\text { (Cochliopidae) }\end{array}$ & $\begin{array}{l}\text { Neohelice granulata y } \\
\text { Cyrtograpsus angulatus }\end{array}$ & Larus atlanticus & $\begin{array}{l}\text { Estuario Bahía Blanca, Puerto } \\
\text { Cuatreros, Argentina }\end{array}$ & $\begin{array}{l}\text { Cremonte \& } \\
\text { Martorelli } \\
(1998) \\
\text { Alda et al. } \\
(2013)\end{array}$ \\
\hline $\begin{array}{l}\text { Maritrema bonaerense } \\
\text { Etchegoin \& Martorelli } \\
, 1997\end{array}$ & $\begin{array}{l}\text { Heleobia australis } \\
\text { (d'Orbingy) } \\
\text { (Cochliopidae) }\end{array}$ & $\begin{array}{l}\text { Neohelice granulata y } \\
\text { Cyrtograpsus angulatus }\end{array}$ & Larus atlanticus & $\begin{array}{l}\text { Estuario Bahía Blanca, Puerto } \\
\text { Cuatreros; Laguna Mar Chiquita, } \\
\text { Buenos Aires, Argentina }\end{array}$ & $\begin{array}{l}\text { Etchegoin \& } \\
\text { Martorelli } \\
\text { (1997) } \\
\text { Alda et al. } \\
\text { (2013) }\end{array}$ \\
\hline $\begin{array}{l}\text { Maritrema madrynense } \\
\text { Diaz \& Cremonte } 2010\end{array}$ & $\begin{array}{l}\text { Siphonaria lessonii } \\
\text { (Blainville) } \\
\text { (Siphonariidae) }\end{array}$ & $\begin{array}{l}\text { Cyrtograpsus altimanus, Idotea } \\
\text { balthica (Malacostraca) y } \\
\text { Siphonaria lessonii (ciclo } \\
\text { abreviado) }\end{array}$ & Larus dominicanus & $\begin{array}{l}\text { costas de Playa Fracasso (Golfo } \\
\text { San José), Puerto Madryn (Golfo } \\
\text { Nuevo), Comodoro Rivadavia, } \\
\text { Puerto Deseado, Argentina }\end{array}$ & $\begin{array}{l}\text { Alda \& } \\
\text { Martorelli } \\
(2009) \\
\text { Diaz \& } \\
\text { Cremonte } \\
\text { (2010) } \\
\text { Gilardoni et al. } \\
\text { (2011) } \\
\text { presente } \\
\text { estudio }\end{array}$ \\
\hline Maritrema sp. 1 & $\begin{array}{l}\text { Crepipatella dilatata } \\
\text { (Lamarck) (Clyptraeidae) }\end{array}$ & desconocido & desconocido & $\begin{array}{l}\text { costas de Playa Fracasso (Golfo } \\
\text { San José), Puerto Madryn (Golfo } \\
\text { Nuevo), Comodoro Rivadavia, } \\
\text { Puerto Deseado, Argentina }\end{array}$ & $\begin{array}{l}\text { Gilardoni et al. } \\
(2011) \\
\text { presente } \\
\text { estudio }\end{array}$ \\
\hline
\end{tabular}


Prospección de potenciales segundos hospedadores intermediarios

De las cuatro especies de crustáceos estudiadas (Cyrtograpsus altimanus, Exosphaeroma sp., Idotea baltica y Balanus glandula Darwin (Balanidae)) se hallaron metacercarias de Microphallidae en tres de ellas: C. altimanus, Exosphaeroma sp. e I. baltica. La secuencia (ITS1) de la metacercaria hallada en Exosphaeroma sp. no pudo ser determinada a nivel molecular (se logró extraer, amplificar y reamplificar ADN pero no se pudo secuenciar). Tampoco pudo estudiarse morfológicamente, ya que sólo se hallaron dos especímenes en una ocasión y no pudieron ser desenquistados. A nivel morfológico y molecular (ITS1, ITS2), las metacercarias halladas en C. altimanus e I. baltica son idénticas y pertenecen al género Maritrema (Fig. 57). Esta metacercaria fue reportada por primera vez en C. altimanus por Diaz \& Cremonte (2010). Una metacercaria del género Maritrema con similares características a la metacercaria hallada en C. altimanus e I. baltica fue registrada en el isópodo Exosphaeroma sp. en Comodoro Rivadavia (Alda \& Martorelli, 2009). Sin embargo, esta metacercaria difiere de las anteriores en el tamaño y distribución de las espinas del cirro (Alda \& Martorelli, 2009; Diaz \& Cremonte 2010). 


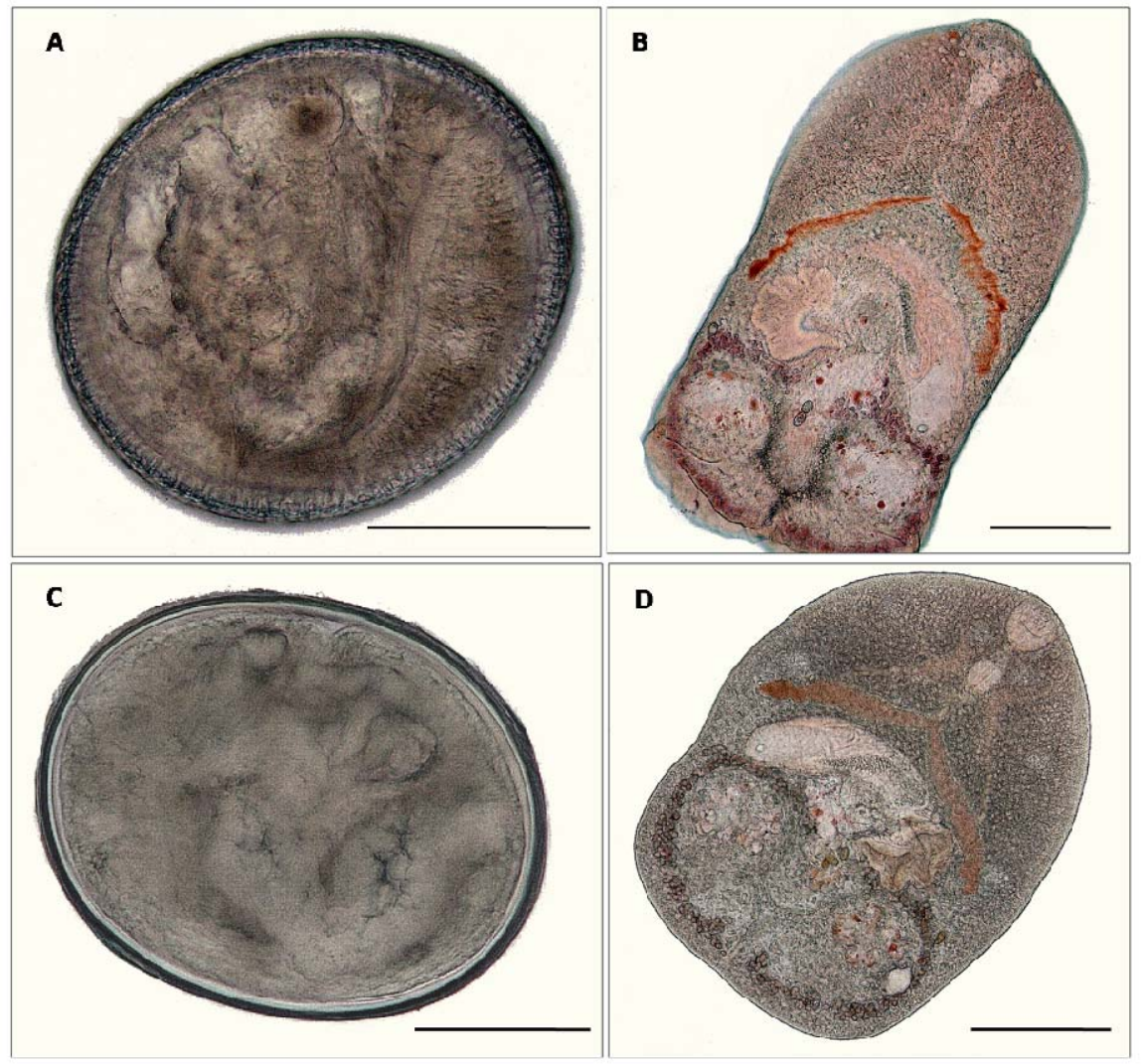

Figura 57. Metacercarias del género Maritrema (Microphallidae) halladas en los crustáceos disecados. A- Metacercaria enquistada en el cangrejo Cyrtograpsus altimanus; B- Metacercaria desenquistada de C. altimanus luego de 24 hs en estufa de cultivo; C- Metacercaria enquistada en el isópodo Idotea baltica; D- Metacercaria desenquistada de I. baltica luego de 48 hs en estufa de cultivo. Escalas: $100 \mu \mathrm{m}$ (A, B, C, D).

\section{Infecciones experimentales}

Las infecciones experimentales realizadas sobre cangrejos C. altimanus de pequeña talla con cercarias de Maritrema sp. 1 emitidas no resultaron exitosas. Los cangrejos fueron disecados luego de 5, 15, 30, 45 y 60 días de post infección y no se hallaron metacercarias.

En el caso de los cangrejos infectados con cercarias de S. lessonii, 6 de los 8 individuos presentaron metacercarias del género Maritrema. Los cangrejos disecados antes de los 15 días post infección presentaron metacercarias, pero estas no se desenquistaron cuando fueron cultivadas en estufa. Las metacercarias halladas en cangrejos disecados a partir de los 30 días post infección, y cultivadas en estufa lograron desenquistarse. El mayor porcentaje de desenquistamiento se registró entre las 2 y 8 hs de cultivo en estufa (29-60\%). A las 24 hs de cultivo en 
estufa, la mayoría de las metacercarias estaban muertas y se obtuvo sólo un adulto (con huevos) luego de 60 días post infección de los cangrejos y de cultivo en estufa (Tabla 11). Las metacercarias son morfológicamente idénticas a las halladas naturalmente en el cangrejo C. altimanus.

Tabla 11. Datos de los cangrejos Cyrtograpsus altimanus infectados con cercarias Maritrema sp. 2 emitidas de Siphonaria lessonii.

\begin{tabular}{|c|c|c|c|c|c|c|c|c|c|c|}
\hline \multirow[b]{2}{*}{ congrelone } & \multirow[b]{2}{*}{ nedlas de port hfecedon } & \multirow[b]{2}{*}{ os } & \multirow[b]{2}{*}{ nop } & \multirow[b]{2}{*}{ ancho } & \multirow[b]{2}{*}{ ne motecercorles vines } & \multicolumn{5}{|c|}{ 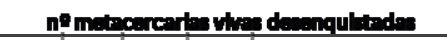 } \\
\hline & & & & & & $2 \mathrm{hes}$ & Ihe & $8 \mathrm{hs}$ & $24 \mathrm{he}$ & me met c/huovos \\
\hline 1 & 5 & hembn & 11 & 12 & 10 & - & - & - & - & - \\
\hline 2 & 15 & hember & 12 & 13 & 13 & - & - & - & - & - \\
\hline 3 & 30 & macho & 11 & 12 & 69 & 20 & 33 & 33 & 4 & 0 \\
\hline 4 & 30 & hentes & 12 & 13 & - & - & - & - & - & - \\
\hline 5 & 45 & macho & g & 10 & 20 & 10 & 8 & $\mathbf{3}$ & 0 & 0 \\
\hline 6 & 45 & macho & 13 & 16 & 5 & - & 3 & 4 & 0 & 0 \\
\hline 7 & 6 & macho & 10 & 12 & - & - & - & - & - & - \\
\hline 8 & 60 & hember & 11 & 12 & 55 & 23 & 23 & 27 & 4 & 1 \\
\hline
\end{tabular}

\section{Cultivo in vitro}

Maritrema madrynense en S. lessonii presentó esporocistos con metacercarias desarrolladas (Fig. 58A). Las metacercarias lograron desenquistarse (Figs. 58B, C) y se obtuvieron adultos (con huevos) cuando fueron cultivadas en estufa a $39-40^{\circ} \mathrm{C}$ (Fig. 58D). La metacercaria presenta características similares a la hallada en el cangrejo C. altimanus (Diaz \& Cremonte, 2010) y en el isópodo I. baltica; sin embargo, existen diferencias en las medidas y en la distribución de las espinas del cirro. Las metacercarias de Maritrema madrynense halladas en S. lessonii son más pequeñas que las halladas en C. altimanus (199 (160-277) $\mu \mathrm{m}$ de longitud por 139 (105-172) $\mu \mathrm{m}$ de ancho vs. 310 (260-350) $\mu \mathrm{m}$ de longitud por 260 (210-320) $\mu \mathrm{m}$ de ancho) y presentan pocas espinas en el cirro, localizadas principalmente en la base (Fig. 59). 

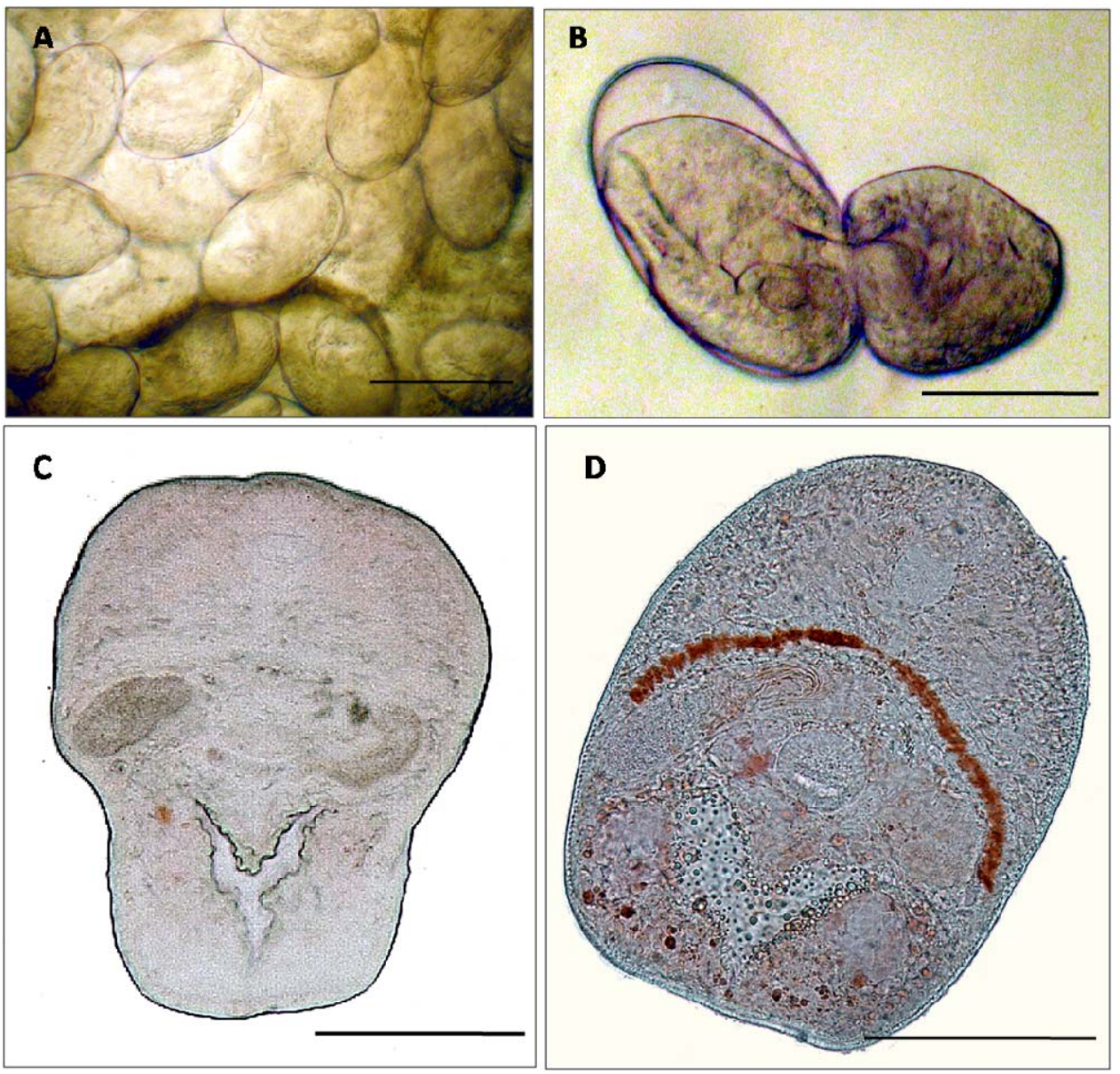

Figura 58. Metacercarias de Maritrema madrynense (Microphallidae) en Siphonaria lessonii. AMetacercarias enquistadas dentro de los esporocistos; B- Metacercaria desenquistando en el portaobjeto luego de ser retirada del esporocisto; C- Metacercaria desenquistada luego de 2 hs de salir del esporocisto; D- Metacercaria desenquistada luego de 20 hs en estufa de cultivo. Escalas: $100 \mu \mathrm{m}(\mathrm{A}, \mathrm{C}, \mathrm{D}) ; \mathbf{5 0} \mu \mathrm{m}$ (B). 

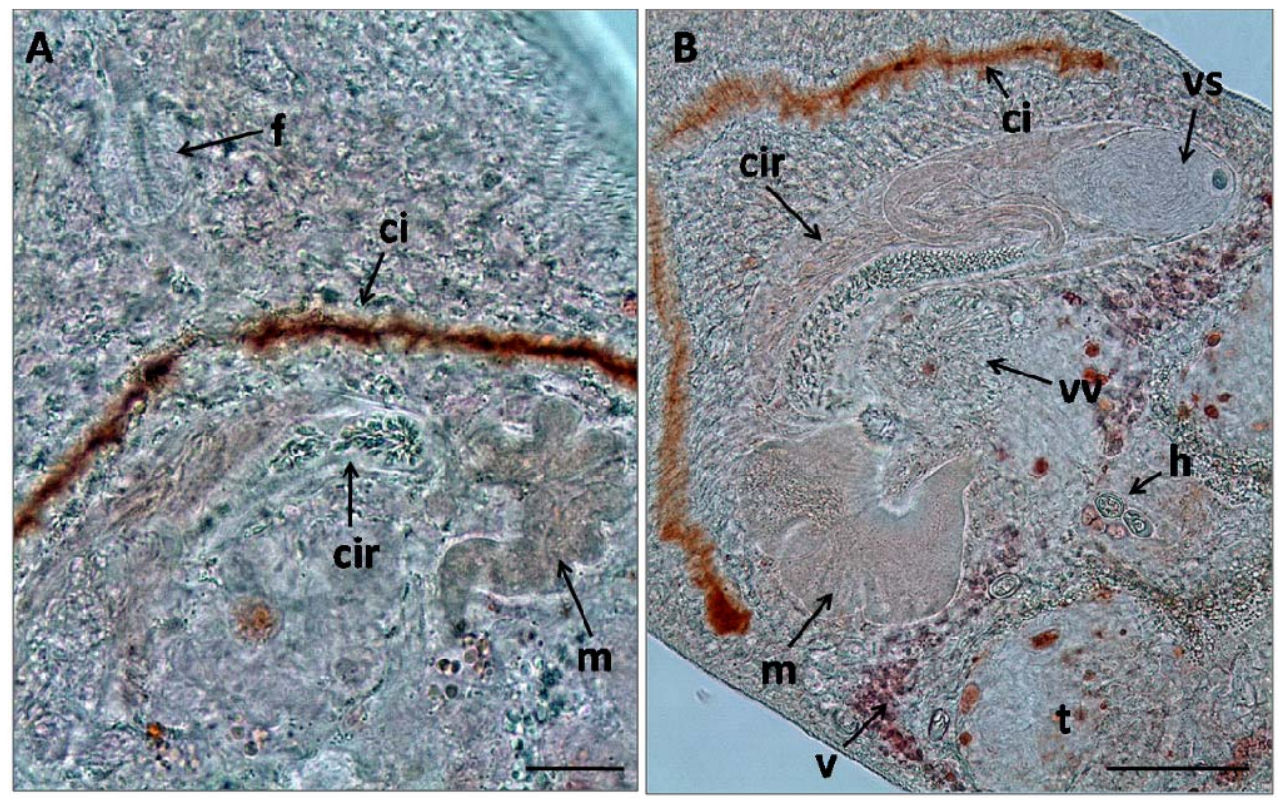

Figura 59. Detalle de las espinas del cirro de Maritrema madrynense (Microphallidae) en ASiphonaria lessonii y B- Cyrtograpsus altimanus, cultivadas en estufa. Abreviaturas: ci- ciego; cir- cirro; f- faringe; h- huevo; $\mathrm{m}$ - metratermo; $\mathrm{t}$ - testículo; v- vitelario; vs- vesícula seminal; vvventosa ventral. Escalas: $20 \mu \mathrm{m}(\mathrm{A}) ; 50 \mu \mathrm{m}(\mathrm{B})$.

\section{Estudios moleculares}

Maritrema sp. 1 no presentó similitud en las secuencias moleculares (ITS1, ITS2) con ninguna de las obtenidas en crustáceos y aves de ambos sitios de estudio. Por el contrario, M. madrynense parásita de S. lessonii, presentó un alto porcentaje de similitud $(97,75 \%)$ en las secuencias ITS1, 5.8S e ITS2 con las metacercarias halladas en los crustáceos C. altimanus e I. baltica. Ambos estadios larvales pueden considerarse pertenecientes a la misma especie, ya que las regiones secuenciadas son no codificantes y menos conservadas, por lo que pueden exhibir variabilidad intraespecífica. Otras especies del género Maritrema presentan un menor porcentaje de similitud con la especie en cuestión (57,28-80,5\%) (Anexo IV). Las secuencias moleculares (ITS1, 5.8S e ITS2) de los crustáceos son idénticas a las secuencias de los adultos de M. madrynense en L. dominicanus, lo que confirma el ciclo de vida de esta especie.

En resumen, M. madrynense es un parásito que habita en el intestino de la gaviota cocinera L. dominicanus. El gasterópodo $S$. lessonii actúa como $1^{\circ} \mathrm{HI}$, albergando esporocistos que pueden liberar cercarias al medio o enquistar dentro 
del esporocisto desarrollando metacercarias (ciclo abreviado). Las cercarias que son liberadas penetran en los crustáceos C. altimanus e I baltica y enquistan en el celoma. Las gaviotas se alimentan de estos gasterópodos o de crustáceos parasitados con metacercarias infectivas que maduran en el ave produciendo huevos (Fig. 60).

El ciclo de vida de Maritrema sp. 1 no pudo ser resuelto. Las secuencias moleculares de los adultos de M. formicae hallados en la gaviota cocinera no se correspondieron con las secuencias de los estadios larvales que parasitan a $C$. dilatata. Los estudios moleculares se realizaron utilizando un pool de especímenes $\mathrm{y}$, en el caso particular de las dos especies de Maritrema en L. dominicanus, M. madrynense y M. formicae, presentan pocas diferencias morfológicas. Sería entonces necesario repetir los estudios moleculares para M. formicae y realizar la extracción con un sólo especímen por especie para evitar que ambas se puedan mezclar. Es probable que exista un $2^{\circ} \mathrm{HI}$, ya que se obtuvieron cercarias emitidas a partir de $C$. dilatata y las metacercarias dentro de los esporocistos se observaron sólo en condiciones de laboratorio (Fig. 61).

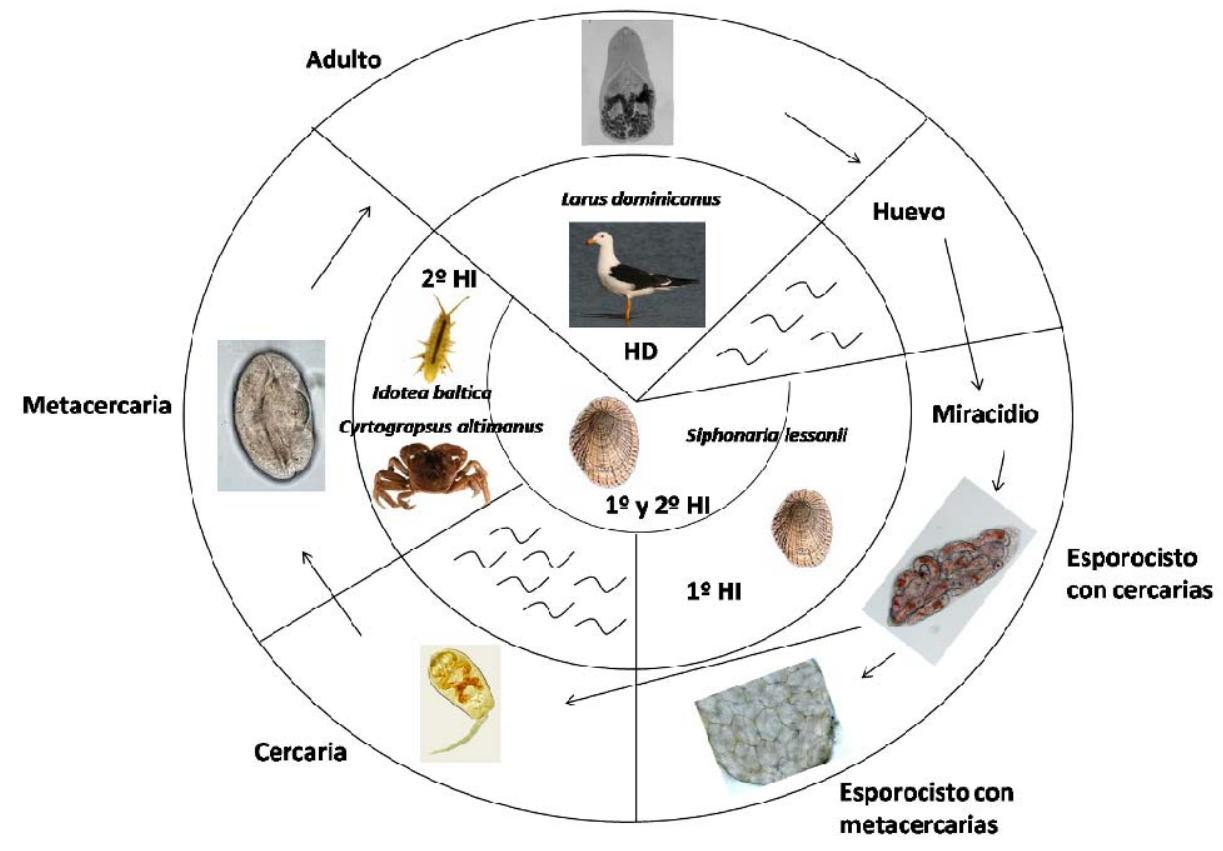

Figura 60. Ciclo de vida de Maritrema madrynense Diaz \& Cremonte, 2010 (Microphallidae). Abreviaturas: HI- hospedador intermediario; HD- hospedador definitivo. 


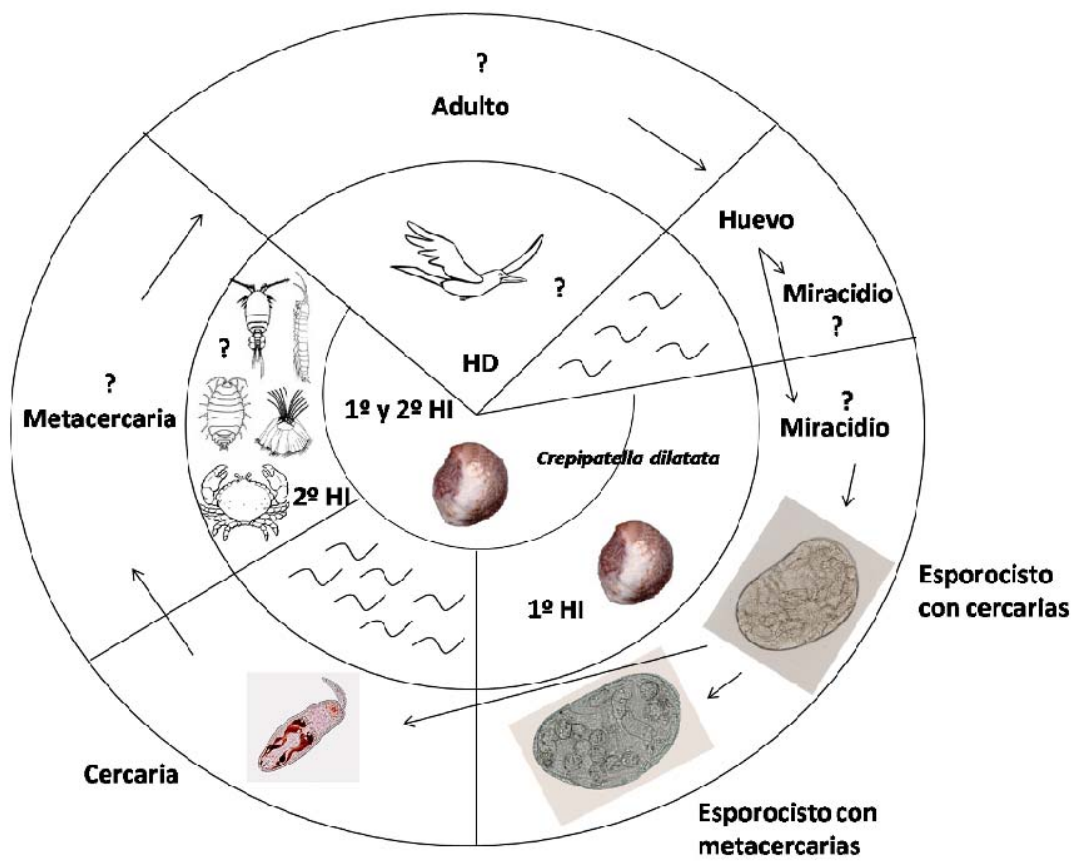

Figura 61. Ciclo de vida de Maritrema sp. 1 (Microphallidae). Los dibujos de hospedadores y los estadios larvales indicados con signo de interrogación no se conocen. Abreviaturas: HIhospedador intermediario; HD- hospedador definitivo. 


\subsubsection{Notocotylidae gen. et sp.}

Los adultos de la familia Notocotylidae Lühe, 1909 se localizan en el tracto digestivo, principalmente en los ciegos intestinales, de aves y mamíferos (Barton \& Blair, 2005). Las cercarias se desarrollan dentro de las redias y pueden enquistar dentro de las mismas o bien salir al medio y enquistar sobre la vegetación o sobre las valvas de otros moluscos (Yamaguti, 1975; Hechinger, 2012).

En Argentina se conocen 14 especies de cercarias de esta familia, todas en agua dulce (Sutton, 1989; Flores, 2004; Flores \& Brugni, 2003, 2005, 2006; Alda, 2011). La mayoría de las cercarias presentan ocelos y una cola larga; sin embargo, la descripta en este estudio no presentó ocelos y posee una cola diminuta. Numerosas cercarias han sido descriptas en el mundo, pero sólo cuatro con los caracteres de ausencia de ocelos y cola diminuta (Tabla 12). En tres de los cuatro casos, las metacercarias enquistan dentro de la redia (ciclo abreviado), al igual que la especie descripta en este estudio. Sólo en el caso de Catatropis verrucosa, la cercaria puede utilizar varias especies de gasterópodos como $1^{\circ} \mathrm{HI}$ y un oligoqueto como $2^{\circ} \mathrm{HI}$ y finaliza su ciclo de vida en el pato Anas platyrhynchos Linnaeus (Anatidae) (Yamaguti, 1975). Las otras especies de este morfotipo utilizan aves Charadriiformes como hospedadores definitivos (Yamaguti, 1975). Es probable que la gaviota cocinera, $L$. dominicanus, o el ostrero negro $H$. ater actúen como hospedadores definitivos de esta especie, ya que se alimentan de lapas (Yorio \& Bertellotti, 2002; Sapoznikow et al., 2008). Nacella (P.) magellanica $\left(1^{\circ} \mathrm{HI}\right)$ es una lapa de gran tamaño que se adhiere fuertemente al sustrato, por lo que es inaccesible para otras aves como patos o playeros que presentan picos de menor porte (Fig. 62). 


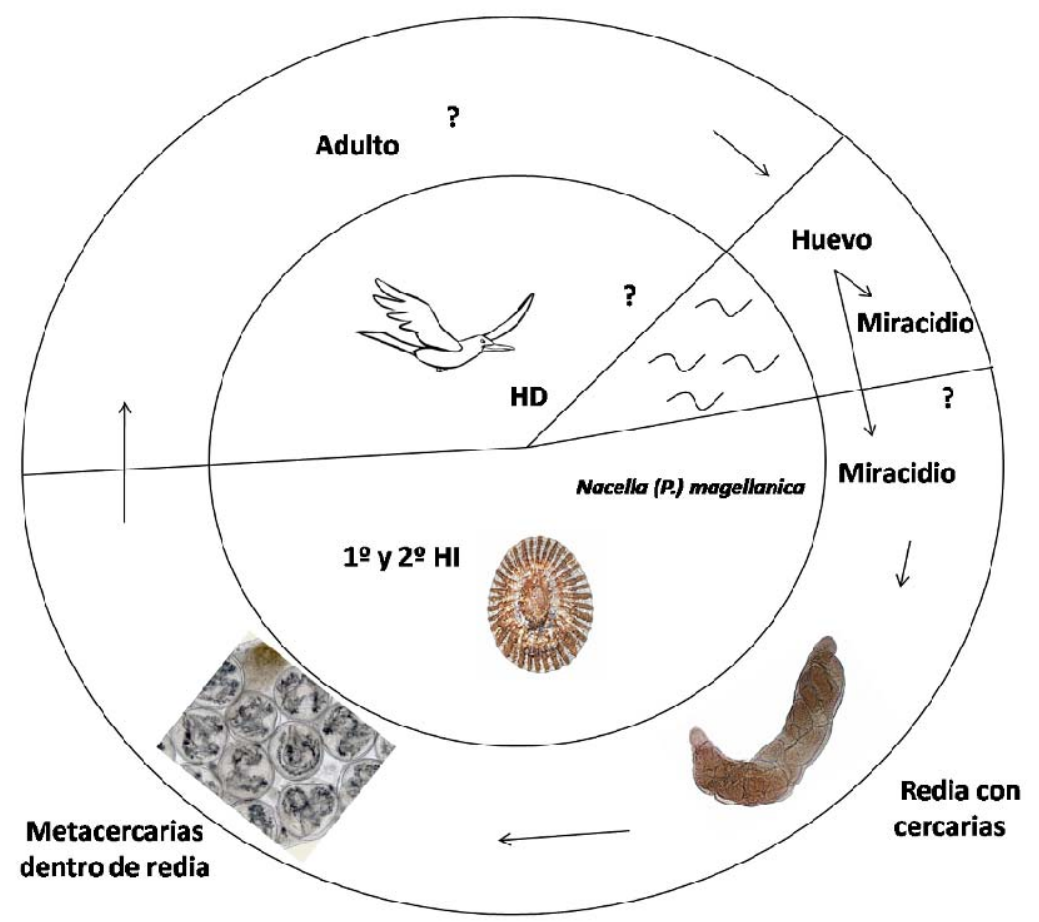

Figura 62. Ciclo de vida de Notocotylidae gen. et $\mathrm{sp}$. Los dibujos de hospedadores y los estadios larvales indicados con signo de interrogación no se conocen. Abreviaturas: HI- hospedador intermediario; HD- hospedador definitivo. 
Tabla 12. Estadios larvales (en los $1^{\circ}$ hospedadores intermediarios) de la familia Notocotylidae (cercarias con ausencia de ocelos y cola diminuta) reportados en el mundo. Se incluye información de los ciclos de vida conocidos $\left(2^{\circ}\right.$ hospedador intermediario y hospedador definitivo), la localidad y las referencias. Los hospedadores indicados entre corchetes fueron determinados a partir de infecciones experimentales.

\begin{tabular}{|c|c|c|c|c|c|}
\hline Especie & $1^{\circ}$ Hosp. Intermediario & $2^{\circ}$ Hosp. Intermediario & Hosp. Definitivo & Localidad & Referencias \\
\hline $\begin{array}{l}\text { Parapronocephalum symmetricum } \\
\text { Belopol'skaia, } 1952\end{array}$ & $\begin{array}{l}\text { Littorina saxatilis (Olivi) } \\
\text { (Littorinidae) }\end{array}$ & $\begin{array}{l}\text { L. saxatilis (ciclo } \\
\text { abreviado, enquista en el } \\
1^{\circ} \mathrm{HI} \text { ) } \\
\text { Calidris maritima (Aves) }\end{array}$ & Aves Charadriiformes & costa de Europa & Yamaguti (1975) \\
\hline $\begin{array}{l}\text { Notocotyloides petasatus } \\
\text { (Deslongchamps, 1824) }\end{array}$ & $\begin{array}{l}\text { Littorina obtusata (Linnaeus) } \\
\text { (Littorinidae) }\end{array}$ & $\begin{array}{l}\text { L. obtusata (ciclo } \\
\text { abreviado, enquista en el } \\
1^{\circ} \mathrm{HI} \text { ) }\end{array}$ & Aves Charadriiformes & costa de Europa & Yamaguti (1975) \\
\hline $\begin{array}{l}\text { Catatropis verrucosa } \\
\text { (Frölich, 1789) }\end{array}$ & $\begin{array}{l}\text { Melania tuberculata (Müller) } \\
\text { (Thiaridae), Planorbis } \\
\text { corneus (Linnaeus), } \\
\text { Segmentina nitida (Müller), } \\
\text { Gyraulus albus (Müller), } \\
\text { Anisus leucostomus (Müller) } \\
\text { (Planorbidae), Bithynia } \\
\text { tentaculata (Linnaeus) y B. } \\
\text { leachi (Leach) (Bithyniidae) }\end{array}$ & $\begin{array}{l}\text { Chaetogaster limnaei } \\
\text { (Oligochaeta) }\end{array}$ & Anas platyrhynchos & $\begin{array}{l}\text { Río Danubio, } \\
\text { Europa }\end{array}$ & $\begin{array}{l}\text { Yamaguti (1975) } \\
\text { Kanev et al. (1994) }\end{array}$ \\
\hline $\begin{array}{l}\text { Pronocephaloid sp. I } \\
\text { Hechinger, } 2012\end{array}$ & $\begin{array}{l}\text { Potamopyrgus antipodarum } \\
\text { (Gray) (Hidrobiidae) }\end{array}$ & $\begin{array}{l}\text { P. antipodarum (ciclo } \\
\text { abreviado, enquista en el } \\
1^{\circ} \mathrm{HI} \text { ) }\end{array}$ & desconocido & $\begin{array}{l}\text { costa de Nueva } \\
\text { Zelanda }\end{array}$ & Hechinger (2012) \\
\hline Notocotylidae gen. et sp. & $\begin{array}{l}\text { Nacella (P.) magellanica } \\
\text { (Gmelin) (Nacellidae) }\end{array}$ & desconocido & desconocido & $\begin{array}{l}\text { costa de Puerto } \\
\text { Deseado y } \\
\text { Usuahia, } \\
\text { Argentina }\end{array}$ & $\begin{array}{l}\text { Martorelli et al. } \\
\text { (2005) } \\
\text { presente estudio }\end{array}$ \\
\hline
\end{tabular}




\subsubsection{Renicolidae gen. et sp. 1 y Renicolidae gen. et sp. 2}

Los adultos de la familia Renicolidae Dollfus, 1939 son parásitos que habitan los riñones de aves marinas (Gibson, 2008). En general, presentan ciclos de vida con tres hospedadores (triexenos); la cercaria se desarrolla dentro de esporocistos en gasterópodos prosobranquios, luego emerge al medio y penetra en el músculo de peces o en bivalvos, donde se desarrolla la metacercaria.

Numerosas cercarias han sido reportadas en el mundo, parasitando principalmente gasterópodos de las familias Cerithiidae, Muricidae, Littorinidae y Potamididae (Tabla 13). Hasta el momento se conocen cinco ciclos de vida en forma completa (Martin \& Gregory, 1951; Stunkard, 1964; 1970; Yoshino, 1975; Sannia \& James, 1977; Prévot \& Bartoli, 1978; Ching, 1989). Diversas especies de peces de la clase Actinopterygii y bivalvos de las familias Veneridae, Pectinidae, Mytilidae, Cardiidae y Ostreidae actúan como $2^{\circ} \mathrm{HI}$. Varias especies de gaviotas han sido reportadas como hospedadores definitivos naturales y en forma experimental también se han reportado patos y pollos (ver ref. Tabla 13).

Los estadios larvales (esporocistos y cercarias) hallados en el presente trabajo en el murícido Trophon geversianus en ambos sitios de estudio y en el patélido Nacella (P.) magellanica en Puerto Deseado, constituyen los primeros registros de Renicolidae en el Mar Argentino. Metacercarias de esta familia fueron halladas en la glándula digestiva de bivalvos mitílidos (Mytilus edulis, Perumytilus purpuratus y Aulacomya atra) intermareales de Patagonia, y en otros bivalvos como Lasaea adansoni y Gaimardia trapesina (Cremonte, 1999 y datos no publicados). Recientemente se halló un adulto de esta familia en el riñón de la gaviota cocinera, L. dominicanus, en Península Valdés (datos no publicados).

La infección experimental de mejillones con cercarias Renicolidae gen. et sp. 1 emitidas por T. geversianus dio resultados negativos. Bajo lupa se observó el ingreso de las cercarias a través del sifón inhalante del bivalvo, sin embargo, al realizar las disecciones de los bivalvos, no se hallaron metacercarias.

A partir de los estudios moleculares (ITS1) se determinó que los esporocistos de Renicolidae gen. et sp. 1 que parasitan T. geversianus y las metacercarias halladas en $M$. edulis pertenecen a la misma especie. Es probable que el adulto hallado 
recientemente en L. dominicanus corresponda a la misma especie, pudiendo quedar así dilucidado el ciclo de vida de este digeneo (Fig. 63).

Renicolidae gen. et sp. 2 se registró en $N$. (P.) magellanica, que sólo estuvo presente en Puerto Deseado. Es probable que su hospedador definitivo esté restringido a la provincia biogeográfica Magallánica, donde este gasterópodo es más abundante. Nuevamente, las aves que podrían actuar como hospedadores definitivos son gaviotas cocineras de la zona o el ostrero negro $H$. ater, que se conoce se alimentan de lapas (Yorio \& Bertellotti, 2002; Sapoznikow et al., 2008).

Futuros estudios morfológicos y moleculares de los adultos, y otras metacercarias presentes en bivalvos de las áreas de estudio, contribuirán a dilucidar los ciclos de vida de las dos especies de la familia Renicolidae halladas (Figs. 63, 64).

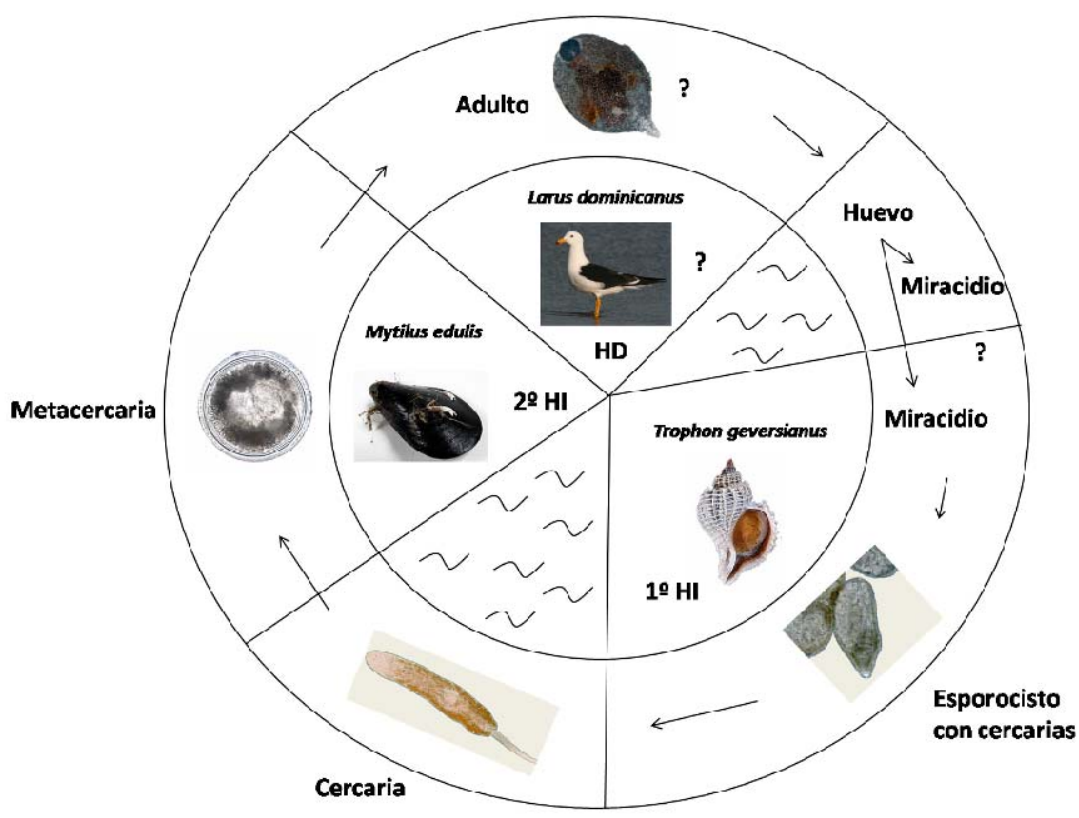

Figura 63. Ciclo de vida de Renicolidae gen. et $\mathrm{sp.}$. Los dibujos de hospedadores y los estadios larvales indicados con signo de interrogación no se conocen. Abreviaturas: HI- hospedador intermediario; HD- hospedador definitivo. 


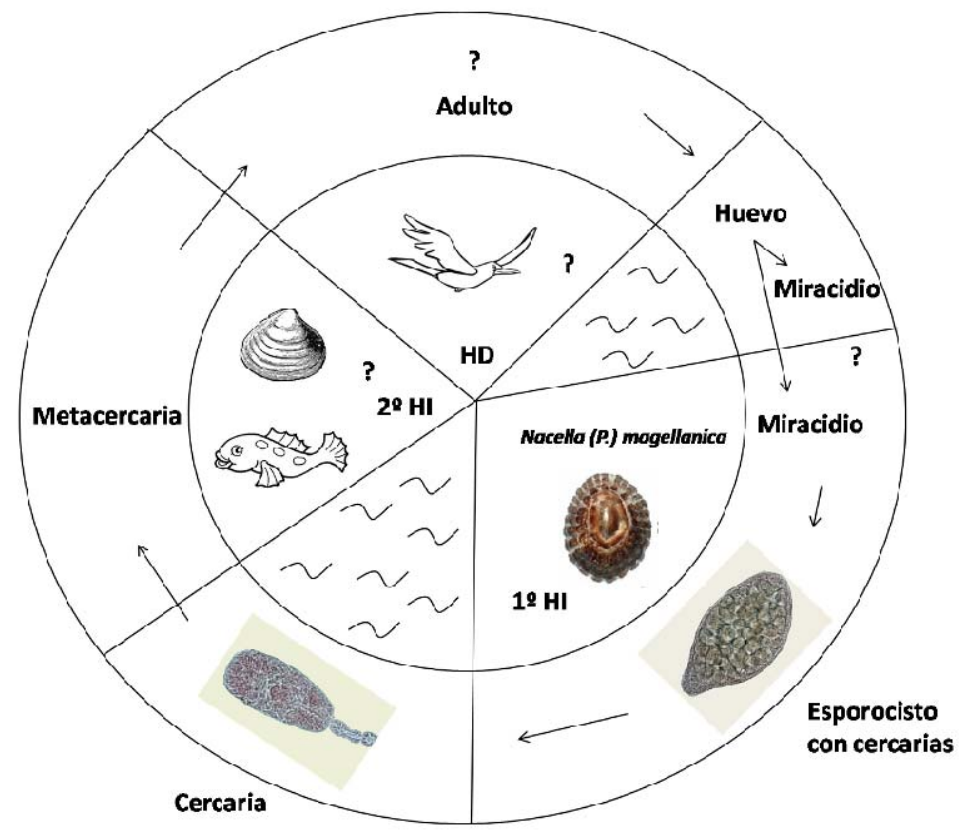

Figura 64. Ciclo de vida de Renicolidae gen. et sp. 2. Los dibujos de hospedadores y los estadios larvales indicados con signo de interrogación no se conocen. Abreviaturas: HI- hospedador intermediario; HD- hospedador definitivo. 
Tabla 13. Estadios larvales (en los primeros hospedadores intermediarios) de la familia Renicolidae reportados en el mundo. Se incluye información del ciclo de vida conocido ( $2^{\circ}$ hospedador intermediario y hospedador definitivo), la localidad y las referencias. Los hospedadores indicados entre corchetes fueron determinados a partir de infecciones experimentales.

\begin{tabular}{|c|c|c|c|c|c|}
\hline Especie & $1^{\circ}$ Hosp. Intermediario & $2^{\circ}$ Hosp. Intermediario & Hosp. Definitivo & Localidad & Referencias \\
\hline $\begin{array}{l}\text { Renicola foliata } \\
\text { Ching, } 1989\end{array}$ & $\begin{array}{l}\text { Planaxis sulcatus (Born) } \\
\text { (Planaxidae) }\end{array}$ & peces Atheriniformes & aves marinas & Isla Heron, Australia & Ching (1989) \\
\hline $\begin{array}{l}\text { Cercaria } \\
\text { littorinae- } \\
\text { saxatilis VI }\end{array}$ & $\begin{array}{l}\text { Littorina saxatilis (Olivi) } \\
\text { (Littorinidae) }\end{array}$ & desconocido & desconocido & costa de North Island, Nueva Zelanda & $\begin{array}{l}\text { Sannia \& James } \\
\text { (1977) }\end{array}$ \\
\hline $\begin{array}{l}\text { Renicola thaidus } \\
\text { Stunkard, } 1964\end{array}$ & $\begin{array}{l}\text { Nucella lapillus (Linnaeus) y } \\
\text { N. lamellosa (Gmelin) } \\
\text { (Muricidae) }\end{array}$ & $\begin{array}{l}\text { Mytilus edulis, Aequipecten } \\
\text { irradians y Gemma gemma } \\
\text { (Bivalvia) }\end{array}$ & [Larus argentinus] & $\begin{array}{l}\text { Costas de North Island, Nueva Zelanda, } \\
\text { Vancouver, BC, Woods Hole, } \\
\text { Massachusetts, Estados Unidos }\end{array}$ & $\begin{array}{l}\text { Stunkard (1964) } \\
\text { Sannia \& James } \\
(1977)\end{array}$ \\
\hline $\begin{array}{l}\text { Renicola roscovita } \\
\text { (Stunkard, 1932) }\end{array}$ & $\begin{array}{l}\text { Littorina littorea (Linnaeus) } \\
\text { (Littorinidae) }\end{array}$ & $\begin{array}{l}\text { Cerastoderma edule y } \\
\text { Crassostrea gigas (Bivalvia) }\end{array}$ & desconocido & $\begin{array}{l}\text { costa de Europa, Estuario Exe, Inglaterra, } \\
\text { Ría de Aveiro, Portugal }\end{array}$ & $\begin{array}{l}\text { Aguirre-Macedo } \\
\text { \& Kennedy (1999) } \\
\text { Russell-Pinto et al. } \\
\text { (2006) } \\
\text { Longshaw \& } \\
\text { Malham (2013) }\end{array}$ \\
\hline $\begin{array}{l}\text { Renicola } \\
\text { cerithidicola } \\
\text { Martin, } 1971 \\
\end{array}$ & $\begin{array}{l}\text { Cerithidea californica } \\
\text { (Haldeman) (Potamididae) }\end{array}$ & $\begin{array}{l}\text { Fundulus parvipinnis } \\
\text { (Actinopterygii) }\end{array}$ & $\begin{array}{l}\text { [patos, pollos y } \\
\text { gaviotas] }\end{array}$ & $\begin{array}{l}\text { Laguna Bolinas, California, Estados } \\
\text { Unidos }\end{array}$ & Yamaguti (1975) \\
\hline $\begin{array}{l}\text { Renicola } \\
\text { buchamani } \\
\text { (Martin \& } \\
\text { Gregory, 1951) }\end{array}$ & $\begin{array}{l}\text { Cerithidea californica } \\
\text { (Haldeman) (Potamididae) }\end{array}$ & $\begin{array}{l}\text { Fundulus parvipinnis y } \\
\text { Gillichthys mirabilis } \\
\text { (Actinopterygii) }\end{array}$ & [gaviotas] & $\begin{array}{l}\text { Laguna Bolinas, California, Estados } \\
\text { Unidos }\end{array}$ & $\begin{array}{l}\text { Martin \& Gregory } \\
(1951) \\
\text { Yoshino (1975) } \\
\text { Stunkard (1970) }\end{array}$ \\
\hline $\begin{array}{l}\text { Renicola lari } \\
\text { J. Timon-David, } \\
1933\end{array}$ & $\begin{array}{l}\text { Cerithium vulgatum } \\
\text { (Bruguière) y C. rupestre } \\
\text { (Risso) (Cerithiidae) }\end{array}$ & $\begin{array}{l}\text { Atherina hepsetus y A. boyeri } \\
\text { (Actinopterygii) }\end{array}$ & $\begin{array}{l}\text { [Larus argentinus y } \\
\text { L. ridibundus] }\end{array}$ & Laguna du Brusc, Var, Francia & $\begin{array}{l}\text { Prévot \& Bartoli } \\
\text { (1978) }\end{array}$ \\
\hline $\begin{array}{l}\text { Renicola Cercaria } \\
\text { mihi10 } \\
\text { Ching \& Sousa, } \\
1986\end{array}$ & $\begin{array}{l}\text { Cerithidea californica } \\
\text { (Haldeman) (Potamididae) }\end{array}$ & desconocido & desconocido & $\begin{array}{l}\text { Laguna Bolinas, California, Estados } \\
\text { Unidos }\end{array}$ & Ching (1991) \\
\hline $\begin{array}{l}\text { Cercaria indica } \\
\text { XIV } \\
\text { Sewell, } 1922 \\
\end{array}$ & $\begin{array}{l}\text { Melanoides tuberculata } \\
\text { (Müller) (Thiaridae) }\end{array}$ & desconocido & desconocido & costa de India & Sewell (1922) \\
\hline
\end{tabular}


Tabla 13 (continuación). Estadios larvales (en los primeros hospedadores intermediarios) de la familia Renicolidae reportados en el mundo. Se incluye información del ciclo de vida conocido $\left(2^{\circ}\right.$ hospedador intermediario y hospedador definitivo), la localidad y las referencias. Los hospedadores indicados entre corchetes fueron determinados a partir de infecciones experimentales.

\begin{tabular}{|c|c|c|c|c|c|}
\hline Especie & $1^{\circ}$ Hosp. Intermediario & $2^{\circ}$ Hosp. Intermediario & Hosp. Definitivo & Localidad & Referencias \\
\hline $\begin{array}{l}\text { Cercaria tandoni } \\
\text { Saxena, } 1982\end{array}$ & $\begin{array}{l}\text { Melanoides tuberculata } \\
\text { (Müller) (Thiaridae) }\end{array}$ & desconocido & desconocido & costa de India & Saxena (1982) \\
\hline $\begin{array}{l}\text { Cercaria leyteensis } \mathrm{n}^{\circ} 10 \\
\text { Ito, } 1977\end{array}$ & $\begin{array}{l}\text { Melanoides tuberculata } \\
\text { (Müller) (Thiaridae) }\end{array}$ & desconocido & desconocido & costa de Filipinas & Ito (1977) \\
\hline $\begin{array}{l}\text { Cercaria levantina Gold \& } \\
\text { Lengy, } 1974\end{array}$ & $\begin{array}{l}\text { Melanoides tuberculata } \\
\text { (Müller) (Thiaridae) }\end{array}$ & desconocido & desconocido & costa de Israel & $\begin{array}{l}\text { Gold \& Lengy } \\
(1974)\end{array}$ \\
\hline $\begin{array}{l}\text { Cercaria indica XIV } \\
\text { Hasseb, } 1980\end{array}$ & $\begin{array}{l}\begin{array}{l}\text { Melanoides tuberculata } \\
\text { (Müller) (Thiaridae) }\end{array} \\
\end{array}$ & desconocido & desconocido & costa de Pakistán & Haseeb (1980) \\
\hline $\begin{array}{l}\text { Cercaria sp. } 1 \\
\text { Vergara \& Velásquez, } \\
2009\end{array}$ & $\begin{array}{l}\text { Melanoides tuberculata } \\
\text { (Müller) (Thiaridae) }\end{array}$ & desconocido & desconocido & costa de Colombia & $\begin{array}{l}\text { Vergara \& } \\
\text { Velásquez (2009) }\end{array}$ \\
\hline $\begin{array}{l}\text { Cercaria rhodometopa } \\
\text { Pérez, } 1924\end{array}$ & $\begin{array}{l}\text { Turritella communis Risso } \\
\text { (Turritellidae) }\end{array}$ & sardinas & desconocido & $\begin{array}{l}\text { costa de Roscoff y Bahía } \\
\text { Morlaise, Francia }\end{array}$ & Stunkard (1932) \\
\hline Cercaria herpsyllis & $\begin{array}{l}\text { Turritella communis Risso } \\
\text { (Turritellidae) }\end{array}$ & desconocido & desconocido & costa de Gran Bretaña & Rothschild (1935) \\
\hline Carcaria nicarete & $\begin{array}{l}\text { Turritella communis Risso } \\
\text { (Turritellidae) }\end{array}$ & desconocido & desconocido & costa de Gran Bretaña & Rothschild (1935) \\
\hline Cercaria puthionike & $\begin{array}{l}\text { Turritella communis Risso } \\
\text { (Turritellidae) }\end{array}$ & Sprattus sprattus (Actinopterygii) & desconocido & costa de Gran Bretaña & $\begin{array}{l}\text { Rothschild (1935) } \\
\text { Wright (1956) }\end{array}$ \\
\hline Cercaria ranzii & $\begin{array}{l}\text { Turritella communis Risso } \\
\text { (Turritellidae) }\end{array}$ & desconocido & desconocido & costa de Gran Bretaña & Rothschild (1935) \\
\hline Cercaria doricha & $\begin{array}{l}\text { Turritella communis Risso } \\
\text { (Turritellidae) }\end{array}$ & $\begin{array}{l}\text { Trisopterus luscus, Sprattus } \\
\text { sprattus (Actinopterygii) }\end{array}$ & desconocido & costa de Gran Bretaña & $\begin{array}{l}\text { Rothschild \& } \\
\text { Sproston (1941) }\end{array}$ \\
\hline $\begin{array}{l}\text { Cercaria doricha } \\
\text { pigmentata } \\
\text { Wright, } 1956\end{array}$ & $\begin{array}{l}\text { Turritella communis Risso } \\
\text { (Turritellidae) }\end{array}$ & desconocido & desconocido & costa de Gran Bretaña & Wright (1956) \\
\hline $\begin{array}{l}\text { Cercaria cooki } \\
\text { Wright, } 1956 \\
\end{array}$ & $\begin{array}{l}\text { Turritella communis Risso } \\
\text { (Turritellidae) }\end{array}$ & & & costa de Gran Bretaña & Wrigth (1956) \\
\hline $\begin{array}{l}\text { Cercaria opaca } \\
\text { Holliman, } 1961\end{array}$ & $\begin{array}{l}\text { Littoraria irrotata (Say) } \\
\text { (Littorinidae) }\end{array}$ & desconocido & desconocido & $\begin{array}{l}\text { costa de Florida, Estados } \\
\text { Unidos }\end{array}$ & Holliman (1961) \\
\hline
\end{tabular}


Tabla 13 (continuación I). Estadios larvales (en los primeros hospedadores intermediarios) de la familia Renicolidae reportados en el mundo. Se incluye información del ciclo de vida conocido ( $2^{\circ}$ hospedador intermediario y hospedador definitivo), la localidad y las referencias. Los hospedadores indicados entre corchetes fueron determinados a partir de infecciones experimentales.

\begin{tabular}{|c|c|c|c|c|c|}
\hline Especie & $1^{\circ}$ Hosp. Intermediario & $2^{\circ}$ Hosp. Intermediario & Hosp. Definitivo & Localidad & Referencias \\
\hline $\begin{array}{l}\text { Cercaria queenslandae } \\
\text { III } \\
\text { Cannon, } 1978\end{array}$ & Cerithium moniliferum (Kiener) (Cerithiidae) & desconocido & desconocido & $\begin{array}{l}\text { Isla Heron, Gran } \\
\text { Barrera de Corales }\end{array}$ & Cannon (1978) \\
\hline $\begin{array}{l}\text { Cercaria parvicaudata } \\
\text { (Stunkard \& Shaw, } \\
\text { 1931) }\end{array}$ & $\begin{array}{l}\text { Mytilus edulis (Linnaeus) (Mytilidae), } \\
\text { Littorina saxatilis (Olivi) y L. obtusata } \\
\text { (Linnaeus) (Littoriniidae) }\end{array}$ & desconocido & desconocido & $\begin{array}{l}\text { Mar Blanco, Sur Oeste } \\
\text { de Islandia }\end{array}$ & $\begin{array}{l}\text { Stunkard \& Shaw } \\
\text { (1931) } \\
\text { Galaktionov \& } \\
\text { Skirnisson (2000) } \\
\text { Nikolaev et al., } \\
(2006)\end{array}$ \\
\hline $\begin{array}{l}\text { Cercaria caribbea } \\
\text { LXVIII } \\
\text { Cable, } 1963 \\
\end{array}$ & $\begin{array}{l}\text { Cerithium eburneum (Bruguière) } \\
\text { (Cerithiidae) }\end{array}$ & desconocido & desconocido & $\begin{array}{l}\text { costa de Kingston } \\
\text { Harbor, Jamaica }\end{array}$ & Cable (1963) \\
\hline $\begin{array}{l}\text { Cercaria caribbea XXXII } \\
\text { Cable, } 1956\end{array}$ & Cerithidea costata (da Costa) (Potamididae) & desconocido & desconocido & $\begin{array}{l}\text { Bahía Sucia, Cabo Rojo, } \\
\text { Puerto Rico }\end{array}$ & Cable (1963) \\
\hline $\begin{array}{l}\text { Cercaria caribbea } \\
\text { XXXIII } \\
\text { Cable, } 1956\end{array}$ & Cerithium lutosum (Menke) (Cerithiidae) & desconocido & desconocido & $\begin{array}{l}\text { Bahía Santa Martha, } \\
\text { Curaçao }\end{array}$ & Cable (1963) \\
\hline $\begin{array}{l}\text { Cercaria kuwaitae X sp. } \\
\text { Abdul-Salam \& } \\
\text { Sreelatha, } 1997\end{array}$ & Cerithium scabrid (Philippi) (Cerithiidae) & desconocido & desconocido & Bahía Kuwai, Arabia & $\begin{array}{l}\text { Abdul-Salam \& } \\
\text { Sreelatha (1997) }\end{array}$ \\
\hline $\begin{array}{l}\text { Cercaria Renicolidae I } \\
\text { Miura \& Chiba, } 2007\end{array}$ & $\begin{array}{l}\text { Batillaria attramentaria (Sowerby) } \\
\text { (Batiilaridae) }\end{array}$ & desconocido & desconocido & $\begin{array}{l}\text { Bahía Katsugigaura, } \\
\text { Miyagi Prefecture, } \\
\text { Japón }\end{array}$ & $\begin{array}{l}\text { Miura \& Chiba } \\
(2007)\end{array}$ \\
\hline $\begin{array}{l}\text { Renicola sp. } \\
\text { Martorelli, } \\
\text { Fredensborg, Leung \& } \\
\text { Poulin, 2008 }\end{array}$ & $\begin{array}{l}\text { Zeacumantus subcarinatus (Sowerby) } \\
\text { (Batillariidae) }\end{array}$ & desconocido & desconocido & $\begin{array}{l}\text { costa de Nueva } \\
\text { Zelanda }\end{array}$ & $\begin{array}{l}\text { Martorelli et al. } \\
(2008)\end{array}$ \\
\hline
\end{tabular}


Tabla 13 (continuación II). Estadios larvales (en los primeros hospedadores intermediarios) de la familia Renicolidae reportados en el mundo. Se incluye información del ciclo de vida conocido ( $2^{\circ}$ hospedador intermediario y hospedador definitivo), la localidad y las referencias. Los hospedadores indicados entre corchetes fueron determinados a partir de infecciones experimentales.

\begin{tabular}{|c|c|c|c|c|c|}
\hline Especie & $1^{\circ}$ Hosp. Intermediario & $2^{\circ}$ Hosp. Intermediario & Hosp. Definitivo & Localidad & Referencias \\
\hline $\begin{array}{l}\text { Renicola sp. } \\
\text { Pinto \& Melo, } \\
2012\end{array}$ & Melanoides tuberculata Müller (Thiaridae) & $\begin{array}{l}\text { Poecilia reticulate } \\
\text { (Actinopterygii) }\end{array}$ & desconocido & $\begin{array}{l}\text { costa de Belo Horizonte, Minas } \\
\text { Gerais, Brasil }\end{array}$ & $\begin{array}{c}\text { Pinto \& } \\
\text { Melo (2012) }\end{array}$ \\
\hline $\begin{array}{l}\text { Renicolidae } \\
\text { gen. et sp. } 1\end{array}$ & $\begin{array}{l}\text { Trophon geversianus (Pallas) } \\
\text { (Muricidae) }\end{array}$ & Mytilus edulis (Bivalvia) & desconocido & $\begin{array}{l}\text { Playa Fracasso (Golfo San José), } \\
\text { Puerto Madryn (Golfo Nuevo) y } \\
\text { Puerto Deseado, Argentina }\end{array}$ & $\begin{array}{l}\text { Gilardoni, et } \\
\text { al., (2011) } \\
\text { Bagnato (2012) } \\
\text { presente } \\
\text { estudio }\end{array}$ \\
\hline
\end{tabular}




\subsubsection{Parorchis sp. (Philophtalmidae)}

Los digeneos adultos del género Parorchis Nicoll, 1907 habitan la cloaca o bursa de Fabricio de aves marinas (Kanev et al., 2005). Hasta el momento se han descripto tres especies de este género cuyo ciclos de vida son conocidos (Tabla 14). Entre ellas, Parorchis acanthus (Nicoll, 1906) es una especie que finaliza su ciclo en aves Charadriiformes y se reportó en diferentes partes del mundo, como América Central y Norte, Europa y Nueva Zelanda (Holliman, 1961; Yamaguti, 1975; Ching, 1991; Latham \& Poulin, 2002).

El ciclo de vida típico involucra un gasterópodo, principalmente de las familias Muricidae, Potamididae o Littorinidae como $1^{\circ}$ HI. Las cercarias se desarrollan dentro de redias, luego emergen al medio y enquistan sobre sustratos duros o sobre valvas, manto u opérculo de moluscos que pueden ser o no el mismo $1^{\circ} \mathrm{HI}$ (ver ref. Tabla 14).

Los estadios larvales de la especie descripta en este estudio presentó una secuencia (ITS1-5.8S-ITS2-28S) idéntica a la secuencia de los adultos de la gaviota cocinera L. dominicanus de Puerto Deseado (Diaz et al., 2011) y del playero de rabadilla blanca Calidris fuscicollis de Bahía Lomas (Tierra del Fuego) (J. Diaz, datos no publicados). Adultos con características morfológicas idénticas fueron hallados también en Calidris bairdii (Coues) (Scolopacidae) (J. Diaz, datos no publicados). El adulto de L. dominicanus, C. fuscicollis y C. bairdii es similar morfológicamente a $P$. acanthus; sin embargo, la identidad de esta especie fue recientemente cuestionada (Dronen \& Blend, 2008) y las secuencias moleculares obtenidas a partir de ejemplares identificados como tales son diferentes (V. Tkach, com. pers.), indicando que se trataría de una nueva especie, siendo la primera del género registrada en Argentina. Al igual que las otras especies de Parorchis estudiadas, se observó un rápido enquistamiento de las cercarias emitidas en el fondo del frasco donde tuvo lugar la emisión. Es probable que en la naturaleza, la metacercaria enquiste sobre valvas de moluscos que sirvan de alimento a la gaviota cocinera y al playero de rabadilla blanca (Fig. 65). 


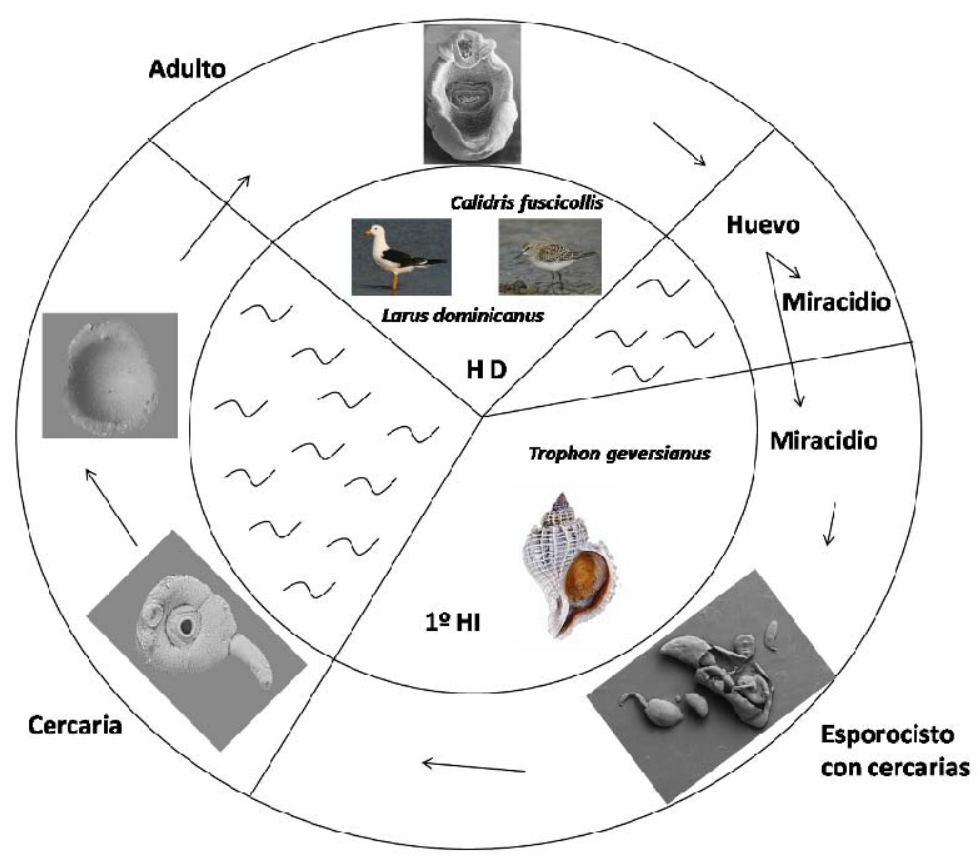

Figura 65. Ciclo de vida de Parorchis sp. (Philophtalmidae). Abreviaturas: HI- hospedador intermediario; HD- hospedador definitivo. 
Tabla 14. Estadios larvales (en los $1^{\circ}$ hospedadores intermediarios) del género Parorchis (Philophtalmidae) reportados en el mundo. Se incluye información de los ciclos de vida conocidos ( $2^{\circ}$ hospedador intermediario y hospedador definitivo), la localidad y las referencias. Los hospedadores indicados entre corchetes fueron determinados a partir de infecciones experimentales.

\begin{tabular}{|c|c|c|c|c|c|}
\hline Especie & $1^{\circ}$ Hosp. Intermediario & $2^{\circ}$ Hosp. Intermediario & Hosp. Definitivo & Localidad & Referencias \\
\hline $\begin{array}{l}\text { Parorchis } \\
\text { avitus } \\
\text { Linton, } 1914\end{array}$ & $\begin{array}{l}\text { Urosalpinx cinerea (Say) y Nucella lapillus } \\
\text { (Linnaeus) (Muricidae) }\end{array}$ & $\begin{array}{l}\text { [enquista en el sustrato y en } \\
\text { valvas de moluscos] }\end{array}$ & $\begin{array}{l}\text { Sterna hirundo y Larus } \\
\text { argentatus }\end{array}$ & $\begin{array}{l}\text { costa de Woode Hole, } \\
\text { Estados Unidos }\end{array}$ & $\begin{array}{l}\text { Stunkard \& } \\
\text { Cable (1932) } \\
\text { Yamaguti (1975) }\end{array}$ \\
\hline $\begin{array}{l}\text { Parorchis } \\
\text { acanthus } \\
\text { (Nicoll, } \\
\text { 1906) } \\
\text { Nicoll, } 1907\end{array}$ & $\begin{array}{l}\text { Nucella lapillus (Linnaeus), N. lamellosa } \\
\text { (Gmelin) y N. emarginata (Deshayes) } \\
\text { (Muricidae), Cerithidea scalariformis (Say), C. } \\
\text { californica (Haldeman) (Potamididae) }\end{array}$ & $\begin{array}{l}\text { [enquista en el sustrato, en } \\
\text { valvas de moluscos, en el manto } \\
\text { de Cardium edule y Mytilus edulis } \\
\text { (Bivalvia)] }\end{array}$ & $\begin{array}{l}\text { [gaviotas, gaviotines } \\
\text { y pollitos], } \\
\text { Larus dominicanus, } L \text {. } \\
\text { argentatus, L. canus, } \\
\text { Tringa melanoleuca }\end{array}$ & $\begin{array}{l}\text { costas de Aberystwyth, } \\
\text { Florida, } \\
\text { Laguna Bolinas, } \\
\text { California } \\
\text { Thetis I., British } \\
\text { Columbia, } \\
\text { Sudoeste de Islandia } \\
\text { Nueva Zelanda, } \\
\text { Noreste de Venezuela }\end{array}$ & $\begin{array}{l}\text { Holliman (1961) } \\
\text { Yamaguti (1975) } \\
\text { Ching (1991) } \\
\text { Skirnisson \& } \\
\text { Galaktionov } \\
\text { (2000) } \\
\text { Latham \& } \\
\text { Poulin (2002) }\end{array}$ \\
\hline $\begin{array}{l}\text { Parorchis } \\
\text { acanthus } \\
\text { australis } \\
\text { Angel, } 1954\end{array}$ & $\begin{array}{l}\text { Bembicium auratum (Quoy \& Gaimard), B. } \\
\text { melanostoma (Gmelin), B. nanum (Lamarck) } \\
\text { (Littorinidae)y Lepsiella flindersi (Adams \& } \\
\text { Agnas) (Muricidae) }\end{array}$ & $\begin{array}{l}\text { [enquista en el sustrato y en el } \\
\text { opérculo de } B \text {. auratum] }\end{array}$ & $\begin{array}{l}\text { [Larus novae- } \\
\text { hollandiae] }\end{array}$ & costa sur de Australia & Yamaguti (1975) \\
\hline Parorchis sp. & Trophon geversianus (Pallas) (Muricidae) & [enquista sobre sustratos duros] & $\begin{array}{l}\text { Larus dominicanus, } \\
\text { Calidris fuscicollis, C. } \\
\text { bairdii }\end{array}$ & $\begin{array}{l}\text { Puerto Madryn, Puerto } \\
\text { Deseado, Bahía Lomas } \\
\text { (Tierra del Fuego), } \\
\text { Argentina }\end{array}$ & $\begin{array}{l}\text { Diaz et al. (2011) } \\
\text { Gilardoni et al. } \\
\text { (2011) } \\
\text { presente estudio }\end{array}$ \\
\hline
\end{tabular}




\subsubsection{Schistosomatidae gen. et sp.}

Los digeneos de la familia Schistosomatidae Stiles \& Hassall, 1898 son un grupo peculiar de trematodes cuyos adultos maduran en el sistema vascular sanguíneo de sus hospedadores definitivos (aves o mamíferos) y son generalmente dioicos (Khalil, 2002).

Los esquistosomátidos de aves son un grupo especializado de trematodes cuyos adultos habitan dentro del sistema circulatorio o tejidos nasales de las aves. Poseen ciclos de vida que involucran dos $\mathrm{HI}$, un $1^{\circ} \mathrm{HI}$ (gasterópodo) en el cual se desarrollan los esporocistos y cercarias y un hospedador definitivo en el cual la cercaria penetra en forma activa atravesando el tegumento. Son importantes patógenos de aves y frecuentemente responsables de la dermatitis humana cercarial causada por la penetración activa de cercarias de especies de los géneros Gigantobilharzia, Ornithobilharzia, Trichobilharzia y Austrobilharzia (Huffman \& Fried, 2008).

La cercaria aquí descripta en S. lessonii de Puerto Deseado, presenta características similares a las del género Gigantobilharzia, siendo éste uno de los dos géneros con especies registradas en gasterópodos marinos (Horák et al., 2002). Hasta el momento, se describieron tres cercarias de este género (Tabla 15) y sólo Gigantobilharzia huttoni (Leigh, 1953) utiliza un gasterópodo marino como $1^{\circ} \mathrm{HI}$ (Yamaguti, 1975). Varios adultos de éste género han sido halladas en aves Charadriiformes, Anseriiformes, Ciconiiformes y Passeriformes (Tabla 13.3 en Huffman \& Fried, 2008). Es probable que la gaviota cocinera, L. dominicanus, actúe como hospedador definitivo de esta especie (Fig. 66). Otras gaviotas fueron reportadas en el mundo como hospedadores definitivos del género Gigantobilharzia, como Gigantobilharzia sp. en L. dominicanus en las costas de Sudáfrica (Appleton \& Randall, 1986) y Gigantobilharzia acotylea Odhner, 1910 en Larus cachinnans Pallas (Laridae) en el noreste de España (Sanmartín et al., 2005). 


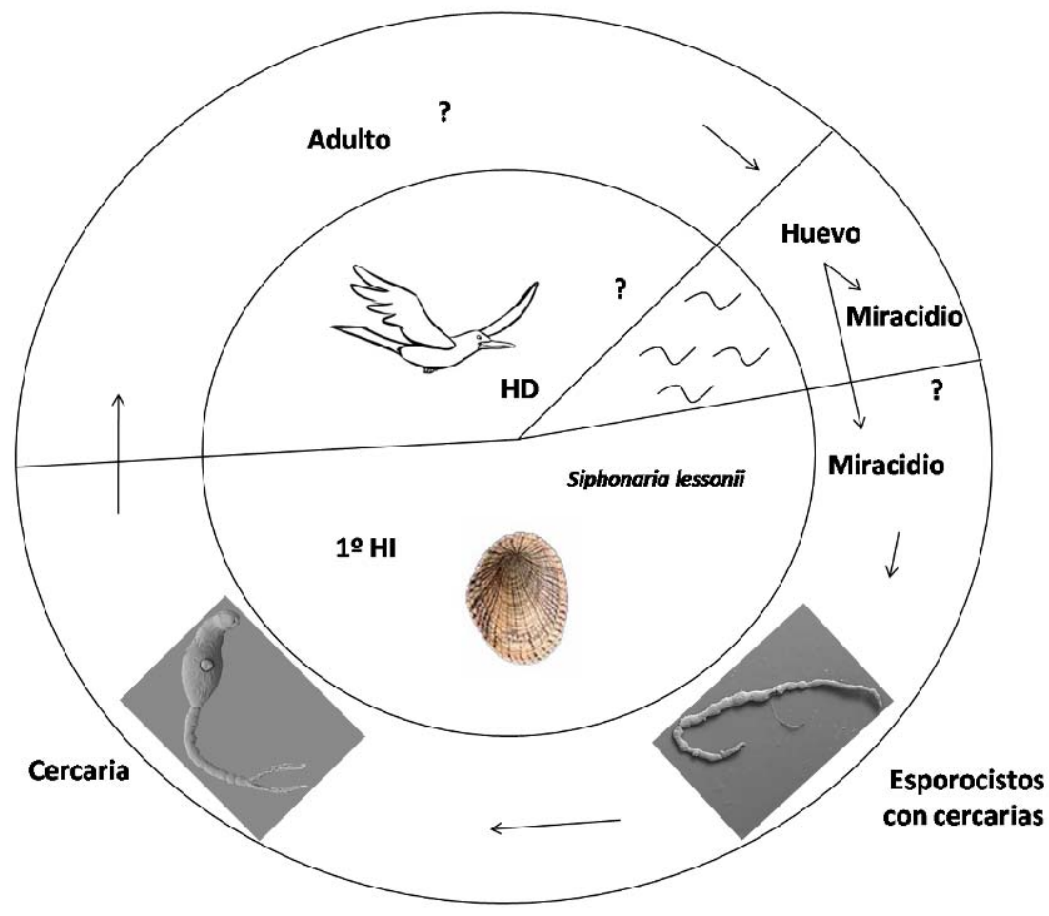

Figura 66. Ciclo de vida de Schistosomatidae gen. et sp. Los dibujos de hospedadores y los estadios larvales indicados con signo de interrogación no se conocen. Abreviaturas: HIhospedador intermediario; HD- hospedador definitivo.

Tabla 15. Estadios larvales (en los $1^{\circ}$ hospedadores intermediarios) del género Gigantobilharzia (Schistosomatidae) reportados en el mundo. Se incluye información de los ciclos de vida conocidos $\left(2^{\circ}\right.$ hospedador intermediario y hospedador definitivo), la localidad y las referencias. Los hospedadores indicados entre corchetes fueron determinados a partir de infecciones experimentales.

\begin{tabular}{|c|c|c|c|c|}
\hline Especie & $1^{\circ}$ Hosp. Intermediario & $\begin{array}{l}\text { Hosp. } \\
\text { Definitivo }\end{array}$ & Localidad & Referencias \\
\hline $\begin{array}{l}\text { Gigantobilharzia } \\
\text { sturniae (Tanabe, } \\
1948 \text { ) }\end{array}$ & $\begin{array}{l}\text { Segmentina nitidella } \\
\text { (Müller) (Planorbidae) }\end{array}$ & desconocido & Japón & $\begin{array}{l}\text { Komiya \& Ito } \\
(1952) \\
\text { Yamaguti } \\
(1975)\end{array}$ \\
\hline $\begin{array}{l}\text { Gigantobilharzia } \\
\text { huronensis } \\
\text { Najim, } 1950\end{array}$ & $\begin{array}{l}\text { Physa gyrina } \\
\text { Schumacher (Physidae) }\end{array}$ & $\begin{array}{l}\text { [pollitos y } \\
\text { canarios] }\end{array}$ & Estados Unidos & $\begin{array}{l}\text { Yamaguti } \\
(1975) \\
\text { Brant et al. } \\
(2011)\end{array}$ \\
\hline $\begin{array}{l}\text { Gigantobilharzia } \\
\text { huttoni (Leigh, 1953) }\end{array}$ & $\begin{array}{l}\text { Haminoea antillarum } \\
\text { guadalupensis (Sowerby) } \\
\text { (Haminoeidae) }\end{array}$ & [pericos] & Estados Unidos & $\begin{array}{l}\text { Yamaguti } \\
\text { (1975) }\end{array}$ \\
\hline $\begin{array}{l}\text { Schistosomatidae } \\
\text { gen. et sp. }\end{array}$ & $\begin{array}{l}\text { Siphonaria lessonii } \\
\text { (Blainville) } \\
\text { (Siphonariidae) }\end{array}$ & desconocido & $\begin{array}{l}\text { Playa Fracasso (Golfo San } \\
\text { José), Comodoro } \\
\text { Rivadavia y Puerto } \\
\text { Deseado, Argentina }\end{array}$ & $\begin{array}{l}\text { Alda \& } \\
\text { Martorelli } \\
(2009) \\
\text { Bagnato } \\
\text { (2012) } \\
\text { presente } \\
\text { estudio }\end{array}$ \\
\hline
\end{tabular}




\subsection{Discusión general y conclusiones}

En el presente trabajo se lograron dilucidar dos ciclos de vida en forma completa, identificando los $1^{\mathrm{o}}$ y $2^{\circ} \mathrm{HI}$ y el hospedador definitivo y tres ciclos de vida en forma parcial, identificando el $2^{\circ} \mathrm{HI}$ o el hospedador definitivo, además del $1^{\circ} \mathrm{HI}$. Las especies cuyos ciclos de vida fueron dilucidados en forma completa son Maritrema madrynense y Parorchis sp., y las especies cuyos ciclos de vida fueron dilucidados en forma parcial son Diphterostomum sp., Gymnophalloides nacellae y Renicolidae gen. et sp. 1 (ver Anexo VIII).

El gasterópodo Siphonaria lessonii de ambos sitios de estudio, actúa como $1^{\mathrm{o}}$ HI del digeneo M. madrynense, albergando esporocistos con cercarias y/ o metacercarias. Las cercarias pueden emergen al medio y penetrar en los crustáceos Cyrtograpsus altimanus e Idotea baltica $\left(2^{\circ} \mathrm{HI}\right)$, enquistar en el celoma y desarrollar a estadio metacercaria. Alternativamente, las metacercarias pueden desarrollarse dentro de los esporocistos en S. lessonii, actuando éste gasterópodo como $1^{\circ}$ y $2^{\circ} \mathrm{HI}$ (ciclo abreviado). El hospedador definitivo de esta especie es la gaviota cocinera Larus dominicanus, que se infecta cuando se alimenta de estos crustáceos o de los gasterópodos parasitados con metacercarias. Este ciclo de vida se dilucidó en Puerto Madryn, ya que en el intermareal de Puerto Deseado no se hallaron estos crustáceos. Es probable que M. madrynense utilice varias especies de crustáceos como $2^{\circ} \mathrm{HI}$, según la disponibilidad en el área, al igual que la mayoría de las especies de Maritrema (ver ref. Tabla 10). Combes (2001) utilizó el termino de "filtros" para explicar los mecanismos responsables del espectro de hospedadores de una especie de digeno. El "filtro de encuentro", que depende de la diversidad y el comportamiento de los hospedadores, se define como la probabilidad de contacto entre el parásito y el hospedador. El filtro de "compatibilidad", que depende de los recursos y de los mecanismos de defensa del hospedador, se define como la probabilidad de que un parásito y un hospedador vivan juntos luego del encuentro. Para que exista una relación parásito-hospedador, ambos filtros deben estar abiertos y esto puede ocurrir en diferentes niveles. En el caso de los microfálidos, el filtro de compatibilidad se limita al subphylum Crustacea, ya que las cercarias pueden 
ingresar en isópodos, copépodos, cirripedios o crustáceos decápodos (ver ref. Tabla 10). Maritrema madryense se registró en varios sitios de la costa patagónica (Alda \& Martorelli, 2009; Gilardoni et al., 2011; Bagnato 2012) y los segundos hospedadores intermediarios (C. altimanus e I. baltica) fueron hallados en Puerto Madryn. Es probable que el espectro de hospedadores intermediarios de esta especies varie de un sitio a otro, dependiendo de los crustáceos disponibles en el área, siendo entonces el filtro de encuentro el principal determinante en la transmisión de esta especie.

El gasterópodo Trophon geversianus de ambos sitios de estudio, actúa como $1^{\circ}$ HI del digeneo Parorchis sp., albergando redias con cercarias. Las cercarias emergen al medio y enquistan sobre el sustrato o probablemente sobre valvas de moluscos. Los hospedadores finales de esta especie son la gaviota cocinera Larus dominicanus y el playero de rabadilla blanca Calidris fuscicollis, que se infectarían cuando se alimentan de moluscos con metacercarias en la valva o de metacercarias enquistadas en el sustrato. Si bien no se pudo establecer el lugar donde enquista la metacercaria, según los registro bibliográficos, podría enquistar en el opérculo o en la valva de T. geversianus, en la valva o manto de otro molusco o sobre el sustrato. Trophon geversianus habita sobre bancos de mejillones o mejillines, de los cuales se alimenta (Andrade \& Ríos, 2007). La gaviota cocinera se alimenta de T. geversianus y de varias especies de mitílidos (Yorio \& Bertelloti, 2002) y, si bien no se registraron mitílidos en la dieta del playero de rabadilla blanca, se conoce que se alimenta de bivalvos, como la almeja Darina solenoides (Hernández et al., 2008) y se observó que se alimenta de mitílidos en el intermareal rocoso (L. Bala, comp. pers.). Este digeneo estaría actuando como un indicador de la dieta y del área de alimentación del playero de rabadilla blanca, ya que $T$. geversianus se localiza exclusivamante en los intermareales rocosos sobre mejillones. En este estudio se observó que la cercaria enquista poco después de su emergencia, lo que indicaría que la metacercaria se desarrolla en las cercanías sobre el sustrato o sobre valvas de mitílidos. Bajo este escenario, para que el ciclo pueda completarse, el playero de rabadilla blanca debe alimentarse en estas áreas. En este caso, es probable, que el filtro de compatibilidad sea amplio, ya que los adultos de esta especie se hallaron en aves Charadriiformes y 
que una vez más, el espectro de hospedadores definitivos dependa del filtro de encuentro (aves alimentándose en el intermareal rocoso).

El gasterópodo Buccinanops globulosus de Puerto Madryn actúa como $1^{\text {o }} \mathrm{HI}$ del digeneo Diphterostomum sp., albergando esporocistos con cercarias y/o metacercarias. Las cercarias pueden emerger al medio y penetrar en un $2^{\circ} \mathrm{HI}$ que aún se desconoce, pero se sospecha que puede ser el bivalvo Tellina petitiana, poliquetos o erizos. Alternativamente, las metacercarias pueden desarrollarse dentro de los esporocistos en B. globulosus, actuando este gasterópodo como $1^{\mathrm{o}}$ y $2^{\mathrm{o}}$ HI (ciclo abreviado). El hospedador definitivo de esta especie es el turco Pinguipes brasilianus, que se infecta cuando se alimenta de estos invertebrados o de gasterópodos parasitados con metacercarias. Futuras disecciones de invertebrados que habitan el submareal somero arenososo de Puerto Madryn contribuirán a conocer el $2^{\circ} \mathrm{HI}$ para esta especie.

El gasterópodo Nacella (P.) magellanica de Puerto Deseado actúa como $2^{\circ} \mathrm{HI}$ del digeneo Gymnophalloides nacellae, albergando metacercarias en el espacio extrapaleal (entre el manto y la valva). El $1^{\circ} \mathrm{HI}$ de esta especie es el bivalvo Gaimardia trapesina, que alberga esporocistos con cercarias. Las cercarias emergen al medio y penetran en $N$. (P.) magellanica, donde desarrollan a estadio metacercaria. El hospedador definitivo se desconoce, pero podría ser la gaviota cocinera $L$. dominicanus o el ostrero negro Haematopus ater, dado que estas aves predan sobre la lapa en otros sitios de la costa patagónica (Yorio \& Bertellotti, 2002; Sapoznikow et al., 2008). Además, los gasterópodos $N$. (P.) magellanica son de gran tamaño y se adhieren fuertemente al sustrato, por lo que es una presa inaccesible para otras aves de la zona. Futuras disecciones de gaviotas cocinera y ostreros negros que se alimentan en el intermareal de Puerto Deseado permitirán establecer si estas aves actúan como hospedadores definitivos en el ciclo de vida.

El gasterópodo Trophon geversianus de ambos sitios de estudio, actúa como $1^{\circ}$ HI del digeneo Renicolidae gen. et sp. 1, albergando esporocistos con cercarias. Las cercarias emergen al medio y penetran en el bivalvo Mytilus edulis ( $\left.2^{\circ} \mathrm{HI}\right)$ y enquistan en la glándula digestiva. Otros bivalvos (Perumytilus purpuratus, Aulacomya atra, Lasaea adansoni y Gaimardia trapesina), en los cuales se hallaron 
metacercarias Renicolidae, también actuarían como $2^{\circ} \mathrm{HI}$ (Cremonte, 1999; datos no publicados). Nuevamente, la presencia de metacercarias en varias especies de bivalvos (filtro por compatibilidad amplio), indicaría que el $2^{\circ} \mathrm{HI}$ depende de la disponibilidad en el ambiente de bivalvos filtradores, ya que la cercaria penetraría pasivamente (filtro por encuentro). El hospedador definitivo de esta especie podría ser la gaviota cocinera L. dominicanus, en la cual recientemente se hallaron adultos de una especie de Renicolidae (datos no publicados). La gaviota cocinera se infectaría al alimentarse de bivalvos con metacercarias. Futuros estudios morfológicos de los adultos y estudios moleculares de las metacercarias y de los adultos contribuirán a completar el ciclo de vida de esta especie.

Para el resto de las especies descriptas en este estudio no se lograron avances en el conocimiento de sus ciclos de vida; sin embargo, se hallaron algunos estadios larvales en invertebrados de los sitios de estudio, lo cual podría contribuir en el futuro a dilucidar los ciclos de vida de algunas de las especies. Entre ellos, se hallaron metacercarias de la familia Hemiuridae en el ctenóforo Mnemiopsis leydi y metacercarias de la familia Lepocreadiidae en los bivalvos G. trapesina (Ituarte et al., 2001, 2005). Futuros estudios moleculares de estas metacercarias contribuirán a establecer si se corresponden con alguno de los digeneos descriptos. Por otro lado, se han registrado en la costa patagónica 26 digeneos de la familia Hemiuridae y dos digeneos de la familia Lepocreadiidae parasitando peces (Szidat, 1950; Gosztonyi, 1979; Suriano \& Sutton; 1980; Sardella et al., 1998; Timi et al., 1999; MacKenzie, 2003; Timi, 2003; Sardella \& Timi, 2004; Carballo, 2006; Braicovich \& Timi, 2008; Braicovich et al., 2009; Timi \& Lanfranchi, 2009). Futuras disecciones de peces y estudios morfológicos y moleculares de los adultos contribuirán a conocer si se corresponden con alguno de los digeneos descriptos.

De las 13 especies descriptas en el presente trabajo, cinco utilizan peces y ocho utilizan aves como hospedadores definitivos. A pesar de que la información sobre las comunidades de parásitos en ecosistemas intermareales a gran escala es escasa, otros trabajos registran una mayor proporción de digeneos finalizando sus ciclos de vida en aves. Por ejemplo, un relevamiento de la comunidad de macroparásitos en moluscos que habitan pozas de marea en el Mar de Wadden, 
reporta 17 especies de digeneos que utilizan aves como hospedadores definitivos y tres especies que utilizan peces (Thieltges et al., 2006). Además, un estudio realizado en seis especies de gasterópodos que habitan varios intermareales en el Sudoeste de Islandia, reportó 18 especies de digeneos que utilizan aves como hospedadores definitivos y sólo una especie de digeneo que utiliza peces (Galaktionov \& Skirnisson, 2000).

Si bien en los sitios de estudio de Puerto Madryn y Puerto Deseado se registró un alto porcentaje de digeneos que finalizan su ciclo de vida en aves (62\%), la proporción de digeneos que finalizan su ciclo de vida en peces es más alta que la esperada para un ecosistema intermareal. Esto podría deberse a la existencia de varios peces de arrecife que habitan las zonas intermareales inferiores en forma permanente, como por ejemplo el diablillo Helcogrammoides cunninghami (Smitt) (Tripterygiidae), juveniles del pez gallo Callorhynchus callorhynchus (Linnaeus) (Callorhinchidae) y varias especies de nototénidos y zoárcidos, o bien, que utilizan el área transitoriamente durante la pleamar para alimentarse, como por ejemplo el róbalo Eleginops maclovinus, el turco Pinguipes brasilianus, la vieja Bovichtus argentinus MacDonagh (Bovichtidae), los pejerreyes Odontesthes smitti y Odontesthes nigricans y lo cornalitos Odontesthes incisa (Jenyns) (Atherinidae) (Di Giacomo \& Perier, 1996; Dyer, 2003; Irigoyen \& Galván, 2009). Los peces pequeños como el diablillo y los juveniles de róbalos, pejerreyes y cornalitos, así como otros invertebrados pelágicos como los ctenóforos, medusas y copépodos actuarían como $2^{\circ} \mathrm{HI}$, permitiendo que los adultos de estas especies de digeneos maduren en peces que habitan a mayores profundidades. Los sitios de estudio, Punta Cuevas en Puerto Madryn y la desembocadura de la Ría Deseado en Puerto Deseado, son áreas con un bajo hidrodinamismo, de aguas calmas, poca pendiente y con gran amplitud de marea (máxima aproximada de 6 m) (Bastida et al., 1992, Servicio de Hidrografía Naval). Las condiciones de estos ambientes intermareales rocosos favorecen que una gran variedad de peces se acerquen a alimentarse durante la pleamar y que una gran diversidad de aves se alimente más tiempo durante la bajamar. 
Los ciclos de vida de los digeneos que finalizan en aves están promovidos por una gran diversidad de aves marinas costeras que nidifican en el supralitoral como cormoranes, láridos, anátidos y aquellas aves que son endémicas de los humedales o migratorias como los playeros, chorlitos, cauquenes, el macá Podiceps gallardoi Rumboll (Podicipedidae) y cuatro especies de pato vapor (Tachyeres spp.) (Gandini \& Frere, 1998; Coconier, 2006). Las aves que suelen alimentarse en los intermareales costeros son el biguá Phalacrocorax brasilianus (Gmelin), el cormorán imperial Phalacrocorax atriceps (King), el cormorán roquero Phalacrocorax magellanicus (Gmelin) (Phalacrocoracidae), el ostrero común Haematopus palliatus Temminck, el ostrero austral Haematopus leucopodus Garnot, el ostrero negro Haematopus ater, el chorlito doble collar Charadrius falklandicus Latham (Charadriidae), la gaviota cocinera L. dominicanus, la gaviota capucho café Larus maculipennis Lichtenstein, la gaviota gris Leucophaeus scoresbii Traill (Laridae), el gaviotín sudamericano Sterna hirundinacea Lesson (Sternidae), el chorlito ceniciento Pluvianellus socialis Gray (Pluvianellidae), el playero blanco Calidris alba (Pallas), el playero rojizo Calidris canutus rufa, el playero de rabadilla blanca Calidris fuscicollis, el playerito trinador Numenius phaeopus (Linnaeus), la becasa de mar Limosa haemastica (Linnaeus) (Scolopacidae), el macá grande Podicipes major, el pato crestón Speculanas specularis King y el pato vapor pico amarillo Tachyeres patachonicus (King) (Anatidae) (Gandini \& Frere, 1998; Sapoznikow et al., 2008; A. Morgenthaler \& A. Millones, com. pers.).

De las ocho especies de digeneos larvales descriptas en este estudio, dos finalizan su ciclo de vida en la gaviota cocinera (M. madrynense y Parorchis sp.). También se sospecha que cinco especies de digeneos utilizarían a L. dominicanus como hospedador definitivo. Esta hipótesis se basa, en el caso de los digeneos G. nacellae y Notocotylidae gen. et sp., en que el gasterópodo $N$. (P.) magellanica constituye parte de la dieta de L. dominicanus (Yorio \& Bertellotti, 2002), en el caso de Renicolidae gen. et sp.1 y Renicolidae gen. et sp. 2 en que se hallaron adultos de esta familia en el riñón de la gaviota (datos no publicados) y en el caso de Schistosomatidae gen. et sp., en que otras gaviotas fueron registradas como hospedadores definitivos de especies del género Gigantobilharzia, género al cual 
pertenecería la larva descripta (Appleton \& Randall, 1986; Sanmartín et al., 2005). La gaviota cocinera es una especie oportunista y generalista, con una amplia dieta constituida principalmente por invertebrados marinos y peces (Bertellotti \& Yorio, 1999). Además, es una especie muy abundante y de amplia distribución en la República Argentina (Yorio et al., 1998). Estas características convierten a la gaviota cocinera en un hospedador definitivo ampliamente explotado por los digeneos.

Ocho de las 13 especies descriptas en el presente trabajo poseen ciclos de vida con dos $\mathrm{HI}$ y un hospedador definitivo (ciclos triexenos). Los ciclos de vida triexenos son los más frecuentes entre los digeneos (Galaktionov \& Dobrovolskij, 2003). Dichos parásitos poseen estructuras especializadas para emerger al medio ambiente y penetrar en forma activa en un $2^{\circ} \mathrm{HI}$ (Ginetsinkaya, 1988). Los digeneos microfálidos (Maritrema sp. 1 y M. madrynense) poseen cola, estilete conspicuo cubierto con una capa refractiva y glándulas de penetración repletas de material de secreción (Galaktionov \& Skirnisson, 2007). Las cercarias de las familias Renicolidae (Renicolidae gen. et sp. 1 y Renicolidae gen. et sp. 2) y Philophthalmidae (Parorchis sp.) poseen glándulas cistógenas bien desarrolladas para enquistarse en el $2^{\circ} \mathrm{HI}$ (bivalvo o pez) o en el sustrato (Prévot \& Bartoli, 1978). Las cercarias cistóforas (Hemiuroidea fam. gen. et sp.) poseen un quiste caudal en el cual la cercaria se protege al emerger al medio y filamentos caudales, los cuales les permiten moverse en la columna de agua y atraer a los $2^{\circ} \mathrm{HI}$ (medusas, ctenóforos, quetognatos, copépodos, peces) (Køie, 1979). Las cercarias lepocreadides (Lepocreadiidae gen. et sp. 1 y Lepocreadiidae gen. et sp. 2) poseen grandes colas provistas de setas para desplazarse en la columna de agua, imitando el movimiento de un poliqueto y manchas oculares fotoreceptoras que le permiten hallar a los $2^{\circ} \mathrm{HI}$ (ctenóforos, medusas, quetognatos, gasterópodos, bivalvos, peces, anélidos y renacuajos) (Stunkard, 1979b; Bartoli, 1983).

El movimiento y las características de las cercarias pueden reflejar adaptaciones comportamentales para incrementar la probabilidad de encontrar un determinado espectro de hospedadores (Ginetsinkaya, 1988; Combes, 2001). Según Ginetsinkaya (1988) exiten tres tipos principales de adaptaciones. La primera consiste en el movimiento activo y continuo, estrategia que utilizan muchas 
especies de xifidocercarias con cola, como son las cercarias microfálides y renicolides. Las cercarias se agrupan cerca de la superficie o cerca del fondo (dependiendo de su taxismo) e ingresan a un invertebrado por filtración o por vía trófica. En este estudio, se observó que tanto las cercarias microfálides como las renicólides emergen del gasterópodo hospedador en forma masiva y se mueven rápidamente de manera continua en la columna de agua; luego de un tiempo continúan su movimiento cerca del fondo. Las cercarias renicólides ingresarían a los mitílidos $\mathrm{u}$ otros bivalvos pasivamente por filtración y las cercarias microfálides ingresarían a los crustáceos a través de las corrientes respiratorias. En muchos casos, las cercarias alternan períodos de movimiento activo con períodos de descanso (Gintesinkaya, 1988). Este tipo de movimiento es típico de las furcocercarias que presentan rápidos movimientos en espiral hacia arriba y luego se dejan caer. En el presente estudio, este tipo de movimiento se observó también en las cercarias lepocreádides. Es probable que durante los períodos de movimiento, con sus grandes colas cubiertas de setas, atraigan a los invertebrados planctónicos y/o bentónicos e ingresen por vía trófica o por filtración. El segundo tipo de adaptación es el deslizamiento pasivo de las cercarias en el agua, que comúnmente desarrollan las especies que utilizan como $2^{\circ} \mathrm{HI}$ a organismos planctónicos. Por ejemplo, las cercarias Hemiuroidea resguardan su cuerpo en un quiste esférico o aplanado provisto con largos filamentos caudales que le permite flotar en la columna de agua durante el tiempo en que viven y ser presa para copépodos y otros organismos planctónicos. En este estudio, no se observó este tipo de movimiento, ya que no se obtuvieron emisiones de cercarias hemiuride. Las emisiones podrían haber fallado porque las condiciones de laboratorio no fueron las adecuadas o bien, porque podría tratarse de una especie progenética. En este caso, la progenesis es poco probable ya que no se observaron metacercarias ni adultos en el gasterópodo pese a que se examinó una cantidad considerable de especímenes $(n=1.236)$. El tercer tipo de adaptación consiste en la habilidad de la cercaria de adoptar una pose determinada. Por ejemplo, las cercarias de la familia Schistosomatidae se adhieren con la ventosa ventral a un alga o a la superficie del agua y permanecen inmóviles hasta la llegada de un vertebrado (frecuentemente un 
ave) y penetran rápidamente por la piel (Ginetsinkaya, 1988). Otro ejemplo son las cercarias lepocreádides, que imitan el movimiento de los poliquetos y atraen a organismos predadores (Bartoli, 1983).

En tres de las especies descriptas (Notocotylidae gen. et sp., Parorchis sp. y Schistosomatidae gen. et sp.), los ciclos de vida son diexeneos y en otras dos especies (Diphterostomum sp. y M. madrynense) presentarían ambas estrategias de transmisión (ciclos diexenos y triexenos). En los casos de Diphterostomum sp., $M$. madrynense y Notocotylidae gen. et sp., las cercarias enquistan dentro de los esporocistos o redias y se trasmiten directamente al hospedador definitivo por vía trófica. La familia Microphallidae es una de las pocas familias de trematodes con numerosas especies con ciclos de vida diexeneos (abreviados) (Galaktionov \& Skirnisson, 2007). En las cercarias de estas especies, las estructuras asociadas con la emergencia al medio ambiente, la penetración en el $2^{\circ} \mathrm{HI}$ y al enquistamiento se han reducido gradualmente (Deblock \& Tran Van Ky, 1966; Galaktionov, 1991; Galaktionov \& Skirnisson, 2007). Tanto las cercarias de Diphterostomum sp. como las de Notocotylidae gen. et sp., presentaron estas estructuras reducidas o ausentes. Las cercarias de Diphterostomum sp. no poseen cola y el estilete es diminuto; la cercaria de Notocotylidae gen. et sp. no posee estilete, ni glándulas de penetración y la cola es diminuta. Sin embargo, las cercarias de M. madrynense presentaron estructuras propias para emerger (cola, estilete y glándulas de penetración) y enquistar en un $2^{\circ}$ HI. A su vez, en varias ocasiones se observaron emisiones de cercarias en condiciones de laboratorio. Es probable que esta especie utilice ambas estrategias de transmisión, incluyendo un amplio espectro de crustáceos que actuarían como $2^{\circ}$ HI. Por otro lado, y en base a los resultados obtenidos, Diphterostomum sp. utilizaría ambas estrategias de transmisión. Si bien se hallaron metacercarias dentro de los esporocistos, también se obtuvieron emisiones en condiciones de laboratorio. Las cercarias de esta especie no poseen cola, lo que indica que el $2^{\circ} \mathrm{HI}$ se localizaría en las cercanías del $1^{\circ} \mathrm{HI}$ (el gasterópodo Buccinanops globulosus que habita el intermareal y submareal somero arenoso). Los resultados coinciden con el único ciclo de vida conocido para una especie de este género, el de Diphterostomum brusinae, que posee ciclo de vida abreviado, 
enquistando la metacercaria dentro de los esporocistos en el gasterópodo que actúa como $1^{\circ} \mathrm{HI}$, y también utiliza un bivalvo y un equinodermo crinoideo como $2^{\circ} \mathrm{HI}$ (Palombi, 1930; Prévot, 1966; Pina et al., 2009).

Los digeneos que poseen dos estrategias de trasmisión alternativas, tendrían una ventaja adaptativa, ya que utilizarían la estrategia más conveniente según las condiciones ambientales. Por ejemplo, bajo condiciones favorables el ciclo sería triexeno, pero bajo condiciones desfavorables (clima adverso, ausencia del $2^{\circ} \mathrm{HI}$ ), sería diexeno o abreviado (Poulin \& Cribb, 2002). Una posible hipótesis para el ciclo de vida de $M$. madrynense podría proponer que en verano predominan los ciclos abreviados, ya que las temperaturas elevadas perjudican la supervivencia de las cercarias en el intermareal y la densidad de cangrejos C. altimanus es menor (Vázquez et al., 2012). Futuros estudios sobe el desarrollo de los estadios larvales en S. lessonii y experimentos de infección en el laboratorio bajo diferentes condiciones, contribuirán a corroborar esta hipótesis.

En el caso de Parorchis sp., al igual que otras especies del mismo género, las cercarias emergen al medio ambiente y enquistan en el sustrato, en las valvas o el manto de otros moluscos o en el opérculo del mismo gasterópodo que actúa como $1^{\mathrm{o}} \mathrm{HI}$ (ver ref. Tabla 14). En este caso, el ciclo no sería abreviado en el mismo sentido de las metacercarias que enquistan en el $1^{\circ} \mathrm{HI}$, sino que estas especies suprimen el $2^{\circ} \mathrm{HI}$ o bien, utilizan un invertebrado como transporte o como un medio para alcanzar el hospedador definitivo (enquistando en la superficie externa), pero prescinden de ellos para su desarrollo.

Los digeneos Schistosomatidae presentan ciclos diexeneos particulares, en los cuales la cercaria penetra directamente en el hospedador definitivo suprimiendo el estadio metacercaria y, por lo tanto, la necesidad de un $2^{\circ} \mathrm{HI}$ (Combes, 2001). Estas cercarias, que ingresan en forma activa al hospedador definitivo, presentan órganos de penetración musculares que pueden evertir y retraer y que generalmente poseen espinas que facilitan la penetración en el tegumento del hospedador (Ginetsinkaya, 1988). El origen de los parásitos esquistosomátidos (Aporocotylidae, Spirorchidae y Schistosomatidae) está asociado a la neotenia (proceso por el cual los digeneos se desarrollan a partir de los estadios larvales con 
una maduración temprana del aparato genital). Por lo tanto, en este caso, la existencia de un ciclo diexeno no sólo está acompañado por la pérdida de un verdadero hospedador definitivo, sino por la pérdida de la fase adulta primaria (Combes, 2001).

Si bien en este trabajo se observaron diferentes estrategias de transmisión, la que predominó fue aquella en la cual se utiliza un $2^{\circ} \mathrm{HI}$ (ciclos de vida triexenos). Este tipo de estrategia se observa en ambientes con presiones ecológicas leves, en donde los digeneos con estadios larvales de vida libre y la presencia de un $2^{\circ} \mathrm{HI}$ en su ciclo de vida se ven favorecidos debido a una alta diversidad y abundancia de potenciales hospedadores definitivos (principalmente peces y aves) y potenciales $2^{\circ}$ HI (invertebrados y peces) (Galaktionov \& Skirnisson, 2000). Sin embargo, se observó una alta proporción de ciclos diexeneos (38\%), lo cual estaría asociado con una adaptación de la transmisión de los digeneos en ambientes intermareales marinos, en los cuales las condiciones de estrés (desecación, variación de la temperatura, viento) reducen considerablemente la supervivencia de la cercaria o la probabilidad de penetración en el $2^{\circ}$ HI (Galaktionov \& Skirnisson, 2007). Este patrón conllevaría una ventaja adaptativa y se observa con mayor frecuencia en ambientes con condiciones extremas, como los intermareales del Ártico (Skirnisson \& Galaktionov, 2002). Por otro lado, James (1968) concluyó que las especies con ciclos de vida triexenos están restringidas a costas protegidas y niveles inferiores de los intermareales y los ciclos diexenos ocurren con mayor frecuencia en costas expuestas y niveles superiores de los intermareales. Los intermareales de Puerto Madryn y Puerto Deseado, pueden considerarse zonas protegidas, ya que el primero se localiza en una bahía dentro de un golfo, y el segundo en la desembocadura de una ría, con grandes amplitudes de mareas y escasa pendiente (bajo hidrodinamismo). En concordancia con las hipótesis sugeridas por James (1968), la mayor proporción de digeneos que parasitan gasterópodos que habitan en los niveles inferiores del intermareal (B. globulosus, C. dilatata y P. plumbea) presentan ciclos triexenos y la mayor proporción de digeneos con ciclos diexenos parasitan gasterópodos que habitan en los niveles superiores del intermareal ( $T$. 
geversianus y S. lessonii). Sin embargo, varias especies de digeneos con ciclos triexenos parasitan gasterópodos que habitan en toda la extensión del intermareal.

En conclusión, las estrategias de transmisión de los parásitos digeneos estarían influenciadas por el tipo de ambiente, la disponibilidad y abundancia de hospedadores intermediarios y la disponibilidad y abundancia de hospedadores definitivos. Si bien se hallaron ciertos patrones coincidentes con otros intermareales registrados en la literatura, es posible que los sitios de estudio del presente trabajo constituyan un sistema intermedio. Varios de los gasterópodos aquí estudiados habitan en ambos niveles del intermareal (superior e inferior), tanto la abundancia de peces como la de aves (hospedadores definitivos) que se alimentan en estos intermareales es elevada, y los factores de estrés no son extremos, ya que los sitios de estudios se encuentran en climas templados. 


\section{CAPÍTULO 3: DINAMICA ESPACIAL Y ESTACIONAL DE LAS POBLACIONES Y COMUNIDADES DE LOS DIGENEOS}

\subsection{Introducción}

Un aspecto ecológico importante es el efecto de la heterogeneidad espacial y temporal del parasitismo en la composición de una comunidad. La variación espacial de las poblaciones y comunidades parásitas está fuertemente influenciada por la distribución y abundancia de los hospedadores definitivos, así como también por otros determinantes, como la vagilidad, la densidad, la susceptibilidad del hospedador a la infección y la dispersión y el comportamiento del parásito (Galaktionov \& Dobrovolskij, 2003; Hechinger \& Lafferty, 2005). La variación temporal depende de la historia de vida y de la presencia del hospedador definitivo, que puede variar diariamente, mensualmente o estacionalmente, creando pulsos en el reclutamiento de parásitos en los hospedadores intermediarios (Smith, 2001). A su vez, la abundancia de los hospedadores definitivos afectará la composición de la comunidad (Galaktionov \& Bustnes, 1999; Fredensborg et al., 2006; Byers et al., 2008).

Los principales factores intrínsecos del $1^{\circ} \mathrm{HI}$ que pueden afectar a los estadios larvales de digeneos son la talla y el sexo. La talla es una de los principales factores que afectan la prevalencia de parásitos y ha sido ampliamente citado en la bibliografía (e.g. Baudoin, 1975; Granovitch, 1992; Jokela \& Lively, 1995; Sokolova, 1995; Poulin \& Mouristen, 2003; Fredensborg et al., 2005). Sin embargo, algunos trabajos han registrado que no existen diferencias significativas de prevalencia entre sexos (Ginetsinkaya, 1988; Oliva \& Diaz, 1988; Sokolova, 1995). En la mayoría de los casos, cuando se registran diferencias de la prevalencia entre sexos suele deberse a variaciones en la abundancia de hospedadores de cada sexo, a diferencias de tallas o de comportamiento etre sexos, teniendo los sexos más abundantes o de tallas más grandes mayor probabilidad de infección (Ginetsinkaya, 1988; Granovitch, 1992).

Entre los factores extrínsecos que afectan a los estadios larvales de digeneos, la temperatura es el principal, debido que afecta directamente a los estadios libres 
infectivos (miracidio y cercaria) (Galaktionov \& Dobrovolskij, 2003; Galaktionov et al., 2006), por lo que es frecuente observar estacionalidad en los ciclos de vida. Cabe destacar que, la mayor parte de los estudios de estacionalidad, se refieren sólo a la presencia de los estadios larvales y no al grado de madurez de las infrapoblaciones analizadas (i.e., esporocistos o redias conteniendo sólo esferas germinales o cercarias desarrolladas) (Galaktionov \& Dobrovolskij, 2003).

Una aplicación de los parásitos como marcadores biológicos es en el estudio de biodiversidad. Los parásitos forman una gran proporción de la diversidad de la vida, y las comunidades de parásitos representan modelos convenientes para la investigación de los patrones de diversidad. Debido a que la riqueza de especies de parásitos generalmente no es muy alta, si se tiene en cuenta sólo un taxón (e.g. digeneos), la enumeración de todas ellas es posible. De esta manera, los parásitos pueden ser utilizados en la realización de diversos estudios ecológicos de diversidad (e. g., Merlo et al., 2010; Poulin, 2010; Boyero, 2011). Por ejemplo, si se estima la diversidad de digeneos presentes en gasterópodos en varios sitios de estudios, estos datos pueden reflejar la diversidad de gasterópodos.

Con el fin de conocer algunos de los factores que explican la dinámica poblacional espacial y temporal de los digeneos hallados en el presente estudio, se analizó la prevalencia de parásitos en función de la talla y el sexo de los hospedadores gasterópodos y en función de las estaciones del año y los sitios de estudio (Puerto Madryn y Puerto Deseado). Por otro lado, para determinar la dinámica de las comunidades de digeneos hallados, se comparó la diversidad, dominancia y similitud de las comunidades parasitas entre los dos sitios de estudio. 


\subsection{Materiales y métodos}

\subsubsection{Estudios descriptivos y análisis estadísticos de la prevalencia en función de}

\section{la talla y el sexo, la estación del año y el sitio de estudio}

En cada sitio de estudio (Puerto Madryn y Puerto Deseado) se determinó la prevalencia total de cada especie de digeneo $\left(\mathrm{n}^{\mathrm{o}}\right.$ de hospedadores parasitados por una especie sobre el $\mathrm{n}^{\mathrm{o}}$ de hospedadores examinados) y se analizó la relación de dicho parámetro con la talla y el sexo del hospedador y con la estación del año y el sitio de estudio. Los análisis correspondientes a la especie Maritema madrynense, que fue hallada en dos especies de gasterópodos, Kerguelenella lateralis y Siphonaria lessonii, se realizarán utilizando solamente la muestra de $S$. lessonii, ya que es la más representativa (presenta una mayor prevalencia de parásitos).

En los casos de Gymnophalloides nacellae, Maritrema sp. 1 y M. madrynense, en los cuales se hallaron prevalencias altas (entre 8,95\% y 92,47\%), se aplicaron regresiones logísticas (estadístico $W_{a l d X^{2}}$ ) (Agresti, 2007) a la presencia o ausencia de parásitos en función de la talla, el sexo, la estación del año y el sitio de estudio. Gymnophalloides nacellae (estadio metacercaria) sólo se registró en Puerto Deseado, por lo que en su análisis no se consideró el sitio. Además, se analizó el número de metacercarias (intensidad parasitaria) de G. nacellae en función de la talla, el sexo y la estación del año utilizando una regresión de Poisson (estadístico WaldX²) (Agresti, 2007).

Para las especies de parásitos con baja prevalencia (el resto de las especies halladas, entre $0,16 \%$ y $4,84 \%$ ) se realizaron tablas de contingencia y pruebas de chicuadrado (estadístico $X^{2}$ ) para analizar las relaciones de la prevalencia (frecuencia de organismos parasitados y no parasitados) con la talla, el sexo, la estación del año y el sitio de estudio (Agresti, 2007).

En los ejemplares de Crepipatella dilatata (hermafrodita consecutivo) parasitados no se pudo determinar el sexo (debido a la castración que causa el digeneo que lo parasita), por lo cual se realizó una comparación de la talla entre los diferentes estadios de madurez y parasitarios (I: inmaduro, M: macho, R: en reversión, $\mathrm{H}$ : hembra y $\mathrm{P}$ : parasitado) mediante una prueba no paramética de 
Kruscall-Wallis (estadístico H) (Siegel, 1990) y contrastes derivados de esta prueba. Utilizando esta misma prueba, se analizó si existían diferencias entre la talla y los sexos en los casos de los gasterópodos gonocóricos.

En el caso de las especies Hemiuroidea fam. gen. et sp., M. madrynense y Schistosomatidae gen. et sp., no se pudo establecer la relación prevalencia-sexo debido a que el gasterópodo hospedador, S. lessonii, es hermafrodita simultáneo.

En el caso de las especies Hemiuroidea fam. gen. et sp., Diphterostomum sp. y Renicolidae gen. et sp. 1 en Puerto Madryn, y las especies Notocotylidae gen. et sp., Renicolidae gen. et sp. 2, Parorchis sp., Schistosomatidae gen. et sp. y Zoogonus sp. en Puerto Deseado, no pudieron realizarse análisis estadísticos debido a que se hallaron muy pocos hospedadores parasitados con estas especies.

Todos los análisis fueron realizados utilizando el programa Infostat /L. (Di Rienzo et al., 2011). Se consideró como límite de significancia una probabilidad menor o igual a 0,05 .

\subsubsection{Análisis de las comunidades de digeneos en los dos sitios de estudio}

Para comparar la diversidad de parásitos en ambos sitios de estudio (Puerto Madryn y Puerto Deseado), se calculó la riqueza de especies y los índices de diversidad y equitatividad de Shannon-Wiener $(H)$ (Ecuación 1). Este índice asume que los individuos fueron colectados al azar de una comunidad infinitamente grande y que todas las especies están representadas en la muestra. Para conocer el índice de diversidad se calculó la prevalencia (pi) como el número de hospedadores de la especie $\mathrm{X}$ parasitado por una especie $\mathrm{Y}$, dividido el número total de hospedadores de la especie X parasitados (en invierno de 2009 y verano de 2010 para ambos sitios). Esta prevalencia (pi) fue considerada como una medida de abundancia para cada especie. Para comparar los índices de diversidad se aplicó el Método de Hutcheson asociado a partir de la varianza de $H^{\prime}$ (Magurran, 2004) (Ecuación 2). 
Ecuación 1. Fórmulas del Índice de diversidad y de equitatividad de Shannon-Wiener. pi= prevalencias de cada especie, $S=$ riqueza de especies.

$$
\begin{array}{ll}
\text { a). } H^{\prime}=-\sum p i \cdot \ln p i \quad \text { b). } E H^{\prime}=\frac{H^{\prime}}{\ln S} \\
\text { Diversidad de Shannon } & \text { Equitatividad de Shannon }
\end{array}
$$

Ecuación 2. Fórmula de estadístico " $t$ " del Método de Hutcheson asociado al Índice de diversidad de Shannon.

$$
t=\frac{H_{1}^{\prime}{ }_{1}-H_{2}^{\prime}}{\sqrt{\operatorname{Var}_{H^{\prime}}+\text { VarH' }_{2}}}
$$

Para evaluar si existe dominancia de una especie en cada sitio, se calculó el Índice de dominancia de Simpson (D) (Ecuación 3). Este índice brinda la probabilidad de que dos individuos cualesquiera elegidos al azar de una comunidad infinitamente grande pertenezcan a la misma especie (pondera las abundancias de las especies más comunes antes que proveer una medida de la riqueza de especies) (Magurran, 2004).

Ecuación 3. Fórmula del Índice de dominancia de Simpson, donde pi es la prevalencia de cada especie.

$$
D=\sum p i^{2}
$$

Para comparar la similitud de las comunidades de parásitos en ambos sitios de estudio, se calculó el Índice de Jaccard (Ecuación 4). Los coeficientes de similitud, como el Índice de Jaccard, expresan el grado en el que dos muestras son semejantes por las especies presentes en ellas (Moreno, 2001). El índice de Jaccard evalúa las diferencias bióticas entre ensambles, tiende a 0 cuando la similitud es muy baja y a 1 cuando es más alta (Magurran, 2004).

Ecuación 4. Fórmula del Índice de Jaccard. Variables: a= Número de especies presentes sólo en el sitio A, b= Número de especies presentes sólo en el sitio B y c= Número de especies presentes en ambos sitios (A y B).

$$
I j=\frac{c}{a+b-c}
$$

Para realizar las comparaciones por sitio de estudio se seleccionaron 2 muestreos en Puerto Madryn (invierno de 2009 y verano de 2010) equivalentes a los 
muestreos realizados en Puerto Deseado (invierno de 2009 y verano de 2010). En los análisis sólo se incluyeron los estadios larvales que utilizaron gasterópodos como primeros hospedadores intermediarios, quedando excluido del análisis G. nacellae (parásito hallado sólo en estadio metacercaria). 


\subsection{Resultados}

\subsubsection{Digeneos larvales del intermareal de Puerto Madryn}

En Puerto Madryn, cuatro de las cinco especies de gasterópodos estudiadas se hallaron parasitadas por al menos una especie de digeneo. El único gasterópodo que no presentó infección por digeneos fue Tegula patagonica (Trochidae) $(n=688)$.

Siphonaria lessonii (Siphonariidae) y Trophon geversianus (Muricidae) presentaron dos especies de digeneos cada uno y Buccinanops globulosus (Nassariidae) y Crepipatella dilatata (Calyptraeidae) sólo estuvieron parasitadas por una especie (Tabla 16). Maritrema sp. 1 y Maritrema madrynense presentaron las mayores prevalencias totales (33,45 y 8,95\% respectivamente). El resto de las especies parásitas presentaron prevalencias totales menores a $1 \%$.

Tabla 16. Prevalencia total (\%) ( $\mathrm{n}^{\mathrm{o}}$ de hospedadores parasitados por una especie de digeneo/ $\mathrm{n}^{0}$ de hospedadores totales examinados) de cada especie hallada por hospedador y por sitio de estudio.

\begin{tabular}{|c|c|c|c|}
\hline \multirow[t]{2}{*}{ Especie parásita } & \multirow[t]{2}{*}{ Especie hospedadora } & \multicolumn{2}{|c|}{ Prevalencia total (\%) } \\
\hline & & Puerto Madryn & Puerto Deseado \\
\hline Hemiuroidea fam. gen. et sp. & Siphonaria lessonii & $0,48(n=1050)$ & $4,84(n=186)$ \\
\hline Lepocreadiidae gen. et sp. 1 & Crepipatella dilatata & - & $3,76(n=266)$ \\
\hline Lepocreadiidae gen. et sp. 2 & Pareuthria plumbea & - & $3,49(n=458)$ \\
\hline Diphterostomum sp. (Zoogonidae) & Buccinanops globulosus & $0,16(n=632)$ & - \\
\hline Zoogonus sp. (Zoogonidae) & Pareuthria plumbea & - & $0,22(n=458)$ \\
\hline $\begin{array}{l}\text { Gymnophalloides nacellae } \\
\text { (Gymnophallidae) }\end{array}$ & Nacella (P.) magellanica & - & $92,47(n=306)$ \\
\hline Maritrema sp. 1 (Microphallidae) & Crepipatella dilatata & $33,45(n=1665)$ & $16,5(n=266)$ \\
\hline Maritrema madrynense & Siphonaria lessonii & $8,95(n=1050)$ & $9,2(n=186)$ \\
\hline (Microphallidae) & Kerguelenella lateralis & - & $0,42(n=237)$ \\
\hline Notocotylidae gen. et sp. & Nacella (P.) magellanica & - & $0,33(n=306)$ \\
\hline Renicolidae gen. et sp. 1 & Trophon geversianus & $0,29(n=689)$ & $4,64(n=151)$ \\
\hline Renicolidae gen. et sp. 2 & Nacella (P.) magellanica & - & $0,98(n=306)$ \\
\hline Parorchis sp. (Philophtalmidae) & Trophon geversianus & $0,87(n=689)$ & $0,66(n=151)$ \\
\hline Schistosomatidae gen. et sp. & Siphonaria lessonii & - & $0,54(n=186)$ \\
\hline
\end{tabular}


Relación prevalencia - talla del hospedador

El único ejemplar del gasterópodo B. globulosus parasitado por Diphterostomum sp. presentó una talla intermedia (Fig. 67A). Se hallaron tres ejemplares de S. lessonii parasitados por Hemiuroidea fam. gen et sp., con tallas intermedias (8-12 mm) (Fig. 67B). Los dos ejemplares de T. geversianus parasitados con Renicolidae gen. et sp. 1 presentaron tallas intermedias $(20-28 \mathrm{~mm})$ y los gasterópodos parasitados con Parorchis sp. presentaron tallas intermedias y mayores (20-32 mm) (Fig. 67C). Sin embargo no se hallaron diferencias significativas entre la frecuencia de individuos parasitados por Parorchis sp. y la talla del hospedador $\left(X^{2}=2,4 ; \mathrm{p}=0,88\right)$.

En los casos de Maritrema sp. 1 y Maritrema madrynese, cuyas prevalencias fueron de las más altas obtenidas, se observó una relación positiva entre la prevalencia y la talla de su hospedador $\left(\right.$ Wald $X^{2}=210,37$; $\mathrm{p}<0,05$ y Wald $X^{2}=42,71$; $\mathrm{p}<0,05$ respectivamente) (Figs. 67B, 67D). Los digeneos Maritrema sp. 1 se hallaron parasitando ejemplares a partir de los 12-14 $\mathrm{mm}$ y el incremento de la prevalencia fue lineal hasta alcanzar un máximo en las tallas mayores. La prevalencia de $M$. madrynense aumentó hasta una talla de 14 a 16 mm, donde alcanzó un máximo de $20 \%$, luego disminuyó a $10 \%$ y volvió a incrementarse a otro máximo de $25 \%$ en las tallas mayores. 
A

Buccinanops globulosus

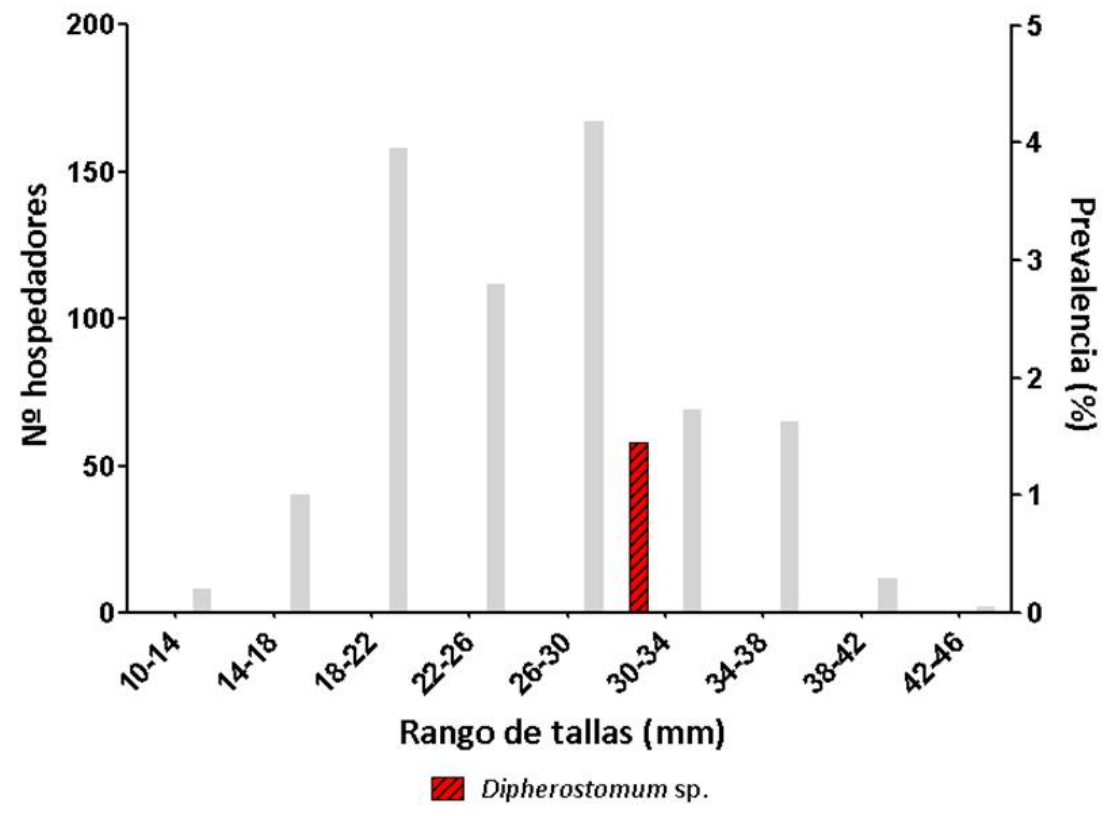

B

Siphonaria lessonii

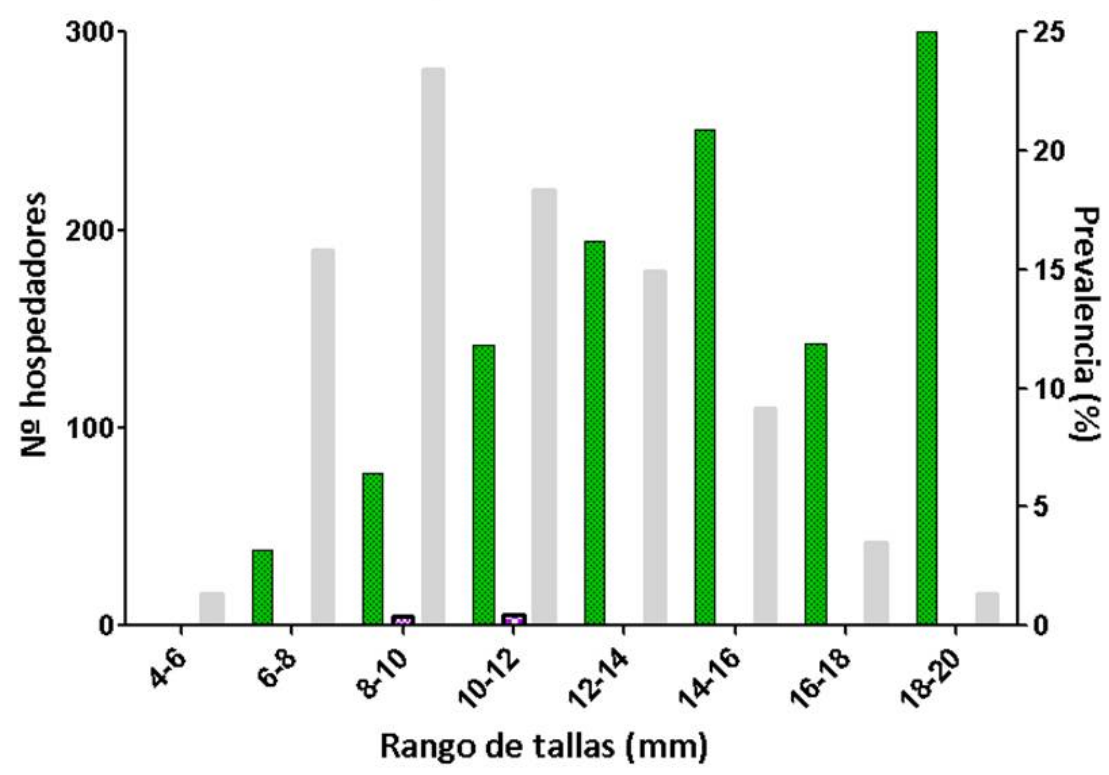

Maritrema madrynense $\mathbf{B}$ Hemiuroidea fam. gen. et sp.

Figura 67. Prevalencia de los estadios larvales en los gasterópodos de Puerto Madryn en función de la talla $(\mathrm{mm})$ de la especie hospedadora. A- Digeneos en Buccinanops globulosus; B- Digeneos en Siphonaria lessonii. 
C

Trophon geversianus

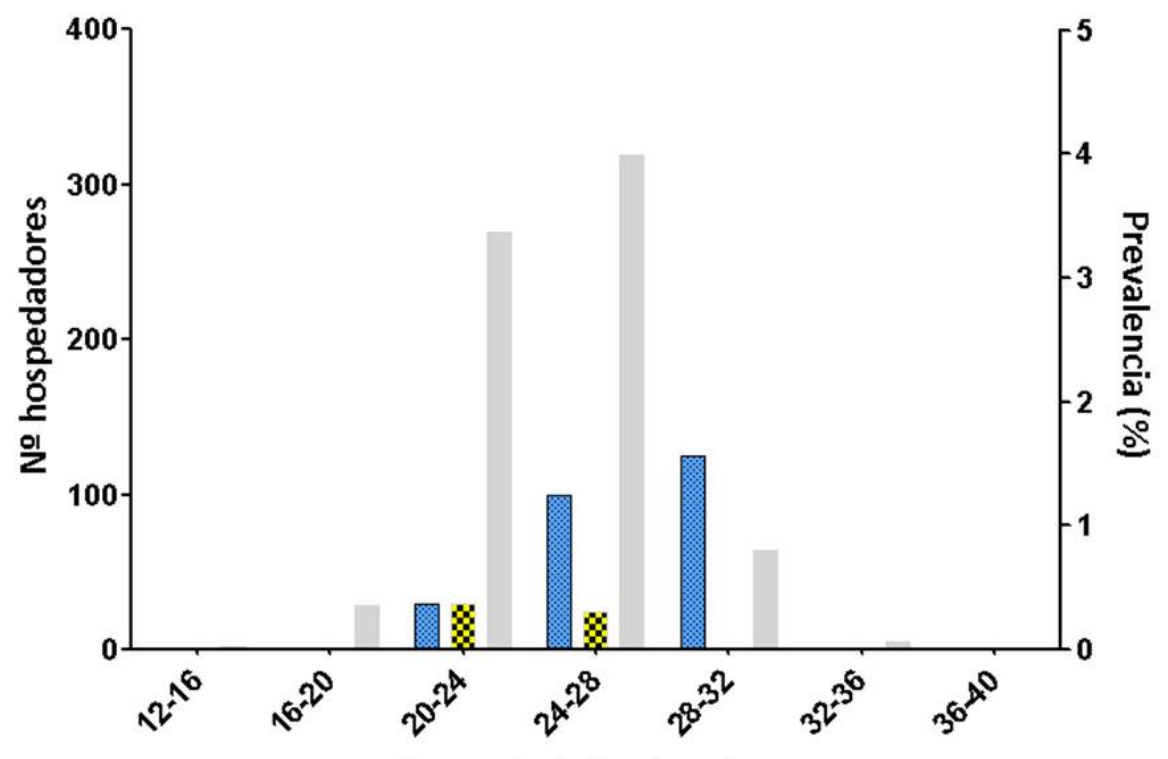

Rango de tallas (mm)

Parorchis sp. $\quad \%$ Renicolidae gen. et sp. 1

D Crepipatella dilatata

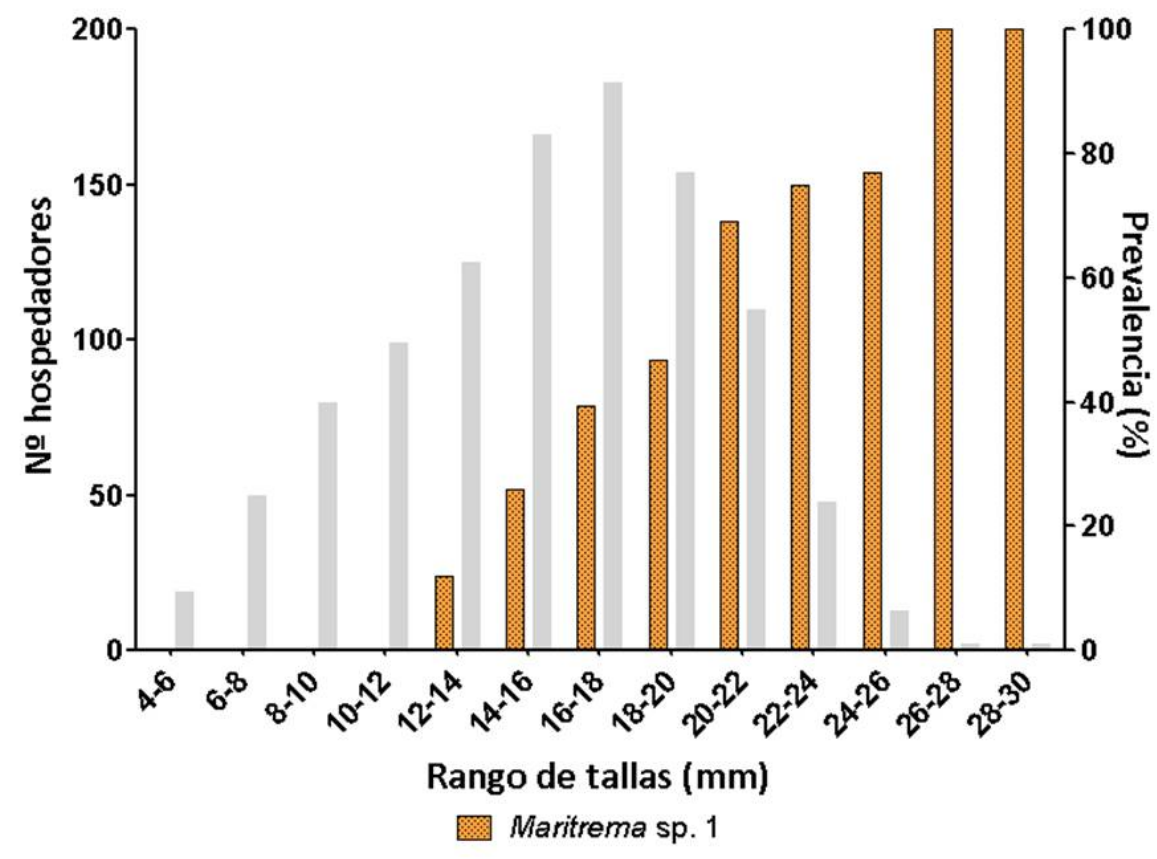

Figura 67 (continuación). Prevalencia de los estadios larvales en los gasterópodos de Puerto Madryn en función de la talla $(\mathrm{mm})$ de la especie hospedadora. C- Digeneos en Trophon geversianus; D- Digeneos en Crepipatella dilatata. 


\section{Relación prevalencia - sexo}

Se observó una diferencia significativa entre los estadios de madurez y parasitarios de Maritrema sp. 1 y la talla de $C$. dilatata $(H=668,26 ; p<0,05)$. La talla de los organismos parasitados fue mayor que las tallas de las hembras (Fig. 68). La relación entre machos y hembras para $T$. geversianus fue de 1:3 y para B. globulosus fue de 1:1. Los dos ejemplares de T. geversianus hallados parasitados por Renicolidae gen. et sp. 1 y el único ejemplar de B. globulosus parasitado por Diphterostomum sp. fueron hembras. No se hallaron diferencias significativas entre la prevalencia de machos y hembras en gasterópodos parasitados por Parorchis sp. $\left(X^{2}=2,06 ; p=0,15\right)$. En ambas especies, la relación talla - sexo resultó significativa $(H=112,18 ; \mathrm{p}<0,05$ en $T$. geversianus y $H=56,94 ; \mathrm{p}<0,05$ en $B$. globulosus), presentando las hembras tallas mayores.

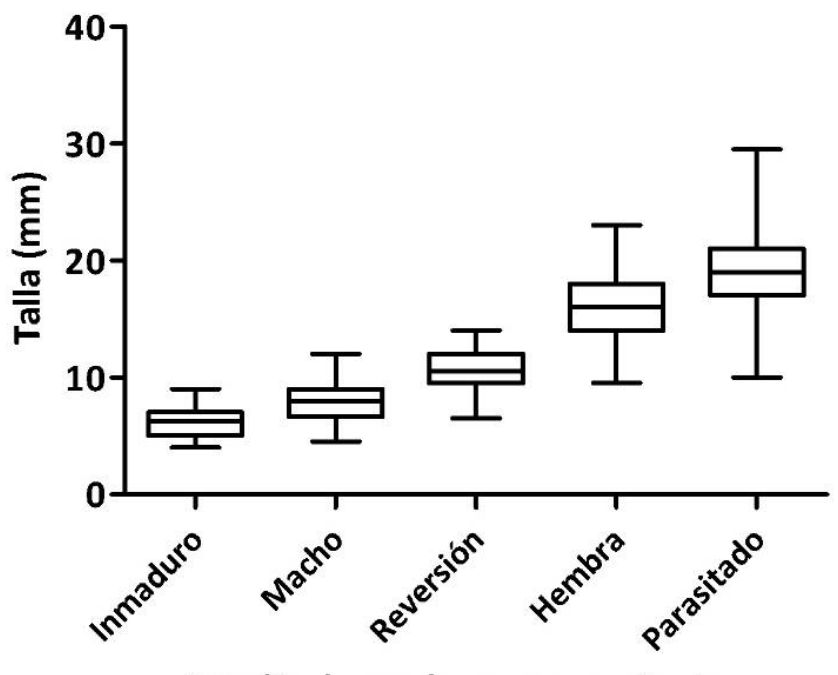

Estadio de madurez y parasitario

Figura 68. Relación entre la talla de Crepipatella dilatata y los estadios de madurez y parasitarios de Maritrema sp. 1 en Puerto Madryn.

Relación prevalencia- estación del año

Los pocos ejemplares de S. lessonii y de T. geversianus que se hallaron parasitados por Hemiuroidea fam. gen. et sp. y Renicolidae gen. et sp. 1 respectivamente, se registraron en las estaciones frías del año y el único ejemplar de B. globulosus parasitado por Diphterostomum sp. se registró en verano (Fig. 69). Las prevalencias de las especies de la familia Microphallidae no presentaron diferencias significativas entre las estaciones del año $\left(X^{2}=2,21 ; p=0,14\right.$ en Maritrema sp. 1 y $X^{2}=$ 
0,98; $\mathrm{p}=0,32$ en M. madrynense). Sin embargo, la prevalencia de Maritrema sp. 1 presentó picos de 40-45\% en verano del 2009 e invierno del 2010 y la prevalencia de M. madrynense presentó un pico de $42 \%$ en verano de 2009 (Fig. 69). En el caso de Parorchis sp., sí existieron diferencias significativas entra la frecuencia de gasterópodos parasitados y la estación del año $\left(X^{2}=11,96 ; \mathrm{p}<0,05\right)$, registrándose especímenes en todas las estaciones a excepción del verano.

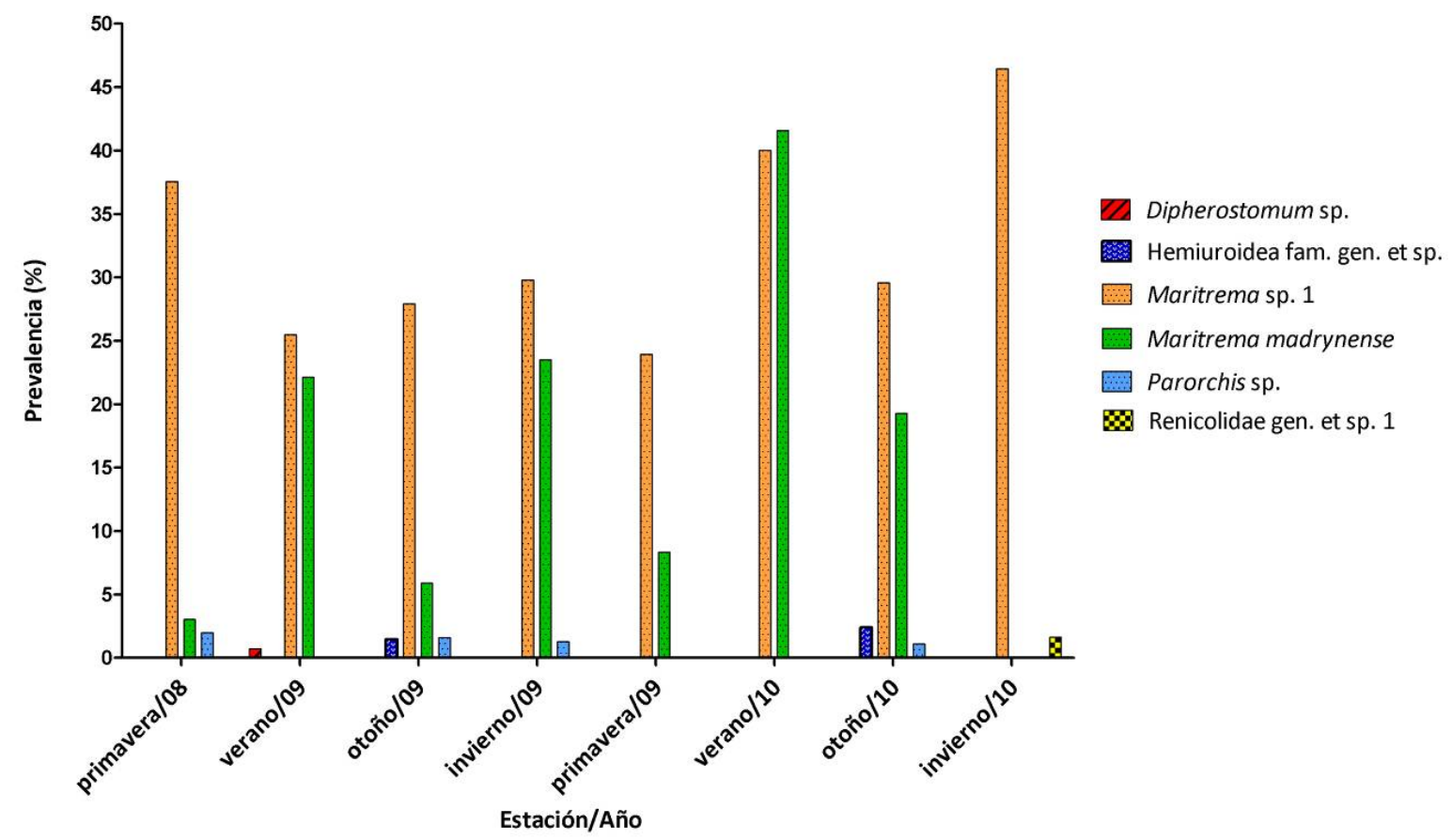

Figura 69. Relación entre la prevalencia de cada especie de parásito y la estación del año, entre septiembre de 2008 y julio de 2010 en Puerto Madryn.

\subsubsection{Digeneos larvales del intermareal de Puerto Deseado}

En Puerto Deseado se hallaron seis de las siete especies de gasterópodos examinadas parasitadas por al menos una especie de digeneo. El único gasterópodo que no presentó infección por digeneos fue Fissurella radiosa $(\mathrm{n}=151)$.

Siphonaria lessonii presentó tres especies de digeneos; C. dilatata, Nacella (P.) magellanica, T. geversianus y Pareuthria plumbea presentaron dos especies de digeneos cada una; Nacella (P.) magellanica también estuvo parasitada por metacercarias de Gymnophalloides nacellae con alta prevalencia (92,47\%), siendo el único gasterópodo que presentó metacercarias que se desarrollan fuera de los esporocistos o redias. Al igual que en Puerto Madryn, Maritrema sp. 1 y M. madrynense presentaron las 
mayores prevalencias totales (16,5 y 9,2\% respectivamente) de los digeneos que se encuentran en estadio esporocisto o redia. El resto de las especies presentaron prevalencias entre 1 y 4\%, a excepción de Parorchis sp. y Schistosomatidae gen. et sp., que presentaron prevalencias menores a $1 \%$ (Tabla 16).

\section{Relación prevalencia - talla del hospedador}

La relación prevalencia - talla de Hemiuroidea fam. gen. et sp. no resultó significativa y por el contrario, sí resultó significativa en Maritrema madrynense $\left(X^{2}=\right.$ 13,54; $\mathrm{p}=0,06$ y $W_{\text {ald }} \mathrm{X}^{2}=12,16 ; \mathrm{p}<0,05$ respectivamente). Sin embargo, ambas especies presentaron un patrón similar (Fig. 70A). Las larvas parasitaron ejemplares a partir de los 15-17 $\mathrm{mm}$ y fue en este rango de tallas, intermedia, en donde se observaron las mayores prevalencias. Las tallas mayores, de 19-23 mm, también estuvieron parasitadas, aunque con menores prevalencias. Los estadios larvales de Schistosomatidae gen. et sp. se registraron sólo en una ocasión en un ejemplar de talla grande (19-21 mm) (Fig. 70A).

Los estadios larvales de Maritrema sp. 1 afectaron a ejemplares de Crepipatella dilatata a partir de tallas de $12-14 \mathrm{~mm}$, y se registró la máxima prevalencia en las tallas mayores, del rango de $24-28 \mathrm{~mm}$; sin embargo, no se registraron diferencias significativas entre la prevalencia y la talla $\left(W_{a l d X}=0,39 ; p=0,53\right)$. En el caso de Lepocreadiidae gen. et sp. 1, cuyas prevalencias fueron menores a las de Maritrema sp. 1, los estadios larvales estuvieron presentes en ejemplares a partir de 14-16 mm, presentando las prevalencias más altas en las tallas de 20-26 mm (Fig. 70B). Sin embargo, tampoco se hallaron diferencias significativas entre la prevalencia de esta especie y la talla del hospedador $\left(X^{2}=15,82 ; p=0,15\right)$.

Lepocreadiidae gen. et sp. 2 se registró en el gasterópodo Pareuthria plumbea en todos los rangos de tallas y se hallaron diferencias significativas entre la prevalencia y la talla del hospedador $\left(X^{2}=29,81 ; \mathrm{p}<0,05\right)$. La mayor prevalencia se registró en el rango de tallas mayor (25-27 mm) (Fig. 70C). Los estadios larvales de Zoogonus sp. se registraron en una ocasión en el rango de tallas de 21-23 mm (Fig. 70C).

Los estadios larvales de Renicolidae gen. et sp. 1 se registraron en ejemplares de $T$. geversianus de tallas mayores a 36-40 $\mathrm{mm}\left(X^{2}=23,65 ; \mathrm{p}<0,05\right)$. A partir de este 
rango de tallas, poco representado en la muestra, se hallaron 1 ó 2 ejemplares parasitados. Parorchis sp. se registró en una sola ocasión, en un ejemplar de $38 \mathrm{~mm}$ (Fig. 70D).

Los estadios larvales de Notocotylidae gen. et sp. y de Renicolidae gen. et sp. 2 se registraron parasitando gasterópodos Nacella (P.) magellanica de tallas intermedias, a partir de 30-34 mm. 
A Siphonaria lessonii

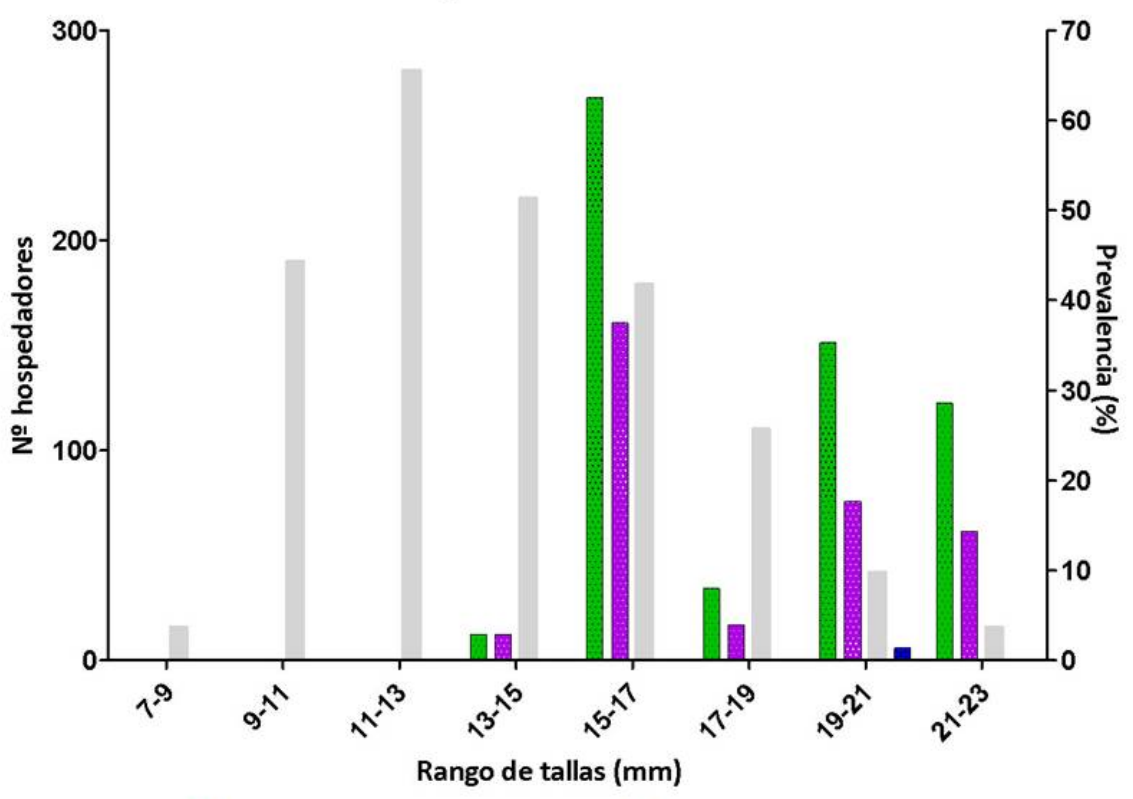

Hemiuroidea fam. gen. et sp. Maritrema madrynense

Schistosomatidae gen. et sp.

B Crepipatella dilatata

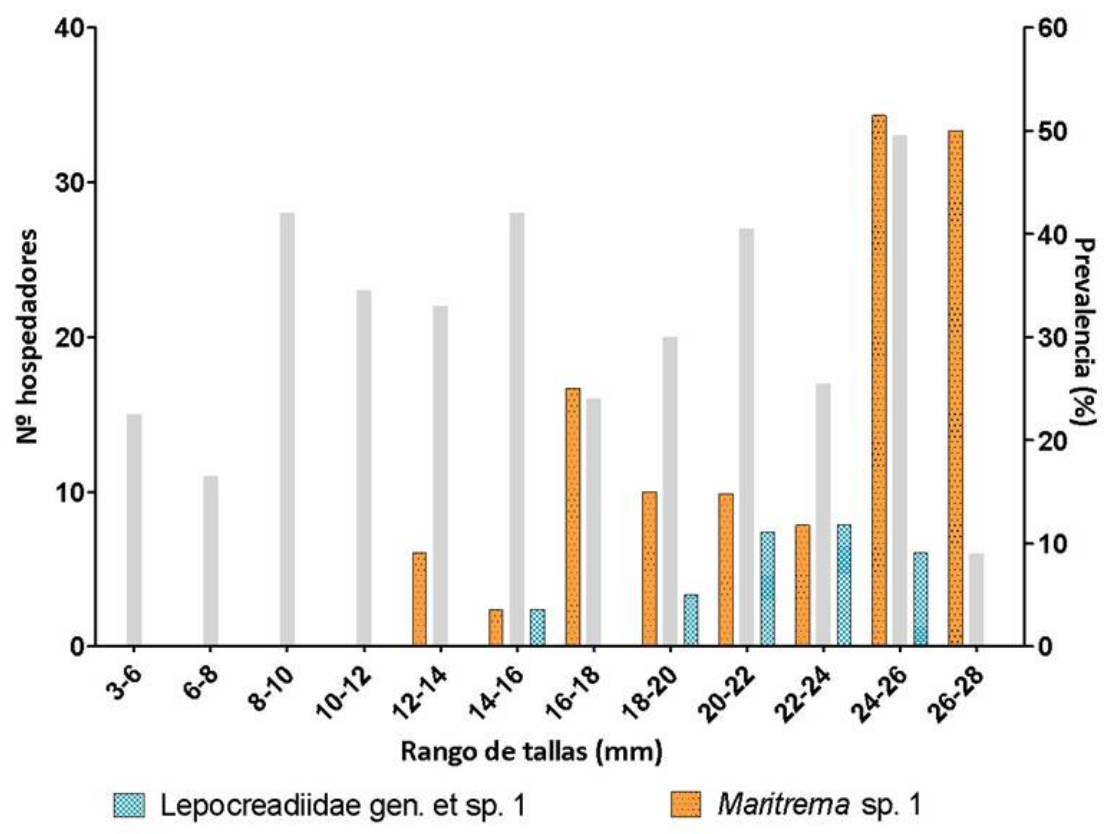

Figura 70. Prevalencia de los estadios larvales en los gasterópodos de Puerto Deseado en función del rango de tallas $(\mathrm{mm})$ de la especie hospedadora. A- Digeneos en Siphonaria lessonii; B- Digeneos en Crepipatella dilatata. 

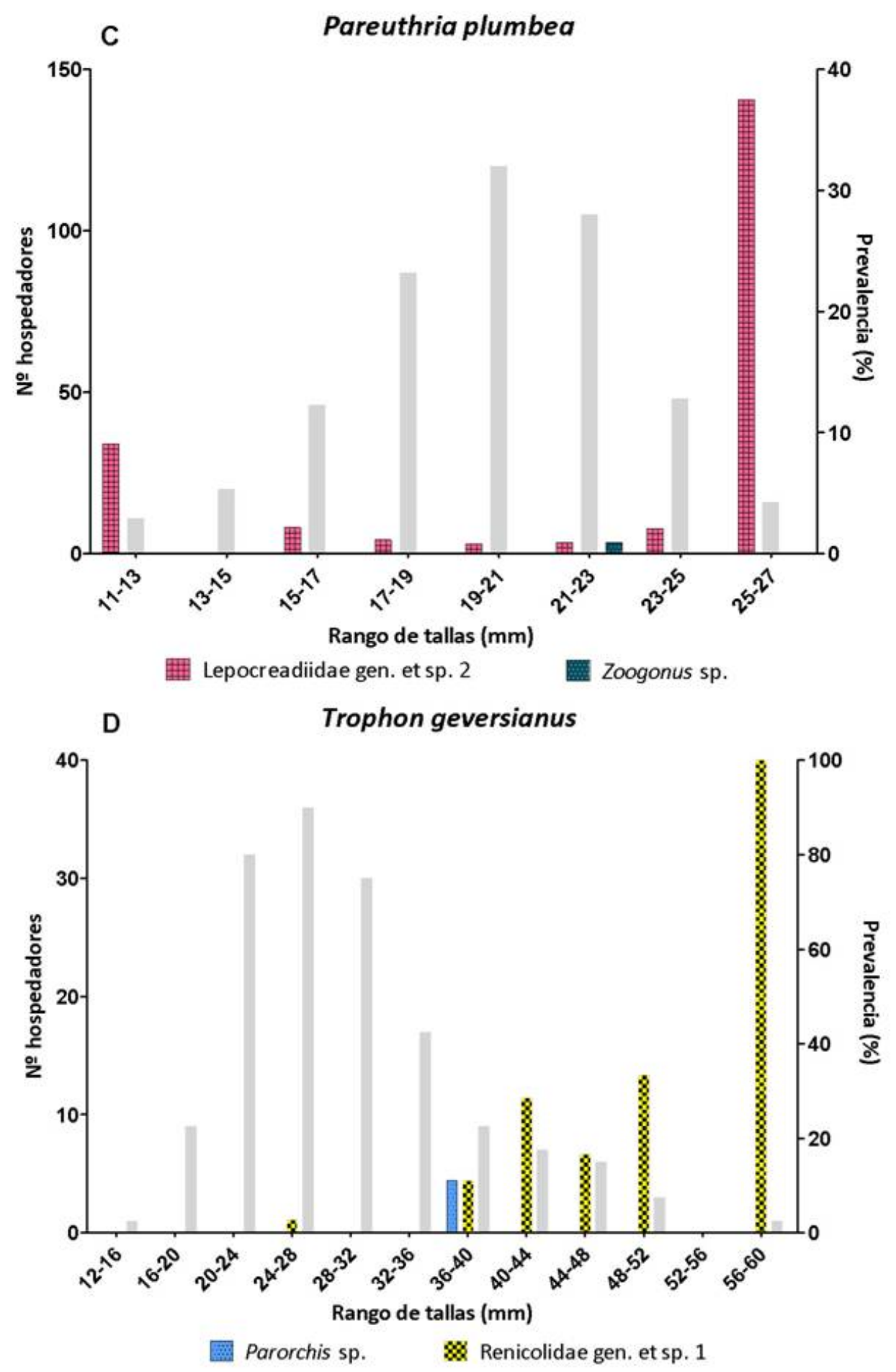

Figura 70 (continuación). Prevalencia de los estadios larvales en los gasterópodos de Puerto Deseado en función del rango de tallas $(\mathrm{mm})$ de la especie hospedadora. CDigeneos en Pareuthria plumbea; D- Digeneos en Trophon geversianus. 


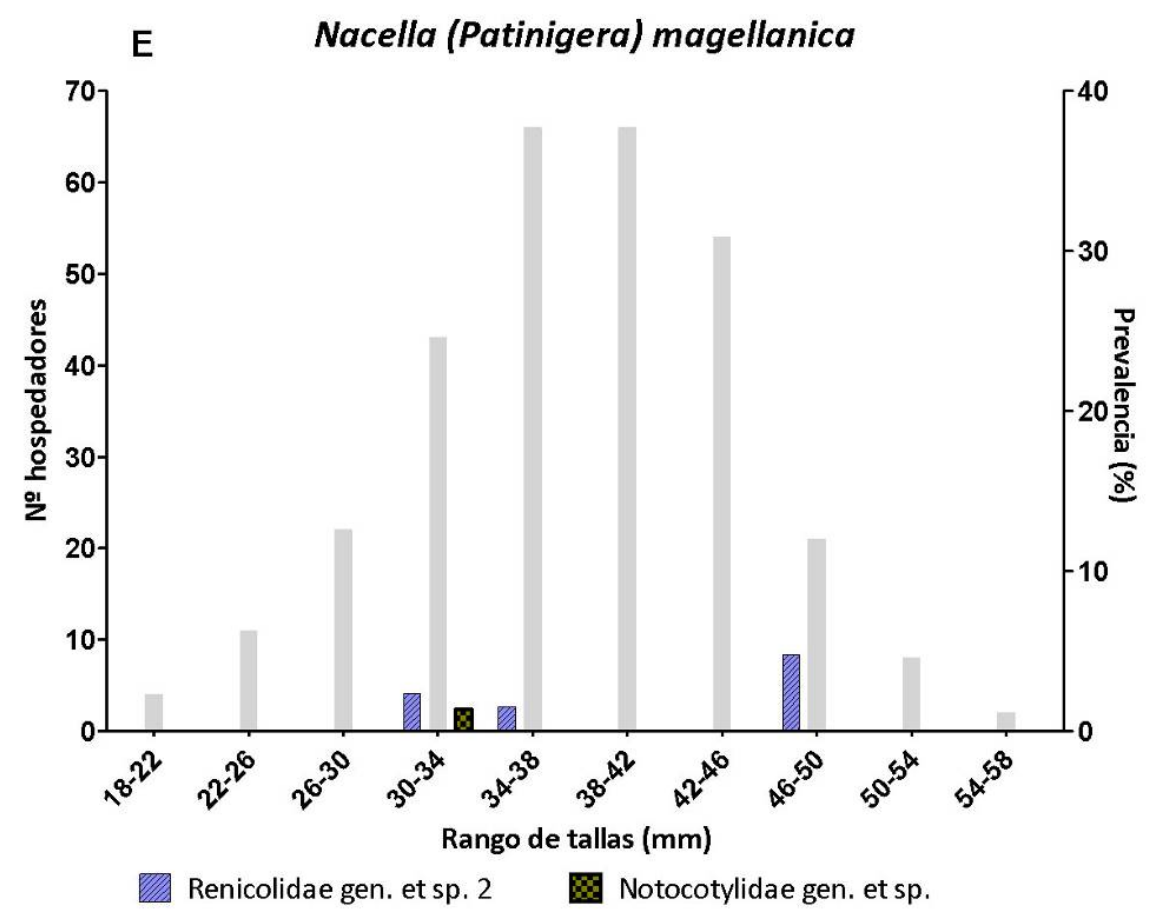

Figura 70 (continuación I). Prevalencia de los estadios larvales en los gasterópodos de Puerto Deseado en función del rango de tallas $(\mathrm{mm})$ de la especie hospedadora. E- Digeneos en Nacella (P.) magellanica.

Las metacercarias de Gymnophalloides nacellae se registraron en todos los rangos de tallas de los gasterópodos $N$. (P.) magellanica. La prevalencia se mantuvo aproximadamente constante a partir del rango de tallas de $26-30 \mathrm{~mm}\left(\right.$ WaldX $^{2}=$ $12 * 10-4, p=0,99)$ y la intensidad media de infección aumentó significativamente hacia las tallas mayores $\left(\right.$ Wald $\mathrm{X}^{2}=1242,38 ; \mathrm{p}<0,05$ ), con excepción del rango de tallas de 50-54 mm que presentó una menor intensidad media que el rango anterior. (Fig. 71). 


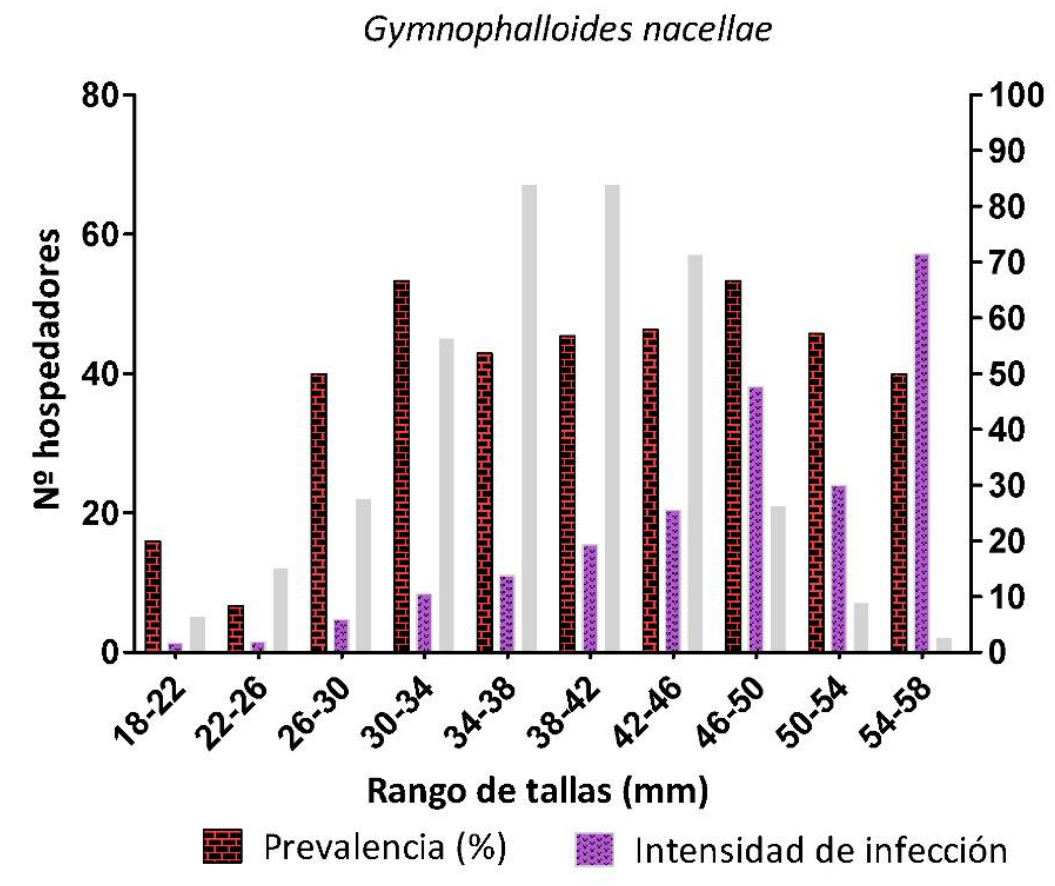

Figura 71. Prevalencia e intensidad media de infección de metacercarias de Gymnophalloides nacellae (Gymnophallidae) en el gasterópodo Nacella $(P$.) magellanica en Puerto Deseado en función del rango de tallas.

\section{Relación prevalencia - sexo del hospedador}

Se observó una diferencia significativa entre los estadios de madurez y parasitarios de Maritrema sp. 1 y Lepocreadiidae gen. et sp. 1 y la talla de C. dilatata ( $H=207, \mathrm{p}<0,05)$. Las tallas de los ejemplares parasitados se solapan con las tallas de las hembras y las tallas de los machos se solapan con los individuos en reversión (Fig. 72). 


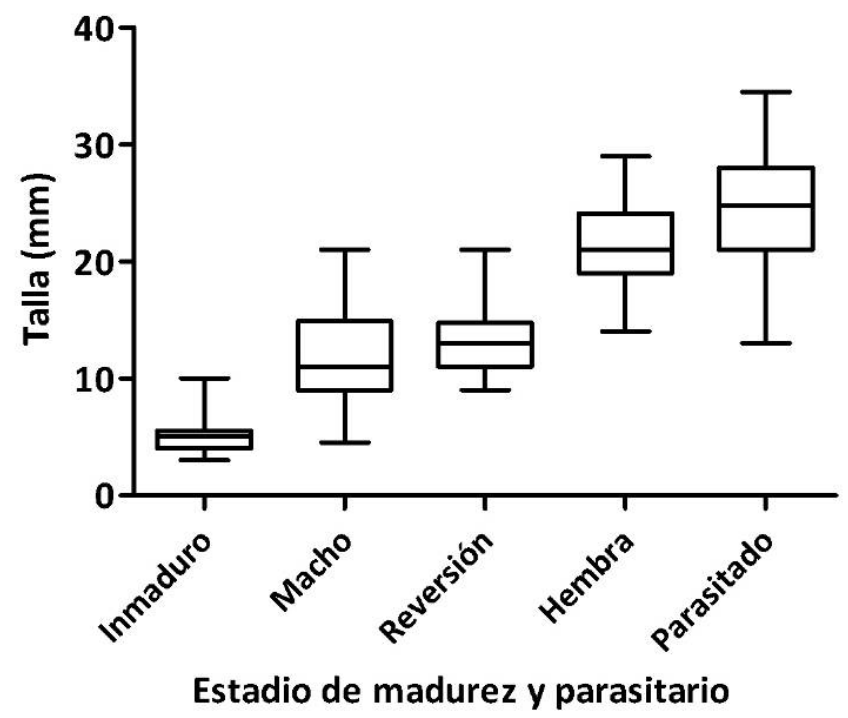

Figura 72. Relación entre la talla $(\mathrm{mm})$ de Crepipatella dilatata y los estadios de madurez y parasitarios de Maritrema sp. 1 y Lepocreadiidae gen. et sp. 1 en Puerto Deseado.

La relación entre la prevalencia de Lepocreadiidae gen. et sp. 2 y el sexo del hospedador P. plumbea resultó ser significativa $\left(X^{2}=4,9 ; p<0,05\right)$, observándose una mayor proporción de hembras parasitadas. A su vez, las hembras fueron significativamente mayores a los machos $(H=35,05 ; \mathrm{p}<0,05)$. La proporción entre machos y hembras fue 1:1. El único registro de Zoogonus sp. fue en un ejemplar macho.

No se observaron diferencias significativas entre la prevalencia de Renicolidae gen. et sp. 1 y el sexo del hospedador $T$. geversianus $\left(X^{2}=2,62 ; p=0,11\right)$. A su vez, las hembras fueron significativamente mayores a los machos $(H=35,05$; $p<0,05)$. La proporción entre machos y hembras fue 1:3. El único registro de Parorchis sp. fue en un ejemplar macho.

El único ejemplar de $N$. (P.) magellanica parasitado por larvas de Notocotylidae gen. et sp. fue un macho. En el caso de Renicolidae gen. et sp. 2, se hallaron tres ejemplares de $N$. magellanica parasitados por esta especie, de los cuales dos eran machos y en el restante no pudo determinarse el sexo. No se observaron diferencias significativas entre la talla y el sexo $(H=0,07, p=0,78)$ y la proporción de machos y hembras fue 2:1. 
No se observaron diferencias significativas entre la prevalencia de metacercarias G. nacellae y el sexo de $N$. (P.) magellanica $\left(\right.$ WaldX $\left.X^{2}=3,3 ; \mathrm{p}=0,07\right)$. Sin embargo, la intensidad media de infección fue mayor en machos que en hembras $\left(\right.$ WaldX $\left.^{2}=66,03 ; \mathrm{p}<0,05\right)$.

Relación prevalencia - estación del año

Los digeneos Notocotylidae gen. et sp., Parorchis sp., Lepocreadiidae gen. et sp. 1, Zoogonus sp. y Schistosomatidae gen. et sp. sólo se registraron en invierno y el resto de las especies se registraron en ambas estaciones del año (Fig. 73).

No se observaron diferencias significativas entre la prevalencia y la estación del año en Hemiuroidea fam. gen. et sp. $\left(X^{2}=1,88 ; p=0,17\right)$, Lepocreadiidae gen. et sp. $2\left(X^{2}=1,66 ; p=0,2\right)$, Maritrema sp. $1\left(\right.$ WaldX $\left.^{2}=0,13 ; p=0,72\right)$ ni en Renicolidae gen. et sp. $2\left(X^{2}=0,17, p=0,68\right)$.

Sin embargo, sí se observaron diferencias significativas entre la prevalencia y la estación del año en Renicolidae gen. et sp. $1\left(X^{2}=12,08 ; \mathrm{p}<0,05\right)$ y M. madrynense $\left(W_{a l d X}^{2}=4,57 ; \mathrm{p}<0,05\right)$. En el primer caso la prevalencia fue mayor en invierno, y en el segundo, mayor en verano. En el caso de G. nacellae, tanto la prevalencia $\left(\right.$ WaldX$\left.^{2}=10,61 ; \mathrm{p}<0,05\right)$ como la intensidad de infección $\left(\right.$ WaldX $\left.X^{2}=1.033,07 ; \mathrm{p}<0,05\right)$ fueron mayores en invierno (Fig. 74). 


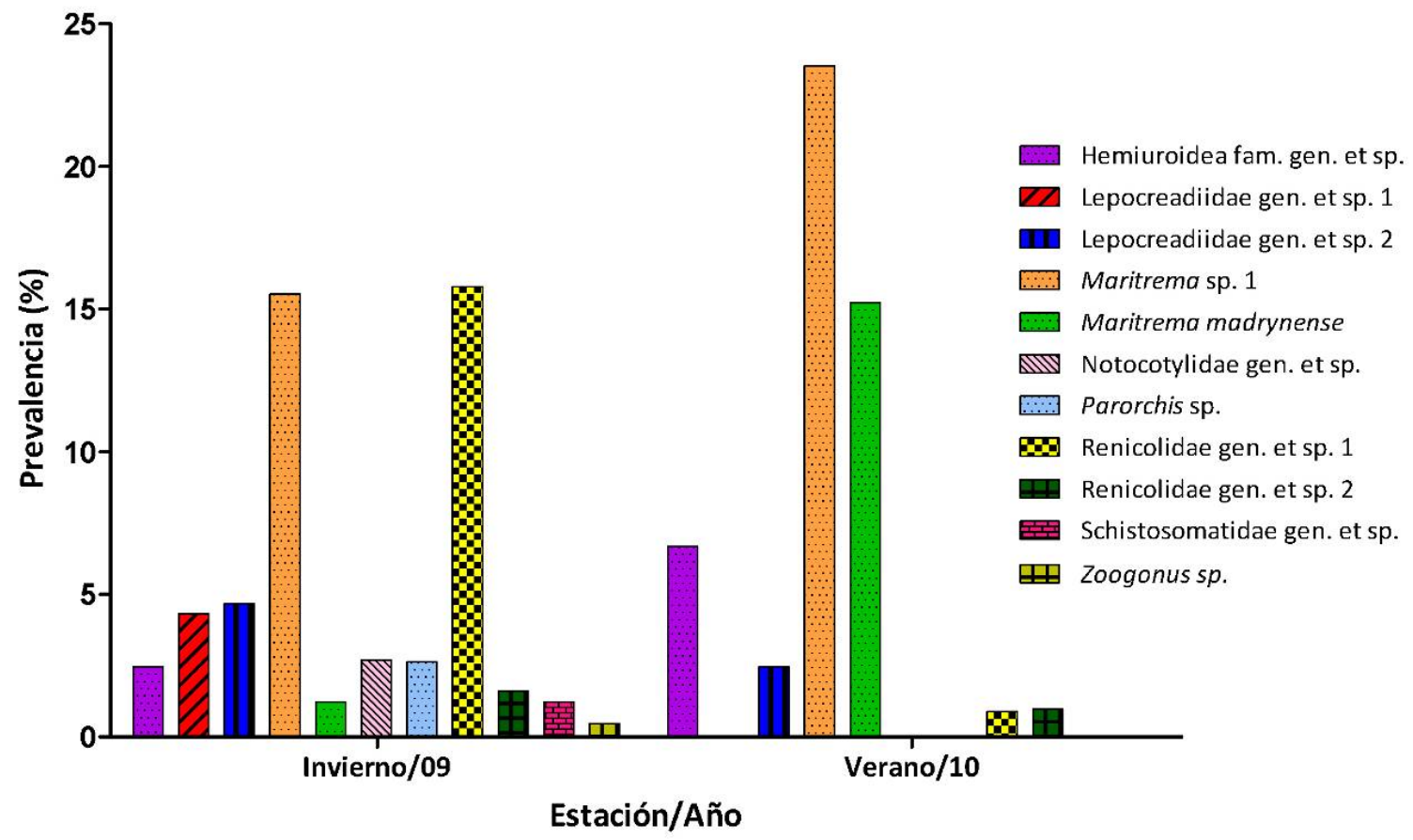

Figura 73. Prevalencia de cada especie de digeneo hallada en Puerto Deseado en dos estaciones del año (invierno y verano).

Gymnophalloides nacellae

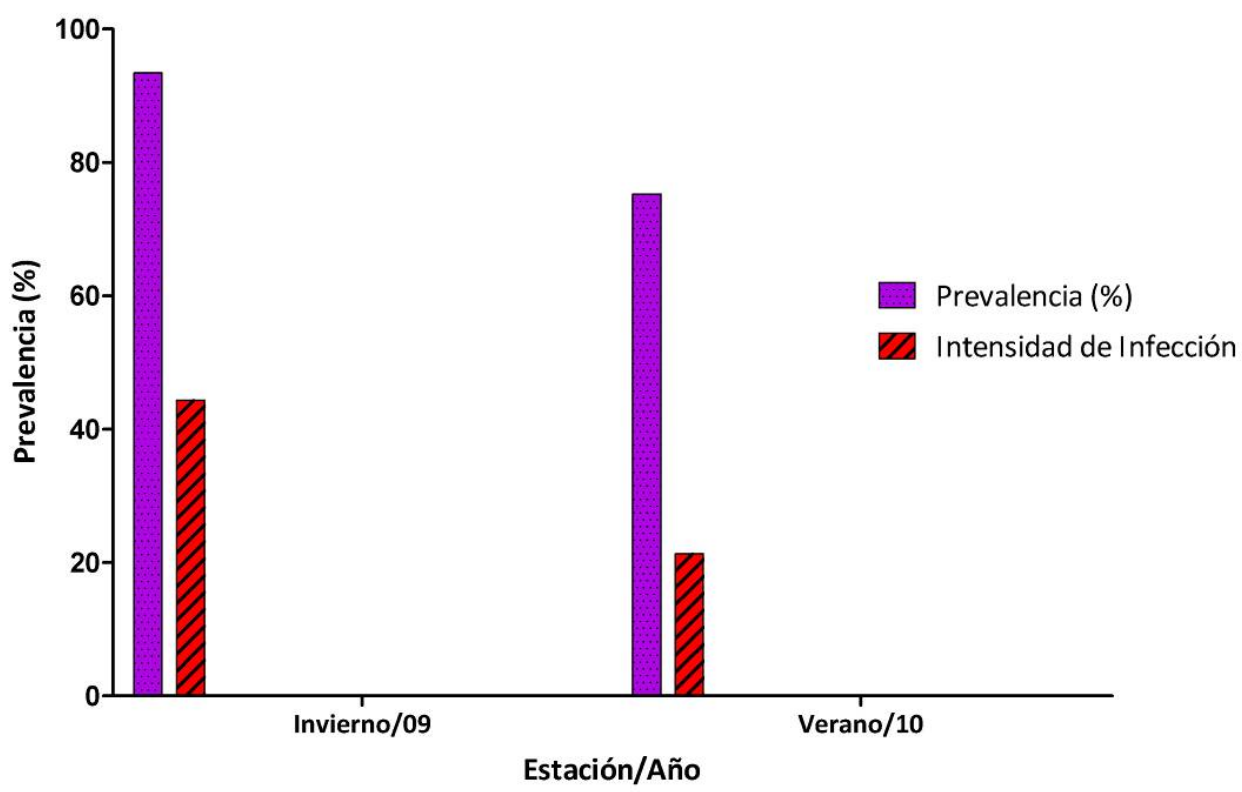

Figura 74. Prevalencia e intensidad de infección de Gymnophalloides nacellae en Puerto Deseado en dos estaciones del año (invierno y verano). 


\subsubsection{Comparación de la prevalencia y diversidad en los intermareales de Puerto}

\section{Madryn y Puerto Deseado}

El número de especies hospedadoras y parásitas halladas en Puerto Deseado fue mayor que en Puerto Madryn. En Puerto Deseado se estudiaron ocho especies de gasterópodos y se hallaron once especies de digeneos; en Puerto Madryn se estudiaron cinco especies de gasterópodos y se hallaron cinco especies de digeneos (considerando todos los meses de colecta en este sitio, desde septiembre de 2008 hasta julio de 2010).

Teniendo en cuenta todas las colectas realizadas, cinco especies de digeneos fueron comunes a ambos sitios (Hemiuroidea fam. gen. et sp., Maritrema sp. 1, M. madrynense, Renicolidae gen. et sp. y Parorchis sp.); uno se halló solamente en Puerto Madryn (Diphterostomum sp.) y siete sólo en Puerto Deseado (G. nacellae, Lepocreadiidae gen. et sp. 1, Lepocreadiidae gen. et sp. 2, Notocotylidae gen. et sp., Renicolidae gen. et sp. 2, Schistosomatidae gen. et sp. y Zoogonus sp.).

Cabe aclarar que en ambos intermareales se colectaron los caracoles más conspicuos y abundantes y que los resultados de esta sección incluyen sólo las colectas de invierno de 2009 y verano de 2010 que fueron las estaciones en donde se realizaron colectas en ambos sitios y por lo tanto son comparables.

Así, y teniendo en cuenta los estadios larvales esporocistos o redias, sólo tres especies estuvieron presentes en ambos sitios (Maritrema sp. 1, M. madrynense y Parorchis sp.). Las prevalencias de Maritrema sp. 1 y M. madryenese fueron mayores en Puerto Madryn $\left(\right.$ WaldX $^{2}=16,13 ; \mathrm{p}<0,05$ y WaldX $^{2}=25,97 ; \mathrm{p}<0,05$ respectivamente) y no se observaron diferencias significativas entre las prevalencias de Parorchis sp. en ambos sitios de estudio $\left(X^{2}=0,01 ; p=0,94\right)$.

Puerto Madryn presentó una menor riqueza de especies; sin embargo, las mayores prevalencias se registraron en este sitio, en las dos especies de la familia Microphallidae (Maritrema sp. 1 y M. madrynense). El resto de las especies presentaron prevalencias muy bajas. Por el contrario, Puerto Deseado presentó una mayor riqueza de especies y todas las especies presentaron prevalencias aproximadamente similares. Al igual que en Puerto Madryn, las prevalencias de los dos digeneos microfálidos fueron las más alta (Fig. 75). 
El índice de diversidad fue mayor en Puerto Deseado $(t=-6,42 ; p<0,05)$ y resultó estar principalmente explicado por la riqueza de especies, ya que no hubo diferencias en la equitatividad. La dominancia fue mayor en Puerto Madryn debido a la presencia de las dos especies de microfálidos con altas prevalencias. El porcentaje de similitud entre ambas comunidades de digeneos fue de 27\% (Tabla 17).

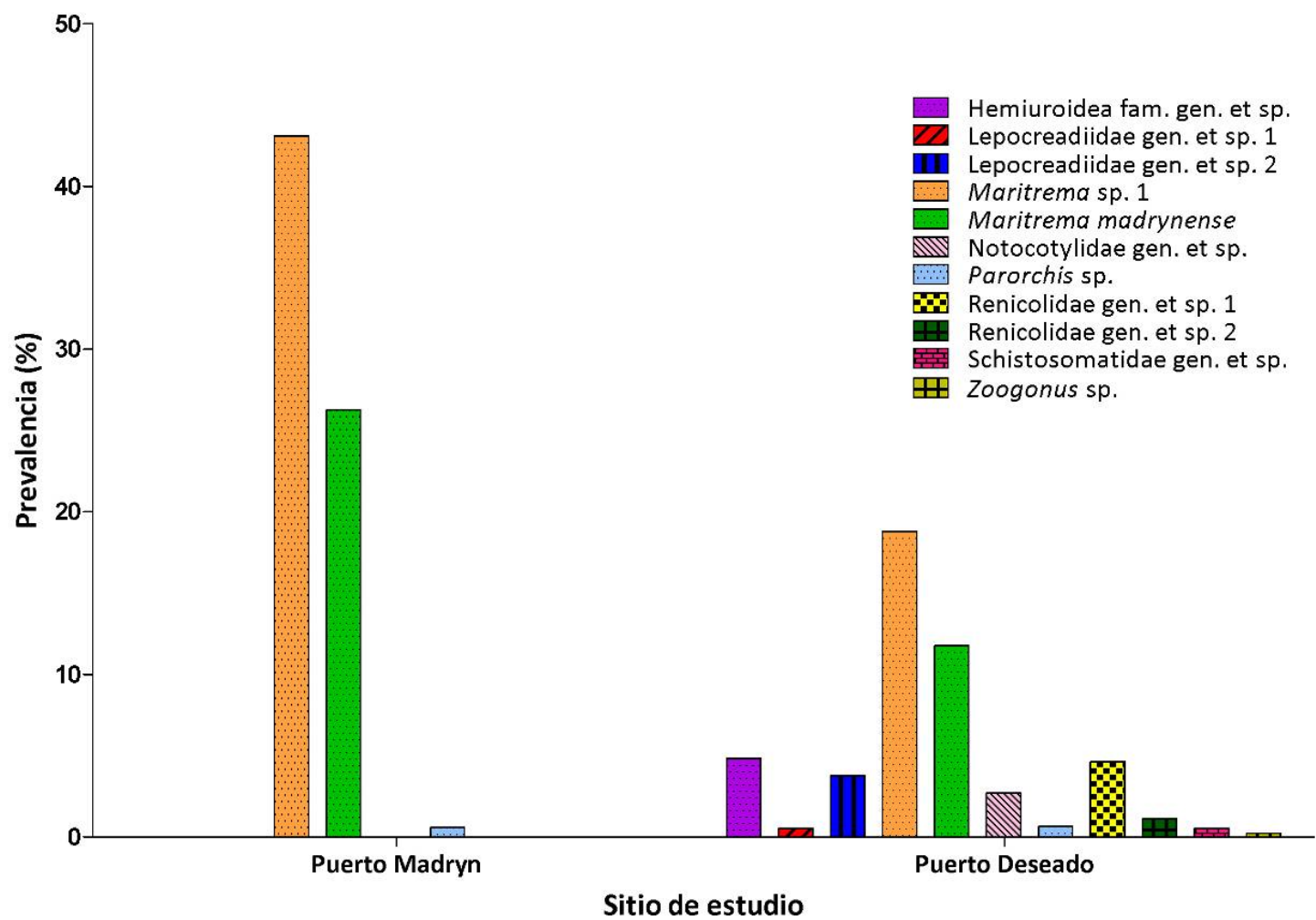

Figura 75. Prevalencia total de especies de digeneos larvales hallados en los gasterópodos estudiados en ambos sitios de estudio (Puerto Madryn y Puerto Deseado) en invierno de 2009 y verano de 2010.

Tabla 17. Índices de diversidad parasitaria en los dos sitios de estudio en inverno de 2009 y verano de 2010.

\begin{tabular}{lcc}
\hline Índice & Puerto Madryn & Puerto Deseado \\
\hline Riqueza de especies & 3 & 11 \\
\hline Índice de diversidad $\left(\mathrm{H}^{\prime}\right)$ & 0,71 & 1,78 \\
\hline Equitatividad & 0,67 & 0,54 \\
\hline Dominancia & 0,52 & 0,23 \\
\hline Índice de similitud & & 0,27 \\
\hline
\end{tabular}




\subsection{Discusión y conclusiones}

En este capítulo se estudiaron algunos factores que afectan la prevalencia de parásitos, tanto a nivel poblacional como a nivel de comunidades. Los dos sitios de estudio presentaron aproximadamente el 40\% (cinco de 13) de las especies de digeneos en común, una especie se registró exclusivamente en Puerto Madryn y siete especies se registraron exclusivamente en Puerto Deseado.

Las prevalencias fueron bajas para la mayoría de las especies que se hallaron en estadio esporocisto o redia, con excepción de las dos especies de microfálidos que presentaron altas prevalencias en ambos sitios de estudio. La prevalencias suelen ser particularmente bajas en los moluscos que actúan como primeros hospedadores intermediarios de los digeneos (Lauckner, 1980; Ginestinkaya, 1988; Galaktionov \& Dobrovolskij, 2003). Esto ocurre principalmente en digeneos con ciclos de vida triexenos y que poseen un amplio espectro de segundos hospedadores intermediarios, ya que los pocos moluscos infectados pueden liberar una gran cantidad de cercarias y éstas tienen un amplio espectro de hospedadores blanco para ingresar y desarrollar a estadio metacercaria (Ginetsinkaya, 1988). Es probable que en los ambientes intermareales marinos, debido a la gran oferta de invertebrados que pueden servir como hospedadores de los digeneos, estas bajas prevalencias se trasladen también a los digeneos con ciclos de vida diexenos. Los digeneos microfálidos suelen presentar altas prevalencias en otros ambientes intermareales (e.g. Granovitch, 1992; Galaktionov \& Bustnes, 1999; Granovitch et al., 2000; Fredensborg et al., 2006). Estas altas prevalencias pueden estar asociadas a una alta abundancia de hospedadores definitivos, en este caso la gaviota cocinera Larus dominicanus, o bien, puede ser una estrategia evolutiva para mejorar la transmisión a los segundos hospedadores intermediarios y/o definitivos. En el caso de Maritrema madrynense, que presentó alta prevalencia en ambas localidades, se demostró que puede utilizar dos estrategias de transmisión, utilizando un crustáceo como segundo hospedador intermediario o enquistando la metacercaria dentro del gasterópodo Siphonaria lessonii (ciclo abreviado). Es probable que esta doble estrategia permita una alta tasa de infección en la gaviota y por lo tanto, una mayor tasa de infección en moluscos. El único digeneo que utilizó un gasterópodo sólo 
como segundo hospedador intermediario fue Gymnophalloides nacellae, que se halló sólo en estadio metacercaria parasitando al gasterópodo Nacella $(P$.) magellanica. La prevalencia de G. nacellae fue alta (aprox. 93\%), en concordancia con lo que ocurre con metacercarias de otras especies de la familia Gymnophallidae en bivalvos (e.g. Cremonte, 1999; Cremonte, 2004; Cremonte et al., 2008). En general, las prevalencias de metacercarias en los segundos hospedadores intermediarios suele ser alta en ambientes con bajo hidrodinamismo (Bartoli, 1974) ya que dichos hospedadores están más accesibles para el ingreso de la cercarias.

El incremento de la prevalencia con la talla del gasterópodo hospedador sólo se observó claramente en Maritrema sp. 1 y Maritrema madrynense en Puerto Madryn. Es posible que este patrón no se haya observado en estas especies de microfálidos en Puerto Deseado o en las otras especies estudiadas debido a las bajas prevalencias. Si bien los microfálidos presentaron las prevalencias más altas en Puerto Deseado, éstas fueron bajas en comparación a las prevalencias registradas en Puerto Madryn. Por otra parte, en Puerto Deseado, el número total de gasterópodos colectados fue menor, ya que se realizaron dos colectas puntuales (invierno y verano). Es probable que, dada las bajas prevalencias, se requiera un número mayor de ejemplares para observar un patrón en la relación prevalencia-talla. Sin embargo, en todas las especies de digeneos se observó que los gasterópodos parasitados presentaron tallas intermedias o mayores y que los gasterópodos de tallas pequeñas no estuvieron parasitados. El incremento de la prevalencia con la talla puede deberse a que los gasterópodos más grandes presentan mayor edad y, por lo tanto, el tiempo de exposición a la infección por miracidios es mayor. Además, gasterópodos más grandes proveen más espacio y nutrientes para el parásito e ingieren más alimento, incrementando la vía de entrada de las larvas, en los casos en los que el huevo es ingerido, como ocurre en las familias Microphallidae y Notocotylidae (Skirnisson et al., 2004). Por otra parte, los gasterópodos más grandes poseen mayor movilidad con lo cual se incrementa la probabilidad de encuentro con las larvas en los casos en los que el miracidio penetra activamente, como ocurre en el resto de las familias halladas (Galaktionov \& Dobrovolskij, 2003; Poulin \& Mouristen, 2003). Este tipo de relación ha sido ampliamente registrada en la literatura para otros digeneos de ambientes marinos y agua dulce (e.g. Baudoin, 
1975; Curtis \& Hurd, 1983; Granovitch, 1992; Jokela \& Lively, 1995; Poulin \& Mouristen, 2003). Alternativamente, los gasterópodos pueden presentar las prevalencias máximas en tallas intermedias (Granovitch, 1992; Fredensborg et al., 2005). En este trabajo, se observó este patrón en las especies Hemiuroidea fam. gen. et sp., Diphterostomum sp. y Renicolidae gen. et sp. 1 en Puerto Madryn y en las especies M. madrynense, Notocotylidae gen. et sp. y Parorchis sp. en Puerto Deseado. Estudios experimentales han demostrado que la mortalidad de los individuos infectados incrementa con la edad, pero no así su resistencia a la infección (Robson \& Williams, 1970), por lo que la prevalencia disminuye en las tallas mayores (mayor edad) como resultado de la alta mortalidad en este rango de tallas. La ausencia de infección en los gasterópodos jóvenes puede deberse a que presentan menor probabilidad de infección debido al menor tiempo de contacto con los miracidios (Ginetsinkaya, 1988). Adicionalmente, varios estudios han concluido que los gasterópodos comienzan a infectarse cuando alcanzan la madurez sexual (e.g. Ginetsinkaya, 1988; Galaktionov \& Dobrovolskij, 2003). Este patrón pudo observarse en Maritrema sp. 1 donde los gasterópodos Crepipatella dilatata parasitados presentaron tallas solapadas con las tallas de las hembras, indicando que los digeneos comienzan a ingresar luego de la reversión de sexo (de macho a hembra). En algunos casos, como en los de Parorchis sp. en Puerto Madryn y Hemiuroidea fam. gen. et sp., Lepocreadiidae gen. et sp. 1 y Maritrema sp. 1 en Puerto Deseado, no se observaron diferencias significativas entre la prevalencia y la talla. Los patrones fueron diferentes, en Lepocreadiidae gen. et sp. 1 donde la prevalencia se mantuvo constante hasta las tallas mayores, en Hemiuroidea fam. gen. et sp. se observó una mayor prevalencia en tallas intermedias y en Maritrema sp. 1 y en Parorchis sp. se observó una mayor prevalencia en las tallas mayores. Sin embargo, los análisis estadísticos no revelaron diferencias significativas para estas cuatro especies. Como se indicó al comienzo, es probable que la falta de significancia en las pruebas estadísticas se asocie al bajo número de ejemplares y a la baja prevalencia de las especies.

El sexo de los gasterópodos hospedadores no ejerció ningún efecto en la prevalencia de digeneos. En los casos donde se hallaron diferencias entre los sexos, estas estuvieron asociadas a la talla o a la abundancia del hospedador. Por ejemplo, 
Maritrema sp. 1 (en Puerto Madryn y Puerto Deseado) y Lepocreadiidae gen. et sp. 1 (en Puerto Deseado) siempre parasitaron hembras de C. dilatata. Este gasterópodo es hermafrodita consecutivo protándrico y los estadios reproductivos (inmaduro, macho, en reversión y hembra) presentaron rangos de talla diferentes. Las hembras presentaron las mayores tallas, en las cuales se registraron los digeneos. Otros digeneos como Diphterostomum sp. (en Buccinanops globulosus en Puerto Madryn), Lepocreadiidae gen. et sp. 2 (en Pareuthria plumbea en Puerto Deseado) y Renicolidae gen. et sp. 1 (en Trophon geversianus en Puerto Madryn) también se hallaron parasitando a ejemplares de sexo femenino. En estos casos, los gasterópodos hembra presentaron tallas mayores que los machos, por lo tanto, las hembras tienen mayor probabilidad de presentar parásitos. Además, en el caso puntual de T. geversianus la proporción de hembras fue tres veces superior, por lo que también se incrementa la probabilidad de infección. Los estudios sobre la influencia del sexo del hospedador sobre la prevalencia de digeneos larvales son escasos. Sin embargo, en la mayoría de ellos, no se registraron diferencias significativas (Oliva \& Diaz, 1988; Sokolova, 1995). En algunos pocos estudios, en los cuales se registró una relación entre la prevalencia y el sexo, las diferencias estuvieron asociadas a otras causas como la talla o el comportamiento diferencial entre machos y hembras (Curtis \& Hurd, 1983; Ginestinkaya, 1988; Granovitch, 1992). En el caso particular de G. nacellae, no hubo diferencias de la prevalencia entre sexos, pero sí hubo diferencias en la intensidad de infección, siendo ésta mayor en machos. A partir de este estudio, se determinó que el bivalvo Gaimardia trapesina actúa como primer hospedador intermediario de esta especie. Este bivalvo habita próximo a la costa sobre el alga Macrocystis pyrifera. Una posible hipótesis para explicar la mayor intensidad de infección en machos sería una distribución espacial diferencial en el intermareal, estando los machos en la parte inferior y las hembras en la parte superior.

No se observó un patrón estacional de la prevalencia en ninguno de los sitios de estudio. Nuevamente, cualquier patrón estacional podría no percibirse debido a la baja prevalencia de la mayoría de las especies. Sin embargo, las especies con alta prevalencia en Puerto Madryn (Maritrema sp. 1 y M. madrynense) tampoco presentaron estacionalidad y en Puerto Deseado, las especies con altas prevalencias 
presentaron patrones contrastantes. Por un lado, G. nacellae y Renicolidae gen. et sp. 1 presentaron mayor prevalencia en invierno y M. madynense presentó mayor prevalencia en verano. El factor estacional en la prevalencia está principalmente asociado a la presencia y abundancia de hospedadores definitivos en el área (Prinz et al., 2010). Los vertebrados liberan los huevos con las heces, los moluscos se infectan en un corto lapso de tiempo y permanecen infectados hasta la muerte. Factores ambientales como la temperatura o la salinidad cobran importancia en el desarrollo de las cercarias y la emergencia al medio ambiente. Varios estudios han revelado que la emergencia de las cercarias se incrementa con el aumento de la temperatura, por lo que la transmisión a los segundos hospedadores intermediarios y/o definitivos es más exitosa en verano (e.g. Køie, 1975; Degel \& McCurdy, 2004; Galaktionov et al., 2006; Poulin, 2006; Prinz et al., 2010). Los digeneos que se hallaron durante todo el año con altas prevalencias, como son los casos de Maritrema sp. 1 y M. madrynense, podrían ser utilizados como modelo para el estudio de la variación estacional en el desarrollo de cercarias.

Por otra parte, tanto en Puerto Madryn como en Puerto Deseado, se observó que la presencia de digeneos (riqueza de especies) es mayor en las estaciones frías del año. Estos son los casos de Hemiuroidea fam. gen. et sp. y Renicolidae gen. et sp. 1 en Puerto Madryn, que se registraron en otoño e invierno respectivamente y Lepocreadiidae gen. et sp. 1, Notocotylidae gen. et sp., Parorchis sp., Schistosomatidae gen. et sp y Zoogonus sp. en Puerto Deseado, que se registraron sólo en invierno. Es probable que en estas estaciones exista una mayor diversidad y abundancia de hospedadores definitivos. La gaviota cocinera Larus dominicanus, que actuaría como hospedador definitivo de la mayoría de las especies que utilizan aves como hospedadores definitivos, presenta una variación estacional en la dieta. Durante la etapa previa a la puesta y a la incubación de los huevos (otoño e invierno) se alimenta principalmente de invertebrados y durante la etapa de pichones (verano) se alimenta principalmente de peces, para cubrir los requerimientos energéticos de las crías (Bertellotti \& Yorio, 1999). Asimismo, en otoño, muchas especies de aves migratorias realizan paradas de alimentación y descanso en varios sitios de la costa patagónica (D’Amico et al., 2004). Si bien se desconoce la existencia de variación estacional para la mayoría de los peces de 
arrecife que se alimentan en los intermareales, algunas especies de peces como los turcos presentan una mayor abundancia en otoño (estación en la cual el agua alcanza la máxima temperatura) (Galván, 2008). En Puerto Deseado sólo se realizaron dos colectas puntuales, en invierno y en verano. Para alcanzar una conclusión más robusta sobre los factores que afectan la prevalencia o riqueza de especies en las diferentes estaciones del año, sería necesario realizar análisis mensuales durante por lo menos un año y conocer los ciclos de vida de las especies involucradas.

Por último, tanto la riqueza como la diversidad de especies parásitas fueron mayores en Puerto Deseado. En general, la diversidad de digeneos en los $1^{\circ} \mathrm{HI}$ está estrechamente relacionada con la presencia de sus hospedadores definitivos (e.g. Skirnisson et al., 2004; Huspeni et al., 2005; Hechinger \& Lafferty, 2005; Hechinger et al., 2008). Dichas conclusiones se basaron en estudios realizados principalmente en gasterópodos de agua dulce o marinos en ambientes estuariales o cerrados (lagunas, charcas), en donde la diversidad de gasterópodos es baja y cada gasterópodo está parasitado por varias especies de digeneos (más de diez) (e. g. Skirnisson et al., 2004; Hechinger \& Lafferty, 2005; Flores \& Semenas, 2008; Merlo \& Etchegoin, 2010). En nuestro sistema de estudio, la mayor diversidad de parásitos en Puerto Deseado estaría explicada por la mayor diversidad de moluscos, particularmente gasterópodos. La mayor diversidad registrada en Puerto Deseado estaría asociada a las características que presenta la provincia biogeográfica Magallánica en comparación con aquellas que presenta la provincia biogeográfica Argentina. Las diferentes características fisiogeográficas y climáticas de ambas regiones caracteriza a la provincia Magallánica como altamente homogénea y con una gran cantidad de taxones propios (Balech \& Erlich, 2008). Una alta diversidad de moluscos y otros invertebrados atraen peces y aves marinas, permitiendo que los intermareales sean áreas activas de alimentación para estos vertebrados que liberan los huevos de digeneos con las heces. En este tipo de ambientes los digeneos encuentran un amplio rango de gasterópodos para utilizar como primeros hospedadores intermediarios, por consiguiente, es esperable que cada gasterópodo esté parasitado por pocas especies (de una a tres) y que la probabilidad de encontrar infecciones dobles sea muy baja. Por lo tanto, la diversidad de 
hospedadores definitivos afectaría la diversidad de digeneos pero de manera indirecta y el factor principal sería la diversidad de moluscos.

Si bien la comunidad de digeneos de Puerto Deseado resultó ser más diversa, las mayores prevalencias se registraron en Puerto Madryn. Las dos especies de microfálidos descriptas, Maritrema sp. 1 y M. madrynense, presentaron prevalencias altas en ambos sitios, pero las prevalencias en Puerto Madryn fueron considerablemente mayores. Estas altas prevalencias podrían estar explicadas por la mayor densidad de gaviotas cocineras en Puerto Madryn. Si bien la gaviota cocinera se distribuye ampliamente en la costa patagónica, la zona de Península Valdés concentra una gran cantidad de estas aves debido a la amplia oferta alimenticia. Por otra parte, la presencia de un basurero urbano a cielo abierto, un basurero pesquero y la existencia de 18 plantas procesadoras incrementan las fuentes de alimento para las gaviotas (Yorio et al., 1996; Giaccardi \& Yorio, 2004). En los últimos años, las gaviotas han incorporado otra fuente de alimento en el área, piel y grasa de ballena franca austral que arriba a la Península Valdés todos los años en la época reproductiva (mayo a noviembre) (Bertellotti \& Pérez, 2008). Un incremento en la abundancia de gaviotas, que también se alimentan en las áreas intermareales, conlleva a un incremento en la presión de depredación sobre los invertebrados. Esta depredación aviar podría reducir las poblaciones de invertebrados en los ecosistemas litorales. Con la concentración de poblaciones de aves aumentaría la prevalencia de infección de parásitos, pero a su vez, se reduciría su diversidad, como se observa en este estudio. Otros estudios también han documentado cómo la actividad humana puede producir cambios de comportamiento o alterar la distribución de los hospedadores definitivos (aves) (Lafferty, 2001; Lafferty et al., 2006b) y afectar directa o indirectamente la distribución y abundancia de las comunidades larvales de digeneos (Bustnes, 2000; Lafferty \& Kuris; 2004).

Si bien las aves marinas presentaron un papel predominante en las comunidades de digeneos estudiadas, muchas de las especies halladas finalizan su ciclo de vida en peces. Existen pocos trabajos en los cuales se reporta la relación de los digeneos larvales y la abundancia de peces. Algunos de ellos registran que la riqueza de digeneos está positivamente relacionada con la densidad de 
Capítulo 3. Dinámica de las poblaciones y de las comunidades

invertebrados bentónicos y peces (Huspeni et al., 2005; Hechinger et al., 2007). Es probable que una alta densidad de peces en Puerto Deseado, debido a la gran diversidad de invertebrados bentónicos en el intermareal, aporten a la mayor diversidad de digeneos. 


\section{DISCUSIÓN Y CONCLUSIONES GENERALES}

En este estudio se registraron y describieron 13 larvas de digeneos parasitando a los gasterópodos más abundantes en dos sitios de la costa patagónica, Puerto Madryn y Puerto Deseado.

Sobre un total de nueve especie de gasterópodos estudiados, siete estuvieron infectadas por al menos una especie de digeneo. Sólo los gasterópodos Tegula patagonica de Puerto Madryn y Fissurella radiosa de Puerto Deseado no presentaron parásitos. Buccinanops globulosus de Puerto Madryn estuvo parasitado por el digeneo Diphterostomum sp. (Zoogonidae) (esporocistos con cercarias y/o metacercarias). Crepipatella dilatata estuvo parasitado por dos especies de digeneos, Maritrema sp. 1 (Microphallidae) (esporocistos con cercarias) en ambos sitios de estudio y Lepocreadiidae gen. et sp. 1 (redias con cercarias) sólo en Puerto Deseado. Kerguelenella lateralis de Puerto Deseado estuvo parasitado por el digeneo Maritrema madrynense (Microphallidae) (esporocistos con cercarias). Nacella (Patinigera) magellanica de Puerto Deseado estuvo parasitado por tres especies de digeneos, Gymnophalloides nacellae (Gymnophallidae) (metacercarias), Notocotylidae gen. et sp. (redias con cercarias y metacercarias) y Renicolidae gen. et sp. 2 (esporocistos con cercarias). Pareuthria plumbea de Puerto Deseado estuvo parasitado por dos especies de digeneos, Lepocreadiidae gen. et sp. 2 (redias con cercarias) y Zoogonus sp. (Zoogonidae) (esporocistos con cercarias). Siphonaria lessonii estuvo parasitado

por tres especies de digeneos, Hemiuroidea fam. gen. et sp. (esporocistos con cercarias) y M. madrynense (esporocistos con cercarias y/o metacercarias) en ambos sitios de estudio y Schistosomatidae gen. et sp. (esporocistos con cercarias) sólo en Puerto Deseado. Por último, Trophon geversianus estuvo parasitado por dos especies de digeneos en ambos sitios de estudio, Parorchis sp. (Philophthalmidae) (redias con cercarias) y Renicolidae gen. et sp. 1 (esporocistos con cercarias).

De las 13 especies descriptas en este estudio, seis son registradas por pimera vez en gasterópodos; dos de las cuales (Parorchis sp. y Zoogonus sp.) constituyen los primeros registros de la familia en Sudamérica y cuatro (Lepocreadiidae gen. et sp. 1, Lepocreadiidae gen. et sp. 2, Maritrema sp. 1 y Renicolidae gen. et sp. 1) los primeros registros de la familia en Argentina. Las siete especies restantes 
(Hemiuroidea fam. gen. et sp., Diphterostomum sp., G. nacellae, M. madrynense, Notocotylidae gen. et sp., Renicolidae gen. et sp. 2 y Schistosomatidae gen. et sp.) habían sido halladas en los mismos gasterópodos estudiados en este trabajo aunque en otras localidades (Martorelli \& Morriconi, 1998; Martorelli et al., 2005; Martorelli et al., 2006; Alda \& Martorelli, 2009). En este estudio se completaron las descripciones y se ampliaron las distribuciones geográficas en todos los casos, se describieron hasta nivel de especie los digeneos G. nacellae y M. madrynense, se reubicó en otro género al digeneo G. nacellae (antes Lacunovermis sp.) y se reubicó en otra familia al digeneo Notocotylidae gen. et sp. (antes Pronocephalidae gen. et sp.).

A partir de este estudio se lograron dilucidar en forma completa dos ciclos de vida, el del microfálido M. madryense y el del filoftálmido Parorchis sp., que ocurren en ambos sitios de estudio, Puerto Madryn y Puerto Deseado.

Maritrema madrynsense utiliza como primer hospedador intermediario al gasterópodo pulmonado Siphonaria lessonii, como segundos hospedadores intermediarios a los crustáceos Cyrtograpsus altimanus e Idotea baltica y a la gaviota cocinera Larus dominicanus como hospedador definitivo. Este gasterópodo también actúa como segundo hospedador intermediario, ya que las metacercarias se encuentran frecuentemente enquistadas dentro de los esporocistos. El ciclo de vida de esta especie ocurre a lo largo de todo el año con dos modalidades, ciclo triexeno o ciclo diexeneo (abreviado), donde la gaviota cocinera se infecta al consumir los crustáceos o a los gasterópodos con metacercarias.

Parorchis sp., que sería una especie aún no descripta, morfológicamente indistinguible de $P$. acanthus, utiliza al gasterópodo murícido Trophon geversianus como primer hospedador intermediario, la cercaria es emitida y enquista en el medio, probablemente sobre las valvas de los bivalvos mitílidos sobre las que vive y se alimenta el gasterópodo que actúa como primer hospedador intermediario; la gaviota cocinera L. dominicanus y el playero de rabadilla blanca Calidris fuscicollis actúan como hospedadores definitivos.

Se lograron dilucidar en forma parcial tres ciclos de vida, los ciclos de Diphterostomum sp. (Zoogonidae) y Renicolidae gen. et sp. 1 en Puerto Madryn y el ciclo de Gymnophalloides nacellae (Gymnophallidae) en Puerto Deseado. Diphterostomum sp., que sería una especie aun no descripta, morfológicamente 
indistinguible de D. brusinae, utiliza al gasterópodo nasárido Buccinanops globulosus como primer hospedador intermediario. Si bien no se conoce el segundo hospedador intermediario, se sospecha que podría ser el bivalvo Tellina petitiana, muy abundante en el submareal somero arenoso del Golfo Nuevo (Hernández et al., 2008) o bien, poliquetos o erizos que habitan en las cercanías del primer hospedador intermediario B. globulosus. Debido al tipo de cercaria (sin cola), es probable que el segundo hospedador intermediario sea bentónico y se encuentre en las cercanías del primer hospedador intermediario. El hospedador definitivo de esta especie es el pez Pinguipes brasilianus. El gasterópodo B. globulosus también actúa como segundo hospedador intermediario, ya que las metacercarias se encuentran frecuentemente enquistadas dentro de los esporocistos. En una colecta de B. globulosus realizada en el submareal somero de Puerto Madryn se observó que la prevalencia de Diphterostomum sp. es mayor en el submareal $(5,1 \%)$ que en el intermareal $(0,16 \%)$. Este resultado indica que este ciclo de vida ocurre principalmente en el submareal somero, debido a que el pez P. brasilianus se acerca a alimentarse a estas zonas durante la marea alta (Irigoyen \& Galván, 2009). Para completar este ciclo de vida y el resto de los que finalizan en peces, es necesario el estudio de los parásitos en invertebrados bentónicos y planctónicos en el submareal somero y en peces costeros. Adicionalmente, podrían realizarse infecciones experimentales de potenciales segundos hospedadores intermediarios con cercarias emitidas de $B$. globulosus para determinar el espectro de hospedadores utilizados y si existe alguna especificidad en algún nivel taxonómico (filtro por compatibilidad) o si depende principalmente de la disponibilidad de hospedadores en el área (filtro por encuentro). Combes (2001) utilizó el término de "filtros" para explicar los mecanismos responsables del espectro de hospedadores de una especie de digeneo. En el caso particular de Diphterostomum sp., los hospedadores blanco para realizar las infecciones experimentales podrían ser la almeja T. petitiana, la anémona de arena Neoparacondylactis haraldoi Zamponi (Actiinidae) y el erizo de mar Arbacia dufresnii (Blainville) (Arbaciidae). También debería determinarse si la cercaria puede enquistar en el medio, ya que existe el antecedente de que la cercaria de $D$. brusinae enquista ocasionalmente sobre plantas acuáticas o algas (Dolgikh \& Naidjenovav, 1967). 
Renicolidae gen. et sp. 1 utiliza como primer hospedador intermediario al gasterópodo murícido T. geversianus y como segundo hospedador intermediario al mitílido Mytilus edulis. Otros bivalvos han sido registrados como segundos hospedadores intermediarios de metacercarias de la familia Renicolidae. Cremonte (1999) halló metacercarias de esta familia en los mitílidos M. edulis, Perumytilus purpuratus y Aulacomya atra y en el bivalvo Lasaea adansoni en varios intermareales de la costa patagónica. Adicionalmente, también se hallaron metacercarias en el bivalvo Gaimardia trapesina (datos no publicados). En base a otros estudios se conoce que las cercarias renicólides pueden ingresar en varias especies de bivalvos (Stunkard, 1964; Sannia \& James, 1977; Aguirre-Macedo \& Kennedy, 1999; RussellPinto et al., 2006; Longshaw \& Malham, 2013). Futuros estudios moleculares de estas metacercarias contribuirán a confirmar el espectro de hospedadores de Renicolidae gen. et sp 1 y Renicolidae gen. et sp. 2 hallada en el gasterópodo Nacella $(P$.$) magellanica. Debido a la distribución de su primer hospedador intermediario, es$ probable que Renicolidae gen. et sp. 2 presente una distribución más acotada que Renicolidae gen. et sp. 1. Para conocer el espectro de hospedadores intermediarios es necesario estudiar y secuenciar las metacercarias halladas en bivalvos de Puerto Deseado y en peces costeros, ya que las metacercarias de esta familia utilizan también peces como segundos hospedadores intermediarios (Rothschild, 1935; Rothschild \& Sproston, 1941; Wright, 1956; Stunkard, 1970; Yamaguti, 1975; Yoshino, 1975; Prévot \& Bartoli, 1978; Ching, 1989). Recientemente se hallaron adultos de la familia Renicolidae en el riñón de la gaviota cocinera L. dominicanus (datos no publicados), quedando pendiente su descripción morfológica y secuenciación molecular, los cuales permitirán establecer su identidad taxonómica. Es probable que este adulto corresponda a la misma especie que la cercarias de Renicolidae gen. et sp. 1 hallada en T. geversianus, ya que la gaviota fue colectada en Puerto Madryn.

Gymnophalloides nacellae utiliza como segundo hospedador intermediario al gasterópodo Nacella (P.) magellanica. Este gasterópodo fue el único hallado en este estudio parasitado por metacercarias que se desarrollan fuera de los esporocistos o redias. El bivalvo G. trapesina actúa como primer hospedador intermediario, alojando esporocistos con cercarias. Si bien aún no se hallaron los adultos de esta 
especie, se sospecha que la gaviota cocinera $L$. dominicanus o el ostrero negro Haematopus ater actúan como hospedadores definitivos, ya que se conoce que se alimentan de estas lapas (Yorio \& Bertellotti, 2002; Sapoznikow, 2008).

La dilucidación de los ciclos de vida es de suma importancia para comprender las diferentes estrategias de transmisión adquiridas por las especies de digeneos a lo largo de la evolución como una adaptación a las condiciones ambientales y la disponibilidad de invertebrados y vertebrados que actúan como hospedadores (Ginetsinkaya, 1988; Combes, 2001). El espectro de hospedadores utilizado por una especie de digeneo depende de varios factores, como el grupo taxonómico y la edad evolutiva del parásito, el grupo taxonómico del hospedador, el modo de infección, la complejidad del ciclo de vida, el microhábitat y el área geográfica (Combes, 2001). Estos factores influirán sobre los filtros de encuentro y compatibilidad entre parásito y hospedador, determinando el espectro de hospedadores utilizados por cada especie en cada estadío del ciclo de vida.

En este estudio se logró determinar parte del espectro de segundos hospedadores intermediarios de las especies G. nacellae, M. madrynense y Renicolidae gen. et sp. 1. Gymnophalloides nacellae utiliza como segundo hospedador intermediario al gasterópodo $N$. (P.) magellanica y se conoce que otras lapas como Nacella (P.) deaurata y Nacella (P.) mytilina (Helbling) también pueden albergar metacercarias de esta especie (Martorelli \& Morriconi, 1998; Gilardoni, obs. pers). La utilización de gasterópodos como segundos hospedadores intermediarios de un digeneo de la familia Gymnophallidae se observó en el presente caso y en otra especie del género Gymnophalloides, G. seoi (Ching, 1995). Comúnmente, los gimnofálidos utilizan bivalvos como primeros y segundos hospedadores intermediarios (Bartoli, 1974; Cremonte, 2011). En este caso, G. nacellae presentaría una alta especificidad (filtro por compatibilidad) por gasterópodos de la familia Nacellidae. Para confirmar esta conclusión en necesario examinar otras lapas del orden Patellogastropoda presentes en el sitio de estudio, Puerto Deseado. Maritrema madrynense utiliza como segundo hospedador intermediario al cangrejo de las rocas C. altimanus, muy abundante en el intermareal de Puerto Madryn (Vázquez et al., 2012) y al isópodo I. baltica. Una metacercaria del género Maritrema fue registrada en el isópodo Exosphaeroma sp. en Comodoro Rivadavia (Alda \& Martorelli, 2009) y 
otra metacercaria Microphallidae fue hallada en el mismo isópodo durante este estudio en Puerto Deseado pero no pudo ser determinada taxonómicamente. Es probable que $M$. madrynense tenga una amplia distribución en la costa patagónica, ya que el hospedador definitivo, L. dominicanus, es muy abundante en la región (Yorio et al., 1998). Además, la larva fue hallada en gasterópodos de Playa Fracasso (golfo San José en la Península Valdés), Puerto Madryn, Comodoro Rivadavia y Puerto Deseado (Alda \& Martorelli, 2009; Gilardoni et al., 2011; Bagnato, 2012). Por lo tanto, es probable que en cada área este digeneo utilice diferentes especies de crustáceos como segundos hospedadores intermediarios, dependiendo de su cercanía al gasterópodo y de su abundancia. En este estudio se hallaron dos especies de la familia Renicolidae, Renicolidae gen. et sp. 1 en T. geversianus y Renicolidae gen. et sp. 2 en $N$. (P.) magellanica y se conocen varias metacercarias en mitílidos, M. edulis (la misma especie que Renicolidae gen. et sp. 1), P. purpuratus, A. ater, L. adansoni y G. trapesina) (Cremonte, 1999; datos no publicados). Nuevamente, la cercaria podría ingresar y desarrollar a estadio metacercaria en varias especies, en este caso de bivalvos, según su disponibilidad en el área.

Otro aspecto de gran importancia en los ciclo de vida de los digeneos son las estructuras desarrolladas por las cercarias y las adaptaciones comportamentales que incrementan la posibilidad de ingreso al segundo hospedador intermediario o al hospedador definitivo (Ginetsinkaya, 1988; Combes, 2001). La cercarias pueden ingresar en forma pasiva a través de filtración, en el caso de bivalvos u otros invertebrados filtradores, o vía trófica, o bien, en forma activa, penetrando en el cuerpo del segundo hospedador intermediario (Ginetsinkaya, 1988). Las dos excepciones son Parorchis sp. cuya metacercaria enquista en el medio y Schistosomatidae gen. et sp., cuya cercaria penetra activamente al ave que actúa como hospedador definitivo. A través del estudio morfológico y del comportamiento de las cercarias emitidas, se pudieron determinar algunas adaptaciones asociadas a la transmisión. Las cercarias microfálides, Maritrema sp. 1 y M. madrynense presentan estiletes y glándulas de penetración que le permiten atravesar los tejidos de los crustáceos que actúan como segundos hospedadores intermediarios. Las cercarias Renicolidae gen. et sp. 1 y Renicolidae gen. et sp. 2 poseen glándulas cistógenas bien desarrolladas para enquistarse en el bivalvo o pez 
que puede actuar como segundo hospedador intermediario. Tanto las cercarias microfálides como las renicólides emitidas de los gasterópodos se mueven activa y continuamente en la columna de agua, luego caen al fondo donde continúan su movimiento y podrían aguardar a ser ingeridas por sus segundos hospedadores intermediarios (bentónicos) o podrían ingresar activamente penetrando los tejidos del hospedador. Las cercarias Lepocreadiidae gen. et sp. 1 y Lepocreadiidae gen. et sp. 2 alternan períodos de movimiento activo con períodos de descanso. Además, son de gran tamaño, presentan manchas oculares para orientarse en la columna de agua (fototaxismo positivo) y poseen grandes colas provistas de setas que le permiten moverse en la columna de agua y exhibirse, de manera de constituirse como presa para los invertebrados planctónicos que actuarían como segundos hospedadores intermediarios. La cercarias Hemiuroidea fam. gen. et sp. poseen un quiste caudal donde resguardan su cuerpo al emerger del primer hospedador intermediario; dicho quiste está provisto de filamentos caudales que le permiten a la cercaria flotar en la columna de agua y ser ingerida por invertebrados planctónicos que constituirían su segundos hospedadores intermediarios (principalmente copépodos). Esta especie se halla en el gasterópodo pulmonado $S$. lessonii que habita en el intermareal superior. Cabe destacar que, a pesar de haber realizado numerosos intentos, nunca se observó emisión de las cercarias en condiciones de laboratorio. En este caso, dos hipótesis son plausibles; que sea una especie progenética, aunque no se observaron metacercarias en el gasterópodo, o que exista un segundo hospedador que se alimente en el intermareal superior durante la marea alta, como copépodos, anfípodos o ctenóforos.

Si bien no se lograron dilucidar los ciclos de vida de todas las especies de digeneos halladas en este estudio, a partir de la bibliografía, el conocimiento de la disponibilidad de hospedadores en el área y de las características morfológicas y comportamentales de las cercarias, es posible plantear hipótesis para cada especie. Las cercarias Hemiuroidea fam. gen. et sp. podrían emerger del gasterópodo pulmonado S. lessonii durante la marea alta y ser ingeridas por un invertebrado planctónico. En este estudio se hallaron metacercarias Hemiuridae en el ctenóforo Mnemiopsis leydi que podrían corresponderse con las larvas en S. lessonii, ya que los ctenóforos se concentran en la superficie del agua en Puerto Madryn (Costello \& 
Mianzán, 2003). Otros potenciales segundos hospedadores intermediarios podrían ser copépodos los cuales han sido ampliamente registrados en la bibliografía como segundos hospedadores intermediaros de hemiúridos (Cable, 1963; Stunkard, 1970; Yamaguti, 1975; Køie, 1979, 1989, 1990b, 1991, 1992, 1995; Køie \& Gibson, 1991). Los adultos de la superfamilia Hemiuroidea han sido registrados en numerosas especies de peces en el mundo (e.g. Gibson, 2002; Kohn et al., 2007) y en la costa patagónica fueron citadas 26 especies (ver ref. Tabla 4). En este caso, cualquier especie de pez que habite en el submareal somero (e.g. diablillos, pez gallo, nototénidos, zoácidos) o que se alimente en los intermareales durante la pleamar (e.g. róbalos, turcos, viejas, pejerreyes) actuaría como hospedadores definitivos.

Las cercarias Lepocreadiidae gen. et sp. 1 y Lepocreadiidae gen. et sp. 2, que emergen de $C$. dilatata y $P$. plumbea respectivamente podrían ingresar en alguno de los bivalvos en los cuales se hallaron metacercarias de esta familia, G. trapesina y Neolepton cobbi (Ituarte et al., 2001, 2005). Sin embargo, otros invertebrados, tanto bentónicos como planctónicos, podrían actuar también como segundos hospedadores intermediarios, como ctenóforos, medusas, quetognatos, gasterópodos, bivalvos, peces y anélidos (e.g. Bartoli, 1966, 1967, 1983; Stunkard, 1970, 1983; Køie, 1975; Watson, 1984; Bray \& Gibson, 1990; Martorelli, 1996; Morandini et al., 2005). El hospedador definitivo de estas especies o de alguna de ellas podría ser el róbalo Eleginops maclovinus, ya que se registraron dos especies en estadío adulto de la familia Lepocreadiidae, Lepocreadium sp. y Neolepidapedon sp. en las costas de Patagonia (Gosztonyi, 1979; MacKenzie, 2003).

Las cercarias Zoogonus sp. fueron registradas en un sólo ejemplar del gasterópodo P. plumbea. Debido a que esta especie de gasterópodo habita desde el intermareal rocoso inferior hasta $\operatorname{los} 80 \mathrm{~m}$ de profundidad (Pastorino \& Penchaszadeh, 2002), es probable que la prevalencia de Zoogonus sp. sea más alta en el submareal y que el ciclo de vida ocurra involucrando hospedadores intermediarios y definitivos que habitan exclusivamente el submareal. La cercaria de esta especie no posee cola, por lo que el segundo hospedador intermediario debería habitar en las cercanías de P. plumbea. Posiblemente se trate de un equinodermo, gasterópodo o poliqueto, ya que estos invertebrados fueron 
registrados como segundos hospedadores intermediaros de otras especies de la familia Zoogonidae (Stunkard, 1938, 1940; Køie, 1976; Curtis 2007).

La cercaria Maritrema sp. 1 emerge del gasterópodo C. dilatata y debido a que este gasterópodo habita en el intermareal inferior y submareal somero (Penchaszadeh et al., 2001), es probable que el crustáceo que actúe como segundo hospedador intermediario habite las mismas zonas. Estos crustáceos podrían ser anfípodos que habitan sobre las algas en los intermareales inferiores, o el cangrejo de las algas Leucippa pentagona Edwards (Epialtidae) que habita sobre algas y fondos duros en el infralitoral (Varisco \& Vinuesa, 2011). En una ocasión se observaron metacercarias poco desarrolladas (recién enquistadas) en los esporocistos de Maritrema sp. 1 en $C$. dilatata. Es probable que este enquistamiento se deba a las condiciones de estrés de los gasterópodos al estar expuestos a temperatura ambiente durante la experiencia de emisión en el laboratorio. No se puede concluir que esta especie presente un ciclo de vida abreviado, como sí lo presenta $M$. madrynense, en el cual se registró una alta proporción de gasterópodos con metacercarias dentro de los esporocistos. Maritrema sp. 1 presentó la mayor prevalencia en ambos sitios de estudio. Esto indicaría que el hospedador definitivo sería la gaviota cocinera L. dominicanus, debido a su gran abundancia y a su amplia distribución en la costa patagónica. En la gaviota cocinera se describió, además de M. madrynense a M. formicae (Diaz et al., 2012). La secuencia de ADN de estos adultos no presentó correspondencia con las larvas en C. dilatata. Sin embargo, es necesario repetir los estudios moleculares, realizando la extracción de ADN a partir de un sólo ejemplar, ya que las pocas diferencias morfológicas entre $M$. madrynense y M. formicae podrían dar lugar a una mezcla de especies al trabajar con un pool de ejemplares (debido a su pequeño tamaño, para extraer el ADN se utilizaron varios especímenes).

Las cercarias de Renicolidae gen. et sp. 2 emergerían del gasterópodo $N$. (P.) magellanica e ingresarían en alguna de las especies de bivalvos presentes en la zona (mencionadas con anterioridad para Renicolidae gen. et sp. 1). El hospedador definitivo es muy probable que sea la gaviota cocinera L. dominicanus o el ostrero negro H. ater, que se alimentan de estas lapas (Yorio \& Bertellotti, 2002; Sapoznikow et al., 2008). 
Por último, la cercaria Schistosomatidae gen. et sp. emerge del gasterópodo pulmonado S. lessonii y penetraría en el ave hospedador definitivo. Hasta el momento no se han registrado digeneos de esta familia en aves marinas en Argentina. Esto podría deberse, además de los escasos estudios parasitológicos que existen en aves marinas, a que los adultos se localizan dentro del sistema circulatorio o de los tejidos nasales de las aves, sitios que no suelen ser examinados en una disección de rutina, ya que es dificultoso cuando el ave no está recién muerta. Debido a que es una cercaria marina y a sus características morfológicas (presencia de ocelos, cola furcada con aletas), es posible que pertenezca al género Gigantobilharzia (Huffman \& Fried, 2008; Alda \& Martorelli, 2009). Otras especies de este género han sido halladas en aves Charadriiformes, Anseriiformes, Ciconiiformes y Passeriformes (Tabla 13.3 en Huffman \& Fried, 2008). En la costa patagónica, varias especies de aves que se alimentan en los intermareales podrían actuar como hospedadores definitivos, como patos, ostreros, chorlos y gaviotas, entre otros. Sin embargo, la gaviota cocinera L. dominicanus sería el primer hospedador para comenzar la búsqueda de adultos, ya que existen registros previos de especies del género Gigantobilharzia, como Gigantobilharzia sp. en L. dominicanus en las costas de Sudáfrica (Appleton \& Randall, 1986) y Gigantobilharzia acotylea en Larus cachinnans Pallas (Laridae) en el noreste de España (Sanmartín et al., 2005).

En este estudio se observó que el 62\% (8 de 13) de las especies halladas finalizan sus ciclos de vida en aves y el $38 \%$ (5 de 13) finalizan su ciclo de vida en peces. En los ambientes intermareales, la planicie que queda al descubierto durante la marea baja, facilita el contacto de los moluscos con los huevos y/o los miracidios de los trematodes. Además, el agua se vuelve más cálida, se establece una abundante vegetación y sedimentación del sustrato y se promueve un ambiente muy frecuentado por diversos invertebrados (inclusive moluscos) que atraen aves marinas y otros vertebrados, favoreciendo la transmisión de los digeneos (Ginetsinkaya, 1988). Si bien existen pocos estudios sobre la helmintofauna de moluscos en ambientes intermareales, en la mayoría de ellos la proporción de ciclos de vida que finalizan en aves es más alta que la hallada en el presente estudio, variando entre $85 \%$ y 95\% (Galaktionov \& Skirnisson, 2000; Thieltges et al., 2006). Si bien en este estudio se obtuvo una mayor proporción de ciclos de vida que finalizan 
en aves con respecto a los que finalizan en peces, existe una alta proporción de estos últimos (38\%). Los sitios de estudio, Punta Cuevas en Puerto Madryn y la desembocadura de la Ría Deseado en Puerto Deseado, son áreas con un bajo hidrodinamismo, de aguas calmas, poca pendiente y con gran amplitud de marea (máxima aproximada de 6 m.) (Bastida et al., 1992, Servicio de Hidrografía Naval). El hidrodinamismo fue definido por Bartoli (1986) como un factor de suma importancia en cuerpos de agua cerrados, donde las corrientes, las olas y las mareas barométricas incrementan la probabilidad de encuentro de la cercaria con el segundo hospedador intermediario. Las condiciones de estos ambientes intermareales rocosos favorecen que una gran variedad de peces se acerquen a alimentarse durante la marea alta y que una gran diversidad de aves se alimenten más tiempo durante la bajamar. Varios peces de arrecife habitan las zonas intermareales inferiores en forma permanente, como por ejemplo, diablillos, juveniles del pez gallo y varias especies de nototénidos y zoárcidos; otros utilizan el área transitoriamente durante la marea alta para alimentarse, como por ejemplo róbalos, turcos, viejas y varias especies de pejerreyes (Di Giacomo \& Pierrer, 1996; Dyer, 2003; Irigoyen \& Galván, 2009). Por otro lado, los intermareales de la costa patagónica constituyen importantes zonas de alimentación para varias especies de aves endémicas y migratorias (Gandini \& Frere, 1998; Coconier, 2006).

Sin embargo, en este estudio se observó que la gaviota cocinera, Larus dominicanus, cumple un rol predominante en los ciclos de vida de los digeneos descriptos. Se ha establecido con certeza que dos especies utilizan como hospedador definitivo a la gaviota cocinera (M. madrynense y Parorchis sp.) y se presupone que otras cinco (G. nacellae, Notocotylidae gen. et sp., Renicolidae gen. et sp. 1, Renicolidae gen. et sp. 2 y Schistosomatidae gen. et sp.) también lo hacen. Este hecho se debería a que la gaviota cocinera es la que presenta mayor abundancia y distribución geográfica más amplia (Yorio et al., 1998), a su vez es una especie oportunista y generalista, con una dieta constituida principalmente por invertebrados marinos y peces (Bertellotti \& Yorio, 1999). Esto no implica que, además de la gaviota cocinera, otras aves que frecuentan el intermareal actúen también como hospedadores definitivos de los digeneos aquí descriptos. 
El 62\% (8 de 13) de los digeneos hallados en el presente estudio presentan ciclos de vida triexenos (tres hospedadores), el 23\% (3 de 13) presentan ciclos de vida diexeneos (dos hospedadores) y el 15\% (2 de 13) presentarían ambas estrategias de transmisión (ciclos diexenos y/o triexenos). Los ciclos de vida abreviados han evolucionado para incrementar la probabilidad de transmisión en ciertos casos. Según Poulin \& Cribb (2002) existen cinco tipos de ciclos abreviados. El primero es el desarrollo progenético, donde la metacercaria enquista en un segundo hospedador intermediario (diferente al primer hospedador intermediario) y alcanza la maduréz sexual precozmente. Este es el caso de especies de los géneros Alloglossidium Simer, 1929 (Macroderoididae) (Smythe \& Font, 2001), Bucephaloides Hopkins, 1954 (Bucephalidae) (Pulsford \& Matthews, 1984) y Coitocaecum Nicoll, 1915 (Opecoelidae) (Holton, 1984), entre otros. Un extremo de este tipo de ciclo abreviado es adoptado por los parásitos sanguíneos (Aporocotylidae, Schistosomatidae y Spirorchidae), cuya cercaria penetra en un hospedador vertebrado donde desarrolla directamente al estadio adulto. Esta modalidad es la más común en los ciclos de vida abreviados y en este estudio se halló una especie que la presenta, Schistosomatidae gen. et sp. El segundo tipo consiste en utilizar al mismo molusco como $1^{\circ}$ y $2^{\circ}$ HI. Este es el caso de algunas especies de los géneros Asymphylodera Looss, 1899 (Lissorchiidae) (Nasincová \& Scholz, 1994), Diphterostomum (Zoogonidae) (Pina et al., 2009), Gymnophallus Odhner, 1900, Parvatrema Cable, 1953 (Gymnophallidae) (Loos Frank, 1969; 1971), Maritrema, Microphallus Ward, 1901 (Microphallidae) (Deblock et al., 1961; Deblock \& Tran Van Ky, 1966), Notocotyloides Dollfus, 1966 y Parapronocephalum Belopol'skaia, 1952 (Notocotylidae) (Yamaguti, 1975; Kanev et al., 1994; Hechinger, 2012), entre otras. En este estudio se observó este tipo de ciclo abreviado en los digeneos Diphterostomum sp., M. madrynense y Notocotylidae gen. et sp. El tercer tipo consiste en la utilización del $2^{\circ} \mathrm{HI}$ como hospedador definitivo, común en digeneos que parasitan anfibios. Por ejemplo, cercarias del digeneo Opisthiogyphe ranae (Frölich, 1791) (Plagiorchiidae) enquistan en el epitelio de la piel de una rana. Cuando la rana muda la piel, esta es ingerida por la rana con la metacercaria enquistada y se desarrolla a estadio adulto (Grabda-Kazubska, 1976). En el cuarto y quinto tipo de ciclo de vida abreviado sólo existe un hospedador; en uno de los casos, los adultos 
se desarrollan dentro de esporocistos o redias en el molusco. Este es el caso de algunas especies de los géneros Genarchella Travassos, Artigas \& Pereira, 1928 (Derogeneidae) (Martorelli, 1989a), Parahemiurus Vaz \& Pereira, 1930 (Hemiuridae) (Jamieson, 1966), Plagioporus Stafford, 1904 (Opecoelidae) (Barger \& Esch, 2000) y Proctoeces Odhner, 1911 (Fellodistomidae) (Stunkard \& Uzmann, 1959; Wardle, 1980), entre otros. En el otro caso, que sólo se observó en una especie, Mesostephanus haliasturis Tubangui \& Masilungan, 1941 (Cyathocotylidae), los esporocistos dentro del $1^{\mathrm{o}} \mathrm{HI}$ (gasterópodo) producen directamente miracidos que infectan otros gasterópodos (Barker \& Cribb, 1993). En el caso de Parorchis sp., el ciclo no es abreviado sino que la cercaria emerge y se enquista en el sustrato o sobre otro molusco, sin utilizar $2^{\circ} \mathrm{HI}$.

Los ciclos de vida abreviados han sido registrados en numerosas familias de digeneos (ver Tabla 1 en Poulin \& Cribb, 2002) y se sugiere que han evolucionado recientemente a partir de ciclos de vida complejos ancestrales (Poulin \& Cribb, 2002). Existen varias hipótesis que explican estos acortamientos en los ciclos. Algunas de ellas, que podrían explicar los ciclos abreviados de los digeneos descriptos en este estudio son la inestabilidad del ambiente, donde los digeneos pueden adaptar sus estrategias de transmisión en hábitats que son inestables temporalmente (Holton, 1984); la escasa disponibilidad de un determinado hospedador, como el caso de aves migratorias $u$ hospedadores que presentan fluctuaciones en su abundancia (Holton, 1984), y las condiciones ambientales extremas que existen en latitudes más altas, ya que la trasmisión mediante un estadio de vida libre puede verse dificultada por las bajas temperaturas (Skirnisson \& Galaktionov, 2002). Los intermareales rocosos, con poca pendiente y grandes amplitudes de mareas, como son ambos sitios estudiados en este trabajo, podrían considerarse ambientes inestables debido a la desecación producida durante la marea baja, las variaciones de temperatura, principalmente en verano, y la exposición a los factores ambientales como viento y lluvia. Con respecto a la disponibilidad de hospedadores, en la costa patagónica, existen varias especies de aves playeras migratorias que visitan los intermareales principalmente en otoño (D’Amico et al., 2004) y peces costeros, como turcos que se alimentan en el submareal somero principalmente a finales de verano y otoño (Galván, 2008). Los 
ciclos de vida de digeneos que utilicen alguno de estos hospedadores definitivos podrían abreviar su ciclo para incrementar la supervivencia de los estadios larvales, por ejemplo, Diphterostomum sp. que finaliza su ciclo de vida en el turco $P$. brasilianus. La última hipótesis, referida a las condiciones extremas a latitudes altas podría ser aplicada pero de una forma diferente. Si bien existen variaciones de temperatura, no se produce congelamiento y descongelamiento, como sí suele ocurrir en las latitudes más altas. Este incremento de temperatura en las pozas de marea durante el verano podría afectar la supervivencia de las cercarias y favorecer la selección de los ciclos de vida abreviados. En este estudio se observó que varias especies, incluso las que presenta ciclos de vida abreviados (Diphterostomum sp. y M. madrynense) y Parorchis sp. que enquista en el ambiente, viven menos de 24 horas a temperatura ambiente y más de 48 horas a una temperatura de $12^{\circ} \mathrm{C}$.

$\mathrm{Si}$ bien los ciclos de vida abreviados confieren ventajas en ciertos ambientes, también pueden tener costos elevados. Por ejemplo, pueden producir una descendencia con baja heterogeneidad genética y con una viabilidad reducida (Font, 1980) o reducir la fecundidad de los digeneos. En ambientes más equilibrados y diversos, con una alta disponibilidad de hospedadores intermediarios y definitivos predominan los ciclos de vida complejos (Galaktionov \& Skirnisson, 2000). Estos ciclos involucran la transmisión trófica y evolucionaron como una forma efectiva de beneficiar la fertilización cruzada, ya que los depredadores que se alimentan de un amplio espectro de presas en un intervalo de tiempo corto concentran a los parásitos adultos (Brown et al., 2001). La gran diversidad de invertebrados, peces y aves en los intermareales aquí estudiados favorecen la predominancia de ciclos de vida triexenos; sin embargo, la proporción de ciclos diexenos y abreviados es elevada, por lo que algunos de los factores mencionados como la variación en el ambiente (desecación, variación de temperatura, viento, lluvia) y la disponibilidad de algunos hospedadores podría estar creando un sistema mixto en el cual se utilizan ambas estrategias de transmisión.

En este estudio, dos especies de digeneos presentaron ciclos de vida tanto diexenos como triexenos. Esta doble estrategia de transmisión podría representar una transición evolutiva entre un ciclo de vida ancestral triexeno y un nuevo ciclo derivado diexeno (Poulin \& Cribb, 2002). Por otro lado, el ciclo complejo triexeno es 
predominante bajo condiciones desfavorables (clima, ausencia de $2^{\circ} \mathrm{HI}$ ), el ciclo abreviado se ve favorecido. Una posible hipótesis para el ciclo de vida de $M$. madrynense podría ser que en verano predominan los ciclos abreviados, ya que el incremento de temperatura en el intermareal perjudicaría la supervivencia de las cercarias y la densidad de cangrejos C. altimanus sería menor (Vázquez et al., 2012).

La mayoría de las especies de digeneos halladas en este estudio presentaron prevalencias bajas (entre 0,16 y 4,84\%). La prevalencias suelen ser particularmente bajas en los moluscos que actúan como primeros hospedadores intermediarios de los digeneos (Lauckner, 1980; Ginestinkaya, 1988; Galaktionov \& Dobrovolskij, 2003). Esto ocurriría principalmente en ambientes como las zonas intermareales con una amplia oferta de moluscos que pueden actuar como primeros hospedadores intermediarios. Por otro lado, los digeneos producen castración de los moluscos que actúan como primeros hospedadores intermediarios (Galaktionov \& Dobrovolskij, 2003), por lo que, con bajas prevalencias, se evitan efectos negativos sobre la población de moluscos. Además, cada molusco infectado constituye una fuente continua de cercarias, pudiendo liberar una gran cantidad durante toda su vida (Ginetsinkaya, 1988). Por otra parte las cercarias desarrollan adaptaciones que favorecen el encuentro y el ingreso al segundo hospedador intermediario. Todas estas características les permiten a los digeneos larvales transmitirse exitosamente sin necesidad de presentar prevalencias altas. De los digeneos que utilizan a los gasterópodos como primeros hospedadores intermediarios, sólo las dos especies de Microphallidae presentaron altas prevalencias (entre 8,95 y 33,45\%) en ambos sitios de estudio (Puerto Madryn y Puerto Deseado), al igual que otras especies de esta familia en otros intermareales del mundo (e.g. Granovitch, 1992; Galaktionov \& Bustnes, 1999; Granovitch et al., 2000; Fredensborg et al., 2006). A partir de los resultados del presente estudio, podría concluirse que las altas prevalencias de estas especies en los moluscos está determinada por la gran abundancia de hospedadores definitivos (la gaviota cocinera), por poseer estrategias de transmisión alternativas (ciclo diexeno y triexeno) y por presentar un amplio espectro de crustáceos como segundos hospedadores intermediarios. Las metacercarias de G. nacellae presentaron prevalencias altas $(92,47 \%)$, como suelen presentar otras metacercarias de la familia Gymnophallidae (e.g. Cremonte, 1999; Cremonte, 2004; Cremonte et al., 
2008) en ambientes con bajo hidrodinamismo, donde la posibilidad de ingreso al segundo hospedador intermediario se incrementa (Bartoli, 1974).

A nivel poblacional, las prevalencias de digeneos estuvieron correlacionadas con la talla del hospedador en la mayoría de los casos. Este tipo de relación ha sido ampliamente registrada en otros digeneos del mundo en sus primeros hospedadores intermediarios (e.g. Baudoin, 1975; Granovitch, 1992; Jokela \& Lively, 1995; Poulin \& Mouristen, 2003; Presta et al., 2013). En algunos casos, como en Maritrema sp. 1, M. madrynense y Parorchis sp. en Puerto Madryn y Lepocreadiidae gen. et sp. 2, Maritrema sp. 1 y Renicolidae gen. et sp. 1 en Puerto Deseado, se observó la prevalencia más alta en las tallas mayores. En los casos de Parorchis sp. en Puerto Madryn y Maritrema sp. 1 en Puerto Deseado, se observó el mismo patrón pero no hubo diferencias significativas. Los gasterópodos más grandes tienen más edad y, por lo tanto, el tiempo de exposición a la infección por miracidios es mayor. Además, gasterópodos más grandes proveen más espacio y nutrientes para el parásito e ingieren más alimento, incrementando la probabilidad de ingreso de los miracidios. En los casos de Hemiuroidea fam. gen. et sp., Diphterostomum sp. y Renicolidae gen. et sp. 1 en Puerto Madryn y de M. madrynense, Notocotylidae gen. et sp. y Parorchis sp. en Puerto Deseado, se observó que los gasterópodos de tallas intermedias presentaron las prevalencias más altas. Estudios experimentales han demostrado que la mortalidad de los individuos infectados se incrementa con la edad, pero no así su resistencia a la infección (Robson \& Williams, 1970), por lo que la prevalencia disminuiría en las tallas mayores (mayor edad) como resultado de la alta mortalidad. En todos los casos de estudio, las tallas menores no estuvieron parasitadas, debido a que los gasterópodos comenzarían a infectarse al alcanzar la madurez sexual (e.g. Ginetsinkaya, 1988; Galaktionov \& Dobrovolskij, 2003).

En general, la prevalencia de parásitos no presentó un patrón estacional. Este resultado es esperable, ya que los factores ambientales que varían estacionalmente, principalmente la temperatura, no afectarían tanto a la prevalencia de digeneos en moluscos, que una vez infectados permanecen de por vida. Lo que sí podría presentar variación estacional sería el grado de desarrollo de las cercarias dentro de los esporocistos o las redias, y por lo tanto la emergencia de las cercarias al medio ocurriría principalmente en alguna época del año en particular (e.g. Køie, 1975; 
Degel \& McCurdy, 2004; Galaktionov et al., 2006; Poulin, 2006; Prinz et al., 2010). Esta hipótesis podría ser puesta a prueba utilizando como modelos de estudio a las dos especies de Microphallidae aquí descriptas, que presentan alta prevalencia. Sin embargo, en ambos sitios de estudio se hallaron algunas especies en las estaciones frías del año que no se hallaron en las estaciones cálidas. En estos casos, la presencia de los digeneos en los moluscos podría verse afectada por la variación estacional que presentan algunas especies de aves y peces, como por ejemplo, la gaviota cocinera, que cambia su dieta en la época reproductiva, alimentándose principalmente de invertebrados en otoño e invierno (Bertellotti \& Yorio, 1999), las aves migratorias, que en otoño utilizan las costas patagónicas como paradas de alimentación y descanso (D’Amico et al., 2004) y algunas especies de peces costeros, como el turco $P$. brasillianus que utilizan las zonas intermareales inferiores con mayor frecuencia en otoño, cuando la temperatura del agua alcanza los valores máximos (Galván, 2008). Por ejemplo, larvas de Renicolidae gen. et sp. 1 en Puerto Madryn y larvas de Notocotylidae gen. et sp., Parorchis sp. y Schistosomatidae gen. et $\mathrm{sp}$, se hallaron únicamente en invierno. El posible hospedador definitivo de estos digeneos, como se mencionó anteriormente, es la gaviota cocinera L. dominicanus, que se alimentaría principalmente de invertebrados en las estaciones frías del año.

A nivel de las comunidades, la diversidad de parásitos estuvo mayormente explicada por la riqueza de especies y resultó ser más alta en Puerto Deseado. Esta mayor diversidad de parásitos estaría directamente relacionada con la mayor diversidad de moluscos (gasterópodos en este caso) que actúan como primeros hospedadores intermediarios de los digeneos. Estudios realizados en la Ría Deseado, han registrado un total de 47 especies de moluscos en intermareales de sustratos rocosos y limosos desde el infralitoral hasta el supralitoral (Otaegui \& Zaixso, 1974; Zaixso; 1975). Si bien no existen estudios sobre la diversidad de moluscos en Punta Cuevas, un estudio realizado en Puerto Pirámides (Península de Valdés), registró 39 especies de moluscos en el intermareal rocoso y arenoso desde el infralitoral hasta el supralitoral (Pastorino, 1994). La gran diversidad de moluscos está dada por las características fisiogeográficas y climáticas de la provincia biogeográfica Magallánica, que es altamente homogénea y presenta una gran cantidad de taxones propios (Balech \& Erlich, 2008). Una alta diversidad de 
moluscos y otros invertebrados atraen peces y aves marinas, permitiendo que los intermareales sean áreas activas de alimentación para estos vertebrados que mantienen y dispersan los complejos ciclos de vida de los digeneos. Otros estudios similares al presente se realizaron principalmente en ambientes cerrados y estuariales, en los cuales la diversidad de moluscos suele ser relativamente baja (con un gasterópodo claramente dominante), comparada con los intermareales marinos. En estos estudios, cada gasterópodo está parasitado por varias especies de digeneos (más de diez) (e. g., Skirnisson et al., 2004; Hechinger \& Lafferty, 2005; Flores \& Semenas, 2008; Merlo \& Etchegoin, 2010) y la diversidad de parásitos suele estar determinada por la presencia de los hospedadores definitivos. La gran diversidad de moluscos en los intermareales marinos, ofrece una amplia oferta de primeros hospedadores intermediarios para los digeneos, por lo cual, como se observó en este estudio, cada gasterópodo es hospedador de una a tres especies. En este estudio, sólo el 22\% (2 de 9) de los gasterópodos examinados no presentó ninguna especie de digeneo. Sin embargo, estas dos especies, F. crassa y T. patagonica, que se distribuyen también en el submareal (McLean, 1984; Cortés \& Narosky, 1997) podrían estar infectadas en dichos ambientes. De las siete especies que estuvieron infectadas por digeneos, el 28,5\% (2 de 7) presentó una especie de digeneo, el 43\% (3 de 7) presentó dos especies de digeneos y el 28,5\% (2 de 7) presentó tres especies de digeneos.

A pesar de que la diversidad de digeneos fue mayor en Puerto Deseado, las prevalencias más altas se observaron en Puerto Madryn, en las dos especies de digeneos Microphallidae. En nuestro sistema de estudio, la presencia de hospedadores definitivos sería un factor predominante en la prevalencia de estos digeneos. La ciudad de Puerto Madryn ha sufrido un importante crecimiento poblacional y un fuerte desarrollo de la actividad pesquera en los últimos años. La existencia de basurales a cielo abierto y de plantas procesadoras pesqueras ha incrementado la oferta alimenticia para las gaviotas cocineras, y por lo tanto su abundancia (Yorio et al., 1996; Giaccardi \& Yorio, 2004). Este incremento en la abundancia de gaviotas, que también se alimentan en los intermareales, conllevaría a una mayor liberación de huevos y a una mayor tasa de infección de los gasterópodos. 
En conclusión, los ciclos de vida de los digeneos son parte de sistemas complejos que pueden verse afectados por diversos factores, como el tipo de ambiente, las condiciones ambientales y geográficas, la presencia, abundancia e historias de vida de hospedadores intermediarios (invertebrados y peces), la presencia de hospedadores definitivos (vertebrados), entre otros. Este estudio constituye una contribución a la biodiversidad, al incrementar el número de especies conocidas en los ecosistemas marinos de Argentina. Se describieron siete nuevas especies de digeneos en la costa patagónica, se registraron y completaron las descripciones de otras seis especies conocidas, se lograron dilucidar dos ciclos de vida en forma completa y tres ciclos de vida en forma parcial, se determinaron diferentes estrategias de transmisión y se dieron a conocer algunos de los factores que afectan las poblaciones y comunidades de digeneos larvales en gasterópodos (ver Anexo VIII). Este tipo de estudios es primordial para el desarrollo de otros más complejos, debido a su alta sensibilidad y a los efectos que producen los digeneos en sus hospedadores (principalmente en moluscos). A partir del conocimiento generado, se pueden plantear nuevas investigaciones a una mayor escala. Por ejemplo, estudios de los cambios comportamentales que pueden sufrir los gasterópodos infectados para incrementar la probabilidad de transmisión (Curtis, 1990; Sokolova, 1995), efectos en la reproducción de los gasterópodos y efectos sobre la dinámica poblacional (Sokolova, 1995; Granovitch, 1992; Fredensborg et al., 2005). Los digeneos Maritrema sp. 1 y M. madrynense constituyen buenos modelos de estudio debido a su amplia distribución y sus altas prevalencias. Por ejemplo, en un estudio poblacional del digeneo Maritrema sp. 1 parásito del gasterópodo C. dilatata en Puerto Madryn, se propuso la existencia de un mecanismo evolutivo de compensación para soportar las altas prevalencias, debido a que castran completamente a su hospedador (Gilardoni et al., 2012). En este trabajo se observó que la proporción de hembras reproductoras se incrementa en los meses de mayores prevalencias parasitarias y que en las poblaciones infectadas, la proporción de hembras reproductoras es mayor que en las poblaciones no infectadas (Gilardoni et al., 2012). Otro tipo de estudio que se podría realizar a nivel poblacional, es evaluar el efecto de los digeneos en la distribución espacial de los gasterópodos. Este trabajo podría realizarse utilizando como modelo al gasterópodo pulmonado $S$. 
lessonii en Puerto Deseado, que está parasitado por tres especies de digeneos, Hemiuroidea fam. gen. et sp., M. madrynense y Schistosomatidae gen. et sp. Las tres especies presentan diferentes tipos de ciclos de vida, en el caso de Hemiuroidea fam. gen. et sp. es posible que el ciclo sea triexeno, en el caso de M. madrynense el ciclo posee ambas modalidades (diexeno y triexeno) y en el caso de Schistosomatidae gen. et sp. el ciclo es diexeno con penetración directa en el hospedador definitivo. Debido a las diferencias en las estrategias de transmisión y al hospedador definitivo (un pez en el caso de Hemiuroidea fam. gen. et sp y aves, principalmente la gaviota cocinera en el caso de M. madrynense y Schistosomatidae gen. et sp.) podría ocurrir que los gasterópodos infectados por cada especie se distribuyan en el intermareal en forma diferente. Por ejemplo, que los gasterópodos infectados por M. madrynense y Schistosomatidae gen. et sp. se localicen en el intermareal superior y los gasterópodos infectados por Hemiuroidea fam. gen. et sp. se localicen en el intermareal inferior. Este tipo de estudio se podría llevar a cabo realizando colectas de gasterópodos en transectas paralelas a la costa en diferentes niveles del intermareal y evaluando la presencia y prevalencia de parásitos en cada nivel.

Para evaluar los efectos de las variables ambientales, como las condiciones climáticas, el tipo de sustrato, la pendiente, la amplitud de marea sobre la helmintofauna, se podrían realizar colectas de los gasterópodos más abundantes en diferentes sitios de la costa patagónica que presenten diferentes características geográficas, abarcando un mayor rango de latitud, por ejemplo, desde el Golfo San José hasta Ushuaia. Para evaluar los efectos de la presencia y abundancia de los hospedadores definitivos sobre la helmintofauna, podrían realizarse censos de aves en los diferentes sitios de colectas. Los censos de peces son más difíciles de realizar, ya que los peces se concentran en los intermareales durante la pleamar; sin embargo se podría obtener una aproximación de la abundancia de peces utilizando una red de costa y contabilizando las especies halladas. Para evaluar los efectos de los primeros hospedadores intermediarios sobre la helmintofauna, podrían realizarse censos de moluscos en los diferentes sitios de colecta mediante transectas perpendiculares a la costa. 
Debido a que los estudios de los digeneos larvales en moluscos marinos de la costa patagónica son escasos, es necesario continuar con las descripciones taxonómicas tanto de estadios larvales como de adultos y la dilucidación de los ciclos de vida. Como se observa en la Tabla 4 del capítulo 2, los registros de digeneos en aves marinas de la zona se limitan a tres especies, L. dominicanus, Calidris canutus rufa y Spheniscus magellanicus y, si bien, existen numerosos registros de digeneos en peces, la mayoría de estos se refieren a peces que habitan en el submareal a profundidades mayores (Tabla 5, capítulo 2). En este estudio se sugiere que las estrategias de transmisión de los digeneos larvales, así como el efecto de la presencia y abundancia de los hospedadores intermediarios y definitivos en la diversidad parasitaria, varía entre los ambientes intermareales marinos y los ambientes cerrados o estuariales. En Argentina se han realizado estudios en estos dos tipos de ambientes. En ambientes marinos intermareales se cuenta con algunos registros de digeneos en gasterópodos (Graefe, 1968; Martorelli, 1991; Martorelli \& Morriconi, 1998; Martorelli et al., 2005; Alda \& Martorelli, 2009; Averbuj \& Cremonte, 2010) y con la información aportada por el presente estudio. En ambientes cerrados y estuariales, se cuenta con numerosos estudios parasitológicos principalmente en la Laguna de Mar Chiquita (e.g. Etchegoin, 1997; Martorelli, 1989b, 1990; Merlo \& Etchegoin, 2010), en el Río de La Plata (e.g. Ostrowski, 1974, 1975), en el estuario de Bahía Blanca (Alda, 2011) y en lagos de la Cordillera de los Andes (e.g. Ostrowski \& Quaggiotto, 1995; Flores \& Brugni, 2003; Flores \& Semenas, 2008). Una revisión bibliográfica comparando la helmintofauna de diferentes ambientes podría reforzar la hipótesis de que en ambientes intermareales la diversidad de parásitos está directamente asociada a la diversidad de moluscos potenciales primeros hospedadores intermediarios. En cambio, en cuerpos de agua cerrados, donde la diversidad de moluscos es baja, la diversidad de parásitos está directamente asociada a la diversidad y abundancia de aves y peces que pueden actuar como hospedadores definitivos.

Por otro lado, los digeneos son relativamente fáciles de estudiar en los gasterópodos, por su abundancia y su escasa movilidad; los ciclos de vida están funcionalmente acoplados con la diversidad de invertebrados y vertebrados, por lo cual, estos parásitos se establecen como buenos indicadores de algunos aspectos de 
las comunidades. En los últimos años, han surgido muchos estudios en los cuales se utilizan a los digeneos de gasterópodos como bioindicadores de determinación de stocks, dieta, redes tróficas, migraciones, biogeografía y filogenia (e.g. Marcogliese \& Cone, 1997; Marcogliese, 2004; Lafferty et al., 2006a; Hechinger et al., 2011; Dunne et al., 2013). El aporte aquí generado sobre los digeneos larvales y sus ciclos de vida podrá ser utilizado para tales fines ampliando el conocimiento de los ecosistemas en la costa patagónica, permitiendo evaluar el impacto de la actividad antrópica y el cambio climático que crecen día a día. Por ejemplo, Puerto Madryn es una ciudad turística, en la cual las playas, inclusive el intermareal rocoso de Punta Cuevas, es ampliamente utilizado como áreas de recreación en verano. A su vez, tanto Puerto Madryn como Puerto Deseado, son puertos pesqueros en los cuales existe tráfico marítimo y se generan desechos resultantes de la actividad de plantas de procesamiento pesquero. La helmintofauna en moluscos de estos ambientes pueden ser contrastadas con la hallada en otros ambientes que presenten bajo impacto antrópico para evaluar los efectos producidos por la actividad humana. 


\section{REFERENCIAS}

Abdul-Salam J, Sreelatha BS. 1997. Studies on Cercariae from Kuwait Bay. X. Description and surface topography of Cercaria kuwaitae X sp. n. (Digenea: Renicolidae). Japanese Journal of Medical Science and Bilogy 50:209-217.

Adlard RD, Barker SC, Blair D, Cribb TH. 1993. Comparison of the second internal transcribed spacer (ribosomal DNA) from population and species of Fasciolidae (Digenea). International Journal for Parasitology 23:423-425.

Agresti A. 2007. An Introduction to Categorical Data Analysis. John Wiley \& Sons, Inc. Gainesville, Florida, 392 p.

Aguirre-Macedo ML, Kennedy CR. 1999. Diversity of metazoan parasites of the introduced oyster species Crassostrea gigas in the Exe Estuary. Journal of the Marine Biological Association 79:57-63.

Al-Kandari WY, Al-Bustan SA, Alnaqueeb M. 2011. Ribosomal DNA sequence characterization of Maritrema fc. eroliae Yamaguti, 1939 (Digenea: Microphallidae) and its life cycle. Journal of Parasitology 97:1067-1074.

Alda P. 2011. Estadios larvales de digeneos parásitos de Heleobia australis (d'Orbigny, 1835) en el estuario de Bahía Blanca [Tesis doctoral]. Universidad Nacional de La Plata. La Plata, Buenos Aires, Argentina, 209 p.

Alda P, Bonel N, Hechinger RF, Martorelli SR. 2013. Maritrema orensense and Maritrema bonaerense (Digenea: Microphallidae): descriptions, life cycles, and comparative morphometric analyses. Journal of Parasitology 99:218-228.

Alda P, Martorelli SR. 2009. Larval digeneans of the siphonariid pulmonates Siphonaria lessoni and Kerguelenella lateralis and the flabelliferan isopod Exasphaeroma sp. from the intertidal zone of the Argentinean Sea. Comparative Parasitology 76:267272.

Almeida FM, Barquete V, Pereira JJ. 2009. Progenetic metacercaria of Parahemiurus merus (Platyhelminthes, Digenea, Hemiuridae) infecting Parasagitta friderici (Chaetognatha) from Southern coast Brazil. Atlántica, Rio Grande 31:35-38.

Andrade C, Montiel A, Quiroga E. 2009. Estimación de producción secundaria y productividad para una población intermareal de Trophon geversianus (Bahía Loredo, Estrecho de Magallanes). Anales Instituto Patagonia (Chile) 37:73-84.

Andrade C, Ríos C. 2007. Estudio experimental de los hábitos tróficos de Trophon geversianus (Pallas, 1774) (Gastropoda, Muricidae): selección y manipulación de presas. Anales Instituto Patagonia (Chile) 35:45-53.

Appleton CC, Randall RM. 1986. Schistosome infection in the kelp gull, Larus dominicanus, from Port Elizabeth, Republic of South Africa. Journal of Helminthology 60:143-146.

Aranzamendi MC, Bastida R, Gardenal C. 2011. Different evolutionary histories in two sympatric limpets of the genus Nacella (Patellogastropoda) in the South-western Atlantic coast. Marine Biology 158:2405-2418.

Armada Argentina. 2007. Puertos argentinos. Capítulo IV. Manual de Intereses Marítimos. Secretaría General Naval. Buenos Aires, Argentina, 49-64.

Avaca MS, Narvarte MA, Martin P. 2013. Age, growth and mortality in Buccinanops globulosus (Gastropoda: Nassariidae) from Golfo Nuevo (Argentina). Marine Biology Research 9:208-219.

Averbuj A, Bigatti G, Penchaszadeh PE. 2010. Gametogenic cycle and size at first maturity of the Patagonic edible snail Buccinanops cochlidium from Argentina. Marine Biology 157:2229-2240. 
Averbuj A, Cremonte F. 2010. Parasitic castration of Buccinanops cochlidium (Gastropoda: Nassariidae) caused by a lepocreadiid digenean in San José Gulf, Argentina. Journal of Helminthology 84:381-389.

Bagnato E. 2012. Parásitos digeneos en gasterópodos intermareales del Golfo San José y comparación de la diversidad parasitaria con otros dos sitios de la costa patagónica. Universidad Nacional de la Patagonia San Juan Bosco. Puerto Madryn, Argentina, 85 p.

Balech E, Ehrlich MD. 2008. Esquema biogeográfico del Mar Argentino. Revista de Investigación y Desarrollo Pesquero 19:45-75.

Barger MA, Esch GW. 2000. Plagioporus sinitsini (Digenea: Opecoelidae): a one-host life cycle. Journal of Parasitology 86:150-153.

Barker SC, Cribb TH. 1993. Sporocysts of Mesostephanus haliasturis (Digenea) produce miracidia. International Journal for Parasitology 23:137-139.

Bartoli P. 1966. Sur le cycle vital de Lepocreadium pegorchis (M. Stossich, 1900) M. Stossich, 1903. (Trematoda, Digenea, Lepocreadiidae). Comptes rendus de l'Académie des sciences. 263:1398-1400.

Bartoli P. 1967. Etude du cycle évolutif d'un Trématode peu connu: Lepocreadium pegorchis (M. Stossich, 1900) (Trematoda, Digenea). Annales de Parasitologie Humaine et Comparée 42:605-619.

Bartoli P. 1974. Recherches sur les Gymnophallidae F.N. Morozov, 1955 (Digenea) parasites d'oiseaux des côtes de Camargue: systématique, biologie et ecologie. Université des Sciences Dáix-Marseille. Marseille, 338 p.

Bartoli P. 1983. Recherches sur la signification de la transmission de Trématodes Lepocreadiinae (T. Odhner, 1905) dans deux écosystèmes marins. Annales de Parasitologie Humaine et Comparée 58:117-139.

Bartoli P. 1984. Distomatosis des lamellibranches marins sur le littoral mediterraneen Francais. Haliotis 14:98-107.

Bartoli P. 1986. Role favorisant de I'hydrodynamisme dans la contamination des deuxièmes hotes intermédiaires par les cercaires de Maritrema misenensis (A. Palombi, 1940) (Digenea, Microphallidae). Annales de Parasitologie Humaine et Comparée 61:35-41.

Bartoli P, Boudouresque CF. 2007. Effect of the digenean parasites of fish on the fauna of Mediterranean lagoons. Parassitologia 49:111-117.

Bartoli P, Jousson O, Russell-Pinto F. 2000. The life cycle of Monorchis parvus (Digenea: Monorchiidae) demostrated by developmental and molecular data. Journal of Parasitology 86:479-489.

Bartoli P, Prévot G. 1978. Le cycle biologique de Holorchis pycnoporus M. Stossich, 1901 (Trematoda, Lepocreadiidae). Zeitschrift für Parasitenkunde 58:73-90.

Barton DP, Blair D. 2005. Family Notocotylidae Lühe, 1909. En: Keys to the Trematoda 2. Editores: Jones A, Bray R, Glbson D. CABI Publishing and The Natural History Museum. London, UK, 383-396.

Bastida R, Roux A, Martínez DE. 1992. Benthic communities of the Argentine continental shelf. Oceanologica Acta 15:687-698.

Baudoin M. 1975. Host castration as a parasitic strategy. Evolution 29:335-352.

Bertellotti M, Pérez D. 2008. Comportamiento de ataque de gaviotas a ballenas: Búsqueda de soluciones y desarrollo de una estrategia de comunicación. Centro Nacional Patagónico. Puerto Madryn, Argentina, 33 p. 
Bertellotti M, Yorio P. 1999. Spatial and temporal patterns in the diet of the Kelp Gull in Patagonia. The Condor 101:790-798.

Blair D, Campos A, Cummings MP, Laclette JP. 1996. Evolutionary biology of parasitic Platyhelminths: The role of molecular phylogenetics. Parasitology Today 12:66-71.

Born-Torrijos A, Kostadinova A, Raga JA, Holzer AS. 2012. Molecular and morphological identication of larval opecoelids (Digenea: Opecoelidae) parasitising prosobranch snails in a Western Mediterranean lagoon. Parasitology International 61:450-460.

Boyero L. 2011. Gradientes latitudinales de biodiversidad. Ecología INFO 32:1-12.

Braicovich PE, Etchegoin JA, Timi JT. 2009. Digenetic trematodes of the Brazilian flathead, Percophis brasiliensis Quoy et Gaimard, 1894 (Percophidae, Perciformes), from Argentinean and Uruguayan waters. Acta Parasitologica 54:368-373.

Braicovich PE, Timi JT. 2008. Parasites as biological tags for stock discrimination of the Brazilian flathead Percophis brasiliensis in the south-west Atlantic. Journal of Fish Biology 73:557-571.

Brant SV, Bochte CA, Loker ES. 2011. New intermediate host records for the avian schistosomes Dendritobilharzia pulverulenta, Gigantobilharzi ahuronensis, and Trichobilharzia querquedulae from North America. Journal of Parasitology 97:946949.

Bray RA. 2008. Family Zoogonidae Odhner, 1902. En: Keys to the Trematoda 3. Editores: Bray R, Glbson D, Jones A. CAB International and Natural History Museum. London, UK, 605-630.

Bray RA, Justine JL. 2012. A review of the Lepocreadiidae (Digenea, Lepocreadioidea) from fishes of the waters around New Caledonia. Acta Parasitologica 57:247-272.

Bray RA, Gibson DI. 1990. The Lepocreadiidae (Digenea) of fishes of the north-east Atlantic: review of the genera Opechona Loos, 1907 and Prodistomum Linton, 1910. Systematic Parasitology 15:159-202.

Bridgman JF. 1971. The life cycle of Maritrema setoensis n. sp. (Trematoda: Microphallidae). Japanese Journal of Parasitology 20:13-23.

Brown SP, Renaud F, Guégan JF, Thomas F. 2001. Evolution of trophic transmission in parasites: the need to reach a mating place? Journal of Evolutionary Biology 14:815820.

Bush AO, Fernandez JC, Esch GW, Seed JR. 2001. Parasitism: the diversity and ecology of animal parasites. Cambridge University Press. Cambridge, UK, 566 p.

Bustnes JO. 2000. Potential threats to littoral biodiversity: is increased parasitism a consequence of human activity? Oikos 90:189-190.

Bustnes JO, Galaktionov K. 1999. Anthropogenic influences on the infestation of intertidal gastropods by seabird trematode larvae on the southern Barents Sea coast. Marine Biology 133:449-453.

Byers JE, Blakeslee AMH, Linder E, Cooper AB, Maguire TJ. 2008. Controls of spatial variation in the prevalence of trematode parasites infecting a marine snail. Ecology 89:439-451.

Cable RM. 1956. Marine cercariae of Puerto Rico. Scientific Survey of Puerto Rico and the Virgin Islands 16:491-577.

Cable RM. 1963. Marine cercariae from Curaçao and Jamaica. Zeitschrift für Parasitenkunde 23:429-469.

Cannon LRG. 1978. Marine cercariae from the gastropod Cerithium moniliferum Kiener at Heron Island, Great Barrier Reef. Proceedings of the Royal Society of Queensland 89:45-57. 
Carballo MC. 2006. Rol de los pejerreyes Odontesthes smitti y O. nigricans (Pisces: Atherinopsidae) como hospedadores de helmintos en los golfos norpatagónicos, Chubut, Argentina [Tesis Doctoral]. Universidad Nacional de La Plata. La Plata, Buenos Aires, $228 \mathrm{p}$.

Carballo MC, Laurenti S, Cremonte F. 2011. A new species of monorchiid digenean from marine fishes in the Southwestern Atlantic Ocean off Patagonia. Systematic Parasitology 78:233-240.

Carcelles AR, Williamson SI. 1951. Catálogo de los moluscos marinos de la provincia Magallánica. Revista del Museo Nacional de Investigación de las Ciencias Naturales Anexo al Museo Argentino de Ciencias Naturales "Bernardino Rivadavia" 2:225-383.

Castellanos ZA, Landoni NA. 1993. Catálogo descriptivo de la malacofauna magallánica marina. 9. Comisión de investigaciones científicas de la provincia de Buenos Aires, La Plata, Argentina.

Coconier E. 2006. Aves acuáticas argentinas. Editor: Blanco DE. Westland International. Buenos Aires, Argentina, $141 \mathrm{p}$.

Combes C. 2001. Parasitism. The ecology and evolution of intimate interactions. Editor: Thompson JN. The University of Chicago. Chicago, USA, $728 \mathrm{p}$.

Cortés CN, Narosky T. 1997. Cien caracoles argentinos. Editorial Albatros. Buenos Aires, Argentina, $158 \mathrm{p}$.

Costello JH, Mianzán HW. 2003. Sampling field distributions of Mnemiopsis leidyi (Ctenophora, Lobata): planktonic or benthic methods? Journal of Plankton Research 25:455-459.

Cremonte F. 1999. Estudio parasitológico de bivalvos que habitan ambientes marinos y mixohalinos en Argentina [Tesis Doctoral]. Universidad Nacional de La Plata. La Plata, Buenos Aires, 196 p.

Cremonte F. 2001. Bartolius pierrei n. g. n. sp. (Digenea: Gymnophallidae) from Península Valdés, Argentina. Systematic Parasitology 49:139-147.

Cremonte F. 2004. Life cycle and geographic distribution of the gymnophallid Bartolius pierrei (Digenea) on the Patagonian coast, Argentina. Journal of Natural History 38:1591-1604.

Cremonte F. 2011. Enfermedades de moluscos bivalvos de interés comercial causada por metazoos. En: Enfermedades de moluscos bivalvos de interés en Acuicultura. Editores: Villalba A, Figueras A. Fundación Observatorio Español de Acuicultura. España, 333-396.

Cremonte F, Etchegoin JA. 2002. First report of the microphallid digenean Odhneria odhneri Travassos, 1921 parasite of two birds from Patagonian coast, Argentina. Neotrópica 48:58-60.

Cremonte F, Etchegoin JA, Martorelli SR. 1999. Nuevos hospedadores de los digeneos Maritrema bonaerensis (Microphallidae) y Stephanoprora podicipei (Echinostomatidae) en Argentina. Stephanoprora manei Holcman-Spector \& Olagüe, 1986 como un nomen nudum. Neotrópica 45:105-107.

Cremonte F, Figueras A. 2004. Parasites as possible cause of mass mortalities of the critically endangered clam Mesodesma mactroides on the Atlantic coast of Argentina. Bulletin of the European Association of Fish Pathologists 24:166-171.

Cremonte F, Figueras A, Burreson EM. 2005. A histopathological survey of some commercially exploited bivalve molluscs in northern Patagonia, Argentina. Aquaculture 249:23-33. 
Referencias

Cremonte F, Ituarte CF. 2003. Pathologies elicited by the gymnophallid metacercariae of Bartolius pierrei in the clam Darina solenoides. Journal of the Marine Biological Association of the United Kingdom 83:311-318.

Cremonte F, Martorelli SR. 1998. Description of a new species of Maritrema (Digenea: Microphallidae) in Larus dominicanus (Aves: Laridae) from Buenos Aires coast, Argentina. Folia Parasitologica 45:230-232.

Cremonte F, Pina S, Gilardoni C, Rodrigues P, Chai JY, Ituarte C. 2013. A new species of gymnophallid (Digenea) and an amended diagnosis of the genus Gymnophalloides Fujita, 1925. Journal of Parasitology 99:85-92.

Cremonte F, Sardella NH. 1997. The parasito fauna of Scomber japonicus Hottuyn, 1782 (Pisces: Scombridae) in two zones of the Argentine Sea. Fisheries Research 31:1-9.

Cremonte F, Vázquez N, Ituarte C. 2008. The development of Gymnophallus australis Szidat, 1962 (Digenea: Gymnophallidae) from the Patagonian coast (Argentina) from metacercaria to adult, with an amended diagnosis of Gymnophallus Odhner, 1905. Systematic Parasitology 69:23-31.

Cribb TH, Bray RA. 2010. Gut wash, body soak, blender and heat-fixation: approaches to the effective collection, fixation and preservation of trematodes of fishes. Systematic Parasitology 76:1-7.

Cribb TH, Bray RA, Littlewood TJ. 2001. The nature and evolution of the association among digeneans, molluscs and fishes. International Journal for Parasitology 31:997-1011.

Cumplido M, Averbuj A, Bigatti G. 2010. Reproductive seasonality and oviposition induction in Trophon geversianus (Gastropoda: Muricidae) from Golfo Nuevo, Argentina. Journal of Shellfish Research 29:423-428.

Curtis LA. 1990. Parasitism and the movements of intertidal gastropod Individuals. Biological Bulletin 179:105- 112.

Curtis LA. 1996. The probability of a marine gastropod being infected by a trematode. Journal of Parasitology 82:830-833.

Curtis LA. 2007. Larval trematode infections and spatial distributions of snails. Invertebrate Biology 126:235-346.

Curtis LA, Hurd LE. 1983. Age, sex, and parasites: spatial heterogeneity in a sandflat population of Ilyanassa obsoleta. Ecological Society of America 64:819-828.

Ching HL. 1963. The description and life cycle of Maritrema laricola sp. n. (Trematoda: Microphallidae). Canadian Journal of Zoology 41:881-888.

Ching HL. 1972. A redescription of Gymnophalloides tokiensis Fujita, 1925 (Trematoda: Gymnophallidae). Canadian Journal of Zoology 50:1299-1302.

Ching HL. 1989. 2 new kidney flukes (Digenea, Renicolidae) from marine birds of Heron Island, Australia. Australian Journal of Zoology 37:59-66.

Ching HL. 1991. Lists of larval worms from marine invertebrates of the Pacific coast of North America. Journal of the Helminthological Society of Washington 58:57-68.

Ching HL. 1995. Evaluation of characters of the digenean family Gymnophallidae Morozov, 1955. Canadian Journal of Fisheries and Aquatic Sciences 52:78-83.

D’Amico VL, Hernández MA, Bala LO. 2004. Selección de presas en relación con las estrategias de forrajeo de aves migratorias en Península Valdés, Argentina. Ornitología Neotropical 15:357-364.

Daponte MC, Gil de Pertierra AA, Palmieri MA, Ostrowski de Núñez M. 2006. Parasite infections (Trematoda, Digenea) of Sagitta friderici (Chaetognatha) from the Southwestern Atlantic Ocean: prevalence and distribution. Diseases of Aquatic Organisms 71:225-232. 
Deblock S. 1971. Contribution à l'étude des Microphallidae Travassos, 1920, XXIV. Tentative de phylogénie et de taxonomie. Bulletin du Muséum National d'Historie Naturelle 7:353-467.

Deblock S, Capron A, Rosé F. 1961. Contribution à létude des Microphallidae Travassos, 1920 (Trematoda). V. Le genre Maritrema Nicoll, 1907: cicle évolutif de $M$. subdolum Jäegerskioeld, 1909. Parassitologia 3:105-119.

Deblock S, Tran Van Ky P. 1966. Contribution à l'etude des Microphallidae Travassos, 1920 (Trematoda) XIII - Description de deux espèces nouvelles à cycle évolutif abrégé originaires de Corse. Annales de Parasitologie 41:313-335.

Degel K, McCurdy DG. 2004. Impacts of temperature on emergence of trematode cercariae from the mud snail Ilyanassa obsoleta (Say). The Online Journal for Undergraduate Research in Marine and Aquatic Science 3:1-9.

Dell RK. 1971. The marine mollusca of the Royal Society Expedition to Southern Chile, 1958-59. Records of the Dominion Museum 7:155-233.

Di Giacomo EE, Perier MR. 1996. Feeding habits of cockfish, Callorhinchus callorhynchus (Holocephali : Callorhynchidae), in Patagonian waters (Argentina). Marine and Freshwater Research 47:801-808.

Di Rienzo JA, Casanoves F, Balzarini MG, Gonzalez L, Tablada M, Robledo CW. 2011. InfoStat [programa de cómputo]. Versión 24-03-2011. Universidad Nacional de Córdoba. Córdoba, Argentina.

Diaz Briz LM, Martorelli SR, Genzano GN, Mianzan HW. 2012. Parasitisim (Trematoda, Digenea) in medusae from the southwestern Atlantic Ocean: medusa hosts, parasite prevalences, and ecological implications. Hydrobiologia 690:215-226.

Diaz JI, Cremonte F. 2004. Himasthla escamosa n. sp. (Digenea: Echinostomatidae) from the Kelp Gull, Larus dominicanus (Charadriiformes: Laridae) on the Patagonian coast, Argentina. Journal of Parasitology 90:308-313.

Diaz JI, Cremonte C. 2010. Development form metacercaria to adult of a new species of Maritema (Digenea: Microphallidae) parasitic in the Kelp Gull, Larus dominicanus, from the Patagonian coast, Argentina. Journal of Parasitology 96:740-745.

Diaz JI, Cremonte C, Navone GT. 2010. Helminths of the Magellanic Penguin, Spheniscus magellanicus (Sphenisciformes), during the breeding season in Patagonian coast, Chubut, Argentina. Comparative Parasitology 77:172-177.

Diaz JI, Cremonte C, Navone GT. 2011. Helminths of the kelp gull, Larus dominicanus, from the northern Patagonian coast. Parasitology Research 109:1555-1562.

Diaz JI, Gilardoni C, Cremonte C. 2012. Description of Maritrema formicae sp. nov. (Digenea, Microphallidae) parasitic in the kelp gull, Larus dominicanus, from the Patagonian coast, Argentina. Acta Parasitologica 57:149-153.

Dolgikh AV, Naidjenovav NN. 1967. Contribution to the study of helminth parasites of Diplodus annularis. Scientific Reports of the Superior School Biological Sciences 11:13-16.

Dronen NO, Blend CK. 2008. Observations on the Parorchis acanthus complex (Philophthalmidae: Parorchiinae) with the description of three new species of Parorchis Nicoll, 1907 and the replacement of the preoccupied junior homonym Paratrema Dronen \& Badley, 1979 with Stenomesotrema nomen novum. Zootaxa 1843:1-23.

Dunne JA, Lafferty KD, Dobson AP, Hechinger RF, Kuris AM, Martinez ND, McLaughlin JP, Mouritsen KN, Poulin R, Reise K y otros. 2013. Parasites affect food web structure primarily through increased diversity and complexity. PLOS Biology 11:e1001579. 
Dyer BS. 2003. Atherinopsidae (Neotropical silversides). En: Checklist of the Freshwater Fishes of South and Central America. Editores: Reis RE, Kullander SO, Ferraris JCJ. EDIPUCRS. Porto Alegre, Brasil, 515-525.

Etchegoin JA. 1997. Sistemas parasitarios presentes en la albúfera Mar Chiquita [Tesis Doctoral]. Universidad Nacional Mar del Plata, Mar del Plata, Buenos Aires, $244 \mathrm{p}$.

Etchegoin JA, Martorelli SR. 1997. Description of a new species of Maritrema (Digenea: Microphallidae) from Mar Chiquita coastal lagoon (Buenos Aires, Argentina) with notes on its life cycle. Journal of Parasitology 83:709-713.

Etchegoin JA, Timi JT, Cremonte F, Lanfranchi AL. 2005. Redescription of Prosorhynchus australis Szidat, 1961 (Digenea, Bucephalidae) parasitizing Conger orbignianus Valenciennes, 1842 (Pisces, Congridae) from Argentina. Acta Parasitologica 50:102104.

Flores VR. 2005. Estructura comunitaria de digeneos larvales en Chilina dombeiana y Heleobia hatcheri (Mollusca: Gasteropoda) de la región andino Patagónica [Tesis doctoral]. Universidad Nacional del Comahue. Bariloche, Argentina: 349 p.

Flores VR, Brugni N. 2003. Catatropis chilinae n. sp. (Digenea: Notocotylidae) from Chilina dombeiana (Gastropoda: Pulmonata) and notes on its life-cycle in Patagonia, Argentina. Systematic Parasitology 54:89-96.

Flores VR, Brugni N. 2005. Notocotylus biomphalariae n. sp. (Digenea: Notocotylidae) from Biomphalaria peregrina (Gastropoda: Pulmonata) in Patagonia, Argentina. Systematic Parasitology 61:207-214.

Flores VR, Brugni N. 2006. Catatropis hatcheri n. sp. (Digenea: Notocotylidae) from Heleobia hatcheri (Prosobranchia: Hydrobiidae) and notes on its life cycle in Patagonia, Argentina. Systematic Parasitology 63:111-118.

Flores VR, Semenas LG. 2008. Larval digenean community parasitizing the freshwater snail, Chilina dombeyana (Pulmonata: Chilinidae) in Patagonia, Argentina, with special reference to the notocotylid Catatropis chilinae. Journal of Parasitology 94:305-313.

Font WF. 1980. The effect of progenesis on the evolution of Alloglossidium (Trematoda, Plagiorchiida, Macroderoididae). Acta Parasitologica Polonica 27:173-183.

Fredensborg BL, Mouritsen KN, Poulin R. 2005. Impact of trematodes on host survival and population density in the intertidal gastropod Zeacumantus subcarinatus. Marine Ecology Progress Series 290:109-117.

Fredensborg BL, Mouritsen KN, Poulin R. 2006. Relating bird host distribution and spatial heterogeneity in trematode infections in an intertidal snail-from small to large scale. Marine Biology 149:275-283.

Fredensborg BL, Poulin R. 2005. Larval helminths in intermediate hosts: Does competition early in life determine the fitness of adult parasites? International Journal for Parasitology 35:1061-1070.

Fried B, Graczyk TK. 1997. Advances in Trematode Biology. CRC Press. Boca Raton, New York, USA, $466 \mathrm{p}$.

Fujita T. 1925. Etudes sur les parasites de I'huitre comestible du Japon Ostrea gigas Thunberg. Annales de Parasitologie Humaine et Comparée 3:37-59.

Galaktionov K. 1991. Some evolutionary tendencies in morphogenesis of the larvae of the hermaphroditic generation of trematode of the family Microphallidae. Parazitologia 25:520-525 (en ruso).

Galaktionov K. 1996. The experimental study of the unusual life cycle of Parvatrema sp. (Trematoda: Gymnophallidae). Parazitologia 30:487-494 (en ruso). 
Galaktionov K. 2007. A description of the parthenogenetic metacercaria and cercaria of Cercaria falsicingulae I larva nov. (Digenea: Gymnophallidae) from the snails Falsicingula spp. (Gastropoda), with speculation on an unusual life-cycle. Systematic Parasitology 68:137-146.

Galaktionov K, Bustnes JO. 1999. Distribution patterns of marine bird digenean larvae in periwinkles along the southern coast of the Barents Sea. Diseases of Aquatic Organisms 37:221-230.

Galaktionov K, Dobrovolskij AA. 2003. The biology and evolution of Trematodes. Kluwer Academic Publishers. The Netherlands, $592 \mathrm{p}$.

Galaktionov K, Irwin S, Prokofiev VV, Saville D, Nikolaev KE, Levakin IA. 2006. Trematode transmission in coastal communities - temperature dependence and climate change perspectives. $11^{\text {th }}$ International Congress of Parasitology ICOPA XI 85-90.

Galaktionov K, Skirnisson K. 2000. Digeneans from intertidal molluscs of SW Iceland. Systematic Parasitology 47:87-101.

Galaktionov K, Skirnisson K. 2007. New data on Microphallus breviatus Deblock \& Maillard, 1975 (Microphallidae: Digenea) with emphasis on the evolution of dixenous life cycles of microphallids. Parasitology Research 100:963-971.

Galazzo DE, Dayanandan S, Marcogliese DJ, McLaughlin JD. 2002. Molecular systematics of some North American species of Diplostomum (Digenea) based on rDNAsequence data and comparisons with European congeners. Canadian Journal of Zoology 80:2207-2217.

Galván DE. 2008. Ensambles de peces en los arrecifes norpatagónicos: diversidad, abundancia y relaciones tróficas y con el hábitat [Tesis doctoral]. Universidad Nacional del Comahue. Bariloche, $137 \mathrm{p}$.

Galván DE, Botto F, Parma AM, Bandieri L, Mohamed N, Iribarne O. 2009. Food partitioning and spatial subsidy in shelter-limited fishes inhabiting patchy reefs of Patagonia. Journal of Fish Biology 75:2585-2605.

Gandini PA, Frere E. 1998. Seabird and shorebird diversity and associated conservation problems in Puerto Deseado, Patagonia, Argentina. Ornitologia Neotropical 9:13-22.

Giaccardi M, Yorio P. 2004. Temporal patterns of abundance and waste use by Kelp Gulls (Larus dominicanus) at an urban and fishery waste site in northern coastal Patagonia, Argentina. Ornitologia Neotropical 15:93-102.

Gibson D. 2002. Superfamily Hemiuroidea Looss, 1899. En: Keys to the Trematoda Volume 1. Editores: Gibson D, Jones A, Bray R. CABI Publishing and The Natural History Museum. London, UK, 299-304.

Gibson D. 2008. Family Renicolidae Dollfus, 1939. En: Keys to the Trematoda 3. Editores: Bray R, Glbson D, Jones A. CAB International and Natural History Museum. London, UK, 591-594.

Gibson D, Bray R. 1986. The Hemiuridae (Digenea) of fishes from the north-east Atlantic. Bulletin of the British Museum (Natural History) 51:1-30.

Gilardoni C, Carballo MC, Cremonte C. 2013. The life cycle and geographical distribution of the monorchiid Proctotrema bartolii (Digenea) in the clam Darina solenoides from the Patagonian coast, Argentina. Journal of Helminthology en prensa.

Gilardoni C, Etchegoin JA, Diaz JI, Ituarte C, Cremonte C. 2011. A survey of larval digeneans in the commonest intertidal snails from Northern Patagonian coast, Argentina. Acta Parasitologica 56:163-179. 
Gilardoni C, Ituarte C, Cremonte C. 2012. Castrating effects of trematode larvae on the reproductive success of a highly parasitized population of Crepipatella dilatata (Caenogastropoda) in Argentina. Marine Biology 159:2259-2267.

Ginetsinskaya TA. 1988. Trematodes, their life cycles, biology and evolution: Amerind Publishing Co.New York, $559 \mathrm{p}$.

Gold D, Lengy J. 1974. Studies of larval stages of digenetic trematodes in aquatic molluscs of Israel 4. On five cercariae from the freshwater snail Melanoides tuberculatus (Müller, 1974). Israel Journal of Zoology 23:143-161.

Gómez del Prado-Rosas MC, Álvarez Cadena JN, Lamothe-Argumedo R, Ordónez-López U, Almaral Mendivil AR. 2007. Larvas de peces parasitadas por metacercarias de Hemiuridae y Fellodistomidae (Trematoda) en la laguna arrecifal de Puerto Morelos, Quintana Roo, México. Hidrobiología 17:233-239.

Gosztonyi AE. 1979. Biología del 'róbalo' Eleginops maclovinus (Cuv. y Val., 1830) [Tesis doctoral]. Facultad de Ciencias Exactas y Naturales, Universidad Nacional de Buenos Aires. Buenos Aires, 129 p.

Grabda-Kazubska B. 1976. Abbreviation of the life cycles in plagiorchid trematodes: general remarks. Acta Parasitologica Polonica 24: 125-141.

Graefe G. 1968. Paramonostomum antarcticum n. sp. (Trematoda: Notocotylidae) und Beobachtungen zur Larvenentwicklung in der Antarktis. Zeitschrift für Parasitenkunde 30:207-232 (en alemán).

Granovitch AL. 1992. The effect of the trematode infection on the population structure of Littorina saxatilis (Olivi) in the White Sea. The Malacological Society of London. 255263.

Granovitch AL, Sergievsky SO, Sokolova IM. 2000. Spatial and temporal variation of trematode infection in coexisting populations of intertidal gastropods Littorina saxatilis and L. obtusata in the White Sea. Diseases of Aquatic Organisms 41:53-64.

Griffin M, Pastorino G. 2005. The genus Trophon Monfort, 1810 (Gastropoda, Muricidae) in the Tertiary of Patagonia. Journal of Paleonthology 79:296-311.

Haseeb MA. 1980. Studies on the systematics and biology of larval trematodes infecting freshwater snails in the Punjab, Pakistan [Tesis doctoral]. University of Punjab. Lahore, India, $510 \mathrm{p}$.

Hassanine RM. 2006. The life-cycle of Diploproctodaeum arothroni Bray and Nahhas, 1998 (Digenea: Lepocreadiidae), with a comment on the parasitic castration of its molluscan intermediate host. Journal of Natural History 40:1211-1223.

Hechinger RF. 2012. Faunal survey and identification key for the trematodes (Platyhelminthes: Digenea) infecting Potamopyrgus antipodarum (Gastropoda: Hydrobiidae) as first intermediate host. Zootaxa 3418:1-27.

Hechinger RF, Lafferty KD. 2005. Host diversity begets parasite diversity: bird final hosts and trematodes in snail intermediate hosts. Proceeding of the Royal Society of London 272:1059-0166.

Hechinger RF, Lafferty KD, Huspeni T, Brooks AJ, Kuris AM. 2007. Can parasites be indicators of free-living diversity? Relationships between species richness and the abundance of larval trematodes and of local benthos and fishes. Oecologia 15:8292.

Hechinger RF, Lafferty KD, Kuris AM. 2008. Trematodes indicate animal biodiversity in the Chilean intertidal and Lake Tanganyika. Journal of Parasitology 94:966-968.

Hechinger RF, Lafferty KD, McLauchlin J, Fredensborg BL, Huspeni TC, Lorda J, Sandhu PK, Shaw JC, Torchin ME, Whitney KE y otros. 2011. Food webs including parasites, 
biomass, body sizes, and life stages for three California/Baja California estuaries. Ecology 92:791.

Hernández MA, Bala LO, Musmeci LR. 2008. Dieta de tres especies de aves playeras migratorias en Península Valdés, Patagonia, Argentina. Ornitología Neotropical 19:605-611.

Holton AL. 1984. A redescription of Coitocaecum parvum Crowcroft, 1945 (Digenea: Allocreadiidae) from crustacean and fish hosts in Canterbury. New Zealand Journal of Zoology 11:1-8.

Holliman RB. 1961. Larval trematodes from Apalachee Bay area, Florida, with a checklist of known marine cercariae arranged in a key to their superfamilies. Tulane Studies in Zoology 9:1-74.

Horák P, Kolárova L, Adema CM. 2002. Biology of the Schistosome genus Trichobilharzia. Advances in Parasitology 52:155-233.

Hudson PJ. 2005. Parasites, diversity, and the ecosystem. En: Parasitism and Ecosystems. Editor: Thomas F. University Press, Oxford, 1-12.

Huffman JE, Fried B. 2008. Schistosomas. En: Parasitic diseases of wild birds. Editores: Atkinson CT, Thomas NJ, Hunter DB. Blackwell Publishing. Iowa, USA, 246-260.

Huspeni TC, Hechinger RF, Lafferty KD. 2005. Trematode parasites as estuarine indicators: opportunities, applications and comparisons with conventional community approaches. En: Estuarine Indicators. Editor: Bortones S. CRC Press. Boca Raton, FL, USA, 297-314.

Irigoyen AJ, Galván DE. 2009. Peces de arrecife argentinos. Proyecto Arrecife. Puerto Madryn, Argentina, $80 \mathrm{p}$.

Isla F, lantanos N, Estrada E. 2004. Dinámica submareal y condiciones ambientales de la Ría Deseado, Santa Cruz. Revista de la Asociación Geológica Argentina 59:367-375.

Ito J. 1977. Studies of the fresh water cercariae in Leyte Island, Philippines 3. Cercariae from Thiaridae. Japanese Journal of Experimental Medicine 47:223-248.

Ito J, Shimura S. 1980. On a new lepocreadiid cercaria, Cercaria isoninae n.sp. Trematoda from a littoral gastropod, Japeuthria ferrea from Kanagawa and Chiba Prefectures, Japan. Japanese Journal of Parasitology 29:181-187.

Ituarte C, Cremonte F, Deferrari G. 2001. Mantle-shell complex reactions elicited by digenean metacercariae in Gaimardia trapesina (Lamarck, 1819) (Bivalvia: Gaimardiidae) from the Southwestern Atlantic Ocean and Magellan Strait. Diseases of Aquatic Organisms 48:47-56.

Ituarte C, Cremonte F, Zelaya DG. 2005. Parasite-mediated shell alterations in Recent and Holocene sub-Antarctic bivalves: the parasite as modeler of host reaction. Invertebrate Biology 124:220-229.

James BL. 1964. The life cycle of Parvatrema homoeotecnum sp. nov. (Trematoda: Digenea) and a review of the family Gymnophallidae Morozov, 1955. Parasitology 54:1-41.

James BL. 1968. The ocurrence of larval Digenea in ten species of intertidal prosobranch molluscs in Cardigan Bay. Journal of Natural History 2:329-343.

Jamieson BGM. 1966. Larval stages of the progenetic trematode Parahemiurus bennettae Jamieson, 1966 (Digenea, Hemiuridae) and the evolutionary origin of cercariae. Proceedings of the Royal Society of Queensland 77:81-91.

Jokela J, Lively CM. 1995. Spatial variation in infection by digenetic trematodes in a population of freshwater snails (Potamopyrgus antipodarum). Oecologia 103:509517. 
Jousson O, Bartoli P. 2000. The life cycle of Opecoeloides columbellae (Pagenstecher, 1863) n. comb. (Digenea, Opecoelidae): evidence from molecules and morphology. International Journal for Parasitology 30:747-760.

Jousson O, Bartoli P, Pawlowski J. 1999. Molecular identification of developmental stages in Opecoelidae (Digenea). International Journal for Parasitology 29:1853-1858.

Jousson O, Bartoli P, Zaninetti L, Pawlowski J. 1998. Use of the ITS rDNA for elucidation of some life cycles of Mesometridae (Trematoda, Digenea). International Journal for Parasitology 28:1403-1411.

Kanev I, Radev V, Fried B. 2005. Family Philophthalmidae Looss, 1899. En: Keys to the Trematoda Volume 2. Editores: Jones A, Bray R, GIbson D. CABI Publishing and The Natural History Museum. London, UK, 87-98.

Kanev I, Vassilev I, Dimitrov V, Radev V. 1994. Life-cycle, delimitation and redescription of Catatropis verrucosa (Frölich, 1789) Odhner, 1905 (Trematoda: Notocotylidae). Systematic Parasitology 29:133-148.

Khalil LF. 2002. Family Schistosomatidae Stiles \& Hassall, 1898. En: Keys to the Trematoda Volume 1. Editores: Glbson D, Jones A, Bray R. CABI Publishing and The Natural Histroy Museum. London, UK, 419-432.

Klimpel S, Seehage A, Palm HW. 2003. Metazoan parasites and feeding behavior of four small-sized fish species from the Central North Sea. Parasitology Research 91:290297.

Kohn A, Fernandez BMM, Cohen SC. 2007. South American Trematodes parasites of fishes. Ministério da Saúde, FIOCRUZ, Fundaçao Oswaldo Cruz. Rio de Janeiro, 318 p.

Køie M. 1975. On the morphology and life-history of Opechona bacillaris (Molin, 1859) Loos, 1907 (Trematoda: Lepocreadiidae). Ophelia 13:63-68.

Køie M. 1976. On the morphology and life-history of Zoogonoides viviparus (Olsson, 1868) Odhner, 1902 (Trematoda, Zoogonidae). Ophelia 15:1-14.

Køie M. 1979. On the morphology and life-history of Derogenes varicus (Müller, 1784) Looss, 1901 (Trematoda, Hemiuridae). Zeitschrift für Parasitenkunde 59:67-78.

Køie M. 1985. On the morphology and life-history of Lepidapedon elongatum (Lebour, 1908) Nicoll, 1910 (Trematoda, Lepocradiidae). Ophelia 24:135-153.

Køie M. 1989. On the morphology and life-history of Lecithaster gibbosus (Rudolphi, 1802) Lühe, 1901 (Digenea, Hemiuroidea). Parasitology Research 75:361-367.

Køie M. 1990a. A new cystophorous cercaria in Lunatia pallida (Broderip \& Sowerby) (Naticidae): possibly the cercaria of Hemiurus levinseni Odhner, 1905 (Digenea, Hemiuridae). Ophelia 31:77-84.

Køie M. 1990b. On the morphology and life-history of Hemiurus luehei Odhner, 1905 (Digenea: Hemiuridae). Journal of Helminthology 64:193-202.

Køie M. 1990c. Redescription of the cercaria of Lecithochirium rufoviride (Rudolphi, 1819) Lühe, 1901 (Digenea, Hemiuridae) (= Cercaria vaullegeardi Pelseneer, 1906). Ophelia 31:85-95.

Køie M. 1991. Aspects of the morphology and life cycle of Lecithocladium excisum (Digenea, Hemiuridae), a parasite of Scomber spp. International Journal of Parasitology 21:597-602.

Køie M. 1992. Life cycle and structure of the fish digenean Brachyphallus crenatus (Hemiuridae). Journal of Parasitology 78:338-343.

Køie M. 1995. The life-cycle and biology of Hemiurus communis Odhner, 1905 (Digenea, Hemiuridae). Parasite 2:195-202. 
Køie M, Gibson DI. 1991. Aspects of the life-cycle of Magnibursatus caudofilamentosa (Reimer, 1971) Gibson \& Køie, 1991 (Digenea, Hemiuroidea, Derogenidae). Ophelia 34:117-127.

Køie M, Karlsbakk E, Nylund A. 2002. A cystophorous cercaria and metacercaria in Antalis entalis (L.) (Mollusca, Scaphopoda) in Norwegian waters, the larval stage of Lecithophyllum botryophorum (Olsson, 1868) (Digenea, Lecithasteridae). Sarsia 87:302-311.

Komiya Y, Ito J. 1952. The morphology of Cercaria sturniae Tanabe, 1948 (cercaria of Gigantobilharzia sturniae Tanabe, 1951), a cause of cercaria dermatitis in Japan. Japanese Journal of Medical Science and Bilogy 5:215-220.

Kuris AM. 1990. Guild structure of larval trematodes in molluscan hosts: prevalence, dominance and significance of competition. En: Parasite communities: patterns and processes. Editores: Esch GW, Bush A, Aho J. Chapman and Hall. London, UK, 69100.

La Sala LF, Martorelli SR, Alda P, Marcotegui P. 2009. Some Digeneans from Olrog's Gull Larus atlanticus Olrog, 1958 (Aves: Laridae) from the Bahía Blanca Estuary, Argentina. Comparative Parasitology 76:113-116.

Lafferty KD. 1997. Environmental parasitology: what can parasites tell us about human impacts on the environment? Parasitology Today 13:251-255.

Lafferty KD. 2001. Birds at Southern California Beach: seasonality, habitat use and disturbance by human activity. Biodiversity and Conservation 10:1949-1962.

Lafferty KD, Dobson AP, Kuris AM. 2006a. Parasites dominate food web links. Proceedings of the National Academy of Sciences 103:11211-11216.

Lafferty KD, Goodman D, Sandoval CP. 2006b. Restoration of breeding by snowy plovers following protection from disturbance. Biodiversity and Conservation 15:2217-2230.

Lafferty KD, Hechinger RF, Shaw JC, Whitney K, Kuris AM. 2006c. Food webs and parasites in a salt marsh ecosystem. En: Disease ecology: community structure and pathogen dynamics. Editores: Collinge S, Ray C. Oxford University Press. Oxford, UK, 119-134.

Lafferty KD, Kuris AM. 2004. Parasitisim and environmental disturbance En: Parasitisim and Ecosystems. Editores: Thomas F, Renault L, Guegán J-F. Oxford University Press. Oxford, UK, 113-123.

Latham ADM, Poulin R. 2002. New records of gastrointestinal helminths from the southern black-backed gull (Larus dominicanus) in New Zealand. New Zealand Journal of Zoology 29:253-257.

Lauckner G. 1980. Diseases of Mollusca: Gastropoda. En: Diseases of Marine Animals. Editor: Kinne O. John Wiley \& Sons. New York, 331-424.

Lauckner G. 1983. Introduction: Bivalvia to Scaphopoda. En: Bivalvia diseases of marine animals. Editor: Kinne O. Biologische Anstalt Helgoland. Hamburg, 477-977.

Lee SH, Chai JY. 2001. A review of Gymnophalloides seoi (Digenea: Gymnophallidae) and human infections in the Republic of Korea. The Korean Journal of Parasitology 39:85-118.

Lee SH, Chai JY, Hong ST. 1993. Gymnophalloides seoi n. sp. (Digenea: Gymnophallidae), the first report of human infection by a gymnophallid. Journal of Parasitology 79:677-680.

Linse K. 1999. Mollusca of the Magellan region. A checklist of the species and their distribution. Scientia Marina 63:399-407. 
Longshaw M, Malham SK. 2013. A review of the infectious agents, parasites, pathogens and commensals of European cockles (Cerastoderma edule and C. glaucum). Journal of the Marine Biological Association of the United Kingdom 93:227-247.

Loos-Frank B. 1969. Zur Kenntnis der gymnophalliden Trematoden des Nordseeraumes I. Die Alternativ-Zyklen von Gymnophallus choledochus Odhner, 1900. Zeitschrift für Parasitenkunde 32:135-156 (en alemán).

Loos-Frank B. 1971. Zur Kenntnis der gymnophalliden Trematoden des Nordseeraumes VI. Übersicht über die gymnophalliden Larven aus Mollusken der Gezeitenzone. Zeitschrift für Parasitenkunde 36:206-232 (en alemán).

MacFarlane WV. 1951. The life cycle of Stegodexamene anguillae n.g., n.sp., an allocreadiid trematode from New Zealand. Parasitology 41:1-10.

MacKenzie K. 2003. Parasites of the Falkland's mullet (Eleginops maclovinus) and their potential as biological tags for stock discrimination. Chapter 6. En: The Falkland Mullet Eleginops maclovinus: biology and fishery in Falkland islands' waters. Falcklands Islands Govermewnt Printing Office Stanley. Falklands Islands, 64 p.

Madhavi R, Shameem U. 1991. Cercaria chilkaensis II, a new zoogonid cercaria from the snail Nassarius orissaensis from Chilka lake, India. Journal of the Helminthological Society of Washington 58:31-34.

Magurran AE. 2004. Measuring Biological Diversity: Blackwell Science Ltd. Oxford, UK, 132 p.

Maldonado JA, Loker ES, Morgan JTA, Rey L, Lanfredi RM. 2001. Description of the adult worms of a new Brazilian isolate of Echinostoma paraensei (Platyhelminthes: Digenea) from its natural vertebrate host Nectomys squamipes by light and scanning electron microscopy and molecular analysis. Parasitology Research 87:840-848.

Marcogliese DJ. 2004. Parasites: small players with crucial roles in the ecological theater. EcoHealth Journal Consortiu 1:151-164.

Marcogliese DJ, Cone DK. 1997. Food webs: a plea for parasites. Trends in Ecology and Evolution 12:320-325.

Martin JP, Bastida R. 2008. El alga invasora Undaria pinnatifida (Harvey) Suringar en la Ría Deseado (Patagonia austral, Argentina): ciclo del esporofito y factores ambientales determinantes de su distribución. Revista de Biología Marina y Oceanografía 43:335-344.

Martin WE. 1938. Studies on trematodes of Woods Hole: the life cycle of Lepocreadium setiferoides (Miller and Northup), Allocreadiidae, and the description of Cercaria cumingiae n. sp. Biological Bulletin 75:463-474.

Martin WE, Gregory VL. 1951. Cercaria buchanani n. sp., an aggregating marine trematode. Transactions of the American Microscopical Society 70:359-362.

Martorelli SR. 1989a. Estudios parasitológicos en biotopos lénticos de la República Argentina. V. Desarrollo del ciclo biológico monoxeno de la metacercaria progenética de Genarchella genarchella Travassos, 1928 (Digenea, Hemiuridae) parásita de Littoridina parchappei (Mollusca, Hydrobiidae). Revista del Museo de La Plata (Nueva Serie) Sección Zoología 14:109-117.

Martorelli SR. 1989b. Estudios parasitológicos en la albúfera de Mar Chiquita, provincia de Buenos Aires, República Argentina. II: Cercarias (Digenea) parásitas de Heleobia conexa (Mollusca: Hydrobiidae), pertenecientes a las familias Schistosomatidae, Haploporidae y Homalometridae. Neotrópica 35:81-90. 
Martorelli SR. 1990. Estudios parasitológicos en la albúfera de Mar Chiquita, provincia de Buenos Aires, República Argentina. III: sobre dos cercarias parásitas de Heleobia conexa (Mollusca: Hydrobiidae) pertenecientes a la Superfamilia Echinostomatidea. Neotrópica 36:5-12.

Martorelli SR. 1991. Primera cita de una cercaria tricocerca parásita de Dorsanum moniliferum (Mollusca: Buccinidae) para el Atlántico Sud-Occidental. Aportes al conocimiento de su ciclo de vida. Neotrópica 37:57-65.

Martorelli SR. 1994. Una nueva cercaria de tipo cystophorous (Digenea, Hemiuriformes) en Potamolithus agapetus (Mollusca, Hydrobiidae): comportamiento de atracción del hospedador. Iheringia 76:15-19.

Martorelli SR. 1996. First record of encysted metacercariae in hydrozoan jellyfishes and Ctenophores of the Southern Atlantic. Journal of Parasitology 82:352-353.

Martorelli SR. 2001. Parasites of jellyfishes and ctenophores of the Southern Atlantic. Hydrobiologia 451:305-310.

Martorelli SR, Fredensborg BL, Leung TLF, Poulin R. 2008. Four trematode cercariae from the New Zealand intertidal snail Zeacumantus subcarinatus (Batillariidae). New Zealand Journal of Zoology 35:73-84.

Martorelli SR, Fredensborg BL, Mouritsen KN, Poulin R. 2004. Description and proposed life cycle of Maritrema novaezelandensis $\mathrm{n}$. sp. (Microphallidae) parasitic in Redbilled gulls, Larus novaehollandiae scopulinus, from Otago Harbor, South Island, New Zealand. Journal of Parasitology 90:272-277.

Martorelli SR, Morriconi E. 1998. A new gymnophallid metacercaria (Digenea) in Nacella (P.) magellanica and N. (P.) deaurata (Mollusca, Patellidae) from the Beagle Channel, Tierra del Fuego, Argentina. Acta Parasitologica 43:20-25.

Martorelli SR, Morriconi E, Marcotegui PS. 2005. Efectos de dos estadios larvales de digeneos sobre la gónada de Nacella $(P$.$) magellanica y Nacella (P$.$) deaurata en$ Ushuaia, Argentina. Parasitología Latinoamericana 60:351-352.

Martorelli SR, Marcotegui PS, Alda P. 2006. Primer registro de una cercaria Zoogonidae en el molusco Buccinanops globulosum del Mar Argentino. VI Jornadas Nacionales de Ciencias del Mar CENPAT/CONICET - UNPSJB - UTN (U.A. Chubut). pp. 259.

Matthews BF. 1982. Cercaria calliostomae Dollfus, 1923 (Digenea: Hemiuridae); development, morphology and emergence. Zeitschrift für Parasitenkunde 67:45-53.

McClintock JB, Lawrence JM. 1986. Movement patterns of the sub-Antarctic pulmonate limpet Kerguelenella lateralis (Gould) (Mollusca: Gastropoda). Polar Biology 5:135138.

McLean J. 1984. Systematic of Fissurella in the preruvian and magellanic faunal province (Gastropoda: Prosobranchia). Contribution in Science, Natural History Museum of Los Angeles County 354:1-76.

Merlo MJ, Etchegoin JA. 2010. Testing temporal stability of the larval digenean community in Heleobia conexa (Mollusca: Cochliopidae) and its possible use as an indicator of environmental fluctuations. Parasitology 138: 249-256.

Merlo MJ, Parietti M, Etchegoin JA. 2010. Evaluation of species richness estimators in studies of diversity involving two larval digenean communities parasitizing snail hosts. Parasitology Research 107:1093-1102.

Miller HM, Northup FE. 1926. The seasonal infestation of Nassa obsoleta (Say) with larval trematodes. Biological Bulletin 50:490-5081.

Miura O, Chiba S. 2007. Effects of trematode double infection on the shell size and distribution of snail hosts. Parasitology International 56:19-22. 
Morandini AC, Martorelli S, Marques AC, Silveira FL. 2005. Digenean metacercaria (Trematoda, Digenea, Lepocreadiidae) parasitizing "coelenterates" (Cnidaria, Scyphozoa and Ctenophora) from Southeastern Brazil. Brazilian Journal of Oceanography 53:39-45.

Moreno CE. 2001. Métodos para medir la biodiversidad. Primera ed. Gorfi S.A. Zaragoza, España, 84 p.

Mouritsen KN, Poulin R. 2002. Parasitism, community structure and biodiversity in intertidal ecosystems. Parasitology 124:101-117.

Narvarte MA. 2006. Biology and fishery of the whelk Buccinanops globulosus (Kiener, 1834) in northern coastal waters of the San Matías Gulf (Patagonia, Argentina). Fisheries Research 77:131-137.

Nasincová V, Scholz T. 1994. The life cycle of Asymphylodora tincae (Modeer 1790) (Trematoda: Monorchiidae): a unique development in monorchiid trematodes. Parasitology Research 80:192-197.

Nicoll W. 1907. Parorchis acanthus, the type of a new genus of trematodes. Quarterly Journal of Microscopical Science 51:345-351.

Nikolaev KE, Sukhotin AA, Galaktionov K. 2006. Infection patterns in White Sea blue mussels Mytilus edulis of different age and size whit metacercariae of Himasthla elongata (Echinostomatidae) and Cercaria parvicaudata (Renicolidea). Diseases of Aquatic Organisms 71:51-58.

Nolan MJ, Cribb TH. 2005. The use and implications of ribosomal DNA sequencing for the discrimination of digenean species. Advances in Parasitology 60:101-163.

Oliva ME, Diaz M. 1988. Aspectos cuantitativos de la infección por Proctoeces humboldti (Trematoda: Fellodistomidae) en la lapa Fissurella crassa (Mollusca: Archaeogastropoda). Revista Chilena de Historia Natural 61:27-33.

Olivier SR, Penchaszadeh PE. 1968. Observaciones sobre la biología y la ecología de Siphonaria (Pachysiphonaria) lessoni (Blainville, 1924) (Gastropoda, Siphonariidae) en el litoral rocoso de Mar del Plata (Buenos Aires). Cahiers de Biologie Marine 9:491-496.

Ostrowski de Núñez M. 1974. Fauna de agua dulce de la República Argentina. II. Cercaria perteneciente a la superfamilia Opistorchioidea y parte de su ciclo evolutivo (Trematoda). Physis, Sección B 33:1-9.

Ostrowski de Núñez M. 1975. Fauna de agua dulce de la República Argentina. IV. Cercarias (Trematoda) de Littoridina piscium. Physis, Sección B 34:63-68.

Ostrowski de Núñez M. 1992. Trematoda. Familias Strigeidae, Diplostomidae, Clinostomidae, Schistosomatidae, Spirorchiidae, Bucephallidae. En: Fauna de agua dulce de la República Argentina. Volumen 9 Trematoda, Fascículo 1 Furcocercarias. Editor: Castellanos ZA. PROFADU (CONICET). La Plata, 55 p.

Ostrowski de Núñez M, Hamann MI, Rumi A. 1990. Larval trematodes of Schistosoma mansoni transmitting snails, Biomphalaria spp., in northeastern Argentina. Acta Parasitologica Polonica 35:85-96.

Ostrowski de Núñez M, Quaggiotto A. 1995. Trematodes larvales (Digenea) de las familias Diplostomidae, Strigeidae y Echinostomatidae en la Región Patagónica Argentina. Boletín Chileno de Parasitología 50:28-33.

Otaegui AV, Zaixso HE. 1974. Distribución vertical de los moluscos marinos del litoral rocoso de la Ría de Puerto Deseado (Santa Cruz, Argentina). Una guía para reconocer los diferentes pisos y horizontes litorales. Physis 33:321-334. 
Palombi A. 1930. II ciclo biologico di Diphterostomum brusinae Stossich (Trematode digenetico: fam. Zoogonidae Odhner). Considerazioni sui cicli evolutivi dell especie affini e dei trematodi in generale. Pubblicazione della Stazione Zoologica di Napoli 10:111-149.

Palombi A. 1934. Gli stadi larvali dei trematodi del Golfo de Napoli, $1^{\circ}$ Contributo allo studio della morfologia, biologia, e sistematica delle cercarie marine. Publicatione di la stazione Zoologique de Napoli 14:51-94.

Palombi A. 1937. II ciclo biologico di Lepocreadium album Stossich sperimentalmente realizzato. Rivista di Parasitologia 1:1-12.

Pastorino G. 1994. Moluscos costeros recientes de Puerto Pirámide, Chubut, Argentina. Academia Nacional de Ciencias (Córdoba, Argentina). Miscelánea 93:1-30.

Pastorino G. 2009. The genus Olivella Swainson, 1831(Gastropoda: Olividae) in Argentine waters. Nautilus 123:189-201.

Pastorino G, Penchaszadeh PE. 1998. Epitonium fabrizioi (Gastropoda, Epitoniidae), a new species of Patagonia, Argentina. Nautilus 112:63-68.

Pastorino G, Penchaszadeh PE. 2002. Spawn of the Patagonian gastropod Pareuthria plumbea. Nautilus 116:105-108.

Penchaszadeh PE. 1971. Aspectos de la embriogénesis de algunos gasterópodos del género Buccinanops d'Orbigny,1841 (Gastropoda, Prosobranchiata, Buccinidae). Physis 30:475-482.

Penchaszadeh PE. 1976. Reproducción de gasterópodos prosobranquios del Atlántico suroccidental. El género Trophon. Physis 35:69-76.

Penchaszadeh PE. 2004. Caracoles, almejas y mejillones. En: La vida entre mareas: vegetales y animales de las costas de Mar del Plata, Argentina. Editores: Boschi \& Cousseau. 253-270. Publicaciones Especiales del INIDEP, Mar del Plata.

Penchaszadeh PE, Cledón M, Bigatti G. 2003. Spatial organization of foraging activity in Siphonaria lessoni from the SW Atlantic, Argentina. Bulletin of the Malacological Society of London 41:14-15.

Penchaszadeh PE, Pastorino G, Cledón M. 2001. Crepidula dilatata Lamarck, 1822, Truly living in the Southwestern Atlantic. Veliger 45:174-176.

Pina S, Tajdari J, Russell-Pinto F, Rodrigues P. 2009. Morphological and molecular studies on life cycle stages of Diphtherostomum brusinae (Digenea: Zoogonidae) from northern Portugal. Journal of Helminthology 83:321-331.

Pinto HA, Melo AL. 2012. Melanoides tuberculata (Mollusca: Thiaridae) harboring renicolid cercariae (Trematoda: Renicolidae) in Brazil. Journal of Parasitology 98:784-787.

Plan de Manejo del Área Protegida Península Valdés. 2001. Dirección general de Áreas Protegidas, Secretaría de Turismo de Chubut, Anexos 6-8.

Popiel I. 1976. A description of the metacercaria of Maritrema arenaria Hadley \& Castle, 1940 Digenea: Microphallidae from Balanus balanoides L. in Britain. Cahiers de Biologie Marine 17:411-412.

Poulin R. 2006. Global warming and temperature-mediated increases in cercarial emergence in trematode parasites. Parasitology 132:143-151.

Poulin R. 2010. Latitudinal gradients in parasite diversity: bridging the gap between temperate and tropical areas. Neotropical Helminthology 4:169-177.

Poulin R, Cribb TH. 2002. Trematode life cycles: short is sweet? Trends in Parasitology 18:176-182.

Poulin R, Moran S. 2004. Parasite Biodiversity. Smithsonian Institution Books. Washington D.C., 216 p. 
Poulin R, Mouritsen KN. 2003. Large-scale determinants of trematode infections in intertidal gastropods. Marine Ecology Progress Series 254: 187-198.

Poulin R, Mouritsen KN. 2006. Climate change, parasitism and the structure of intertidal ecosystems. Journal of Helminthology 80:183-191.

Presta ML, Cremonte C, Ituarte C. 2013. The fit between parasites and intermediate host population dynamics: larval Digeneans affecting the bivalve Neolepton cobbi (Galeommatoidea) from Patagonia. Marine Biology Research (en prensa).

Prévot G. 1966. Sur deux Trématodes larvaires d'Antedon mediterranea Lmk. (Echinoderme): Metacercaria sp. (Monorchiidae Odhner, 1911) et métacercaire de Diphterostomum brusinae Stoss., 1904 (Zoogonidae Odhner, 1911). Annales de Parasitologie Humaine et Comparée 41:233-242.

Prévot G, Bartoli P. 1978. Le cycle de développement de Renicola lari J. Timon-David, 1933. Annales de Parasitologie Humaine et Comparée 53:561-575.

Prévot G, Bartoli P, Deblock S. 1976. Cycle biologique de Maritrema misenensis (A. Palombi, 1940) n. comb. (Trematoda: Microphallidae Travassos, 1920) du Midi de la France. Annales de Parasitologie (Paris) 51:433-446.

Prinz K, Kelly TC, O'Riordan RM, C. Culloty SC. 2010. Temporal variation in prevalence and cercarial development of Echinostephilla patellae (Digenea, Philophthalmidae) in the intertidal gastropod Patella vulgata. Acta Parasitologica 55:39-44.

Pulsford A, Matthews RA. 1984. An ultrastructural study of the cellular response of the plaice, Pleuronectes platessa L., to Rhipidocotyle johnstonei nom. nov. (proGasterostomum sp. Johnstone, 1905) Matthews, 1968 (Digenea: Bucephalidae). Journal of Fish Diseases 7:3-14.

Rebecq JM. 1960. Présence en France de Maritrema subdolum Jägerskiold $1909=$ Maritrema rhodanicum Carrère 1936 (Trematoda, Microphallidae) (I). Vie et Milieu 11:69-74.

Ringuelet RA, Amor A, Magaldi N, Pallares R. 1962. Estudio ecológico de la fauna intercotidal de Puerto Deseado en febrero de 1961 (Santa Cruz, Argentina). Physis 23:35-53.

Robson EM, Williams IC. 1970. Relationships of some species of Digenea with the marine prosobranch Littorina littorea (L.) I. The ocurrence of larval Digena in L. littorea of the North Yorskshire coast. Journal of Helminthology 44:153-168.

Rocka A. 2006. Helminths of Antarctic fishes: Life cycle biology specificity and geographical distribution. Acta Parasitologica 51:26-35.

Rothschild M. 1935. Trematode parasites of Turritella comunis Lmk. Parasitology 27:152170.

Rothschild M. 1938. Notes on the clasification of cercariae of the superfamily Notocotyloidea (Trematoda), with special reference to the excretory system. Novitates Zoologicae 41:75-83.

Rothschild M, Sproston NG. 1941. The metacercaria of Cercaria doricha Roths. 1934, or a closely related species. Parasitology 33:359-362.

Russell-Pinto F, Gonçalves JF, Bowers E. 2006. Digenean larvae parasitizing Cerastoderma edule (Bivalvia) and Nassarius reticulatus (Gastropoda) from Ria de Aveiro, Portugal. Journal of Parasitology 92:319-332.

Ryang YS, Yoo JC, Lee SH, Chai JY. 2000. The palearctic oystercatcher Haematopus ostralegus, a natural definitive host for Gymnophalloides seoi. Journal of Parasitology 86:418-419. 
Sanmartín ML, Cordeiro JA, Alvarez MF, Leiro J. 2005. Helminth fauna of the yellow-legged gull Larus cachinnans in Galicia, north-west Spain. Journal of Helminthology 79:361371.

Sannia A, James BL. 1977. The Digenea in marine molluscs from Eyjafjördur, North Iceland. Ophelia 16:97-109.

Sapoznikow A, Reeves C, Sessa G, Mansur L, de la Reta M. 2008. Aves marinas y playeras. Fundación Patagonia Natural. Puerto Madryn Argentina, 54 p.

Sardella NH, Avendaño MF, Timi JT. 1998. Parasite communities of Genypterus blacodes and G. brasiliensis (Pisces: Ophidiidae) from Argentina. Helminthologia 35:209-218.

Sardella NH, Timi JT. 2004. Parasites of Argentine hake in the Argentine Sea: population and infracommunity structure as evidence for host stock discrimination. Journal of Fish Biology 65:1472-1488.

Saxena SK. 1982. A gymnocephallous cercaria, Cercaria tandoni n. sp. from Melanoides tuberculata (Müller). Helminthologia 19:211-217.

Scarabino V. 1977. Moluscos del Golfo San Matías (Provincia de Río Negro, República Argentina), inventario y claves para su identificación. Comunicaciones de la Sociedad Malacológica del Uruguay IV:131-132.

Schell, SC. 1970. How to know the Trematodes. W.C. Brown Company Publishers, Dubuque, $355 \mathrm{p}$.

Scholz T. 2002. Family Gymnophallidae Odhner, 1905. En: Keys to the Trematoda Volume 1. Editores: Glbson D, Jones A, Bray R. CAB International and The Natural History Museum. London, UK, 245-254.

Schulenburg JH, Englisch U, Wägele JW. 1999. Evolution of ITS1 rDNA in the Digenea (Platyhelminthes: Trematoda): 3'end sequence conservation and its phylogenetic utility. Journal of Molecular Evolution 48:2-12.

Servicio de Hidrografía Naval. Tablas de Mareas. http://www.hidro.gov.ar/Oceanografia/Tmareas/Form_Tmareas.asp

Sewell RBS. 1922. Cercaria indicae. Indian Journal of Medical Research 10:1-370.

Shameem U, Rao NN, Madhavi R. 1990. Cercaria chilkaensis No. 1, a new cystophorous cercaria from the snail Stenothyra blanfordiana from Chilka lake, India. Journal of Natural History 24:261-270.

Shimura S, Ito J. 1980. Two new cercariae, Cercaria brachycaeca n.sp. and Cercaria misakiana n.sp., from top shells, Batillus cornutus and Marmarostoma stenogyrum, with notes of their effects on the hosts. Japanese Journal of Parasitology 29:69-76.

Siegel S. 1990. Estadística no paramétrica aplicada a ciencias de la conducta. Editorial Trillas. México, $344 \mathrm{p}$.

Simpson RD, Harrington SA. 1985. Egg masses of three gastropods, Kerguelenella lateralis (Siphonariidae), Laevilitorina caliginosa and Macquariella hamiltoni (Littorinidae), from Macquarie Island (sub-Antarctic). Journal of the Malacological Society of Australia 7:17-28.

Skirnisson K, Galaktionov K. 2002. Life cycles and transmission patterns of seabird digeneans in SW Iceland. Sarsia 87:144-151.

Skirnisson K, Galaktionov K, Kozminsky EV. 2004. Factors influencing the distribution of digenetic trematode infections in a mudsnail (Hydrobia ventrosa) population inhabiting salt marsh ponds in Iceland. Journal of Parasitology 90:50-59.

Smith N. 2001. Spatial heterogeneity in recruitment of larval trematodes to snail intermediate hosts. Oecologia 127:115-122. 
Smythe AB, Font WF. 2001. Phylogenetic analysis of Alloglossidium (Digenea: Macroderoididae) and related genera: life-cycle evolution and taxonomic revision. Journal of Parasitology 87:386-391.

Sokolova IM. 1995. Influence of trematodes on the demography of Littorina saxatilis (Gastropoda: Prosobranchia: Littorinidae) in the White Sea. Diseases of Aquatic Organisms 21:91-101.

Sousa WP. 1990. Spacial scale and the processes structuring a guild of larval trematode parasites. En: Parasite communities: patterns and processes. Editores: Esch GW, Bush A, Aho J. Chapman and Hall. London, UK, 41-67.

Studer A, Poulin R. 2012. Effects of salinity on an intertidal host-parasites system: Is the parasite more sensitive than its host? Journal of Experimental Marine Biology and Ecology 412:110-116.

Stunkard HW. 1932. Some Larval Trematodes from the Coast in the Region of Roscoff, Finistère. 1. Parasitology 24:321-343.

Stunkard HW. 1938. Distomum lasium Leidy, 1891 (syn. Cercariaeum lintoni Miller and Northup, 1926), the larval stage of Zoogonus rubellus (Olsson, 1868) (syn. Z.mirus Looss, 1901). Biological Bulletin 75:308-334.

Stunkard HW. 1940. The morphology and life history of the digenetic trematode, Zoögonoides laevis Linton, 1940. Biological Bulletin 85:227-237.

Stunkard HW. 1964. Studies on the trematode genus Renicola: observations on the lifehistory, specificity, and systematic position. Biological Bulletin 126:467-489.

Stunkard HW. 1969. The morphology and life-history of Neopechona pyriforme (Linton, 1900) n. gen., n. comb. (Trematoda: Lepocreadiidae). Biological Bulletin 136:96-113.

Stunkard HW. 1970. The marine cercariae of the Woods Hole Massachusetts region. Biological Bulletin 138:66-76.

Stunkard HW. 1979a. The morphology, life-history, and taxonomic relations of Odhneria odhneri Travassos, 1921 (Digenea: Microphallidae). Biological Bulletin 156:234-245.

Stunkard HW. 1979b. Observations on the life-history of lepocreadiid trematodes. Revista Ibérica de Parasitología 39:493-503.

Stunkard HW. 1980a. The morphology, life-history, and taxonomic relations of Lepocreadium aerolatum (Linton, 1900) Stunkard, 1969 (Trematoda: Digenea). Biological Bulletin 158:154-163.

Stunkard HW. 1980b. Successive hosts and develpomental stages in the life history of Neopechona cablei sp. n. (Trematode: Lepocreadiidae). Journal of Parasitology 66:636-641.

Stunkard HW. 1983. The marine cercariae of the Woods Hole, Massachusetts region, a review and a revision. Biological Bulletin 164:143-162.

Stunkard HW, Cable RM. 1932. The life history of Parorchis avitus (Linton) a trematode from the cloaca of the gull. Biological Bulletin 62:328-338.

Stunkard HW, Shaw R. 1931. The effects of dilution of sea water on the activity and longevity of certain marine cercarie, with descriptions of two new species. Biological Bulletin 61:242-271.

Stunkard HW, Uzmann JR. 1959. The life-cycle of the digenetic trematode, Proctoeces maculatus (Loos, 1901) Odhner, 1911 [syn. P. subtenuis (Linton, 1907) Hanson, 1950], and description of Cercaria adranocerca n. sp. Biological Bulletin 116:184193.

Suriano DM, Martorelli SR. 1983. Estudios parasitológicos en la albúfera de Mar Chiquita, provincia de Buenos Aires, República Argentina. Neotrópica 29:195-207. 
Suriano DM, Sutton CA. 1980. Contribución al conocimiento de la fauna parasitológica argentina 7. Digeneos de peces de la plataforma del Mar Argentino. Revista del Museo de La Plata, Nueva Serie 124:261-267.

Sutton CA. 1989. Catalogo preliminar de los helmintos parasitos de roedores neotropicales. Comisión de Investigaciones Científicas de la provincia de Buenos Aires (Monografia n.12). La Plata, Buenos Aires, Argentina, 119 p.

Szidat L. 1950. Los parásitos del róbalo ("Eleginops maclovinus" Cuv. \& Val.). Primer Congreso Nacional de Pesquerías Marítimas e Industrias Derivadas 2:235-270.

Szidat L. 1961. Versuch einer Zoogeographie des Süd-Atlantik mit hilte von Leitparasiten der meeresfishe. Parasitologische Schriftenreihe 13:1-98.

Szidat L. 1963. Los parásitos de los mitílidos y los daños por ellos causados I. Los parásitos de los "mejillines", Brachydontes rodriguezi y Semymitilus algosus. Neotrópica 29:80-86.

Szidat L. 1965. Los parásitos de los mitílidos y los daños por ellos causados II. Los parásitos de Mytilus edulis platensis (Orb.) (mejillón del plata). Comunicaciones del Museo Argentino de Ciencias Naturales "Bernardino Rivadavia" 1:1-16.

Tanzola RD, Guagliardo SE. 2000. Helminth fauna of the Argentine conger, Conger orbignyanus (Pisces: Anguilliformes). Helminthologia 37:229-232.

Thieltges DW, Krakau M, Andersen H, Fottner S, Reise K. 2006. Macroparasite community in molluscs of a tidal basin in the Wadden Sea. Helgoland Marine Research 60:307316.

Timi JT. 2003. Parasites of Argentina anchovy in the south-west Atlantic: latitudinal patterns and their use for discrimination of host populations. Journal of Fish Biology 63:90-107.

Timi JT, Lanfranchi AL. 2009. The metazoan parasite communities of the Argentinean sandperch Pseudopercis semifasciata (Pisces: Perciformes) and their use to elucidate the stock structure of the host. Parasitology 136:1209-1219

Timi JT, Lanfranchi AL, Etchegoin JA, Cremonte F. 2008. Parasites of the Brazilian sandperch Pinguipes brasilianus Cuvier: a tool for stock discrimination in the Argentine Sea. Journal of Fish Biology 72:1332-1342.

Timi JT, Martorelli S, Sardella NH. 1999. Digenetic trematodes parasitic on Engraulis anchoita (Pisces: Engraulidae) from Argentina and Uruguay. Folia Parasitologica 46:132-138.

Torres A, Caille G. 2009. Las comunidades del intermareal rocoso antes y después de la eliminación de un disturbio antropogénico: un caso de estudio en las costas de Puerto Madryn (Patagonia, Argentina). Revista de Biología Marina y Oceanografía 44:517-521.

Tkach V, Pawlowski J, Sharpilo VP. 2000. Molecular and morphological differentiation between species of the Plagiorchis vespertilionis group (Digenea, Plagiorchiidae) ocurring in European bats, with a redescription of $P$. vespertilionis (Muller, 1780). Systematic Parasitology 47:9-22.

Varisco M, Vinuesa J. 2011. Reproductive biology of the spider crab Leucippa pentagona (Decapoda: Epialtidae), in Bustamante Bay, Argentina. Latin American Journal of Aquatic Research 39:471-480.

Vázquez MG, Bas CC, Spivak ED. 2012. Population structure of the intertidal crab Cyrtograpsus altimanus (Brachyura: Varunidae) in a northern Patagonia mussel bed. Journal of the Marine Biological Association of the United Kingdom 92:327-334. 
Vázquez N, Ituarte C, Navone GT, Cremonte F. 2006. Parasites of the stout razor clam Tagelus plebeius (Psammobiidae) from the southwestern Atlantic Ocean. Journal of Shellfish Research 25:877-886.

Vázquez N, Pérez Bruno E, Márquez F, Van der Molen S, Gilardoni C, Cremonte C. 2013. A histopathological survey of de razor clam Ensis macha (Pharidae) along the Patagonia Argentina coast. Journal of Invertebrate Pathology 112:253-259.

Vergara D, Velásquez LE. 2009. Larvas de Digenea en Melanoides tuberculata (Gastropoda: Thiaridae) en Medellín, Colombia. Acta Biológica Colombiana 14:135-142.

Videla LS, Rostagno CM, Toyos MA. 2008. La materia orgánica particulada: comparación de métodos para su determinación y su valor como indicador de calidad de suelos del Chubut. Cl Suelo (Argentina) 26:219-227.

Vilas R, Criscione CD, Blouin MS. 2005. A comparison between mitochondrial DNA and the ribosomal internal trancribed regions in prospecting for cryptic species of platyhelminth parasites. Parasitology 131:839-846.

Villot A. 1875. Recherches sur les helminthes libres ou parasites des côtes de la Bretagne. Archives de Zoologie Expérimentale et Générale 4:451-482.

Wang Y. 1995. Studies on the later period of the life cycle of Tangiopsis chinensis (Trematoda: Hemiuridae). Acta Parasitologica et Medica Entomologica Sinica 2:1418.

Wardle WJ. 1975. Cercaria anadarae sp. n. parasitizing a bivalve mollusc, Anadara brasiliana (Lamarck), from the northwest Gulf of Mexico. Journal of Parasitology 61:1048-1049.

Wardle WJ. 1980. On the life cycle stages of Proctoeces maculatus (Digenea: Fellodistomidae) in mussels and fishes from Galveston Bay, Texas. Bulletin of Marine Science 30:737-743.

Watson RA. 1984. The life cycle and morphology of Tetracerasta blepta, gen. et sp. nov., and Stegodexamene callista, sp. nov. (Trematoda: Lepocreadiidae) from the longfinned eel, Anguilla reinhardtii Steindacher. Australian Journal of Zoology 32:177204.

Williams JEH, Williams LB. 1996. Parasites of Offshore Big game fishes of Puerto Rico and Western Atlantic. Sportfihs Disease Project, Department of marine Science and Department of Biology, University of Puerto Rico. Puerto Rico, 383 p.

Wright CA. 1956. Studies on the life-history and ecology of the Trematode genus Renicola Cohn, 1904. Departament of Zoology and Applied Entomology, Imperial Collegue of Science and Technology. London, UK, $51 \mathrm{p}$.

Yamaguti S. 1971. Sinopsis of digenetic trematodes of vertebrates -Digenea of Bird-. Keigaku Publishing Co. Tokyo, 475-686.

Yamaguti S. 1975. A synoptical review of life histories of digenetic trematodes of vertebrates with special reference to the morphology of their larval forms. Keigaku Publishing Co. Tokyo, 1-575.

Yorio P, Bertellotti M. 2002. Espectro trófico de la Gaviota Cocinera (Larus dominicanus) en tres áreas protegidas de Chubut, Argentina. Hornero 17:91-95.

Yorio P, Bertellotti M, Gandini P, Frere E. 1998. Kelp Gulls Larus dominicanus breeding on the Argentine coast: population status and relationship with coastal management and conservation. Marine Ornithology 26:11-18.

Yorio P, Frere E, Gandini PA, Giaccardi M. 1996. Uso de basurales urbanos por gaviotas: Magnitud del problema y metodologías para su evaluación. Informes técnicos del 
Referencias

Plan de Manejo Integrado de la Zona Costera Patagónica. Fundación Patagonia Natural. Puerto Madryn, Argentina, 26 p.

Yoshino TP. 1975. A seasonal and histologic study of larval Digenea infecting Cerithidea californica (Gastropoda: Prosobranchia) from Goleta Slough, Santa Barbara County, California. Veliger 18:156-163.

Zaixso HE. 1975. Distribución vertical de los moluscos marinos de la Ría Deseado (Santa Cruz, Argentina) sustratos con fracción limosa. Physis 34:229-243. 


\section{ANEXOS}

Anexo I. Comparación de las regiones 18S, ITS1, ITS2 Y 28 S del ADN ribosomal de Lepocreadiidae gen. et sp. 1 con Lepocreadiidae gen. et sp. 2 y con otras especies de la familia Lepocreadiidae disponibles en Gen Bank. Se presentan el número de pares de bases (pb) diferentes, en común y total y el porcentaje de similitud entre cada par de especies comparadas.

\begin{tabular}{|c|c|c|c|c|c|c|c|c|c|c|c|c|c|c|c|c|}
\hline Especies & & Regió & $18 \mathrm{~S}$ & & & Regiór & ITS1 & & & Regió & ITS2 & & & Regió & 285 & \\
\hline Lepocreadiidae gen. et sp. 1 & $\begin{array}{c}\mathrm{n} \circ \mathrm{pb} \\
\text { diferentes }\end{array}$ & $\begin{array}{l}\text { no pb } \\
\text { común }\end{array}$ & $\begin{array}{l}\text { no pb } \\
\text { total }\end{array}$ & $\%$ similitud & $\begin{array}{c}\mathrm{n} 0 \mathrm{pb} \\
\text { diferentes }\end{array}$ & $\begin{array}{l}\text { no pb } \\
\text { común }\end{array}$ & $\begin{array}{l}\text { no } \mathrm{pb} \\
\text { total }\end{array}$ & $\%$ similitud & $\begin{array}{c}\mathrm{n} \text { - } \mathrm{pb} \\
\text { diferentes }\end{array}$ & $\begin{array}{l}\text { no pb } \\
\text { común }\end{array}$ & $\begin{array}{l}\text { no } \mathrm{pb} \\
\text { total }\end{array}$ & $\%$ similitud & $\begin{array}{c}\mathrm{n} \circ \mathrm{pb} \\
\text { diferentes }\end{array}$ & $\begin{array}{l}\text { no pb } \\
\text { común }\end{array}$ & $\begin{array}{l}\text { no pb } \\
\text { total }\end{array}$ & $\%$ similitud \\
\hline Lepocreadiidae gen. et sp. 2 & 7 & 939 & 946 & 99,26 & 8 & 473 & 481 & 98,34 & 1 & 328 & 329 & 99,7 & 5 & 900 & 905 & 99,45 \\
\hline Preptetos trulla & 5 & 941 & 946 & 99,47 & & & & & & & & & 19 & 901 & 920 & 97,93 \\
\hline Preptetos laguncula & & & & & & & & & 53 & 228 & 281 & 81,14 & & & & \\
\hline Opechona sp. & 2 & 944 & 946 & 99,79 & & & & & 33 & 303 & 336 & 90,18 & 22 & 893 & 915 & 97,6 \\
\hline Opechona kahawai & & & & & & & & & & & & & 14 & 905 & 919 & 98,48 \\
\hline Opechona baciliaris & & & & & 61 & 423 & 484 & 87,40 & & & & & & & & \\
\hline Tetracerasta blepta & 28 & 918 & 946 & 97,04 & & & & & & & & & 84 & 848 & 932 & 91 \\
\hline Lepocreadium album & 13 & 923 & 936 & 98,61 & & & & & 18 & 318 & 336 & 94,64 & 16 & 899 & 915 & 98,25 \\
\hline Lepidapedon elongatum & 18 & 928 & 946 & 98,1 & 121 & 363 & 484 & 75,00 & & & & & & & & \\
\hline Austroholorchis sprenti & 32 & 914 & 946 & 96,62 & & & & & & & & & & & & \\
\hline Neohypocreadium dorsoporum & & & & & & & & & 85 & 213 & 298 & 71,47 & & & & \\
\hline Prodistomum keyam & & & & & & & & & & & & & 14 & 918 & 932 & 98,5 \\
\hline Diploproctodaeum momoaafata & & & & & & & & & & & & & 70 & 862 & 932 & 92,49 \\
\hline Holorchis castex & & & & & & & & & & & & & 104 & 828 & 932 & 88,84 \\
\hline Cadenatella pacifica & & & & & & & & & & & & & 178 & 754 & 932 & 80,9 \\
\hline Neolepidapedon smithi & & & & & & & & & & & & & 81 & 837 & 918 & 91,18 \\
\hline Profundivermis intercalarius & & & & & & & & & & & & & 86 & 832 & 918 & 90,63 \\
\hline Bulbocirrus aulostomi & & & & & & & & & & & & & 89 & 843 & 932 & 90,45 \\
\hline Diplocreadium tsontso & & & & & & & & & & & & & 69 & 863 & 932 & 92,6 \\
\hline Intusatrium robustum & & & & & & & & & & & & & 87 & 845 & 932 & 90,66 \\
\hline Lepotrema clavatum & & & & & & & & & & & & & 66 & 866 & 932 & 92,92 \\
\hline Multitestis magnacetabulum & & & & & & & & & & & & & 66 & 866 & 932 & 92,92 \\
\hline
\end{tabular}


Anexo I (continuación). Comparación de las regiones 18S, ITS1, ITS2 Y 28S del ADN ribosomal de Lepocreadiidae gen. et sp. 1 con Lepocreadiidae gen. et sp. 2 y con otras especies de la familia Lepocreadiidae disponibles en Gen Bank. Se presentan el número de pares de bases (pb) diferentes, en común y total y el porcentaje de similitud entre cada par de especies comparadas.

\begin{tabular}{|c|c|c|c|c|c|c|c|c|c|c|c|c|c|c|c|c|}
\hline Especies & \multicolumn{4}{|c|}{ Región 18S } & \multicolumn{4}{|c|}{ Región ITS1 } & \multicolumn{4}{|c|}{ Región ITS2 } & \multicolumn{4}{|c|}{ Región 28S } \\
\hline Lepocreadiidae gen. et sp. 1 & $\begin{array}{c}\mathrm{n} \circ \mathrm{pb} \\
\text { diferentes }\end{array}$ & $\begin{array}{l}\mathrm{n}=\mathrm{pb} \\
\text { común }\end{array}$ & $\begin{array}{l}\text { no pb } \\
\text { total }\end{array}$ & $\%$ similitud & $\begin{array}{c}\mathrm{n} \text { - } \mathrm{pb} \\
\text { diferentes }\end{array}$ & $\begin{array}{l}\text { no pb } \\
\text { común }\end{array}$ & $\begin{array}{l}\mathrm{n} \cong \mathrm{pb} \\
\text { total }\end{array}$ & $\%$ similitud & $\begin{array}{c}\mathrm{n} \text { - } \mathrm{pb} \\
\text { diferentes }\end{array}$ & $\begin{array}{l}\mathrm{n} \cong \mathrm{pb} \\
\text { común }\end{array}$ & $\begin{array}{l}\mathrm{n}=\mathrm{pb} \\
\text { total }\end{array}$ & $\%$ similitud & $\begin{array}{c}\mathrm{n} \cong \mathrm{pb} \\
\text { diferentes }\end{array}$ & $\begin{array}{l}\mathrm{n} \cong \mathrm{pb} \\
\text { común }\end{array}$ & $\begin{array}{l}\mathrm{n} \text { ㅇ pb } \\
\text { total }\end{array}$ & $\%$ similitud \\
\hline Postlepidapedon uberis & & & & & & & & & & & & & 131 & 801 & 932 & 85,94 \\
\hline Bianium spongiosum & & & & & & & & & & & & & 62 & 870 & 932 & 93,35 \\
\hline Clavogalea trachinoti & & & & & & & & & & & & & 30 & 902 & 932 & 96,78 \\
\hline Echeneidocoelium indicum & & & & & & & & & & & & & 55 & 877 & 932 & 94,1 \\
\hline Lepidapedoides angustus & & & & & & & & & & & & & 30 & 888 & 918 & 96,73 \\
\hline Lobatocreadium exiguum & & & & & & & & & & & & & 67 & 865 & 932 & 92,81 \\
\hline Myzoxenus insolens & & & & & & & & & & & & & 94 & 840 & 934 & 89,93 \\
\hline Neolepocreadium caballeroi & & & & & & & & & & & & & 108 & 826 & 934 & 88,43 \\
\hline Aephnidiogenes major & & & & & & & & & & & & & 103 & 829 & 932 & 88,95 \\
\hline Neopreptetos arusettae & & & & & & & & & & & & & 71 & 844 & 915 & 92,24 \\
\hline Lepidapedon arlenae & & & & & & & & & & & & & 80 & 836 & 916 & 91,27 \\
\hline Hypocreadium toombo & & & & & & & & & & & & & 51 & 881 & 932 & 94,53 \\
\hline
\end{tabular}

Anexo II. Comparación de las regiones ITS1 e ITS2 del ADN ribosomal de Diphterostomum sp. y Zoogonus sp. con otras especies de la familia Zoogonidae disponibles en Gen Bank. Se presentan el número de pares de bases (pb) diferentes, en común y total y el porcentaje de similitud entre cada par de especies comparadas.

\begin{tabular}{|c|c|c|c|c|c|c|c|c|}
\hline \multirow{2}{*}{$\begin{array}{c}\text { Especies } \\
\text { Diphterostomum sp. }\end{array}$} & \multicolumn{4}{|c|}{ Región ITS2 } & & & & \\
\hline & nopb diferentes & nopb común & $\mathrm{n}=\mathrm{pb}$ total & $\%$ similitud & & & & \\
\hline Diphterostomum brusinae & 30 & 200 & 230 & 86,96 & & & & \\
\hline \multirow[t]{2}{*}{ Zoogonus rubelus } & 94 & 136 & 230 & 59,13 & & & & \\
\hline & \multicolumn{4}{|c|}{ Región ITS1 } & \multicolumn{4}{|c|}{ Región ITS2 } \\
\hline Zoogonus sp. & $\mathrm{n} \cong \mathrm{pb}$ diferentes & nọb común & $\mathrm{n}=\mathrm{pb}$ total & $\%$ similitud & $\mathrm{n}-\mathrm{pb}$ diferentes & nọpb común & $\mathrm{n}=\mathrm{pb}$ total & $\%$ similitud \\
\hline Zoogonus rubelus & 113 & 396 & 509 & 77,8 & 68 & 181 & 249 & 72,69 \\
\hline Diphterostomum sp. & & & & & 82 & 148 & 230 & 64,35 \\
\hline Diphterostomum brusinae & 191 & 318 & 509 & 62,47 & 87 & 143 & 230 & 62,17 \\
\hline
\end{tabular}

ज 
Anexo III. Comparación de las regiones 18S, ITS1, 5.8S, ITS2 y $28 \mathrm{~S}$ del ADN ribosomal de Gymnophalloides nacellae con otras especies de la familia Gymnophallidae disponibles en Gen Bank. Se presentan el número de pares de bases (pb) diferentes, en común y total y el porcentaje de similitud entre cada par de especies comparadas (* la secuencia $28 \mathrm{~S}$ de Bartolius pierrei no se obtuvo en forma completa).

\begin{tabular}{|c|c|c|c|c|}
\hline Especies & \multicolumn{4}{|c|}{ Región 18S-ITS1-5.8S-ITS2-28S } \\
\hline Gymnophalloides nacellae & $\mathrm{n}$ - pb diferentes & $\mathrm{n}$ - pb común & $\mathrm{n}$ - pb total & $\%$ similitud \\
\hline Gymnophalloides seoi & 309 & 2936 & 3245 & $\mathbf{9 0 , 4 8}$ \\
\hline Parvatrema sp. & 453 & 2741 & 3194 & 85,82 \\
\hline Gymnophallus choledocus & 441 & 2770 & 3211 & 86,27 \\
\hline Gymnophallus australis & 336 & 2913 & 3249 & 89,66 \\
\hline Meiogymnophallus minutus & 513 & 2753 & 3266 & 84,29 \\
\hline Bartolius pierrei* & 368 & 1862 & 2230 & 83,50 \\
\hline Lacunovermis macomae & 446 & 2776 & 3222 & 86,16 \\
\hline
\end{tabular}


Anexo IV. Comparación de las regiones ITS1 e ITS2 del ADN ribosomal de Maritrema sp. 1 y Maritrema madrynense sp. con otras especies de la familia Microphallidae disponibles en Gen Bank. Se presentan el número de pares de bases (pb) diferentes, en común y total y el porcentaje de similitud entre cada par de especies comparadas.

\begin{tabular}{|c|c|c|c|c|c|c|c|c|}
\hline \multirow[b]{2}{*}{ Maritrema sp. 1} & \multicolumn{4}{|c|}{ Región ITS1 } & \multicolumn{4}{|c|}{ Región ITS2 } \\
\hline & $n \circ p b$ diferentes & noppb común & $n \circ p b$ total & $\%$ similitud & $n \circ p b$ diferentes & nopb común & $n \circ p b$ total & $\%$ similitud \\
\hline Maritrema madrynense & 257 & 420 & 677 & 62,04 & 113 & 261 & 374 & 69,79 \\
\hline Maritrema arenaria & 135 & 288 & 423 & 68,09 & 155 & 280 & 435 & 64,37 \\
\hline Maritrema sobdolum & 126 & 309 & 435 & 71,03 & 123 & 251 & 374 & 67,11 \\
\hline Maritrema oocysta & 127 & 297 & 424 & 70,05 & 110 & 264 & 374 & 70,59 \\
\hline Maritrema portucalensis & 132 & 545 & 677 & 80,50 & & & & \\
\hline Maritrema eroliae & 182 & 244 & 426 & 57,28 & & & & \\
\hline Microphallus primas & 272 & 405 & 677 & 59,82 & & & & \\
\hline Microphallus similis & 253 & 367 & 620 & 59,19 & 102 & 268 & 370 & 72,43 \\
\hline Probolocoryphe uca & 262 & 415 & 677 & 61,30 & & & & \\
\hline \multirow[t]{2}{*}{ Gynaecotyla ongiintestinata } & 258 & 399 & 657 & 60,73 & & & & \\
\hline & \multicolumn{4}{|c|}{ Región ITS1 } & \multicolumn{4}{|c|}{ Región ITS2 } \\
\hline Maritrema madrynense & $n \div$ opb diferentes & $n \varrho p b$ común & nopb total & $\%$ similitud & $n \circ p b$ diferentes & nopb común & no pb total & $\%$ similitud \\
\hline Maritrema arenaria & 83 & 340 & 423 & 80,38 & 122 & 295 & 417 & 70,74 \\
\hline Maritrema sobdolum & 78 & 357 & 435 & 82,07 & 75 & 303 & 378 & 80,16 \\
\hline Maritrema oocysta & 61 & 363 & 424 & 85,61 & 48 & 330 & 378 & 87,30 \\
\hline Maritrema portucalensis & 151 & 519 & 670 & 77,46 & & & & \\
\hline Maritrema eroliae & 51 & 619 & 670 & 92,39 & & & & \\
\hline Microphallus primas & 276 & 394 & 670 & 58,81 & & & & \\
\hline Microphallus similis & 184 & 437 & 621 & 70,37 & 92 & 286 & 378 & 75,66 \\
\hline Probolocoryphe uca & 257 & 413 & 670 & 61,64 & & & & \\
\hline Gynaecotyla longiintestinata & 259 & 398 & 657 & 60,58 & & & & \\
\hline
\end{tabular}


Anexo V. Comparación de la región ITS1 del ADN ribosomal de Renicolidae gen. et sp. 1 con Renicolidae gen. et sp. 2. No se hallaron otras secuencias pertenecientes a esta región de la familia Renicolidae disponibles en Gen Bank. Se presentan el número de pares de bases (pb) diferentes, en común y total y el porcentaje de similitud entre cada par de especies comparadas.

\begin{tabular}{|c|c|c|c|c|}
\hline & \multicolumn{4}{|c|}{ Región ITS1 } \\
\hline Renicolidae gen. et sp. 1 & no pb diferentes & no pb común & no pb total & \% similitud \\
\hline Renicolidae gen. et sp. 2 & 190 & 377 & 567 & 66,49 \\
\hline
\end{tabular}

Anexo VI. Comparación de la región ITS1 del ADN ribosomal de Notocotylidae gen. et sp. con otra secuencia de una especie de la familia Notocotylidae disponible en Gen Bank. Se presentan el número de pares de bases (pb) diferentes, en común y total y el porcentaje de similitud entre cada par de especies comparadas.

\begin{tabular}{|l|c|c|c|c|}
\hline & \multicolumn{4}{|c|}{ Región ITS1 } \\
\hline Notocotylidae gen. et sp. & nopb diferentes & nopb común & no pb total & $\%$ similitud \\
\hline Notocotylus malhamensis & 82 & 720 & 802 & 89,78 \\
\hline
\end{tabular}

Anexo VII. Comparación de las regiones ITS1, ITS2 y $28 \mathrm{~S}$ del ADN ribosomal de Parorchis sp. con otras especies de la familia Philophthalmidae disponible en Gen Bank. Se presentan el número de pares de bases (pb) diferentes, en común y total y el porcentaje de similitud entre cada par de especies comparadas.

\begin{tabular}{|c|c|c|c|c|c|c|c|c|c|c|c|c|}
\hline \multirow[b]{2}{*}{ Parorchis sp. } & \multicolumn{4}{|c|}{ Región ITS1 } & \multicolumn{4}{|c|}{ Región ITS2 } & \multicolumn{4}{|c|}{ Región 28S } \\
\hline & $\mathrm{n}$ o $\mathrm{pb}$ diferentes & no pb común & $\mathrm{n}=\mathrm{pb}$ total & $\%$ similitud & no $\mathrm{pb}$ diferentes & no pb común & $\mathrm{n} \cong \mathrm{pb}$ total & $\%$ similitud & $\mathrm{n}$ - $\mathrm{pb}$ diferentes & no pb común & no pb total & $\%$ similitud \\
\hline Philophtalmus sp. 191 & 54 & 394 & 448 & 87,95 & 106 & 630 & 736 & 85,6 & 61 & 1238 & 1299 & 95,3 \\
\hline Philophtalmus lucipetus & 53 & 395 & 448 & 88,17 & 108 & 628 & 736 & 85,33 & 11 & 260 & 271 & 95,94 \\
\hline Philophtalmid sp. & & & & & & & & & 60 & 1239 & 1299 & 95,38 \\
\hline Cloacitrema narrabeenensis & & & & & & & & & 65 & 1143 & 1208 & 94,62 \\
\hline Philophtalmus gralli & & & & & & & & & 60 & 1148 & 1208 & 95,03 \\
\hline
\end{tabular}


Anexo VIII. Resumen de los digeneos hallados en los gasterópodos más abundantes de Puerto Madryn y Puerto Deseado. Abreviaturas: (b) inferido mediante registros bibliográficos, (h) inferido mediante una hipótesis, (c) conocido y corroborado, (HD) hospedador definitivo, (HI) hospedador intermediario.

\begin{tabular}{|c|c|c|c|c|c|c|c|c|}
\hline \multirow[b]{2}{*}{ Especie parásita } & \multirow[b]{2}{*}{ Estadio larval } & \multirow{2}{*}{$\begin{array}{c}\text { Especie de gasterópodo } \\
\text { hospedadora }\end{array}$} & \multicolumn{2}{|c|}{ Prevalencia total (\%) } & \multirow{2}{*}{$\begin{array}{c}\text { Rol del } \\
\text { gasterópodo en el } \\
\text { ciclo de vida }\end{array}$} & \multirow{2}{*}{$\begin{array}{l}\text { Segundo hospedador } \\
\text { intermediario }\end{array}$} & \multirow{2}{*}{$\begin{array}{l}\text { Hospedador } \\
\text { definitivo }\end{array}$} & \multirow{2}{*}{$\begin{array}{l}\text { Tipo de } \\
\text { ciclo de } \\
\text { vida }\end{array}$} \\
\hline & & & $\begin{array}{l}\text { Puerto } \\
\text { Madryn }\end{array}$ & $\begin{array}{c}\text { Puerto } \\
\text { Deseado }\end{array}$ & & & & \\
\hline Hemiuroidea fam. gen. et sp. & $\begin{array}{l}\text { esporocistos } \\
\text { con cercarias }\end{array}$ & Siphonaria lessonii & $\begin{array}{c}0,48 \\
(\mathrm{n}=1.050)\end{array}$ & $\begin{array}{c}4,84 \\
(n=186)\end{array}$ & $1^{\circ} \mathrm{HI}$ & $\begin{array}{c}\text { Mnemiopsis leydi } \\
\text { (ctenóforo) (h), } \\
\text { copépodos, ostrácodos } \\
\text { (b) }\end{array}$ & pez (b) & triexeno \\
\hline Lepocreadiidae gen. et sp. 1 & $\begin{array}{l}\text { redias con } \\
\text { cercarias }\end{array}$ & Crepipatella dilatata & - & $\begin{array}{c}3,76 \\
(n=266)\end{array}$ & $1^{\circ} \mathrm{HI}$ & $\begin{array}{c}\text { Gaimardia trapesina, } \\
\text { Neolepton cobbi (bivalvos) } \\
\text { (h), meduzas, ctenóforos } \\
\text { (b) }\end{array}$ & $\begin{array}{c}\text { Eleginops } \\
\text { maclovinus }(\mathrm{h})(\mathrm{pez})\end{array}$ & triexeno \\
\hline Lepocreadiidae gen. et sp. 2 & $\begin{array}{l}\text { redias con } \\
\text { cercarias }\end{array}$ & Pareuthria plumbea & - & $\begin{array}{c}3,49 \\
(n=458)\end{array}$ & $1^{\circ} \mathrm{HI}$ & $\begin{array}{c}\text { Gaimardia trapesina, } \\
\text { Neolepton cobbi (bivalvos) } \\
\text { (h), meduzas, ctenóforos } \\
\text { (b) }\end{array}$ & $\begin{array}{c}\text { Eleginops } \\
\text { maclovinus (h)(pez) }\end{array}$ & triexeno \\
\hline $\begin{array}{l}\text { Diphterostomum sp. } \\
\text { (Zoogonidae) }\end{array}$ & $\begin{array}{c}\text { esporocistos } \\
\text { con cercarias y } \\
\text { metacercarias } \\
\end{array}$ & Buccinanops globulosus & $\begin{array}{c}0,16 \\
(\mathrm{n}=632)\end{array}$ & - & $1^{\circ}$ y $2^{\circ} \mathrm{HI}$ & $\begin{array}{c}\text { B. globulosus (c) } \\
\text { Tellina petitiana (bivalvo) } \\
(\mathrm{h})\end{array}$ & $\begin{array}{c}\text { Pinguipes } \\
\text { brasilianus (c) (pez) }\end{array}$ & $\begin{array}{l}\text { diexeno } \\
\text { y/o } \\
\text { triexeno }\end{array}$ \\
\hline Zoogonus sp. (Zoogonidae) & $\begin{array}{l}\text { esporocistos } \\
\text { con cercarias }\end{array}$ & Pareuthria plumbea & - & $\begin{array}{c}0,22 \\
(n=458)\end{array}$ & $1^{\circ} \mathrm{HI}$ & $\begin{array}{l}\text { poliquetos, } \\
\text { gasterópodos, } \\
\text { equinodermos (b) }\end{array}$ & pez (b) & triexeno \\
\hline $\begin{array}{l}\text { Gymnophalloides nacellae } \\
\text { (Gymnophallidae) }\end{array}$ & metacercarias & Nacella (P.) magellanica & - & $\begin{array}{c}92,47 \\
(n=306)\end{array}$ & $2^{\circ} \mathrm{HI}$ & $\begin{array}{l}\text { Gaimardia trapesina } \\
\text { (bivalvo) (c) } 1^{\circ} \mathrm{HI}\end{array}$ & $\begin{array}{l}\text { Larus dominicanus } \\
\text { (h), Haematopus } \\
\text { ater (h) (aves) }\end{array}$ & triexeno \\
\hline $\begin{array}{c}\text { Maritrema sp. } 1 \\
\text { (Microphallidae) }\end{array}$ & $\begin{array}{l}\text { esporocistos } \\
\text { con cercarias }\end{array}$ & Crepipatella dilatata & $\begin{array}{c}33,45 \\
(\mathrm{n}=1.665) \\
\end{array}$ & $\begin{array}{c}16,5 \\
(\mathrm{n}=266)\end{array}$ & $1^{\circ} \mathrm{HI}$ & crustáceos (b) & $\begin{array}{l}\text { Larus dominicanus } \\
\text { (h) (ave) }\end{array}$ & triexeno \\
\hline $\begin{array}{l}\text { Maritrema madrynense } \\
\text { (Microphallidae) }\end{array}$ & $\begin{array}{l}\text { esporocistos } \\
\text { con cercarias y } \\
\text { metacercarias }\end{array}$ & $\begin{array}{c}\text { Siphonaria lessonii } \\
\text { Kerguelenella lateralis }\end{array}$ & $\begin{array}{c}8,95 \\
(\mathrm{n}=1.050) \\
-\end{array}$ & $\begin{array}{c}9,2 \\
(n=186) \\
0,42 \\
(n=237)\end{array}$ & $1^{\circ}$ y $2^{\circ} \mathrm{HI}$ & $\begin{array}{c}\text { S. lessonii (c), } \\
\text { Cyrtograpsus altimanus, } \\
\text { Idotea baltica (crustáceos) } \\
\text { (c) }\end{array}$ & $\begin{array}{l}\text { Larus dominicanus } \\
\text { (c) (ave) }\end{array}$ & $\begin{array}{l}\text { diexeno } \\
\text { o } \\
\text { triexeno }\end{array}$ \\
\hline Notocotylidae gen. et sp. & $\begin{array}{c}\text { redias con } \\
\text { cercarias y } \\
\text { metacercarias }\end{array}$ & Nacella (P.) magellanica & - & $\begin{array}{c}0,33 \\
(n=306)\end{array}$ & $1^{\circ}$ y $2^{\circ} \mathrm{HI}$ & $N(P$.$) magellanica (\mathrm{c})$ & $\begin{array}{c}\text { Larus dominicanus } \\
\text { (h), Haematopus } \\
\text { ater (h) (aves) }\end{array}$ & diexeno \\
\hline Renicolidae gen. et sp. 1 & $\begin{array}{l}\text { esporocistos } \\
\text { con cercarias }\end{array}$ & Trophon geversianus & $\begin{array}{c}0,29 \\
(n=689)\end{array}$ & $\begin{array}{c}4,64 \\
(n=151)\end{array}$ & $1^{\circ} \mathrm{HI}$ & $\begin{array}{c}\text { Mytilus edulis (c), otros } \\
\text { bivalvos (h) }\end{array}$ & $\begin{array}{c}\text { Larus dominicanus } \\
\text { (s), (ave) }\end{array}$ & triexeno \\
\hline Renicolidae gen. et sp. 2 & $\begin{array}{l}\text { esporocistos } \\
\text { con cercarias }\end{array}$ & Nacella (P.) magellanica & - & $\begin{array}{c}0,98 \\
(n=306)\end{array}$ & $1^{\circ} \mathrm{HI}$ & $\begin{array}{c}\text { bivalvos mitílidos, Lasaea } \\
\text { adansoni, Gaimardia } \\
\text { trapesina }(\mathrm{h})\end{array}$ & aves marinas (b) & triexeno \\
\hline
\end{tabular}




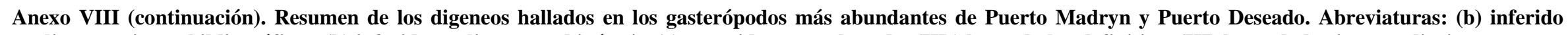
mediante registros bibliográficos, (h) inferido mediante una hipótesis, (c) conocido y corroborado, (HD) hospedador definitivo, (HI) hospedador intermediario.

\begin{tabular}{|c|c|c|c|c|c|c|c|c|}
\hline \multirow{2}{*}{ Especie parásita } & \multirow{2}{*}{ Estadio larval } & \multirow{2}{*}{$\begin{array}{c}\text { Especie de gasterópodo } \\
\text { hospedadora }\end{array}$} & \multicolumn{2}{|c|}{ Prevalencia total (\%) } & \multirow{2}{*}{$\begin{array}{l}\text { Rol del } \\
\text { gasterópodo en el } \\
\text { ciclo de vida }\end{array}$} & \multirow{2}{*}{$\begin{array}{l}\text { Segundo hospedador } \\
\text { intermediario }\end{array}$} & \multirow{2}{*}{$\begin{array}{c}\text { Hospedador } \\
\text { definitivo }\end{array}$} & \multirow{2}{*}{$\begin{array}{l}\text { Tipo } \\
\text { de ciclo } \\
\text { de vida }\end{array}$} \\
\hline & & & Puerto Madryn & $\begin{array}{c}\text { Puerto } \\
\text { Deseado }\end{array}$ & & & & \\
\hline Parorchis sp. (Philophtalmidae) & $\begin{array}{l}\text { redias con } \\
\text { cercarias }\end{array}$ & Trophon geversianus & $\begin{array}{c}0,87 \\
(n=689)\end{array}$ & $\begin{array}{c}0,66 \\
(n=151)\end{array}$ & $1^{\circ} \mathrm{HI}$ & $\begin{array}{l}\text { enquista en el sustrato o } \\
\text { sobre valvas de mitílidos } \\
\text { (c) }\end{array}$ & $\begin{array}{l}\text { Larus dominicanus } \\
\text { (c), Calidris } \\
\text { fuscicollis (c) (aves) }\end{array}$ & diexeno \\
\hline Schistosomatidae gen. et sp. & $\begin{array}{l}\text { esporocistos con } \\
\text { cercarias }\end{array}$ & Siphonaria lessonii & - & $\begin{array}{c}0,54 \\
(n=186)\end{array}$ & $1^{\circ} \mathrm{HI}$ & penetra en el HD & $\begin{array}{c}\text { aves marinas y } \\
\text { migratorias (b), } \\
\text { Larus dominicanus } \\
(\mathrm{h})\end{array}$ & diexeno \\
\hline
\end{tabular}


